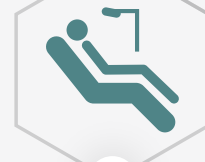

Paola María Botero Mariaca Natalia Vélez Trujillo Claudia Cecilia Restrepo Serna Libbe Mariaca Cartagena

\title{
Manual de ortodoncia interceptiva: teoría y práctica
}
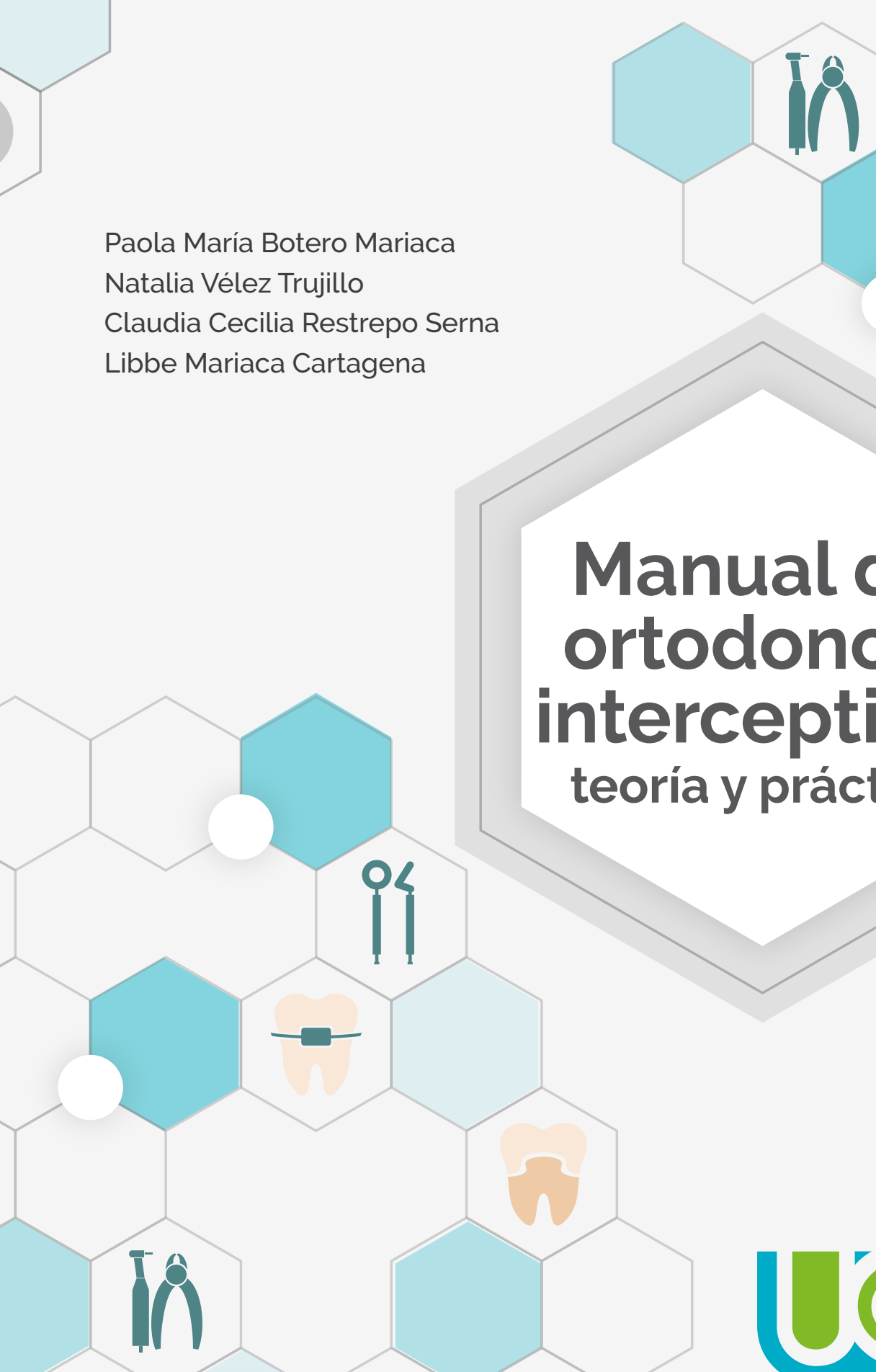


\section{MANUAL DE ORTODONCIA INTERCEPTIVA: TEORÍA Y PRÁCTICA}

\section{Paola María Botero Mariaca}

Natalia Vélez Trujillo

Claudia Cecilia Restrepo Serna

Libbe Mariaca Cartagena

Universidad Cooperativa de Colombia

\section{NOTA LEGAL}

El presente documento de trabajo ha sido incluido dentro de nuestro repositorio institucional como Apropiación social de conocimiento por solicitud del autor, con fines informativos, educativos o académicos. Asimismo, los argumentos, datos y análisis incluidos en el texto son responsabilidad absoluta del autor y no representan la opinión del Fondo Editorial o de la Universidad.

\section{DISCLAIMER}

This coursework paper has been uploaded to our institutional repository as Social Appropriation of Knowledge due to the request of the author. This document should be used for informational, educational or academic purposes only. Arguments, data and analysis included in this document represent authors' opinion not the Press or the University.

Apropiación social del conocimiento Generación de contenidos impresos http://repository.ucc.edu.co/handle/20.500.12494/7375

N. ${ }^{0} 11$, noviembre de 2020

DOI: https://doi.org/10.16925/gcgp.28

ISBN (PDF): 978-958-760-295-1 


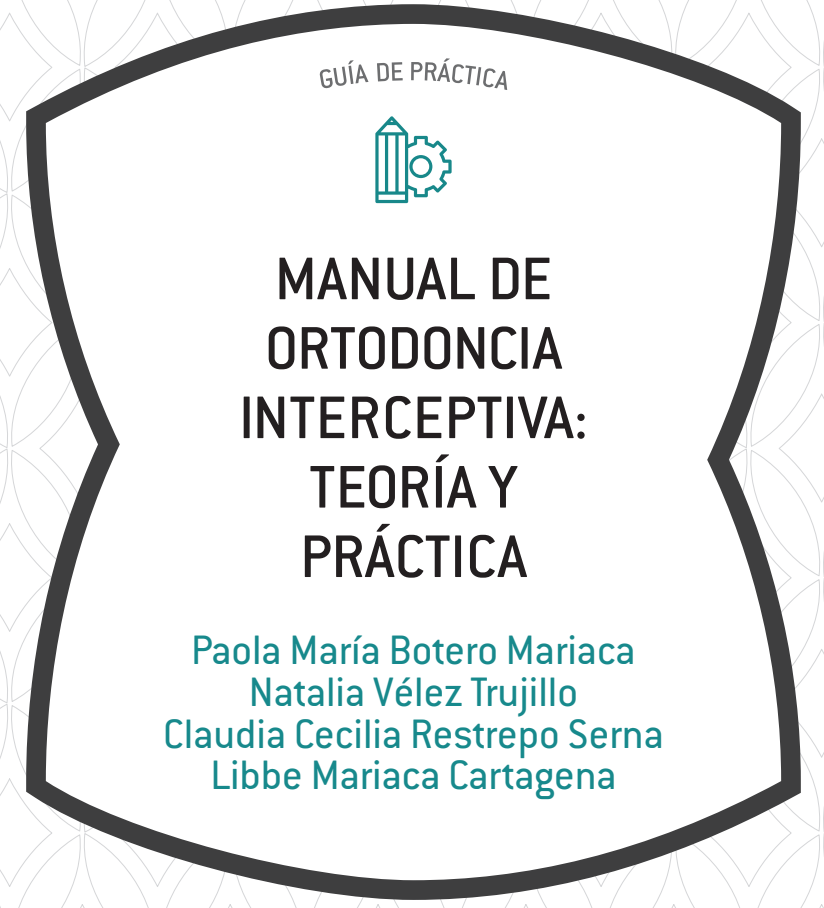




\section{ACERCA DE LAS AUTORAS}

Paola María Botero Mariaca, odontóloga, ortodoncista y magíster en Ciencias Odontológicas de la Universidad CES. Profesora de posgrado en Ortodoncia, Universidad Cooperativa de Colombia (UCC), sede Medellín. Investigadora del Grupo de Investigación Odontológica Multidisciplinario (GIOM) de la UCC.

Correo electrónico: paola.botero@ucc.edu.co ORCID: https://orcid.org/0000-0002-4445-3349

CvLac: https://scienti.minciencias.gov.co/ cvlac/visualizador/generarCurriculoCv.do?cod_rh=0000989762

GrupLac: https://scienti.minciencias.gov.co/ gruplac/jsp/visualiza/visualizagr.jsp? nro= 00000000005649

Natalia Vélez Trujillo, odontóloga, ortodoncista y magíster en Psicología. Coordinadora y profesora del posgrado de Ortodoncia, Universidad Cooperativa de Colombia (UCC), sede Medellín. Investigadora del Grupo de Investigación Odontológica Multidisciplinario (GIOM) de la UCC.

Correo electrónico: natalia.velez@campusucc.edu.co

CvLac: https://scienti.minciencias.gov.co/ cvlac/visualizador/generarCurriculoCv.do?cod_rh=0001129996

GrupLac: https://scienti.minciencias.gov. co/gruplac/jsp/visualiza/visualizagr.jsp?nro $=00000000005649$

Claudia Cecilia Restrepo Serna, odontóloga, odontopediatra y doctora en Odontología y Neurociencias. Investigadora del grupo de investigación CES-LPH y profesora, Universidad CES.

Correo electrónico: martinezrestrepo@une. net.co

CvLac: https://scienti.minciencias.gov.co/cvlac/ visualizador/generarCurriculoCv.do?cod_ $r h=0000151670$

Libbe Mariaca Cartagena, odontóloga, odontopediatra y magíster en Ciencias. Profesora titular, Universidad de Antioquia, Medellín. Correo electrónico: libemarica@gmail.com

\section{Cómo CITAR ESTE DOCUMENTO}

Botero-Mariaca PM, Vélez-Trujillo N, Restrepo-Serna CC, Cartagena-Mariaca L. Manual de ortodoncia interceptiva: teoría y práctica (Generación de contenidos impresos, N. $\left.{ }^{\circ} 11\right)$. Bogotá: Ediciones Universidad Cooperativa de Colombia, 2020. doi: https://doi.org/10.16925/gcgp.28

Este documento puede ser consultado, descargado o reproducido desde nuestro repositorio institucional (http://repository.ucc. edu.co/handle/20.500.12494/7369) para uso de sus contenidos, bajo la licencia de Creative Commons Reconocimiento-No Comercial-Sin Obra Derivada 4.0 Internacional. http://creativecommons.org/licenses/by-nc-nd/4.0/ 


\section{TABLA DE CONTENIDO}

$\begin{array}{ll}\text { INTRODUCCIÓN } & \text { I7 }\end{array}$

CAPÍTULO I. ANÁLISIS FUNCIONAL

Claudia Cecilia Restrepo Serna

CAPÍtulo 2. DesarRollo de oclusión 32

Natalia Eugenia Vélez

CAPÍtUlo 3. Apiñamiento 69

Paola María Botero Mariaca

Capítulo 4. Control de espacio 82

Paola María Botero Mariaca, Libbe Mariaca de Botero

CAPÍtulo 5 I IO

Paola María Botero Mariaca, Libbe Mariaca de Botero

Capítulo 6. Tratamiento de alteraciones transversales

Paola María Botero Mariaca

CAPítUlo 7. TRAtAmiento De Alteraciones SAgitales - Clase II

Paola María Botero Mariaca

Capítulo 8. Tratamiento de alteraciones de Clase III

Paola María Botero Mariaca

CAPítulo 9. Tratamiento de Alteraciones Verticales 202

Paola María Botero Mariaca 


\section{LISTA DE FIGURAS}

\section{CAPÍTULO I}

$\begin{array}{ll}\text { Figura 1. Análisis postural corporal de frente } & 20\end{array}$

Figura 2A. Ángulo craneovertebral para determinar postura 21 craneocervical clínicamente

$\begin{array}{ll}\text { Figura 2B. Análisis postural de frente de cara } & 21\end{array}$

Figura 3. Evaluación de la postura craneocervical en radiografías 22

Figura 4. Prematuro 26

Figura 5. Examen para trastornos temporomandibulares 26

(palpación muscular y de ATM con fuerzas estandarizadas)

\section{CAPÍTULO 2}

Figura 1. Fases de la erupción $\quad 35$

Figura 2. Reborde alveolar superior $\quad 39$

Figura 3. Rebordes alveolares mandibulares $\quad 39$

Figura 4. Cordón fibroso de Robin y Magilot 39

Figura 5. Secuencia de erupción en la dentición decidua $\quad 42$

Figura 6. Espacios de la dentición decidua 43

Figura 7. Overjet negativo $\quad 44$

Figura 8. Arco superior e inferior tipo II 45

Figura 9. Escalón mesial y plano terminal recto 45

Figura 10. Relaciones caninas clase I y clase III en la dentición temporal 46

Figura 11. Dientes sucesionales y accesionales 49

Figura 12. Erupción de primeros molares permanentes superiores e $\quad 50$ inferiores e inicio de erupción del grupo incisivo

Figura 13. Alteración de la erupción del primer molar 50 permanente superior

Figura 14. Clasificación molar de Edward Angle clases II, I y III 52

Figura 15. Pérdida prematura de molares temporales 54

Figura 16. Erupción del ectópica lateral superior en posición lingual 55

Figura 17. Dentición mixta silente 56

Figura 18. Alteración en la vía y guía de erupción 61

Figura 19. Radiografía panorámica que muestra la relación de los 63 terceros molares con los segundos molares permanentes 


\section{CAPÍtUlo 3}

Figura 1. (A) Arcos deciduos consolidados con los respectivos sucedáneos en formación. (B) Cambios en las dimensiones de los arcos con el crecimiento

Figura 2. Arcos espaciados tipo I en dentición decidua

Figura 3. (A) Arcos deciduo tipo II. (B) Arco deciduo apiñado

Figura 4. Espacio primate superior

Figura 5. Inclinación a vestibular de los permanentes al erupcionar

Figura 6. Proceso de erupción de incisivos permanentes

Figura 7. Espacio de Leeway

Figura 8. Mesialización de primer molar

Figura 9. (A) Molares deciduos en oclusión. (B) Primer molar con migración mesial tardía a expensas del espacio de Leeway

Figura 10. (A) Apiñamiento anterior. (B) Pérdida prematura de canino deciduo

Figura 11. Incisivos laterales superiores e inferiores erupcionando por lingual

Figura 12. Desarrollo en la región de la tuberosidad

Figura 13. Reabsorción en media luna de canino deciduo inferior

Figura 14. Pérdida prematura de canino deciduo

Figura 15. Apiñamiento superior e inferior severo

\section{CAPÍTULO 4}

Figura 1. Separador de alambre de cobre y elastómeros

Figura 2. Banda en acero inoxidable superior derecha

Figura 3. Band setter y band pusher

Figura 4. Pinza contorneadora de bandas

Figura 5. Pinza tumba-bandas

Figura 6. Adaptación anterior del arco lingual

Figura 7. Arco lingual semifijo con ansa y arco lingual fijo sin ansa

Figura 8. Arco lingual contorneado en la zona anterior

Figura 9. Arco lingual modificado

Figura 10. Bicarbonato para realizar profilaxis

Figura 11. Ionómero de vidrio, presentación con polvo y líquido

Figura 12. Arco lingual en posición

Figura 13. Botones palatinos

Figura 14. Botón palatino con ganchos de entrega en la zona anterior 
$\begin{array}{ll}\text { Figura 15. Barra transpalatina } & 91\end{array}$

Figura 16. Barra transpalatina lisa $\quad 91$

Figura 17. Barra transpalatina con ansa $\quad 91$

Figura 18. Banda y abrazadera en el arco superior e inferior 92

Figura 19. Banda y abrazadera con alambre cerca a gingival 92

Figura 20. Radiografía de banda y abrazadera en posición 93

Figura 21. Zapata distal en posición 93

Figura 22. Mantenedor fijo para reemplazar anteriores superiores 93

Figura 23. Placa de Hawley 94

Figura 24. Placa de Hawley inferior 94

Figura 25. Clases de arcos: corto y largo 95

Figura 26. Ganchos de retención tipo Adams y circunferencial 96

Figura 27. Diseños de bilaterales de acrílico 96

Figura 28. Caries oclusodistal de primer molar inferior izquierdo 98

Figura 29. Pérdida prematura de dientes deciduos 98 en arcos superior e inferior

Figura 30. Mesialización de primeros molares superiores por 99 pérdida prematura de segundos molares deciduos

Figura 31. Migración mesial de primeros molares por pérdida prematura 100 de segundos molares deciduos

$\begin{array}{ll}\text { Figura 32. Pérdida prematura de canino deciduo } & 100\end{array}$

Figura 33. Separación del labio generado por la bompereta 102

$\begin{array}{ll}\text { Figura 34. Apiñamiento previo a bompereta en posición } & 103\end{array}$

$\begin{array}{ll}\text { Figura 35. Ansa de la bompereta } & 103\end{array}$

Figura 36. Secuencia radiográfica de paciente con bompereta 105

Figura 37. Placas de Hawley con ganchos de entrega 105

Figura 38. Resortes usados en las placas de Hawley 106

Figura 39. Placa de Hawley con tornillo lateral y llave en alambre 107

$\begin{array}{ll}\text { Figura 40. Hawley con silla de montar } & 107\end{array}$

$\begin{array}{ll}\text { Figura 41. Apiñamiento moderado } & 107\end{array}$

\section{CAPÍtUlO 5}

Figura 1. Exámenes diagnósticos para un paciente en crecimiento 111

Figura 2. Presencia de supernumerario en oclusal de primer bicúspide 111 inferior izquierdo

Figura 3. Radiografía Cone Beam de un paciente con canino impactado 
Figura 4. (A) Radiografía panorámica: medición de ángulos del eje de canino y línea media, y eje bicondilar. (B) Radiografía periapical: ubicación del canino según los sectores de Lindauer

Figura 5. Reabsorción de lateral superior

Figura 6. Evolución posición del 13

Figura 7. Evolución posición de canino

Figura 8. Caninos superiores en estadio 6 de Nolla 117

Figura 9. Canino que sobrepasa la mitad de la raíz del lateral 118

$\begin{array}{ll}\text { Figura 10. Canino inferior retenido } & 119\end{array}$

Figura 11. Tipos de erupciones ectópicas, grados I al IV 120

Figura 12. Línea tangente a la superficie distal del segundo molar 121 deciduo perpendicular al plano oclusal

Figura 13. Apiñamiento leve anteroinferior $\quad 122$

Figura 14. Discrepancia dentoalveolar $\quad 125$

Figura 15. Apiñamiento severo anteroinferior $\quad 126$

Figura 16. Paciente clase I 126

Figura 17. Proceso de erupción de centrales y laterales con 128 apiñamiento por discrepancia en la longitud de arco

Figura 18. Exodoncia de caninos deciduos 129

Figura 19. Incisivos alineados luego de exodoncia de caninos 129 e indicación de exodoncia de primeros molares

$\begin{array}{ll}\text { Figura 20. Exodoncia de primeros premolares antes } & 129\end{array}$ de erupción de caninos

Figura 21. (A-B) Angulaciones de las raíces en los dientes próximos a la extracción y presencia de espacios residuales. (C) tratamiento de ortodoncia posterior a extracción seriada.

Figura 22. Exfoliación prematura de caninos deciduos 130 por erupción de laterales

Figura 23. Caninos en erupción luego de exodoncia 130 de primeros premolares

Figura 24. Exodoncia de primeros molares deciduos antes de caninos deciduos

Figura 25. Exodoncia de los primeros molares deciduos y enucleación de los primeros molares permanentes

Figura 26. Espacios residuales e inclinación radicular de 


\section{CAPÍtulo 6}

Figura 1. Mordida cruzada posterior bilateral 135

Figura 2. Mordida en tijera posterior en un solo diente 135

Figura 3. Distancia yugal-yugal maxilar y 136 antegonial-antegonial mandibular

Figura 4. Esquema de estadios de formación de la sutura media palatina 138

Figura 5. Preguntas para guiar el proceso de determinar el tipo de sutura 139

Figura 6. (A) Desplazamiento anterior del maxilar durante la 139 disyunción (B) Desplazamiento posterior del maxilar durante la disyunción

$\begin{array}{ll}\text { Figura 7. Patrón de disyunción en sentido frontal } & 140\end{array}$

Figura 8. Patrón de disyunción visto desde oclusal. 140

Figura 9. Expansor tipo Hass 145

Figura 10. Expansor tipo Hyrax 146

Figura 11. Tornillo tipo Fisher 146

Figura 12. Llave para activar tornillo 146

Figura 13. Paciente con Hyrax y planos de mordida posterior en boca $\quad 147$

Figura 14. Hyrax con dos tipos de rejillas en la zona anterior 148

$\begin{array}{ll}\text { Figura 15. Arco en W } & 148\end{array}$

Figura 16. Quad Helix 149

Figura 17. Quad Helix 150

Figura 18. Quad Helix con la ubicación de la pinza tres picos 150 y pinza tres picos

Figura 19. (A-B) Quad Helix con rejilla. (C) Quad Helix 151 con brazos anteriores

Figura 20. Expansor de Nitanium [63] 151

Figura 21. Placa de Hawley con tornillo 152

Figura 22. Bihelix 152

Figura 23. Crozat 153

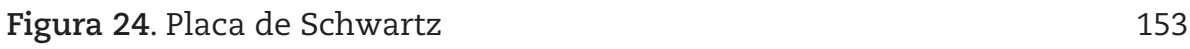


Figura 1. Paciente clase II esquelética por prognatismo maxilar 156

Figura 2. Maloclusión clase II división 1 y división 2

Figura 3. Paciente con tracción cervical en posición 158

Figura 4. Arco extraoral para tracciones 158

Figura 5. Marca en forma de L en la soldadura que une el arco 159 interno con el arco externo

$\begin{array}{ll}\text { Figura 6. Arco interno con ansas } & 159\end{array}$

Figura 7. Regla flexible milimetrada $\quad 159$

Figura 8. (A) Arco interno estándar sin dobleces. (B-C) Bayonetas 160 realizadas en arco externo con ayuda de pinza tres picos

Figura 9. (A) Pinza 139. (B) Pinza tres picos 160

Figura 10. Arco externo en posición en la mitad de los labios 161

Figura 11. (A) Gancho para anclaje de la banda elástica 161

(B) Arco extraoral de tracción

Figura 12. Cinta elástica y mecanismo de ajuste para 162 establecer fuerza necesaria

Figura 13. Protector de cuello para insertar banda elástica 162

Figura 14. Banda elástica en posición dentro del protector 162

Figura 15. Dinamómetro 162

Figura 16. Forma de medir la fuerza con el dinamómetro 163

Figura 17. Banda y tubo doble (tubo rectangular y tubo 163 redondo de 0.45 " o 0.5 ")

Figura 18. Centros de resistencia. (A) Centro de resistencia del maxilar.

(B) Centro de resistencia dentoalveolar. (C) Centro de resistencia dental

Figura 19. Dirección del momento de fuerzas, que pasan por encima o 165 por debajo del centro de resistencia del molar

Figura 20. Sistema de fuerzas aplicadas a un molar a través de un arco externo con diferente inclinación. (A) Fuerza encima del C. R. que genera extrusión, movimiento mesial de la corona y distal de la raíz. (B) Fuerza por debajo del C. R. hacia arriba que genera movimiento distal de la corona, con momento horario. (C) Arco interno adaptado al tubo de la banda del primer molar. (D) Fuerza por debajo del C. R. hacia abajo que genera extrusión, movimiento distal de la corona, con momento horario

Figura 21. Pacientes con tracción alta en posición, con diferentes tipos de gorro

Figura 22. Gorro de tela para tracción alta y aditamentos 168 que lo unen a las bandas elásticas

Figura 23. Bandas elásticas y aditamento que permite 
que las bandas se acorten o se alarguen

$\begin{array}{ll}\text { Figura 24. Banda plástica para tracciones altas } & 169\end{array}$

Figura 25. Ensamble de la banda plástica en el gorro 169

Figura 26. Tracción extraoral combinada en posición 170

Figura 27. Vectores de fuerza de tracción combinada. 170

Figura 28. Medición de las fuerzas con dinamómetro 171

Figura 29. Placa de Hawley con ganchos circunferenciales 172

y arco vestibular corto

Figura 30. Antes y después del tratamiento con tracción alta 173

\section{CAPÍtulo 8}

Figura 1. (A) Paciente clase III por prognatismo mandibular.

(B) Paciente clase III por micrognatismo maxilar.

(C) Paciente con retrognatismo maxilar y prognatismo mandibular

Figura 2. (A) Paciente clase III esquelético por hipoplasia maxilar con birotrusión bimaxilar. (B) Paciente clase III esquelética por prognatismo mandíbula

Figura 3. Relación anterior en céntrica en un paciente pseudo III 176

$\begin{array}{ll}\text { Figura 4. Plano inclinado en posición } & 178\end{array}$

$\begin{array}{ll}\text { Figura 5. Diferentes vistas del Progenie } & 179\end{array}$

Figura 6. Vista lateral y oclusal del Progenie con brazos y tornillo 179

Figura 7. Pacientes con mordida cruzada anterior por hipoplasia maxilar 179

$\begin{array}{ll}\text { Figura 8. Máscara facial } & 180\end{array}$

Figura 9. Aparato Hyrax con brazos para máscara facial 181

Figura 10. Quad Helix para traccionar maxilar 181

Figura 11. Centro de resistencia del maxilar superior 183

Figura 12. Angulación de línea de acción de la fuerza 184 con respecto al plano oclusal

Figura 13. Barra transversal y llave con la que se regula su posición $\quad 184$

Figura 14. Hyrax con diseños de arcos vestibulares diferentes 184

Figura 15. Secuencia de elástico sugerida por Baccetti 185

Figura 16. Elásticos 3/8 de $14 \mathrm{oz} \quad 185$

Figura 17. Efectos de la máscara facial en paciente clase III 186 esquelético por hipoplasia maxilar

Figura 18. Antes y después de la máscara facial de tratamiento de un año 187

Figura 19. Evolución anual después de concluido el tratamiento, 187 en este período solo tuvo un péndulo

Figura 20. Mentonera occipital 
Figura 21. Banda cefálica

Figura 22. Apoyo en el mentón 191

Figura 23. Bandas elásticas 191

Figura 24. Centro de resistencia de la mandíbula 191

Figura 25. Línea de acción de la fuerza que pasa 192 a través del cóndilo. Línea de acción de la fuerza que pasa por detrás del cóndilo)

Figura 26. Arco en posición en las bandas de los primeros molares 192

Figura 27. Tracción cervical mandibular en posición 193

Figura 28. Cambios esqueléticos en paciente clase III por 194 prognatismo mandibular luego de tracción cervical mandibular

Figura 29. Antes y después del tratamiento interceptivo y correctivo 195

Figura 30. Comparación de las radiografías al inicio y al final de 196 la ortodoncia correctiva

\section{CAPÍtulo 9}

$\begin{array}{ll}\text { Figura 1. Mordida abierta anterior } & 201\end{array}$

$\begin{array}{ll}\text { Figura 2. Mordida profunda } & 201\end{array}$

Figura 3. (AB) Patrones de crecimiento vertical. 202

(C) Patrón de crecimiento horizontal

Figura 4. Mentonera parietal o vertical 204

Figura 5. Línea de acción de la fuerza (amarillo) 206

anterior al cóndilo mandibular (rojo)

Figura 6. Tracción alta 206

Figura 7. Placa de Hawley superior con planos de mordida posterior $\quad 207$ (vista oclusal y lateral)

Figura 8. Planos de mordida posterior para el arco inferior al 207 que se le adiciona rejilla

Figura 9. Rejillas en posición 208

Figura 10. Rejilla en forma de canastilla 209

Figura 11. Quad Helix con rejilla 209

Figura 12. Rejilla inferior soldada a arco lingual 210

Figura 13. Mordida profunda anterior en diferentes etapas del desarrollo 210 dental. (A) Dentición mixta intertransicional. (B) Dentición mixta final

Figura 14. Placa de Hawley con plano de mordida anterior 211

Figura 15. Radiografía antes y después del tratamiento con rejilla 211 lingual de mordida abierta anterior 


\section{LISTA DE TABLAS}

\section{CAPÍtUlo 2}

Tabla 1. Relación entre las etapas del desarrollo dental y las alteraciones dentales posibles

Tabla 2. Calcificación en dentición temporal

Tabla 3. Etapas relevantes de maduración aplicando el diagrama de Nolla

Tabla 4. Diagrama de estadios de maduración dental de Demirjian

Tabla 5. Etapas del desarrollo de la dentición

Tabla 6. Dientes natales, neonatales y preerupcionados

Tabla 7. Características de dientes natales y neonatales

Tabla 8. Variaciones en la secuencia de erupción en la dentición temporal [40]

Tabla 9. Probabilidad de apiñamiento en la dentición permanente, basada en los espacios disponibles en la dentición primaria

Tabla 10. Tipos de arcos en la dentición decidua

Tabla 11. Análisis de arcos

Tabla 12. Proceso de erupción de los dientes permanentes

Tabla 13. Factores que condicionan la posición del primer molar permanente

Tabla 14. Cambio de la relación molar decidua a la permanente

Tabla 15. Patrones que se pueden establecer en

la clase II - división 2

Tabla 16. Variaciones en la clasificación de las relaciones molares para el diagnóstico

Tabla 17. Secuencia de erupción de la dentición permanente en arcos superior e inferior

\section{CAPÍTUlo 4}

Tabla 1. Tipos de mantenedores de espacio

Tabla 2. Desventajas según mantenedores de espacio

Tabla 3. Efectos de la pérdida

\section{CAPÍTULO 5}

Tabla 1. Análisis para determinar la impactación de caninos

Tabla 2. Efectos de los tratamientos en la erupción del canino 


\section{CAPÍtUlO 6}

Tabla 1. Promedio de las dimensiones faciales transversales 135

Tabla 2. Efectos de los diferentes tipos de expansión

CAPÍTUlo 7

Tabla 1. Pico de crecimiento maxilar y mandibular 157

Tabla 2. Tabla de registro de gramos y onzas del dinamómetro 162

Tabla 3. Representación del dinamómetro 163

Tabla 4. Medidas iniciales y finales de radiografías cefálica lateral 173

\section{CAPÍtUlo 8}

Tabla 1. Picos de crecimiento 177

Tabla 2. Diferencias entre el anclaje óseo y convencional 189 en la máscara facial

Tabla 3. Resumen de los efectos de los tratamientos clase III 195

Tabla 4. Medidas iniciales, intermedias y finales de radiografía 196 cefálica lateral

\section{CAPÍTULO 9}

Tabla 1. Diferencias en los patrones de rotación mandibular 


\title{
11 MANUAL DE ORTODONCIA PRÁCTICA
}

\author{
Paola María Botero Mariaca \\ Natalia Vélez Trujillo \\ Claudia Cecilia Restrepo Serna \\ Libbe Mariaca Cartagena
}

\begin{abstract}
Resumen
El proceso de transición dental para prevenir o interceptar las maloclusiones, es decir, el desarrollo de la dentición humana, se demora 12 años, por lo que muchos factores externos influyen en él. El grado de desarmonía oclusal que resulta luego del desarrollo es determinado por los cambios compensatorios que suceden con el crecimiento; las interferencias en el desarrollo de oclusión pueden llevar a una maloclusión. En la literatura se contemplan tres términos que importa diferenciar: ortodoncia preventiva, ortodoncia interceptiva y ortodoncia correctiva. La primera busca prevenir las interferencias potenciales que se presentan en el desarrollo de la oclusión para evitar que el problema se desarrolle, mientras que la ortodoncia interceptiva tiene como finalidad la eliminación de interferencias existentes durante el desarrollo de la oclusión. Muchas veces es difícil distinguir entre estos términos debido a que no siempre es posible discriminar un problema potencial de uno existente, motivo por el que se consideran ambos términos en conjunto. Entre los beneficios del tratamiento interceptivo se encuentran una mayor habilidad para modificar el crecimiento, el mejoramiento de la autoestima del paciente, la satisfacción de los padres, resultados óptimos y más estables, y una terapia posterior más corta. Los objetivos de la terapia son lograr un estado de normalidad lo más tempranamente posible para mejorar el crecimiento y desarrollo del paciente, obtener cambios esqueléticos, proveer la oportunidad de un cambio funcional, eliminar los factores externos y los hábitos dañinos, y tomar ventaja de las fuerzas oclusales del desarrollo para su corrección.
\end{abstract}

Palabras clave: desarrollo de oclusión, maloclusión, ortodoncia interceptiva, tratamiento interceptivo. 


\section{INTRODUCCIÓN}

El proceso de enseñanza-aprendizaje se ha transformado con los años, y ahora le otorga al estudiante un papel protagónico. El profesor, aunque sigue ejerciendo un rol fundamental, debe además actuar como facilitador del aprendizaje de sus estudiantes y brindarles la posibilidad de generar un pensamiento crítico, para siempre estar en la búsqueda del nuevo conocimiento. En este sentido, la aplicación clínica de los conocimientos teóricos que adquieren los estudiantes durante su proceso de formación es esencial para el desarrollo integral de las competencias exigidas durante la formación de profesionales en el área odontológica. En consecuencia, es imperante disponer de herramientas que faciliten los procesos, y entre estas se destacan las guías y manuales.

La atención de pacientes en crecimiento siempre ha sido un reto para los profesionales, debido a que abarca muchos ámbitos de formación y exige el desarrollo de conceptos y habilidades que deben aplicarse durante la atención. La ortodoncia interceptiva parte integral de la ortodoncia- es aplicada en pacientes escolares en crecimiento. Se basa en el concepto de tratamiento temprano e intercepción de las maloclusiones, con la finalidad de facilitar el proceso de crecimiento del individuo, fomentando un medio ambiente adecuado sin hábitos o parafunciones; adicionalmente ayuda a la intercepción de maloclusiones que, sin ninguna intervención, acarrearían tratamientos de ortodoncia y cirugía ortognática más complejos.

El presente Manual de ortodoncia interceptiva provee información detallada de los elementos que intervienen durante la atención de pacientes escolares con respecto al componente de tratamiento interceptivo; un tema importante tanto para los estudiantes de pregrado como de posgrado. En el texto se presentan las alternativas de tratamiento disponibles para todos los tipos de maloclusiones que tengan la mejor evidencia reportada, así como los elementos biomecánicos requeridos para su instalación, supervisión y control.

El trabajo es el resultado de un proceso de revisión exahustiva de literatura en la que se comparan diferentes abordajes existentes para las distintas terapeúticas, iniciando con un análisis funcional fundamental para el logro del diangóstico adecuado, y abordando los conceptos de desarrollo de oclusión necesarios para entender el proceso de crecimiento de este tipo de pacientes. 


\section{CAPÍTULO 1}

\section{ANÁLISIS FUNCIONAL}

Claudia Cecilia Restrepo Serna

En este capítulo se revisa el análisis funcional como un examen que debe ir más allá del conocimiento de las ciencias odontológicas. Se determina la aproximación que el clínico debe realizar a las funciones fisiológicas del paciente, involucrando no solo las funciones orales, sino también las psicosociales, cervicales, respiratorias, musculares y articulares. Debido al complejo funcionamiento del sistema nervioso simpático y parasimpático, y a la red anatómica muscular, nerviosa y tendinosa, deben ser examinadas, además de las funciones orales, las funciones corporales y cervicales. Esto permite tener un panorama amplio de la fisiología y/o patofisiología del ser humano que se atiende en la consulta odontológica.

\section{¿QUÉ ES EL ANÁLISIS}

\section{FUNCIONAL?}

El análisis funcional es la evaluación del equilibrio que deben guardar las estructuras somáticas, cervicales, de los maxilares y del sistema estomatognático. Para realizarlo de manera adecuada, el clínico debe tener amplio conocimiento de la anatomía, la fisiología y, sobre todo, el equilibrio que deben guardar las estructuras durante su funcionamiento.

\section{ESTRUCTURA DEL ANÁLISIS FUNCIONAL}

El análisis funcional debe realizarse desde lo macro hacia lo micro. Esto muchas veces implica ir más allá de lo que el clínico percibe a simple vista. Situaciones como la postura corporal, cervical y de la cabeza, y funciones como la de la articulación temporomandibular son afectadas por las emociones y afecciones biopsicosociales, que a su vez están asociadas a las maloclusiones [1]. En este orden de ideas, es indispensable establecer empatía con el paciente - y con sus padres, de ser el caso- y tener la mente abierta a un trabajo interdisciplinario.

\section{POSICIÓN CRANEOCERVICAL Y FUNCIONES ORALES FISIOLÓGICAS}

Las interconexiones nerviosas y anatómicas entre la columna cervical y el sistema estomatognático [2] hacen que las posiciones alteradas de alguna de ellas afecten las demás [3]. Estas alteraciones pueden relacionarse con las maloclusiones [4], la función y el desarrollo de las estructuras dentofaciales [5], las alteraciones en la articulación temporomandibular [6], las modificaciones en la vía área superior [7-9], entre otras. Poder reconocer las relaciones mencionadas y los trastornos recíprocos [10] es muy importante para el establecimiento del diagnóstico y el tratamiento de los problemas cervicofaciales, a través de un enfoque más integral de las patologías.

Varios elementos son afectados por las alteraciones posturales: la posición mandibular [11], la oclusión, la estructura muscular, las posiciones mandibulares y trayectoria de cierre muscular [12] y la articulación temporomandibular tanto en céntrica como en dinámica. Ante una posición de la cabeza en sentido posterior con anteproyección, se genera un desplazamiento posterior a la normal; mientras que con una posición de rotación anterior se produce desplazamiento anterior de la mandíbula [11]. Con ambos cambios se ven alterados los contactos oclusales, produciéndose una inestabilidad oclusal, lo que, en consecuencia, genera cambios en los patrones musculares y en la posición del cóndilo en su cavidad glenoidea [11]. 
Las relaciones esqueléticas afectan la postura de la cabeza [13] y las relaciones oclusales [14, 15]. Con el establecimiento de la dentición permanente, ocurren cambios oclusales constantes durante la dentición mixta [16], por lo que puede verse afectada la postura craneocervical [17]; mientras que, en etapas previas de la dentición decidua, la posición craneocervical es estable gracias a que las dimensiones del arco no sufren cambios importantes en este periodo $[18,19]$.

Las angulaciones craneocervicales y craneovertebrales tienen connotaciones aún más profundas. Así, por ejemplo, niveles altos de ansiedad, rasgos de personalidad retraídos [21] y preocupados [22] se correlacionan con cambios en las posturas de la cabeza [20]. Estas condiciones de comportamiento se consideran signos y/o síntomas de parafunciones orales, las cuales inician desde la infancia y se manifiestan con patologías como el bruxismo o los hábitos de succión; sin embargo, la relación causa-efecto no ha sido establecida adecuadamente en la literatura. La relación de la oclusión y la postura también ha sido reportada, aunque tampoco se ha encontrado una relación causal [23].

\section{EVALUACIÓN DE LA POSTURA CORPORAL}

La postura del individuo se evalúa de manera estática y dinámica, lo cual significa que deben tomarse medidas para evaluar al paciente en reposo y en movimiento. La importancia de esta evaluación radica en que situaciones odontológicas, como maloclusiones, neuralgias y desórdenes temporomandibulares, podrían ser un síntoma de alteraciones en las tracciones musculares, tendinosas y ligamentosas, y en las conexiones neurales, generadas muchas veces en puntos distantes a la boca o el sistema craneofacial. Por esta razón, es importante que el odontólogo conozca las compensaciones corporales; cuando estas existen, la afectación del sistema estomatognático realmente es mínima, pero cuando no se dan, la malla anatómica y neural afecta las demás estructuras, entre ellas las craneofaciales.

Para la evaluación de la postura corporal estática, el sujeto debe pararse con las piernas abiertas a nivel de la cadera y balancearse tres veces de punta a talón. Los brazos deben estar relajados y ubicados a los lados durante esta maniobra. Cuando el balanceo termina, el clínico debe observar la posición de los pies, que deben estar paralelos entre sí y con una orientación anterior (posición normal), o levemente divergentes entre sí, con las puntas de los dedos hacia afuera [24]. Los brazos deben estar paralelos al cuerpo. Si alguno de ellos se encontrara fuera de este plano, al corregir la postura, el otro debería compensar la posición sin que el cuerpo se mueva. Si esto no sucede, el centro de equilibrio del cuerpo podría estar descompensado y es importante tenerlo en cuenta porque los centros de apoyo para los movimientos ortopédicos u ortodóncicos también podrían estar alterados.

En esta posición debe determinarse transversalmente el paralelismo del plano frontal (formado por la unión de los puntos entre las suturas frontomalares), los hombros y la pelvis. Estos planos deben estar paralelos o compensados. Anteroposteriormente, es necesario evaluar la línea recta que deberían formar la sutura frontomalar, el hombro, la pelvis y el tobillo [24] (Figura 1). 


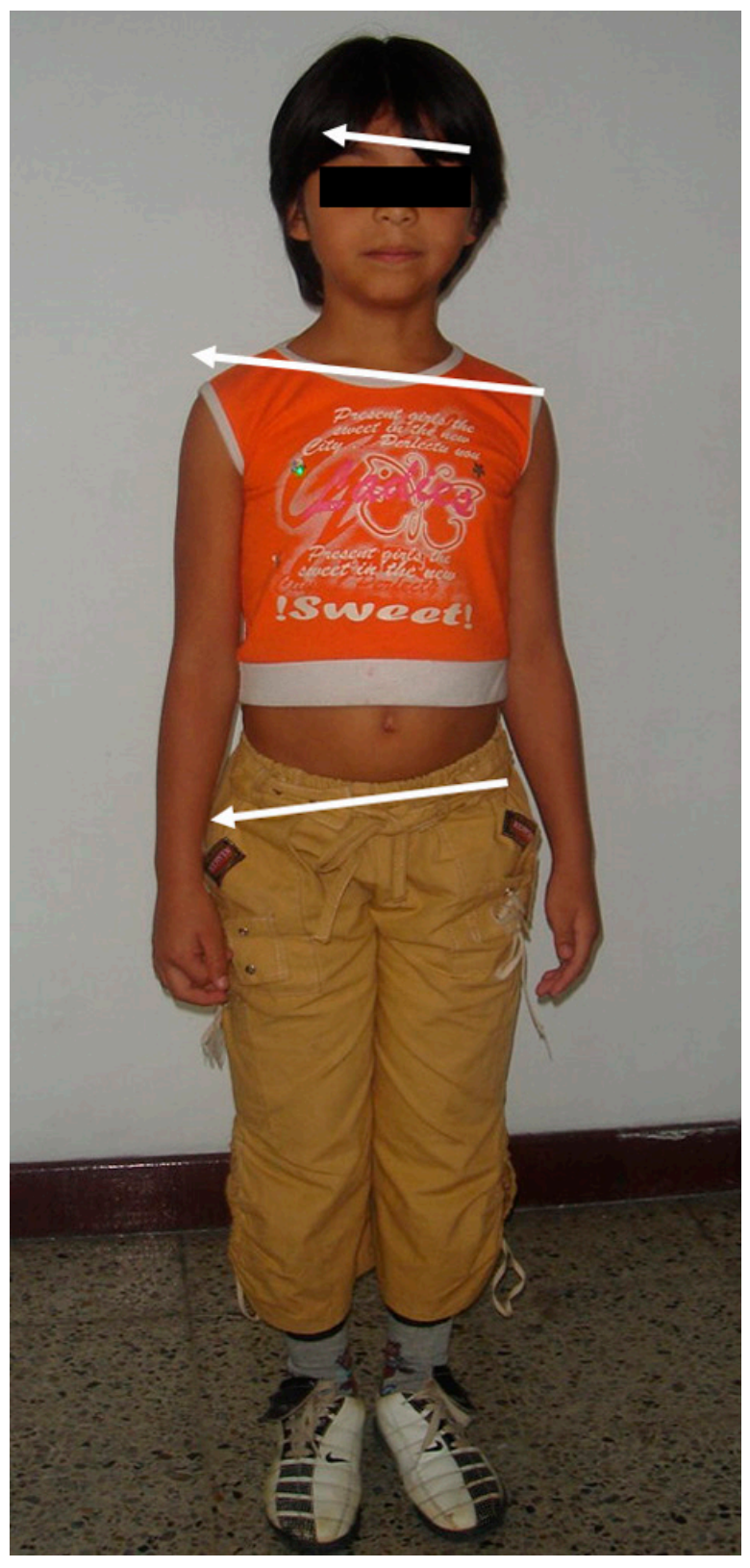

FIGURA 1. Análisis postural corporal de frente

Fuente: elaboración propia.

Cuando sea posible, la evaluación estática de la postura deberá incorporar el examen de la columna cervical, dorsal y lumbar, incluyendo palpación para determinar la posición de toda la cadena vertebral. Por otro lado, la evaluación dinámica de la postura debe realizarse con el sujeto en marcha, para determinar el patrón cruzado; es decir, que el individuo camine con la postura estática adecuada o compensada (como se explicó antes), y que además presente un patrón cruzado de marcha (pie derecho con mano izquierda, y viceversa), con asentamiento de talón y punta adecuado [24].

\section{EVALUACIÓN DE LA POSTURA CRANEOCERVICAL}

La posición craneocervical puede ser evaluada con técnicas radiográficas, clínicas o fotográficas [25]. En el examen ortodóntico u odontopediátrico, la radiografía cefálica lateral es utilizada de rutina. Esta radiografía se emplea no solo para determinar posiciones, tamaños y rotaciones maxilomandibulares, sino también para el análisis de la postura craneocervical [26]. La relación de la columna cervical con el complejo craneofacial en las radiografías se describe a través de diferentes trazados cefalométricos. Un buen trazado depende en la técnica que se emplee para la toma de las radiografías, donde se debe asegurar la posición natural de la cabeza [27]. Esta es considerada una técnica altamente reproducible [28] que permite la valoración de la posición de las vértebras respecto al cráneo; consiste en pedirle al paciente que se balancee desde la punta hasta al talón tres veces, estableciendo una mirada fija y perpendicular al espejo [27]. En casos de niños en crecimiento, la posición es guiada por las ojivas.

Para determinar la postura craneocervical, el trazado de la cefalometría debe realizarse con la técnica vertical verdadera [27, 28], que utiliza los ángulos formados por las tangentes al proceso odontoides y la apófisis de la vértebra cervical cuatro, con las líneas vertical y horizontal verdaderas; la primera obtenida perpendicularmente al Nasion mecánico, y la segunda, a la vertical verdadera. La técnica propuesta por Rocabado [29] sirve para establecer la estabilidad del cráneo en la columna con la revisión de los siguientes parámetros: ángulo posteroinferior (plano de McGregor y plano odontoideo), espacio entre C0-C1 y, finalmente, uso del triángulo hioideo. 
A través de análisis fotográficos se puede establecer la posición del cráneo con respecto a la columna. Es una técnica estandarizada [30] empleada para los análisis del bruxismo y su relación con la postura [31]. Este análisis es similar al cefalométrico en cuanto al uso de puntos de referencia y ángulos, siendo el ángulo craneocervical la principal medida empleada para la evaluación de postura (Figuras 2A, 2B y 3). El ángulo está formado por las líneas tangentes a través de C7 y su proceso espino y el tragus de la oreja como referencia, con un valor normal promedio de $61.4^{\circ} \pm 5.3^{\circ}$. La técnica clínica que se describe está fundamentada en la formulada para la columna realizada por Kendall [32] y en la evaluación de la postura de Raines y Twomey [30], Grimmer [33] y Evcik et al. [34].

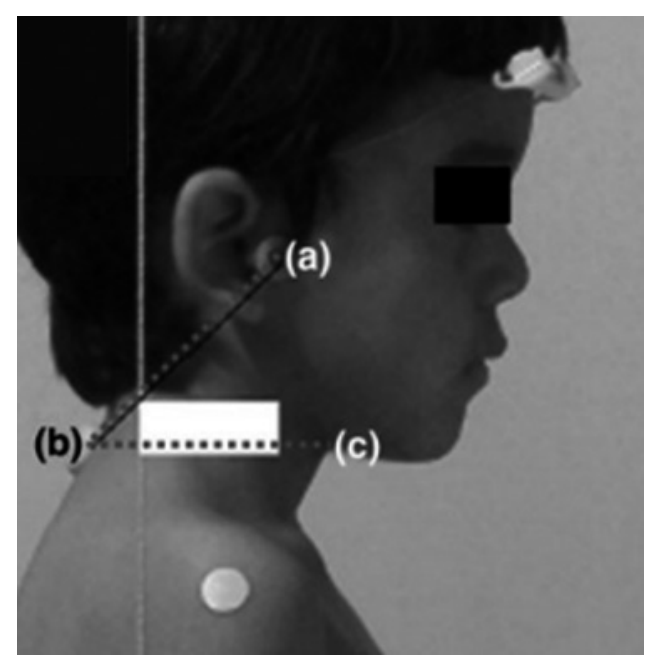

FIGURA 2A. Ángulo craneovertebral para determinar postura craneocervical clínicamente Fuente: elaboración propia.

\section{EXAMEN DE POSTURA DE CABEZA}

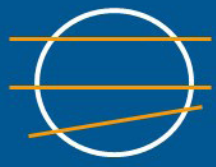

Problema Dental

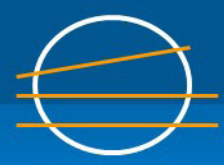

Problema Craneal

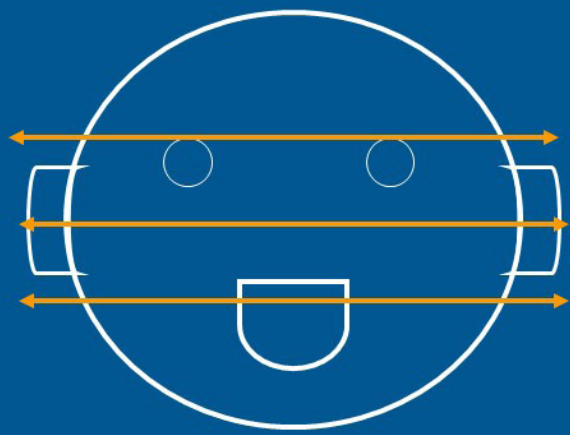

SANO

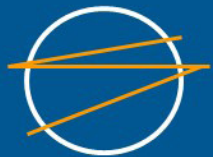

Alteración postural

FIGURA 2B. Análisis postural de frente de cara Fuente: elaboración propia. 


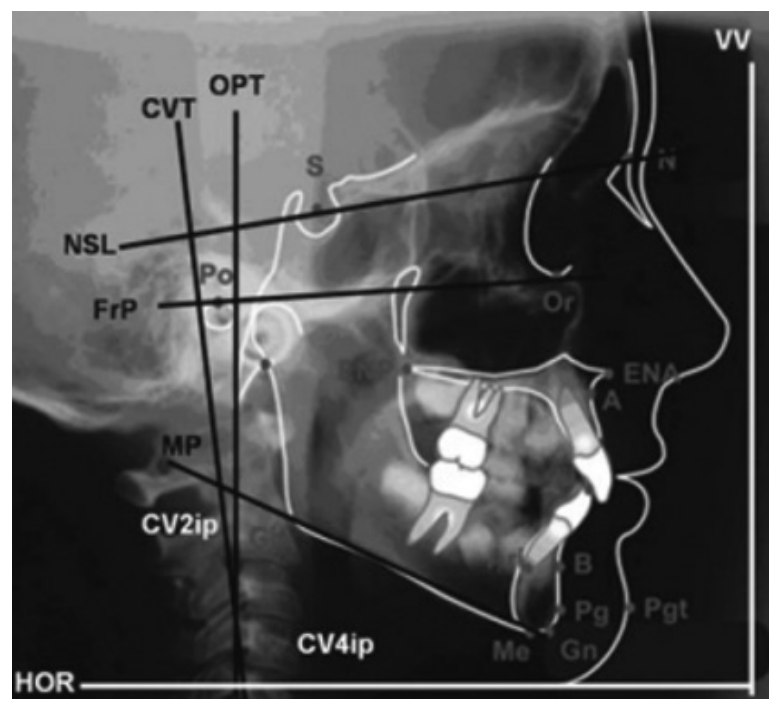

FIGURA 3. Evaluación de la postura craneocervical en radiografías

Fuente: elaboración propia.

\section{SUCCIÓN}

La succión es el primer reflejo alimentario del ser humano. Con la erupción de la dentición temporal sucede un cambio en el patrón deglutorio [35], que también cambia el proceso de succión; y esto hace que cualquier hábito de succión (dedo, chupón, objetos, etc.) pueda ser diagnosticado desde muy temprana edad. El diagnóstico de los hábitos de succión resulta principalmente de la historia clínica y de las consecuencias causadas por el hábito. Las familias suelen acudir a consulta por motivo de este hábito. A partir del diálogo, debe definirse su frecuencia (número de veces que se realiza en el día), duración (tiempo que persiste el hábito en cada evento) e intensidad (fuerza ejercida en cada evento). Asimismo, es importante conocer si el paciente presenta algún punto gatillo que dispare el hábito (objeto de transición, apego a uno de los padres y/o situaciones psicosociales). Esta información permitirá determinar la etiología del hábito, ya sea como un reflejo de succión perpetuado simple o complejo (cuando está acompañado de algún disparador o conducta concomitante). Los efectos que puede tener el hábito en el sistema craneofacial y psicológico dependen, en gran medida, de esta evaluación detallada.

La succión parafuncional recurrente y sistemática presenta diferentes efectos a nivel corporal, como alteraciones oclusales, problemas dermatológicos, ortopédicos y psicológicos [36], que producen consecuencias como rechazo social [37] y aumento en infecciones cruzadas por mayor acumulación de placa bacteriana [38]. A nivel oclusal, la mordida abierta anterior, la protrusión de incisivos superior, la lingualización de incisivos inferiores, el aumento de la sobremordida horizontal, el paladar profundo y la mordida cruzada se asocian a la presencia de este tipo de hábitos [39, 40]. Estas maloclusiones dependen del modo en que se ejecuta el hábito. Por ejemplo, en el caso de la succión digital, si esta es del pulgar, debe analizarse el tipo de presión ejercido en el paladar y en los incisivos superiores e inferiores. Si la succión se hace en los dedos índice y medio, las presiones ejercidas son diferentes y deben analizarse detalladamente para establecer la terapia adecuada. También es importante determinar el estado de maduración de lenguaje y comunicación del paciente, para establecer la terapia cognitiva o conductual. La succión del labio genera despigmentaciones en la piel circundante de la boca, mientras que la del dedo puede presentar consecuencias dérmicas [41] e infecciones que pueden llegar a ser hospitalarias.

\section{DEGLUCIÓN}

La deglución es una función vital existente desde la vida intrauterina. Está asociada a la limpieza de la faringe: a través suyo se remueve la comida y los detritos que son aspirados, protegiendo así la vía aérea y los pulmones [42]. Para usar de manera conjunta la lengua y la dentición, la cavidad oral posee una de las más ricas interconexiones sensoriales que hay en el cuerpo. La cavidad oral y la faringe están 
inervadas por varios pares craneales: trigémino (V), glosofaríngeo (IX), vago (X), accesorio (XI) e hipogloso (XII). Las señales somatosensoriales de la cavidad oral proveen al sistema nervioso central la habilidad de percibir y discriminar sabores, texturas y formas en la boca. A partir de esta inervación, la lengua posee dos reflejos diferentes: el de orientación y el de modulación.

Las fuerzas de modelación dependen del reflejo de modulación. La presión que ejercen sobre los arcos dentales, cuando son adecuadamente balanceadas y armoniosas, favorecen la oclusión [43]. Las alteraciones pueden ocasionar discrepancias en el desarrollo óseo y el crecimiento, pues los huesos siguen la modulación muscular para el crecimiento. Los desórdenes miofuncionales del empuje lingual se han descrito como "desviación de la deglución", "deglución infantil” o "deglución anormal” [44], por nombrar algunas. Para realizar una adecuada deglución, se requiere un selle labial y un selle dental correctos. Si alguno falta, la lengua lo compensa. Por ello, la evaluación de la deglución debe realizarse con el paciente sentado (no acostado) con la boca cerrada. La yema de los dedos del examinador debe ubicarse en la posición de los músculos milohioideos para percibir el movimiento, el cual debe ser continuo cuando la lengua asciende al paladar durante el movimiento de deglución. Cuando la deglución no es adecuada y la lengua se ubica entre los incisivos, la palpación de los milohioideos es discontinua [45]. De existir alguna alteración, otros exámenes más específicos pueden ser practicados para determinar la trayectoria del movimiento de la lengua $[46,47]$.

\section{RESPIRACIÓN}

La respiración, proceso fundamental para la vida, inicia a través de los orificios nasales, los cuales están conformados de manera tal que puedan cumplir con actividades bactericidas y de calentamiento del aire circulante. Normalmente, durante la fase de inspiración, el aire ingresa por las fosas nasales mientras la cavidad oral se encuentra cerrada, lo que genera una presión negativa entre lengua y paladar. Así se potencia el desarrollo de estas estructuras durante el crecimiento [48].

En el caso de respiraciones orales, la lengua cambia de posición: desciende para permitir el ingreso del aire, lo que produce un aumento de la presión intraoral. Una respiración oral puede ser considerada fisiológica solo en casos de esfuerzos físicos cuando la cantidad de ingreso de aire al cuerpo debe ser mayor en conjunto al que ingresa por las fosas nasales o en casos de infecciones respiratorias [49]. En casos en los que la respiración oral sea crónica, se producen alteraciones anatómicas en diferentes estructuras (por ejemplo, el paladar sufre una profundización o hay una atrofia de senos maxilares por falta del paso de aire), lo que finalmente puede resultar en un paciente con signos de facies adenoideas o de cara larga [50]. Los efectos se extienden a la función masticatoria, cuya eficiencia disminuye [51], y a la postura corporal, que presenta alteraciones [52].

La respiración debe ser evaluada clínicamente y con ayuda diagnóstica para determinar su origen. La respiración bucal puede clasificarse en anatómica o funcional. La primera se origina en obstrucciones del paso del aire, debido a la presencia de interferencias mecánicas o a enfermedades alérgicas o inflamatorias; la segunda está exclusivamente ligada a una función respiratoria bucal per se, no asociada a patrones obstructivos. La respiración bucal anatómica puede presentarse como consecuencia de alteraciones nasales como desviaciones del septum, masas, cornetes, amígdalas y adenoides hipertróficos, secreciones nasales, cierre o estenosis de las coanas, rinitis, infecciones que producen inflamaciones, tumores, pólipos, entre otras. 
La respiración bucal funcional puede ser causada por un mal hábito respiratorio o por hiperlaxitud ligamentosa. Entre las obstrucciones funcionales se encuentran los malos hábitos respiratorios, que generalmente están provocados por la falta de reentrenamiento del patrón respiratorio tras la remoción de factores obstructivos. Algunas alteraciones posturales tienen su origen en ligamentos hiperlaxos, donde se evidencian individuos con mayor capacidad de flexión de articulaciones y pie plano. Finalmente, en esos casos hay problemas de posición de diferentes articulaciones como la columna, las rodillas y la mandíbula, lo que produce que se abra la boca, favoreciendo la respiración bucal. El establecimiento de un diagnóstico diferencial es fundamental para identificar los respiradores bucales falsos, es decir, aquellos que, a pesar de tener respiración nasal normal, mantienen la boca abierta de manera permanente. Puede presentarse en estos pacientes una interposición lingual o una lengua que se apoya en el paladar duro. Se presentan, por tanto, pacientes con boca abierta, pero sin respiración oral.

Por lo anterior, debe realizarse una evaluación completa de la historia clínica, una observación clínica de los patrones faciales y un examen del patrón respiratorio del paciente, sentado en la silla y luego acostado. Esto último permite determinar si el patrón respiratorio cambia con el asentamiento del tejido linfoide (amígdalas y adenoides), por lo que tendríamos indicios de un patrón respiratorio mixto: nasal en el día y bucal en la noche. El examen se efectúa con la observación del flujo de aire en un espejo o el movimiento del papel producido con el aire expirado nasalmente.

Ante la sospecha de un patrón respiratorio bucal, está clínicamente indicada la evaluación de la vía aérea superior con el examen de Malampatti [53]. Un Malampatti 3 o 4 indicaría una hipermegalia moderada-severa de las amígdalas, obstruyendo la vía aérea superior.
La radiografía panorámica se usa para identificar desviaciones septales o alguna obstrucción de las narinas; la radiografía cefálica lateral podría indicar la obstrucción de la vía aérea por adenomegalia. Adicionalmente, posturas anteriores de la cabeza, han sido correlacionadas con una vía aérea estrecha (Figura 3).

\section{ONICOFAGIA}

La onicofagia (del griego ónix, 'uña', y phagein, 'comer') es una enfermedad de origen psicológico que aparece generalmente en la infancia y puede permanecer hasta la adolescencia. Aunque la mayoría la supera en la juventud, otros se comen las uñas incluso en la edad adulta, lo que complica su salud, su bienestar y su calidad de vida [54]. Las uñas tienen entre sus funciones proteger la piel y ejercer de pinza, como prolongación de los dedos. La etiología de la onicofagia está relacionada con una respuesta inconsciente a situaciones conflictivas de la vida diaria. También puede ser el reflejo de angustias, temores no resueltos, vacíos emocionales, problemas de autoestima, entre otros [54].

Más allá de lo que implica en la imagen y la presentación personal, la onicofagia representa un alto riesgo de contraer infecciones por contaminación cruzada entre la boca y las uñas [38]; de provocar hemorragias y heridas en los dedos y las uñas; de causar inflamaciones alrededor de las uñas, deformaciones de los dedos, daño y desgaste de los dientes y úlceras. La evaluación de la onicofagia no solo se efectúa a partir de las uñas, sino del desgaste asimétrico de tipo abrasivo en los incisivos.

\section{BRUXISMO}

El bruxismo es un desorden caracterizado por una actividad muscular mandibular excesiva, originada en una alteración en la transmisión 
catecolaminérgica, principalmente de la dopamina. Tiene dos ciclos circadianos: el diurno y el del sueño. Según la clasificación de expertos, el bruxismo del sueño puede ser determinado como: a) posible, cuando solo se establece el reporte de rechinamiento por parte del sujeto o del acompañante de sueño; b) probable, cuando el relato está acompañado de la presencia de signos clínicos: desgaste dental, presencia de DTM o señales de mordisqueo en carrillos o lengua; y c) definitivo, cuando el reporte es confirmado con polisomnografía (PSG) [55].

El reporte de rechinamiento es el método más usado y la alternativa disponible, sobre todo cuando se trata de establecer datos epidemiológicos [56, 57]. En la literatura se encuentran diferentes métodos para medir los factores asociados al bruxismo, que contribuyen a determinar la presencia de probable bruxismo del sueño; sin embargo, solo algunos estudios han sido enfocados a evaluar realmente su origen catecolaminérgico [58-60]. Existen herramientas para diferenciar el desgaste dental patológico del fisiológico [61]; la psicometría apunta a evaluar la ansiedad y el estrés [62, 63], y también hay métodos para detectar los desórdenes temporomandibulares (de los que se hablará más adelante); pero ninguno es patognomónico de bruxismo propiamente.

La polisomnografía, que es el estándar de referencia para el diagnóstico de bruxismo del sueño en adultos [64], no se ha reportado con frecuencia en niños debido a los altos costos, la falta de criterios para este grupo etario y la baja disponibilidad. Aunque la evidencia actual no es contundente a la hora de evaluar la etiología del bruxismo, es pertinente que los factores asociados a la exacerbación de dopamina sean revisados a profundidad en la historia clínica. Así se podrá establecer su asociación con el bruxismo y, en consecuencia, a buscar vías para reducir los eventos de rechinamiento o apretamiento. Entre esos factores están la presencia de alteraciones hormonales; la alimentación estimulante de la dopamina, como café, té, licor y dulces, antes de dormir [65]; el uso de alucinógenos [66] y fármacos dopaminérgicos, como los usados para el tratamiento de la hiperactividad y déficit de atención [67]. También debe evaluarse la presencia de ondas electromagnéticas provenientes del computador, los juegos de video y el uso de celulares y tabletas [68] antes de dormir.

Dado que el bruxismo también ha sido relacionado con la necesidad de humectación de las vías aéreas [69], los pacientes con obstrucciones o respiración bucal, que presentan mayor riesgo de falta de humedad en el tracto respiratorio, son más propensos a padecer bruxismo del sueño [70]. De hecho, existen estudios que muestran diferencias significativas en las vías aéreas de sujetos con y sin bruxismo del sueño [71].

\section{ARTiCULACIÓN \\ TEMPOROMANDIBULAR}

Los trastornos temporomandibulares (DTM) son un complejo de condiciones psicosociales y anatómicas. Dependiendo de la severidad de la sintomatología, pueden llegar a obstaculizar seriamente la calidad de vida de la persona que los padece, pues imitan las funciones en la región orofacial [72]. El estrés, los factores hormonales, los factores genéticos, el origen étnico, la condición social y el género, el rol de las parafunciones y las alteraciones de la articulación actualmente se consideran factores de riesgo desencadenantes de los DTM. También el bruxismo está contemplado entre los factores del desarrollo de trastornos temporomandibulares [73]. Asimismo, las maloclusiones que generen prematuros y deflexiones han sido asociadas a la etiología de los DTM, razón por la que deben evaluarse cuidadosamente. Cuando se lleva al paciente a relación céntrica, es importante establecer los puntos de contacto prematuros, así como la dirección y la magnitud de la deflexión (Figura 4). 


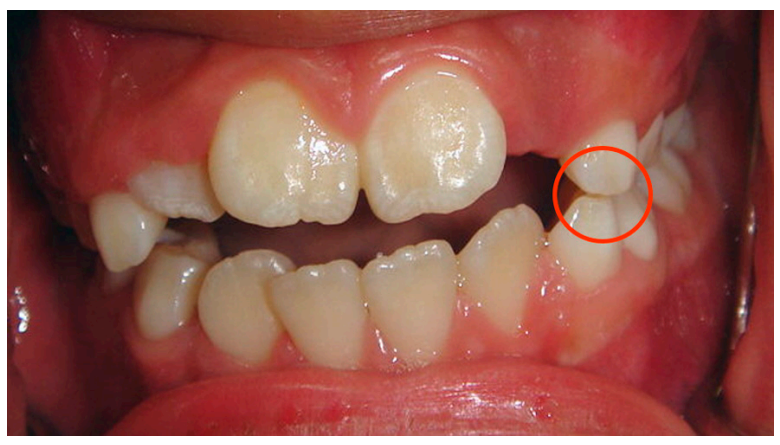

FIGURA 4. Prematuro

Fuente: elaboración propia.

Para la evaluación y el diagnóstico de los DTM, se han utilizado exclusivamente instrumentos clínicos, como el análisis de la vibración conjunta [74] y el índice de Helkimo [75, 76]. Estos están enfocados más a la búsqueda de signos y síntomas que a la etiología de los DTM. La resonancia magnética, las radiografías panorámicas e instrumentos validados que combinan el componente clínico (Figura 5) y psicosocial, como el CD/DTM —utilizado exclusivamente con fines investigativos [77, 78] - han sido empleados para la exploración de DTM. Recientemente, el CD/DTM se ha constituido en el estándar de oro para la evaluación de estos trastornos [79], pues ha sido validado con ayudas diagnósticas como la resonancia magnética funcional. Además, puede ser usado de manera más reproducible en la investigación y la clínica.

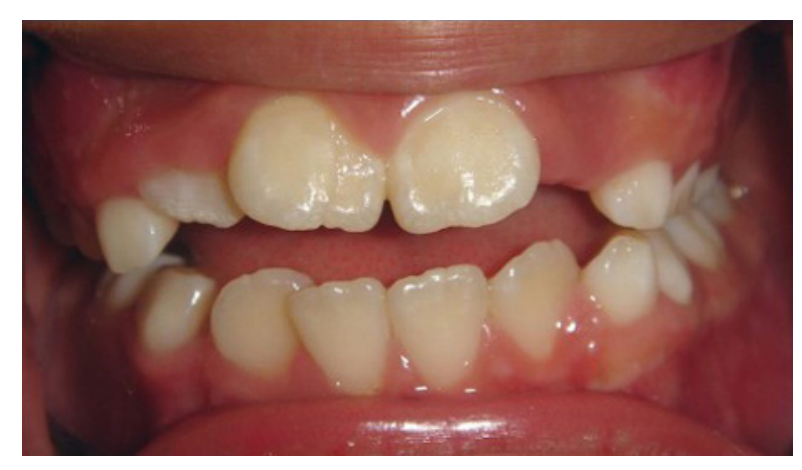

FIGURA 5. Examen para trastornos temporomandibulares (palpación muscular y de ATM con fuerzas estandarizadas]

\section{CD/DTM}

El CD/DTM [80] es un instrumento empleado en la clínica para la detección, evaluación y diagnóstico definitivo de los desórdenes temporomandibulares (DTM); posee un lenguaje fácil de utilizar para los odontólogos que optan por él y tiene métodos para la búsqueda o conocimiento del dolor y su diagnóstico en la ATM. Consta de dos ejes: el Eje I es un examen clínico en el que se evalúan todos los músculos de cara y la ATM, según unos pasos guiados por dicho instrumento, con lo cual se busca llegar al diagnóstico de mialgia, cefalea, dolor miofacial y artralgia, relacionados con la articulación; el Eje II está constituido por una encuesta que valora el aspecto psicosocial del individuo. Con la combinación de ambos ejes, se pretende mejorar el pronóstico y el diagnóstico de DTM, asociado a factores psicosociales. Antes de empezar con el examen, se deben tener en cuenta los siguientes aspectos [81]:

a. El paciente está sentado cómodamente en posición vertical en una silla que se puede ajustar en altura.

b. El examinador está de pie, a la derecha del paciente y de frente a él. Esta posición le permite llevar a cabo el examen completo, utilizando una mano según sea necesario, en tanto la otra se utiliza para estabilizar la cabeza o la mandíbula del paciente.

c. Hay tres posturas estáticas de la mandíbula:

- Posición de confort: la boca está cerrada (es decir, tocan los labios, para la mayoría de los individuos) y los dientes no están en contacto.

- Posición intercuspídea máxima (MICP): la mandíbula se cierra y los dientes tocan totalmente. 
- La mandíbula se sostiene en el final de un movimiento (por ejemplo, la apertura).

d. Las placas y otros aparatos removibles, que no reemplacen piezas dentales, deben ser removidos.

Es necesario explicar al paciente que puede experimentar dolor durante el examen clínico. Puede ser un dolor familiar (similar al experimentado en los últimos 30 días en la misma región); un dolor de cabeza familiar en la sien (similar al experimentado en los últimos 30 días en el área temporal); o un dolor referido, si el paciente reporta dolor más allá del límite del músculo o articulación que se palpa (es decir, se percibe en otra estructura).

Las especificaciones completas están destinadas a facilitar la máxima fiabilidad en la técnica clínica, tanto para el investigador como para el clínico. a. Cuestionario de la historia del paciente: se realiza un cuestionario al paciente. Contiene 14 preguntas relacionadas con dolor, dolor de cabeza, ruidos articulares y bloqueo articular cerrado y abierto.

b. Evaluación clínica: se realiza una evaluación al paciente conducente a la localización del dolor y de cefalea; las relaciones incisales; el patrón de apertura; los movimientos de apertura, de lateralidad y protrusivos; los ruidos articulares durante movimientos de apertura y cierre, de lateralidad y protrusión; el bloqueo articular; y el dolor muscular a la palpación. El examen se hace siguiendo unos comandos preestablecidos.

c. Árbol de decisiones diagnósticas: se llegan a los diagnósticos de mialgia, dolor miofascial referido, artralgia, cefalea atribuida a la ATM, dependiendo de los hallazgos en la historia del paciente y en la evaluación clínica.

\section{REFERENCIAS}

[1] Rubleva IA, Persin LS, Slabkovskaya AB, Zavadenko NN, Deregibus A, Debernardi CL. Psycho-neurological status in children with malocclusions and muscle pressure Habits. Int. J. Orthod. Milwaukee. 2015;26:21-24.

[2] Friedman MH, Weisberg J. The craniocervical connection: A retrospective analysis of 300 whiplash patients with cervical and temporomandibular disorders. Cranio. 2000;18:163-167.

[3] Zúñiga C, Miralles R, Mena B, Montt R, Moran D, Santander H, Moya H. Influence of variation in jaw posture on sternocleidomastoid and trapezius eletromyographic activity. Cranio. 1995;13:157-162.

[4] Bergamini M, Pierleoni F, Gizdulich A, Bergamini C. Dental occlusion and body posture: A surface EMG study. Cranio. 2008;26:25-32.

[5] Santander H, Miralles R, Pérez J, Valenzuela S, Ravera MJ, Ormeno G, Villegas R. Effects of head and neck inclination on bilateral sternocleidomastoid EMG activity in healthy subjects and in patients with myogenic cranio-cervical-mandibular dysfunction. Cranio. 2000;18:181-191.

[6] Wright EF, Domenech MA, Fischer JR Jr. Usefulness of posture training for patients with temporomandibular disorders. J. Am. Dent. Assoc. 2000;131:202-210.

[7] Amis TC, O’Neill N, Wheatley JR. Oral airway flow dynamics in healthy humans. J. Physiol. 1999;515:293298.

[8] Reiterer F, Abbasi S, Bhutani VK. Influence of head-neck posture on airflow and pulmonary mechanics in preterm neonates. Pediatr. Pulmonol. 1994;17:149-154.

[9] Carlo WA, Beoglos A, Siner BS, Martin RJ. Neck and body position on pulmonary mechanics in infants. Pediatrics. 1989;84:670-674. 
[10] Fernández de las Peñas C, Pérez de Heredia M, Molero-Sánchez A, Miangolarra-Page JC. Performance of the craniocervical flexion test, forward head posture, and headache clinical parameters in patients with chronic tension-type headache: a pilot study. J. Orthop. Sports Phys. Ther. 2007;37:33-39.

[11] Miles TS. Postural control of the human mandible. Arch. Oral Biol. 2007 abr;52(4):347-352.

[12] Petricevic N, Celebic A, Celic R, Baucic-Bozic M. Natural head position and inclination of craniofacial planes. Int. J. Prosthodont. 2006;19:279-280.

[13] D'Attilio M, Caputi S, Epifania E, Festa F, Tecco S. Evaluation of cervical posture of children in skeletal class I, II and III. Cranio. 2005;23:219-228.

[14] Cesar GM, Tosato J de P, Biasotto-González DA. Correlation between occlusion and cervical posture in patients with bruxism. Compend. Contin. Educ. Dent. 2006;27(8):463-468.

[15] Gadotti IC, Berzin F, Biasotto-González DA. Preliminary rapport on head posture and muscle activity in subjects with class I and II. J. Oral Rehabil. 2005;32:794-799.

[16] Slaj M, Jezina MA, Lauc T, Rajic-Mestrovic S, Miksic M. Longitudinal dental arch changes in the mixed dentition. Angle Orthod. 2003;73:509-514.

[17] Solow B, Sonnesen L. Head posture and malocclusions. Eur. J. Orthod. 1998;20:685-693.

[18] Bishara SE, Jakobsen JR, Treder J, Nowak A. Arch length changes from 6 weeks to 45 years. Angle Orthod. 1998;68:69-74.

[19] Moorrees CF, Reed RB. Changes in dental arch dimensions expressed on the basis of tooth eruption as a measure of biologic age. J. Dent. Res. 1965;44:129-141.

[20] Ohno H, Wada M, Saitoh J, Sunaga N, Nagai M. The effect of anxiety on postural control in humans depends on visual information processing. Neurosci. Lett. 2004;364(1):37-39.

[21] Kornilova LN, Solov'eva AD, Oknin VYu, Arlashchenko NI. Effect of the character of autonomic response and the emotional and personality features of a human being on reactions of the vestibular system. Hum. Physiol. 1999;25:549-554.

[22] Kampe T, Edman G, Bader G, Tagdae T, Karlsson S. Personality traits in a group of subjects with long-standing bruxing behavior. J. Oral Rehabil. 1997;24:588-593.

[23] Michelotti A, Buonocore G, Manzo P, Pellegrino G, Farella M. Dental occlusion and posture: an overview. Prog. Orthod. 2011;12:53-58.

[24] Conti PB, Sakano E, Ribeiro MA, Schivinski CI, Ribeiro JD. Assessment of the body posture of mouth-breathing children and adolescents. J. Pediatr. (Rio J). 2011;87(4):357-363.

[25] Jiang J, Xu T, Lin J. The relationship between estimated and registered natural head position. Angle Orthod. 2007;77:1019-1024.

[26] Lundström A, Lundström F, Lebret LM, Moorrees CF. Natural head position and natural head orientation: basic considerations in cephalometric analysis and research. Eur. J. Orthod. 1995;17:111-120.

[27] Solow B, Tallgren A. Head posture and craniofacial morphology. Am. J. Phys. Anthropol. 1976;44:417-435.

[28] Vig PS, Showfety KJ, Phillips C. Experimental manipulation of head posture. Am. J. Orthod. Dentofacial Orthop. 1980;77:258-268.

[29] Rocabado M. Biomechanical relationship of the cranial, cervical, and hyoid regions. J. Craniomandibular Pract. 1983;1:61-66.

[30] Raine S, Twomey L. Posture of head, shoulders and thoracic spine comfortable erect standing. Aust J Phisiother 1994; 40: 25-32.

[31] Quintero Y, Restrepo CC, Tamayo V, Tamayo M, Vélez AL, Gallego G, Peláez- Vargas A. Effect of awareness through movement on the head posture of bruxist children. J Oral Rehabil. 2009 ene;36(1):18-25.

[32] Kendall HO, Kendall FP. Músculos, pruebas y funciones. 2. ${ }^{a}$ ed. Barcelona: Wadsworth: Editorial Jims; 1985.

[33] Grimmer K. An investigation of poor cervical resting posture. Aust. J. Phisiother. 1997;43(1):7-16. 
[34] Evcik D, Aksoy O. Correlation of temporomandibular joint pathologies, neck pain and postural differences. J. Phys. Ther. Sci. 2000;12:97-100.

[35] Linder A. Measurement of intra-oral negative air pressure during dummy sucking in human newborn. Eur. J. Orthod. 1991;13:317-321.

[36] Friman P. Thumb sucking: Pediatricians guidelines. Clinical Pediatrics. 1989;28(10): 438-440.

[37] Friman P, McPherson K, Warzak W, Evans J. Influence of thumb sucking on peer social acceptance in first-grade children. Pediatrics. 1993;91:784-786.

[38] Kamal FG, Bernard RA. Influence of nail biting and finger sucking habits on the oral carriage of Enterobacteriaceae. Contemp. Clin. Dent. 2015 abr-jun;6(2):211-214.

[39] Da Silva Filho O, Gomes Goncalves R, Ajalmar Maia F. Sucking habits: Clinical management in dentistry. J. Clin. Pediatr. Dent. 1991;15:137-156.

[40] Fukuta O, Braham R, Yokoi K, Kurosu K. Damage to the primary dentition resulting from thumb and finger sucking. J. Dent. Child. 1996;63:403-417.

[41] Cambiaghi S, Pistritto G. Suction pads related to thumb sucking and chewing. Br. J. Dermatol. 1998;138:1096-1097.

[42] Sato D, Nakashima T. Sleep-related deglutition in children. Ann. Otol. Rhinol. Laryngol. 2007;116(10):747753.

[43] Nahás ACR, Scavone-Junior H, Jabur LB, Guedes-Pinto E. Vertical interincisal trespass assessment in children with speech disorders. Braz. Oral Res. 2008;22(3):247-251.

[44] Fraser C. Tongue thrust and its influence in orthodontics. Int. J. Orthod. Milwaukee. 2006;17:9-18.

[45] Rabelo AT, Campos FR, Friche CP, Silva BS, Friche AA, Alves CR, Goulart LM. Speech and language disorders in children from public schools in Belo Horizonte. Rev. Paul. Pediatr. 2015;33(4):453-459.

[46] Shauker T, Sonies B, Stone M, Baum B. Real-time Ultrasound visualization of tongue movement during swallowing. J. Clin. Ultrasound. 1983;11:485-494.

[47] Fabaron JP, Nadau R. The Payne method of the use of black light in the current diagnosis of atypical deglutition. Orthod. Fr. 1976;47:157-161.

[48] Pacheco MC, Casagrande CF, Teixeira LP, Finck NS, Araújo MT. Guidelines proposal for clinical recognition of mouth breathing children. Dental Press. J. Orthod. 2015;20:39-44.

[49] Bilston LE, Gandevia SC. Biomechanical properties of the human upper airway and their effect on its behavior during breathing and in obstructive sleep apnea. J. Appl. Physiol. (1985). 2014;116(3):314-324.

[50] Al Ali A, Richmond S, Popat H, Playle R, Pickles T, Zhurov AI, Marshall D, Rosin PL, Henderson J, Bonuck K. The influence of snoring, mouth breathing and apnea on facial morphology in late childhood: A three-dimensional study. BMJ Open. 2015;5(9):e009027.

[51] Nagaiwa M, Gunjigake K, Yamaguchi K. The effect of mouth breathing on chewing efficiency. Angle Orthod. 2015;86(2):227-234.

[52] Conti PB, Sakano E, Ribeiro MA, Schivinski CI, Ribeiro JD. Assessment of the body posture of mouth-breathing children and adolescents. J. Pediatr. (Rio J). 2011;87:357-363.

[53] Mateos Rodríguez AA, Navalpotro Pascual JM, Pardillos Ferrer L, Fernández Domínguez JJ, Barragán Chávez J, Martínez González EP. Validity of airway predictors in outpatient medicine. An. Sist. Sanit. Navar. 2014;37:91-98.

[54] Pacan P, Reich A, Grzesiak M, Szepietowski JC. Onychophagia is associated with impairment of quality of life. Acta Derm. Venereol. 2014;94:703-706.

[55] Lobbezoo F, Ahlberg J, Glaros AG, Kato T, Koyano K, Lavigne GJ et al. Bruxism defined and graded: An international consensus. J. Oral Rehabil. 2013;40:2-4.

[56] Manfredini D, Restrepo C, Díaz-Serrano K, Winocur E, Lobbezoo F. Prevalence of sleep ruxism in children: A systematic review of the literature. J. Oral Rehabil. 2013;40:631-642. 
[57] Manfredini D, Winocur E, Guarda-Nardini L, Paesani D, Lobbezoo F. Epidemiology of bruxism in adults: A systematic review of the literature. J. Orofac. Pain. 2013;27:99-110.

[58] Seraidarian P, Seraidarian PI, das Neves Cavalcanti B, Marchini L, Claro Neves AC. Urinary levels of catecholamines among individuals with and without sleep bruxism. Sleep Breath. 2009;13:85-88.

[59] Vanderas AP, Menenakou M, Kouimtzis T, Papagiannoulis L. Urinary catecholamine levels and bruxism in children. J. Oral Rehabil. 1999;26:103-110.

[60] Restrepo CC, Santamaria A, Castrillon E, Lobbezoo F, Manfredini D, Svensson P. Catecholaminergic predictors of parental-report, polysomnographic and electromyographic sleep bruxism in children. J. Den. Res. 2015.

[61] Restrepo C, Peláez A, Álvarez E, Paucar C, Abad P. Digital imaging of patterns of dental wear to diagnose bruxism in children. Int. J. Paediatr. Dent. 2006;16(4):278-285.

[62] Serra-Negra JM, Paiva SM, Abreu MH, Flores-Mendoza CE, Pordeus IA. Relationship between tasks performed, personality traits, and sleep bruxism in Brazilian school children. A population based cross sectional study. PloS One. 2013;8(11):e80075.

[63] Restrepo CC, Vásquez LM, Álvarez M, Valencia I. Personality traits and temporomandibular disorders in a group of children with bruxing behavior. J. Oral Rehabil. 2008;35:585-593.

[64] Lavigne GJ, Rompré PH, Montplaisir JY. Sleep bruxism: Validity of clinical research diagnostic criteria in a controlled polysomnographic study. J. Dent. Res. 1996;75:546-552.

[65] Inclair D, Purves-Tyson TD, Allen KM, Weickert CS. Impacts of stress and sex hormones on dopamine neurotransmission in the adolescent brain. Psychopharmacology (Berl). 2014;231(8):1581-1599.

[66] Hollenweider FX, Gamma A, Liechti M, Huber T. Psychological and cardiovascular effects and shortterm sequelae of MDMA ("ecstasy") in MDMA-naïve healthy volunteers. Neuropsychopharmacology. 1998;19:241-251.

[67] Macedo CR, Macedo EC, Torloni MR, Silva AB, Prado GF. Pharmacotherapy for sleep bruxism. Cochrane Database Syst. Rev. 2014 oct 23;10:CD005578. doi:10.1002/14651858.CD005578.

[68] Restrepo CC, Manfredini D, Lobbezoo F. Sleep predictors of sleep bruxism in children. Sleep. 2015. [En proceso]

[69] Thie NM, Kato T, Bader G, Montplaisir JY, Lavigne GJ. The significance of saliva during sleep and the relevance of oromotor movements. Sleep Med. Rev. 2002;6(3):213-227.

[70] Oksenberg A, Arons E. Sleep bruxism related to obstructive sleep apnea: the effect of continuous positive airway pressure. Sleep Med. Rev. 2002;3:513-515.

[71] Restrepo CC, Álvarez CP, Jaimes J, Gómez AF. Cervical column posture and airway dimensions in clinical bruxist adults: a preliminary study. J. Oral Rehabil. 2013;40:810-817.

[72] Durham J, Steele JG, Wassell RW, Exley C, Meechan JG, Allen PF, et al. Creating a patient-based condition-specific outcome measure for Temporomandibular Disorders (TMDs): Oral Health Impact Profile for TMDs (OHIP-TMDs). J. Oral Rehabil. 2011;38:871-883.

[73] Magalhães BG, De-Sousa ST, Mello VV, Da-Silva-Barbosa AC, De-Assis- Morais MP, Barbosa-Vasconcelos MM, Caldas-Júnior AD. Risk factors for temporomandibular disorder: binary logistic regression analysis. Med. Oral Patol. Oral Cir. Bucal. 2014;19(3):232-236.

[74] Sharma S, Crow HC, McCall WD Jr, Gonzalez YM. Systematic review of reliability and diagnostic validity of joint vibration analysis for diagnosis of temporomandibular disorders. J. Orofac. Pain. 2013;27:51-60.

[75] Köhler AA, Hugoson A, Magnusson T. Clinical signs indicative of temporomandibular disorders in adults: time trends and associated factors. Swed. Dent. J. 2013;37:1-11.

[76] De Felicio CM, Melchior M de O, Da Silva MAMR. Clinical validity of the protocol for multi-professional centers for the determination of signs and symptoms of temporomandibular disorders. Part II. Cranio. 2009;27(1):62-67. 
[77] Manfredini D, Borella L, Favero L, Ferronato G, Guarda-Nardini L. Chronic pain severity and depression/ somatization levels in TMD patients. Int. J. Prosthodont. 2010;23:529-534.

[78] Manfredini D, Ahlberg J, Winocur E, Guarda-Nardini L, Lobbezoo F. Correlation of CDI/DTM axis I diagnoses and axis II pain-related disability. A multicenter study. Clin. Oral Investig. 2011;15:749-756.

[79] Schiffman E. Diagnostic Criteria for Temporomandibular Disorders (CD/DTM) for clinical and research applications: Recommendations of the International CDI/DTM Consortium Network and Orofacial Pain Special Interest Group. J. Oral Facial Pain Headache. 2014;28:6-27.

[80] Schiffman E, Ohrbach R, Truelove E, Look J, Anderson G, Goulet JP, List T, Svensson P, Gonzalez Y, Lobbezoo F, Michelotti A, Brooks SL, Ceusters W, Drangsholt M, Ettlin D, Gaul C, Goldberg LJ, Haythornthwaite JA, Hollender L, Jensen R, John MT, De Laat A, de Leeuw R, Maixner W, van der Meulen M, Murray GM, Nixdorf DR, Palla S, Petersson A, Pionchon P, Smith B, Visscher CM, Zakrzewska J, Dworkin SF, International RDC/TMD Consortium Network, International association for Dental Research, Orofacial Pain Special Interest Group, International Association for the Study of Pain. Diagnostic Criteria for temporomandibular disorders (dc/tmd) for clinical and research applications: Recommendations of the International RDC/TMD Consortium Network and Orofacial Pain Special Interest Group. J. Oral Facial Pain Headache. 2014;28(1):6-27.

[81] Vilanova LS, García RC, List T, Alstergren P. Diagnostic criteria for temporomandibular disorders: self-instruction or formal training and calibration? J. Headache Pain. 2015;16:505. 


\section{CAPÍTULO 2}

\section{DESARROLLO DE OCLUSIÓN}

Natalia Eugenia Vélez

El desarrollo de oclusión es un elemento fundamental dentro del proceso de tratamiento temprano, constituye la base para la correcta aplicación de un tratamiento preventivo e interceptivo. El odontólogo general y el especialista deben conocer el desarrollo oclusal desde el nacimiento hasta completar el crecimiento. De este modo se instaurará la terapeútica más acertada en el momento adecuado, sin generar sobretratamientos y evitando complicaciones durante los procesos de establecimiento de las denticiones decidua y permanente. En el capítulo se presentan de manera detallada y cronológica los eventos que tienen lugar durante el desarrollo de la oclusión.

\section{HISTOEMBRIOLOGÍA DENTAL}

El crecimiento craneofacial y, en particular, el crecimiento de los maxilares comprende procesos biológicos en los que participan células de origen ectodérmico, que forman el epitelio de la cavidad bucal, y las células de origen mesodérmico, formadas por la inducción de las células de la cresta neural en su migración a los procesos maxilares y mandibulares [1] Esto desencadena acciones recíprocas de citogénesis, histogénesis, morfodiferenciación, síntesis y secreción de sustancias específicas [2] Así, el desarrollo, el tiempo de erupción, la morfología, la estructura y la localización del proceso del desarrollo dental están mediados por una cascada de eventos moleculares, regulados, a su vez, por cientos de genes [3].

De los numerosos eventos que ocurren en el proceso de la odontogénesis, es importante iniciar con la formación del estomodeo, que corresponde a la boca primitiva. Esta se encuentra cubierta por un epitelio escamoso estratificado llamado ectodermo, que a partir de la sexta semana embrionaria prolifera en una banda gruesa conocida como lámina dental o listón dentario. Así comienza la formación dental [3]. El epitelio ectodérmico da origen a la formación de los dos listones dentarios primarios: la lámina vestibular y la lámina dentaria.

La lámina vestibular prolifera dentro del ectomesénquima; su característica principal es que sus células se hipertrofian, degeneran y forman una hendidura que corresponde al surco vestibular, separando así labios y mejillas. La lámina dentaria se establece a partir de una actividad proliferativa y localizada, durante la octava semana de vida intrauterina. No existen cambios morfológicos ni funcionales, pero sí de tipo molecular: se evidencian 10 crecimientos epiteliales que corresponden a los futuros esbozos dentales de la dentición primaria en el ectomesénquima de cada uno de los maxilares. Esta lámina también da origen a los gérmenes de la dentición permanente, los cuales se ubican por lingual de los temporales, a excepcion de los molares, que se desarrollan en el extremo distal de la lámina. La formación del primer molar se establece en el cuarto mes, a diferencia de los segundos y terceros molares que se desarrollan postnatalmente, entre el cuarto y quinto año $[2,3]$.

El resultado de la división mitótica de las células de la capa basal origina una proliferación celular con alto contenido de glucógeno, conocida como estadio de brote, que corresponde al propio crecimiento dental [1]. De estos cambios histológicos, se continúa una proliferación dentro del mesénquima, que adopta una forma de caperuza a expensas del crecimiento de sus caras laterales, llamada etapa de casquete. La relevancia está dada por la histodiferenciación de tres estructuras: el órgano del esmalte, el esbozo de la papila dental y el saco dentario. Es de resaltar que cada folículo define una concentración de 
células ectomesenquimas, donde se identifican los elementos formativos del diente y los tejidos de sostén [3].

A medida que el germen crece, se forma la futura corona dental a partir de cambios histoquímicos y estructurales. Esta se conoce como etapa de campana y tiene dos estados: inicial (campana temprana) y avanzado (campana tardía). El primero hace referencia a la diferenciación de las células ectomesénquimas indiferenciadas. El segundo es la fase de aposición: existe una diferenciación odontoblástica en la periferia de la papila, el primer signo es la aposición de la matriz (predentina, preesmalte) y el segundo es la calcificación de la matriz [2, 3]. La diferenciación, la deposición de la matriz y la mineralización comienzan en los extremos de las cúspides, descienden cervicalmente para alcanzar la futura unión amelocementaria e iniciar el desarrollo radicular.

De ahí que el mecanismo fundamental del desarrollo dental sea la relación epitelio-mesénquima. El epitelio determina el tipo de diente a formar y el destino odontogénico de las células mesenquimales, las cuales, a su vez, tienen la capacidad de regular la morfogénesis del epitelio y la forma dental. Los principales eventos de diferenciación de odontoblastos, ameloblastos y cementoblastos se deben a las interacciones celulares y redes de señalización molecular, que dependen del órgano a formar. Esto resulta útil para resaltar las diferencias de la expresión génica, donde destacan las proteínas Hedgehog (Shh), el factor de crecimiento del fibroblasto (FGF), las proteínas morfogenéticas del hueso (BMP) y las proteínas Wnt.

Sin embargo, es importante valorar los trastornos que pueden establecerse durante el desarrollo de cada una de las etapas de formación dental, considerando aspectos como las variaciones de número, tamaño y forma; los defectos en la estructura del esmalte, la dentina y el cemento, que desencadenan cambios en la composición de la estructura de las matrices extracelulares y/o en la mineralización; y los problemas del proceso de erupción (Tabla 1).

TABLA 1

Relación entre las etapas del desarrollo dental y las alteraciones dentales posibles
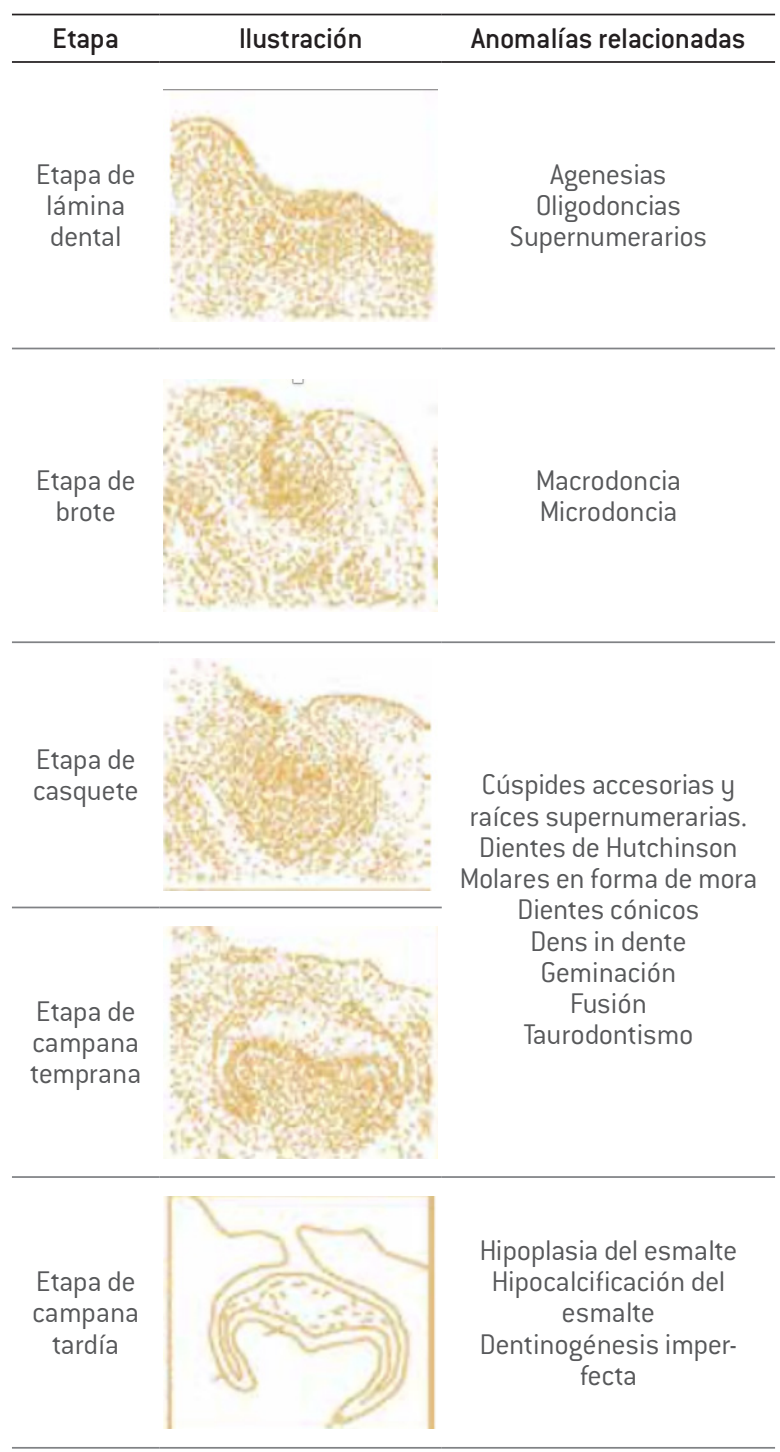

Fuente: elaboración propia

\section{TEORÍAS DE ERUPCIÓN DENTAL}

La erupción dental es el mecanismo complejo en el que intervienen mecanismos celulares y moleculares, que conducen al diente 
desde su posición en la cripta a la cavidad oral, en busca de una oclusión funcional [5, 6]. Durante este proceso, el diente se desplaza en los tres planos del espacio, especialmente en dirección axial, en respuesta a diversos cambios. La velocidad de erupción está dada por un equilibrio entre la formación ósea y el proceso de reabsorción, que a su vez se encuentra regulado por diferentes señales moleculares, como factores de crecimiento, citoquinas, hormonas, que llevan el diente hacia la boca $[3,7]$.

Al ser un proceso múltiple, se han presentado varias teorías que abordan múltiples señales generadas por el folículo dental:

a. Crecimiento de la raíz: al ir desarrollándose la raíz, se ejerce una presión en el fondo del alveolo, que desencadena la erupción dental. Esta es una teoría sin validez ya que existen casos en los que hay dientes sin formación radicular que emergen a la cavidad bucal, o, por el contrario, dientes con formación radicular que no alcanzan el epitelio bucal.

b. Ligamento periodontal, en hamaca: el propio ligamento pasa por debajo del ápice, factor que estimula al diente a emerger a la cavidad bucal. Conociendo que el ligamento es un elemento viscoelástico no lineal, sin conexiones óseas, no tiene la acción para producir el efecto eruptivo que soporta esta teoría.

c. Proliferación celular apical: se crea una fuerza eruptiva que produce una dirección coronal del diente.

d. Contracción de la papila por disminución progresiva del volumen de la cavidad pulpar dada por la formación de dentina radicular. Se descarta por la consideración presentada en el caso de la primera teoría. e. Teoría vascular: los vasos sanguíneos del tejido folicular apical producen una tensión elevada en la zona responsable de los movimientos eruptivos.

f. Remodelado óseo con aposición de hueso en el fondo del alveolo: este factor guarda relación, pero no es suficiente; la formación radicular es una consecuencia y no el factor causal del proceso. Marks y Cahill [8] determinaron que los mecanismos de reabsorción y formación del hueso alveolar, que se producen alrededor de un diente en erupción, están regulados por partes adyacentes al folículo dental.

g. Adaptabilidad o reorganización en la membrana periodontal: se ha evidenciado necrosis celular en la capa más cercana a la raíz del periodonto en los dientes que están en erupción [8].

h. Espacio en el trayecto de erupción: durante el desarrollo del folículo coronal se reabsorbe el tejido óseo suprayacente, generando espacio para el proceso de erupción. Esto ocurre en función de los procesos moleculares y biológicos que están en relación con el ectodermo del folículo.

i. Los patrones de inervación en el maxilar y la mandíbula son diferentes; por eso, los tiempos de erupción varían en cada uno de los arcos.

j. Defectos en el folículo dentario: se generan alteraciones en la erupción dental.

Es concluyente que la erupción es un evento localizado más que sistémico, que depende de eventos moleculares generados por el folículo dental. Entre estos se destacan el factor de crecimiento epidermal (EGF), la proteína quemotáctica de los monocitos 1 (MOC-1), factores de transcripción, la interleucina L, 
el factor transformante de crecimiento alfa (TGF), el receptor activador del factor nuclear к B (RANKL), la proteína morfogenética ósea (BMP), la citoquina Colony stimulating factor 1 (CSF-1), entre otros [9].

\section{ERUPCIÓN DENTAL}

Al igual que el concepto de erupción, es importante destacar el término emergencia, que se define como el momento de aparición del diente en la cavidad bucal [10]. Se reporta que la correlación individual entre la edad cronológica y el tiempo de erupción es débil, y es específica para niños y niñas. Suele afirmarse que los primeros incisivos y molares de un niño hacen erupción a la edad de 6-7 años, pero en los diferentes grupos de dientes la erupción no está interrelacionada: un niño puede tener sus primeros molares a los 6 años y los incisivos varios años después.

El desarrollo de la erupción se establece en tres etapas, desde la formación hasta el contacto con su antagonista, incluyendo la fase de crecimiento vertical intramaxilar [1]:

a. Fase preeruptiva: se caracteriza por la invaginación del ectodermo sobre la mesén- quima subyacente. Comienza con la formación dental hasta que se establece el contacto del borde incisal con la mucosa bucal, y ocurre un desplazamiento lateral de la lámina dental hacia la encía de recubrimiento. El folículo dental se agranda y se desplaza gradualmente, debido a los movimientos mesiodistales; pero no existe desplazamiento de estos con relación a los procesos alveolares.

b. Fase eruptiva: llamada también acelerón posemergente. Se inicia cuando el diente perfora la encía hasta alcanzar el nivel oclusal. Guarda relación con las fuerzas masticatorias, respaldando la actividad metabólica del ligamento periodontal como parte significativa del proceso de erupción. Depende de factores como la presencia o ausencia de dientes, la velocidad de reabsorción de los dientes primarios, la pérdida prematura de dientes primarios y condiciones patológicas localizadas.

c. Fase poseruptiva: es la etapa de equilibrio oclusal, en la que la posición del diente en oclusión se mantiene conforme los maxilares continúan creciendo.

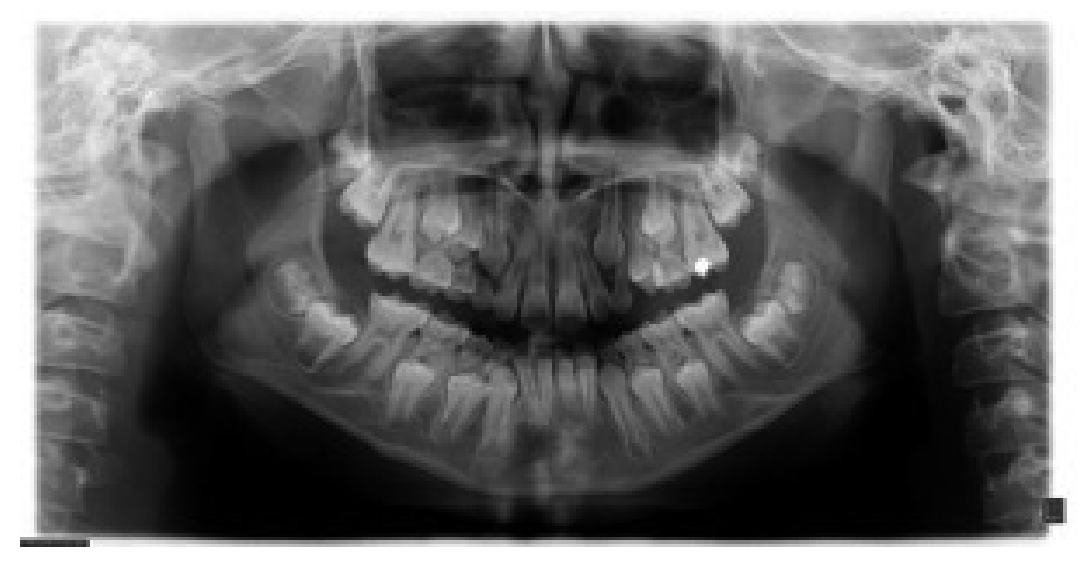

FIGURA 1. Fases de la erupción

Fuente: elaboración propia 
Es preciso tener en cuenta que existen diversos factores respecto de los tiempos de erupción:

- Cuando el diente se ve sometido a las fuerzas de masticación, que se oponen a la erupción, el ritmo de erupción disminuye.

- Una vez los dientes alcanzan el nivel oclusal, la erupción continúa de forma casi imperceptible.

- La rotación mandibular y la remodelación ósea favorecen, en gran parte, la erupción dental [11].

- La velocidad de erupción cambia según la fase en que se encuentre. La fase preeruptiva es más lenta, el ritmo aumenta en la eruptiva y decrece al acercarse al plano oclusal. También está relacionada con el desarrollo radicular.

\section{CALCIFICACIÓN DENTAL}

Para identificar los esquemas de la oclusión, es fundamental partir de los conceptos de normalidad, basados en el desarrollo de la dentición pre- y posnatal, los factores esqueletales que repercuten a nivel facial, las alteraciones en el tamaño, forma y disposición de los dientes en el arco [12], sin dejar de lado los cambios funcionales significativos que ocurren con la edad. La calcificación es el proceso de consolidación de la estructura dental, determinada en las fases de formación [13] y mineralización dental. Es uno de los pocos métodos biológicos para evaluar el desarrollo fisiológico de la dentición [14]; además contribuye a estimar la edad cronológica en aquellos casos de menores que carecen de documentación legal [15, 16].

Existen aspectos de significancia biológica en el proceso de calcificación: a. La calcificación de la matriz del esmalte se inicia en la porción más incisal u oclusal, cubriendo progresivamente de la parte externa a la interna, hasta alcanzar el límite dentinal. Esto ocurre de manera contraria a la formación de la matriz de esmalte, que se da desde la superficie interna a la externa. Los incisivos alcanzan su dimensión mesiodistal en una etapa temprana de desarrollo; en los molares se inicia en los vértices de las cúspides hacia cervical, por lo que alcanzan su calcificación posteriormente.

b. El diente no cambia de forma ni tamaño una vez la corona ha completado su calcificación.

c. El metabolismo intrauterino protege la formación de los tejidos duros, evitando variaciones estructurales en la etapa prenatal de los dientes que presentan calcificación posnatal [11, 12].

Las diferencias registradas en el desarrollo dental de los niños de la misma edad cronológica han dado lugar al concepto de edad fisiológica, como un medio para definir uno de los tantos estatus en el progreso de madurez. Por lo tanto, la edad fisiológica —o todos sus sinónimos biológicos, e incluso edad de desarrollo- es la medida para la descripción de una situación en particular, mientras que la edad cronológica o edad calendario transmite solo una aproximación a una situación, debido al amplio desarrollo en un ser. La maduración se escala por la ocurrencia de una secuencia de eventos. La edad dental puede ser un evento de desarrollo de madurez, que se establece por la emergencia y formación del diente. Sin embargo, las inferencias de la maduración somática con la formación ósea y dental deben hacerse con cautela, puesto que no siguen la misma secuencia de desarrollo [17]. 
En el momento del nacimiento, las coronas de los incisivos centrales, laterales, las cúspides de los caninos y molares se encuentran calcificadas (Tabla 2) [18]. Asimismo, se inicia la calcificación del primer molar permanente y las criptas de los primeros premolares, caninos e incisivos centrales superiores permanentes; la formación radicular se da un año después de la erupción, y el cierre apical se establece a dos meses de haber erupcionado el diente. A edades más tempranas se puede evaluar con mayor precisión por la formación de los dientes y porque los intervalos entre las etapas morfológicas son más cortos [19].

TABLA 2

Calcificación en dentición temporal

\begin{tabular}{|c|c|c|c|c|c|c|c|c|}
\hline \multirow[t]{2}{*}{ Diente } & \multicolumn{2}{|c|}{$\begin{array}{c}\text { Inicio de } \\
\text { calcificación } \\
\text { [vida intrauterina] }\end{array}$} & \multicolumn{2}{|c|}{$\begin{array}{c}\text { Coronas } \\
\text { calcificadas } \\
\text { [meses] }\end{array}$} & \multicolumn{2}{|c|}{$\begin{array}{l}\text { Erupción } \\
\text { [meses] }\end{array}$} & \multicolumn{2}{|c|}{$\begin{array}{l}\text { Raíz completa } \\
\text { [años] }\end{array}$} \\
\hline & Superior & Inferior & Superior & Inferior & Superior & Inferior & Superior & Inferior \\
\hline Central & 14 & 14 & $11 / 2$ & $21 / 2$ & 10 & 8 & $11 / 2$ & $11 / 2$ \\
\hline Lateral & 16 & 16 & $21 / 2$ & 3 & 11 & 13 & 2 & $11 / 2$ \\
\hline Canino & 17 & 17 & 9 & 9 & 19 & 20 & $31 / 4$ & $31 / 4$ \\
\hline 1. ${ }^{\text {er }}$ molar & 15 & 15 & 6 & $51 / 2$ & 16 & 16 & $21 / 2$ & $21 / 2$ \\
\hline $2 .^{\circ} \mathrm{molar}$ & 19 & 18 & 11 & 10 & 29 & 27 & 3 & 3 \\
\hline
\end{tabular}

Fuente: elaboración propia

El método más fiable para estimar el momento de la erupción fue formulado por Carmen Nolla en 1960 y se basa en el estado de maduración dental antes de la erupción. Está información se obtiene a partir de una radiografía panorámica o periapical, en la que se fundamentan diez estadios de formación dental, donde cero indica ausencia de cripta y diez corresponde a una formación dental completa (Tabla 3) [20, 21].

A partir de 2928 radiografías panorámicas, correspondientes a 1446 niños y 1482 niñas, en edades comprendidas entre los 2 y 20 años, Demirjian [17] estableció ocho estadios de maduración (Tabla 4), describiéndolos con letras desde la A (inicio de la calcificación) hasta la $\mathrm{H}$ (cierre apical) [17].
TABLA 3

Etapas relevantes de maduración aplicando el diagrama de Nolla

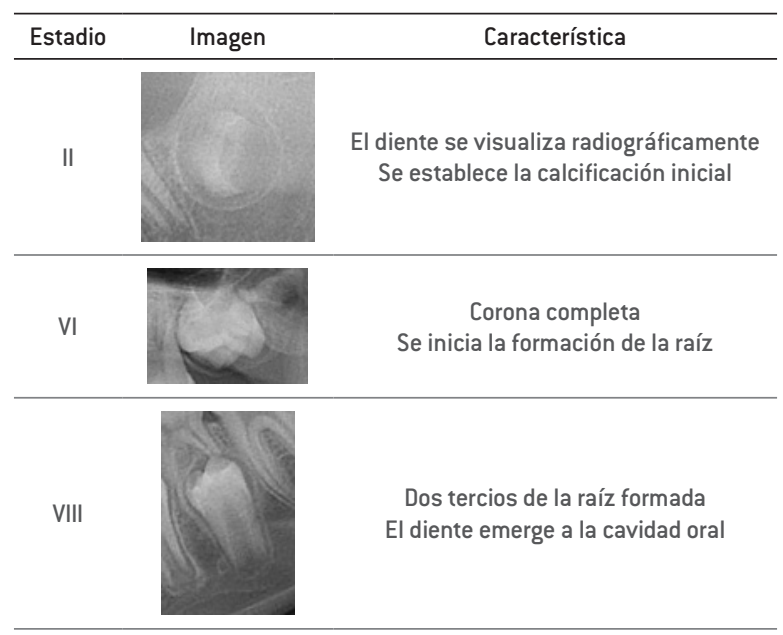

Fuente: elaboración propia 
TABLA 4

Diagrama de estadios de maduración dental de Demirjian

\begin{tabular}{|c|c|c|}
\hline Estadio & Característica & Representación \\
\hline A & $\begin{array}{l}\text { - Los dientes unirradiculares y multi- } \\
\text { rradiculares presentan comienzo de } \\
\text { calcificación en la zona superior de la } \\
\text { cripta con forma de conos } \\
\text { - No existe fusión entre estos dientes }\end{array}$ & \\
\hline B & $\begin{array}{l}\text { - La fusión de los puntos de calcifica- } \\
\text { ción crea una o varias cúspides que } \\
\text { se unen formando una superficie } \\
\text { oclusal regular }\end{array}$ & \\
\hline C & $\begin{array}{l}\text { - La formación de esmalte está com- } \\
\text { pleta en la superficie oclusal } \\
\text { - Se inicia el depósito de dentina } \\
\text { - El contorno de la cámara pulpar tiene } \\
\text { forma de curva en el borde oclusal }\end{array}$ & \\
\hline D & $\begin{array}{l}\text { - La formación de la corona se ha com- } \\
\text { pletado hasta la unión amelocemental } \\
\text { - En los dientes unirradiculares, el borde } \\
\text { superior de la cámara pulpar tiene } \\
\text { forma curva, y es más cóncava hasta } \\
\text { la región cervical } \\
\text { - La proyección de los cuernos pulpares } \\
\text { - si están presentes- dan al contor- } \\
\text { no pulpar el aspecto de paraguas } \\
\text { - En los molares, la cámara pulpar tiene } \\
\text { forma trapezoidal }\end{array}$ & \\
\hline \multirow[t]{2}{*}{$\mathrm{E}$} & $\begin{array}{l}\text { - En los dientes unirradiculares, la pa- } \\
\text { red de la cámara pulpar forma líneas } \\
\text { rectas, cuya continuidad se ve rotada } \\
\text { por la presencia del cuerno pulpar; } \\
\text { la longitud radicular es menor que la } \\
\text { altura de la corona }\end{array}$ & \\
\hline & $\begin{array}{l}\text { - En los molares, la formación inicial } \\
\text { de la furca se observa como un punto } \\
\text { calcificado con forma semilunar; la } \\
\text { longitud de la raíz es aún menor que } \\
\text { la longitud de la corona. }\end{array}$ & \\
\hline$F$ & $\begin{array}{l}\text { - En los dientes unirradiculares, las } \\
\text { paredes de la cámara pulpar forman un } \\
\text { triángulo isósceles, el ápice termina en } \\
\text { forma de embudo; la longitud radicular } \\
\text { es igual o mayor a la altura de la corona } \\
\text { - En los molares, la zona calcificada en la } \\
\text { furca se ha desarrollado, dando forma } \\
\text { definida a las raíces y terminando en } \\
\text { embudo; la longitud de la raíz es igual o } \\
\text { mayor que la altura de la corona }\end{array}$ & \\
\hline G & $\begin{array}{l}\text { - Las raíces están paralelas, pero los } \\
\text { ápices están abiertos }\end{array}$ & \\
\hline H & $\begin{array}{l}\text { - El ápice está totalmente cerrado } \\
\text { - La membrana periodontal tiene una } \\
\text { anchura uniforme alrededor de la raíz } \\
\text { y el ápice }\end{array}$ & \\
\hline
\end{tabular}

Fuente: elaboración propia

\section{DESARROLLO DE LA DENTICIÓN Y OCLUSIÓN}

El desarrollo de la dentición abarca cambios desde la vida prenatal hasta la edad adulta, y presenta cuatro etapas: almohadillas gingivales, dentición primaria, dentición mixta y dentición permanente (Tabla 5).

\section{TABLA 5}

Etapas del desarrollo de la dentición

\begin{tabular}{ll}
\hline \multicolumn{1}{c}{ Etapa } & \multicolumn{1}{c}{ Periodo } \\
\hline Almohadillas gingivales & Nacimiento a 6 meses \\
\hline Dentición decidua & 6 meses a 6 años \\
\hline Dentición mixta & 6 años a 12 años \\
\hline Dentición permanente & 12 años en adelante \\
\hline
\end{tabular}

Fuente: elaboración propia

\section{ALMOHADILLAS GINGIVALES}

En su anatomía, los maxilares en un recién nacido están representados por rodetes gingivales, con elevaciones y surcos que delinean la posición de los dientes deciduos. Presentan una consistencia firme, gruesa, de color rosa $[23,24]$. Las porciones bucal y lingual se encuentran separadas por un surco dental, donde cada diente primario en desarrollo tiene un lugar específico según los patrones genéticos de crecimiento [25]. La forma de cada almohadilla está determinada prenatalmente y puede verse modificada posnatalmente por fuerzas físicas, como los hábitos previos a la erupción dental [26].

En una vista oclusal se proyectan tres surcos: a) surco gingival, que separa la almohadilla gingival del paladar; b) surco dental, que inicia en la papila incisiva hasta tocar el surco gingival en la región del canino, terminando en la región del molar; c) surco lateral, que se adhiere por el vestibular al frenillo labial y a las bridas laterales, y por el palatino, en el segmento anterior, con el paladar propiamente dicho, la papila palatina y sus rugosidades (Figura 2). En el 
segmento posterior, se encuentra la transición del paladar duro y blando; este último se evidencia por el color rojizo [26]. Esta etapa se extiende desde el nacimiento hasta la erupción del primer diente temporal (incisivo central inferior), aproximadamente a los seis meses.

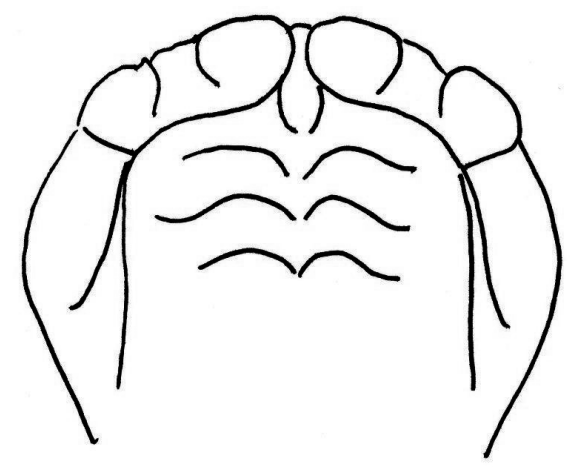

FIGURA 2. Reborde alveolar superior

Fuente: elaboración propia

La forma rectangular del arco inferior se caracteriza por un surco gingival que corresponde a la extensión lingual de las almohadillas gingivales; un surco dental que se une al surco gingival en la región del canino, y un surco lateral. En el vestibular se adhiere al frenillo labial y a las bridas; en el sector lingual, se encuentra el piso junto con el frenillo lingual [26] (Figura 3).

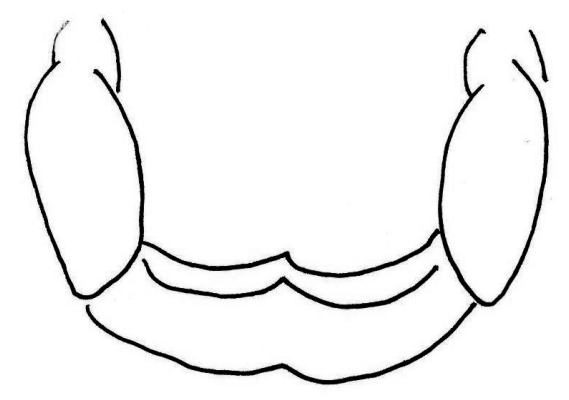

FIGURA 3. Rebordes alveolares mandibulares

Fuente: elaboración propia

Leighton reporta que el tamaño de las almohadillas gingivales está determinado por el estado de madurez del niño en el momento del nacimiento: el tamaño al nacer (expresado por el peso de nacimiento), el tamaño de los dientes primarios en desarrollo y ciertos factores genéticos [27]. En una vista oclusal, la región de incisivos, caninos y bordes libres de los rodetes presenta el cordón fibroso de Robin y Magilot: permite la deglución durante la época de lactancia y desaparece en la época de la erupción dentaria [23, 28] (Figura 4).

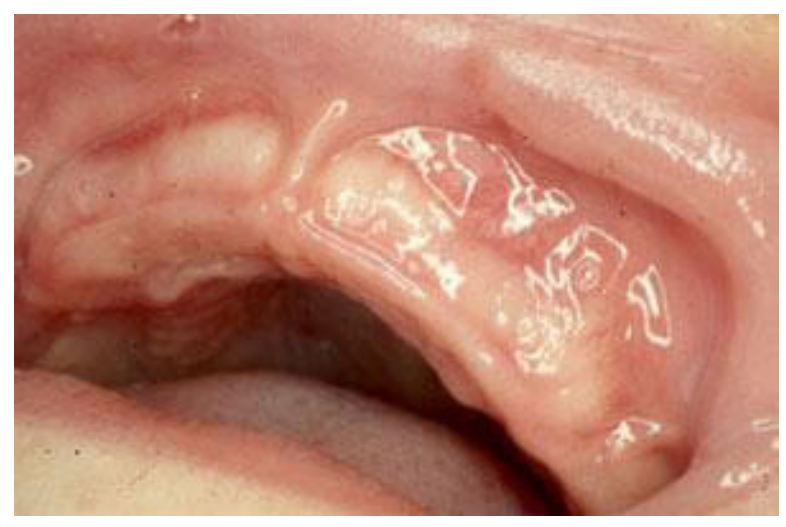

FIGURA 4. Cordón fibroso de Robin y Magilot

Fuente: elaboración propia

La relación entre ambas almohadillas no es precisa y regular, por lo que no puede ser utilizada para predecir la relación futura de los arcos. En el plano sagital, el maxilar se proyecta más anterior, tanto en sentido bucal como labial; el espacio que queda entre ambas es ocupado por la lengua, hasta que hacen erupción los dientes anteriores, que sirven de guía para el nuevo posicionamiento de esta, que es conocida como "postura neonatal" [29]. Leighton reporta que la relación sagital de las almohadillas varía entre 0 y $10.0 \mathrm{~mm}$, con un promedio de $5.5 \mathrm{~mm}$. Para la edad de cinco años, se ha reducido a $3 \mathrm{~mm}$ [27]. En el plano vertical, la relación es variable, con un rango de +4.0 mm a -4.0 mm, con un promedio de +0.65; siendo mayor en hombres que en mujeres [30].

Durante el primer año, las almohadillas crecen con rapidez, debido a que la boca del neonato está dotada de un sistema sensorial que impulsa las funciones neuromusculares: succión, respiración y deglución. La alimentación materna es un determinante para el posicionamiento anterior de la mandíbula. Esto 
significa que la maduración de la función oral sigue un gradiente anteroposterior: al nacer los labios son maduros, facilitando el lactar con fuerza; por su parte, las estructuras posteriores requieren con el tiempo mayor actividad de la parte posterior de la lengua [18]. Durante esta fase se pueden presentar dientes natales, neonatales o preerupcionados. Se diferencian por el tiempo de erupción, producto de una alteración en la lámina dental (Tabla 6) [26].

\section{TABLA 6}

Dientes natales, neonatales y preerupcionados

\begin{tabular}{ll}
\hline Alteraciones de la erupción & Tiempo de erupción \\
\hline Dientes natales & Presentes en el nacimiento \\
\hline Dientes neonatales & Durante el primer mes de vida \\
\hline Dientes preerupcionados & Durante el segundo o tercer mes de vida \\
\hline
\end{tabular}

\section{Fuente: elaboración propia}

Los dientes natales son más frecuentes que los neonatales en una proporción de 3:1 (el incisivo central mandibular es el que más se reporta) [32]. Su forma y su tamaño pueden estar dentro de los estándares; también pueden presentar morfología cónica, color amarillo opaco [33], poco desarrollo radicular [34] y formación irregular de dentina y cemento [35]. Se adhieren al borde de la encía por medio de tejido blando, lo que causa irritación en el bebé y en la madre, en el momento de la lactancia (Tabla 7) [36, 37].

\section{TABLA ?}

Características de dientes natales y neonatales

\begin{tabular}{ll}
\hline & Dientes natales y neonatales \\
\hline & - Posición superficial del germen \\
& - Herencia \\
& - Trastornos endocrinos \\
Etiología & - Hipovitaminosis \\
& - Estado febril \\
& - Efectos de síflis congénita \\
& - Asociación a síndromes \\
\hline Esmalte & - Inmaduro \\
& - Sin formación de capa prismática; apariencia \\
& - de panal de abejas \\
&
\end{tabular}

\begin{tabular}{cl}
\hline & Dientes natales y neonatales \\
\hline & - Hipoplasia del esmalte en diversos grados \\
& - Cámara pulpar amplia \\
& - Cemento irregular \\
& - Disposición irregular de túbulos dentinales \\
\hline Tamaño y forma & Normal o cónica \\
\hline Raíz & Incompleta \\
\hline Pronóstico & $\begin{array}{l}\text { Depende del grado de madurez de la estructura } \\
\text { dental }\end{array}$ \\
\hline
\end{tabular}

Fuente: elaboración propia

\section{DENTICIÓN TEMPORAL}

Esta etapa del desarrollo dental se inicia con la erupción del incisivo central inferior, cerca de los seis meses de edad, y termina con la erupción del primer molar permanente, en una edad promedio de seis años. Las zonas del arco maxilar que contienen los dientes deciduos, desde los centrales hasta los primeros molares, crecen considerablemente desde el nacimiento hasta los 6-8 meses de vida. Este aumento no sobrepasa los $5 \mathrm{~mm}$ en sentido transversal y los $4 \mathrm{~mm}$ en sentido sagital, contando incluso con el crecimiento $[37,38]$.

El desarrollo se inicia entre el tercer y cuarto mes de vida intrauterina, y se identifican tres etapas: a) inicial activa [39], en la que la tasa de crecimiento del hueso circundante guarda relación con el desarrollo y crecimiento lento de los gérmenes dentales; b) formación de los dientes permanentes, que se extiende desde que los dientes primarios emergen hasta encontrar el antagonista, tiene un ritmo de erupción acelerado, y los gérmenes permanentes se desarrollan cambiando sus posiciones constantemente; y c) oclusión funcional de la dentición temporal, que está acompañada por el desarrollo continuo de los gérmenes permanentes [40].

El desarrollo de la raíz de los dientes primarios ocurre una vez se inicia la erupción, dejando el germen del permanente atrás, con su hueso alveolar [24]. La resorción de las raíces de los dientes temporales se da al completarse el desarrollo radicular. En la dentición primaria se presenta una línea neonatal, cuya localización 
varía según la función de desarrollo al momento de nacer. Esta puede verse afectada por traumas, estados febriles, que producen un esmalte manchado o hipocalcificado, y puede afectar a ambas denticiones [18].

Los incisivos alcanzan gran parte de la dimensión mesiodistal de la corona en una etapa temprana de desarrollo. En contraste, los molares continúan su incremento intercuspideo cuando las cúspides están parcialmente calcificadas, y parecen aumentar su diámetro mesiodistal con relación al crecimiento de la mandíbula [41]. La longitud del arco y el tamaño de los dientes temporales antes del nacimiento generan discrepancias: los dientes deciduos se encuentran superpuestos y apiñados, y se establecen cuatro patrones de ubicación en el arco, pero con el proceso de erupción, crecimiento y desarrollo de las bases óseas se van alineando [41]. Los gérmenes de los anteriores se encuentran muy cercanos, el incisivo lateral queda ubicado lingual del central, y los posteriores están alineados por septos óseos separados de manera marcada [42]. Al momento del nacimiento, ya están formados el esmalte de las coronas de los incisivos y caninos; la superficie oclusal y la mitad de la corona de los primeros molares, y las cúspides de los segundos molares [42].

\section{Calcificación}

La calcificación en la dentición temporal prevalece en los varones, primero en el arco mandibular. Comienza con los incisivos centrales inferiores y finaliza con los segundos molares [22]. En el momento del nacimiento, se presentan las siguientes características en cada tipo de diente:

- Incisivo central superior: la corona está completamente formada y gran parte de la raíz se ha desarrollado.

- Incisivo lateral: está desarrollado como el central, tiene dos terceras partes del esmalte formado.

- Caninos: se ha formado un tercio del esmalte. Los gérmenes permanentes maxilares se ubican en el ángulo entre la nariz y el seno maxilar, y el canino inferior se ubica debajo de la corona de los caninos.

- Primer molar primario: la corona está completamente formada y el esmalte se ha unido a la cúspide.

- Segundo molar primario: está menos calcificado que el primer molar primario, sin inicio de formación radicular. El germen solo es un brote epitelial.

\section{Secuencia de erupción}

El límite de tiempo para evaluar si hay un adelanto o un retraso en la erupción es de 6 meses; sin embargo, la secuencia de erupción trata de mantenerse. Existe un 80\% de influencia genética, y un 20\% está relacionado con factores ambientales [43] (Tabla 8).

\section{TABLA 8}

Variaciones en la secuencia de erupción en la dentición temporal [40]

\begin{tabular}{lccccccc} 
& \multicolumn{2}{c}{ Temprana } & \multicolumn{3}{c}{ Promedio } & & Tardía \\
\hline Dientes/percentiles & Min. & 10 & 30 & 50 & 70 & 90 & 100 \\
\hline Incisivo central inferior & 4 & 5 & 6 & 7.8 & 9 & 11 & 17 \\
\hline Incisivo central maxilar & 5 & 6 & 8 & 9.6 & 11 & 12 & 15 \\
\hline Incisivo lateral maxilar & 6 & 7 & 10 & 11.5 & 13 & 15 & 21 \\
\hline Incisivo lateral mandibular & 6 & 7 & 11 & 12.4 & 14 & 18 & 27 \\
\hline $1{ }^{\text {er }}$ molar maxilar & 8 & 10 & 13 & 15.1 & 16 & 20 & 28 \\
\hline $1{ }^{\text {er }}$ molar mandibular & 8 & 10 & 14 & 15.7 & 17 & 20 & 27 \\
\hline
\end{tabular}




\begin{tabular}{llllllll} 
& \multicolumn{2}{c}{ Temprana } & & Promedio & & Tardía \\
\hline Canino mandibular & 8 & 11 & 16 & 18.2 & 19 & 24 & 29 \\
\hline Canino maxilar & 8 & 11 & 17 & 18.3 & 20 & 24 & 29 \\
\hline $2 .{ }^{\circ}$ molar mandibular & 8 & 13 & 24 & 26.0 & 28 & 31 & 34 \\
\hline $2 .{ }^{\circ}$ molar maxilar & 8 & 13 & 24 & 26.2 & 28 & 31 & 34 \\
\hline
\end{tabular}

\section{Fuente: elaboración propia}

Canut establece tres fases en el proceso de erupción en la dentición temporal. La primera corresponde a la erupción del grupo incisivo; existe un intervalo de erupción de 2 a 3 meses entre los dientes homólogos, que genera un adelantamiento posicional en el patrón eruptivo. La segunda fase es la de la erupción de los primeros molares a los 16 meses, seguida por la erupción de caninos a los 20 meses. Existe un periodo silente de 4 a 6 meses, luego del cual comienza la tercera fase con la erupción de los segundos molares, que tardan alrededor de 4 meses [15].

La secuencia de erupción en la dentición decidua lleva este orden: incisivo central (A), incisivo lateral (B), primer molar (D), canino (C) y segundo molar (E) $[44,45]$. Se pueden presentar variaciones; no obstante, no existen diferencias en el género. Usualmente, los incisivos laterales, primeros molares y caninos tienden a erupcionar primero en la mandíbula que en el maxilar.

\begin{tabular}{llll} 
& $A B$ & $D C$ & $E$ \\
\hline$A$ & $B D$ & $C E$ &
\end{tabular}

FIGURA 5. Secuencia de erupción en la dentición decidua

Fuente: elaboración propia

En una secuencia cronológica en años, el desarrollo de la dentición temporal se establece así:

- Primer año de vida. Entre el quinto y octavo mes de vida emerge el incisivo central inferior, seguido por el lateral. Este proceso se da más por retracción gingival que por crecimiento vertical. Se establece un escalón acentuado entre las piezas superiores e inferiores, de tal manera que, estando los incisivos en boca, los rebordes alveolares laterales mantienen su contacto [2].

- Segundo año de vida. Las raíces de los incisivos están completamente calcificadas. Las raíces de los demás dientes se encuentran en las fases finales. Incisivos, caninos y primeros premolares permanentes presentan estadios de mineralización más avanzados [46]. Hacia la mitad del segundo año, se pierde el contacto de los rebordes alveolares con la erupción de los primeros molares mandibulares y maxilares, en un intervalo de 3 a 4 meses. La cúspide palatina superior encuentra la fosa excéntrica hacia distal del primer molar inferior, donde se establece la primera llave de la oclusión. Se inicia la función de articular disminuyendo la sobremordida profunda anterior. Después de un periodo de 3 a 4 meses, los caninos mandibulares rompen el epitelio, seguidos por los caninos maxilares. Entre los 24 y 30 meses erupcionan los segundos molares inferiores, seguidos de los superiores; su intercuspidación está determinada por la primera llave. Las dos cúspides vestibulares superiores quedan en posición distal respecto a las inferiores. En promedio, el molar inferior es un milímetro mayor que su antagonista; presenta una tercera cúspide, que al establecer contacto con la fosa distal condiciona a un cierre posterior de la oclusión, el "plano lácteo posterior" [42].

- Tercer año de vida. Todos los dientes temporales entran en oclusión funcional, con raíces totalmente mineralizadas. Las 
coronas de los primeros molares permanentes están casi calcificadas y los demás dientes permanentes presentan estadios de calcificación en sus coronas.

- Cuarto año de vida. Los dientes permanentes presentan estadios de mineralización avanzados y el primer molar permanente tiene área de bifurcación visible. La tercera parte de las raíces de los incisivos temporales se ha reabsorbido.

- Quinto año de vida. Los incisivos y los primeros molares permanentes poseen un desarrollo radicular evidente para dar paso al proceso de erupción.

\section{Características de la oclusión en la dentición temporal}

Evaluar el desarrollo de la dentición decidua da al clínico lineamientos para establecer el patrón de normalidad con cada una de las variables. Las características que se presentan en esta dentición hacen posible una oclusión dinámica y funcional, la cual da lugar a la transición hacia una dentición mixta, y de esta a la permanente. Dichas características son descritas a continuación.

\section{Espacios fisiológicos o espacios de desarrollo}

En 1918, Delabarrre fue el primero en describir el espaciamiento interproximal en la dentición primaria. Baume señala que dichos espacios son considerados una condición congénita [48, 49], se presentan en dos terceras partes de la población infantil [50, 49]. Constituyen un factor importante para el alineamiento de los incisivos permanentes, ya que compensan las diferencias de tamaño entre los incisivos temporales y sus sucedáneos. Cuantificando los espacios disponibles en la dentición primaria, Leighton [28] llega a predecir la presencia de apiñamiento (Tabla 9). En el arco maxilar, el espaciamiento interdental puede variar de 0 a $10.0 \mathrm{~mm}$, con un promedio de $5.0 \mathrm{~mm}$; a nivel mandibular, varía de 0 a 6.0 $\mathrm{mm}$, con un promedio de $3.0 \mathrm{~mm}$. Foster (1982) reporta que los espacios generalizados ocurren en el 75\% de los individuos en la dentición primaria [12].

\section{TABLA 9}

Probabilidad de apiñamiento en la dentición permanente, basada en los espacios disponibles en la dentición primaria

\begin{tabular}{cc}
\hline $\begin{array}{c}\text { Espacios en la } \\
\text { dentición primaria }\end{array}$ & $\begin{array}{c}\text { Posibilidades de apiñamiento } \\
\text { en la dentición permanente }\end{array}$ \\
\hline $0 \mathrm{~mm}$ y apiñamiento & $100 \%$ \\
\hline $0 \mathrm{~mm}$ & $70 \%$ \\
\hline 0 a $3 \mathrm{~mm}$ & $50 \%$ \\
\hline 3 a $6 \mathrm{~mm}$ & $20 \%$ \\
\hline Mayor a $6 \mathrm{~mm}$ & $0 \%$ \\
\hline
\end{tabular}

Fuente: elaboración propia

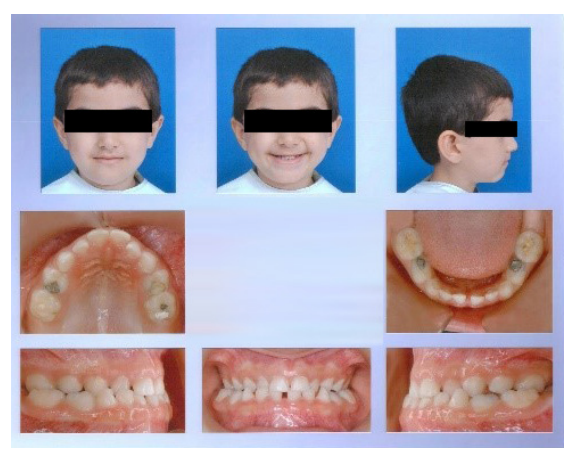

FIGURA 6. Espacios de la dentición decidua

Fuente: elaboración propia

\section{Espacios primates}

Lewis y Lehman (1929) describen estos espacios como una característica normal en la dentición permanente en los primates y están presentes en la dentición decidua del hombre. Además de los espacios fisiológicos, Baume registró los espacios primates, que se encuentran ubicados en mesial de caninos superiores y distal de caninos inferiores, facilitando la relación canina clase I, una vez el primer molar primario hace erupción. Estos espacios son consecuencia del 
patrón inherente de los caninos en el momento de la erupción dental [47].

\section{Inclinación de los ejes axiales de los incisivos}

La implantación casi perpendicular de los dientes temporales con relación a sus bases óseas genera un paralelismo entre sus raíces, con una mínimainclinación vestibular delosincisivos. Se establece un plano oclusal plano, sin inclinación mesio-distal ni vestíbulo-lingual; es decir, no existe curva de Spee en sentido anteroposterior ni curva de Wilson en sentido transversal.

\section{Relación horizontal (overjet)}

Se establece como la distancia en milímetros entre la cara palatina del incisivo superior más vestibularizado y la cara vestibular del incisivo inferior. En la dentición temporal, el patrón normal de overjet varía entre 0 y 4.0 mm [22]. El crecimiento sagital de la mandíbula contribuye a que el overjet disminuya con la edad. Si los incisivos superiores se encuentran lingualizados respecto a los mandibulares, se establece un overjet negativo (Figura 7), que en términos de maloclusión se expresa como una mordida cruzada anterior.

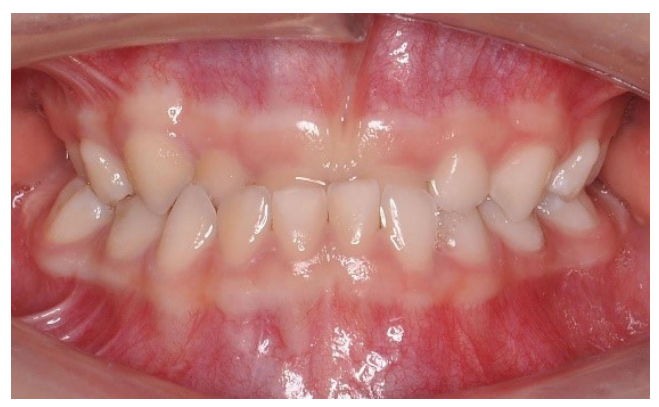

FIGURA ?. Overjet negativo

Fuente: elaboración propia

\section{Relación vertical o sobremordida}

Se describe como la magnitud de superposición vertical de los incisivos centrales maxilares y mandibulares, y se expresa en porcentajes. En la dentición decidua varía entre 10\% y 40\%. Un aumento del overbite es común en la etapa inicial del desarrollo de la dentición, ya que los incisivos mandibulares contactan con el cíngulo de los incisivos superiores en relación céntrica, y se ubican en una posición más vertical con relación a los permanentes. Esta mordida abierta se puede autocorregir con la erupción de los molares deciduos y el crecimiento diferencial de los procesos alveolares.

Foster reporta que la relación vertical ideal se establece en un 19\%; en un 37\% disminuye; $24 \%$ presenta mordida abierta, y en el $20 \%$ aumenta [22]. Cuando los bordes de los incisivos superiores e inferiores se encuentran en el mismo plano, se describe como borde a borde, si no entran en contacto se establece una mordida abierta y se cuantifica en milímetros. La atrición y el desgaste de los dientes temporales, resultado de una menor mineralización de las estructuras dentales, produce una disminución de la sobremordida. Existen otros factores determinantes en el establecimiento del overbite, como la presencia de hábitos bucales (succión digital, empuje lingual persistente) y pérdida de estructuras dentales en el sector posterior.

\section{Tipo de arcos en la dentición decidua}

En 1950 Baume encontró dos tipos de arcos con relación a la presencia o ausencia de espacios: arcos tipo I (arcos espaciados), con espacios primates y fisiológicos en la zona de incisivos; y arcos tipo II (arcos cerrados), que pueden o no presentar espacios primates sin espacios en la zona incisiva [46] (Tabla 10, Figura 8). La distribución de los espacios en el tipo I muestra variaciones, incluyendo el tipo II en el arco opuesto. Los arcos dentales sin espacio tienen un promedio de $1.5 \mathrm{~mm}$ a $1.7 \mathrm{~mm}$, lo que representa arcos más reducidos [46]. La ausencia de espacios no siempre se debe al diámetro de los anteriores primarios, sino a la falta de crecimiento alveolar, o a una 
combinación de ambos factores. Este no es un análisis concluyente, pero determina pronóstico o tendencias $[46,51,52]$.

TABLA 10

Tipos de arcos en la dentición decidua

\begin{tabular}{ccc}
\hline Arco & Diastema & Alineación de grupo incisivo \\
\hline Tipo I & Presente & Favorable \\
\hline Tipo II & Ausente & Menos favorable \\
\hline
\end{tabular}

\section{Fuente: elaboración propia}
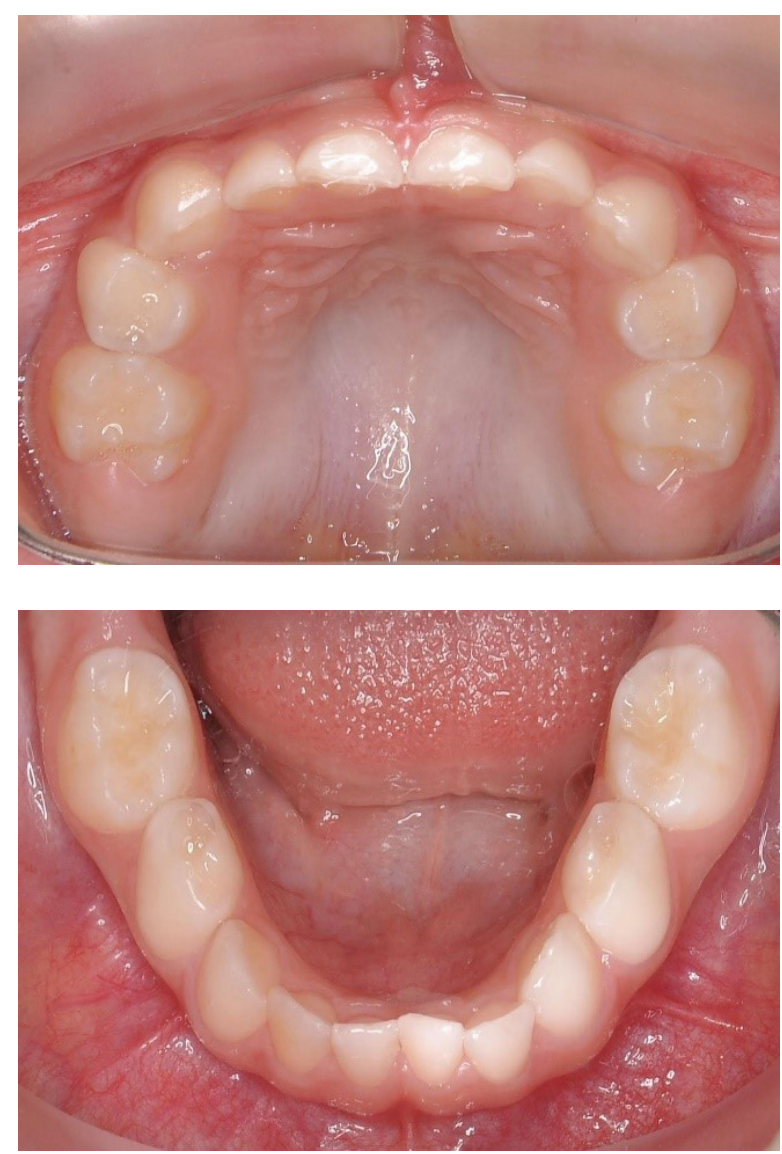

FIGURA 8. Arco superior e inferior tipo ॥

Fuente: elaboración propia

En la dentición temporal se desarrollan arcos amplios, capaces de soportar todos los dientes temporales. El arco maxilar puede presentar varias formas, en aspecto normal, y el arco inferior acompaña el maxilar mostrando una figura de U.

\section{Relación molar}

En la dentición decidua, la relación anteroposterior de los molares es descrita en función de las caras distales de los segundos molares deciduos.

- Plano terminal recto: la cara distal del segundo molar deciduo inferior está en el mismo plano vertical de la cara distal del segundo molar deciduo superior.

- Escalón mesial: la cara distal del segundo molar inferior se encuentra delante de la cara distal del segundo molar superior.

- Escalón distal: la cara distal del segundo molar inferior se encuentra detrás de la cara distal del segundo molar inferior.
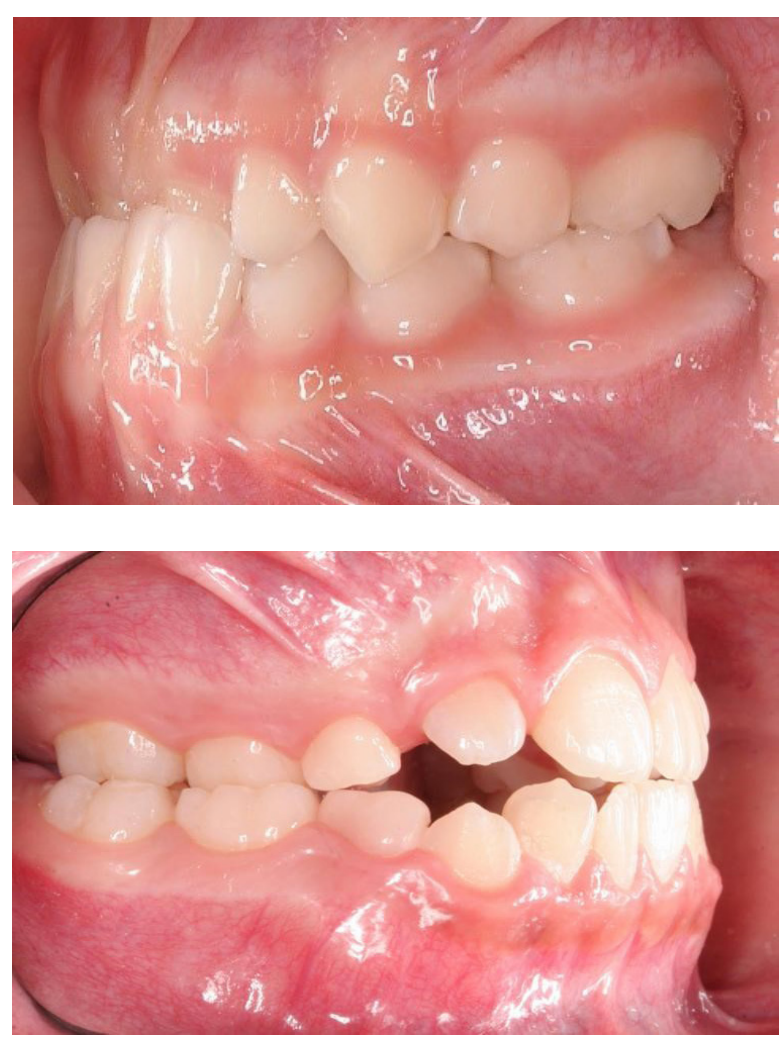

FIGURA 9. Escalón mesial y plano terminal recto

Fuente: elaboración propia

Baume afirma que las caras distales de los segundos molares son las que guían la erupción de los molares permanentes. En este proceso se pueden presentar varias situaciones clínicas: 
- Si no existe espacio primate en la mandíbula, al erupcionar los primeros molares se establece una relación borde a borde, que en condiciones favorables tiende a una oclusión normal, con el recambio de los sectores posteriores de la dentición decidua a la permanente.

- Si existe espacio primate en el arco inferior, con la erupción del primer molar permanente inferior se cierra el espacio por la migración mesial; pero si erupciona el primer molar superior antes que el inferior, se cierra el espacio primate superior, generando una relación distal con respecto al molar permanente inferior [46].

El cierre del espacio primate superior puede llevar a una retención prolongada de los laterales superiores, que emergen por lingual o en giroversión en el momento de su erupción.

En 1950 Baume determinó que una relación de escalón mesial menor a $3 \mathrm{~mm}$ es ideal para que se establezca una intercuspidación de los primeros molares permanentes a una relación clase I. Destaca que una relación de plano terminal recto es la que el clínico debe evaluar con mayor criterio, pues por diversos factores puede guiar a los molares permanentes a una clase I o a una clase II, lo cual reduce la longitud del arco superior o inferior. Una relación de escalón distal siempre guía a los molares permanentes a desarrollar una relación clase II (Tabla 11) [51, 52].

TABLA 11

Análisis de arcos

\begin{tabular}{cc}
\hline Arco & Conducta \\
\hline Tipo II & $\begin{array}{c}\text { Observación } \\
\text { Intervención en caso necesario }\end{array}$ \\
\hline Tipo I & $\begin{array}{c}\text { Observación } \\
\text { Mantener la integridad del arco }\end{array}$ \\
\hline Arco & Conducta \\
\hline Plano terminal recto & Observación \\
\hline
\end{tabular}

\begin{tabular}{cc}
\hline Escalón distal & $\begin{array}{c}\text { Observación } \\
\text { Mantener la integridad del arco } \\
\text { Verificar la relación incisal }\end{array}$ \\
\hline Escalón mesial & Observación \\
& $\begin{array}{c}\text { Mantener la integridad del arco } \\
\text { Verificar la relación incisal }\end{array}$ \\
\hline
\end{tabular}

Fuente: elaboración propia

\section{Relación canina}

En la dentición primaria, la clasificación de la relación canina se valora a partir de la vertiente cúspidea del canino superior con relación al canino inferior y el primer molar deciduo:

- Clase r: la vertiente de la cúspide del canino superior ocluye entre el canino y el primer molar inferior primario.

- Clase ir: la vertiente de la cúspide del canino superior está por delante del punto de contacto del canino y primer molar primario

- Clase iII: la vertiente de la cúspide del canino superior está situada distal del área de contacto del canino y el primer molar primario.
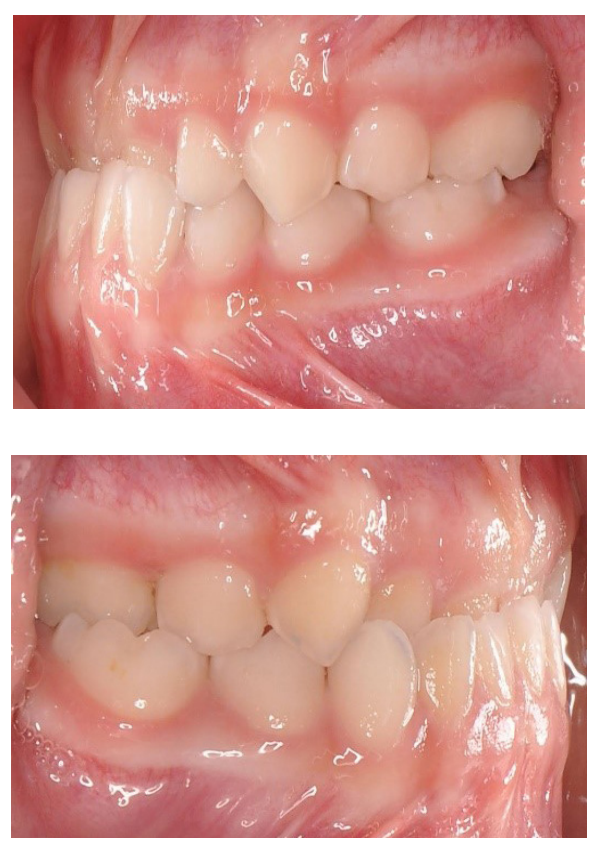

FIGURA 10. Relaciones caninas clase I y clase III en la dentición temporal Fuente: elaboración propia 
El desarrollo de la dentición decidua comprende un periodo de tres años, en el que las dimensiones transversales y sagitales permanecen estables. La atrición fisiológica desencadena una oclusión deslizante, haciendo que la mandíbula avance y que el plano poslácteo se transforme en escalón; esta condición favorece el segundo avance fisiológico de la oclusión. Si este último no existe, la mandíbula asume una posición adaptativa debido a interferencias oclusales. En algunas situaciones, esto puede desencadenar una mordida cruzada posterior unilateral, mostrando un desgaste significativamente menor en el lado de la alteración oclusal y un patrón inadecuado de la masticación. Cabe señalar que el grado de abrasión dental difiere en diferentes poblaciones y grupos étnicos en relación con los hábitos diarios [52]. En síntesis, existe una tendencia al acortamiento del arco en longitud, siempre y cuando existan espacios en los sectores laterales: los espacios a nivel de los molares se cierran y los que están distal de los caninos, disminuyen, y es marcado en el maxilar inferior.

\section{Cambios dimensionales de los arcos en la dentición temporal}

Baume evaluó las dimensiones de los arcos en treinta niños en edades comprendidas entre los tres y cuatro años, considerando los siguientes lineamientos:

- Longitud de arco: distancia perpendicular a la línea tangencial de la cara distal de los segundos molares temporales hasta los puntos infradental y prostion, tanto en el arco superior como inferior.

- Perímetro del arco: se determina desde la cara distal del segundo molar deciduo, siguiendo los puntos de contacto de los molares y bordes incisales, hasta la cara distal del segundo molar deciduo del otro lado.
- Distancia intercanina: corresponde a la distancia lineal desde la punta de los caninos de ambos lados, la cual es medida en milímetros [46]. Entre los tres y cuatro años la dimensión transversal anterior no tiene cambios, salvo que existan factores ambientales. Al respecto, Moorrees señala que esta distancia disminuye desde los dos años y medio, cuando los dientes deciduos hacen erupción, hasta los seis años, cuando erupcionan los primeros molares permanentes. Esto se debe a la migración mesial de los segundos molares primarios, siendo más marcado en el arco inferior por la migración mesial de los primeros molares permanentes. Lo ideal es que esta distancia sea suficientemente amplia para la alineación de los cuatro incisivos permanentes, la cual se incrementa $3 \mathrm{~mm}$ con la emergencia de estos dientes, tanto superiores como inferiores [46]. En un estudio longitudinal, Sillman reportó un incremento en el maxilar de $5.0 \mathrm{~mm}$ y de $3.5 \mathrm{~mm}$ en la mandibular, desde el nacimiento hasta los dos años de edad [53].

- Ancho intermolar: se establece desde el tubérculo lingual en el margen gingival entre los segundos molares deciduos de cada lado [6].

Finalmente, Baumer apunta las siguientes conclusiones:

a. Longitud de arco:

- Maxilar: entre los cuatro a seis años, antes de la erupción de los primeros molares permanentes; la longitud permaneció constante en 25 casos.

- Mandíbula: no se modificó en 23 de los casos.

En seis casos se observó una leve disminución en el maxilar, y en la mandíbula, ocho casos; 
debido a la migración mesial de los segundos molares temporales o caninos.

b. Ancho intercanino:

- Maxilar: entre los cuatro y seis años, el ancho intercanino no tuvo cambios en 24 casos.

- Mandíbula: en 26 casos no hubo cambios.

c. Ancho intermolar: tanto para el maxilar como para la mandíbula, no hubo cambios 42, 46, 51.

Bishara, como refieren Tolaro et al. [51], confirmó que entre los tres y cinco años en la dentición temporal se da un aumento de $1.5 \mathrm{~mm}$ en el ancho intermolar. Al trabajar en las áreas de odontología pediátrica y de ortodoncia, es esencial tener un conocimiento adecuado del tiempo y del patrón de erupción de los dientes permanentes para el diagnóstico y tratamiento, pues existen diversos factores que inciden en este aspecto. Se reportan diferencias en la erupción de los permanentes, asociadas a grupo étnico, género y otros factores.

\section{Consideraciones en el tamaño dental}

Un aspecto de relevancia para el clínico son las dimensiones de los dientes primarios y permanentes. En 1902 Black fue el primer autor en asignar importancia al tamaño mesiodistal de las piezas dentarias, que es utilizado para demostrar el espacio adicional requerido en la acomodación de los dientes permanentes. El diámetro combinado de los incisivos centrales, laterales, caninos, primero y segundo molar es de $68.2 \mathrm{~mm}$ para el arco maxilary de $61.8 \mathrm{~mm}$ para el arco mandibular [54]. El tamaño de los dientes permanentes es de $74.0 \mathrm{~mm}$ en el arco maxilar y de $64.4 \mathrm{~mm}$ en el arco inferior, por lo que se requiere un espacio adicional de 5,8 mm para la alineación de los dientes en el arco superior y de $2.6 \mathrm{~mm}$ para el arco inferior [54].

El ancho combinado de los dientes incisivos permanentes con relación a los incisivos temporales es de $7.6 \mathrm{~mm}$ para el arco superior y de $6.0 \mathrm{~mm}$ para el arco inferior. Ocurre lo contrario en los sectores posteriores, donde la combinación de los anchos dentarios de los dientes primarios es mayor: en el arco inferior es de $2.4 \mathrm{~mm}$ y en el arco superior es de $1.4 \mathrm{~mm}$, con relación a sus sucesores; este espacio es llamado espacio de Leeway o de deriva. Conviene destacar que, al finalizar esta etapa, el proceso de recambio guarda relación con la reabsorción de la raíz del diente temporal, la calcificación de las raíces de los permanentes, la proliferación celular y la aposición ósea alveolar.

\section{DENTICIÓN MIXTA}

Es la etapa de transición en la que los dientes primarios se exfolian de manera secuencial, a lo que le sigue la erupción de sus sucesores permanentes. Se inicia con la erupción del primer molar o el incisivo central inferior y termina con la exfoliación del último diente primario, hasta que los segundos molares permanentes lleguen a oclusión. La primera fase de la erupción de los dientes permanentes se superpone a todas las fases de erupción de la dentición decidua, caracterizada por la reabsorción y aposición ósea dentro del proceso alveolar, y que guarda relación con el movimiento y crecimiento de los gérmenes dentales. Al igual que en la dentición primaria, se desarrollan tres fases. Se inicia con un movimiento lento, que corresponde al crecimiento óseo constante, como la deposición lenta, capa por capa, en el fondo y cresta ósea. La segunda fase es la exfoliación paulatina de los dientes temporales, en ella los movimientos dentales son rápidos. La fase de erupción lenta es la tercera fase, en la que los dientes entran en función oclusal [55]. 
TABLA 12

Proceso de erupción de los dientes permanentes

\begin{tabular}{l}
\hline Cambios del proceso de erupción de la dentición permanente \\
\hline 1. El diente deciduo se reabsorbe \\
\hline 2. Aumento de la longitud radicular del germen permanente \\
\hline 3. Proceso alveolar aumenta en altura \\
4. Diente permanente se dirige a oclusal \\
\hline
\end{tabular}

Fuente: elaboración propia
El proceso de desarrollo de la dentición decidua a la permanente va acompañado de dos periodos activos. El primero en función de la dentición mixta inicial: hacen erupción los incisivos y los primeros molares permanentes; se encuentran dientes temporales y permanentes (dientes sucesionales, precedidos por un permanente; dientes accesionales, sin predecesor), estos últimos se ubican en la parte distal de los arcos (primer, segundo y tercer molares; Figura 11).

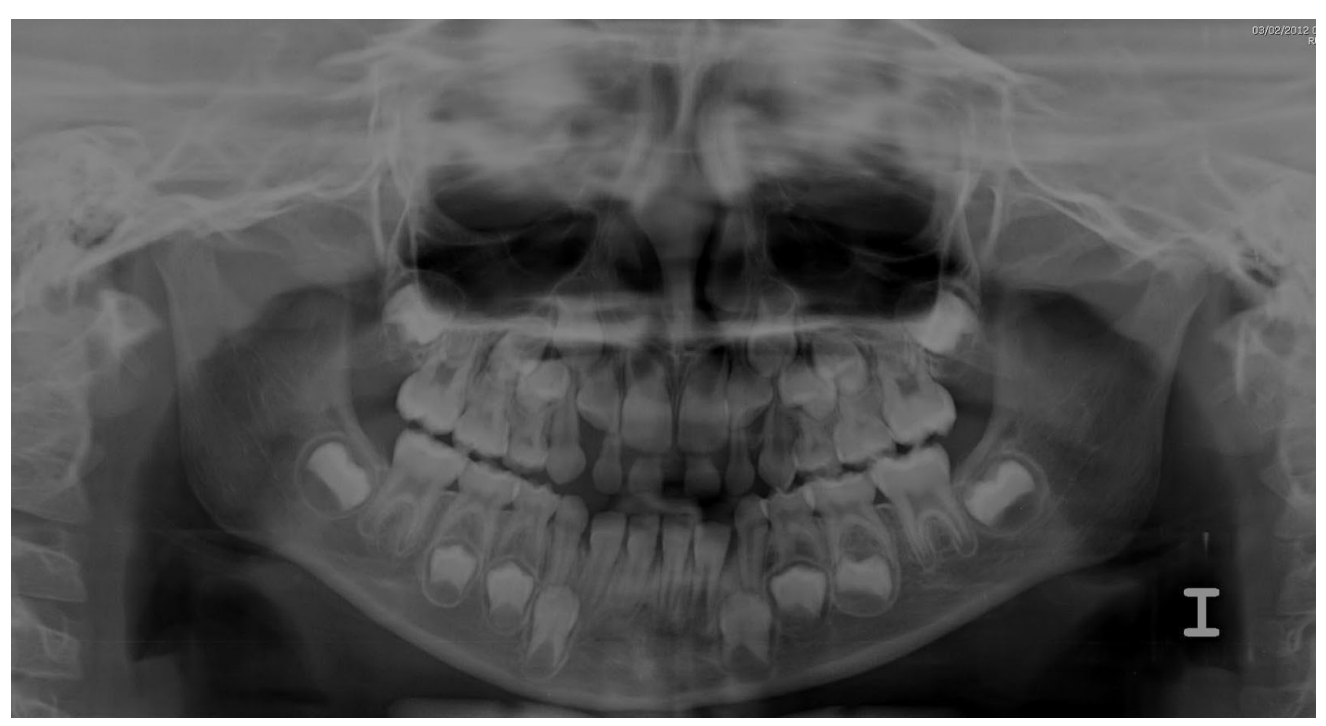

FIGURA 11. Dientes sucesionales y accesionales

Fuente: elaboración propia

Seguidamente, se establece una etapa transicional o periodo de reposo (intertransicional), por un lapso de 1.5 a 2 años. No existe erupción de ningún diente, pero sí procesos de gran actividad resortiva de las raíces de los primarios, y la formación y calcificación de los permanentes. En esta fase se encuentra la zona de sostén de Korkhaus. Se trata de la línea comprendida entre distal del incisivo lateral y mesial del primer molar permanente, cuya función es mantener la dimensión vertical, la oclusión dentaria y el engranaje. El segundo periodo activo, denominado dentición mixta final, está relacionado con el recambio de los sectores laterales (erupción de caninos, premolares y segundos molares permanentes).

\section{Primer periodo: dentición mixta inicial o temprana}

Esta primera fase de erupción de los dientes permanentes se caracteriza por la erupción casi simultánea de los primeros molares e incisivos centrales inferiores. Ocasionalmente, el incisivo central inferior puede hacer erupción primero, sin tener significancia clínica en el desarrollo de la oclusión. Para el arco mandibular, los incisivos preceden a la erupción del primer molar en un 64\% y erupcionan después del primer molar en un 34\%. En el arco maxilar, los molares preceden a los incisivos en un 98\% [56]. 


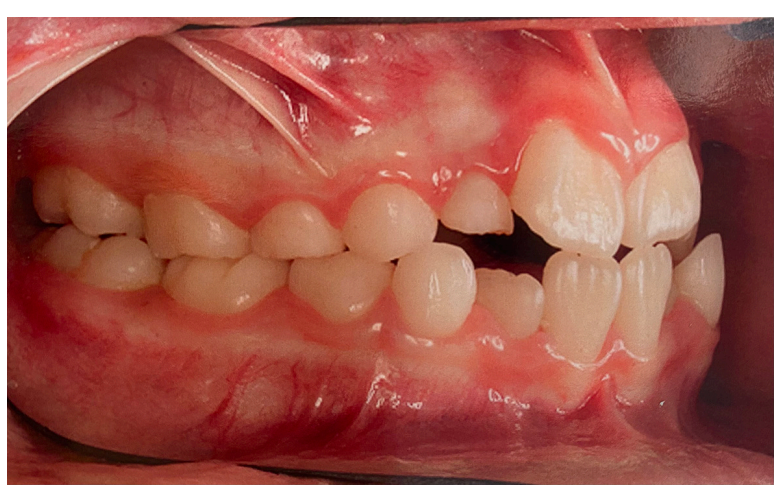

FIGURA 12. Erupción de primeros molares permanentes superiores e inferiores e inicio de erupción del grupo incisivo

Fuente: elaboración propia

El tiempo de calcificación completa de las coronas de los incisivos permanentes es de cuatro a cinco años; en los otros dientes permanentes, se extiende entre seis y ocho años, a excepción de los terceros molares. Por tanto, el periodo total de calcificación dura, aproximadamente, diez años. En la dentición permanente, el ápice se completa dos o tres años después de su aparición en la cavidad oral [57].

\section{Erupción primer molar permanente inferior}

El primer molar permanente comienza su calcificación en el quinto mes de vida, con una inclinación mesial y lingual, formando un ángulo con el cuerpo mandibular y el borde anterior de la rama. Su movimiento hacia la superficie oclusal está dado por la reabsorción del borde anterior de la rama ascendente. Durante su trayecto de erupción, el molar se somete a una rotación que reorienta la corona en relación con el plano de oclusión, logrando su orientación definitiva por una ligera inclinación lingual y mesial respecto del eje transversal. En promedio, erupciona entre los cinco y seis años, guiado por la superficie distal de los segundos molares; el molar infenior precede al superior. Este proceso puede llegar a durar de 2 a 3 meses y medio [57]. La erupción precoz del primer molar inferior es ideal, pues previene la excesiva extrusión del primer molar maxilar [58]. Las mujeres preceden a los varones en la erupción del primer molar.

\section{Primer molar permanente superior}

En las criptas, las coronas de los primeros molares superiores tienen una posición distal y vestibular. A partir del proceso de aposición en la tuberosidad del maxilar, el arco se elonga, lo que hace que los molares roten mesialmente y sus coronas se verticalicen hacia el plano oclusal en el momento de la emergencia. Después de completar la erupción, los primeros molares maxilares están inclinados mesialmente con relación a su eje axial y bucalmente con su eje transversal. Al entrar en oclusión, los molares se verticalizan tanto en posición sagital como transversal, quedando su eje axial correctamente situado con su base ósea, que se establece como el segundo levante fisiológico de la oclusión, guiado por los segundos molares deciduos [38]. La prevalencia de erupciones ectópicas es mayor en el arco superior que en el inferior (Tabla 13, Figura 13) [58, 59].

\section{TABLA 13}

Factores que condicionan la posición del primer molar permanente

\begin{tabular}{l}
\hline Pérdida temprana del segundo molar deciduo \\
\hline Vía ectópica de los primeros molares superiores \\
\hline Reabsorción de la raíz distal del segundo molar deciduo \\
\hline Ausencia congénita de segundos premolares superiores \\
\hline Retención de los segundos molares deciduos \\
\hline Caries distal del segundo molar deciduo \\
\hline Alteraciones en la estructura del esmalte y/o dentina
\end{tabular}

Fuente: elaboración propia

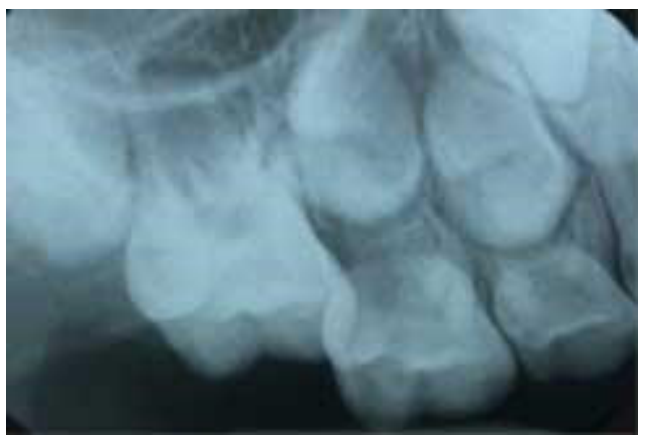

FIGURA 13. Alteración de la erupción del primer molar permanente superior Fuente: elaboración propia 
Establecimiento de la oclusión de los primeros molares

Con el objetivo de describir los cambios en las relaciones molares desde la dentición decidua hasta establecerse la dentición permanente, Bishara trabajó un estudio longitudinal con 121 sujetos entre los cinco y los trece años de edad, evaluando la asociación entre las variaciones dentofaciales y los cambios en las relaciones molares. Cada sujeto fue evaluado en las tres etapas del desarrollo dental (en la dentición temporal, al emerger los primeros molares permanentes y al completar la erupción de todos los dientes permanentes), a excepción de los terceros molares. En este caso, subraya lo siguiente (Tabla 14):

- Si la relación molar en la dentición decidua es un escalón distal, en la dentición permanente se desarrolla una clase II, lo que indica que el tratamiento se debe iniciar a temprana edad.

- En los sujetos que presentaron plano terminal recto en la dentición decidua se estableció una relación molar clase I en un 56\%; y un 44\% desarrolló una clase II. Esto indica que el clínico debe evaluar con periodicidad el plano terminal recto en un paciente, para iniciar un tratamiento oportuno [60].

- Los sujetos que en la dentición decidua presentaron un escalón mesial de $1 \mathrm{~mm}$ evolucionaron a clase I en un $76 \%$, el $23 \%$ a clase II y el 1\% a clase III [55]. De aquellos con un escalón mesial de 2 mm o más, el $68 \%$ evolucionó a clase I, el 13\% a clase II y el $19 \%$ a clase III [60].

TABLA 14

Cambio de la relación molar decidua a la permanente

\begin{tabular}{l}
\hline Factores que condicionan la posición del primer molar permanente \\
\hline Pérdida temprana del segundo molar deciduo \\
\hline Vía ectópica de los primeros molares superiores \\
\hline Reabsorción de la raíz distal del segundo molar deciduo \\
\hline
\end{tabular}

\begin{tabular}{l}
\hline Factores que condicionan la posición del primer molar permanente \\
\hline Ausencia congénita de segundos premolares superiores \\
\hline Retención de los segundos molares deciduos \\
\hline Caries distal del segundo molar deciduo \\
\hline Alteraciones en la estructura del esmalte y/o dentina \\
\hline
\end{tabular}

Fuente: elaboración propia

\section{Establecimiento de la relación molar clase I}

En presencia de un plano terminal recto, la relación inicial que asumen los primeros molares permanentes es de cúspide a cúspide; estos tienen que migrar a mesial para que se establezca una relación molar clase I. Esta migración puede ocurrir precoz o tardíamente:

a. Migración mesial temprana o precoz: se establece en la dentición mixta inicial, con la presencia de los espacios fisiológicos de la dentición primaria. La fuerza eruptiva del primer molar genera una migración mesial de los molares deciduos, ocupando ese espacio.

b. Migración mesial tardía: se establece en la dentición mixta final, al no existir espacios de desarrollo en la dentición primaria. La erupción del primer molar no es capaz de establecer una relación clase I en el periodo de dentición mixta temprana. De modo que se mantiene una relación cúspide a cúspide hasta el momento en que se exfolia el segundo molar deciduo. Así, el primer molar permanente migra hacia mesial utilizando el espacio de Leeway, resultado de la dimensión mesiodistal del segundo bicúspide en relación con el segundo molar temporaI.

Moorrees confirma que la migración mesial de los molares permanentes ocupa la mayor parte del espacio de Leeway, generando disminución del arco [44]. Dicho espacio depende de la secuencia de erupción de los segundos molares por sus sucedáneos, de la intercuspidación de los molares y de la posición de los segundos premolares [61]. 


\section{Clasificación de la relación molar en la dentición permanente}

Para establecer un diagnóstico oclusal, es necesario tener conceptos de oclusión, pues este término debe ser el mismo para todas las áreas, aunque sea visto bajo diferentes perspectivas, valorando la etiología, la edad, las exigencias y las posibilidades terapéuticas. Lo relevante es diferenciar las variaciones que se pueden presentar dentro de los diversos patrones, ya que "maloclusión" es un término genérico, universalmente aceptado, fácilmente comprensible, pero hace que sea necesario diferenciar entre lo ideal, lo normal y lo alterado, pues es un hecho biológico difícilmente divisible.

La clasificación forma parte del diagnóstico para objetivar un tratamiento orientado al tipo y la magnitud de los problemas y para facilitar la comunicación entre los profesionales -algo imperativo-. El diagnóstico basado en un sistema de clasificación morfológica se define como "el arte de reconocer entre enfermedad o deformidad, y diferenciarlas por sus signos y síntomas característicos" [59]. Se han desarrollado métodos de clasificación como el de Kingsley, Anderson, Simon, Ackerman y Proffit, Bennet, Katz, entre otros. Sin embargo, el más utilizado hoy en día es el método de Edward Angle, que evaluó el primer molar superior como el punto de referencia más fiable debido a su relación con el hueso yugal (cresta clave). Esta es una protuberancia ósea que desciende hacia abajo y adelante de la cigoma, marcando la unión en la parte anterior y posterior de las paredes bucales [62].

El término clase fue introducido por Angle para establecer las relaciones mesiodistales de los dientes, las arcadas y los maxilares, en una posición sagital de los primeros molares permanentes, sin considerar las relaciones transversales y verticales, como el factor desencadenante de la maloclusión en términos funcional u óseo. La clasificación de Angle relaciona la cúspide mesiovestibular del primer molar permanente con el surco bucal del primer molar inferior en el plano sagital, y establece tres relaciones (Figura 14):

a. Relación molar clase I: la cúspide mesiovestibular del primer molar permanente superior ocluye con la fosa bucal del primer molar mandibular.

b. Relación molar clase II: la cúspide mesiovestibular del primer molar permanente superior ocluye mesial con relación a la fosa bucal del primer molar mandibular.

c. Relación molar clase III: la cúspide mesiovestibular del primer molar permanente superior se encuentra distal con relación a la fosa bucal del primer molar mandibular.
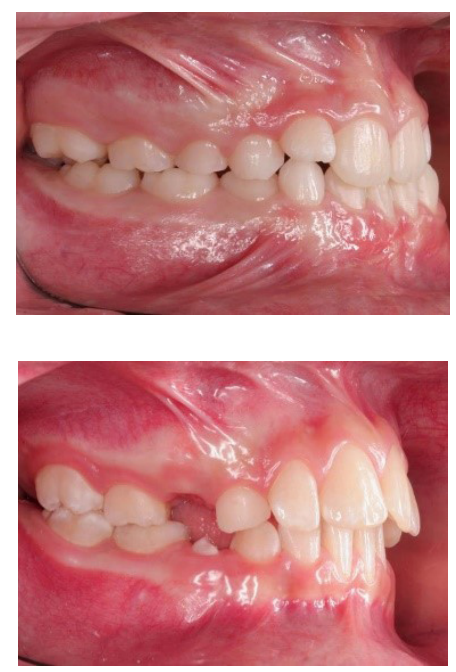

FIGURA 14. Clasificación molar de Edward Angle a las clases II, I y III

Fuente: elaboración propia

Dentro de las maloclusiones clase II se distinguen diferentes tipos, según la posición que adopta el grupo incisivo:

a. Clase II - división 1: caracterizada por la posición proinclinada de los incisivos superiores, lo que desencadena un aumento en el resalte.

b. Clase II - división 2: los incisivos centrales superiores están retroinclinados hacia el palatino, y los laterales presentan una 
inclinación hacia el vestibular, lo que provoca una disminución del overjet y un aumento de la sobremordida (Tabla 15).

TABLA 15

Patrones que se pueden establecer en la clase II - división 2

\begin{tabular}{|c|c|}
\hline & $\begin{array}{l}\text { Clase II } \\
\text { División } 2\end{array}$ \\
\hline A & $\begin{array}{l}\text { Grupo incisivo en posición lingual } \\
\text { Caninos hacia mesial y vestibular }\end{array}$ \\
\hline B & $\begin{array}{l}\text { Incisivos centrales en linguoversión } \\
\text { Incisivos laterales en vestibuloversión } \\
\text { Caninos alineados al resto de la arcada }\end{array}$ \\
\hline C & Incisivos y caninos en linguoversión \\
\hline
\end{tabular}

Fuente: elaboración propia

Según su intensidad, la desviación sagital entre los molares con una relación clase II es completa cuando la cúspide mesiovestibular del primer molar superior está a nivel del surco vestibular inferior. Es incompleta, como una categoría menor, si se da una inadecuada relación entre ambos molares [47]. En las relaciones molares existen variaciones: en un lado, se puede presentar una clase I y una clase II o clase III en su contralateral, de modo que el diagnóstico oclusal se realiza con base en el lado donde existe la variación y se habla de subdivisión (Tabla 16) [47].

TABLA 16

Variaciones en la clasificación de las relaciones molares para el diagnóstico

\begin{tabular}{ll}
\hline \multicolumn{1}{c}{ Tipo de relación } & \multicolumn{1}{c}{ Diagnóstico } \\
\hline $\begin{array}{l}\text { Clase I molar derecha } \\
\text { Clase I molar izquierda }\end{array}$ & Clase I \\
\hline $\begin{array}{l}\text { Clase I molar izquierda } \\
\text { Clase II molar derecha }\end{array}$ & Clase II, subdivisión derecha \\
\hline $\begin{array}{l}\text { Clase I molar derecha } \\
\text { Clase II molar izquierda }\end{array}$ & Clase II, subdivisión izquierda \\
\hline $\begin{array}{l}\text { Clase I molar izquierda } \\
\text { Clase III molar derecha }\end{array}$ & Clase III, subdivisión derecha \\
\hline $\begin{array}{l}\text { Clase I molar derecha } \\
\text { Clase III molar izquierda }\end{array}$ & Clase III, subdivisión izquierda \\
\hline
\end{tabular}

Fuente: elaboración propia
Las críticas al sistema de Angle son amplias y tienen que ver con la no inclusión de variaciones en las dimensiones transversal y vertical. Por otro lado, existe la clasificación de Katz, que toma como referencia la cúspide vestibular del primer premolar. Cuando este entra en oclusión con el primer premolar y el segundo premolar, se asigna un valor de cero (0). Un signo + indica tendencia a clase II y un signo - indica tendencia a clase III. La ventaja de esta clasificación es que establece un objetivo de tratamiento específico, cuantificando el grado de maloclusión en milímetros por hemiarco y valorando si hay una tendencia a clase II o clase III [47] (Figura 16).

Lo anterior se justifica en que los objetivos actuales del manejo de las maloclusiones aspiran a tener una oclusión clase I, con un engranaje ideal, y no una clase I, con una amplia gama. Se concluye que todos los "ideales" son las oclusiones de clase I, pero no todas las oclusiones clase I son "ideales". Entonces, es relevante para el clínico comprender los conceptos de oclusión funcional y dinámica más allá de una relación molar clase I, y así lograr objetivos realistas [62].

\section{Factores que contribuyen a los cambios en la relación molar}

- Espacio deriva, espacio de Leeway o espacio de Nance. Corresponde a la diferencia de tamaño mesiodistal de caninos, primer molar y segundo molar temporal en relación con los dientes sucedáneos (canino, primer premolar y segundo premolar). Esta diferencia de tamaño se conoce como espacio de Leeway o de deriva. En el arco maxilar, la diferencia en promedio es de $0.9 \mathrm{~mm}$ por lado; en el arco inferior, el espacio es de $1.8 \mathrm{~mm}$ por hemiarco. Esto permite que los primeros molares tengan una migración mesial mayor en el arco inferior [60]. Uno de los factores por tener en cuenta es la secuencia de recambio de los segundos molares temporales respecto a los segundos premolares. Cuando el tamaño de los dientes 
no erupcionados (canino, primer premolar y segundo premolar) es mayor que el de los temporales, existe una deficiencia del espacio deriva, que generalmente desencadena un apiñamiento. Para que se establezca una relación clase I es necesario que se dé una mesialización del primer molar inferior, de modo que la cúspide mesiovestibular del primer molar permanente se ubique en el surco vestibular del primer molar permanente.

- Crecimiento mandibular. Durante la fase de dentición mixta, la mandíbula crece más hacia adelante que el maxilar, factor que contribuye a la migración del primer molar. Los estudios demostraron una baja asociación entre el crecimiento maxilomandibular y la migración del primer moral [60].

- Factores locales. Existen varios factores asociados a los cambios de la relación molar, como la pérdida temprana del primer molar o segundo molar temporal; la caries interproximal; las erupciones ectópicas; la anquilosis, y las alteraciones de la estructura del esmalte y/o dentina. Es importante tener presente que se pierde más espacio en el primer año después de la pérdida de un diente deciduo que en los años sucesivos (Figura 15) [60].

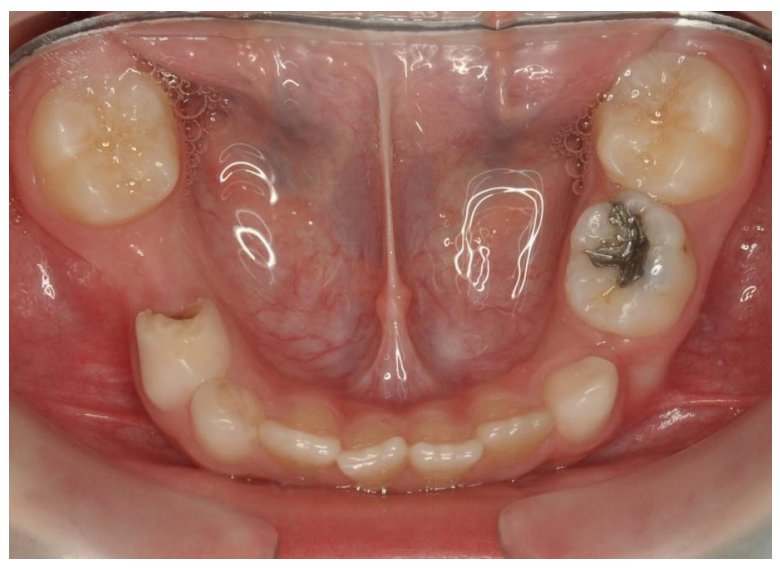

FIGURA 15. Pérdida prematura de molares temporales Fuente: elaboración propia

\section{Erupción grupo incisivo}

Existe una diferencia entre el tamaño del grupo incisivo de la dentición temporal y el de la dentición permanente, que Warren Mayne denomina responsabilidad incisal (pasivo incisivo). El espacio disponible en el arco, seguido de la exfoliación de los temporales, es menor que el espacio necesario para la acomodación de los incisivos permanentes. Los incisivos superiores permanentes son $7.6 \mathrm{~mm}$ más anchos que los temporales, y $6.0 \mathrm{~mm}$ en el arco inferior, lo que hace que esta diferencia sea negativa y, clínicamente, puede generar un apiñamiento transitorio durante el periodo de dentición mixta. Entonces, es necesario evaluar a los niños desde temprana edad, para tener un seguimiento continuo del desarrollo de la oclusión y determinar cuál es el momento oportuno para iniciar una estrategia terapéutica [22].

Algunos factores permiten lograr el ajuste y mantener el equilibrio dinámico para la alineación de los dientes anteriores en el arco [22]:

- Espacios en la dentición primaria.

- Incremento del ancho intercanino, correlacionado con el recambio de la dentición mixta tardía a la permanente, con la erupción de los incisivos permanentes y caninos; factor que contribuye a la alineación de los incisivos en los arcos.

- Cambio en la inclinación labial de los incisivos permanentes, que erupcionan $2 \mathrm{~mm}$ más anterior con relación a los temporales, aumentando así la longitud del arco [22].

\section{Dentición mixta inicial}

Los incisivos centrales inferiores inician la erupción seguidos por los incisivos centrales superiores, que al emerger ejercen presión sobre los incisivos laterales temporales. Estos migran hacia distal, ocupando el espacio 
primate. Continúan el proceso de erupción hasta entrar en contacto con el cíngulo de los incisivos superiores.

Los incisivos centrales superiores comienzan su erupción por lingual del ápice de los incisivos, desplazándose hacia abajo y vestibular. Las coronas tienen una inclinación distal durante la erupción, lo que condiciona un diastema fisiológico en la mayoría de los individuos; espacio que se cerrará gradualmente con la erupción de los incisivos laterales y caninos. La inclinación distal de los incisivos centrales contribuye al estímulo fisiológico transversal en la región anterior. Los incisivos laterales inferiores erupcionan después de los incisivos centrales superiores, en la posición lingual de sus antecesores, y es la posición de la lengua la que propicia que se alineen en el arco.

Los laterales superiores hacen erupción una vez que los centrales superiores han alcanzado el plano de oclusión. Tienen una vía de erupción distal que, al ir alcanzando el plano vertical, contribuyen a cerrar el espacio interincisal fisiológico. Alcanzan su posición final cuando los caninos deciduos se exfolian tomando la posición final. Es relevante evaluar en la radiografía la relación de los ápices de los laterales permanentes y las coronas de los caninos permanentes que no han hecho erupción.

Al erupcionar, los laterales inferiores también generan un efecto de cuña distal en los caninos, llevando a estos a migrar, de modo que se cierra el espacio de Leeway y aumenta la distancia intercanina. Dada la situación clínica en que no exista espacio suficiente para la erupción de los laterales inferiores, estos erupcionan desplazando lateralmente a los centrales inferiores hasta lograr espacio; y el contralateral inferior puede conducir a la reabsorción y exfoliación prematura del canino inferior. La relación interoclusal de los incisivos, tanto en posición como en inclinación, es regulada por los labios y la lengua. El periodo de erupción del grupo incisivo dura alrededor de tres años, puesto que un incisivo, desde que emerge, tarda un año en alcanzar a su antagonista [47].

La localización y el punto de erupción dependen de la formación intraalveolar y del espacio disponible, así como de factores funcionales y ambientales (Figura 16).
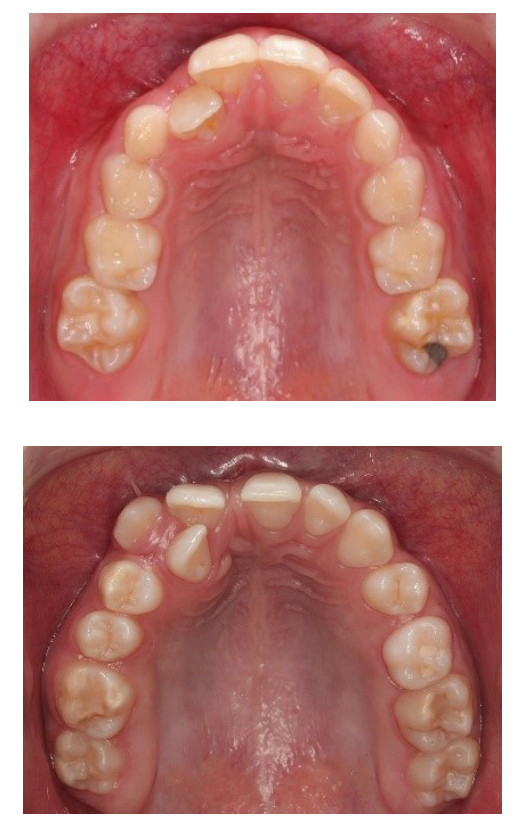

FIGURA 16. Erupción del ectópica lateral superior en posición lingual

Fuente: elaboración propia

Durante la fase de dentición mixta es frecuente la presencia de un diastema entre los incisivos centrales superiores, el cual varía de 1.0 a $3.0 \mathrm{~mm}$. Con el proceso de erupción de los incisivos laterales y caninos, este se cierra espontáneamente [22]. Al emerger, los incisivos centrales utilizan el exceso de espacio encontrado en la dentición temporal, lo que no es posible en la erupción de los incisivos laterales porque el espacio es más crítico en ambos arcos. La cantidad de espacio necesario para los incisivos y el espacio disponible es una situación clínica llamada "desventaja de los incisivos"; esto genera un apiñamiento en la zona de los incisivos inferiores [61]. 
Una vez han alcanzado el plano de oclusión, el grupo incisivo y los molares entran en contacto. El clínico puede llegar a establecer si se cumplen las características de esta fase dentro de un patrón de normalidad, considerando los siguientes aspectos [22]:

- Relación molar y canina clase I

- Espacio deriva positivo

- Rotaciones menores

- Inclinaciones bucolinguales y mesiodistales adecuadas

- Contactos proximales firmes

- Crestas marginales niveladas verticalmente

- Plano oclusal recto o leve

\section{Periodo transicional o periodo silente}

Una vez los primeros molares permanentes y el grupo incisivo entran en oclusión, esta se estabiliza. Se da paso a un periodo intermedio de uno y dos años, antes de iniciar el segundo periodo activo. Esta etapa es estable, presenta mínimos cambios y se caracteriza por la presencia de 12 dientes deciduos (caninos, primeros y segundos molares) y 12 permanentes (primeros molares, incisivos centrales y laterales; Figura 17).

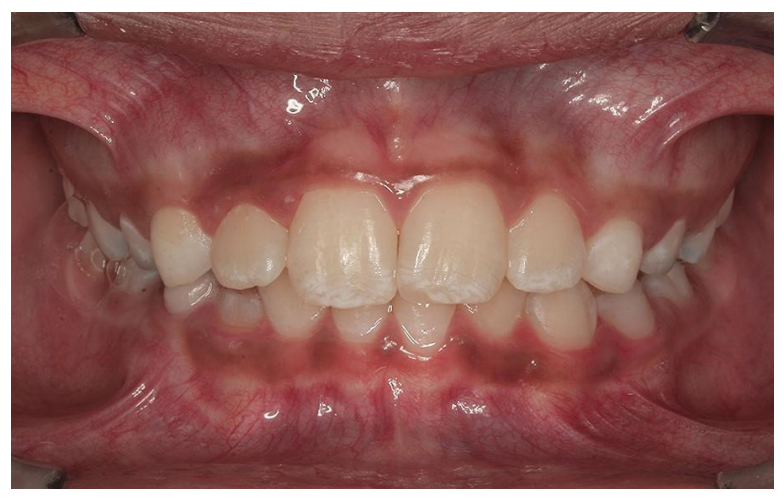

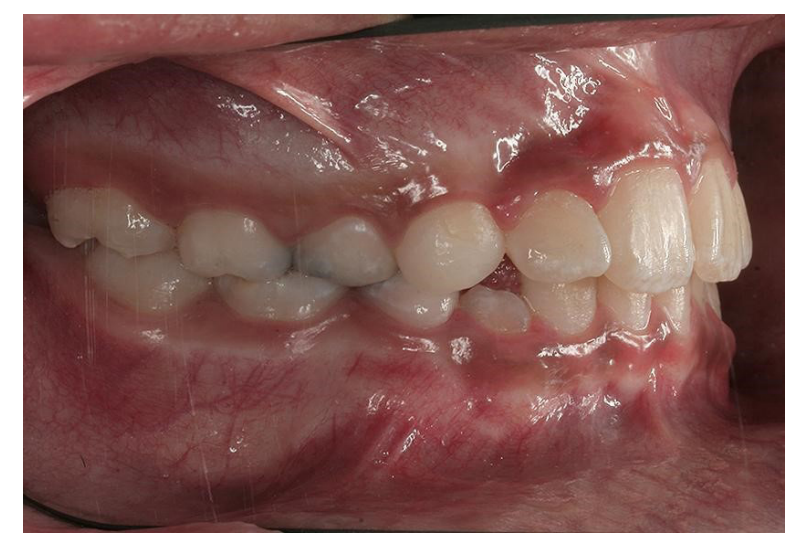

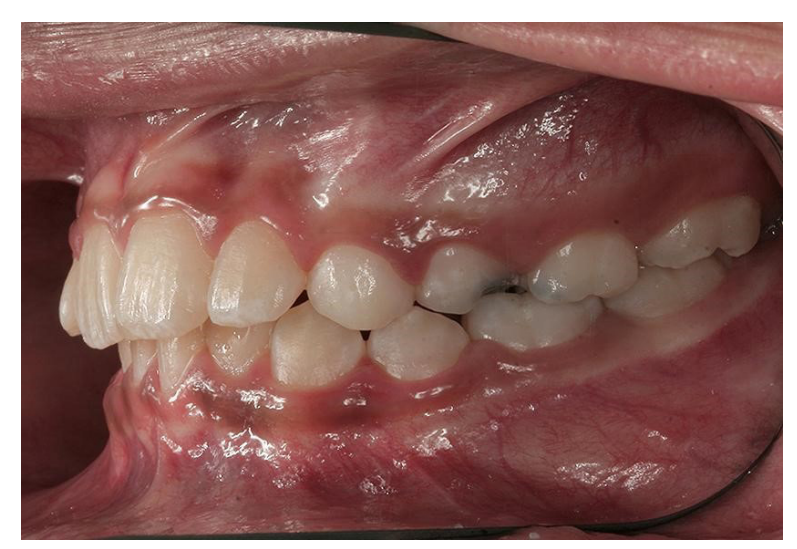

FIGURA 17. Dentición mixta silente

Fuente: elaboración propia

\section{Tercer periodo: dentición mixta final}

Esta etapa comprende la exfoliación de los dientes deciduos (canino, primer y segundo molar) y la erupción de los dientes permanentes (caninos, bicúspides y segundos molares permanentes). La zona incisiva es caracterizada por la presencia de un diastema en la línea media del arco superior, el cual se define como el espacio que existe entre los incisivos centrales superiores, y tiende a cerrarse como resultado de la erupción, migración y ajuste fisiológico de las piezas dentarias [63]. Este periodo es descrito por Broadbent como la etapa del patito feo [64], debido a la disposición que adoptan los incisivos en la erupción, condición clínica que se resuelve espontáneamente con la erupción de los caninos superiores. 


\section{Erupción de los primeros premolares superiores}

Hacen erupción después de los laterales superiores, seguidos por los segundos premolares o caninos. Su vía de erupción es similar a la de los primeros premolares inferiores; sin embargo, existen factores que determinan su posición, como la retención de los primeros y/o las transposiciones.

\section{Erupción de los segundos premolares inferiores}

Se desarrollan por debajo de las raíces de los segundos molares deciduos. Su vía de erupción varía de un individuo a otro y puede ser de tres tipos:

- Erupción distal. Esta es la mejor vía, siempre que no exista pérdida de espacio del segundo molar. Al erupcionar distalmente reabsorbe la raíz distal del segundo molar primario, deslizándose a lo largo de la superficie mesial del primer molar permanente para erupcionar en el arco dental. Esta vía es referida como normal, aunque esto no significa que es la habitual o más común. En este caso, "normal" implica que hay mínima pérdida de espacio durante el recambio del segundo molar deciduo por el segundo premolar.

- Erupción oclusal. Esta vía es la que se observa comúnmente, no debe considerarse normal. Hay pérdida de espacio debido a la migración del primer molar permanente en el momento de la exfoliación del segundo molar deciduo.

- Erupción mesial. Si transcurre demasiado tiempo entre la exfoliación de segundo molar temporal y la erupción del segundo premolar, el primer molar permanente se inclinará hacia mesial. Esto causará una pérdida de espacio y, consecuentemente, un bloqueo en la erupción del segundo premolar [58]. Cuando desarrollan

a impedir la erupción. 
impactación, los segundos premolares inferiores se inclinan hacia distal en una posición oblicua u horizontal [65].

\section{Erupción de los segundos premolares superiores}

Los segundos premolares superiores erupcionan antes que los caninos y después de los primeros premolares, aunque esta secuencia puede ser alterada con la erupción del segundo premolar después del canino. Su espacio está asegurado por el tamaño de su predecesor; sin embargo, existen factores que pueden llegar a modificar su posición, como la pérdida prematura del segundo molar primario. En este caso, el primer molar permanente gira alrededor de su raíz palatina haciendo que la cúspide mesiopalatina rote lingualmente, invadiendo el espacio requerido para el premolar.

En ciertas condiciones, la erupción de los premolares se ve afectada. Por ejemplo, si se ha perdido el segundo molar entre los cuatro y cinco años, su erupción se retrasa; después de los cinco años hay un retraso gradual en la erupción y un aumento gradual en la erupción hasta la edad de ocho años; ante la pérdida de un segundo molar deciduo, después de los ocho, nueve y diez años, la erupción del premolar se acelera [66].

Existen aspectos a considerar en la secuencia de erupción en relación con el grupo incisivo y el sector lateral:

a. Hay un periodo de al menos dos años entre la erupción del incisivo central superior y la erupción del canino o segundo premolar. Igualmente, existe un intervalo mínimo de dos años entre la emergencia del incisivo lateral inferior y los caninos o premolares.

b. En el $80 \%$ de los hombres, en los dientes maxilares, los incisivos centrales erupcionan de 2.5 a 4.5 años antes del primer premolar, de 3 a 5 años antes que el canino, y de 3 a 5.5 años antes del segundo premolar. En el 90\% de los hombres, el canino inferior y el primer premolar erupcionan de 2.5 a 4 años después del incisivo lateral, y la erupción del segundo premolar ocurre de 2.5 a 5 años después de la del incisivo lateral mandibular [56]. Los caninos y los premolares superiores no rompen el epitelio hasta 6 años después de la emergencia del incisivo central. El tiempo de emergencia del incisivo lateral, el canino y los premolares puede ser de más de 5 años [56].

Lo y Moyers evaluaron la secuencia de erupción del sector posterior en una muestra de 220 niños de ambos sexos. Reportaron que la secuencia 4-5-3-7 se estableció en el 49\% y la 4-3-5-7 en $16 \%$, en el maxilar superior. En el maxilar inferior se dio la secuencia 3-4-5-7 en 46\% y la 3-4-7-5 en el 19\% [66]. Los premolares se desarrollan debajo de las raíces divergentes de los molares deciduos. En los procesos alveolares, los primeros premolares se ubican de modo más oclusal que los caninos y los segundos premolares, antes de la erupción [22]. Existe una diferencia de erupción de los caninos en ambos arcos: en el superior hacen erupción después de los premolares; en el arco inferior erupcionan antes que los premolares. Si el canino permanente entra en erupción después del primer premolar inferior, es muy probable que erupcione en una posición labial [58].

Existen factores que pueden llevar a que la erupción de premolares se adelante. Como resultado de necrosis de larga data en dientes deciduos, algunas veces emergen con desarrollo radicular inmaduro. En contraste, con la extracción de molares deciduos en un periodo posterior, cuando el premolar tiene una formación incompleta radicular, genera un movimiento eruptivo retardado debido a la formación de un tejido cicatricial; esto proporciona una barrera mecánica para la erupción del diente permanente [67]. 
Asimismo, se debe tener presente que, si el primer molar deciduo se exfolia prematuramente, la erupción del primer premolar puede causar la exfoliación del segundo molar deciduo, lo que genera falta de espacio para el segundo premolar o una posición de linguoversión. La pérdida temprana del primer molar deciduo inferior en niñas puede provocar la impactación del primer premolar, debido al rápido desarrollo y emergencia del canino. En los niños, la retención del primer premolar es menos probable, ya que el canino permanente se desarrolla a un ritmo más lento y erupciona más tarde que en las niñas [67].

\section{Espacio de Leeway}

Uno de los rasgos más característicos del paso de la dentición mixta a la permanente es el espacio de deriva o de Leeway. El primero en describirlo fue Nance, y hace referencia a la diferencia del tamaño mesiodistal entre los dientes posteriores, tanto temporales como permanentes [68]. Nance reporta que el ancho combinado del canino y de los molares deciduos en cada lado del arco mandibular es $1.7 \mathrm{~mm}$ mayor que el ancho mesiodistal del canino, y el primer y segundo premolar permanentes [68]. Este espacio mayor en el arco mandibular se considera espacio reservado. Esta situación es aprovechada cuando los primeros molares permanentes están en una relación cúspide a cúspide; al exfoliarse los segundos molares, migran logrando una relación molar permanente clase I [22]. El ancho mesiodistal de cada uno de los dientes deciduos y los sucesores permanentes varía entre 0.2 y $0.5 \mathrm{~mm}$. En el arco maxilar, el espacio de Leeway promedio es $0.9 \mathrm{~mm}$ por hemiarco.

El espacio de Leeway mayor en el arco inferior se debe a que el diámetro mesiodistal de los molares deciduos es más grande con relación a los superiores. Es deficiente cuando el tamaño de los premolares y caninos no erupcionados es mayor que el espacio disponible.

\section{Canino inferior}

Erupciona después el incisivo lateral y antes del primer premolar, lo que previene la inclinación lingual de los incisivos, al mantener el perímetro del arco. Después de completarse la dentición primaria, las coronas están parcialmente desarrolladas, situándose a una gran distancia del plano oclusal.

Las coronas de los caninos permanentes están posicionadas relativamente a labial de los incisivos laterales permanentes, y se encuentran situados lingual y distalmente con respecto a los caninos deciduos. Una vez sus coronas están completas (los incisivos permanentes han erupcionado), se inician sus movimientos eruptivos hacia el plano oclusal. Los ejes se direccionan hacia mesial y lingual, dándose la reabsorción de la raíz de los caninos en sus superficies linguales. Erupcionan distal a las raíces del incisivo lateral y su erupción marca un incremento en el ancho del arco intercanino. Su erupción finaliza hacia labial, con una inclinación mesial.

La erupción del canino inferior puede verse afectado por diferentes aspectos, entre los que se cuentan los siguientes:

- El espacio disponible es inadecuado, haciendo que su vía de erupción se altere.

- La posición lingual o la rotación de los incisivos hacen que los caninos permanentes se desplacen hacia la línea media.

- La falta de guía de los incisivos laterales desvía la vía de erupción de los caninos.

- Se da una exfoliación prematura de caninos deciduos, pues al erupcionar los incisivos laterales pueden reabsorber las raíces de los caninos deciduos, generando disminución en la longitud del arco en el segmento anterior.

- Hay ausencia congénita de caninos permanentes o presencia de supernumerarios [58]. 


\section{Canino superior}

Al evaluar una radiografía panorámica, la posición que adopta el canino inferior en las fases del desarrollo de la dentición es significativa para el clínico:

a. En la dentición temporal, el canino está en la zona más profunda del hueso.

b. En la dentición mixta, tanto el canino como el primer premolar se encuentran verticalmente a la misma altura y el segundo premolar está más abajo.

c. Durante la erupción pueden existir dos patrones: el canino erupciona primero o lo hace el primer premolar.

A pesar de que comienza a calcificarse casi tan pronto como el primer molar y el incisivo central, el canino superior tarda casi el doble de tiempo para lograr una erupción completa. Esto lo hace más susceptible a las influencias ambientales, ya sean favorables o desfavorables [69]. El canino maxilar inicia el desarrollo dental entre los cuatro y 5 meses de vida a nivel de la pared anterior del seno maxilar por debajo del piso de órbita. Cuando el individuo alcanza los 3 años, el canino se encuentra arriba del piso nasal, entre esta y el seno maxilar, ubicado con una inclinación mesiolingual respecto al canino deciduo y el primer bicúspide. Para los 6 años de edad la corona desciende a nivel del piso nasal con la misma inclinación; finalmente, en la etapa de preerupción migra con el patrón mesial hasta llegar a la superficie distal de la raíz de lateral permanente, que finalmente guía el canino para ubicarse en boca [70].

Las cúspides de los caninos están lingual a los ápices de los caninos primarios, y las raíces de los primeros molares superiores están muy cerca de la proximidad distal de las coronas de los caninos permanentes. Su erupción al plano oclusal comienza después de la formación de sus coronas. Se dirigen hacia la cara distal de las raíces de los incisivos laterales, y ejercen presión sobre estas haciendo que las raíces se direccionen a mesial y sus coronas a distal. Así crean un espacio transitorio entre los incisivos permanentes superiores, que se cierra una vez los caninos alcanzan el plano oclusal.

La posición correcta del canino superior puede verse afectada por los siguientes factores:

a. La posición lingual de los incisivos laterales superiores o su rotación, que hacen que los caninos pierdan la guía y erupcionen labialmente.

b. La alteración en la vía de erupción, que da lugar a diferentes situaciones:

- Angulación marcada a mesial de los caninos, que puede reabsorber las raíces de los incisivos laterales permanentes.

- La ausencia de incisivos laterales superiores permanentes, por lo que los caninos pueden ocupar los espacios de los incisivos laterales.

- La impactación muy alta de los caninos, debido a su alta posición durante su desarrollo en las criptas y las variaciones que tiene durante el proceso de erupción hasta alcanzar el plano oclusal. Puede tener como factor etiológico la falta de espacio, la ausencia congénita de incisivos laterales, los supernumerarios, las alteraciones genéticas, y así también la pérdida de guía de los incisivos laterales superiores.

c. El canino deciduo persistente, que hace que el canino permanente cambie la vía de erupción hacia lingual o vestibular, debido a que la raíz del canino primario no se ha reabsorbido.

Con la erupción gradual de los dientes temporales y el aumento natural de la altura del 
proceso alveolar, el germen del canino permanente se desplaza cada vez más de la cara lingual, hasta que el canino deciduo se exfolia. El promedio de edad de erupción del canino es de 13 años en los varones y de 12 años y 3 meses en las mujeres [71]. Durante esta etapa de desarrollo, existe una maloclusión transitoria con la presencia de un diastema entre los incisivos superiores, que es frecuente a edades tempranas del desarrollo de la dentición permanente. Williams sugiere la toma de radiografías en intervalos de 6 meses después de la extracción del canino temporal, a fin de hacer el seguimiento interóseo de la erupción del canino permanente hasta que finalmente lo haya conseguido [70]. Si los caninos deciduos superiores tienen una exfoliación prematura y el espacio en el sector posterior se encuentra reducido, el canino busca una posición diferente (vestibular, lingual, rota o queda impactado). En el caso de que no existiera exfoliación de los caninos deciduos superiores, los incisivos laterales erupcionan en linguoversión o rotación.

Frente a la exfoliación prematura del canino temporal, su sucesor permanente puede tener dos alternativas: reabsorber la raíz del primer molar deciduo ocasionando su exfoliación o erupcionar en vestibular. Esta posición también se establece en los casos en que la secuencia de erupción esté alterada, es decir, el primer premolar erupciona antes que el canino. Se relacionan varios factores asociados con caninos impactados, entre los que destacan el tamaño mesiodistal menor de laterales superiores, la hipoplasia del esmalte, la agenesia de segundos premolares, la infraoclusión de primeros premolares, entre otros $[59,71]$ (Figura 18).

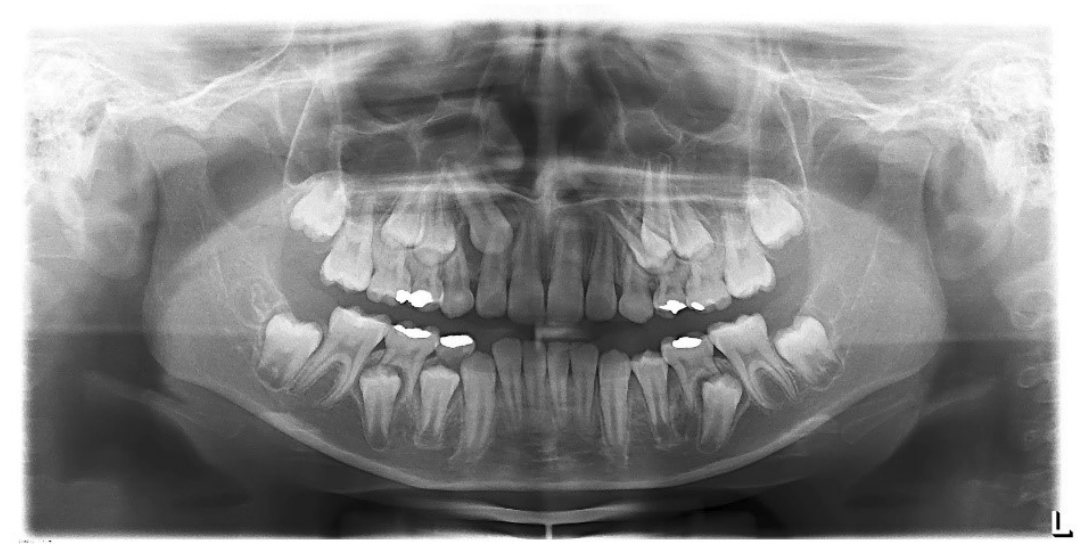

FIGURA 18. Alteración en la vía y guía de erupción

Fuente: elaboración propia

\section{Segundos molares permanentes}

Las criptas de los segundos molares mandibulares están posicionadas en la base de la rama ascendente. Sus coronas adoptan una posición mesial y forman un ángulo recto con el plano oclusal. Con la reabsorción del borde anterior de la rama, la corona rota en una dirección distal y erupciona hacia el plano oclusal, guiada por la superficie distal del primer molar. Esto genera que el arco dental se prolongue por detrás del primer molar permanente [58].

Cabe señalar que, dentro de la cripta, los segundos molares superiores ocupan la misma posición morfológica en el hueso maxilar que el primer molar permanente, y su dirección de erupción es similar. Hacen erupción una vez 
que los segundos molares inferiores están en la cavidad oral, pero si los segundos molares erupcionan antes que los inferiores, la oclusión que se establece es una relación clase II. ocurre lo mismo cuando los primeros molares superiores erupcionan antes que los primeros molares inferiores.

Helm y Seidler describen que, en el caso de las mujeres, el tiempo de emergencia normal para los segundos molares del maxilar superior es a los 11.9 años, y en los hombres, a los 12.4 años. En el arco inferior, ocurre a los 11.4 años en las mujeres y a los 11.9 años en los hombres [59]. El segundo premolar antecede al segundo molar en un 62\% [62], tan pronto se han exfoliado todos los dientes deciduos, lo que contribuye a establecer relaciones oclusales favorables [73]. Si erupcionan antes de los premolares, el perímetro del arco se reduce significativamente y disminuye el espacio para el premolar, que podría quedar bloqueado o fuera del arco.

En ocasiones, y por diferentes condiciones, el desarrollo normal del segundo molar cambia su inclinación y se ubica en una posición oblicua o impactado horizontalmente [74]. La etiología de la impactación dental incluye pérdida de espacio, inclinación, presencia de supernumerarios, odontomas u otras entidades patológicas. La malposición en el desarrollo del tercer molar es una importante barrera; es más frecuente en hombres que en mujeres, y se presenta más en el lado derecho que en el izquierdo, con una inclinación hacia mesial [73].

La mayor parte de las impactaciones se deben a la falta de espacio en la mandíbula, más que en el maxilar, contrariamente a lo que reportan otros estudios que señalan que se deben al exceso de espacio entre el desarrollo de la corona del segundo molar y las raíces del primer molar. Esto daría lugar a que el segundo molar se incline más hacia mesial en el transcurso de su erupción y se impacte en la protuberancia distal del primer molar [74].

El tiempo apropiado para el tratamiento de las impactaciones de los segundos molares es entre los 11 y 14 años, cuando la raíz del segundo molar está todavía incompleta y antes de que los terceros molares completen su desarrollo, entrando en contacto con la superficie distal del segundo molar [74].

La erupción del segundo molar se clasifica en tres categorías [72]:

a. Erupción completa a nivel oclusal, a nivel del molar vecino.

b. Erupción parcial, inferior a la unión amelocemental del molar vecino.

c. Mínima erupción, superior a la unión amelocemental del molar vecino.

\section{Terceros molares}

El tercer molar se localiza en la parte más distal de los maxilares, histológicamente tienen su origen en el cordón del segundo molar permanente. Alrededor de los 3 años comienza la formación del órgano del esmalte , y a los 6 años la papila y la pared folicular hacen su aparición (Figura 16). En promedio, la calcificación del tercer molar se da durante los 8 años, aunque podría ser más variable que la calcificación del primer molar [75]. Su desarrollo puede comenzar tan temprano como a los 5 años y tan tarde como a los 14 años, con el periodo de formación en el pico de los 8 o 9 años. Una vez el tercer molar alcanza el estadio H de Demirjian (estadio de mineralización), la probabilidad de que el individuo sea mayor de edad supera el $90 \%$, independientemente del origen étnico, el sexo o el diente evaluado [76].

Las criptas de los terceros molares superiores e inferiores están situadas en la misma posición relativa ocupada por los primeros y segundos 
molares permanentes, en las etapas tempranas de la odontogénesis [77]. Durante el desarrollo normal dentro de la cripta ósea, el tercer molar comienza con una angulación horizontal, que cambia hacia la superficie oclusal en dirección mesial en el arco mandibular, y distal en el arco maxilar, igual que el primer molar y el segundo molar permanentes. Para asumir una relación oclusal normal, debe someterse a un movimiento de verticalización de mayor o menor grado, dependiendo de su desarrollo en las bases óseas [78].

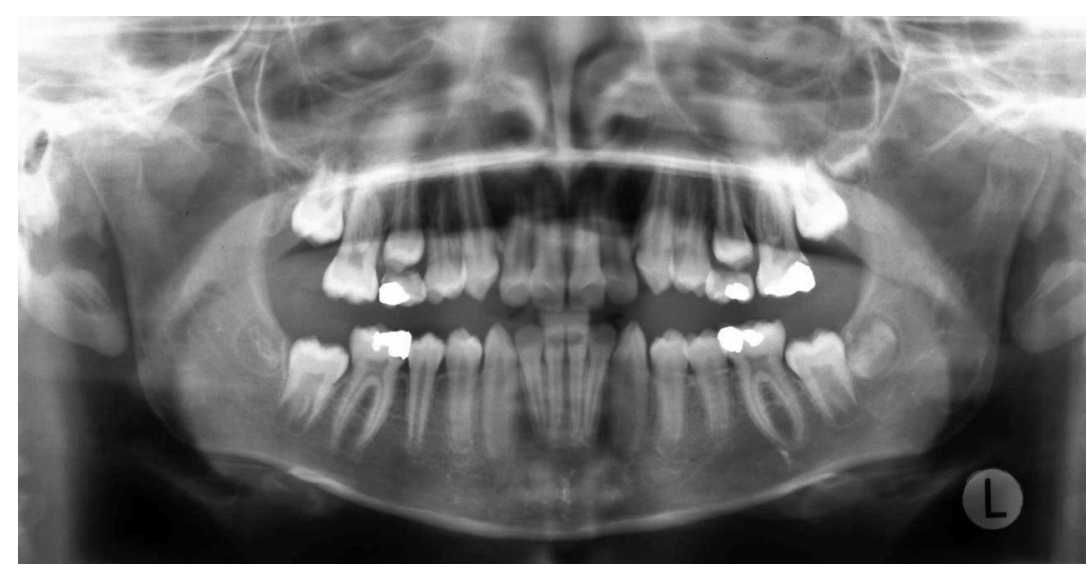

FIGURA 19. Radiografía panorámica que muestra la relación de los terceros molares con los segundos molares permanentes

Fuente: elaboración propia

En su desarrollo, los terceros molares cambian continuamente sus posiciones angulares y se someten a importantes movimientos de rotación preeruptivos, que se dan cuando el brote del tercer molar entra en las proximidades del segundo molar [79]. Al final de la adolescencia, después de la formación de los premolares y caninos, solo los terceros molares continúan formándose. Son los dientes más variables, generalmente erupcionan entre los 16 y los 24 años [80]. Entre los 8 y 9 años de edad es posible predecir, con un $90 \%$ de exactitud, la posición que tendrá el tercer molar, lo que permite tomar decisiones para prevenir futuras desarmonías oclusales [81].

El tercer molar comienza su desarrollo en la rama mandibular con la superficie oclusal en ángulo con el plano mandibular. El crecimiento de la mandíbula es un factor que contribuye a la erupción del tercer molar, así como la reabsorción del borde anterior de la rama en relación con el reborde alveolar; el movimiento hacia delante de la dentición y el crecimiento sagital propio de la mandíbula [76, 82].

Existen diferencias en los tiempos de formación de los molares, los superiores tienden a desarrollarse un poco más rápido que los inferiores, al igual que la simetría intraarco en el arco superior [76]. Con relación a los hombres, en las mujeres la formación del tercer molar suele ser más tardía, tanto en la formación radicular como en la erupción [83]. Las fallas en la rotación, angulares a la dirección vertical, generan impactaciones o una inadecuada longitud del arco respecto a la dimensión del diente. Estos factores se suman, causando que el tercer molar no erupcione apropiadamente. En el arco superior, la causa más común es el espacio inadecuado entre el segundo molar y la tuberosidad, que limita el crecimiento [84]. 
Björk evaluó el crecimiento mandibular en dirección vertical y sagital, y encontró que la retención de los terceros molares ocurre cuando el crecimiento de la mandíbula es vertical [85]. Con ello se confirma que el crecimiento y el desarrollo faciales son factores asociados directamente con la posición del tercer molar [85]. Un mayor espacio molar se debe al gran crecimiento global de la mandíbula y a la erupción de la dentición con dirección hacia delante [76]. Por otro lado, el tercer molar no puede ser utilizado como un marcador de desarrollo debido a su ausentismo, malformación, impactación, tiempo de formación, erupción y variación morfológica. En la clínica, para promediar la edad dental sería más útil considerar si existe una simetría intraarco, que tomarlos por separado [76].

La impactación de los terceros molares está asociada con un componente vertical mandibulary una alta inclinación mesial de la corona del tercer molar. Además, se ha observado que en pacientes con terceros molares impactados la longitud mandibular es menor que la de pacientes sin molares impactados [85]. Poder predecir la erupción del tercer molar con la cefálica lateral fue descrita por Ricketts en 1972, en cuya investigación se encuentra que en el molar incluido en la rama existe el $50 \%$ de probabilidad de erupción normal, mientras que el 100\% se logra en molares ubicados mesialmente respecto al borde anterior de la rama. En un estudio posterior de 1976, el mismo autor establece que una distancia de 30 mm es suficiente para asegurar la erupción del tercer molar, por lo que medidas menores a $20 \mathrm{~mm}$ la dificulta [85].

Para clasificar los terceros molares retenidos hay que valorar aspectos como la posición del segundo molar con respecto al tercer molar, el espacio retromolar, el ángulo del eje longitudinal del diente y la cantidad de tejido óseo o mucoso que lo recubre. Winter fundamenta su clasificación en la posición del eje del tercer molar respecto al eje axial del segundo molar: vertical, mesioangulado, distoangulado, horizontal, vestibuloversión, linguoversión e invertido [85].

Pell y Gregory hacen esta clasificación según la relación con la rama ascendente y la profundidad relativa del tercer molar [80]:

a. Relación con la rama ascendente:

- Clase i: el espacio entre la superficie distal del segundo molar y la rama ascendente mandibular es mayor que el diámetro mesiodistal del tercer molar.

- Clase ir: el espacio entre la superficie distal del segundo molar y la rama ascendente mandibular es menor que el diámetro mesiosdistal del tercer molar.

- Clase iII: el tercer molar está parcial o totalmente dentro de la rama ascendente mandibular.

b. Profundidad relativa del tercer molar:

- Posición A: la parte más alta del tercer molar está en el mismo nivel o por encima del plano de la superficie oclusal del segundo molar.

- Posición B: la parte más alta del tercer molar está entre la línea oclusal y la línea cervical del segundo molar.

- Posición C: la parte más alta del tercer molar está en el mismo nivel o por debajo del plano de la línea cervical del segundo molar.

La dentición permanente se estabiliza con la erupción de los segundos molares. Su secuencia de erupción es más variable que la de la dentición decidua (Tabla 17). 
TABLA 1?

Secuencia de erupción de la dentición permanente en arcos superior e inferior

\begin{tabular}{lll}
\hline \multicolumn{2}{c}{ Secuencia de erupción } \\
\hline \multirow{2}{*}{ Maxilar } & Común & 6-1-2-4-3-5-7-8 \\
\cline { 2 - 3 } & Variación & 6-1-2-4-5-3-7-8 \\
\hline \multirow{2}{*}{ Maxilar inferior } & Común & $(6-1)-2-3-4-5-7-8$ \\
\cline { 2 - 3 } & Variación & 6-1-2-4-3-5-7-8 \\
\hline
\end{tabular}

Fuente: elaboración propia

En promedio, la erupción de los incisivos y los caninos del arco inferior precede a la de los dientes correspondientes en el maxilar superior. En cuanto a la variabilidad de la edad de erupción, se observa que es baja para los primeros molares, intermedia para los incisivos laterales y alta para los caninos y segundos premolares. Por otro lado, el intervalo de la emergencia de los dientes y sus homólogos muestra menos dispersión para los primeros molares y mayor dispersión para los segundos premolares. Las relaciones de las edades de erupción de los dientes homólogos, tanto del lado derecho como izquierdo, en cada arco son moderadamente estrechas [56]. Nanda señala que no existe una asociación clara entre una buena oclusión y un orden particular en la erupción [58].
Finalmente, cabe señalar las características oclusales en una dentición permanente:

- En una oclusión normal, los dientes del arco superior se encuentran más labiales con relación a los inferiores.

- Los dientes permanentes tienen angulaciones bucolinguales y mesiodistales.

- Cada diente permanente ocluye con dos dientes antagonistas, lo que permite tener una oclusión balanceada; a excepción de los incisivos centrales inferiores y terceros mandibulares.

- La curvatura anteroposterior del arco maxilar se denomina curva de compensación, y en el arco inferior es denominada curva de Spee. En sentido bucolingual, la curvatura en el arco superior es llamada curva de Monson y en el arco inferior, curva de Wilson.

- Las relaciones incisales verticales (overjet) oscilan entre el 10\% y el 50\%, y las horizontales (overbite) entre 1 y $3 \mathrm{~mm}$, considerando la edad del paciente.

- Relaciones molares y caninas clase I.

\section{REFERENCIAS}

[1] Ten Cate, AR, editor. Histología oral: desarrollo, estructura, y función. 5. a ed. Buenos Aires: Editorial Médica Panamericana; 1998.

[2] Wright T. Normal formation and development defects of the human dentition. Pediatr. Clin. North Am. 2000;47(5):975-1000

[3] Zohrabian V, Poon C, Abrahams J. Embryology and anatomy of the jaw and dentition. Semin. Ultrasound CT MRI. 2015;36:397-406.

[4] Thesleff I, Vaahtokari A, Kettunen P, Aberg T. Epithelial-mesenchymal signaling during tooth development. Connect Tissue Res. 1995;32:9-15.

[5] Barbería EL. Erupción dentaria. Prevención y tratamiento de sus alteraciones. Pediatr. Integral. 2001;6(3):229-240. 


\section{6 - Generación de contenidos impresos}

[6] Valmaseda E, Castellón C, Gay-Escoda C. Eruption disturbances of the first and second permanent molars: Results of treatment in 43 cases. Am. J. Orthod. Orthop. Dentofacial. 1999;116:651-8.

[7] Wise G, King G. Mechanisms of tooth eruption and orthodontic tooth movement. J. Dent. Res. 2008;87(5):414-434.

[8] Marks SC Jr, Cahill DR. Regional control by the dental follicle of alterations in alveolar bone metabolism during tooth eruption. J. Oral Pathol. 1987;16(4):164-169.

[9] Wize GE, Frazier S. Cellular, molecular, and genetic determinants of tooth eruption. Crit. Rev. Oral Biol. Med. 2002;13(4):323-335.

[10] Kjaer, I. Mechanism of human tooth eruption: Review article including a new theory for future studies on the eruption process. Scientifica. 2014:1-13.

[11] Marks SC, Schroeder HE. Tooth eruption: Theories and facts. Anat. Rec. 1996;245:374-393.

[12] Demirjian, A. The dentition. En Falkner F, Tanner JM, editores. Human growth. Postnatal Growth. Vol 2. Nueva York: Plenum Press; 1978. pp. 413-444.

[13] Mincer H, Harris E, Berryman H. Study of third molar development and its use as an estimator of chronological age. J. Forensic. Sci. 1993;38:2,379-390

[14] Smith, BE. Standards of human tooth formation and dental age assessment. En: Kelley MA, Larsen CS, editores. Advances in Dental Anthropology. Nueva York: Wiley-Liss; 1991. pp. 143-168.

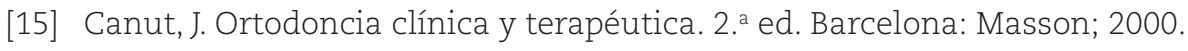

[16] Bishara S. Guía de la oclusión en la dentición mixta: procedimientos de extracción seriada. Ortodoncia. Ohio: McGraw-Hill; 2001.

[17] Demirjian A, Goldstein H, Tanner D. A new system of dental age assessment. Hum. Biol. 1973;45(2):211.

[18] Figueiredo WL, Ferelle A, Issao M. Odontología para el bebé. Odontopediatría desde el nacimiento hasta los tres años. 1. a ed. São Paulo: Actualidades Médico-Odontológicas Latinoamérica; 2000.

[19] Carrollo D, Hoffman R, Brodie A. Histology and function of the dental gubernacular cord. Angle Orthod. 1971:41-44.

[20] Nolla CM. The development of the permanent dentition. ASDC J. Dent. Child. 1960;27:254-266.

[21] Chertkow S. Tooth mineralization as an indicator of the pubertal growth spurt. Am. J. Orthod. Orthop. Dentofacial. 1980;77:79-91

[22] Hägg,U, Matsson, L. Dental maturity as an indicator of chronologic age: The accuracy and precision of three methods. Eur. J. Orthod. 1985;7(1):25-34.

[23] Leighton BC. Early recognition of normal occlusion. En: McNamara JA Jr, editor. The biology of occlusal development. Craniofacial Growth Series. Monograph 7. Ann Arbor: The University of Michigan, 1977.

[24] Moyers E. The biology of occlusal development. Craniofacial Growth Series. Monograph 7. Ann Arbor: University of Michigan; 1977

[25] McDonald RE, Avery DR. Principios de patología estomatológica. En: Odontología pediátrica y del adolescente. 6. ${ }^{\text {a }}$ ed. Buenos Aires: Harcourt Brace; 1998. pp. 234-244.

[26] Stillman, J H. Relationship of maxillary and mandibular gum pads in the newborn infants. Am. J. Orthod. Orthop. Dentofacial. 1938;24:409-424.

[27] Leighton BC. The early signs of malocclusion. Eur. J. Orthod. 2007;29:89-95.

[28] Leighton BC. Some observations on vertical development and the dentition. Proc. R. Soc. Med. 1968;61(12):1273-1277.

[29] Moyers, R. Manual de ortodoncia. 4. ${ }^{a}$ ed. Buenos Aires: Panamericana; 1992, pp. 125-144.

[30] Boyd JD, Miles AE. An erupted tooth in a cyclops foetus. Br. Dent. J. 1951;91(7):173-181.

[31] Galassi MS, Santos-Pinto L, Ramalho LT. Natal maxillary primary molars: Case report. J. Clin. Pediatr. Dent. 2004;29(1):41-44.

[32] Bodenhoff J, Gorlin R. Natal and neonatal. Folklore and fact. Pediatrics. 1963;32(6):1087-1093. 
[33] Allwright WC: Natal and neonatal teeth: A study among Chinese in Hong Kong. Br. Dent. J. 1958;105:163172.

[34] Spouge JD, Feasby WH. Erupted teeth in the newborn. Oral Surg. Oral Med. Oral Pathol. 1966;22(2):198208.

[35] Van Der Linden F. Development of the dentition. Chicago: Quintessence Publishing; 1983.

[36] Hotz R. Odontopediatría. Buenos Aires: Panamericana; 1988.

[37] Van Der Linden F, McNamara J, Burdi A. Tooth size and position before birth. J. Dent. Res. 1972;51(1):714.

[38] Weinmann J. Bones changes related to eruption of the teeth. Angle Orthod. $1941 \mathrm{abr}$.

[39] Van Waes H, Stóckli PW. Atlas de odontología pediátrica. Barcelona: Masson; 2001

[40] Gron AM. Prediction of tooth emergence. J. Dent. Res. 1962 may-jun;41:573-585.

[41] Sandler HC. The eruption of deciduous teeth. J. Pediatr. 1994;25:140-147.

[42] Moorrees CF. Normal variation in dental development determined with reference to tooth eruption statistics. J. Dent. Res. 1965 ene-feb;44:161-173.

[43] Moorrees CF, Gron AM, Lebret LM, Yen PK, Frohlich FJ. Growth studies of the dentition: a review. Am. J. Orthod. 1969 jun;55:600-616.

[44] Foster TD, Hamilton MC. Occlusion in the primary dentition. Br. Dent. J. 1969;126:76-79.

[45] Baume LJ. Developmental and diagnostic aspect of the primary dentition. Int. Dent. J. 1959;9:349-366.

[46] Baume LJ. Physiological tooth migaration and its significance for the development of occlusion I. The biogenetic course of the deciduous. J. Dent. Res. 1950;29:253.

[47] Proffit, W. Ortodoncia contemporánea. Teoría y práctica. 3. a ed. Madrid: Ed. Mosby. p. 70.

[48] Baume LJ. Physiological tooth migration and its significance for the development of occlusion. II. The biogenesis of accesional dentition. J. Dent. Res. 1950; 29:338. J. Dent. Res. 1950; 29:331-337.

[49] Baume LJ. Physiological tooth migration and its significance for the development of occlusion. III. The biogenesis of the succesional dentition. J. Dent. Res. 1950;29:338.

[50] Nanda S. Factors influencing occlusal development: The development basis of occlusion and malocclusion. Chicago: Quitessence Publishing Co.; 1983. p. 30

[51] Tollaro I, Efisio D, Marinelli A, Alarashi M. Tooth abrasion in unilateral posterior crossbite in the deciduous dentition. Angle Ortho. 2002;72(5):426-430.

[52] Sillman JM. Dimensional changes of the dental arches: longitudinal study from birth to 25 years. Am. J. Orthod. Orthop. Dentofacial. 1964;55: 824-842.

[53] Weinmann J. Bone changes related to eruption of the teeth. Angle Orthod. 1941;11(2): 83-99.

[54] Sturdivant JE, Knott V, Meredith H. Interrelations from serial data for eruption of the permanent dentition. Angle Orthod.1962;32(1).

[55] Vellini, F. Ortodoncia. Diagnóstico y planificación clínica. Sao Paulo: Artes Médicas; 2002.

[56] Nanda S. The developmental basis of occlusion and malocclusion. Chicago: Quintessence plublishing; 1983. $p$

[57] Bondemark L, Tsiopa J. Prevalence of Ectopic Eruption, Impaction, Retention and Agenesis of the Permanent Second Molar. Angle Orthod. 2007;77(5):773-778.

[58] Bishara SE, Hoppens BJ, Jakobsen J, Kohout F. Changes in the molar relationship between the primary and permanent dentitions: a longitudinal study. Am. J. Orthod. Orthop. Dentofacial. 1988;93(1):19-28.

[59] Katz M. Angle classification revisited 2: A modified Angle Classification. Am. J. Orthod. Orthop. Dentofacial. 1992;102:277-84.

[60] Moorrees CF, Chadha JM. Available space for the incisors during dental development--a growth study based on physiologic age. Angle Orthod. 1965;35:12-22.

[61] Broadbent BH. Ontogenic development of occlusion. Angle Orthod. 1941;XI(4):223-241. 
[62] Ceremello PJ. The superior labial frenum, the midline diastema, and their relation to growth and development of the oral structures. Am. J. Orthod. Orthop. Dentofacial. 1953;39(2):120-139.

[63] Shapira Y, Borell G, Nahlieli O, Kuftinec M, Stom D. Uprighting mesially impacted mandibular permanent second molars. Angle Orthod. 1998;68(2):173-178.

[64] Posen AL. The effect of premature loss of deciduous molars on premolar eruption. Angle Orthod. 1965:249-252.

[65] Moyers RE. Development of occlusion. Dent. Clin. North. Am. 1969;13(3):523-536.

[66] Lo RT, Moyers RE. Studies in the etiology and prevention of malocclusion: I The sequence of eruption of the permanent dentition. Am. J. Orthod. Orthop. Dentofacial. 1953;39:460-467.

[67] Dewel, BF. The upper cuspid, it's development and impaction. Angle Orthod. 1949.

[68] Mariaca L, Botero P. Diagnóstico y tratamiento temprano de la malposición intralveolar de caninos permanentes. Rev. Fac. Odont. Univ. Antioquia. 2002 1er semestre;13(2).

[69] Sambataro S, Baccetti T, Franchi L, Antonini F. Early predictive variables for upper canine impactation as derived from posteroanterior cephalograms. Angle Orthod. 2004;75:28-34.

[70] Williams BH. Diagnosis and prevention of maxillary cuspid impactation. Angle Orthod. 1981;51:30-40.

[71] Salentijn EG, Ras F, Mesink G. The unerupted maxillary second molar due to an overlying and malformed upper third molar: treatment and follow-up. J. Orthod. 2008;35:20-24.

[72] Wellfert B, Varpio M. Disturbed eruption of the permanent lower second molar: treatment and results. J. Dent. Child. 1988;55:183-189.

[73] Richardson M. Pre-eruptive movements of the mandibular third molar. Angle Orthod. 1978;48(3):187-193.

[74] Garn S, Lewis A, Bonne B. Third molar formation and its development course. Angle Orthod. 1962; 32(2):270-279.

[75] Prieto JL. La maduración del tercer molar y el diagnóstico de la edad. Evolución y estado actual de la cuestión. Cuad. Med. Forense. 2008;14(51).

[76] Jaina S, Valiathanb A. Influence of first premolar extraction on mandibular third molar angulation. Angle Orthod. 2009;79(6).

[77] Ay S, Agär U, Bıçakçı AA, Kösger HH. Changes in mandibular third molar angle and position after unilateral mandibular first molar extraction. Am. J. Orthod. Dentofacial Orthop. 2006;129:36-41.

[78] Nanda S. Events in the life cycle of each permanent tooth: The development basis of occlusion and malocclusion. Chicago: Quintessence publishing; 1983.

[79] Ricketts R. Third molar enucleation: diagnosis and technique: J. California Dent. Assoc. 1976;4:52-57.

[80] Ricketts R. A principle of facial growth of the mandible. Angle Orthod. 1972;42:368-386.

[81] Garn SM, Lewis Arthur B, Batsheva B. Third molar formation and its development course. Angle Orthod. 1962;32(4):270-227.

[82] Sökücü O, Öztürk F, Babacan H, Altuğ A. Does rapid maxillary expansion affect the eruption of upper third molars? Angle Orthod. 2008;78(2):195-200.

[83] Bjork A, Jensen E, Palling M. Mandibular growth and third molar impactation. Eur. Orthod. 1956;14:231272.

[84] Cappellij. Mandibular growth and third molar impaction in extraction cases. Angle Orthod. 1991;61(3):223229.Ricketts R. A principle of facial growth of the mandible. Angle Orthod. 1972;42:368-386 


\section{CAPÍTULO 3}

\section{APIÑAMIENTO}

Paola María Botero Mariaca

Durante el establecimiento de la dentición permanente se pueden generar discrepancias entre el tamaño dental y el tamaño del arco, dependiendo del tipo de maloclusión, los hábitos y la salud oral del paciente. La presencia de apiñamiento dental es muy común en los periodos de desarrollo. Su prevención e intercepción son primordiales para evitar muchos de los tratamientos correctivos que se hacen en pacientes adultos jóvenes. En este capítulo se hace referencia a los conceptos básicos para establecer un adecuado diagnóstico y a los diferentes tipos de tratamientos existentes para esta maloclusión.

\section{Aspectos GENERALES}

El apiñamiento se puede definir como la discrepancia entre el tamaño dental y el tamaño del arco. Puede deberse a dientes grandes, arcos pequeños, la combinación de ambos, alteraciones en el arco que generen disminución de su longitud, pérdidas prematuras de dientes deciduos o caries interproximales (Figura 1) [1]. La prevalencia de apiñamiento en Estados Unidos es de 30\% [14], de los cuales el $40 \%$ tiene $4 \mathrm{~mm}$ de apiñamiento y el 17\% presenta $7 \mathrm{~mm}$ [15]. En Colombia, Thilander realizó un estudio en el que encontró una prevalencia de 52.1\% en Bogotá [16], en tanto en el área metropolitana de Medellín fue de 47\% [17] y en Envigado, de 46.6\% [18]. Con respecto a las diferencias entre sexos, se ha reportado mayor apiñamiento en mujeres, que aumenta entre los 13 o 14 años y luego disminuye, debido a que ellas presentan arcos más pequeños que los hombres [19].
El arco dental es una entidad dinámica y cambiante, sujeta a influencias genéticas: el crecimiento, el tamaño dental, el patrón de erupción, el desarrollo muscular y el tamaño de arco. También depende de influencias medioambientales, como los patrones funcionales, la presencia de caries y otros hábitos orales que generan alteraciones en su desarrollo normal, modificando su forma y tamaño (Figuras 1A y 1B) [1].

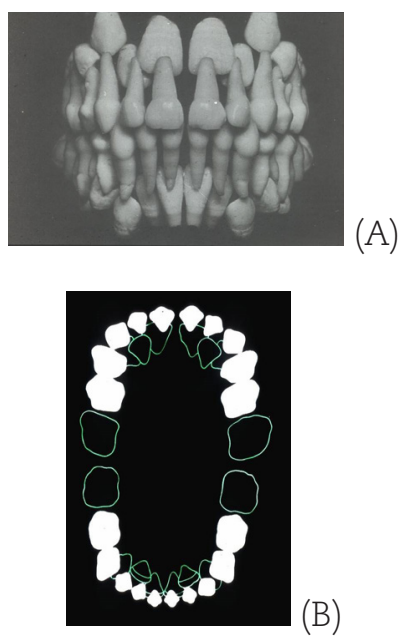

FIGURA 1. (A) Arcos deciduos consolidados con los respectivos sucedáneos en formación. (B) Cambios en las dimensiones de los arcos con el crecimiento

Fuente: elaboración propia

En la dentición decidua es normal encontrar arcos alineados, abiertos o tipo I, con espacios generalizados o con diastemas primates (Figuras 2A, 2B, 2C y 2D); o arcos cerrados o tipo II (Figuras 3A y 3B), que sufren cambios con el proceso de recambio dental. Por lo general, los dientes permanentes son mayores que los deciduos en su diámetro mesiodistal (a excepción de los premolares) [2], así que el desarrollo del hueso alveolar, el aumento de distancia intercanina, los espacios primates, el patrón de erupción labial, entre otros, son factores que facilitan su acomodación [1]. Cuando uno o más de estos factores no están presentes en el desarrollo normal, se produce el apiñamiento [3]. 

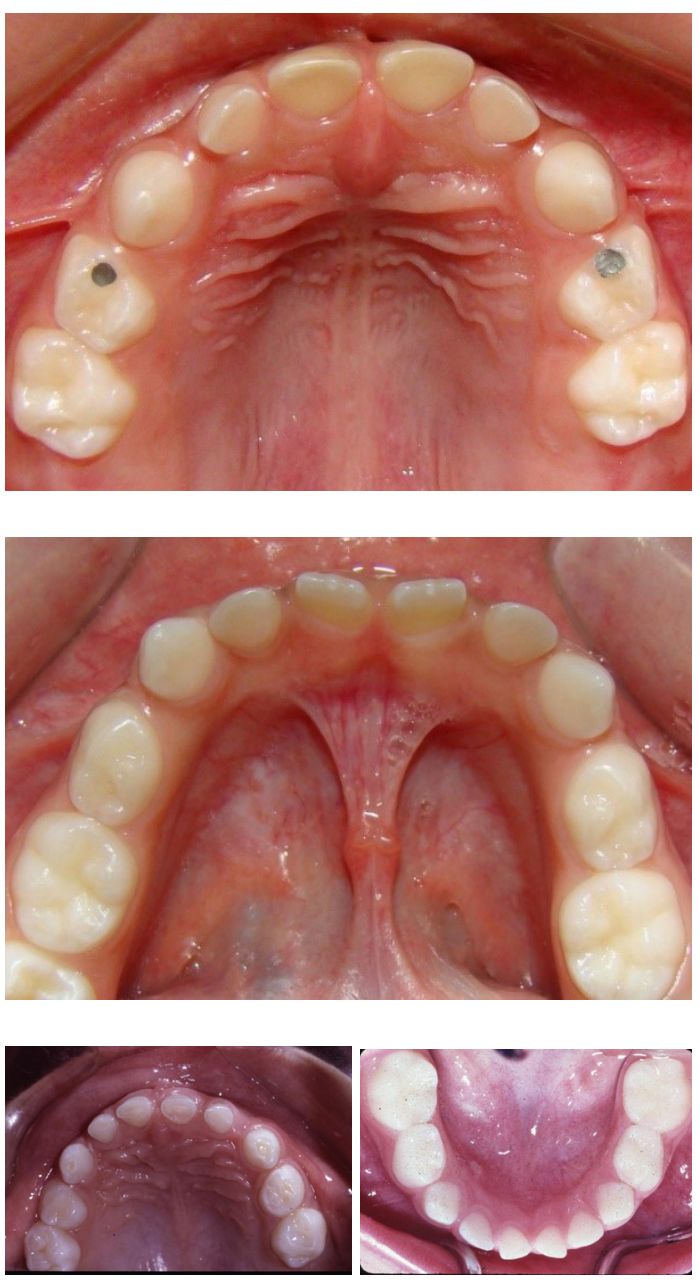

FIGURA 2. Arcos espaciados tipo I en dentición decidua Fuente: elaboración propia
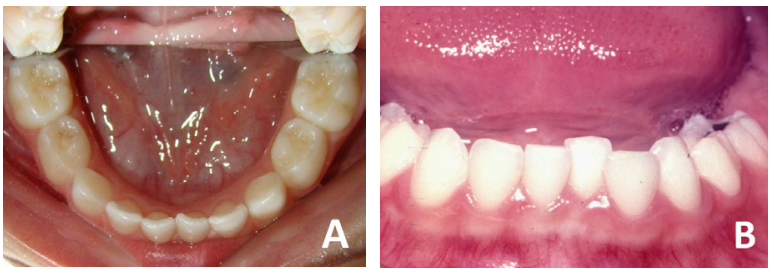

FIGURA 3. (A) Arcos deciduo tipo II. (B) Arco deciduo apiñado

Fuente: elaboración propia

Los estudios reportan la presencia de apiñamiento en la dentición permanente en un 85\% de los casos, con un promedio de $4.5 \mathrm{~mm}$ [5]. En otros estudios la prevalencia ha resultado más baja, entre el 30\% y el 50\% [6, 7], con apiñamiento de $4 \mathrm{~mm}$ en el 40\% [8]. En el ENSAB IV, el apiñamiento va del 56\% al 60\% entre los 12 y 16 años [8].

\section{MECANISMOS QUE FAVORECEN \\ EL CORRECTO ALINEAMIENTO \\ DE LOS DIENTES PERMANENTES}

\section{ESPACIOS FISIOLÓGICOS EN DENTICIÓN DECIDUA}

Uno de los factores favorables para que el apiñamiento no se presente es la existencia de espacios en la dentición decidua. En los arcos abiertos, esos espacios se encuentran en un $70 \%$ en el maxilar superior y en un $63 \%$ en el maxilar inferior [4], y el espaciamiento interdentario va de 0 a $10 \mathrm{~mm}$ (4 mm en promedio) en el maxilar superior y de 0 a $6 \mathrm{~mm}$ ( $3 \mathrm{~mm}$ en promedio) en la mandíbula (Figuras 2 y 4). Cuando existe espacio entre el primer molar y el segundo molar deciduos, es utilizado por el primer molar permanente durante su erupción, por lo cual se debe evitar esta migración mesial temprana en caso de ser necesario. Un apiñamiento en la dentición decidua no implica su continuidad en la dentición permanente; sin embargo, Sanin y Savara aseguran que el $89 \%$ de sujetos con apiñamiento en la dentición decidua lo tendrá en la dentición permanente (Figura 3) [5].

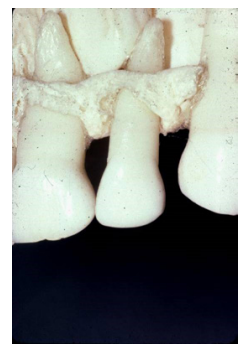

FIGURA 4. Espacio primate superior

Fuente: elaboración propia

\section{ERUPCIÓN LABIAL DE ANTERIORES SUPERIORES}

Los incisivos superiores permanentes presentan un patrón de erupción labial, lo cual aumenta la longitud y el perímetro del arco [4]. Al presentarse este tipo de patrón de erupción hacia 
vestibular y distal, se genera una posición anterior de los incisivos que favorece su acomodación en el arco: 2.2 mm en maxilar superior y $1.3 \mathrm{~mm}$ en la mandíbula (Figura 5) [1].

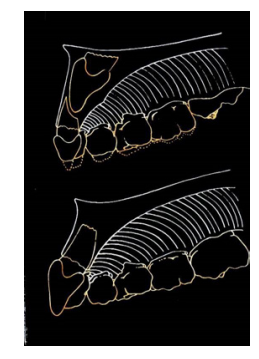

FIGURA 5. Inclinación a vestibular de los permanentes al erupcionar

Fuente: elaboración propia

\section{AUMENTO DE LA DISTANCIA INTERCANINA}

Durante la erupción de los incisivos superiores e inferiores, principalmente los laterales, se genera un aumento en la distancia intercanina (Figura 6) [3], que es mayor en el maxilar y en los arcos cerrados (por un mecanismo de compensación ante la ausencia de espacios). Moorrees reporta un aumento de $1.5 \mathrm{~mm}$ en hombres y $0.5 \mathrm{~mm}$ en mujeres [2, 3]. En la mandíbula, el aumento ocurre entre los 6 y 9 años para los hombres, y de los 6 a 8 años para las mujeres; en el maxilar, aumenta en mayor proporción hasta los 16 años en hombres y hasta los 12 años en mujeres [1].

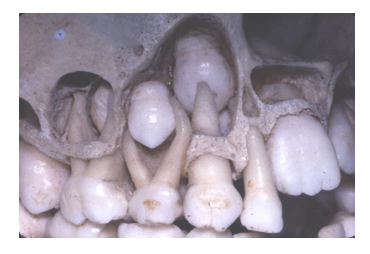

FIGURA 6. Proceso de erupción de incisivos permanentes

Fuente: elaboración propia

Otro evento que puede suceder durante el desarrollo que facilita la acomodación de los incisivos es el fenómeno llamado "desplazamiento secundario". Ocurre solo en arcos abiertos donde el canino deciduo inferior es desplazado a distal, hacia el espacio primate, durante la erupción de los incisivos laterales inferiores [1].

\section{ESPACIO DE LEEWAY}

En 1947 Nance describió el término espacio de Leeway o espacio libre, el cual representa la diferencia de tamaño entre caninos y molares deciduos versus caninos y premolares permanentes. Normalmente, la magnitud de este espacio es en promedio de $1.7 \mathrm{~mm}$ por hemiarcada para el arco inferior y $0.9 \mathrm{~mm}$ por lado en el arco superior. Sin embargo, también existe la posibilidad de que no se halle en ninguno de los dos arcos o que sea mayor que el promedio (Figura 7) [2].
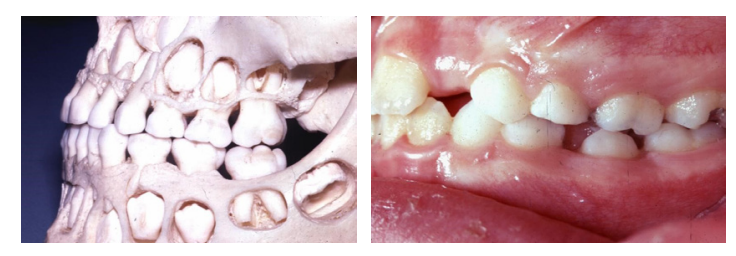

FIGURA ?. Espacio de Leeway

Fuente: elaboración propia

Durante la etapa de dentición mixta, la utilización de este espacio es variable, dependiendo de las características oclusales de cada individuo y la terapia que se instaure. Si no se instaura ninguna, este espacio es usado principalmente para la migración mesial de los primeros molares permanentes (migración mesial tardía) al exfoliarse el segundo molar deciduo. También puede emplearse para el alineamiento de los incisivos permanentes, siempre y cuando se realice algún tipo de intervención [4]. La mesialización de molares a expensas del espacio de Leeway depende de la interdigitación de los primeros molares (Figura 9). Cuando la oclusión es estable en clase I, la migración es menor que cuando hay una relación molar cúspide a cúspide. Otro aspecto que puede afectar la mesialización de los molares es el patrón de exfoliación de los segundos molares: si estos se pierden al mismo tiempo (tanto superiores 
como inferiores), es más probable que ocurra el movimiento de los primeros molares [2].

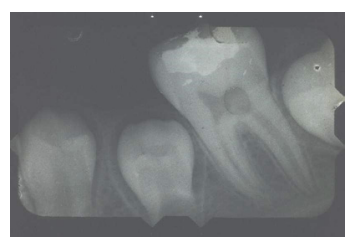

FIGURA 8. Mesialización de primer molar

Fuente: elaboración propia

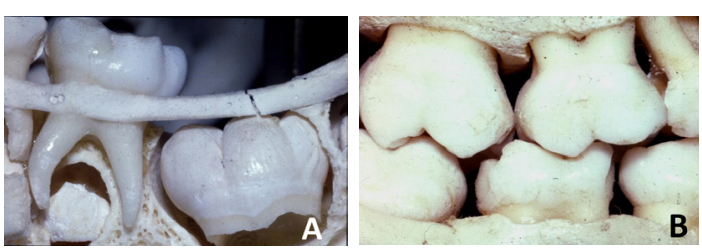

FIGURA 9. (A) Molares deciduos en oclusión. (B) Primer molar con migración mesial tardía a expensas del espacio de Leeway

Fuente: elaboración propia

\section{DIFERENCIA ENTRE LOS TAMAÑOS DENTARIOS ENTRE DECIDUOS Y PERMANENTES}

En la zona anterior también se encuentran diferencias entre los tamaños dentales de incisivos deciduos y permanentes, pero sucede al contrario: los permanentes son más grandes entre 3.2 y $3.5 \mathrm{~mm}$ en el maxilar y de $2.4 \mathrm{a}$ $2.5 \mathrm{~mm}$ en la mandíbula. Esta diferencia es conocida con el término de "liabilidad de incisivos" o "riesgo incisivo" [8]. Por otro lado, Black [10] asegura que los cuatro incisivos permanentes superiores son, en promedio, $7.6 \mathrm{~mm}$ mayores que los deciduos y los inferiores son $6 \mathrm{~mm}$ más grandes, dando así diferencias negativas. Sin embargo, la acomodación sin apiñamiento de los incisivos permanentes sucede en los casos en los que existe: a) espaciamiento en la dentición temporal o por la generación del espaciamiento secundario; b) erupción labial de los incisivos; c) aumento de la distancia intercanina. El espaciamiento secundario es el espacio que aparece entre los anteriores superiores durante su proceso de exfoliación [4]. Estos espacios pueden llegar a compensar la diferencia del tamaño dental, permitiendo así la alineación [5].

Si los factores anteriores no ocurren durante el desarrollo de los arcos, puede generarse un apiñamiento. Existen varios signos tempranos que permiten predecir estas discrepancias: la falta de espacios interdentales o presencia de apiñamiento anterior en dentición decidua; la ausencia de espacios primates; la pérdida prematura del canino deciduo inferior durante la exfoliación de los laterales permanentes (Figura 14); y la reabsorción mesial de la raíz del canino deciduo, a causa de una erupción hacia distal del lateral (la reabsorción que se genera tiene forma de media luna; Figura 10) [11, 12].
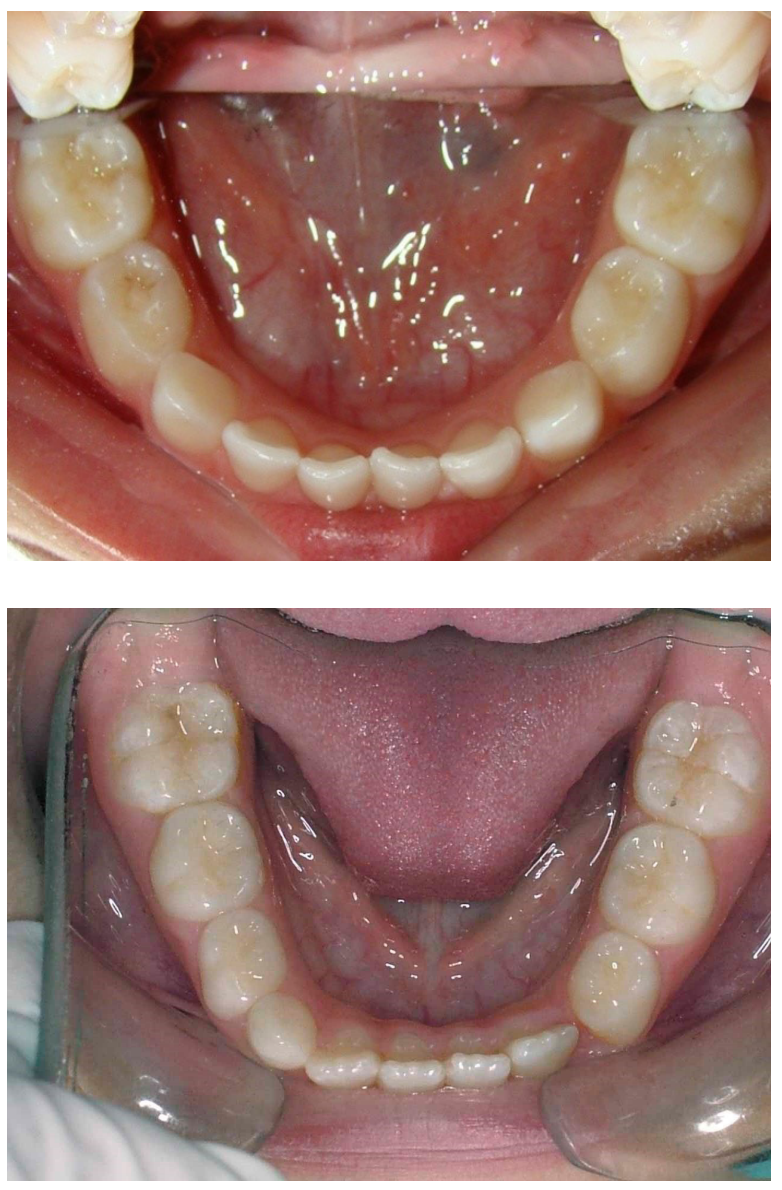

FIGURA 10. (A) Apiñamiento anterior. (B) Pérdida prematura de canino deciduo

Fuente: elaboración propia 
Por otro lado, Little [13] complementa la descripción de los signos con los siguientes: desplazamiento de la línea media inferior por un bloqueo del incisivo lateral en lingual; erupción pasiva acelerada o incluso recesión gingival en un incisivo inferior permanente prominente; erupción ectópica del primer molar (Figura 11); disposición vertical de gérmenes de primer, segundo y tercer molar por falta de desarrollo de la tuberosidad (Figura 12) [13]; falta de espacios interdentales en dentición decidua y apiñamiento en anteroinferiores en la dentición mixta.

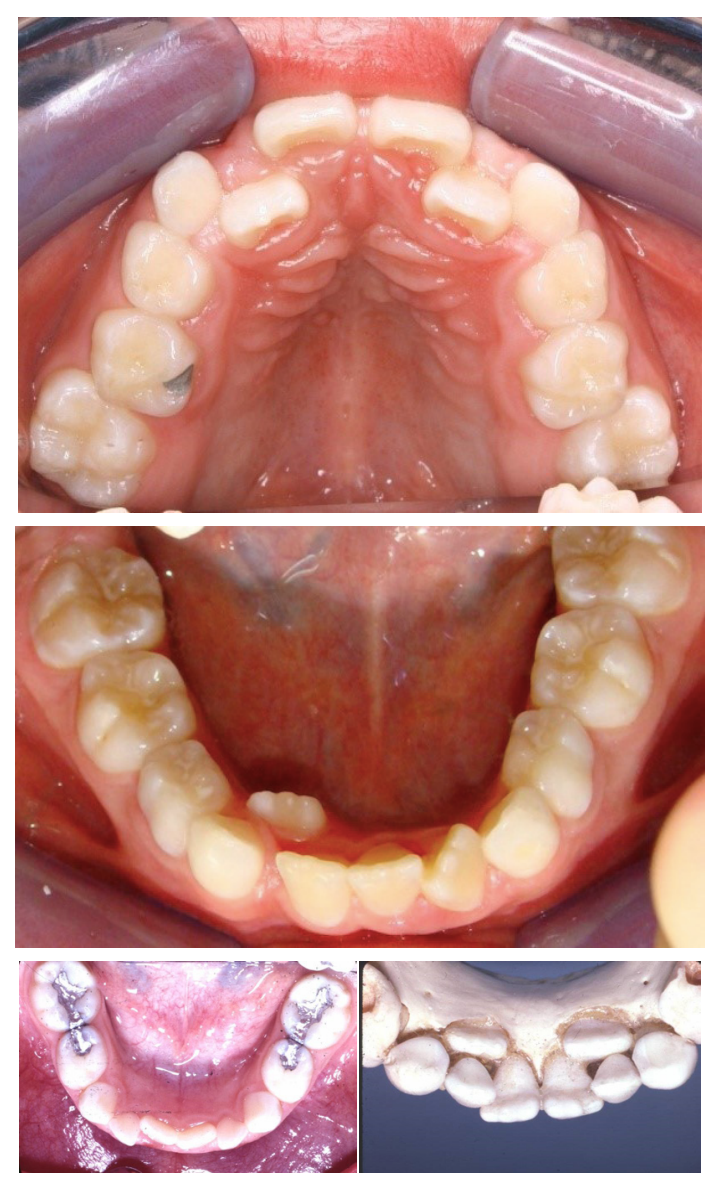

FIGURA 11. Incisivos laterales superiores e inferiores erupcionando por lingual

Fuente: elaboración propia

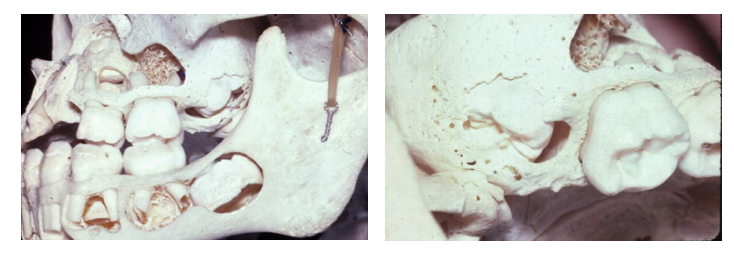

FIGURA 12. Desarrollo en la región de la tuberosidad Fuente: elaboración propia

\section{ETIOLOGÍA DEL APIÑAMIENTO}

Respecto a la etiología del apiñamiento, existen varios estudios que buscan establecer la relación entre el apiñamiento y el tamaño dental. Se ha determinado que los diámetros mesiodistales de las coronas de los seis anteriores son mayores en pacientes con apiñamiento, y en los pacientes no apiñados la longitud del arco es mayor, aunque no de modo significo [20]. Sin embargo, no se ha encontrado una asociación directa entre esos factores; por lo tanto, concluyen que lo más importante en la generación del apiñamiento es la presencia de un perímetro del arco reducido [21, 22]. Dentro de los factores etiológicos también encontramos los siguientes:

a. La evolución por cambio en la dieta, que genera menor expresión de crecimiento óseo.

b. La herencia.

c. El cambio en la dieta (dieta más blanda que reduce la función muscular y el tamaño de los arcos).

d. Una menor expresión de crecimiento óseo.

e. El tamaño dental: aunque se ha tratado de establecer la relación entre el tamaño de los dientes permanentes y la presencia de apiñamiento, no se ha podido comprobar que el tamaño dental sea un factor de causalidad [21]. 
f. El tamaño de los arcos: en varios estudios se ha comprobado que los tamaños de los arcos dentarios tienen una relación directa con la presencia de apiñamiento dental; por tanto, en arcos pequeños se encuentra más apiñamiento [21].

Para algunos autores, la presencia de un apiñamiento leve de 1 a $2 \mathrm{~mm}$ constituye un rasgo característico de la dentición [11]. Los signos que se pueden presentar -y que llevan al profesional a diagnosticar un problema de apiñamiento actual o posible- pueden usarse como factores predictores, dependiendo del análisis individual que se haga del paciente.

La predicción de apiñamiento en la dentición permanente es difícil [11]. Algunos autores aseguran que si la suma mesiodistal de los 20 dientes da como resultado 140 mm o más, puede decirse que existe una tendencia al apiñamiento [19]. Por otro lado, una distancia intercanina de $28 \mathrm{~mm}$ o más supone menor riesgo de apiñamiento, y una distancia menor a $26 \mathrm{~mm}$ se asocia con su aparición [23]. Asimismo, se ha tratado de relacionar el tamaño de los dientes deciduos con el de sus sucedáneos y se ha encontrado que no existe ninguna relación entre ambos: pacientes con dientes deciduos grandes no necesariamente tendrán dientes permanentes de tamaño aumentado [22]. Deigual modo, no existe relación entre el apiñamiento y el tamaño mesiodistal de los incisivos, al relacionarlo con el diámetro bucolingual [22].

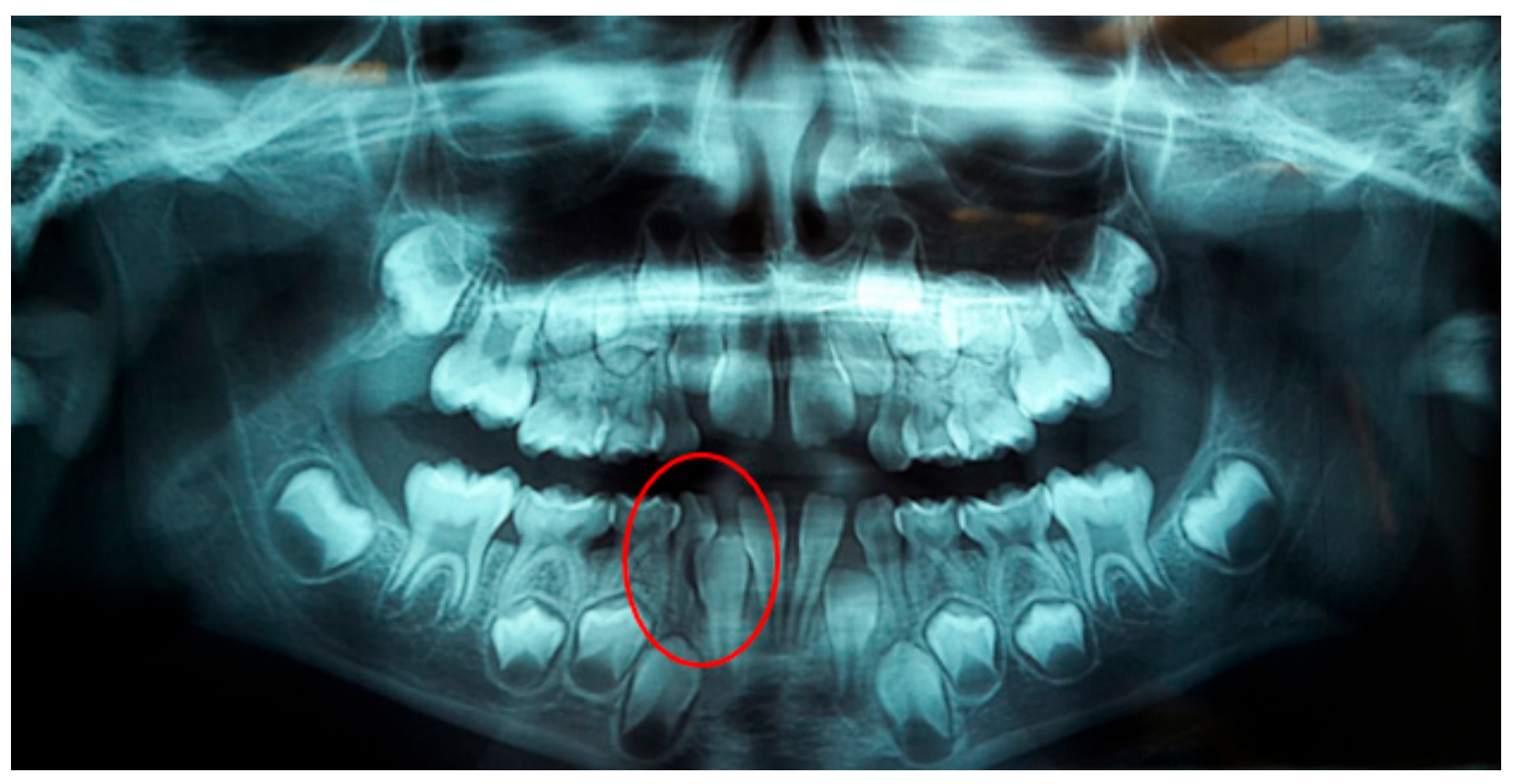

FIGURA 13. Reabsorción en media luna de canino deciduo inferior

Fuente: elaboración propia 


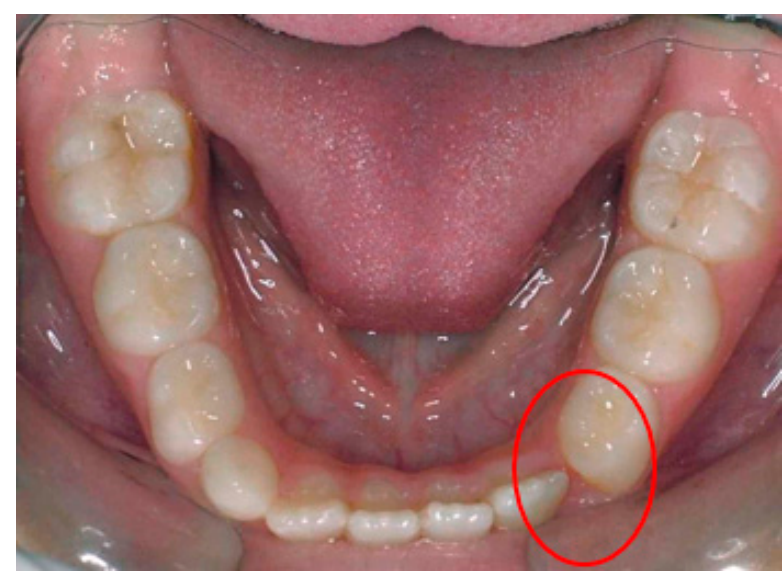

FIGURA 14. Pérdida prematura de canino deciduo

Fuente: elaboración propia

Finalmente, otros autores mencionan factores periodontales, como la erupción pasiva acelerada en anteroinferiores.

\section{CLASIFICACIÓN DEL}

\section{APIÑAMIENTO}

El apiñamiento se clasifica en primario, secundario y terciario. El primario consiste en la discrepancia entre el tamaño de los arcos y el tamaño de los dientes, y es determinado genéticamente. El secundario es causado por factores medioambientales, como la pérdida prematura de deciduos, las erupciones ectópicas, la caries interproximal y las restauraciones proximales planas. El terciario ocurre durante la etapa de la adolescencia y posadolescencia. Al realizar una evaluación al final del recambio dental es difícil establecer si el apiñamiento que presenta el paciente es primario o secundario, ya que no fue posible la observación durante el desarrollo. El apiñamiento primario no es prevenible mediante medidas interceptivas; el secundario sí, lo cual muestra la importancia de monitorear el desarrollo de la oclusión en un individuo en crecimiento [24].

El apiñamiento terciario presenta una etiología multifactorial y se ha generado mucha controversia para determinar cuál es el factor más influyente. Dentro de las causas asociadas tenemos las siguientes:

- Verticalización de los incisivos durante la posadolescencia (los mandibulares más que los maxilares), producto del crecimiento esqueletal tardío y el crecimiento mandibular residual, que ocurre entre los $12 \mathrm{y}$ 20 años. Debido a este crecimiento, el perfil se vuelve más recto y se aumenta el ángulo interincisal entre 4.5 y 4.2 grados [25].

- Erupción de los terceros molares (posadolescencia), que pueden generar fuerza mesial que produce un apiñamiento anterior; sin embargo, en la literatura existe una gran controversia con estudios a favor y en contra. Algunos estudios muestran que la fuerza generada por los molares durante su erupción no es suficiente para generar apiñamiento en la zona anterior; otros han encontrado apiñamiento incluso en pacientes sin terceros molares o en aquellos en los que fueron extraídos. Los estudios que evalúan el papel de los terceros molares en la etiología del apiñamiento terciario no son concluyentes debido a que no presentan una metodología rigurosa [25-27].

- Movimiento mesial de posteriores junto con el componente anterior de fuerzas y los vectores de contracción muscular [28]. El componente anterior de fuerza es generado por la inclinación mesial de los dientes posteriores, que los obliga a inclinarse a mesial durante la carga oclusal. La magnitud es de $5 \mathrm{lb}$ a nivel del segundo bicúspide, y se va disipando a través de los puntos de contacto hacia la zona anterior, llegando a $1 \mathrm{lb}$ en los caninos. En un estudio en el que se midió la fuerza generada por el componente anterior de fuerza, se observó que las fuerzas posteriores se disipan hacia anterior, y que las fuerzas que se generan en caninos e incisivos pueden ocasionar un apiñamiento terciario. Esto se incrementa sobre todo 
en pacientes bruxómanos [29]. Definitivamente, los caninos no juegan un papel importante en la disipación de las fuerzas en el sector anterior como se creía, pues solo son efectivos para disipar la fuerza en los casos en que se presentan diastemas mesiales a ellos [30]. Los estudios que buscan la relación directa entre la magnitud del componente anterior de fuerza y el apiñamiento anterior no han logrado establecerla [31].

- Fuerzas periodontales y cambios degenerativos en los tejidos, entre los que se cuentan los cambios en tejidos blandos o alteración de sus funciones, los cambios hormonales y la pérdida del soporte óseo, como resultado del envejecimiento o de la enfermedad periodontal [28].

- Dieta y evolución, pues el apiñamiento es una alteración común en los hombres modernos posindustriales, resultado del aumento en el procesamiento de las comidas modernas, lo que disminuye la necesidad de acción masticatoria. En poblaciones actuales, la menor presencia de apiñamiento se debe principalmente a la existencia de arcos grandes [32].

- Deflexión mandíbular: puesto que el apiñamiento anteroinferior multifactorial, no se puede predecir el apiñamiento tardío mediante una observación temprana [33].

\section{CLASIFICACIÓN DEL APIÑAMIENTO SEGÚN SU MAGNITUD}

El apiñamiento también se puede clasificar según su magnitud [5]:

a. Leve: de 1 a $3 \mathrm{~mm}$

b. Moderado: de 3 a $5 \mathrm{~mm}$

c. Severo: mayor de $5 \mathrm{~mm}$ (Figura 15)
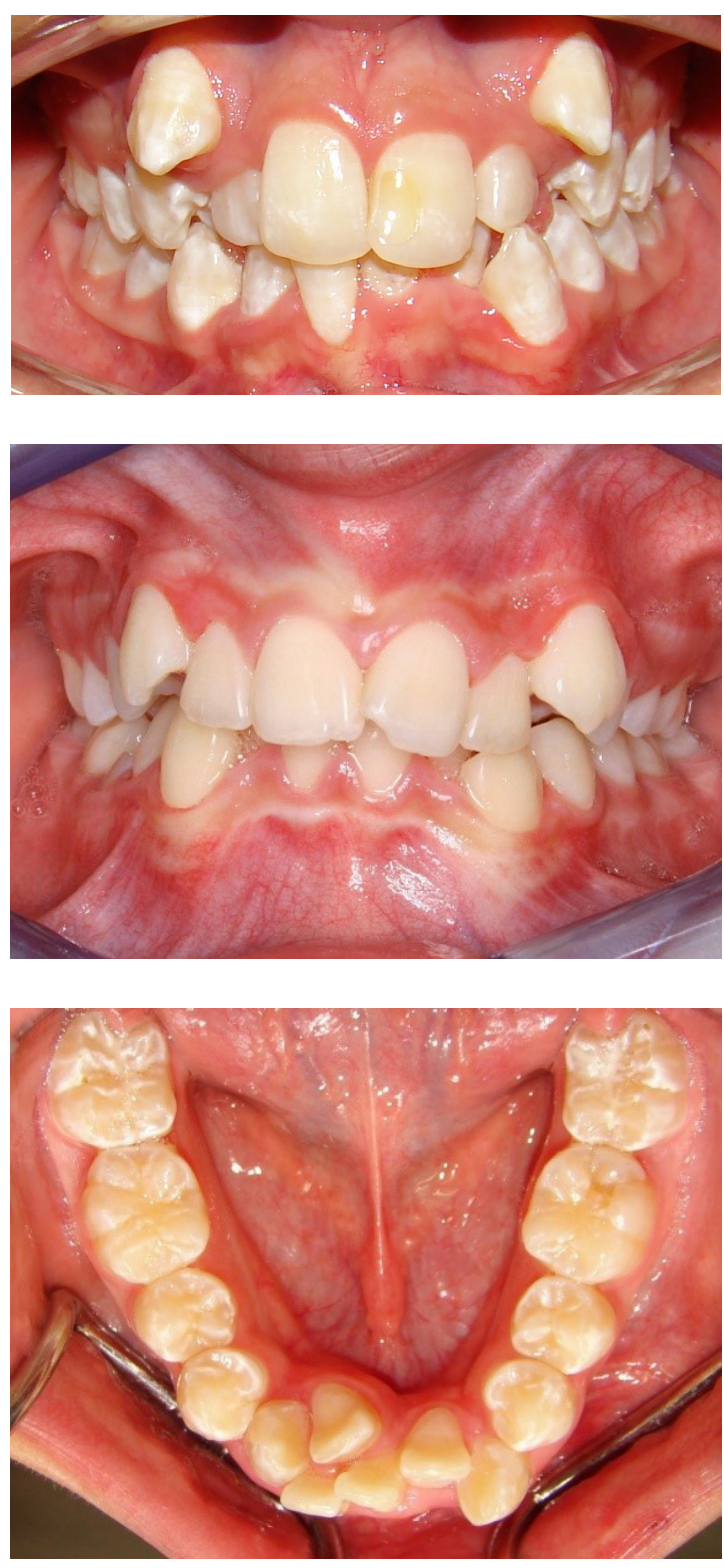

FIGURA 15. Apiñamiento superior e inferior severo

Fuente: elaboración propia

Para cuantificar la discrepancia presente en la etapa de dentición mixta temprana, se puede aplicar un análisis de dentición mixta. El más usado es el análisis de Moyers [34]; sin embargo, su precisión es limitada, pues ha visto que este análisis sobreestima el tamaño de los permanentes en $1.7 \mathrm{~mm}$, cuando se aplica en el percentil 75. Algunos autores utilizan el percentil 95, lo que implica que el 95\% de la población tendrá caninos y premolares más pequeños. Otro análisis es el de Tanaka y 
Jhonston, que es más fácil de realizar, pero presenta la misma limitación del anterior $[35,36]$. Se sugiere, por tanto, el uso de un análisis como el de Hixon y Oldfather, que involucren medición en modelos y radiografías, para lograr mayor precisión en la predicción del tamaño dentario (v. cap. 4) [37].

\section{TRATAMIENTO DEL APIÑAMIENTO}

El plan de tratamiento aplicado debe ser acorde a la etiología del apiñamiento. No obsante, también hay que tener en cuenta otras características del paciente: el tipo esquelético (considerando el crecimiento sagital y el crecimiento vertical); el tipo de maloclusión (con el análisis de los tres planos del espacio: transversal, sagital y vertical); la inclinación y posición de los incisivos; el perfil facial; la posición de los labios; el selle labial, y la edad del paciente. Además, se debe tener presente la estabilidad que se puede lograr en la corrección del apiñamiento con los diferentes métodos disponibles.

\section{TRATAMIENTO PARA EL APIÑAMIENTO PRIMARIO}

Este tratamiento depende de la severidad del apiñamiento: leve, moderado o severo. Para algunos autores, puede corregirse en casos leves solo esperando el proceso de desarrollo normal de la oclusión, con eventos como el desplazamiento secundario (uso del espacio primate), cuando existe espaciamiento secundario (espacios que aparecen entre los incisivos superiores durante la erupción de los incisivos inferiores permanentes), el aumento de distancia intercanina (por crecimiento intrínseco dentoalveolar o por la fuerza generada durante la erupción de los incisivos laterales) y el aumento de la longitud de arco (los incisivos permanentes erupcionan con una angulación más vestibular y distal) [4]. Estudios clínicos han reportado que el uso del espacio de
Leeway con la colocación de un mantenedor de espacio, durante la dentición mixta, fue suficiente para alinear el 62\% de los pacientes [11].

Sin embargo, debe considerarse que estos eventos no ocurren en todos los pacientes y no en todos son de la misma magnitud. Por tanto, no siempre se puede lograr una corrección completa del apiñamiento y se requiere de un tratamiento encaminado a la creación de espacio en el arco, aplicado por el especialista. Después de la erupción de los incisivos laterales no se puede esperar una corrección espontánea del apiñamiento [23]. En casos de apiñamiento moderado o severo, el tratamiento puede ir desde la obtención de espacio hasta la planeación de una extracción seriada.

\section{TRATAMIENTO DE APIÑAMIENTO SECUNDARIO}

Al ser un problema completamente diferente al apiñamiento primario en su etiología, debe determinarse inicialmente cuál es el factor desencadenante y enmarcarlo dentro del análisis completo del paciente (facial, esquelético, dental). Otro aspecto que los diferencia es la ubicación del apiñamiento: el primario hace referencia al apiñamiento anterior; el secundario puede presentarse en el sector anterior o en el posterior. Básicamente, se pueden escoger dos caminos en el tratamiento, que dependerán de la magnitud del apiñamiento, la presencia de discrepancia dentoalveolar, la magnitud del espacio de Leeway, el tipo esquelético, el crecimiento vertical y el perfil del paciente:

a. El primer enfoque considera la posibilidad de recuperar el espacio perdido que generó el apiñamiento. Esta recuperación puede ser en sentido anteroposterior, mediante la distalización de molares y la vestibularización de incisivos. Es el mecanismo más eficiente ya que por cada milímetro de distalización y cada grado de vestibularización 
se obtiene $1 \mathrm{~mm}$ de espacio en el arco. Cuando este primer enfoque no es posible, se tendrá que recurrir a otro, el cual se basa en extracciones.

b. La otra alternativa que la literatura presenta es la expansión transversal. Este tipo de tratamiento no se considera un enfoque ideal, debido a su ineficiencia en el aumento del perímetro del arco: por cada milímetro de expansión se logran de 0.4 a $0.7 \mathrm{~mm}$ en el arco. Solo debe ser utilizada en casos donde existan alteraciones transversales en los pacientes, para no generar mordidas en tijera [38].

\section{TRATAMIENTO DE APIÑAMIENTO TERCIARIO}

Se puede ampliar el arco dentario principalmente mediante la vestibularización de incisivos o aumentando la distancia intercanina (en no más de $1 \mathrm{~mm}$ para lograr adecuada estabilidad). Otra forma de tratamiento consiste en la exodoncia de dientes permanentes (bicúspides o un incisivo inferior, dependiendo del paciente). La selección del tipo de tratamiento dependerá de un examen completo del paciente - como se ha descrito para los otros tipos de apiñamiento-, que tenga en cuenta los factores dentales, esqueléticos, faciales y funcionales. Además, según los factores etiológicos que puedan estar asociados, para este tipo de apiñamiento se debe considerar la eliminación de factores parafuncionales y determinar el tipo de retención a aplicar. Los diferentes tratamientos serán descritos con mayor profundidad en los próximos capítulos de manera independiente.

\section{RETENCIÓN Y ESTABILIDAD}

La retención es el mantenimiento de los dientes luego del tratamiento interceptivo o de la ortodoncia. Se aplica por un periodo necesario para mantener el resultado y permitir la reorganización periodontal y gingival; minimizar los cambios con el crecimiento; permitir una adaptación neuromuscular a una posición dental, y mantener una posición dental estable. Son factores que afectan la estabilidad [39]:

a. Desarrollo normal: los cambios postratamiento pueden deberse a procesos fisiológicos de adaptación dentoalveolar. Por ejemplo, la distancia intercanina aumenta hasta la erupción de caninos y luego disminuye; mientras que la distancia intermolar permanece estable.

b. Cambios en la forma del arco: durante los tratamientos, se debe procurar no cambiar drásticamente la forma del arco ni aumentar sus dimensiones más allá de lo que es considerado estable. Idealmente, el aumento de la distancia intercanina inferior debe estar entre 1 y $3 \mathrm{~mm}$.

c. Tejidos periodontales y gingivales: las fibras colágenas generan recidiva de las posiciones dentales debido a que su proceso de remodelación es lento (en promedio se demora 232 días); por tanto, en los casos donde hubo cambios en las posiciones dentales, se debe considerar su mantención, al menos durante un año, luego de terminar el movimiento activo.

d. Dimensión de incisivos mandibulares: la estabilidad aumenta con una reducción mesiodistal; sin embargo, esta teoría no cuenta con una adecuada evidencia para establecer el desgaste como protocolo en todos los pacientes que presentaron apiñamiento.

e. Factores medioambientales y neuromusculares: los dientes a los que se les modifica significativamente la angulación bucolingual (principalmente posteriores), a través de expansiones no controladas, recidivan a su posición original debido a que la función 
neuromuscular no se adapta correctamente.

f. Crecimiento continuo: el crecimiento ocurre hasta edades posteriores a la adolescencia, lo que puede generar cambios ligeros en la posición mandibular, aplanando el perfil y lingualizando los incisivos inferiores. Estos cambios pueden ocasionar recidiva de las posiciones dentales.

g. Oclusión funcional y posicionamiento dental: es importante obtener una oclusión funcional estable durante el tratamiento. Un adecuado ángulo interincisal ayuda a la estabilidad del overbite; y una buena oclusión posterior ayuda a evitar una recidiva transversal y sagital. Asimismo, permite obtener una igualdad en la oclusión y la relación céntrica. h. Influencia de la maloclusión original: la recidiva generalmente ocurre en los primeros 2 años postratamiento; si la distancia intercanina se mantiene durante ese periodo, se puede aumentar la estabilidad.

i. Extracciones: se ve recidiva en pacientes a los que se les realiza extracción seriada, así como en aquellos a los que se les hacen extracciones terapéuticas.

j. El índice de irregularidad aumenta con el tiempo $(1.3 \mathrm{~mm})$ : el 74\% muestra una irregularidad aceptable (menor a $3.5 \mathrm{~mm}$ ) y el $1.5 \%$ una irregularidad severa. Así también, la forma de los arcos cambia con el tiempo: el arco mandibular se vuelve rectangular y un arco amplio en la zona anterior muestra mayor estabilidad. Las restauraciones interproximales son factores de riesgo para la retención [40].

\section{REFERENCIAS}

[1] Stewart E, Barber T. Pediatric dentistry, scientific foundation and clinical practice. St. Louis: Mosby; 1982.

[2] Moorrees C. The consideration of dental development in serial extraction. Angle Orthod. 1963;33(1):44.

[3] Moorrees C. Changes in dental arch dimensions expressed on the basis of tooth eruption as a measure of biological age. J. Dent. Res. 1965;44:129.

[4] Baume L. Physiological tooth migration and its significance for the development of occlusion III. The biogenesis of succesional dentition. J. Dent. Res. 1950;29:338.

[5] Proffit W, Fields H Jr, Sarver D. Contemporary orthodontics. 4. ${ }^{\text {a }}$ ed. St. Louis: Mosby; 2007.

[6] Hill P. The prevalence and severity of malocclusion and the need for orthodontic treatment in 9, 12 and 15 year-old Glasgow schoolchildren. British J. Orthod. 1992;19:87-96.

[7] Urrego-Burbano P, Jiménez-Arroyave L, Londoño-Bolívar M, Zapata-Tamayo M, Botero Mariaca P. Perfil epidemiológico de la oclusión dental en escolares de Envigado, Colombia. Rev. Sal. Públ. 2011;13(6):10101021.

[8] Buschang PH, Shulman JD. Incisor crowding in untreated persons 15-50 years of age. United States, 19881994. Angle Orthod. 2003; 73:502-508.

[9] Ministerio de Salud de Colombia. IV Estudio Nacional de Salud Bucal (ENSAB IV). Bogotá: Ministerio de Salud; 2014.

[10] LeBlanc S, Black B. A long term in tooth size in the Eastern Mediterranean. Am. J. Phys. Anthropol. 1974;41(3):417-422.

[11] Gianelly A. Leeway space and the resolution of crowding in the mixed dentition. Semin. Orthod. 1995;1(3):188-194. 
[12] Dale J. Serial extraction. JCO. 1976 ene;10(1):44. feb;10(2):116. mar; 10(3):196.

[13] Little R. The effects of eruption guidance and serial extraction on development dentition. Pediatr. Dent. 1987;9(1):65.

[14] Brunelle JA, Bhat M, Lipton JA. Prevalence and distribution of selected oclusal characteristics in the US population, 1988-1991. J. Dent. Res. 1996;75:706-713.

[15] Bishara SE. Changes in the molar relationship between the deciduous and permanent dentitions: A longitudinal study. Am. J. Orthod. Dentofacial Orthop. 1988;93:19-28.

[16] Thilander B, Pena L, Infante C, Parada S, Mayorga C. Prevalence of malocclusion and orthodontic treatment need in children and adolescents in Bogota, Colombia. An epidemiological study related to different stages of dental development. Eur. J. Orthod. 2001;23(2):153.

[17] Álvarez EF, Roldán S, Mejía J, Tobón P, Velásquez L. Estudio de la prevalencia, distribución y severidad de la maloclusión de la población escolar de 7 a 16 años de la ciudad de Medellín. Acad. Colom. Odont. Ped. 2002;4(1):25-34.

[18] Botero P. Perfil epidemiológico de la oclusión dental de Envigado, Colombia. Alemania: Editorial Académica Española; 2012.

[19] Howe R, McNamara J, O'Connoer K. An examination of dental crowding and its relationship to tooth size and arch dimension. AJO. 1983;83(5):363.

[20] Melo L, Ono Y, Takagi Y. Indicators of mandibular dental crowding in the mixed dentition. Pediatr. Dent. 2001;23(2):118.

[21] Radnzic D. Dental crowding and its relationship to mesiodistal crown diameters and arch dimensions. Am. J. Orthod. Dentofacial Orthop. 1988;94:50.

[22] Gilmore C, Little R. Mandibular incisor dimensions and crowding. Am. J. Orthod. Dentofacial Orthop. 1984;86:493.

[23] Foley F, Wright G, Weinberger S. Management of lower incisor crowding in the early mixed dentition. J. Dent. Child. 1996;63(3):169-174.

[24] Van der Linden F. Theoretical and practical aspects of crowding in the human dentition. J. Am. Dent. Assoc. 1974;89(1):139

[25] Richardson M. Late lower arch crowding in relation to primary crowding. Angle Orthod. 1982;52:300.

[26] Richardson M. Late lower arch crowding in the third decade. Eur. J. Orthod. 1998;20(5):597.

[27] Richardson M. Lower arch crowding in the young adult. Am. J. Orthod. Dentofacial Orthop. 1992;101(2):132.

[28] Richardson, M. Late lower arch crowding: the effect of second molar extraction. Am. J. Orthod. Dentofacial Orthop. 1990;98:242.

[29] Acar A, Alcan T, Erverdi N. Evaluation of the relationship between the anterior component of occlusal forcé and postretention crowding. Am. J. Orthod. Dentofacial Orthop. 2002;122:366-370.

[30] Southard T, Behrents R, Tolley E. The anterior component of occlusal force. Part 1. Measurement and distribution. Am. J. Orthod. Dentofacial Orthop. 1989;96:493-520.

[31] Southard T, Behrents R, Tolley E. The anterior component of occlusal force. Part 2. Relationships with dental malalignment. Am. J. Orthod. Dentofacial Orthop. 1989;96:493-520.

[32] Normando D, Ameida M, Quintao C. Dental crowding: the role of genetics and tooth wear. Angle Orthod. 2013;83:10-15.

[33] Lundy H, Richardson M. Developmental changes in alignment of the lower labial segment. Br. J. Orthod. 1995 nov;22(4):339-345.

[34] Moyers R. Análisis de dentición mixta. Manual de ortodoncia. 4. a ed. Buenos Aires: Panamericana; 1992.

[35] Tanaka H, Johnston LE. The prediction of the size of unerupted canines and premolars in the contemporary orthodontic population. Am. Dent. Assoc. 1974 abr;88(4):798-801. 
[36] Botero P, González, S, Álvarez G. Espacio de Leeway y pasivo incisivo en pacientes en crecimiento. Alemania: Editorial Académica Española; 2012.

[37] Nanda SK. The developmental basis of occlusion and maloclusion. Chicago: Quintessence; 1983.

[38] Adkins M, Nanda R, Currier G. Arch perimeter changes on rapid palatal expansion. Am. J. Orthod. Dentofacial Orthop. 1990;97:194-199.

[39] Blake M, Bibby K. Retention and stability: A review of the literature. Am. J. Orthod. Dentofacial Orthop. 1998;114:299-306.

[40] Myser S, Campbell P, Buschang P. Long term stability: postretention changes of mandibular anterior teeth. Am. J. Orthod. Dentofacial Orthop. 2013;144:420-429. 


\section{CAPÍTULO 4}

\section{CONTROL DE ESPACIO}

Paola María Botero Mariaca, Libbe Mariaca de Botero

Dentro del tratamiento interceptivo, el control de espacio es un concepto que engloba el manejo integral del espacio en el arco en desarrollo. Es fundamental para generar un desarrollo adecuado de los arcos, con el respectivo acomodamiento de los dientes en erupción. El proceso involucra muchos procesos adicionales, basados en el conocimiento del desarrollo de oclusión y el crecimiento y desarrollo de los individuos. En este capítulo se describe la terminología que se debe usar en el correcto control de espacio, así como las indicaciones de las diferentes terapias por aplicar.

\section{Aspectos Generales}

El control de espacio es la supervisión de la dentición en desarrollo, aplicando todos los conocimientos de crecimiento y desarrollo de oclusión, para impedir la pérdida de la longitud del arco, puesto que no implica solamente la colocación de un aparato. La longitud de arco puede estar afectada por factores medioambientales, congénitos o genéticos: caries, anomalías dentarias de estructura y número (hipodoncias), forma (fusiones), erupciones ectópicas, extracciones prematuras de dientes deciduos, restauraciones clase II deficientes y traumas [1, 2].

Es fundamental tener en cuenta que los dientes deciduos son los principales actores en el control y mantenimiento de espacio, pues aseguran una función masticatoria adecuada, un buen desarrollo de los arcos dentarios y una excelente guía de erupción para los dientes permanentes. La ausencia o pérdida prematura de estos dientes genera una serie de problemas como migraciones dentarias (hacia mesial o distal), linguoversiones, labioversiones, rotaciones y sobreerupciones de antagonistas, entre otros $[1,2]$.

\section{MANTENIMIENTO DE ESPACIO}

El término mantenimiento de espacio hace referencia a la conservación, por cualquier medio, del perímetro de arco con el que nace el paciente, en situaciones donde se presenten eventos que lo comprometan. En 1986, Gafhari estableció varios factores que obligan a mantener el espacio en un arco en desarrollo (dentición decidua o mixta): pérdida prematura de deciduos, lesiones cariosas proximales sin restaurar, pérdida de incisivos permanentes por trauma, ausencia congénita de permanentes, erupciones ectópicas y malformaciones dentales [3].

El tiempo transcurrido entre la exfoliación normal del deciduo y la erupción del permanente es aproximadamente de una semana para premolares y de cuatro meses para caninos e incisivos. La conservación del espacio es necesaria si el deciduo se perdió mucho tiempo antes de que la erupción del permanente suceda, pues además esta se retrasará. Se considera pérdida prematura de molares cuando el permanente tiene el 75\% de su raíz formada o hay más de $1 \mathrm{~mm}$ de hueso alveolar para atravesar [4]. Cabe recordar que el mantenimiento de espacio se aplica cuando el diente que está erupcionando hace contacto con los dientes adyacentes; de lo contrario, se puede presentar pérdida de espacio.

El mantenedor de espacio es un aparato que se coloca para mantener la longitud de arco, cuando aún no ha habido pérdida. Su uso tiene los siguientes objetivos:

- Permitir una guía de erupción y secuencia adecuada de la dentición permanente.

- Mantener la longitud del arco evitando la migración mesial de los dientes posteriores. 
- Evitar que los caninos deciduos migren hacia distal ante la pérdida de molares deciduos.

- Evitar el colapso lingual de los incisivos permanentes o la desviación de la línea media.

- Evitar la impactación dentaria.

- Disminuir costos, tiempo y complejidad del tratamiento ortodóntico.

Para evaluar la necesidad de un mantenedor de espacio, deben tenerse en cuenta los siguientes parámetros:

- Edad dental: a partir de la evaluación radiográfica se determina el estadio de Nolla del diente sucedáneo; una pérdida prematura genera un retraso en la erupción cuando el permanente se encuentra por debajo del estadio 7 de Nolla.

- Tiempo trascurrido desde la pérdida: cuanto más tiempo trascurre desde la pérdida del diente, la posibilidad de que se cierre el espacio es mayor; este cierre es más acentuado en los primeros seis meses.

- Ausencia congénita de diente permanente: el clínico evaluará si se mantendrá o cerrará el espacio, dependiendo del tipo de oclusión, el tamaño de los dientes permanentes, el tipo de perfil del paciente, entre otros.

- Cantidad de hueso que recubre el diente no erupcionado: la presencia de hueso sobre las coronas de los permanentes es una forma de predecir el momento de erupción del diente permanente. Se requiere de $4 \mathrm{a}$ 6 meses para que el diente permanente se mueva $1 \mathrm{~mm}$ en el hueso.

- Secuencia de erupción de los dientes permanentes.

- Presencia de hábitos orales.

- Zona donde se da la pérdida: anterior o posterior.
Antes de definir la necesidad de un mantenedor, se deben tener las ayudas diagnósticas completas del paciente para evaluar adecuadamente la necesidad del aparato. Estas ayudas consisten en lo siguiente:

- Historia clínica completa.

- Evaluación clínica.

- Modelos de estudio, tanto cualitativo como cuantitativo.

- Radiografía panorámica, recomendada a los 5 o 6 años con el fin de evaluar el desarrollo y la vía de erupción de los primeros molares permanentes.

- Radiografía cefálica, si se requiere según la evaluación clínica.

- Fotografías clínicas intraorales y extraorales.

\section{CLASIFICACIÓN DE LOS MANTENEDORES}

Los mantenedores de espacio se clasifican en fijos y removibles, dependiendo de la forma de anclaje. A su vez, los fijos se clasifican en unilaterales y bilaterales, según su extensión en la arcada; mientras que los removibles siempre son bilaterales [3, 4] (Tabla 1). Un adecuado mantenedor debe cumplir con las siguientes características [6]:

a. Ser pasivo, de fácil manipulación y permitir una adecuada higiene oral.

b. Preservar adecuadamente el espacio.

c. Permitir la erupción de los dientes adyacentes y sucedáneos.

d. Restablecer la función masticatoria.

e. Prevenir la sobreerupción.

f. Ser compatible con los tejidos blandos.

g. Ser económico y resistente a la distorsión. 
h. Ser de aplicación universal.

i. No interferir con las funciones básicas de deglución, fonación, respiración y masticación.

j. Evitar que se den interferencias oclusales.

TABLA 1

Tipos de mantenedores de espacio

\begin{tabular}{cl}
\hline \multirow{2}{*}{ Fijos unilaterales } & Banda y abrazadera \\
\cline { 2 - 2 } & Corona y abrazadera \\
\hline \multirow{2}{*}{ Fijos bilaterales } & Arco lingual \\
\cline { 2 - 2 } & Botón palatino \\
\cline { 2 - 2 } Removibles bilaterales & $\begin{array}{l}\text { Placas de Hawley superiores e } \\
\text { inferiores }\end{array}$ \\
\hline
\end{tabular}

Fuente: elaboración propia

Tanto los mantenedores fijos como los removibles presentan ciertas desventajas que deben tenerse en cuenta para realizar una adecuada elección (Tabla 2) [4]. Existen contraindicaciones en la aplicación de mantenedores de espacio, entre las que se pueden mencionar las siguientes:

a. Si al realizar el análisis de modelos se determina que el espacio disponible es mayor al espacio requerido.

b. Si existe una discrepancia arco-diente marcada que requiere extracción de permanentes.

c. Si ya ha ocurrido la pérdida de espacio.

d. Si el espacio requerido no es igual al espacio disponible.

e. Si se presenta agenesia dental, siempre y cuando se determine que el espacio no será necesario para reemplazar el diente ausente.
TABLA 2

Desventajas según mantenedores de espacio

\begin{tabular}{|c|c|c|c|}
\hline Desventajas & Fijo & Removible & Ambos \\
\hline Impactación en el tejido blando & & & $x$ \\
\hline $\begin{array}{l}\text { Interferencia con la erupción del } \\
\text { sucedáneo }\end{array}$ & & & $x$ \\
\hline Erosión tisular & & & $x$ \\
\hline Dolor & & & $x$ \\
\hline Movimiento dental indeseado & $x$ & & \\
\hline Acumulación de placa & $x$ & & \\
\hline Caries & $x$ & & \\
\hline Fracturas & & & $x$ \\
\hline Desalojo del aparato & & & $x$ \\
\hline
\end{tabular}

Fuente: elaboración propia

\section{MANTENEDORES DE ESPACIO FIJOS}

La selección de un mantenedor de espacio fijo depende de los siguientes factores $[3,4]$ :

a. Grado de erupción de los dientes adyacentes al espacio por mantener.

b. Grado de erupción de dientes antagonistas al espacio.

c. Calidad de la higiene oral del paciente.

d. Colaboración del paciente.

e. Estado de desarrollo de la oclusión.

f. Los mantenedores fijos se clasifican de acuerdo con la cantidad de apoyos o anclajes que presenten (Tabla 1). Para su colocación y anclaje intraoral, requieren de la adaptación de bandas de acero inoxidable en los dientes de anclaje (deciduos o permanentes). 


\section{Construcción y elaboración de los mantenedores fijos}

\section{Adaptación de bandas}

Antes de adaptar una banda, se debe lograr una separación interproximal de los molares, utilizando alambres separadores o elastómeros (Figura 1). Los alambres son hechos en cobre, se colocan por debajo del punto de contacto interproximal y se entorchan hacia vestibular. Se deben dejar allí ocho días, como mínimo, para lograr una adecuada separación; no se recomienda más tiempo debido a la acumulación de placa que genera. Los elastómeros se colocan con una pinza especial (similar a una portagrapas) o usando dos sedas dentales en cada extremo. La finalidad es que se estiren para atravesar el punto de contacto, quedando un lado debajo de este y el otro por encima.

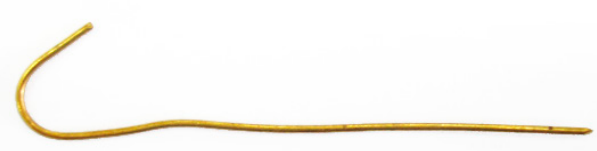

FIGURA 1. Separador de alambre de cobre y elastómeros Fuente: elaboración propia

\section{Proceso}

A continuación, se detalla el proceso de adaptación de una banda en boca:

a. Selección del tamaño de banda para el molar o los molares de anclaje. Es importante tener en cuenta que, en la zona mesial, las bandas presentan el número que indica su tamaño y unas letras que establecen si corresponde a superior o inferior, derecha o izquierda (UL: superior izquierda, UR: superior derecha, LL: inferior izquierda, RL: inferior derecha; Figura 2). Para seleccionar el tamaño, el especialista se puede ayudar con el modelo de estudio del paciente; así tendrá un tamaño más aproximado para medir en la boca.

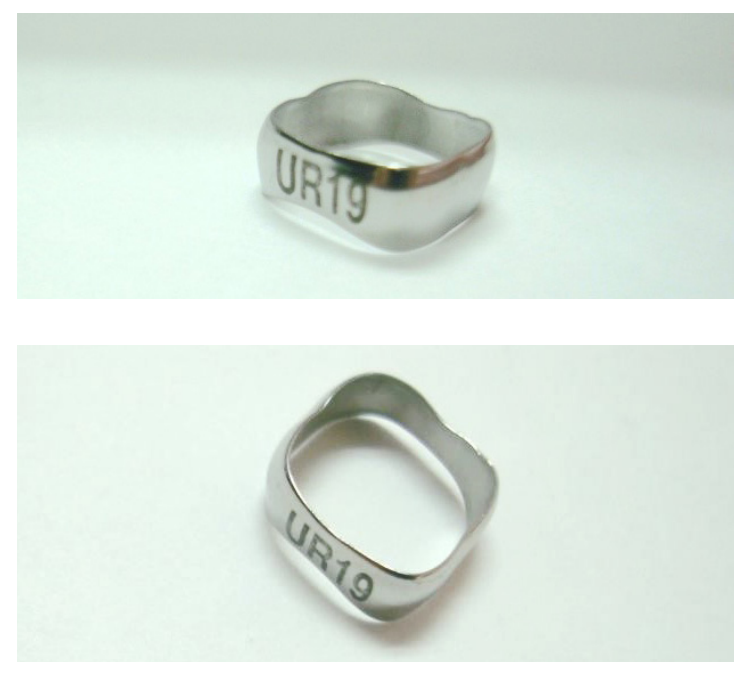

FIGURA 2. Banda en acero inoxidable superior derecha

Fuente: elaboración propia

b. Adaptación de banda metálica. Para este paso se emplean el band pusher y el band setter (Figura 3), haciendo presión hacia gingival sobre la banda en las zonas proximales (mesial o distal), nunca en las zonas bucales o linguales porque la banda se doblaría hacia oclusal, impidiendo su adaptación. La fuerza inicial para posicionar la banda debe ejercerla el odontólogo; una vez que esté, más o menos, a la mitad de la corona clínica, se puede ayudar con la fuerza de mordida del paciente, a través del band setter. Durante el proceso de adaptación de las bandas, puede ser necesaria la utilización de una pinza contorneadora de bandas (Figura 4) para adaptar mejor la forma de la banda al molar, logrando que quede adosada a todas las superficies. Esta pinza se coloca en la parte interna de la banda para contornearla. 
Para retirar la banda del molar, se requiere la pinza tumba-bandas (Figura 5): tiene un extremo con un tope plástico que sirve de apoyo en la superficie oclusal del molar (existen pinzas con topes metálicos que son peligrosas, generan lesiones en el paciente por su falta de estabilidad) y un extremo metálico que se coloca en el borde inferior de la banda (zona gingival del diente), en vestibular de los inferiores y en lingual de los superiores, para ejercer la fuerza hacia oclusal de manera adecuada. Una banda correctamente adaptada no debe interferir con la oclusión y debe estar nivelada con los rebordes marginales o ligeramente por debajo de estos, para así asegurar que sobrepasa la línea del Ecuador del diente y no quedar expulsiva ante las fuerzas oclusales. En algunos casos, cuando la banda queda larga y muy subgingival en mesial, es necesario recortarla para evitar romper la adherencia epitelial y las lesiones gingivales.
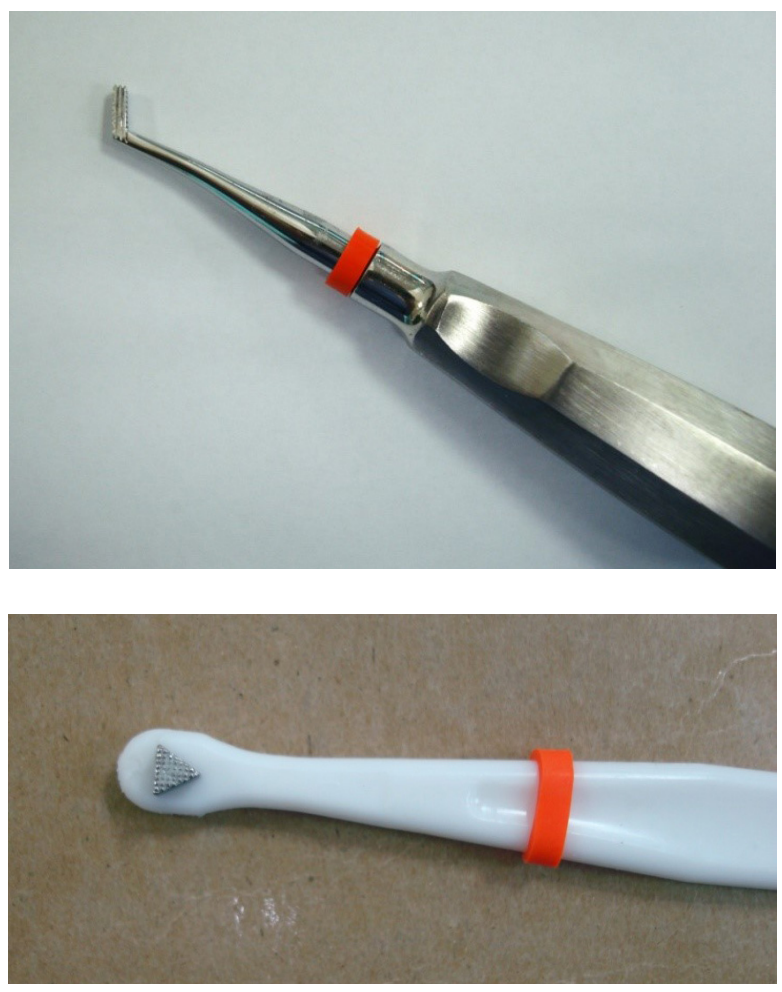

FIGURA 3. Band setter $y$ band pusher

Fuente: elaboración propia

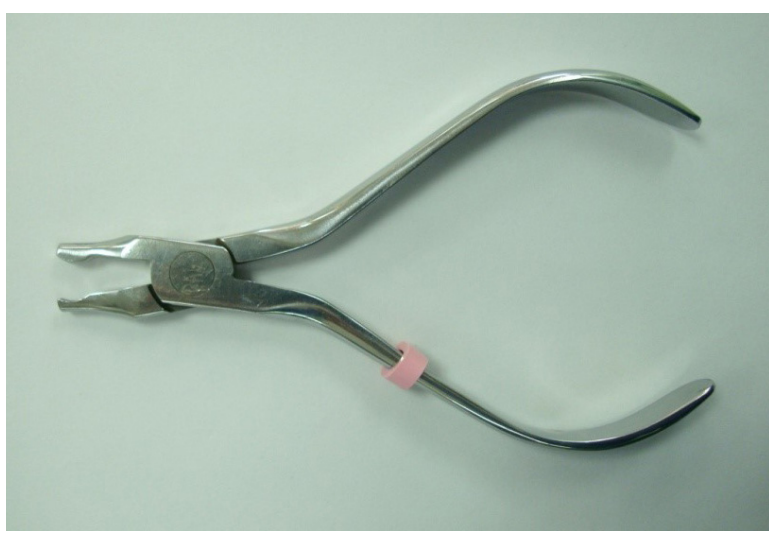

FIGURA 4. Pinza contorneadora de bandas

Fuente: elaboración propia

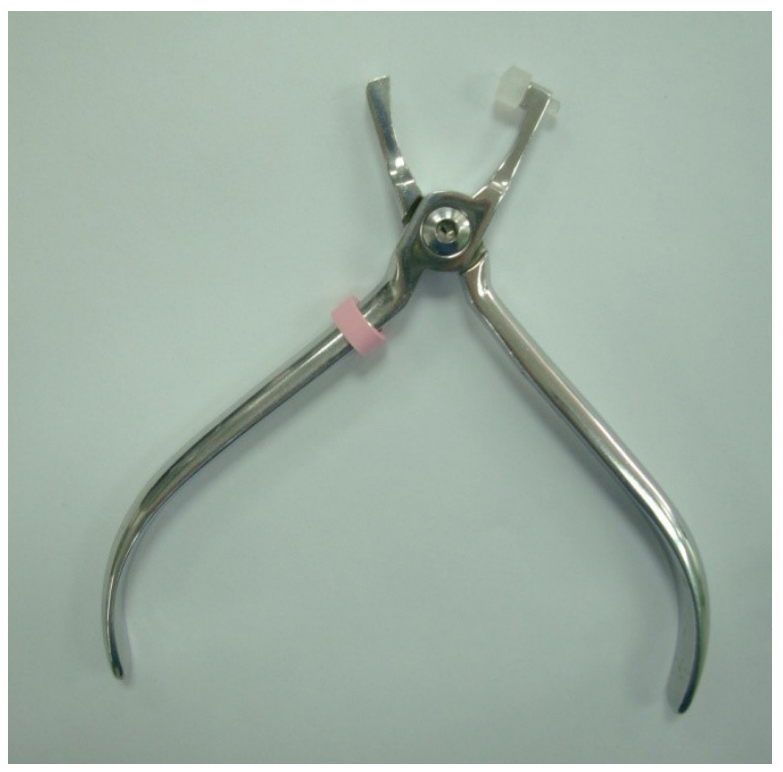

FIGURA 5. Pinza tumba-bandas

Fuente: elaboración propia

c. Impresión en alginato con la banda en boca. Una vez adaptadas las bandas, se procede a tomar la impresión, sea superior o inferior, dependiendo del caso.

d. Retiro de la impresión y de la banda de la boca del paciente. Para retirar la banda se emplea nuevamente la pinza tumba-bandas.

e. Lavado de la impresión y ubicación de la banda. Es importante tener en cuenta la correcta ubicación de la banda en la impresión, como si fuera la boca del paciente. 
f. Colocado de capa de cera. Se pone una delgada capa de cera pegajosa en la banda, con el objetivo de que no se desplace durante el vaciado. También se pueden utilizar ganchos de cosedora.

g. Vaciado en yeso. Se realiza el vaciado en yeso tipo III.

\section{Arco lingual}

Es un mantenedor de espacio fijo bilateral, utilizado durante la etapa de dentición mixta. Controla la posición anteroposterior de los primeros molares permanentes, teniendo como soporte los anteriores inferiores, contra la posición de los incisivos mandibulares [7, 8].

\section{Indicaciones}

Este aparato está indicado en los siguientes casos:

a. Pérdida prematura bilateral de uno o varios molares temporales, o unilateral de más de un molar deciduo.

b. Pérdida prematura de caninos deciduos, para evitar el colapso de anteriores inferiores.

c. Sistema de anclaje ortodóntico.

\section{Construcción}

Una vez obtenido el modelo con las bandas, se construye el aparato en alambre en acero inoxidable de 0.036" [9] o 0.040", para que resista las fuerzas de la masticación [10]. Debe contactar de manera pasiva el cingulum de los incisivos (Figura 6) [8] y estar separado de 1 a
$2 \mathrm{~mm}$ de lingual de los molares para permitir la erupción de los bicúspides. El alambre puede quedar fijo soldándolo a las bandas de los primeros molares o quedar semifijo entrando en cajuelas soldadas en lingual de los molares (Figura 7). El arco soldado presenta más ventajas: tiene una terminación más suave, disminuye la hipertrofia del tejido y requiere menos supervisión (Figura 7). El arco lingual debe ser contorneado en la zona anterior, de manera tal que contacte en lingual de todos los incisivos (centrales y laterales), aunque se encuentren apiñados (Figura 8).

Al cementar se debe asegurar que su inserción sea pasiva. Una vez colocado el aparato, se puede pasar un trozo de seda dental entre el alambre y los incisivos; si pasa con facilidad, significa que el aparato está pasivo [11]. El diseño del aparato puede o no tener ansas en mesial de los primeros molares permanentes, dependiendo de las necesidades de ajuste que demande el paciente. Los aparatos con ansas tienen mayor versatilidad (Figura 6), pero son más delicados en el control de la fuerza y pueden presentar distorsión y desadaptación si se activan. Esta situación debe evitarse, pues el arco lingual no es un reganador de espacio.

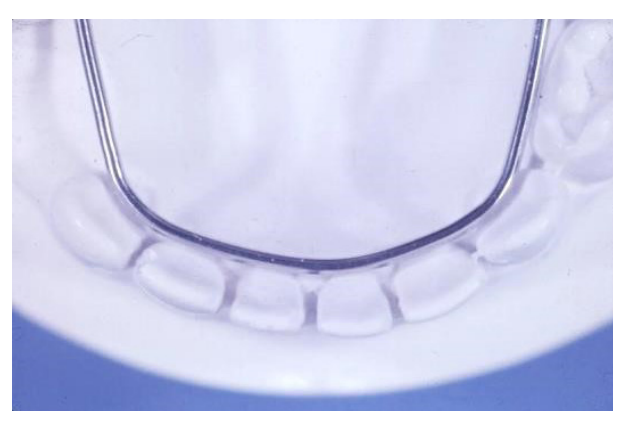

FIGURA 6. Adaptación anterior del arco lingual Fuente: elaboración propia 

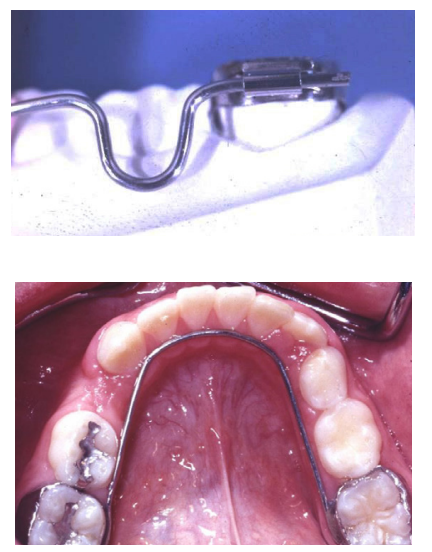

FIGURA ?. Arco lingual semifijo con ansa y arco lingual fijo sin ansa

Fuente: elaboración propia
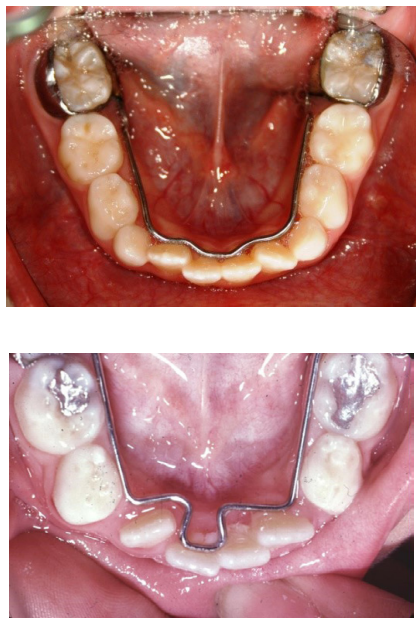

FIGURA 8. Arco lingual contorneado en la zona anterior

Fuente: elaboración propia

\section{Errores en la construcción del aparato}

Es importante tener en cuenta que el arco lingual debe ser removido cada dos meses, con el objetivo de realizar profilaxis de los molares de anclaje para prevención de caries. Algunos de los errores que pueden cometerse en la construcción del aparato son los siguientes:

a. Inadecuada selección y adaptación de las bandas, que comprometen la retención del aparato. b. Mala ubicación de las bandas en la impresión.

c. Arco de alambre activo, que provoca movimiento de los primeros molares. Si el arco no contacta los incisivos, produce movimiento lingual de los incisivos y mesial de los molares; y si queda demasiado amplio en posterior, los molares toman posición hacia vestibular.

d. Contorneado inadecuado del alambre, que produce lingualización de los incisivos o mesialización de los molares.

Al arco lingual se le pueden adicionar elementos como ganchos pasivos, que eviten el desplazamiento distal de los incisivos. Algunos profesionales realizan activaciones a estos aparatos, pero el movimiento dental que se genera no puede ser controlado adecuadamente, y, por tanto, no es recomendable (Figura 9).

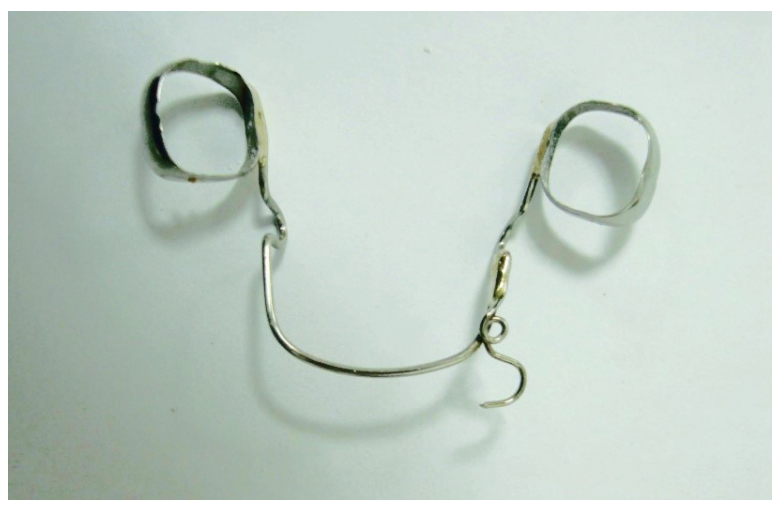

FIGURA 9. Arco lingual modificado

Fuente: elaboración propia

\section{Cementación}

Una vez confeccionado, el aparato debe ser medido en boca para revisar su adecuada adaptación. Posteriormente, se realiza profilaxis a nivel de los molares de anclaje, preferiblemente con piedra pómez o bicarbonato (Figura 10), y luego se cementa con un ionómero de vidrio (Figura 11). 


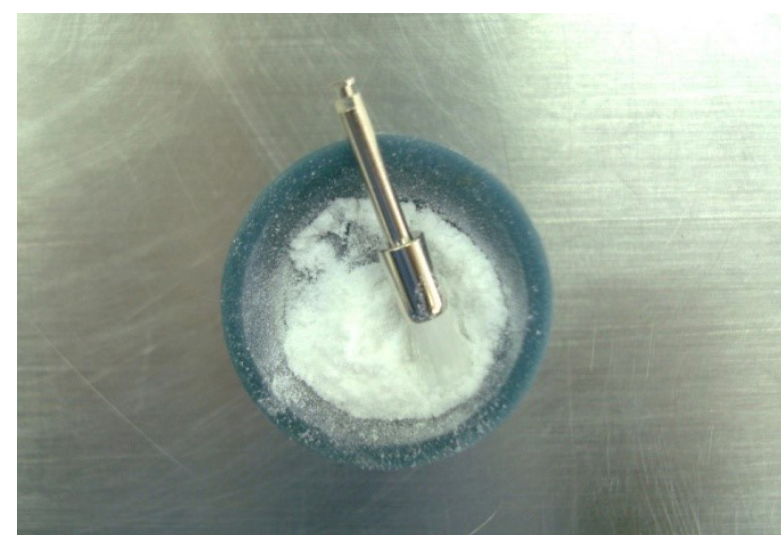

FIGURA 10. Bicarbonato para realizar profilaxis

Fuente: elaboración propia

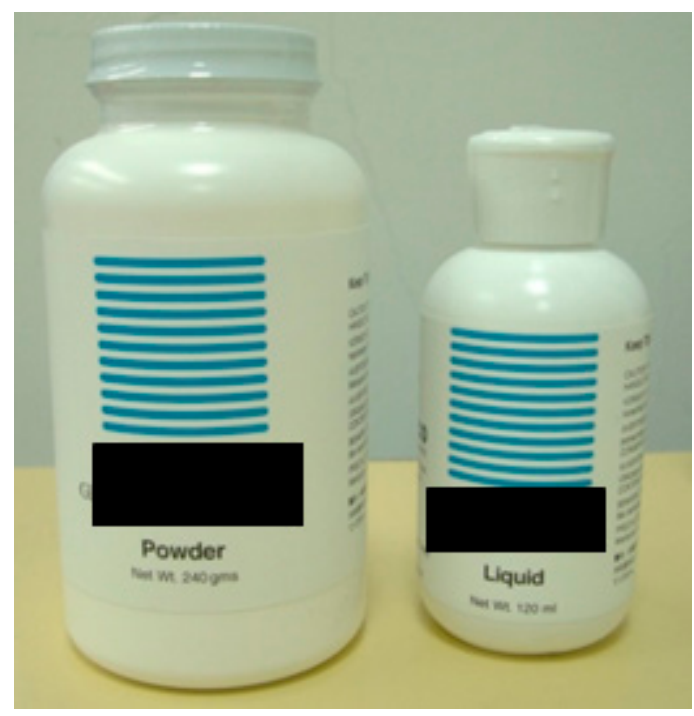

FIGURA 11. Ionómero de vidrio, presentación con polvo y líquido

Fuente: elaboración propia

\section{Efectos}

El principal efecto de un arco lingual es la conservación de espacio. Sin embargo, los estudios reportan que también se logra un aumento en la longitud de arco, en la amplitud intermolar y, por ende, menor pérdida de su profundidad [8]. Durante la transición de dentición mixta a permanente, ocurren cambios en el desarrollo, que consisten en leves aumentos y leves pérdidas, como la mesialización del primer molar y la disminución en la longitud de arco. Debido a la utilización del espacio libre, se ha demostrado que, manteniendo la longitud de arco durante este período, se alivia el apiñamiento en un 60\%, disminuyendo hasta en 4.85 mm (Figura 12) [8].

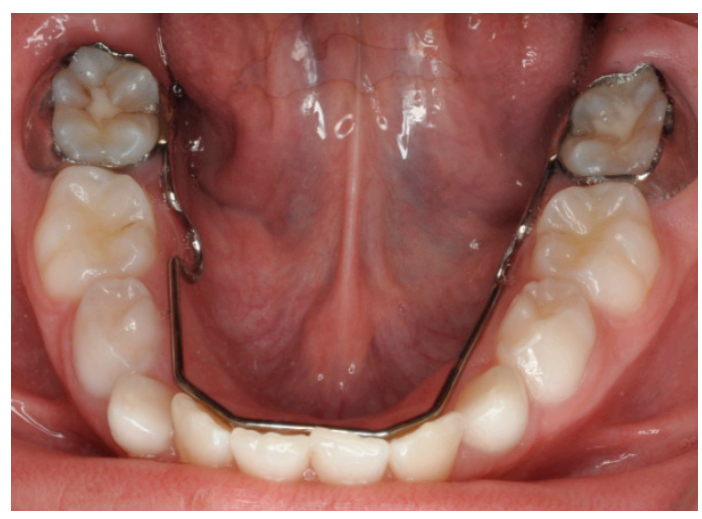

FIGURA 12. Arco lingual en posición

Fuente: elaboración propia

El arco lingual es un aparato efectivo para mantener la longitud de arco, pues controla el movimiento mesial del molar y evita el colapso por lingualización de incisivos. Se ha comprobado que el molar se mueve a distal 0.54 grados y los incisivos adelante 0.11 grados. Además, al controlar y preservar el espacio libre o leeaway, se puede ganar $0.07 \mathrm{~mm}$ en la longitud de arco [7]. Por tanto, los efectos del arco lingual son la verticalización de molares y la protrusión de incisivos. En los estudios se reporta que, en los pacientes a los que no se les coloca el arco lingual, el molar se inclina a mesial 2.32 grados y los incisivos se lingualizan 3 grados.

El control vertical que puede ejercer el arco lingual no ha sido muy estudiado. Solo existe un reporte respecto a que, después de un año de uso, se advierte un control vertical del primer molar inferior, con una extrusión de $0.29 \mathrm{~mm}$. Durante el mismo periodo, los pacientes no tratados presentaron una erupción del molar de $2.12 \mathrm{~mm}$ [12]. En la literatura, es indiscutible que el arco lingual controla y preserva espacio libre [7]; sin embargo, el efecto de aumento en el perímetro del arco y en la longitud del arco- mencionado en algunos artículos - es controversial, pues la metodología empleada no es la apropiada. 


\section{Riesgos}

Los riesgos que se presentan en el uso del arco lingual son:

- Desmineralización del esmalte en los molares donde se cementan las bandas.

- Descementación de las bandas.

- Laceración de la mucosa de la lengua.

- Caries en los primeros molares.

- Pérdida de la soldadura.

- Movimientos dentarios no deseados por desadaptación del alambre.

\section{Botón palatino}

Conocido también como arco palatal de Nance, al haber sido descrito por el autor en 1947 [6]. Es un mantenedor de espacio bilateral para el arco superior, que además sirve como anclaje anteroposterior y vertical de los molares en tratamientos de ortodoncia. Se utiliza cuando hay pérdida unilateral o bilateral de caninos y molares deciduos en el arco superior [13].

\section{Construcción}

Es un aparato fijo que consta de bandas en primeros molares permanentes o en segundos molares deciduos, según el estadio de desarrollo del paciente; un botón acrílico en el paladar, en la región de las rugas palatinas de la zona anterior, conectado con las bandas por medio de un alambre redondo de 0.36" o 0.040" (Figura 13). El acrílico debe entrar en contacto con la mucosa del paladar para dar soporte y evitar la mesialización de los molares.

El apoyo palatino con el acrílico y la dificultad para realizar una buena higiene pueden producir irritación del paladar (eritema) e hiperplasia tisular [6]. El aparato puede ser confeccionado con el acrílico separado de la mucosa para evitar la irritación, pero perdería su función de mantenedor [6]. Es importante realizar un mantenimiento periódico del aparato, removiéndolo cada 2 o 3 meses para limpieza $[13,14]$. Con esto se pretende evaluar su estabilidad y evitar la presencia de caries. No se recomienda hacer ningún movimiento por medio de la adición de ganchos con este aparato, porque puede generar problemas en la mucosa palatina y movimientos indeseados de los molares de anclaje.
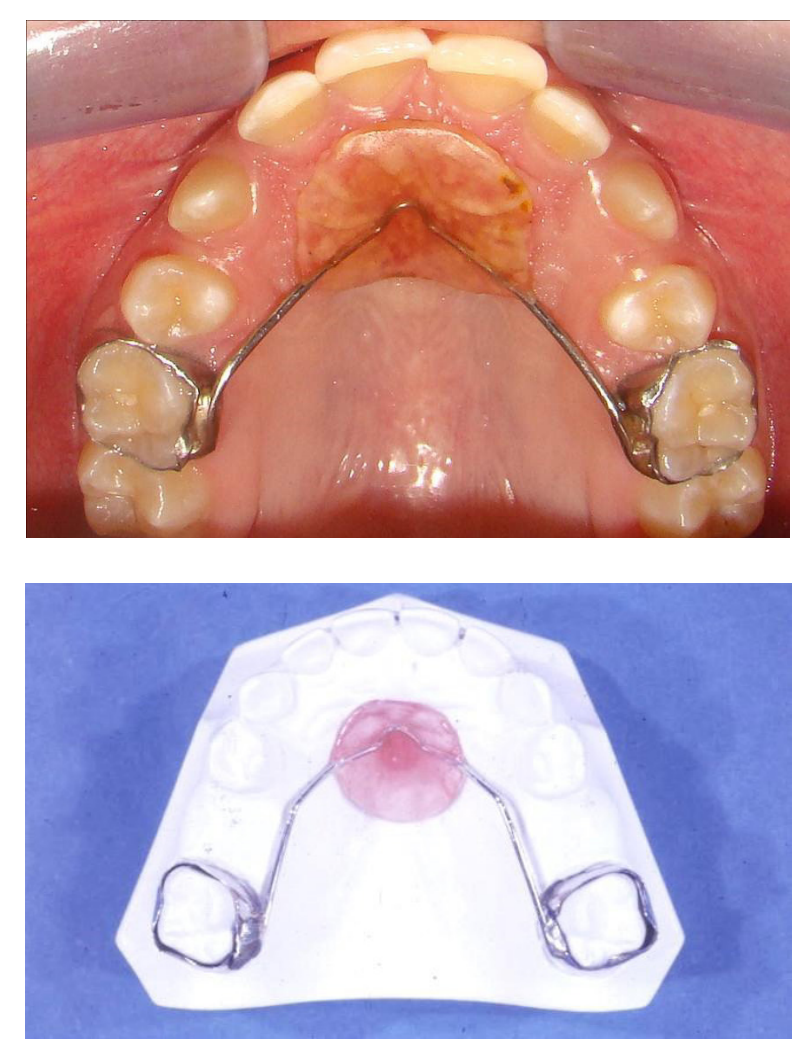

FIGURA 13. Botones palatinos

Fuente: elaboración propia

Algunos odontólogos agregan ganchos de entrega para desrotar o vestibularizar los incisivos superiores. Sin embargo, además de producir problemas en la mucosa, este tipo de ganchos produce un movimiento de inclinación no controlada del diente. En etapas de dentición mixta, puede generar reabsorciones radiculares, al llevar la raíz de los incisivos en contra de los gérmenes de los otros dientes permanentes. Por tanto, no se recomienda el uso de estos aditamentos (Figura 14). 


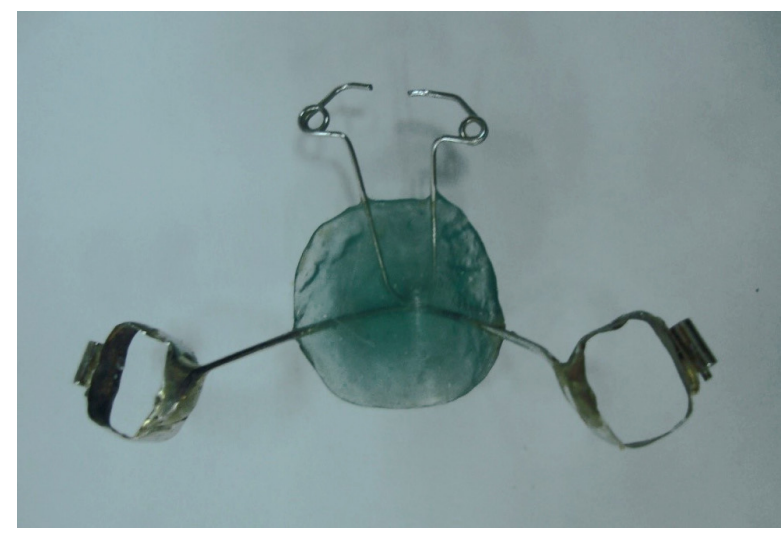

FIGURA 14. Botón palatino con ganchos de entrega en la zona anterior

Fuente: elaboración propia

\section{Efecto}

Su principal efecto es contrarrestar la mesialización de los molares superiores en casos de pérdida prematura de deciduos. También sirve como anclaje en casos de movimientos dentales cuya reacción indeseada sea la mesialización del segmento posterior del arco $[6,14,15]$. Su uso implica la adaptación de bandas y una cementación igual a la descrita para el arco lingual.

\section{Barra transpalatina}

Aunque es un aparato usado como mantenedor de espacio, no es recomendado porque produce la mesialización de los dos molares al tiempo, al no tener un tope anterior que la impida. Los que defienden su uso como mantenedor se basan en que, antes de la mesialización, los molares rotan mesiolingualmente; cuando se impide este movimiento, se evita la mesialización. Esta teoría no tiene una fundamentación científica adecuada [6]. Otra indicación importante de este aparato es su uso en la desrotación de los primeros molares, en casos de rotación mesiovestibular. Aunque, como se ha reportado varias veces, son movimientos muy difíciles de controlar y, por lo tanto, deben evitarse.

\section{Construcción}

El aparato consta de bandas en molares, soldadas a una barra en alambre de acero de 0.036" o 0.040", con disposición transversal, siguiendo el contorno de paladar sin hacer contacto (Figura 15). La barra, al estar separada de la mucosa, no provoca irritación e inflamación; y no debe tener dobleces (Figuras 15, 16 y 17). El aparato también puede ser semifijo, construyéndolo con alambre que entra en unas cajuelas soldadas a las bandas. La cementación debe ser pasiva para evitar movimientos indeseados [6].

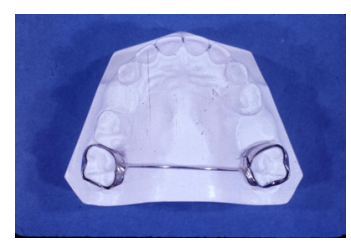

FIGURA 15. Barra transpalatina

Fuente: elaboración propia
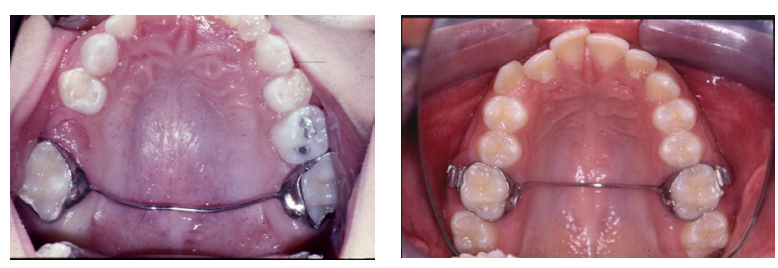

FIGURA 16. Barra transpalatina lisa

Fuente: elaboración propia
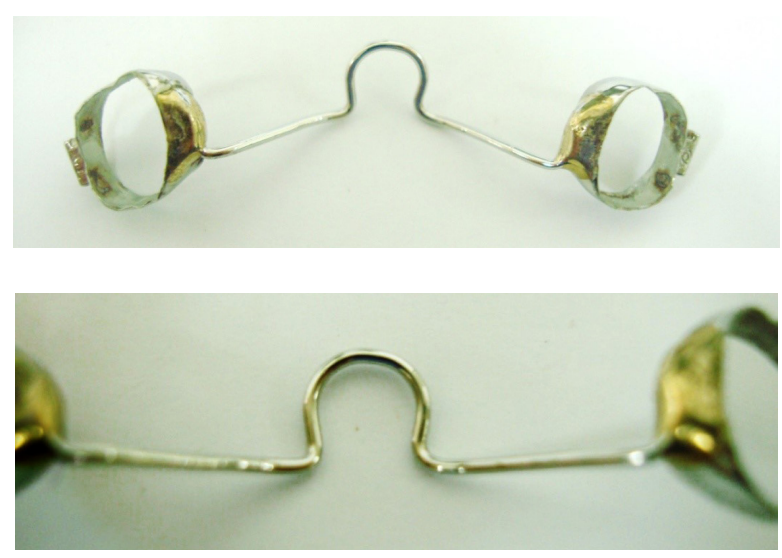

FIGURA 17. Barra transpalatina con ansa

Fuente: elaboración propia 


\section{Efectos}

Como mantenedor, el aparato debe ser pasivo y tener una disposición transversal que permita el control bucolingual [6]. Respecto al botón, la ventaja de la barra es la que tiene mayor compatibilidad con los tejidos blandos, mejor control vertical y puede usarse de manera segura como mantenedor unilateral [6]. Las barras con dobleces o ansas (Figura 17) se emplean como coadyudantes del control vertical y transversal en tratamientos de ortodoncia [6].

\section{Banda y abrazadera}

Es un mantenedor de espacio fijo, empleado en casos de pérdidas unilaterales de primeros molares deciduos. Tiene el fin de evitar la mesialización de los molares permanentes durante la dentición mixta [13].

\section{Indicaciones}

Se recomienda su uso en los siguientes casos:

a. Pérdida prematura del primer molar deciduo.

b. Pérdida prematura del segundo molar deciduo, una vez erupcionado el primer molar permanente.

c. Pérdida bilateral del molar primario inferior, antes de la erupción de los incisivos y el primer molar permanente. No se coloca arco lingual para evitar interferir la erupción de los incisivos, ya que su patrón de erupción es lingual a los dientes temporales.

\section{Construcción}

Se fabrica en alambre 0.036" o 0.040". Su diseño consiste en un bucle de alambre soldado a la banda y un extremo libre que se apoya en la superficie distal al diente adyacente que se perdió (Figura 18). El alambre (bucle) no debe tocar los tejidos blandos y debe ser amplio en sentido vestibulolingual, a fin de no interferir con la erupción del diente sucedáneo (Figura 19]. La parte lateral del bucle debe llevar una convexidad hacia el reborde; no debe estar recto, pues hay peligro de que las fuerzas masticatorias lo empujen hacia abajo (Figura 19).
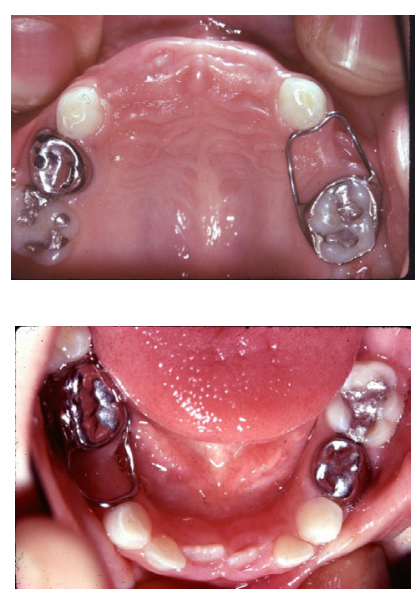

FIGURA 18. Banda y abrazadera en el arco superior e inferior Fuente: elaboración propia

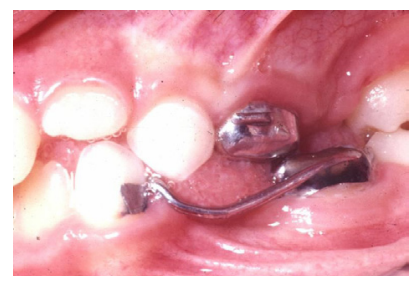

FIGURA 19. Banda y abrazadera con alambre cerca a gingival

Fuente: elaboración propia

Su confección y diseño deben ser pasivos, solo como mantenedor. En los casos en que el segundo molar presente una corona de acero, es recomendable colocar en ella una banda para hacer posible su mejor adaptación, cementación y seguimiento (Figura 20). Este aparato debe ser reemplazado por uno bilateral (arco lingual o botón palatino) cuando se pierda anclaje mesial al aparato por exfoliación del canino, debido al orden de erupción en el arco inferior [15]. 


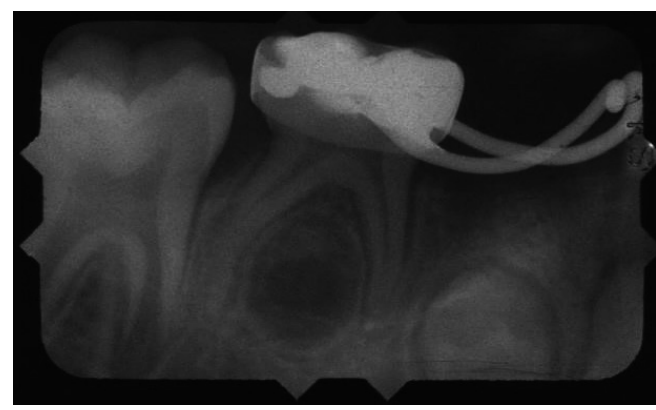

FIGURA 20. Radiografía de banda y abrazadera en posición

Fuente: elaboración propia

\section{Zapata distal}

Es un mantenedor de espacio diseñado en 1929 para guiar la erupción del primer molar permanente, en casos de pérdida temprana del segundo molar deciduo. Su retención debe darse en el primer molar deciduo, mediante la colocación de bandas o coronas de acero (Figura 21) [15].

\section{Construcción}

Para su construcción se debe calcular la medida mesiodistal del segundo molar perdido, a fin de mantener adecuadamente el perímetro de arco, en los casos donde sea posible colocarlo al momento de la exodoncia del segundo molar. El procedimiento incluye colocación de anestesia y presión de la zapata dentro del tejido, con la preparación previa de un canal por medios quirúrgicos. Se han reportado infecciones o daños al germen del primer molar durante su colocación o posteriormente. En el arco superior la necesidad de la zapata es mínima por el patrón distal de erupción del primer molar [1]. Actualmente no se recomienda el uso de este aparato por las desventajas que presenta.

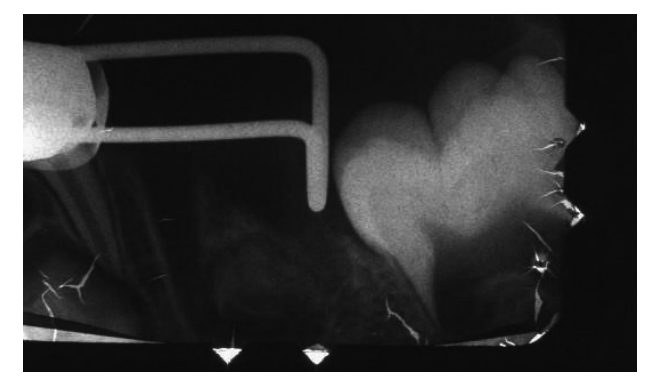

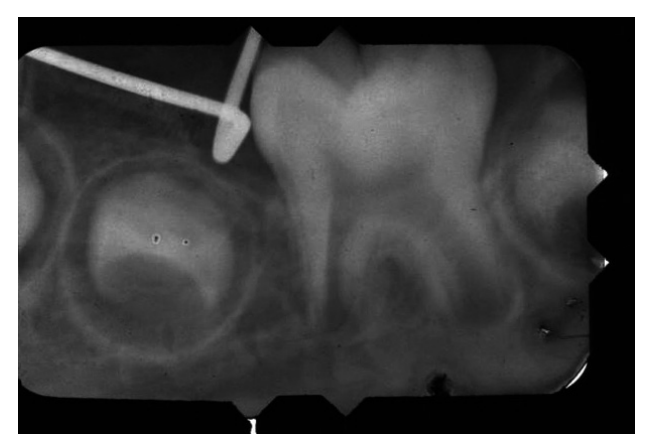

FIGURA 21. Zapata distal en posición

Fuente: elaboración propia

\section{Mantenedor fijo para reemplazar anteriores superiores}

Mantenedor de espacio superior, que tiene como objetivo el reemplazo estético de los dientes anteriores cuando estos se pierden prematuramente. Además, contribuye a mantener la fonación de manera adecuada.

\section{Construcción}

El aparato está formado por bandas en los molares (deciduos o permanentes) y por un alambre de acero inoxidable que se extiende desde posterior hasta la zona anterior, en forma de U. Sobre este se adhieren unos dientes de acrílico, seleccionados de acuerdo con el color de los dientes adyacentes del paciente (Figura 22). El aparato debe ser reemplazado por otro tipo de mantenedor cuando alguno de los incisivos comience su proceso de erupción. No es recomendable por la dificultad que presenta para realizar una buena higiene oral y por la alta posibilidad de lacerar la mucosa.

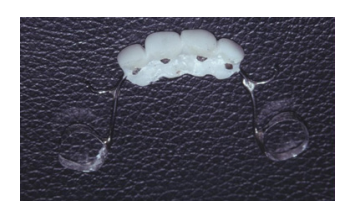

FIGURA 22. Mantenedor fijo para reemplazar anteriores superiores

Fuente: elaboración propia 


\section{MANTENEDORES DE ESPACIO REMOVIBLES}

Los mantenedores de espacio removibles son indicados en los siguientes casos:

a. Cuando existe buena colaboración del paciente.

b. Cuando se prevén cambios o modificaciones en un corto periodo.

c. Cuando hay que evitar la sobreerupción de los dientes antagonistas.

d. Cuando hay que restaurar la función masticatoria.

\section{Placa de Hawley}

Es un mantenedor de espacio mucodentosoportado. Consta de una base de acrílico adaptada a la mucosa y al área cervical de los dientes; de un arco vestibular, y de ganchos de retención, lo que le da el anclaje y estabilidad (Figura 23). Fue introducida en la ortodoncia en 1919, como dispositivo de retención después de finalizado el tratamiento, y se usa tanto para el arco superior como para el arco inferior. También puede ser utilizada para realizar movimientos dentarios menores, como reganadores de espacio. En estos casos, las placas dejan de ser pasivas y se convierten en activas. Los elementos activos que generan movimientos son ganchos y resortes, y los tornillos que se emplean como reganadores de espacio. Los resortes o elementos activos se describirán más adelante, en las placas activas [16] (Figura 24; ver apartado de recuperación de espacio).

\section{Componentes}

Los componentes de la placa son la porción acrílica (de autocurado o termocurado) y los ganchos de retención.

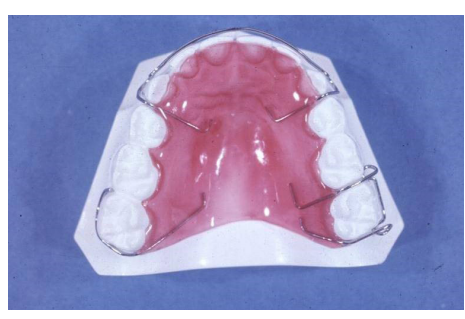

FIGURA 23. Placa de Hawley

Fuente: elaboración propia

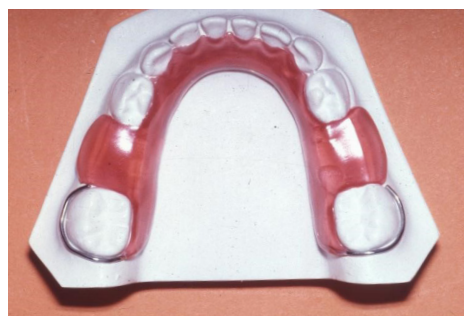

FIGURA 24. Placa de Hawley inferior

Fuente: elaboración propia

\section{Construcción}

Consta de una placa acrílica, un arco vestibular y ganchos de retención. El arco vestibular convencional posee dos ansas verticales a nivel de caninos — deben ser lo más largas posible sin llegar a lastimar el tejido [16, 17]y una porción horizontal a nivel del tercio medio de los incisivos. Se elabora con alambre de acero de 0.032 " y va adosado a vestibular a los incisivos (Figura 25). Este arco puede ser corto cuando termina distal del canino, entrando por proximal, y su rango de acción es limitado; o largo, cuando es soldado a ganchos de Adams. 

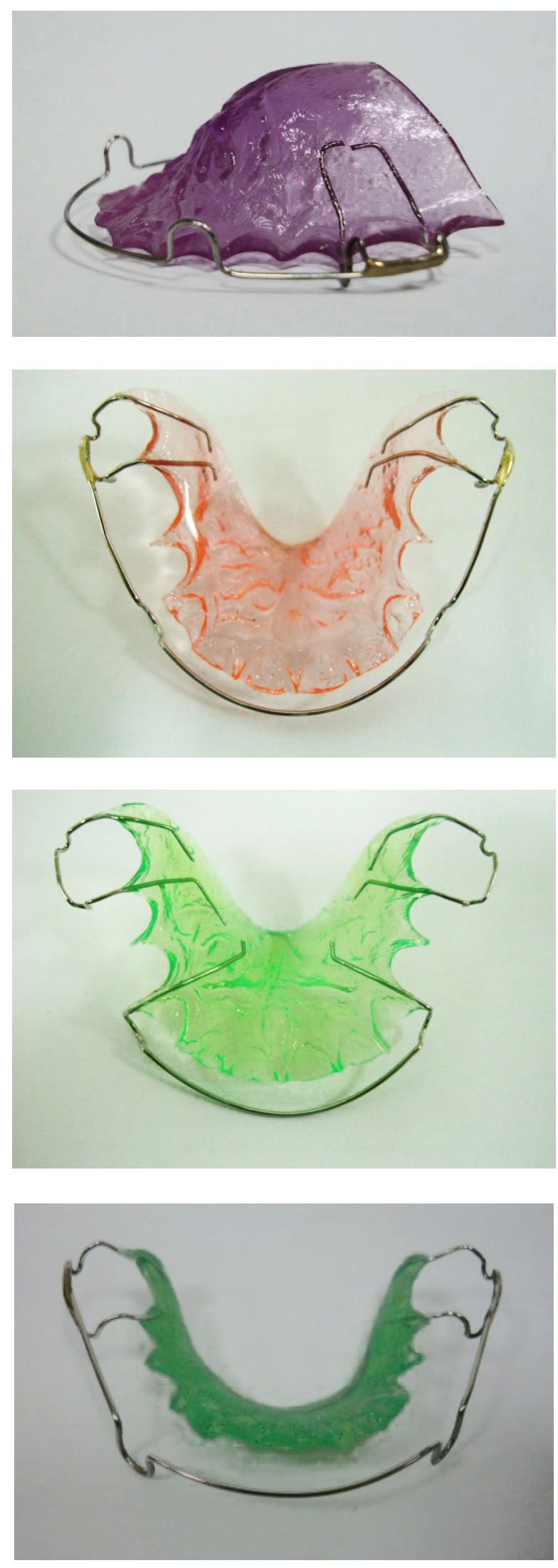

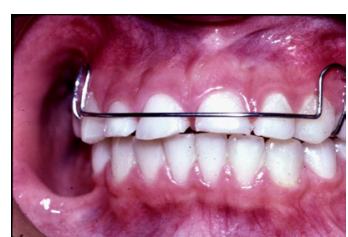

FIGURA 25. Clases de arcos: corto y largo

Fuente: elaboración propia

Los ganchos de los molares son elementos pasivos cuya función es mantener la placa en posición logrando estabilidad y retención. Deben ubicarse en la zona retentiva del diente, entre la máxima circunferencia y la unión cementoamélica. Las retenciones pueden ser proximales (mesial y distal), que son más pronunciadas y por lo tanto más efectivas, como el gancho de Adams y gancho en gota [18]. También pueden existir retenciones cervicales en bucal y lingual, que se usan solo si el diente está completamente erupcionado, como el gancho circunferencial o número 1 (Figura 26), que no está indicado cuando el diente tiene la corona clínica muy corta o el diente no está bien erupcionado [18].

El gancho de Adams fue diseñado por Philip Adams en 1948. Es uno de los instrumentos más eficaces: es simple, fuerte y fácil de construir (Figura 25). El gancho en gota es otro tipo de gancho de retención que se puede emplear. Está formado por un alambre único que se inserta en el nicho interproximal entre dos dientes.

Estos ganchos deben estar perfectamente adosados al reborde marginal para que no estorben la oclusión. El arco vestibular se construye en alambre de acero de 0.032", consta de dos ansas verticales a nivel de los caninos, estas deben ser lo más largas posibles, cuidando de que no lastimen los tejidos blandos y tener una amplitud de $5 \mathrm{~mm}$, aproximadamente. En la zona anterior, se ubica en el tercio medio de los incisivos. Se construye adosado o separado, según las necesidades del paciente. 

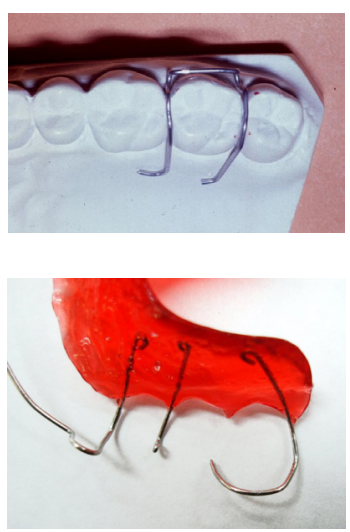

FIGURA 26. Ganchos de retención tipo Adams y circunferencial

Fuente: elaboración propia

La placa base de acrílico debe tener un grosor de entre 0.5 a $2 \mathrm{~mm}$. Se extiende a distal del molar y luego entra hacia la porción anterior del paladar duro, para no producir náuseas. La placa de Hawley puede presentar dos tipos de fallas: deformación por masticación, y fractura o deformación del arco por remoción frecuente. La falla en el arco vestibular puede deberse a la fuerza que se le aplica al colocárselo y quitárselo, provocando la fatiga del material. Las fuerzas masticatorias también lo pueden deformar, generando falta de control. También es posible que se fracture principalmente por fuerzas ejercidas sobre él, cuando está fuera de la boca.

El Hawley para el arco inferior se puede denominar bilateral de acrílico. Es un aparato que ese utiliza para pérdidas unilaterales o bilaterales de caninos o molares en el arco inferior. Tiene acrílico y ganchos de anclaje; se le pueden adicionar dientes para mejorar la función masticatoria y preservar la estética. Permite mantener la dimensión vertical y facilita una buena higiene oral (Figura 27).

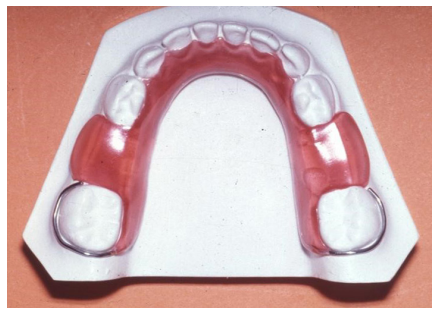

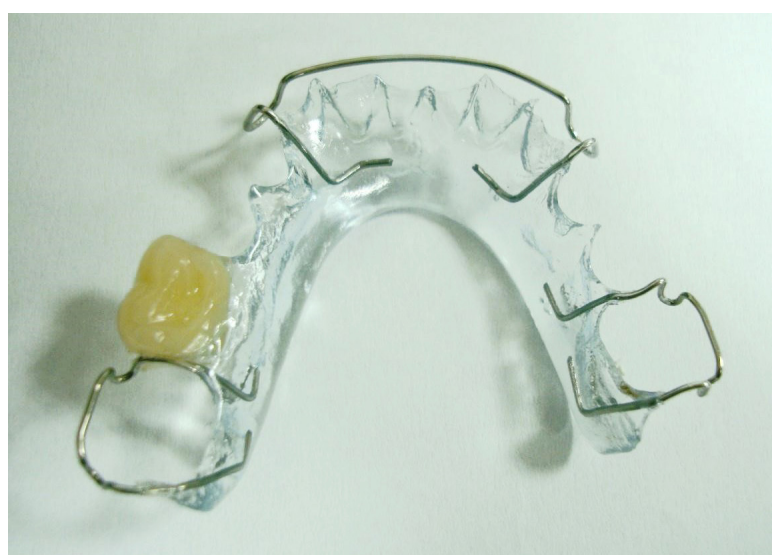

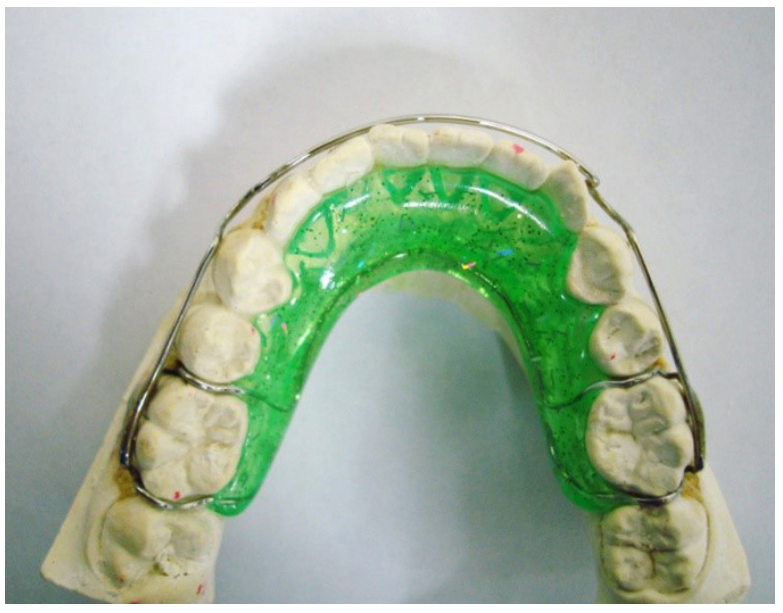

FIGURA 27. Diseños de bilaterales de acrílico

Fuente: elaboración propia

\section{DURABILIDAD DE LOS MANTENEDORES DE ESPACIO FIJOS Y REMOVIBLES}

Los estudios respecto a la colocación de mantenedores después de la pérdida prematura de deciduos demuestran una longevidad limitada de los aparatos. Su promedio de supervivencia es de 7 a 14 o 18 meses. Los aparatos unilaterales muestran un mejor comportamiento en ambos arcos, al compararlos con los bilaterales, que tienen mayor duración en el arco maxilar [19]. Entre los problemas reportados, el de mayor incidencia es el de las bandas que se sueltan por pérdida de cemento, lo que puede generar un aumento en el índice de caries. Les siguen los daños en la soldadura, los daños en las bandas, las lesiones en tejidos blandos, las pérdidas del 
aparato y las interferencias con la erupción de los permanentes. Se propone microarenar la banda y realizar la cementación con cementos que posean mayor resistencia al desalojo, como el ionómero de vidrio [20].

En 1998, Quidmat evaluó a 159 pacientes con 336 mantenedores (banda y abrazadera, arco lingual, botón palatino, zapata distal y removibles) durante un período de 5 años, y halló un $8 \%$ de éxito y un 63\% de fallas en estos aparatos (190 mantenedores). De los mantenedores que fallaron, 141 eran fijos y 49 removibles, la causa más común fue la falla parcial o completa en la cementación. El promedio de supervivencia de los mantenedores fue de 7 meses. El arco lingual registró el menor tiempo, 4 meses, seguido del botón palatino, con 6 meses, y los removibles, con 9 meses. El mayor tiempo fue de 13 meses en el caso de la banda y abrazadera. En general, los aparatos unilaterales duran más que los bilaterales [21]. En este estudio, las fallas más comunes se produjeron debido a la pobre construcción del aparato, los puntos de soldadura incompletos, el sobrecalentamiento del alambre y el adelgazamiento de la soldadura.

Otro estudio realizado por Tulunoglu en 2005 [5], con 663 pacientes durante 5 años, reportó mayores fallas en los puntos de soldadura, a las que le sigue la inflamación en la encía, provocada por las ansas en los aparatos fijos. La falla más frecuente en los aparatos removibles es la deformación de los ganchos. Con respecto a la duración, este estudio mostró que fue mayor en los fijos que en los removibles y que los unilaterales superaron a los bilaterales. El arco lingual muestra una durabilidad de 40\% a los 24 o 36 meses de colocado; mientras que el botón palatino y la banda y abrazadera, un 70\% en el mismo periodo [22].

Se sugiere un seguimiento estricto del paciente y de los aparatos, para lograr un mayor éxito en el tratamiento y la permanencia del mantenedor en boca, aplicando recementaciones preventivas con intervalos de 2 a 3 meses.

\section{EFECTOS ADVERSOS DE LOS MANTENEDORES DE ESPACIO FIJOS YREMOVIBLES}

Estos aparatos pueden afectar la fonación temporalmente, sobre todo durante la primera semana. Tienen impacto sobre la postura de la lengua y el volumen palatal. Las consonantes que más se comprometen son las labiodentales (f, v) y las linguoalveolares (d, t, s, z), ya que la lengua es forzada a una posición más posterior; es por esto que el acrílico debe ser lo más delgado posible. Al pasar el periodo de adaptación, que es variable y depende del paciente, se advierte cómo la posición de la lengua se adapta y la fonación se recupera completamente. La afectación es de mayor o menor grado, según su diseño: los fijos son los que menos efectos producen y el que más influencia tiene es el Nawley. Esta afectación disminuye si se emplea un acrílico delgado [23].

\section{PÉRDIDA DE ESPACIO}

Se considera pérdida de espacio cuando el análisis de la dentición mixta da como resultado falta espacio en el arco, por mesialización del primer molar permanente. Las causas pueden ser las siguientes:

- Caries interproximal (Figura 28)

- Pérdida prematura de dientes por caries (más frecuente)

- Alteraciones estructurales de esmalte y/o dentina

- Agenesia dental

- Fracturas dentales

- Malposición dental

- Anquilosis

- Vía de erupción alterada

- Secuencia de erupción alterada 
La pérdida de espacio en un arco puede ser estática o dinámica, y de esto depende el tipo de tratamiento a aplicarse. Se define estático cuando no ocurre más pérdida de espacio en el arco (en casos donde la pérdida prematura del diente deciduo ocurrió hace varios años); la dinámica se refiere a la pérdida progresiva [24]. El 51\% de pérdida de primeros molares deciduos y el 70\% de pérdida de segundos molares deciduos causan pérdida de espacio en el arco, debido a inclinaciones del primer molar, o malposición e impactación de algún diente permanente (Figura 29) [7].

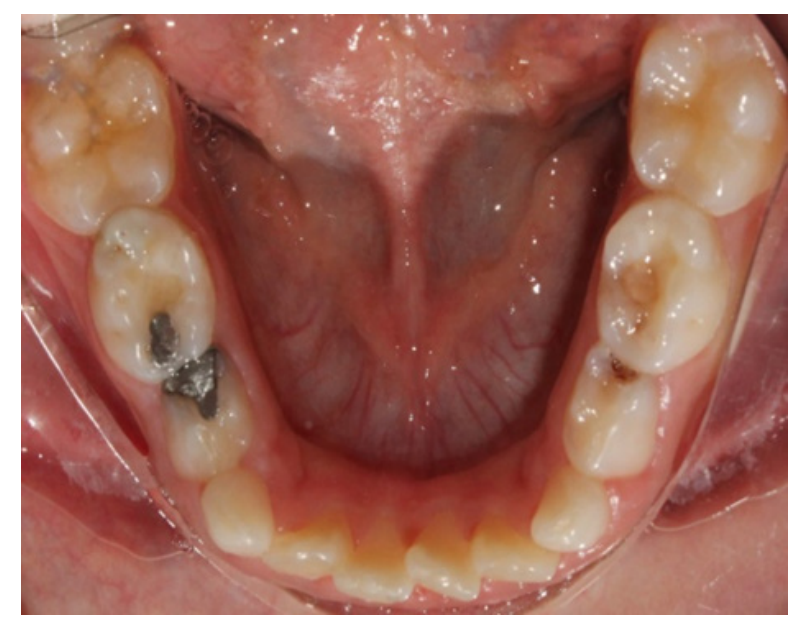

FIGURA 28. Caries oclusodistal de primer molar inferior izquierdo

Fuente: elaboración propia

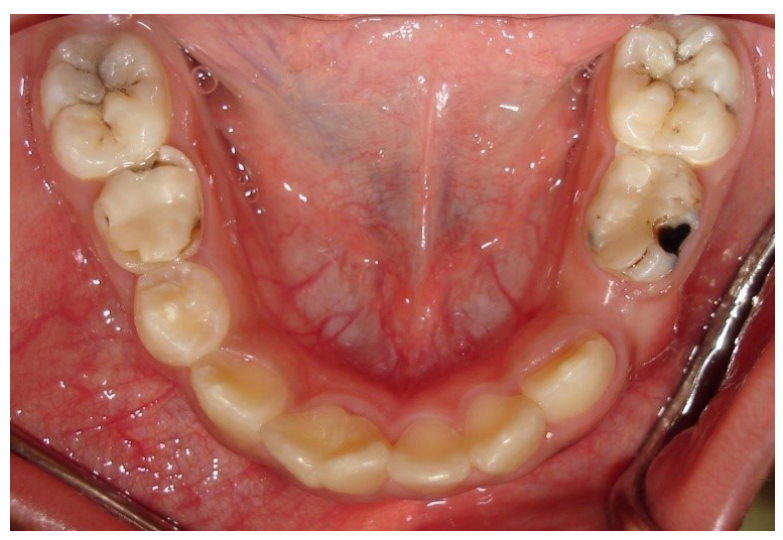

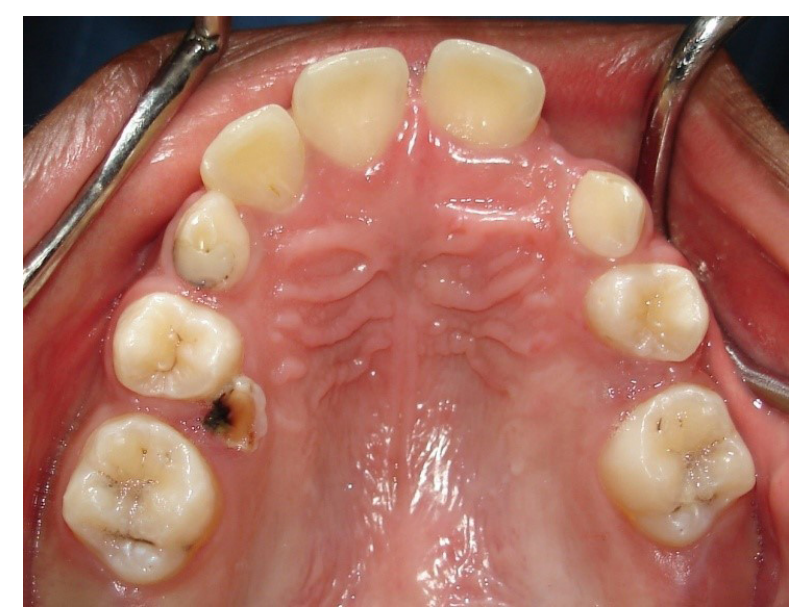

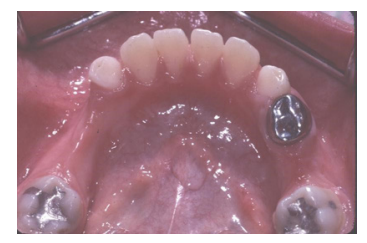

FIGURA 29. Pérdida prematura de dientes deciduos en arcos superior e inferior

Fuente: elaboración propia

\section{PÉRDIDA PREMATURA DE DIENTES DECIDUOS}

La colocación de un aparato depende de la necesidad de recuperación de espacio para la ubicación adecuada del sucedáneo. Es importante tener en cuenta el momento y el tipo de pérdida. Northway realizó un estudio longitudinal con 5 años de seguimiento, en 107 pacientes de Canadá, desde los 6 años de edad. Reportó entre sus resultados que la prevalencia de pérdida de espacio es del 11\% al 83\%, más frecuente en la mandíbula, pero con efectos más severos en el maxilar (Figura 30). Encontró, además, que la rata de pérdida de espacio inicial fue mayor en el maxilar que en la mandíbula: en el maxilar fue de $1.5 \mathrm{~mm}$ por mes y en la mandíbula de $1.0 \mathrm{~mm}$ [25]. Aunque la pérdida de espacio es más severa en el arco superior, es más difícil recuperarlo en el inferior. 


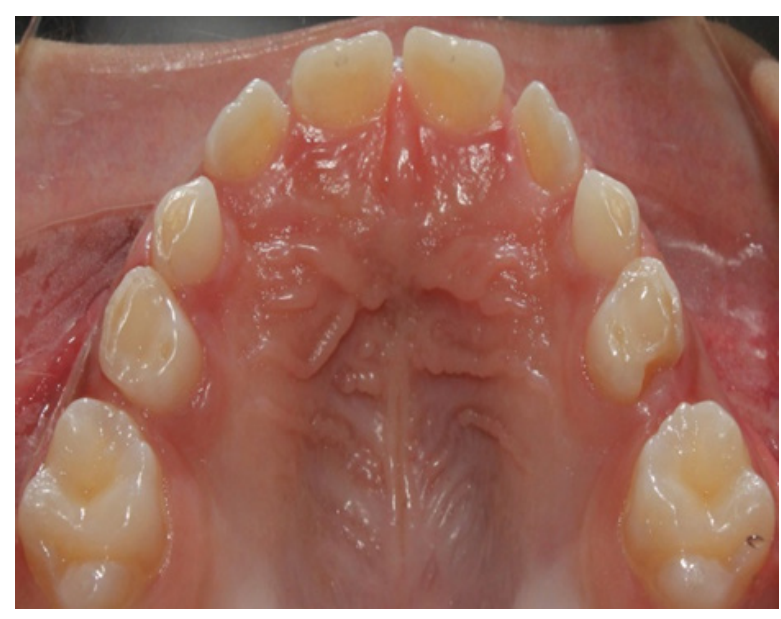

FIGURA 30. Mesialización de primeros molares superiores por pérdida prematura de segundos molares deciduos

Fuente: elaboración propia

En términos del tipo de pérdida, la exfoliación temprana de D (primer molar deciduo) y de los incisivos es menos deletérea que la pérdida de E (segundo molar deciduo) y el canino. En estos casos, los dientes vecinos no solamente presentan movimientos hacia mesial, como el primer molar permanente, sino también a distal y lingual, como ocurre después de la pérdida del canino (Figura 31).

\section{Pérdida del primer molar deciduo}

Con la pérdida de D (primer molar deciduo) superior, el canino se distaliza durante el primer año, y se mesializan el segundo molar deciduo y el primer molar permanente. Como consecuencia, el canino permanente queda sin espacio donde erupcionar. La cantidad de espacio perdido depende de la duración de la ausencia y de la edad de la pérdida. Si la pérdida ocurre muy temprano, mucho antes de erupcionar el primer molar permanente tanto en el arco superior como en el inferior, el espacio puede ser evaluado periódicamente sin necesidad de colocar mantenedor, siempre y cuando esta observación sea rigurosa. Pero si la pérdida es cercana a la erupción del permanente, el mantenedor está indicado especialmente en el arco inferior, debido al patrón de erupción del primer molar permanente, que es mesial y lingual. Sin embargo, pueden existir hábitos que generen alteraciones en el arco; por tanto, se recomienda una medición mensual del espacio, mediante impresiones o de manera directa, para llevar un control adecuado [20].

\section{Pérdida del segundo molar deciduo}

En los casos de pérdida de E (segundo molar deciduo) superior, el primer molar permanente migra mesial; el canino y el primer molar deciduos migran a distal, y se impacta el segundo bicúspide. La pérdida temprana de este diente tiene un mayor efecto en la disminución de la longitud del arco que cualquier otra, y resulta en el cierre del espacio de 2 a $4 \mathrm{~mm}$ por cuadrante (Figura 31) [10]. En los casos de pérdida combinada del primery segundo molares deciduos (D más E), el potencial para la pérdida de espacio es aún mayor; además, entre más temprana es la pérdida, más espacio se pierde. Si el primer molar permanente no se ha acabado de formar, se mesializa en cuerpo, principalmente en el arco superior. Pero si el deciduo se pierde cuando el primer molar ya se formó, solo se inclina y la magnitud de la pérdida es menor. Por otro lado, la impactación del segundo bicúspide es más fácil en la mandíbula [1].

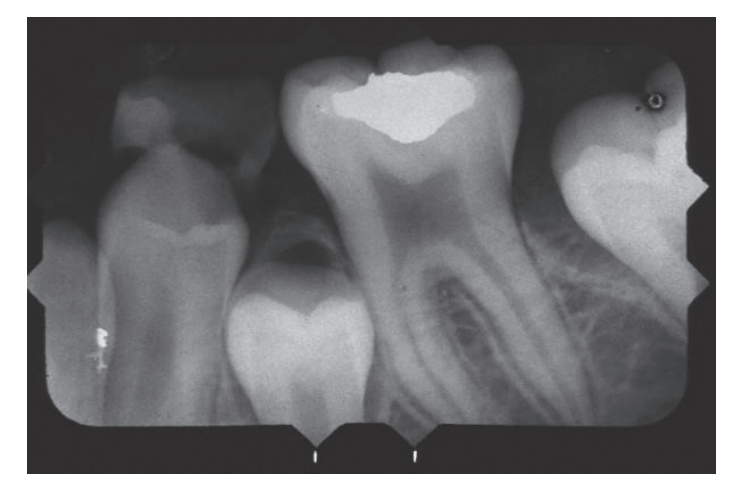




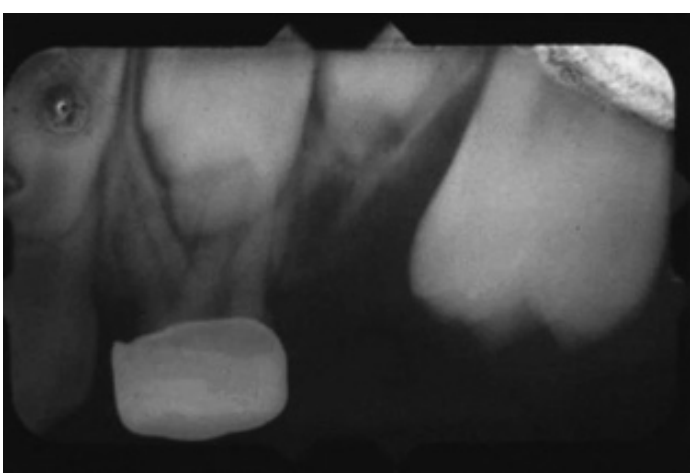

FIGURA 31. Migración mesial de primeros molares por pérdida prematura de segundos molares deciduos

Fuente: elaboración propia

\section{Pérdida de anteriores deciduos}

En situaciones de pérdida prematura de incisivos deciduos por caries o trauma, las fuerzas de la oclusión normalmente no generan ninguna influencia en el sector anterior, debido a la implantación vertical de los dientes deciduos [1]. Sin embargo, puede ocurrir un imbalance muscular por hábitos orales, cuyo efecto deletéreo en el arco genera pérdida de espacio. Al perderse un incisivo en el arco superior, los dientes se inclinan si existe un hábito, pero es más fácil reganar pues solo es necesario desinclinarlos. En el arco inferior, la pérdida del sector anterior, cuando no es por trauma, es indicativo de problemas en longitud de arco y tamaño dentario; es decir, de discrepancia óseo-dentaria [25].

\section{Pérdida de caninos deciduos}

La pérdida prematura de caninos en el arco inferior, no causada por caries, generalmente es unilateral. Esto genera la desviación de la línea media por inclinación distal de incisivos y la pérdida de perímetro por lingualización de esos dientes. Por lo general, este colapso ocurre en casos de mordidas profundas y hábitos labiales. Si no ha habido pérdida, se debe colocar un mantenedor; si la hubo, se presenta desviación de la línea media y se recomienda hacer exodoncia o tallado del canino contralateral, para evitar mayor pérdida de perímetro y colapso bilateral del arco (Figura 32 y Tabla 3) [1]. Esta situación también puede presentarse en el arco superior, pero las consecuencias son menos severas.

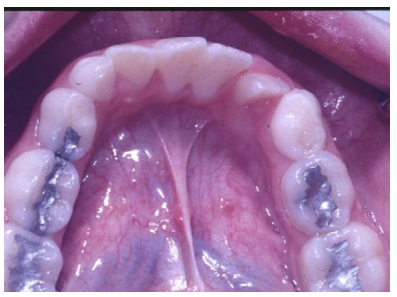

FIGURA 32. Pérdida prematura de canino deciduo Fuente: elaboración propia

TABLA 3

Efectos de la pérdida

\begin{tabular}{|c|c|c|c|c|}
\hline Dientes perdidos & Factor etiológico & $\begin{array}{l}\text { Objetivo del } \\
\text { tratamiento }\end{array}$ & Tratamiento & Tiempo \\
\hline \multirow{3}{*}{$\begin{array}{l}\text { Grupo Incisivo } \\
\text { (uno o más } \\
\text { incisivos) }\end{array}$} & & Estética & No siempre es necesario & \multirow{3}{*}{$\begin{array}{l}\text { Hasta que se inicie el } \\
\text { proceso de erupción } \\
\text { grupo incisivo }\end{array}$} \\
\hline & Trauma & $\begin{array}{l}\text { Función en la deglu- } \\
\text { ción y fonación }\end{array}$ & \multirow{2}{*}{$\begin{array}{l}\text { Puede ser fijo o, preferentemente, removible } \\
\text { Depende del desarrollo radicular de suce- } \\
\text { dáneos, compromiso estético y funcional, } \\
\text { desarrollo radicular y colaboración paciente }\end{array}$} & \\
\hline & Erupción ectópica & $\begin{array}{l}\text { Mantener la longitud } \\
\text { de arco }\end{array}$ & & \\
\hline
\end{tabular}




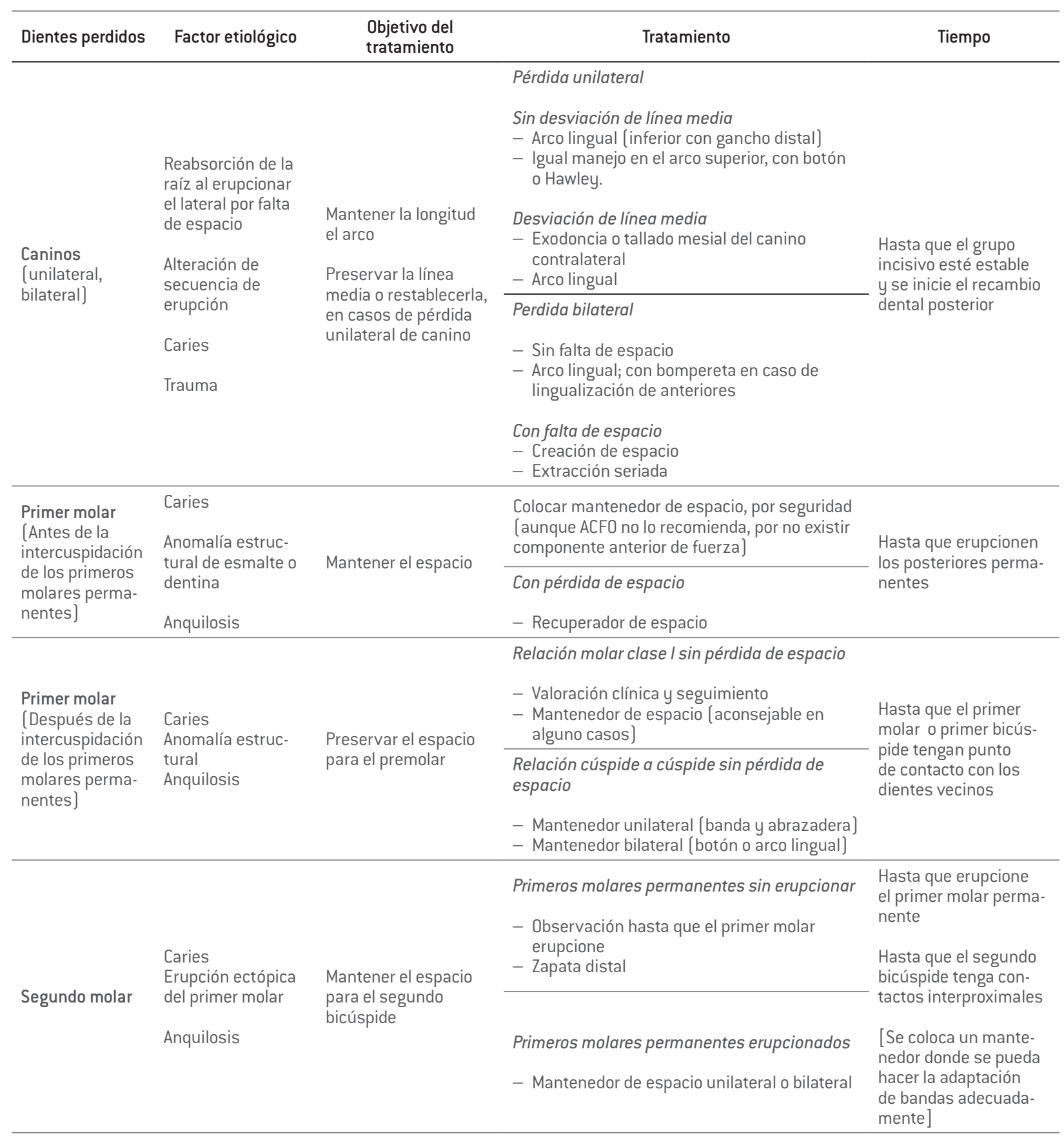

\section{Fuente: elaboración propia}

Normalmente, la pérdida de espacio es más pronunciada en ciertos casos. A continuación, se mencionan algunos [5]:

a. Cuando se presenta en el maxilar, más que en la mandíbula, durante el primer año (a partir de allí la pérdida superior se estabiliza, pero la inferior continúa a la misma rata) (Figura 30). b. En la pérdida de segundo molar, más que del primer molar deciduo.

c. Si se pierde el primer molar deciduo antes de los 7 años.

d. En pacientes con apiñamiento, respecto a pacientes con espaciamiento. 
e. En pacientes retrognáticos, en comparación con los prognáticos, en el arco inferior y viceversa.

f. Durante los primeros 6 meses y el año de la pérdida, si no ha erupcionado el primer molar.

\section{RECUPERACIÓN DE ESPACIO}

Para una adecuada recuperación de espacio, es importante atender las siguientes consideraciones:

a. Evitar movimientos recíprocos.

b. Aplicar la fuerza en dirección correcta.

c. Evitar rotaciones e interferencias oclusales que impidan el movimiento, utilizando para esto bloques de mordida.

d. Evitar movimientos complejos.

Luego de recuperar un espacio, se debe dar inicio a su mantenimiento, con la finalidad de que no se pierda nuevamente [3]. A continuación, se describen los tipos de recuperadores que pueden emplearse.

\section{RECUPERADORES FIJOS}

\section{Bompereta}

La bompereta puede usarse para ganar longitud y amplitud del arco. Se describe como un aparato funcional: trabaja a expensas de las fuerzas ejercidas por el músculo mentoniano para hacer efecto en el movimiento dentario [3, 26]. El aparato debe ubicarse entre 2.5 y $4 \mathrm{~mm}$ separado de la superficie vestibular de los incisivos inferiores. Para un mejor funcionamiento, la separación ideal es de $4 \mathrm{~mm}$, pues se ha reportado que, entre más anterior es su ubicación (4 mm), más fuerza se genera (al pasar de 2 a $4 \mathrm{~mm}$ de separación sagital, la fuerza aumenta en un 72\%). Con esta separación se logra alterar el equilibrio entre las fuerzas de labios y carrillo, y lengua. La fuerza del labio es de 100 a 300 gr. [27] (Figura 33); la lengua imprime cuatro veces más fuerza. La ubicación vertical de la bompereta debe ser en el tercio gingival hacia vestibular de los incisivos, lo que aumenta en un 17\% la fuerza [28].

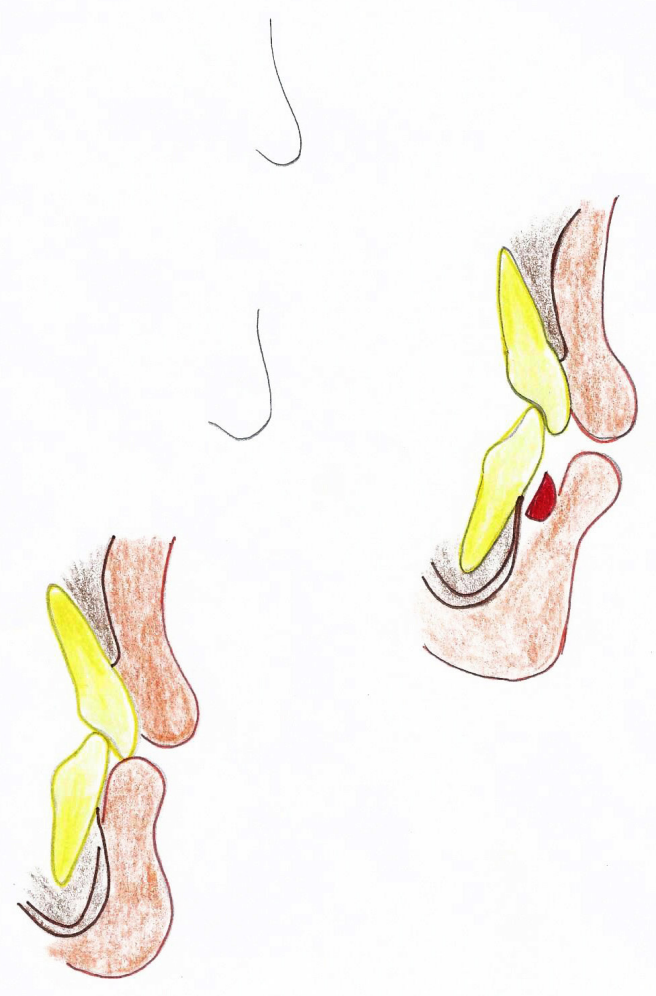

FIGURA 33. Separación del labio generado por la bompereta

Fuente: elaboración propia

A través del aparato, las fuerzas del labio se transmiten hacia los molares, manteniendo su posición o generando su distalización por inclinación o movimiento en cuerpo [31]. Es usado para la prevención de hábitos labiales y la creación o recuperación de espacio en arcos mandibulares [30]. Está descrito para ser usado en el arco inferior; sin embargo, algunos autores lo han aplicado en el arco superior, ya que es un aparato activado por el labio. Aunque se ha visto que el labio superior posee menor fuerza que el inferior y los resultados no necesariamente son los mismos (Figura 34). 

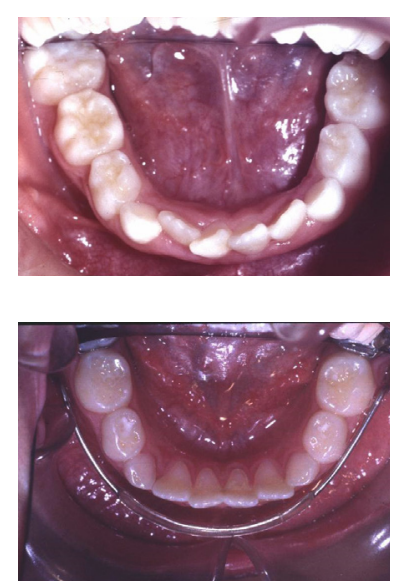

FIGURA 34. Apiñamiento previo a bompereta en posición Fuente: elaboración propia

\section{Construcción}

Su diseño depende del efecto requerido y de la adaptación del individuo [28]. Se confecciona en alambre de acero de 0.036 ", con ansas mesiales a los primeros molares, extendiéndose facialmente al arco mandibular sin contactar los dientes. En sentido vertical, la bompereta se ubica a nivel del margen gingival (profunda, en el vestíbulo) para permitir el selle labial [29]. En la zona anterior, es cubierta con acrílico o plástico, que evita que el alambre se clave en el labio [32] y genera diferentes aplicaciones de fuerza. La bompereta con acrílico ejerce más fuerza que la de plástico. Por otro lado, no se observan diferencias en las fuerzas según los diferentes grosores labiales.

Es fija cuando va soldada en vestibular de las bandas de los primeros molares permanentes; si se asegura con elásticos a tubos dobles es semifija, y es removible en casos donde entra libremente a nivel de tubos dobles soldados a las bandas. La longitud de la bompereta se debe mantener mediante ansas, resortes o stops soldados (Figura 35) [3]. Para mantener su posición original, la activación debe hacerse mensualmente o cada 3 semanas [29].
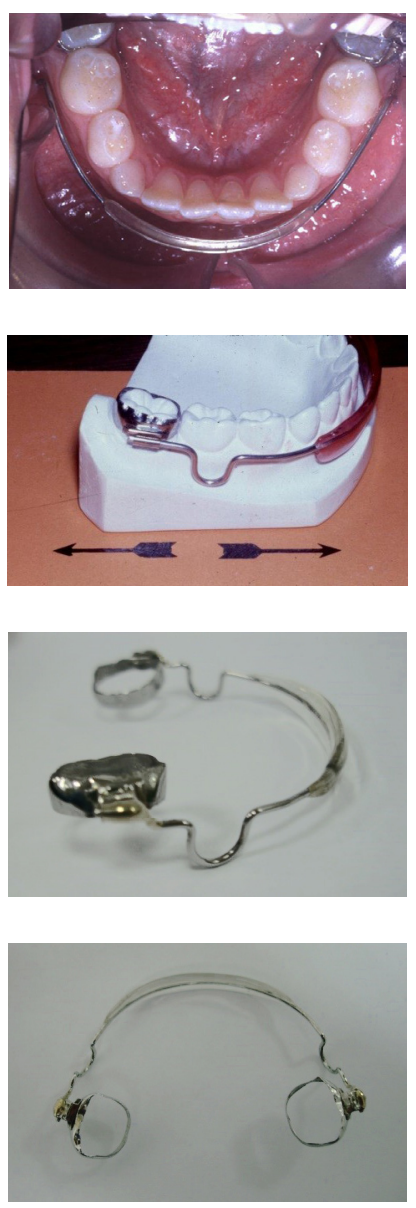

FIGURA 35. Ansa de la bompereta

Fuente: elaboración propia

\section{Efectos}

Debido al uso de la bompereta, se pueden observar cambios dentoalveolares y musculares. El efecto depende de a) el tipo de aparato usado, b) la posición labial de la bompereta respecto a los incisivos y c) las variaciones anatómicas y funcionales [3, 26]. Entre los cambios musculares, se observa el aumento en la fuerza perioral durante la fonación y la deglución. Los cambios dentales incluyen a) la inclinación vestibular de incisivos; b) la distalización o inclinación de molares; c) el aumento en la distancia intermolar, interpremolar y canina (al separar los carrillos) [27]; 
d) el aumento de perímetro de arco (en un estudio en 25 pacientes de 13 años) [29], y e) el aumento de la circunferencia del arco y extrusión de molares [27].

Como se mencionó, la inclinación vestibular de los incisivos es mayor con las bomperetas que llevan acrílico que con aquellas de tubo plástico. Además, según un estudio con 40 pacientes realizado por Nevant, la bompereta de acrílico produce mayor distalización de los molares que la de plástico [28]. El aumento en la circunferencia se debe al aumento de la amplitud y la vestibularización de incisivos, así se observa en el estudio de 32 pacientes de entre 9 y 17 años de edad [30]. Un movimiento distal de $0.5 \mathrm{~mm}$ requiere 60 días de uso de la bompereta y 1.5 $\mathrm{mm}$ requieren de 81 días, pero el movimiento labial de incisivos no es dependiente del tiempo de uso del aparato [28]. Según Ghafari, la bompereta presenta tres efectos importantes [3]:

a. Aumento de la circunferencia de arco, vestibularizando incisivos al variar el balance labio-diente. Esto genera aposición ósea en apical de las raíces y se logra movimiento en cuerpo de los incisivos (sin embargo, algunos autores aseguran que lo que se da es una inclinación de los incisivos y que no genera cambios en la posición de su ápice). Se afirma que, a los 78 días de uso, el movimiento hacia vestibular de los incisivos fue de $1.45 \mathrm{~mm}$, lo que proporciona un aumento en la amplitud del arco de $1.2 \mathrm{~mm}$ [30]. El aumento en la circunferencia del arco también se produce por un aumento transversal del arco a nivel de molares y premolares.

b. Verticalización y distalización de los molares (efecto de mantenedor y recuperador de espacio). La fuerza generada por el labio es transmitida a los molares, el movimiento del molar depende de la resistencia que ofrezca el segundo molar y el borde anterior de la rama. En un estudio de revisión sistemática se encontró que la distalización de molares ocurre entre el $88 \%$ y el $95 \%$ de los pacientes [30]. En algunos casos, la distalización del primer molar permanente puede generar impactación del segundo molar permanente (Figura 36), por tanto, se recomienda hacer una supervisión frecuente de la erupción del segundo molar.

c. Eliminación del hábito y reacondicionamiento muscular, mediante ejercitación del músculo, lo que mejora su hipertonicidad.

d. En relación con el punto 2 que antecede, la secuencia de radiografías panorámicas presentadas en la Figura 36 muestran la posición que adoptan los primeros molares inferiores y la impactación de los segundos molares:
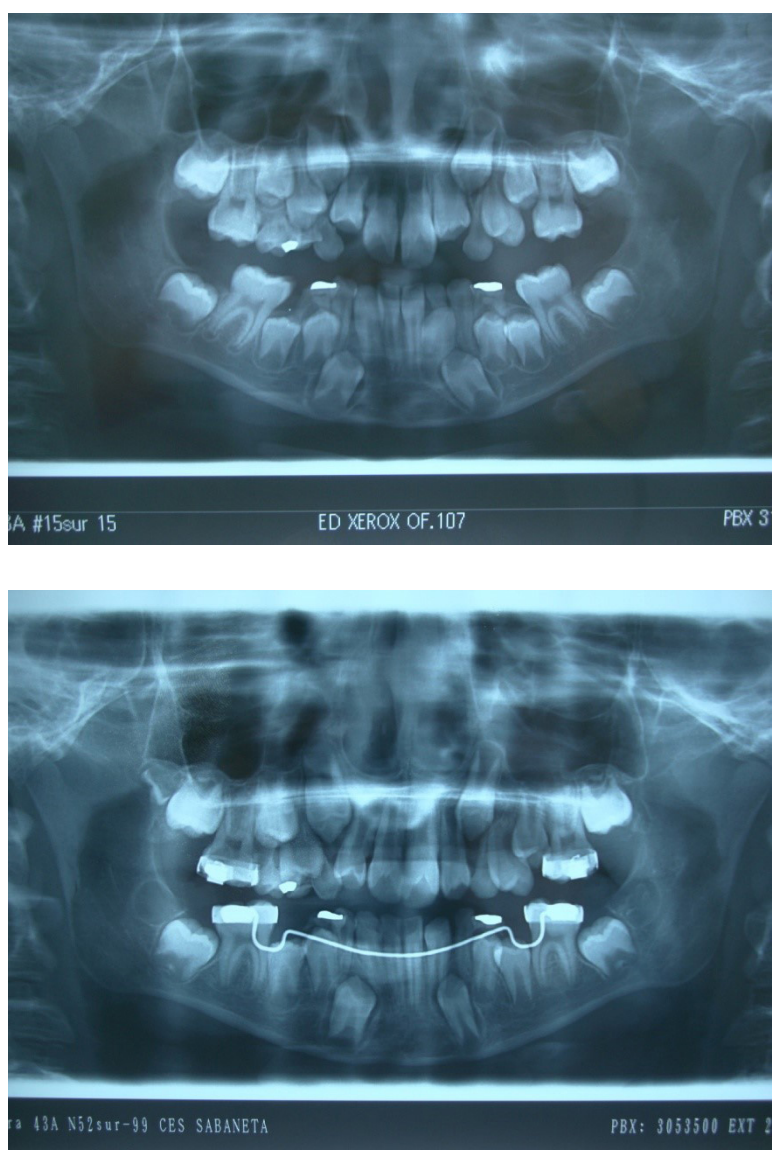


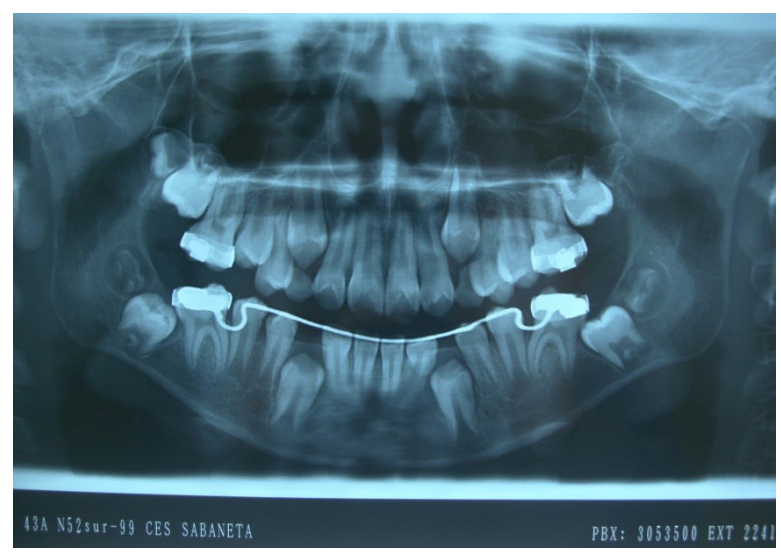

FIGURA 36. Secuencia radiográfica de paciente con bompereta

Fuente: elaboración propia

La bompereta se puede combinar con un plano anterior de mordida, que incrementa los efectos dentales con relación a un aumento mayor del perímetro de arco [25, 31].

\section{RECUPERADORES REMOVIBLES}

\section{Placas de Hawley con tornillos laterales y sillas de montar}

Las placas activas tienen los mismos elementos que las placas de Hawley descritas anteriormente (cfr. apartado de mantenimiento de espacio). Se le adicionan elementos activos que generan movimientos dentales menores, básicamente inclinaciones (Figura 37).
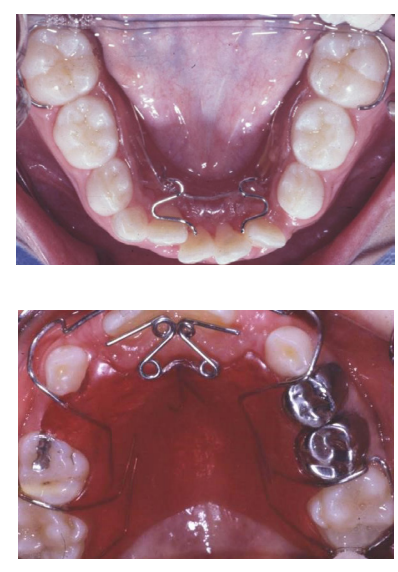

FIGURA 37. Placas de Hawley con ganchos de entrega Fuente: elaboración propia
Con las placas activas se utilizan fuerzas controladas e intermitentes, que permiten un movimiento dentoalveoar más fisiológico sin dañar al periodonto; por tanto, no produce reabsorción radicular. Además, estas placas no incrementan la incidencia de caries, dado que, al ser removibles, permiten la adecuada limpieza de los dientes y del aparato. Entre las desventajas que presenta están la necesidad de cooperación del paciente; los problemas fonéticos, y la duración de los tratamientos, pues son más largos al producir movimientos dentales más lentos [13]. Además, solo genera movimientos de inclinación.

\section{Construcción}

Los resortes que generan los movimientos dentales se clasifican en simples y compuestos. Los simples no presentan hélices, los compuestos tienen una hélice incorporada o ansas. Normalmente se fabrican de acero inoxidable de $0.9 \mathrm{~mm}$. Deben ser mecánicamente fuertes para soportar las interferencias que ocurren al comer, hablar o realizar la limpieza. El resorte digital simple o compuesto presenta una hélice cerca al acrílico y un extremo libre, que constituye el brazo activo de 12 a 15 mm de largo. La hélice debe estar situada en sentido opuesto a la dirección del movimiento, a lo largo del eje longitudinal de dientes a ser movido y perpendicular a la dirección del movimiento. Es usado para movimientos mesiodistales con activaciones de $3 \mathrm{~mm}$; la activación se logra abriendo la hélice. El resorte en $\mathrm{Z}$ o de dos hélices se activa abriendo las dos hélices a la vez. La activación de una sola sirve para corregir rotaciones; con las dos activadas se corrigen lingualizaciones (Figura 38).

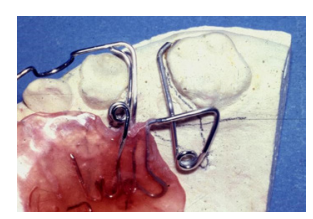



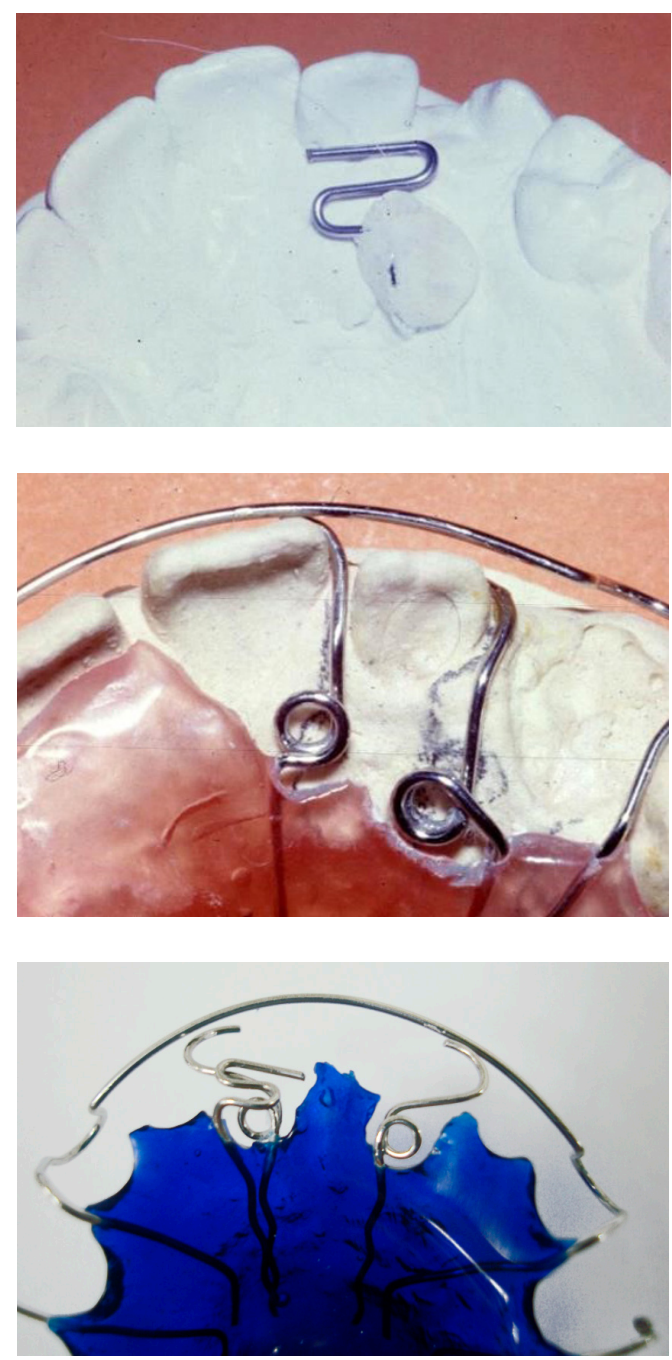

FIGURA 38. Resortes usados en las placas de Hawley

Fuente: elaboración propia

Como se mencionó, con este tipo de aparatos solo se logran movimientos dentales de inclinación; por tanto, cuando se usan este tipo de placas activas es fundamental no olvidar el desarrollo de la oclusión. Por ejemplo, los laterales superiores permanentes malposicionados (rotados o inclinados a vestibular) durante la etapa del patito feo tendrán el canino permanente en contacto sobre la superficie distal de la raíz del lateral. La colocación de una placa para enderezar los laterales podría generar reabsorción de la raíz del lateral, al inclinarla hacia distal. En estos casos, es mejor utilizar un sistema que produzca movimientos radiculares, como los brackets [13].
Las placas con tornillos de expansión se utilizan para ampliar transversalmente los arcos (hasta $5 \mathrm{~mm}$ ), al generar un movimiento dental de vestibularización (ver capítulo de expansión transversal). En individuos menores a 7 años, se puede observar separación de la sutura media palatina. Los tornillos también pueden tener una ubicación lateral en el aparato, para producir movimientos anteroposteriores de los molares, principalmente en casos de pérdida de espacio. La activación se realiza con la ayuda de una llave elaborada en alambre, que se introduce en los orificios que trae el tornillo. Esta posee un doblez, al final hacia arriba, que permite una activación más cómoda (Figura 39). Al abrir el tornillo en una vuelta completa, se obtiene de 0.8 a $1 \mathrm{~mm}$ de disalización.
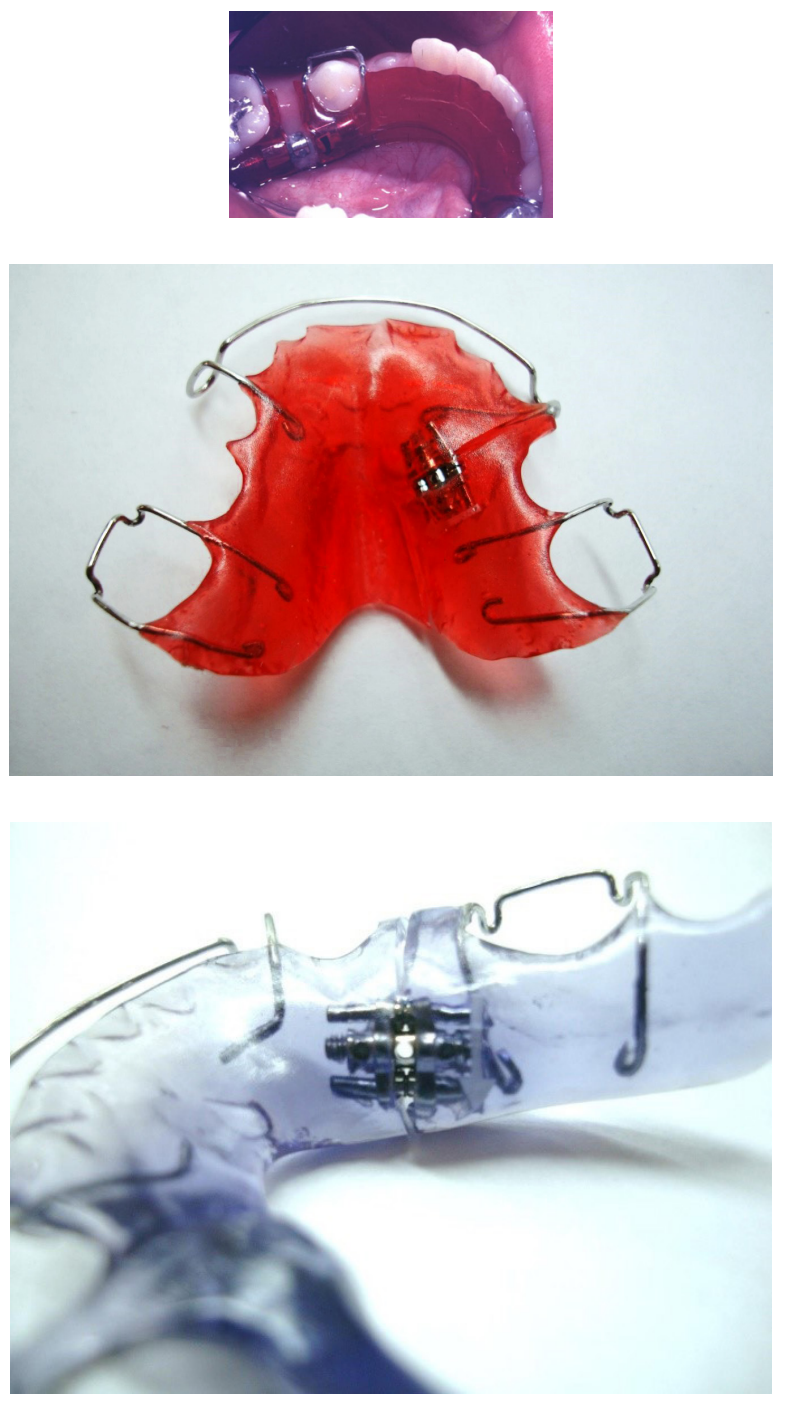

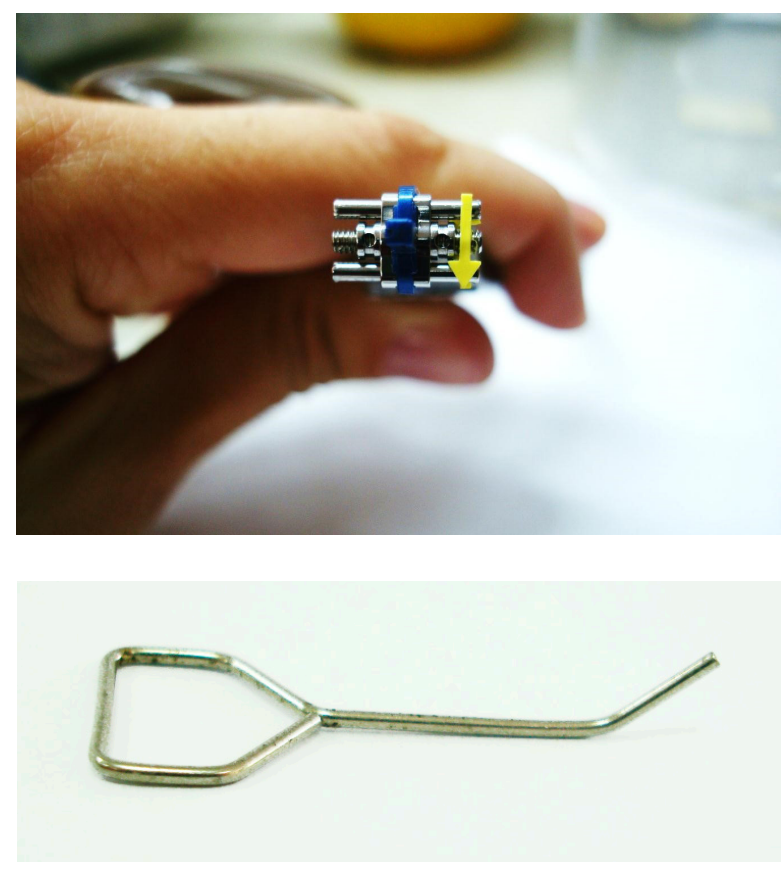

FIGURA 39. Placa de Hawley con tornillo lateral y llave en alambre

Fuente: elaboración propia

Para reganar espacio, también se puede agregar un gancho en forma de silla de montar a la placa, el cual distaliza o verticaliza el molar que se inclinó debido a la pérdida prematura de un deciduo. Se activa dos veces al mes, genera $0.5 \mathrm{~mm}$ de distalización y se usa en casos de inclinación a mesial de primeros molares, en un máximo $2 \mathrm{~mm}$. Se activa abriendo el ansa. Es un aparato similar al bilateral de acrílico, se le adicionan ansas de alambre en la zona edéntula adyacente al molar que se quiere distalizar. Su anclaje son los dientes y el tejido blando. Una vez recuperado el espacio, el aparato sirve como mantenedor. Produce movimientos de inclinación y, si son bilaterales, puede vestibularizar los incisivos (Figura 40).
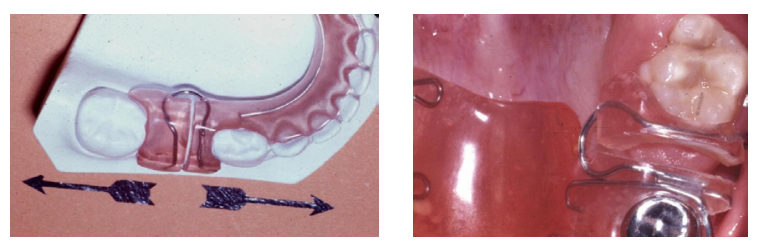

FIGURA 40. Hawley con silla de montar

Fuente: elaboración propia

\section{CREACIÓN DE ESPACIO}

Es importante considerar que el término "crear espacio" se emplea en los casos en que no ha ocurrido pérdida, sino que existe apiñamiento primario; es decir, en los casos de discrepancia óseodentaria. Los movimientos que se pueden realizar para aumentar el perímetro de un arco son la distalización de molares, la vestibularización de incisivos y la ampliación transversal de los arcos. Al respecto, se debe tener en cuenta lo siguiente:

a. El movimiento distal de molares es más restringido en el arco inferior debido a la anatomía y a la ubicación de los segundos molares permanentes.

b. La expansión del arco superior se recomienda solo si hay constricción, es decird, mordida cruzada posterior. Por cada milímetro de expansión, se genera en el arco entre 0.4 y $0.7 \mathrm{~mm}$ (principalmente, en la zona posterior) [32, 33].

c. La labialización de incisivos dependerá del estado periodontal, del perfil y del overjet [3]. Solo es indicado para solucionar apiñamientos de 2 a 4 mm (ver capítulo 3, 'Apiñamiento'; Figura 41).

d. La expansión transversal superior e inferior con aparatos funcionales bimaxilares.

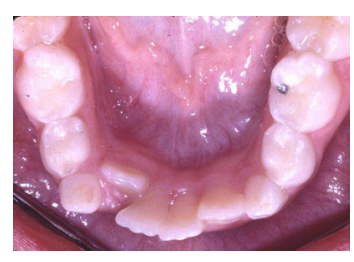

FIGURA 41. Apiñamiento moderado Fuente: elaboración propia 


\section{REFERENCIAS}

[1] Stewart E, Barber T. Pediatric dentistry, scientific foundation and clinical practice. St. Louis: Mosby; 1982.

[2] Dincer M, Haydar S, Unsal B, Turk T. Space maintainers effects on intercanine width and length. J. Clin. Pediatr. Dent. 1996 otoño;21(1):47.

[3] Ghafari J. Early treatment of dental arch problems. I. Space maintenance, space gaining. Quintessence International. 1986;17(7):423.

[4] Brithwell P. Guidelines on the use of space maintainers following premature loss of primary teeth. J. Can. Dent. Assoc. 1997; 63(10):763.

[5] Tulunoglu O, Ulusu T, Genc Y. An evaluation of survival of space maintainers: A six year follow up study. J. Contem. Dent. Prac. 2005;6(1):74.

[6] Kupietzky A, Tal E. The transpalatal arch: An alternative to the Nance appliance for space maintenance. Pediatr. Dent. 2007;29(3):235.

[7] Viglianisi Azzurra. Effects of lingual arch used as space maintainer on mandibular arch dimension: A systematic review. Am. J. Orthod. Dentofacial Orthop. 2010 oct;138(4):382.

[8] Rebellato J, Lindauer S, Rubenstein L, Isaacson R, Davidovitch M, Vroom K. Lower arch perimeter preservation using the lingual arch. Am. J. Orthod. Dentofacial Orthop. 1997;112(4):449-456.

[9] Brennan M, Gianelly A. The use of lingual arch in the mixed dentition to resolve incisor crowding. Am. J. Orthod. Dentofacial Orthop. 2000;117(1):81.

[10] Owais A, Rousan M, Bradan S. Effectiveness of a lower lingual arch as a space holding device. Eur. J. Orthod. 2011; 33(1):37-42.

[11] Ferdianakis K. Laskou M, Spyrou L. Lingual arch appliance fabrication in the dental office. J. Clin. Pediatr. Dent. 1998;22(4):277-280.

[12] [12] Villalobos $F$ et al. Longitudinal assessment of vertical and sagittal control in the mandibular arch by mandibular fixed ach. Am. J. Orthod. Dentofacial Orthop. 2000;118: 366-370.

[13] Cárdenas JM, Cárdenas D, Agudelo J, Gómez C, Arango C. Manejo de los espacios intraorales en niños. Guías de práctica clínica basadas en la evidencia. Manizales: Graficas JES; 1998.

[14] Sigh P, Cox S. Nance palatal arch: A cautionary tale. J. Orthod. 2009;36:272-276.

[15] Shpack N, Davidovitch M, Sarne O, Panayi N, Vardimon A. Duration and anchorage management of canine retraction with bodly versus tipping mechanics. Angle Orthod. 2008;78(1):95.

[16] Nikolai R, Horner K, Blackwell D, Carr R. On the designed of loop orthodontic retainer wires. Angle Orthod, 1991;61(3):211.

[17] Stein J, Nikolai R On the selection and preparation of a wire for the labial bow of an orthodontic retainer. Angle Ortho. 1994;64(4):291-298.

[18] Sheridan J et al. A Hawley clasp modification. J. Clin. Orthod. 2010 feb;44(2):104.

[19] Fathian M, Kennedy D, Nouri R. Laboratory made space maintainers. A 7-year retrospective study from private pediatric dental practice. Pediatr. Dent. 2007;29:500-506.

[20] Qudeimat M. The longevity of space mantainers: a retrospect study. Am. Acad. Pediatr. Dent. 1998;20(4):267.

[21] Baroni C, Fracchini A, Rimondini L. Survival of different types of space mantainers. Pediatr. Dent. 1994;16(5):361.

[22] Norton A, Wickwire N, Guellin M. Space management in the mixed dentition. J. Dent. Child. 1975;42(2):112118.

[23] Kula K, Akan S, Ciger S, Ozkan S. Effects of Hawley retainers on consonants and formant frequencies of vowels. Angle Orthod. 2012;82:14-21.

[24] Northway W. Effects of premature loss of deciduos molars. Angle Orthod. 1984;54(4):295.

[25] Simon J, Farrage J, Misner L. Reganinig space in the mixed dentition. Dent. Clin. North Am. 1978;22(4):669. 
[26] Bjerregaard J, Bundgaard M, Melsen B The effect of the mandibular lip bumper and maxillary bite plateon tooth movement, occlusion and space conditions in the lower dental arch. Eur. J. Orthod. 1980;2:257-265.

[27] Nevant CT, Buschang PH, Alexander RG, Steffen JM. Lip bumper therapy for gaining arch length. Am. J. Orthod. Dentofacial Orthop. 1991;100(4):330-336.

[28] Bergersen EO. A Cefhalometric study of the clinical use of the mandibular labial bumper. Am. J. Orthod. Dentofacial Orthop. 1972 jun;61(6):578-602.

[29] O'Donnell S, Nanda R, Ghosh J. Perioral forces and dental changes resulting from mandibular lip bumper treatment. Am. J. Orthod. Dentofacial Orthop. 1998;113:247-255.

[30] Osborn W, Nanda R, Currier F. Mandibular arch perimeter changes with lip bumper treatment. Am. J. Orthod. Dentofacial Orthop. 1991;99(6):527-532.

[31] Hashish DI, Mostafa YA. Effect of lip bumpers on mandibular arch dimensions. Am. J. Orthod. Dentofacial Orthop. 2009 ene;135(1):106-109.

[32] Gianelly A. Leeway Space and the Resolution of Crowding in the Mixed Dentition. Semin. Orthod. 1995;1(3):188-194.

[33] Binder D. Correction of Posterior Crossbites: Diagnosis and Treatment. Pediatr. Dent. 2004;26:266-272. 


\section{CAPÍTULO 5}

\section{GUÍA DE ERUPCIÓN Y EXTRACCIÓN SERIADA}

Paola María Botero Mariaca, Libbe Mariaca de Botero

Uno de los tratamientos preventivos e interceptivos más importantes es la guía de erupción, con la cual se obtiene el desarrollo adecuado de los arcos. Asegura que los dientes en erupción se acomoden correctamente y logra la intercepción de problemas que de lo contrario requerirían tratamientos correctivos. El capítulo muestra el paso a paso de la evaluación de la condición de los pacientes para establecer un tratamiento de guía de erupción, así como las diferentes terapias involucradas.

\section{AsPeCtOS GENERALES}

En 1986, Gafhari define la guía de erupción como todos los procedimientos usados para facilitar la erupción normal, el posicionamiento de los dientes permanentes en el arco y el logro de adecuadas relaciones oclusales. Su objetivo es evitar la necesidad de tratamiento activo de ortodoncia o reducirlo al mínimo, al lograr prevenir, interceptar o corregir problemas del desarrollo. Comprende cirugías (supernumerarios, frenectomías),

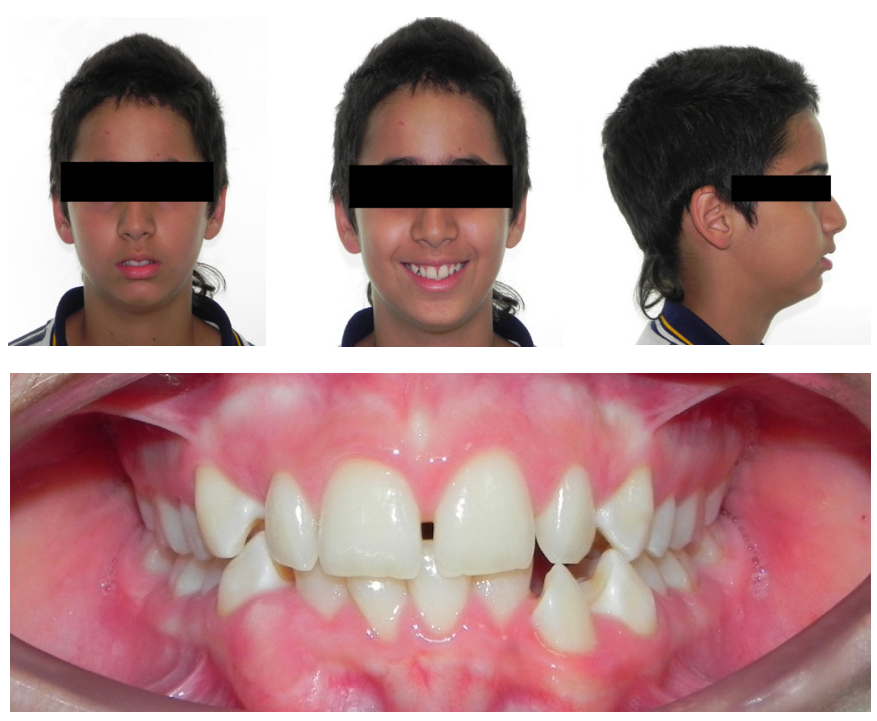

restauraciones, tallado selectivo, mantenimiento de espacio, tallado interproximal, extracciones de deciduos y hasta de permanentes (extracción seriada), colocación de aparatos fijos, removibles y ortopédicos, entre otros [1]. Este es un concepto más amplio que el brindado por Hotz en 1970, quien se refería a la guía de erupción como tratamiento para el apiñamiento primario: tallado de deciduos, exodoncia de deciduos y exodoncia de deciduos y permanentes (extracción seriada). En este capítulo revisaremos lo que Hotz expresa y que Gafhari complementa.

Además de una historia clínica completa, la guía de erupción requiere una evaluación individual de registros diagnósticos, en los cuales se debe aplicar el conocimiento del crecimiento y desarrollo craneofacial, así como el desarrollo de la oclusión. Para llegar a un correcto diagnóstico y a un plan de tratamiento adecuado, se consideran, por ejemplo, el tipo esquelético; las relaciones oclusales; la relación de los dientes con sus maxilares; el espacio disponible en la zona posterior de los arcos, para la erupción adecuada de los dientes permanentes; la secuencia de erupción; el tamaño de las bases apicales; el estado de la erupción dental; la formación radicular; las ausencias dentales; la posición de dientes no erupcionados; la intercuspidación de primeros molares, y las anomalías (Figura 1) [2].
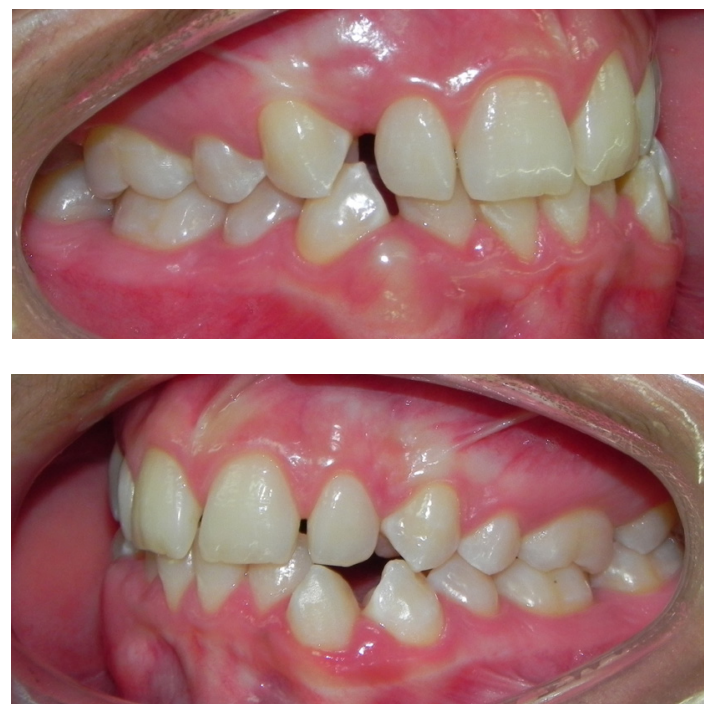

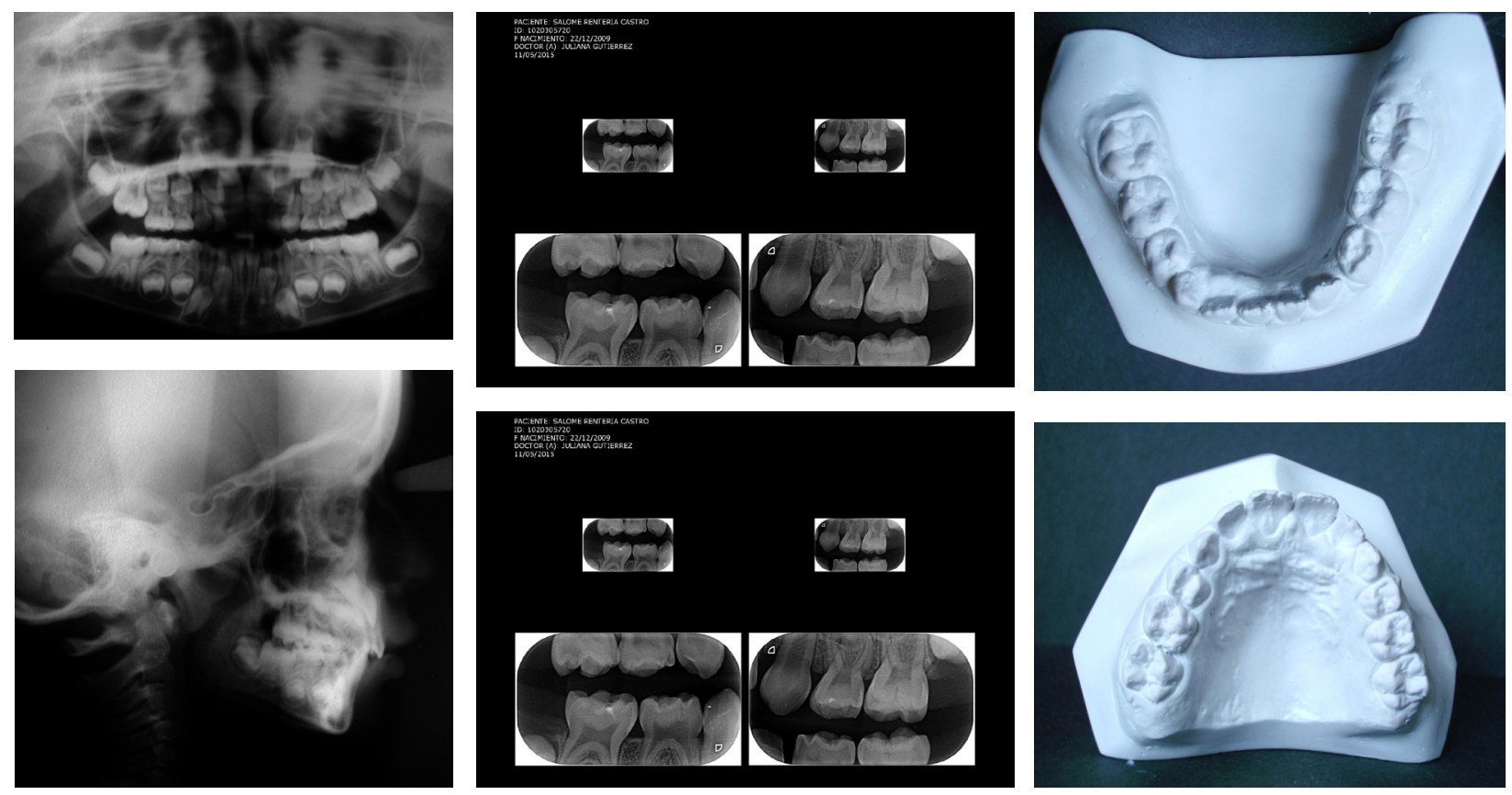

FIGURA 1. Exámenes diagnósticos para un paciente en crecimiento: figuras extraorales, figuras intraorales, radiografía panorámica, radiografía cefálica, radiografías Bite Wing y modelos de estudio

Fuente: elaboración propia

\section{REMOCIÓN DE OBSTÁCULOS EN}

\section{LA ERUPCIÓN}

La presencia de supernumerarios (Figura 2) y de dientes anquilosados puede generar alteraciones durante el proceso de desarrollo, como impactación de dientes permanentes, desviación en la vía de erupción del germen, inclinación de los dientes adyacentes, reabsorción de raíces de permanentes adyacentes y erupción ectópica o retrasada de los permanentes. Asimismo, colocando los aparatos necesarios o realizando las cirugías y exodoncias recomendadas, deben prevenirse e interceptarse alteraciones como dientes primarios traumatizados; factores patológicos como quistes; factores no patológicos como fusiones dentales; factores iatrogénicos como restauraciones sobrecontorneadas o mantenedores deformados; e interferencias oclusales como sobreerupción de dientes antagonistas [1].
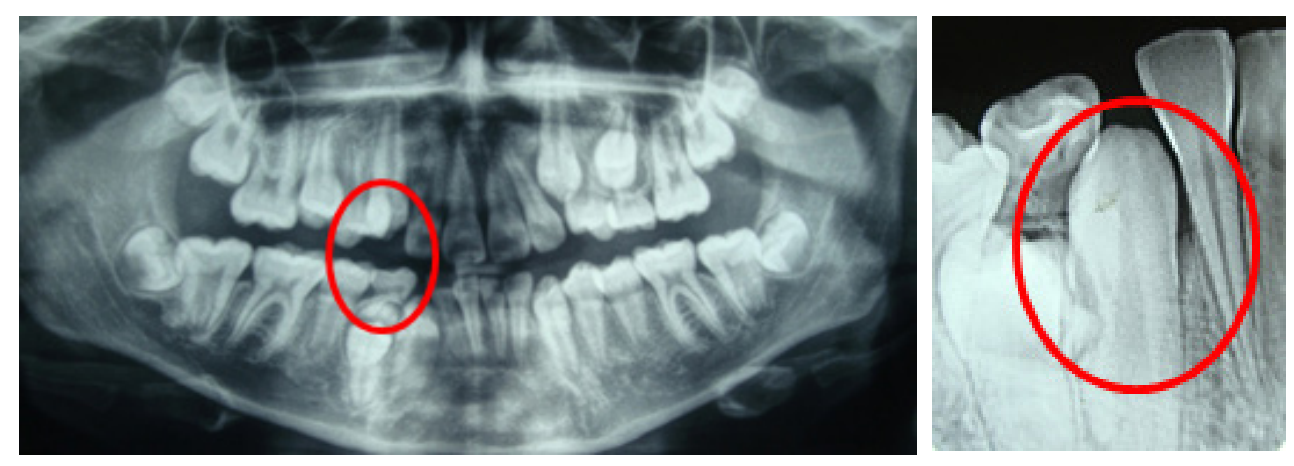

FIGURA 2. Presencia de supernumerario en oclusal de primer bicúspide inferior izquierdo 


\section{GUIAR LA ERUPCIÓN DE DIENTES MALPOSICIONADOS EN UNA CORRECTA POSICIÓN EN EL ARCO}

Dependiendo de su posición intralveolar, los dientes permanentes pueden erupcionar rotados o inclinados a pesar de que exista espacio para ellos dentro del arco. En estos casos, el objetivo es corregir las posiciones de los dientes una vez hagan erupción y evitar una posible pérdida de espacio en el arco. Esto ocurre, por ejemplo, con los dientes que erupcionan ectópicamente; si no se tratan temprano, podrían generar pérdida de espacio. Para lograr estos objetivos, se pueden utilizar aparatos removibles con ganchos de entrega y, en muy pocos, casos ortodoncia fija [1].

El caso contrario es el exceso de espacio debido a anomalías dentales, como microdoncias (anomalías de tamaño dentario); anomalías de forma, como dientes en clavija; anomalías de número, como hipodoncia; y fusiones. No puede darse el tratamiento definitivo en ese momento, de modo que este debe ser orientado al futuro (implante, prótesis o cierre de los espacios). Esto dependerá de muchos factores, entre ellos, el tamaño de los dientes, el tamaño de los arcos y, principalmente, las relaciones dentarias y esqueléticas [1]. En esta guía de erupción trataremos la alteración de la erupción de los caninos y los primeros molares superiores.

\section{ALTERACIONES DE LA ERUPCIÓN DE CANINOS MAXILARES}

Para la planeación de este tipo de terapia, se debe tener en cuenta que los caninos maxilares erupcionan a una edad aproximada de 10.5 años en niñas y 11.5 años en niños, con una variación de 3 a 4 años. La prevalencia de impactación es del 2\% al 3\%, y esta ocurre por obstrucción de tejido duro o blando, o por un patrón ectópico de erupción. Las medidas preventivas son ideales por el riesgo de reabsorción de las raíces de los dientes adyacentes, especialmente los laterales (existe 47\% de incidencia de reabsorción entre los 10 y 13 años, 9\% para centrales y 38\% en laterales). La falta de tratamiento de estas alteraciones puede causar, además de quistes, infecciones o dolores referidos [41, 42]. El diagnóstico y el tratamiento en general deben realizarse tempranamente.

\section{Fisiopatología de la erupción de los} caninos maxilares

Los caninos superiores normalmente deben hacer erupción entre los 12 y 14 años, pero desde los 9 años debemos empezar a observar su patrón de erupción, radiográficamente y también clínicamente, mediante una palpación por vestibular y por palatino. Comienza cercano a la cavidad nasal y luego utiliza la superficie distal de la raíz del lateral como guía para su erupción. Erupciona después del primer y el segundo bicúspides.

La evaluación de la posición intralveolar del canino permanente es fundamental para la determinación del pronóstico. Esta evaluación se debe hacer con un examen clínico completo, complementado con radiografías panorámicas y periapicales con técnica paralela. Estas permiten evaluar la altura, angulación, posición vertical y su relación con los dientes adyacentes (incisivo lateral). Los caninos con angulación mesial mayor a 25 grados con respecto a la línea media (Figura 3) [43] o con posición intralveolar mesial en sector III O IV (Figura 4) [13] son los indicados para el inicio de la guía de erupción. La posición del canino (bucal o lingual) y la presencia o no de alteraciones en los dientes adyacentes, como la reabsorción radicular del incisivo lateral, se deben analizar en su orden, idealmente con el uso de tomografías axiales localizadas llamadas Cone Beam (Figura 21) y radiografías con técnica deslizante o técnica de Clark. 


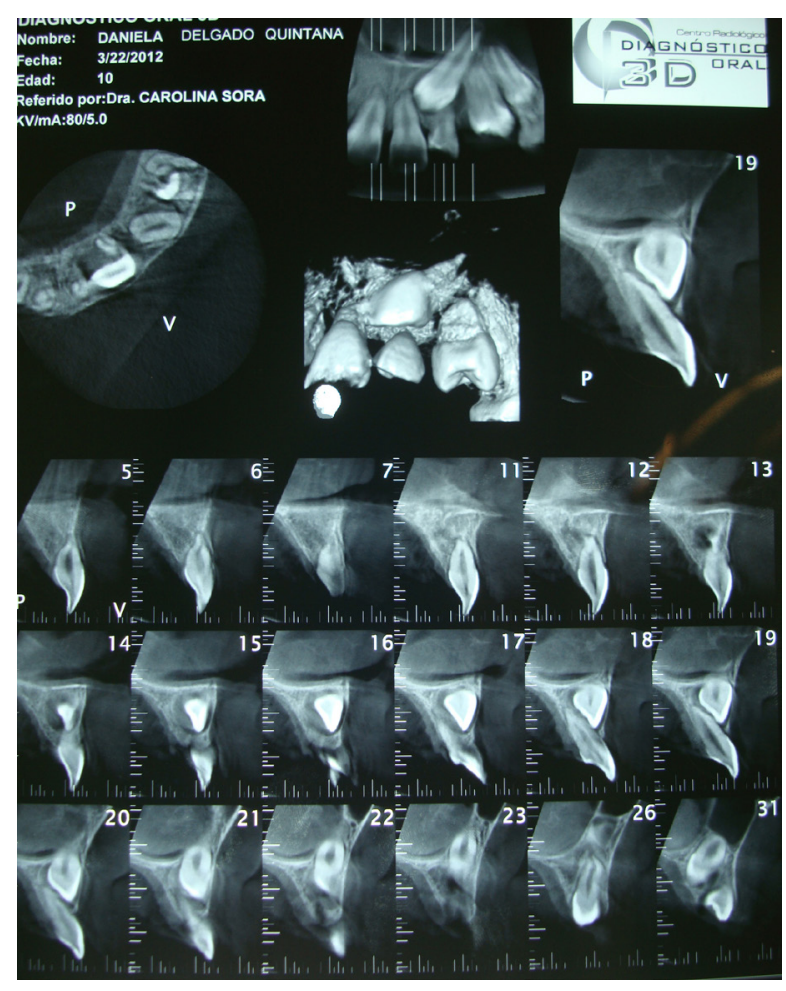

FIGURA 3. Radiografía Cone Beam de un paciente con canino impactado

Fuente: elaboración propia

En radiografías panorámicas se pueden evaluar varios aspectos respecto a la ubicación del diente en los planos vertical y horizontal, su grado de inclinación, su relación con el plano oclusal y la proximidad a la zona media (Figura 4):

a. Inclinación del canino. Para determinar esta inclinación, se mide el ángulo formado por el eje longitudinal del canino y la línea media [43]. Cuando ese ángulo es mayor a 25 grados, la tendencia de impactación del canino aumenta. En inclinaciones mayores como la de 31 grados la efectividad de la exodoncia de caninos deciduos en la erupción del permanente disminuye [43]. Otra referencia para medir la inclinación del canino es la referida por Warford, la cual emplea el eje bicondilar y el eje longitudinal del canino. Cuando el ángulo es menor a 59 grados se incrementa el riesgo de impactación. Esta última medida no es muy usada debido a la dificultad de ubicación del plano bicondilar en las radiografías panorámicas [44, 45] (Figura 4).

b. Solapamiento del canino. Mide la distancia desde el vértice de la cúspide del canino hasta la línea media [45].

c. Altura del canino. Mide la distancia desde el vértice del canino hasta el plano oclusal. Con esta medida se obtiene el nivel de erupción del canino en relación con los bordes incisales [45].

d. Distancia incisivo-canino. Mide la distancia vertical desde el vértice de la cúspide del canino hasta el ápice del incisivo central. Valora también el nivel de erupción del canino [45].

Si se halla un grado aumentado de inclinación y de solapamiento del canino, además de una disminución en la distancia entre el canino y la línea media, hay mayor riesgo de impactación. El pronóstico empeora cuando el canino se encuentra muy alto con respecto al plano oclusal [45].

Existe otra forma de establecer la probabilidad de impactación de caninos en un 78\%. Esta fue descrita por Lindauer y comprobada por Warford, y describe cuatro diferentes sectores según los cuales se determina la probabilidad de impactación. Sobre el incisivo lateral se trazan tres líneas: una tangente a la superficie distal, otra tangente a la superficie mesial y la última a nivel central, como una bisectriz. Las tres líneas dan origen a cuatro sectores: el sector I es distal a la tangente distal del lateral; el sector II se encuentra entre la tangente distal y la bisectriz; el sector III, entre la bisectriz y la tangente mesial; y el sector IV se encuentra mesial a la tangente mesial. Cuando el canino se ubica en los sectores iII y IV, existe riesgo de impactación [44, 45] (Tabla 1). 
TABLA 1

Análisis para determinar la impactación de caninos

\begin{tabular}{clll}
\hline \multirow{2}{*}{ Análisis } & \multicolumn{3}{c}{ Pronóstico } \\
\cline { 2 - 4 } & \multicolumn{1}{c}{ Bueno } & \multicolumn{1}{c}{ Regular } & \multicolumn{1}{c}{ Malo } \\
\hline Lindauer & Sector I & Sector II & Sector III y IV \\
\hline Power & $0-15$ & $15-30$ & Mayor de 31 \\
\hline Warford & Mayor de 75 & $59-75$ & Menor de 59 \\
\hline
\end{tabular}

Cuando el canino se encuentra sobre el conducto radicular o sobrepasándolo a mesial, el riesgo de impactación es muy alto; si está más distal de la línea media del conducto, el riesgo es menor. En el caso de que solo sobrepase la raíz del lateral en su porción distal, el riesgo es mínimo si se realiza el tratamiento en ese momento.

Fuente: elaboración propia
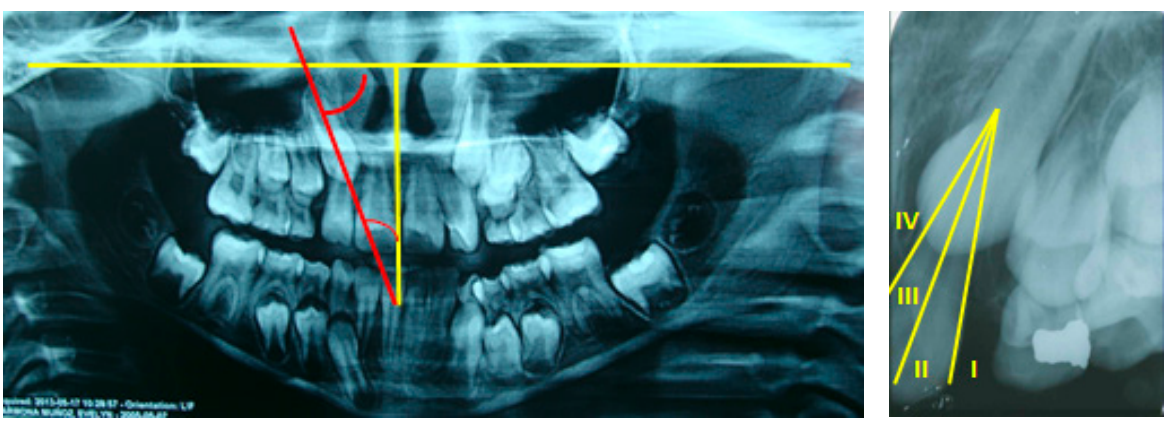

FIGURA 4. (A) Radiografía panorámica: medición de ángulos del eje de canino y línea media, y eje bicondilar. (B) Radiografía periapical: ubicación del canino según los sectores de Lindauer

Fuente: elaboración propia

\section{Tratamiento}

La guía de erupción de caninos desplazados intralveolarmente o con posibilidad de impactación o erupción ectópica puede realizarse de varias maneras, según estadio de formación dentario, la edad del paciente y su alteración esquelética o dentaria. Las alternativas de tratamiento comprenden desde la exodoncia del canino deciduo hasta la exodoncia acompañada de cirugía para exponer la corona del canino permanente. Antes de realizar alguna de estas opciones es necesario un examen clínico y radiográfico exhaustivo.

Para establecer qué exodoncia realizar y cómo sería su secuencia, se deben considerar los aspectos mencionados anteriormente: el estadio de formación radicular de los dientes permanentes en formación, la posición intralveolar del germen permanente y los principios del desarrollo de la oclusión (secuencias de erupción, momento de erupción de cada diente, cambios dimensionales de los arcos y etapa de la dentición del paciente). Normalmente, en los casos en los que se busca mejorar la secuencia de erupción, se debe extraer el deciduo que precede al permanente que se quiera acelerar; por tanto, el germen del permanente debe estar al menos en el estadio 7 [45].

Los efectos de las distintas estrategias de guía de erupción, que facilitan la erupción de los caninos maxilares, se pueden evidenciar en los estudios que se describen a continuación.

\section{Exodoncia de canino deciduo}

Los estudios muestran que la exodoncia del canino deciduo, realizada cuando el permanente se encuentra en el estadio 7 de Nolla o uno mayor (aproximadamente entre los 10 
y 11 años de edad), corrige el desplazamiento intralveolar del canino permanente. Esto permite su erupción espontánea en un 67\% de los casos, en comparación con el 42\% de erupción cuando no se hace la exodoncia. A mayor edad (entre los 12 y 14 años), el porcentaje de erupción espontánea después de la exodoncia del canino deciduo es menor: existe un apiñamiento mayor, el patrón de erupción se vuelve más horizontal y puede ocurrir la reabsorción de los dientes vecinos. Así también, los caninos ubicados en los sectores IV y $\mathrm{V}$ de Lindauer presentan menor porcentaje de éxito con esta terapia. Baccetti reporta que, después de la exodoncia del canino, el porcentaje de erupción en estas edades es de 65.2\%, y solo el $30 \%$ erupciona sin ningún tipo de terapia [15].

Es importante aclarar que la exodoncia del canino deciduo sería suficiente para facilitar el cambio de dirección del canino permanente, con su subsecuente erupción; sin embargo, el momento indicado para hacer la exodoncia es cuando el canino permanente ha comenzado su proceso de erupción y no se encuentra muy alto a nivel intraalveolar [46].

La posición intralveolar de los caninos (altura, angulación y relación con la raíz del incisivo lateral), su estadio de formación radicular y la magnitud de apiñamiento influyen en la posibilidad de que el canino permanente erupcione espontáneamente. En caninos permanentes que no han sobrepasado la línea media de la raíz del incisivo lateral, el porcentaje de erupción espontánea del permanente es del 92\%, después de un año de la exodoncia del deciduo. En los casos en que los caninos sobrepasan la línea media del lateral, solo el 64\% erupciona [16]. Resulta importante realizar un control radiográfico a los 3 meses de la exodoncia para evaluar los cambios en la posición y angulación. De no registrarse cambios, es necesario valorar la aplicación de otro tipo de terapia. Cuando se comparan los casos de caninos desplazados con apiñamiento y sin él, se ve que en los casos de apiñamiento solo el 50\% de los caninos erupciona adecuadamente [13].

Durante la ejecución del tratamiento de guía de erupción, se debe controlar sus efectos en el perímetro de arco; por tanto, se recomienda hacer el tratamiento combinado con un mantenedor de espacio.

Si los caninos permanentes presentan un desplazamiento intraalveolar hacia mesial, con alto riesgo de impactación (ver caso clínico 1, Figura 5), el procedimiento de guía de erupción por medio de exodoncia de dientes deciduos no es suficiente. Es necesario combinarlo con la tracción del canino permanente. Se realiza entonces la exodoncia del canino deciduo y la colocación de un aditamento en la corona del canino permanente (botón de cementación directa o bracket), para luego colocar un sistema que aplique la fuerza (ortodoncia fija, aparatos removibles o aparatos fijos); esto se hace después de la cirugía. En la planeación de la mecánica para traccionar el canino y antes de realizar la remisión del paciente a cirugía, se debe definir la posición intralveolar en sentido bucolingual con el uso de radiografías, idealmente Cone Beam, o radiografías periapicales con técnica deslizante.
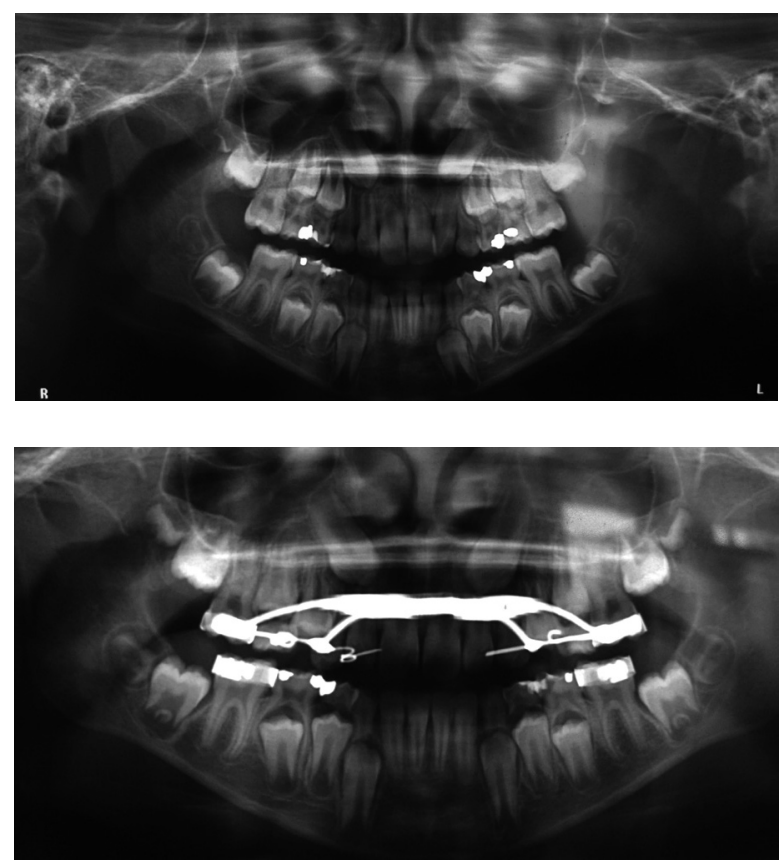


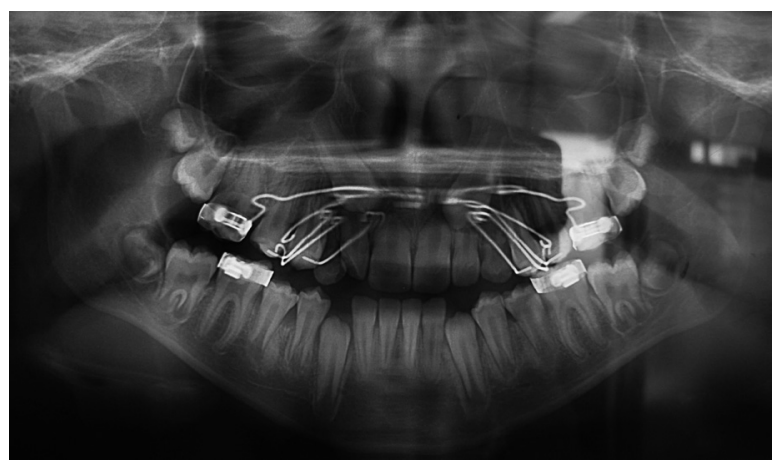

FIGURA 5. Reabsorción de lateral superior

Fuente: elaboración propia

Procedimiento. La colocación del botón se puede realizar durante una cirugía que deje expuesta la corona del canino permanente en boca. Idealmente, el tipo de cirugía debe ser técnica abierta. Su realización depende en primer lugar de que la ubicación del canino sea bucal o palatina, ya que las características de los tejidos blandos circundantes son diferentes. Para lograr un movimiento más predecible y eficiente, y establecer una banda de encía queratinizada en cervical del canino, se debe realizar un colgajo de desplazamiento apical. En los casos en que no se pueda realizar dicho procedimiento, debido a la ubicación alta y profunda del canino, se recurre a la cirugía cerrada, que consiste en el levantamiento de un colgajo, la adhesión del botón con hilo metálico y el posterior cubrimiento del diente, dejando solo el hilo metálico expuesto en boca. Es importante considerar la dirección en la que se debe traccionar el canino para que la ubicación en la que se deje el hilo metálico lo facilite y se evite un daño en los dientes adyacentes durante el movimiento dental. Sin embargo, es una cirugía que puede tener efectos secundarios, especialmente la afectación de los tejidos blandos circundantes y la pérdida ósea, por lo cual no es muy recomendable.

Casos clínicos. A continuación, se describen casos clínicos que muestran pacientes con alteraciones en la erupción y requirieron como tratamiento la guía de erupción:

- Caso clínico 1: paciente de 8 años de edad al inicio del tratamiento. Se programó la cirugía de caninos, que solo pudo realizarse 2 años después de lo previsto, cuando ya presentaba reabsorción del 12 (lateral superior derecho; Figura 5).

- Caso clínico 2: evolución de paciente con alteración en la erupción del 13 por inclinación mesial (25 grados) y posición anterior (sector IV), hasta completar distalización y erupción en buena posición (Figura 6).

- Caso clínico 3: secuencia radiográfica de paciente con canino superior izquierdo con desplazamiento intralveolar, ubicado en sector IV y angulación de 30 grados (Figura 7).
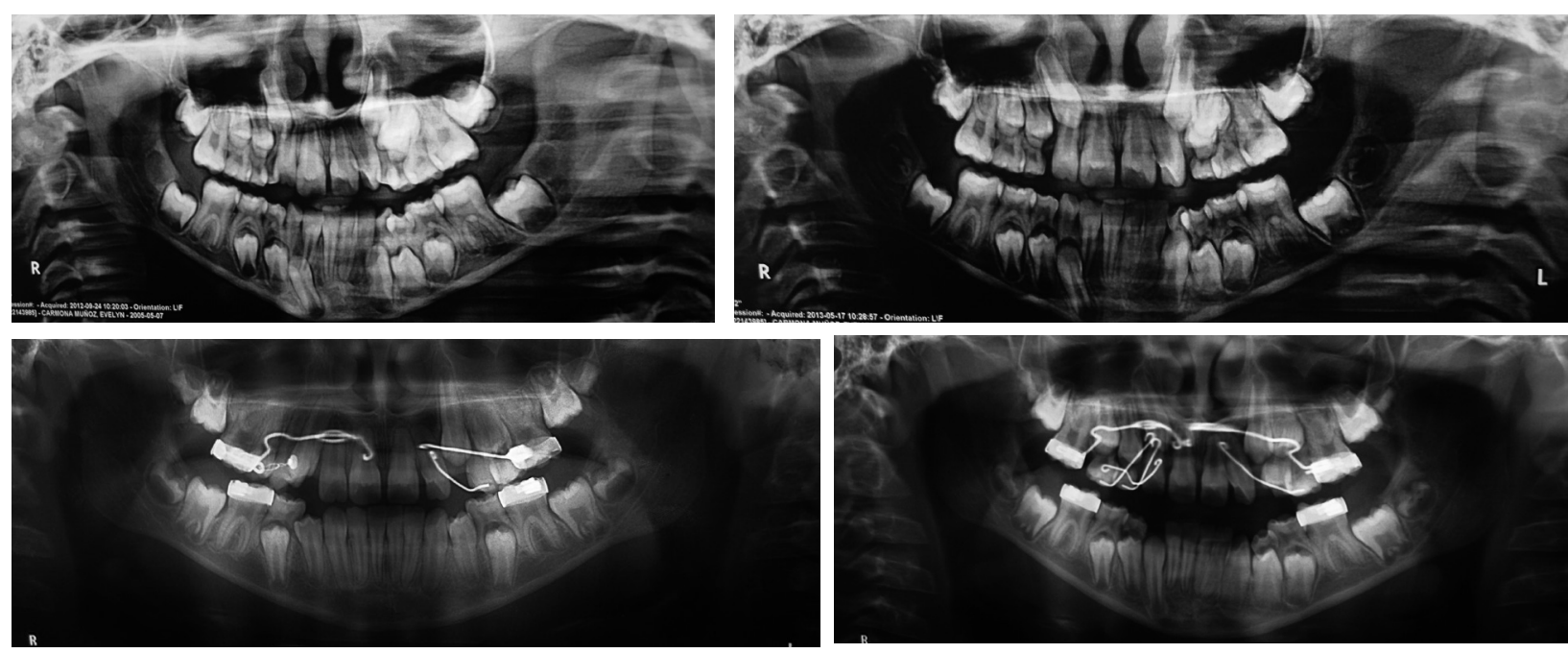

FIGURA 6. Evolución posición del 13 

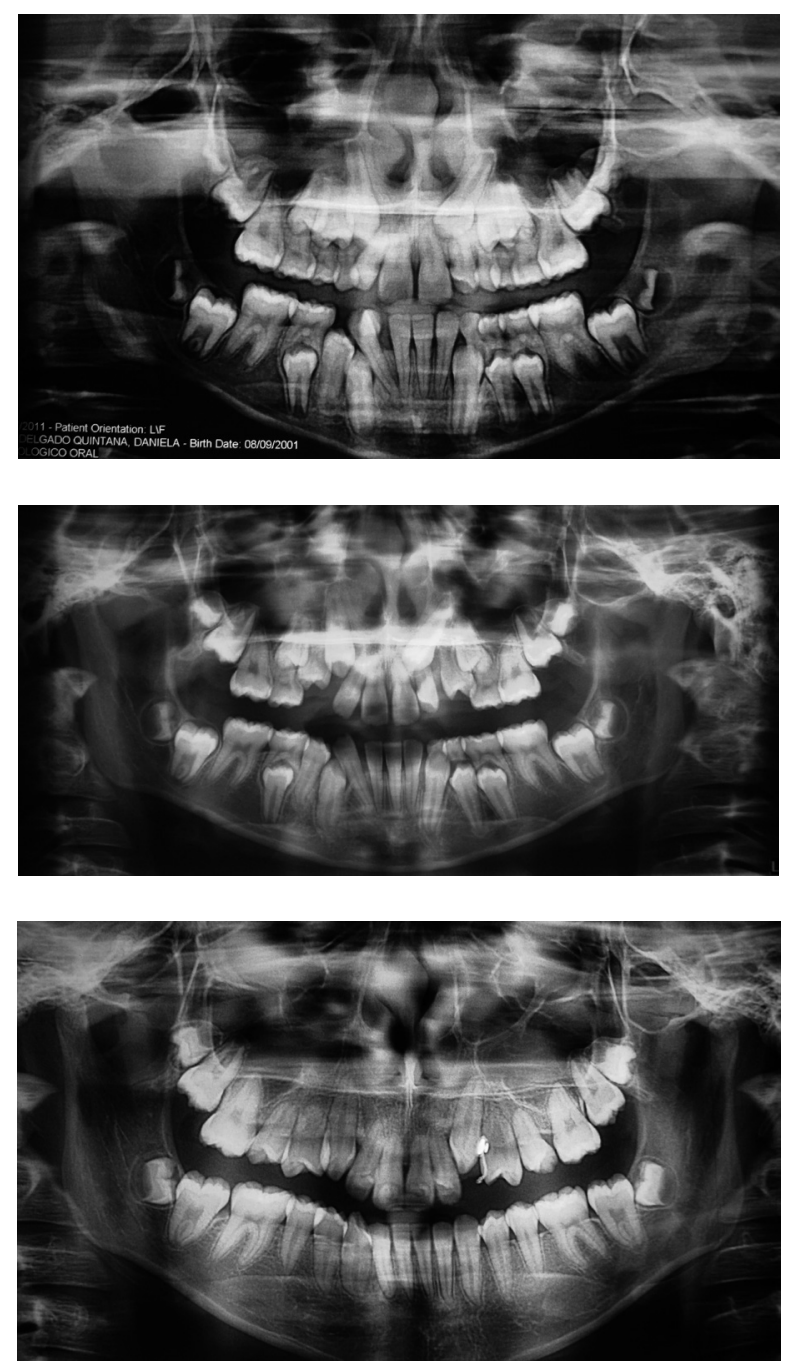

FIGURA 7. Evolución posición de canino

Fuente: elaboración propia

\section{Exodoncia del primer molar deciduo}

La guía de erupción del canino permanente también se puede realizar mediante la exodoncia del primer molar deciduo; según el momento del desarrollo dental del paciente, puede hacerse al mismo tiempo que la exodoncia del canino deciduo. Se ha visto que este procedimiento tiene mejores resultados pues acelera la erupción del bicúspide y provee más espacio para que el canino corrija su posición. Tiene un 97.3\% de éxito, comparado con el $78.6 \%$ de la exodocia solo de caninos [16], y también en los casos en los que el estadio de formación radicular del canino no ha llegado al estadio 7 (Figura 8) [11]. Al acelerar la erupción del bicúspide, se genera un espacio intralveolar en distal del canino permanente, que puede favorecer el cambio de vía de erupción del canino hacia distal.

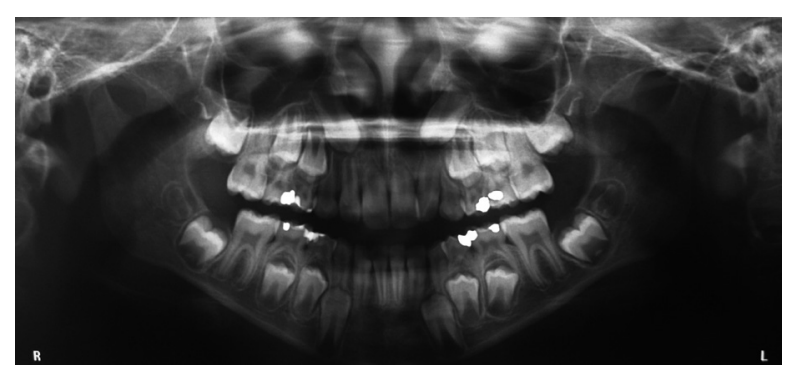

FIGURA 8. Caninos superiores en estadio 6 de Nolla Fuente: elaboración propia

\section{Exodoncia de canino deciduo y de primer molar deciduo}

Se realizan las dos exodoncias al mismo tiempo en los casos en los que se quiera agilizar la erupción del primer bicúspide y la del canino. Esto por lo general sucede en pacientes que comienzan el tratamiento en dentición mixta final.

\section{Exodoncia de canino deciduo junto con otro tratamiento activo: tracción y/o expansión}

La guía de erupción puede ser acompañada con otras terapias para aumentar su efectividad. Como se había mencionado, con la exodoncia de caninos deciduos erupcionan entre el $50 \%$ y el $78 \%$ de los caninos desplazados. Al realizar la exodoncia y usar tracción cervical al mismo tiempo, se aumenta el porcentaje de éxito entre el $80 \%$ y el $87.5 \%$, en casos de falta de espacio y relaciones oclusales o esquelética clase II. La combinación de la exodoncia de caninos y el uso de expansores tipo Hyrax, en casos de mordidas cruzadas posteriores (v. cap. 6), da como resultado que el $80 \%$ de los caninos erupcionen. El uso de barra transpalatina junto con las exodoncias hace posible la erupción en el 79\% de los casos [16]. 
A modo de resumen, en la Tabla 2 se puede observar el efecto de cada uno de los tratamientos en el canino permanente [17]. En casos donde la corona del canino se encuentre sobrepasando el eje longitudinal del lateral (Figura 9), se indica la realización de un tratamiento quirúrgico. En estos casos inicialmente se recomienda distalizar el canino para luego ejercer fuerzas verticales [15].

TABLA 2

Efectos de los tratamientos en la erupción del canino

\begin{tabular}{cl}
\hline & $\begin{array}{l}\text { Caninos en sector III e inclinación } \\
\text { mayor a 25 grados } \\
\text { Erupción: } 65.2 \%-92 \%\end{array}$ \\
\cline { 2 - 2 } $\begin{array}{c}\text { Exodoncia de canino } \\
\text { deciduo }\end{array}$ & $\begin{array}{l}\text { Caninos en sector III y IV } \\
\text { Erupción: } 64 \%\end{array}$ \\
\cline { 2 - 2 } & $\begin{array}{l}\text { Caninos en sector III y IV con apiña- } \\
\text { miento } \\
\text { Erupción: } 50 \%\end{array}$ \\
\hline $\begin{array}{c}\text { Exodoncia de primer } \\
\text { molar deciduo }\end{array}$ & $\begin{array}{l}\text { Caninos en sector III } \\
\text { Erupción: } 97.3 \%\end{array}$ \\
\hline $\begin{array}{c}\text { Uso de aparatos } \\
\text { adicionales }\end{array}$ & $\begin{array}{l}\text { Tracción cervical } \\
\text { Éxito: } 80 \%-87 \%\end{array}$ \\
\cline { 2 - 2 } & $\begin{array}{l}\text { Expansión } \\
\text { Éxito: } 80 \%\end{array}$ \\
\hline
\end{tabular}

Fuente: elaboración propia

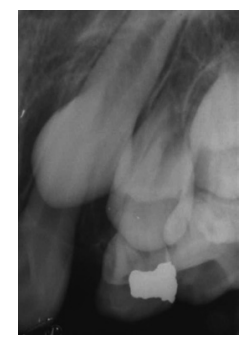

FIGURA 9. Canino que sobrepasa la mitad de la raíz del lateral

Fuente: elaboración propia

\section{Efectos secundarios producidos por caninos desplazados intralveolarmente}

La reabsorción de laterales y centrales permanentes, generada por la presencia de un canino superior desplazado o por un canino impactado, tiene una prevalencia de 12\% cuando es determinada a través del uso de radiografías tradicionales (periapicales, panorámicas). Sin embargo, con el uso de tomografías, la prevalencia aumenta al 38\%. El uso de estas nuevas radiografías incremente en un $67 \%$ la probabilidad de detectar la reabsorción en centrales y laterales. La reabsorción es más común en mujeres que en hombres, con una relación 5:1. Esto podría deberse a que el pico puberal sucede de manera más temprana y la cantidad de hormonas aumenta durante la época de erupción del canino. La reabsorción es mayor cuando los caninos están en una dirección horizontal de erupción y más cercanos a la línea media. La presencia de folículos agrandados en los caninos y laterales malformados también se relacionan en pacientes que presentan reabsorciones.

\section{ALTERACIÓN EN LA ERUPCIÓN DE CANINOS MANDIBULARES}

Los caninos mandibulares no presentan una prevalencia tan alta de impactación como los maxilares, pero su vía de erupción puede estar alterada con una inclinación mesial aumentada. La posición intralveolar del canino permanente es labial al incisivo lateral y se encuentra situado lingual y distal con respecto al canino primario. Una vez formada completamente la corona, se inicia el desplazamiento intralveolar hacia el plano oclusal, con un eje hacia mesial y lingual. El canino permanente erupciona a través del aspecto distal del lateral permanente. Su posición final en relación con el canino deciduo es más labial, con una leve inclinación mesial [18].

El canino permanente puede presentar alteraciones o cambios en su vía de erupción, asumiendo una más mesial, debido a falta de espacio, laterales permanentes rotados o lingualizados y pérdida prematura de caninos deciduos $[18,19]$. Existen otros factores, como los hereditarios (desplazamiento anormal de 
la lámina dental), quistes e incisivos inferiores proinclinados. La frecuencia del desplazamiento intalveolar de caninos permanentes inferiores es de $0.3 \%$ a 5.1\%. La observación de la secuencia y momento de la erupción, muestra que, en niños de 8 a 9 años de edad, con una inclinación mesial del canino permanente, se debe realizar supervisión y tratamiento interceptivo [20].

\section{Tratamiento}

Guía de erupción: exodoncia de canino deciduo retenido, exodoncia de canino deciduo y primer molar deciduo. Tracción ortodóntica: realizar guía de erupción junto con una cirugía de exposición del canino, colocando aditamento para traccionarlo hacia distal inicialmente y luego hacia oclusal.

\section{Casos clínicos}

Caso clínico 4: Paciente con canino inferior retenido; se realiza cirugía y tratamiento ortodóntico para llevar el canino a la cavidad oral (Figura 10).
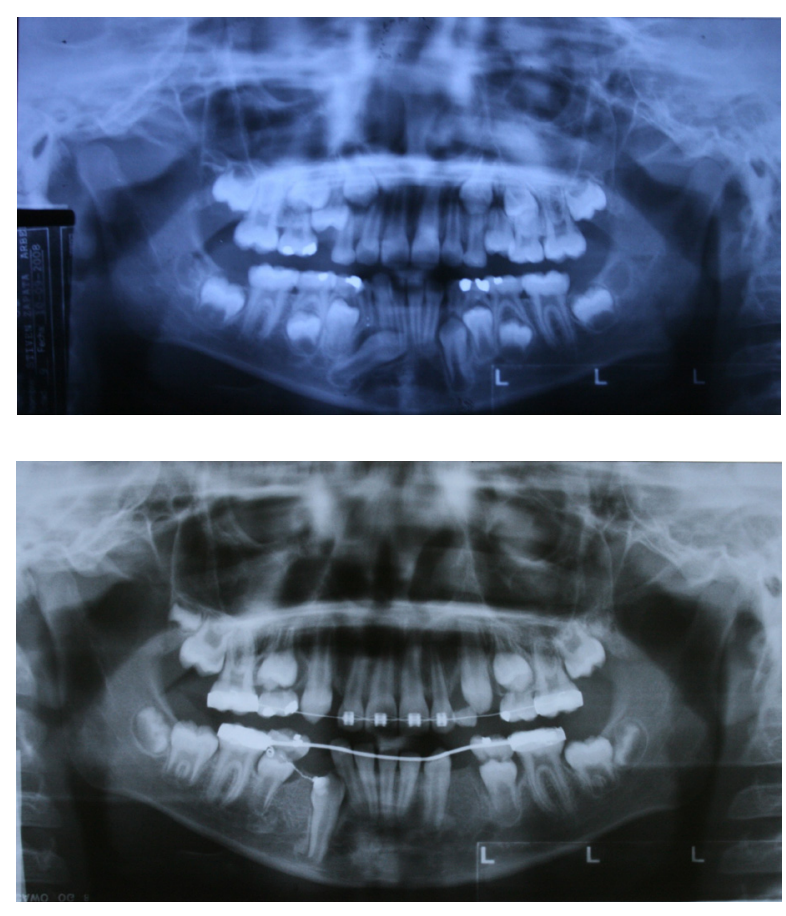

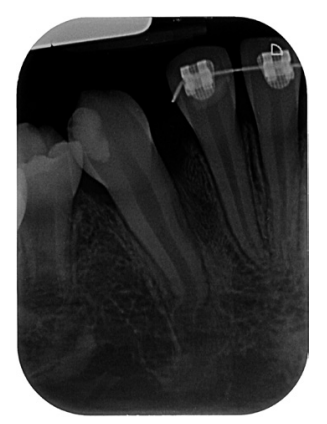

FIGURA 10. Canino inferior retenido

Fuente: elaboración propia

\section{ALTERACIÓN EN LA ERUPCIÓN DE PRIMEROS MOLARES MAXILARES}

Los primeros molares maxilares pueden presentar alteraciones en su proceso de erupción, como erupción ectópica y falla primaria en la erupción. Su erupción normal es hacia distal y vestibular. La erupción ectópica del primer molar permanente es considerada una alteración local: el diente erupciona en una posición anormal, con una dirección mesial, quedando atrapado debajo de la superficie distal del segundo molar deciduo; no llega al plano de oclusión y se establece así una discrepancia posterior. Esta anomalía tiene una prevalencia de $1.8 \%$ a $6 \%$, sin diferencias entre razas, y se presenta cuatro veces más en pacientes con paladar hendido. El 63.6\% es bilateral y el $36.4 \%$ unilateral; es más frecuente en el lado derecho que en el izquierdo, con una proporción de 3 a 1 [21, 22].

\section{Diagnóstico}

Dentro de los factores etiológicos se reportan los siguientes:

- Maxilares pequeños

- Posición posterior del maxilar relativo a la base craneal

- Patrón de erupción anormal del primer molar 
- Erupción prematura del primer molar

- Aumento en amplitud mesiodistal del segundo molar deciduo

- Mala sincronización entre el crecimiento de la tuberosidad y la erupción del primer molar

El diagnóstico se puede hacer antes de la erupción, entre los 5 y 7 años. Existen dos signos clínicos de los que el profesional debe estar pendiente durante el desarrollo de la oclusión: la erupción de las cúspides distales antes que las mesiales y el retraso en la edad de erupción [21, 22].

El grado de impactación puede ser determinado en las radiografías panorámicas a través de varias mediciones que serán descritas más adelante. La angulación se mide con base en el plano orbital (unión de infraorbital derecho e izquierdo); y el inferior, con respecto al plano gonial [21, 22].

La erupción ectópica se clasifica según la relación del primer molar con respecto al ancho del reborde marginal del segundo molar deciduo, y toma los siguientes valores:

0: normal

1: leve o impactado menos de la mitad de la amplitud del reborde

2: moderado o impactado más de la mitad de la amplitud del reborde

\section{3: severa}

Según el grado de compromiso que tenga el segundo molar deciduo, la erupción ectópica se clasifica de la siguiente manera (Figura 11):

0: No reabsorción

I: leve, reabsorción que compromete cemento y menos de la mitad de la dentina

II: moderada, con más de la mitad de la dentina comprometida

III: severa, involucra reabsorción de pulpa

IV: muy severa, afecta la raíz mesial del deciduo
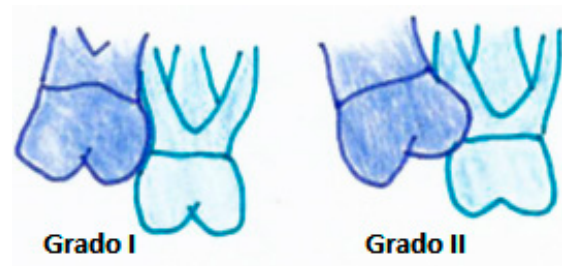

Grado II
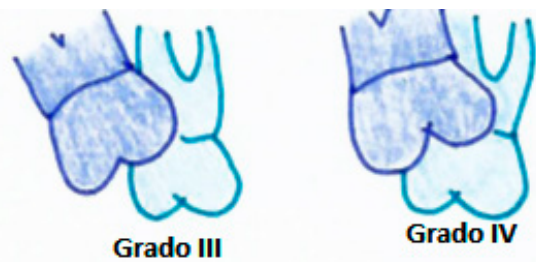

FIGURA 11. Tipos de erupciones ectópicas, grados I al IV

Fuente: elaboración propia

Se puede trazar una línea tangente a la superficie distal del segundo molar deciduo, perpendicular al plano oclusal, extendiéndose hacia apical (Figura 12). La magnitud de la impactación se puede determinar en milímetros, midiendo la distancia desde la parte más convexa del primer molar superior a la tangente. 


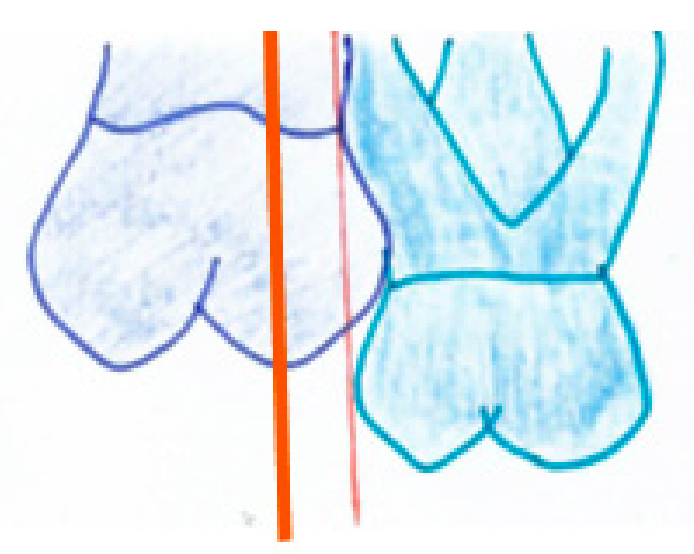

FIGURA 12. Línea tangente a la superficie distal del segundo molar deciduo perpendicular al plano oclusal

Fuente: elaboración propia

\section{Fisiopatología}

Normalmente, antes de erupcionar, el germen del primer molar está orientado hacia abajo, atrás y afuera; luego el diente asume una posición más vertical. En los casos de erupciones ectópicas, toma una dirección mesial. De los casos que se presentan, el $69.4 \%$ se autocorrige (grado I y grado iI) y el $30.6 \%$ se impacta (grado III y grado IV) [21, 22]. Se puede clasificar en reversible o irreversible, dependiendo de su severidad y evolución. En la reversible, el molar termina erupcionando y solo compromete el borde marginal en menor grado, leve o moderado. La irreversible causa exfoliación del diente deciduo y migración mesial del molar, que ocupa el lugar del segundo molar, generando disminución en la longitud del arco. Cuando el primer molar erupciona, la reabsorción del diente deciduo se detiene y se aposiciona la dentina.

\section{Tratamiento}

El tratamiento depende del grado y angulación del primer molar. El más sencillo consiste en usar alambre de latón o elásticos separadores: se colocan en el punto de contacto entre el segundo molar deciduo y el primer molar permanente, cuando el primer molar ha erupcionado parcialmente. En casos más severos, se debe desinclinar el molar para evitar la exfoliación del deciduo y, por tanto, una mayor pérdida de espacio. Esto puede realizarse cementando un botón en la superficie oclusal del primer molar, se hace un aparato fijo o removible con extensión distal para aplicar fuerza a través de un elástico o de manera directa con una hélice. Otros autores reportan la exodoncia del segundo molar deciduo, para permitir la erupción del molar y posteriormente realizar su desinclinación y distalización.

\section{GUÍA DE ERUPCIÓN SIN EXTRACCIONES}

Este tipo de terapia se recomienda en casos de pacientes que presentan apiñamiento dental primario leve (Figura 13) y que, luego de un análisis de la dentición mixta, se determina la existencia de espacio libre de Nance o espacio de Leeway, suficientes para solucionar el apiñamiento. La guía de erupción comprende tallados interproximales en caninos, primeros molares y segundos molares deciduos.

La corrección del apiñamiento se inicia mediante la realización de desgastes interproximales de los caninos deciduos, de 0.5 a $1.5 \mathrm{~mm}$ a cada lado, con lo cual se permite la alineación de los cuatro incisivos permanentes [1]. Una vez que se exfolie el canino deciduo y el canino permanente esté en proceso de erupción, se realiza el mismo tallado en los primeros molares deciduos; y se repite en los segundos molares deciduos durante la erupción del primer bicúspide, para así utilizar el espacio de Leeway o espacio libre. A lo largo del procedimiento, se debe hacer mantenimiento de espacio en la mayoría de los casos, a excepción del primer paso en el que se tallan los caninos deciduos [1, 3]. 

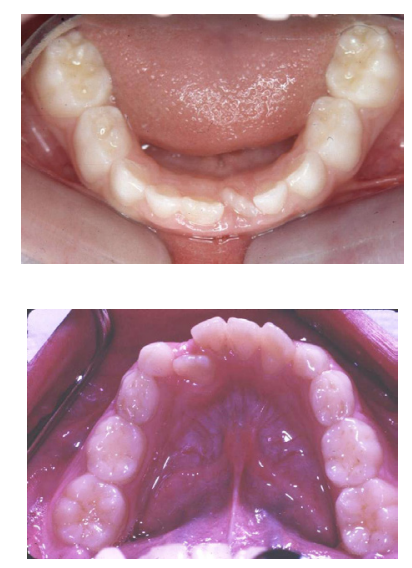

FIGURA 13. Apiñamiento leve anteroinferior

Fuente: elaboración propia

En los casos en los que, además del apiñamiento primario, la línea media se encuentra desviada, la corrección podría hacerse mediante desgaste, inicialmente solo de uno de los caninos deciduos, del lado hacia el que deba corregirse la línea media [1].

En pacientes en los que el espacio libre no es suficiente para corregir el apiñamiento primario, se tiene que elegir otro tipo de terapia para crear espacio en el arco. Esta depende de la colaboración del paciente, de la cantidad de espacio faltante, del perfil del paciente, del estado periodontal en vestibular de los incisivos inferiores y de su inclinación [1]. Las consideraciones tempranas sobre las medidas correctivas para remediar cualquier tipo de maloclusión deben ser la primera preocupación de la odontopediatría. Cualquiera que sea el método elegido, debe tener como objetivo un tiempo de tratamiento mínimo, pues no se recomienda la existencia de una relación dental, esquelética o de tejidos blandos desfavorable, durante muchos años, si es posible corregir tempranamente $[7,8,9,10]$.

Es fundamental tener en cuenta que el tratamiento de apiñamiento primario a expensas del espacio libre se logra evitando la disminución de la longitud del arco, que ocurre durante la migración mesial tardía. La longitud de arco disminuye normalmente durante la transición de dentición mixta a permanente, especialmente en la mandíbula, con un promedio de $1.8 \mathrm{~mm}$. El control de esta disminución, mediante el uso de mantenedores, provee suficiente espacio para el alineamiento de los dientes, puesto que preserva el espacio libre, según lo han reportado diversos estudios.

En un estudio realizado en 100 pacientes tratados con arco lingual, se encontró que el 68\% presentaba espacio suficiente para alinear los incisivos solo manteniendo el perímetro del arco y utilizando el espacio libre (el 76\% de los pacientes tenía un apiñamiento menor a $1 \mathrm{~mm}$ ). También se reportó un aumento de la distancia intercanina de $1.49 \mathrm{~mm}$ y de distancia interpremolar de $2.27 \mathrm{~mm}$. Este tipo de terapia posee un enfoque no extraccionista, pero puede ser criticada por generar un mayor grado de impactación de terceros molares [4]. En los casos en que la severidad del apiñamiento es mayor, como un apiñamiento moderado [3 a $5 \mathrm{~mm}$ ), se puede considerar la necesidad de realizar extracciones de dientes deciduos e incluso de dientes permanentes.

\section{GUÍA DE ERUPCIÓN CON EXTRACCIONES DE DIENTES PRIMARIOS}

El procedimiento de guía de erupción puede comprender las extracciones secuenciales de dientes deciduos, en los casos en que un análisis de dentición mixta muestre una discrepancia dentoalveolar moderada (3 a $5 \mathrm{~mm}$ ) y que el espacio libre sea suficiente para solucionarla. Para realizar este tipo de procedimiento, el profesional debe tener conocimientos adecuados acerca del crecimiento, desarrollo y sobredesarrollo de la oclusión. Los factores que definen el momento óptimo para la exodoncia son el efecto de la extracción del diente primario en la erupción del sucesor permanente; la formación radicular al momento de emergencia, y el tiempo que 
lleva lograr los diferentes estadios de desarrollo radicular.

En casos de apiñamiento moderado de incisivos (3 a $5 \mathrm{~mm}$ ), la terapia se inicia con las extracciones de caninos deciduos para permitir la alineación de los incisivos. Paralelamente, se debe usar un mantenedor de espacio fijo o removible que evite la lingualización de los incisivos y su distalización al sitio de la extracción. En el arco superior se puede usar mantenedor solo en caso de que el overjet y el overbite no controlen la posición de los incisivos, o cuando los molares no tengan una adecuada interdigitación. Sin embargo, se aconseja usar siempre el mantenedor.

Si la discrepancia óseodentaria lleva a una erupción no armónica de los incisivos, estos pueden migrar a mesial desviando la línea media. Es por esto que la guía de erupción empieza con la extracción unilateral del canino del lado opuesto a la desviación de la línea media. Esta se corrige espontáneamente $y$, una vez que esto ha ocurrido, se hace la exodoncia del otro canino [1].

Logrado el alineamiento de los cuatro incisivos, se procede a la exodoncia del primer molar deciduo, debido a que el apiñamiento que estaba en la zona anterior se traslada a la de los caninos y premolares permanentes [9]. La terapia termina con la exodoncia de los segundos molares deciduos para facilitar la erupción de los premolares.

Es importante recordar que para que este procedimiento sea exitoso y no se genere apiñamiento en la zona posterior al terminar las extracciones, el resultado del análisis de dentición mixta previo a la terapia debió mostrar que el espacio libre era suficiente para corregir el apiñamiento anterior. En los casos en que el espacio libre es insuficiente, se puede combinar la guía de erupción con la utilización de aparatos que creen espacios en los arcos, en vez de emplear mantenedores de espacio.
El tallado y las extracciones de dientes deciduos son procedimientos que se pueden requerir, en diferentes momentos y de manera combinada, en el arco maxilar y en la mandíbula.

Cuando se realiza exodoncia de caninos deciduos, los incisivos pueden asumir una posición más lingual, con la consecuente disminución de la longitud del arco, además de la mesialización de los primeros molares permanentes [9] y la profundización de la mordida. Para evitar estos efectos, el procedimiento debe acompañarse de mantenedores de espacio [10] durante todo el proceso.

\section{GUÍA DE ERUPCIÓN MEDIANTE EXTRACCIÓN SERIADA}

Se puede emplear la extracción seriada, como parte de los procedimientos que involucra la guía de erupción. Esta ha sido descrita por autores como Gafhari [1] para el tratamiento de apiñamientos severos. Se define como la extracción secuencial de dientes primarios terminando con la extracción de dientes permanentes (premolares), con la finalidad de guiar la erupción de caninos y segundos premolares, en casos de discrepancias dentoalveolares severas (más de $5 \mathrm{~mm}$ por hemiarcada) $[7,8]$.

El término extracción seriada viene desde Francia en el siglo XVIII con Robert Brunon, quien realizaba la remoción de dientes deciduos para darle más espacio a los permanentes. En el siglo xx, la terapia de extracciones perdió seguidores cuando Edward Angle aseguró que las extracciones eran mutilaciones; sin embargo, en 1929, Kjellgren reabrió la discusión en Estocolmo y acuñó el término de "extracción seriada" [4].

En 1947, se publica el procedimiento en la Sociedad Ortodóntica Europea: Hotz desde Suiza y Kjellgran en Suecia describen de manera detallada la secuencia del procedimiento. 
Kjellgren, como ya se dijo, usó el término de "extracción seriada", mientras que Hotz impuso un término más descriptivo: "guía de erupción dental por medio de extracción”. Por su parte, Dewel en Estados Unidos manejaba el término de "extracciones en arcos deficientes", pero luego de escuchar a Kjellegren lo cambió por el de "extracción seriada" [4].

Sin importar el término que se emplee, existen cuatro aspectos importantes para tener en cuenta antes de comenzar este tipo de procedimiento $[18,23]$ :

a. Conocimiento profundo de crecimiento y desarrollo, y desarrollo de oclusión.

b. Diagnóstico correcto, como resultado de historia clínica y elementos diagnósticos (radiografías, modelos y figuras).

c. La dentición en desarrollo debe recibir supervisión continua por parte del odontólogo y/o especialista.

d. Ningún diente se debe remover sin realizar un análisis de modelos exacto y preciso.

e. El análisis de modelos debe repetirse antes de cualquier exodoncia, una vez iniciada la secuencia. Esto es imprescindible pues los análisis de dentición mixta presentan imprecisiones que dan lugar a diagnósticos de discrepancias dentoalveolares severas para casos de discrepancias moderadas, en los que la exodoncia de los premolares no es necesaria.

f. El tratamiento de ortodoncia debe comenzar cuando esté indicado. La decisión de extraer en dentición decidua es más difícil que en la dentición permanente, debido al potencial de crecimiento y la imposibilidad de predecirlo [19].
Hay varias consideraciones que influencian la decisión de empezar la guía de erupción con extracción seriada: el patrón esquelético; la relación de los tejidos blandos extraorales; la oclusión; la posición de incisivos (overjet, overbite e inclinación); la posición de los molares; el tiempo de emergencia en boca de caninos y premolares (determinado por la formación radicular, la cantidad de hueso sobre el germen y el nivel de reabsorción del diente deciduo); la secuencia de erupción; la inclinación de los gérmenes; la presencia de interferencias oclusales, y el estado del arco dental (cantidad de discrepancia dentoalveolar que exista mesial al primer molar; Figura 14). Moyers señala que es necesaria una discrepancia de al menos 5 $\mathrm{mm}$ en cada cuadrante para dar paso a este tipo de terapia. Sin embargo, en ciertos casos, una discrepancia de $3 \mathrm{~mm}$ en cada cuadrante obliga a una extracción seriada debido a que, después de todos los análisis, se determina que es posible crear el espacio [1, 24-31].

El momento para realizar la extracción seriada se basa en la formación dental y, por tanto, debe individualizarse en cada paciente. Además, el orden de las extracciones varía con la secuencia de erupción de caninos y premolares. En el arco superior, los primeros bicúspides erupcionan antes que el canino; en el arco inferior, ocurre al contrario. Esto implica alterar la secuencia para retardar la erupción de los caninos, al extraer los deciduos antes de que los permanentes alcancen los tres cuartos de raíz formada. Cabe señalar que estas exodoncias además sirven para el autoalineamiento de los incisivos permanentes [1, 7, 24].

Otra manera de llevar a cabo el procedimiento es acelerando la erupción de los premolares mediante la exodoncia del primer molar deciduo, cuando este ha alcanzado dos tercios de la raíz formada (aproximadamente a los 9 años de edad). 


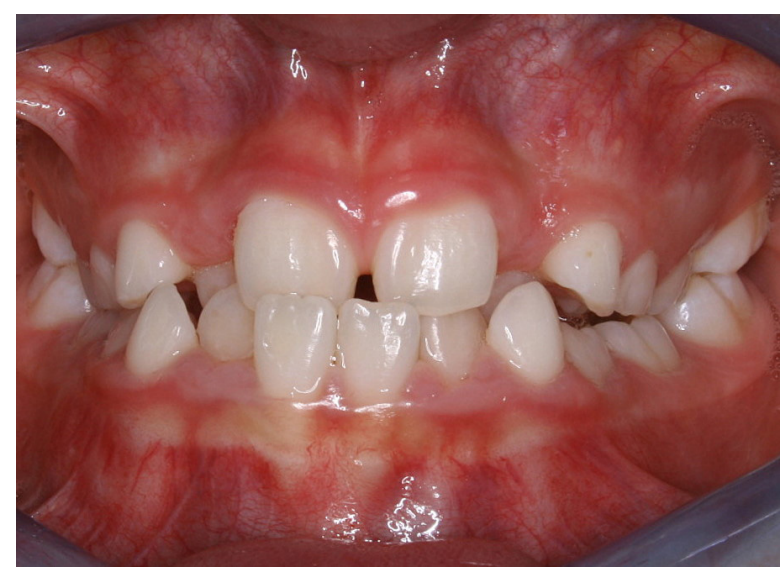

FIGURA 14. Discrepancia dentoalveolar

Fuente: elaboración propia

La secuencia de las extracciones depende de la severidad del apiñamiento anterior, la secuencia de erupción de caninos y premolares, y el desarrollo dental del paciente [32-35], que -recordemos - no se refiere a la edad cronológica. La extracción seriada en el maxilar no presenta tantos problemas adicionales porque el cierre espontáneo de los espacios de las extracciones se facilita debido a las inclinaciones axiales de los dientes y a la secuencia normal de erupción. Situación contraria a la de la mandíbula, donde puede quedar un espacio residual [36-40].

El objetivo de usar la extracción seriada es disminuir la severidad de la maloclusión en desarrollo, interceptando el inicio de una deficiencia en la longitud de arco. Además, en ciertos casos se logra que el tratamiento de ortodoncia correctiva sea más fácil, y que tenga una mecanoterapia menos complicada y más corta durante la adolescencia [7, 25]. Un tratamiento que en la mayoría de los casos es indispensable para la corrección de las inclinaciones dentales inapropiadas y el cierre de los espacios remanentes.

El propósito final de la extracción seriada clásica es acelerar la erupción del primer bicúspide, para que erupcione antes que el canino, y así pueda ser extraído tempranamente. Esto permite que el canino erupcione en una posición adecuada en el arco superior, pues en este la secuencia favorece la extracción. A través del tiempo, diversos autores han asegurado que este procedimiento beneficia la estabilidad de las posiciones dentales. Dale, por ejemplo, consideraba lógico que un diente, al completar su formación en el sitio donde quedará luego del tratamiento, asegura su estabilidad. Por otro lado, Tweed creía que un autoalineamiento temprano debía dar como resultado una estabilidad mayor. Sin embargo, en un estudio realizado por Little en 1990, con una muestra de 30 pacientes evaluados 10 años después de la remoción de la retención, se encontró que la corrección del apiñamiento temprano mediante extracción seriada no mejora, a largo plazo, el pronóstico de la estabilidad. Incluso se reportó apiñamiento luego de 10 años [26].

Este procedimiento puede durar 5 años, comenzando a los 7 años, después de la erupción de incisivos, y terminando con la erupción de bicúspides, alrededor de los 12 años. A pesar de su extensión, el intervalo entre cada etapa del tratamiento (secuencia de exodoncias) puede ser de 12 meses [7, 27 -29], y las revisiones del paciente deben hacerse cada mes y medio como máximo.

\section{INDICACIONES [8]}

- Pacientes con características extraorales y esqueléticas bien balanceadas en sentido sagital, vertical y transversal.

- Pacientes con protrusión moderada dentoalveolar o con incisivos rectos.

- Pacientes con oclusión sagital clase I, con overbite moderado o leve verticalmente, y transversalmente sin mordidas cruzadas o desviaciones de la línea media.

- Pacientes con arcos dentales sin espacio libre, sin espacio distal de seis y con apiñamiento severo (Figura 15). 


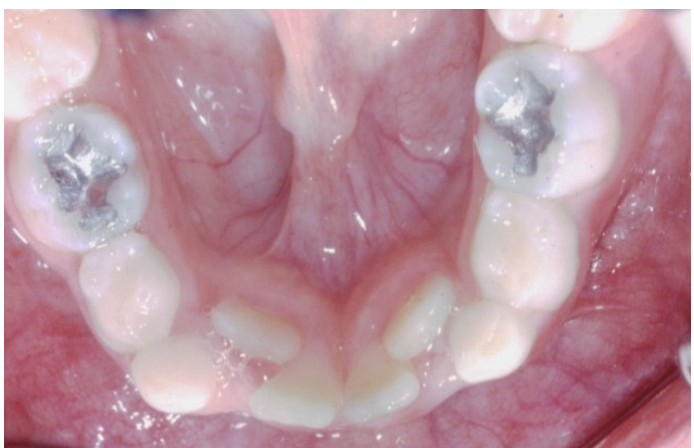

FIGURA 15. Apiñamiento severo anteroinferior

Fuente: elaboración propia

\section{CONTRAINDICACIONES [8, 13]}

- Pacientes con características extraorales y esqueléticas de clase II o clase III. Verticalmente, con hipodivergencia o hiperdivergencia (mordida abierta o mordida profunda) y con perfil recto o cóncavo [24].

- Pacientes con incisivos muy rectos o lingualizados [24].

- Pacientes con alteraciones dentales: dientes malformados [24], posición mesial de canino en relación con el lateral, diastema de línea media (debe cerrarse antes de la extracción), inclinación a mesial de la raíz del lateral por el empuje del canino permanente, rotación mesiolabial del incisivo lateral superior, agenesia y forma atípica de raíz y corona de algún diente permanente [30].

- Pacientes con alteraciones transversales como mordidas cruzadas y discrepancias de líneas medias.

- Pacientes con arcos dentales con suficiente espacio de Leeway, con espacio distal de 6 y discrepancias de tamaño dental, arcos menores a 3 o $4 \mathrm{~mm}$ [24]

Dale señala como caso ideal para la extracción seriada al paciente con herencia de discrepancia dentoalveolar severa, con escalón mesial que lleva a clase I molar, con overjet y overbite mínimos, con patrón facial ortognático o leve protrusión maxilo-mandibular y maloclusión clase I (Figura 16) [7, 29, 31-33].
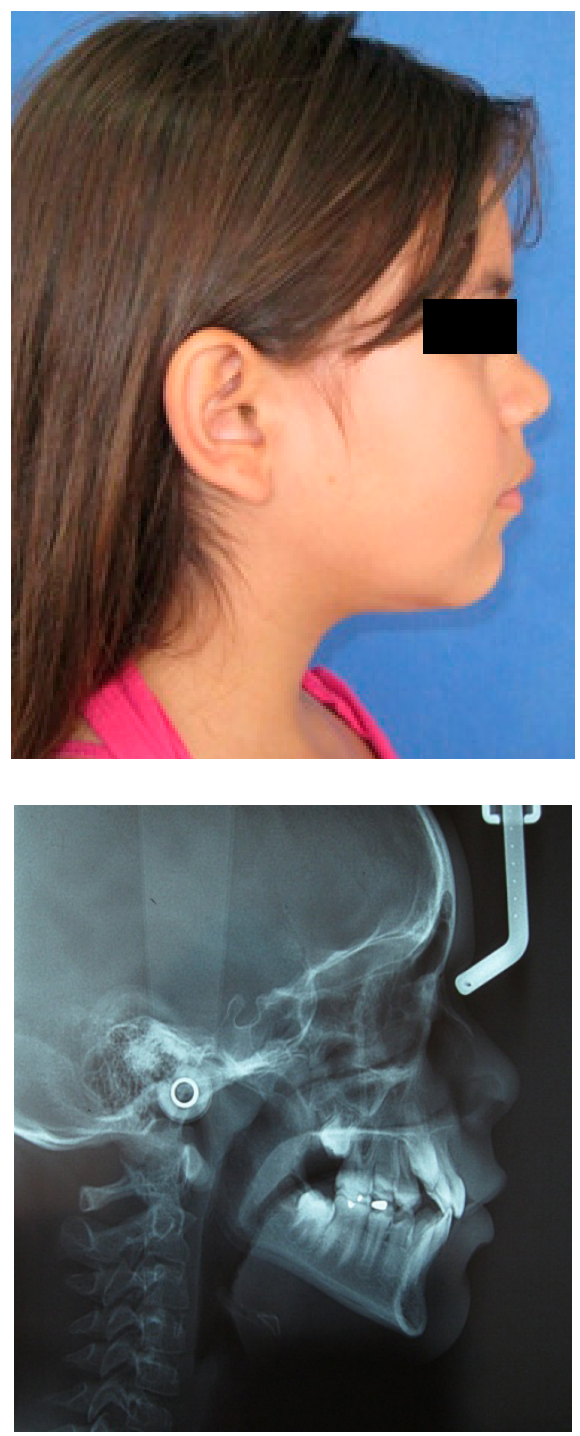

FIGURA 16. Paciente clase I

Fuente: elaboración propia

Este procedimiento puede aplicarse en otras maloclusiones, pero con precaución, e idealmente por parte de un especialista que pueda aplicar un tratamiento coadyuvante interceptivo de manera paralela. No es recomendable en pacientes clases II división 2: aplana el perfil debido al mentón prominente característico de estas maloclusiones. Se recomienda exodoncia de primeros molares permanentes en casos de 
mordida abierta esquelética con plano mandibular empinado, mandíbula retrognática, aumento de la dimensión vertical, protrusión maxilomandibular, rama corta, ángulo goniaco aumentado, aumento de erupción de molares y base craneal posterior corta, pues se obtendría el mismo efecto que la intrusión de molares. En otros casos, se extraen los primeros molares deciduos y los premolares para permitir la mesialización de los posteriores [7]. La exodoncia de caninos deciduos inferiores puede agravar la mordida profunda; si además se extrae el primer molar deciduo antes de que el bicúspide sobrepase la mitad de la formación radicular, se generaría una mayor profundización [7].

\section{VENTAJAS}

- Autoalineación de incisivos, que aumenta la estabilidad, disminuye el tiempo de tratamiento ortodóntico, facilita la higiene oral, la salud de tejidos de soporte y el movimiento fisiológico de los dientes.

- Reducción considerable del tiempo de tratamiento debido al componente de autocorrección.

- Disminución en el tiempo de retención.

- Menor daño periodontal y alveolar.

- Diminución de los problemas psicológicos en el paciente.

- Menor carga sobre unidad de anclaje.

- Reducción de la severidad del apiñamiento.

- Aceleración del tratamiento ortodóntico.

- Evita que los dientes en proceso de erupción se impacten y erupcionen sin banda de encía adherida $[4,24,25,30]$.

\section{DESVENTAJAS}

- Retroinclinación y extrusión de incisivos, que genera mordida profunda (en los casos en que no se utilice aparatología de control).
- Aplanamiento del perfil facial, con concavidad en la zona del tercio inferior (tercio inferior en forma de plato) [7, 32].

- Inclinación mesial de posteriores, principalmente el segundo premolar. De no corregirse con ortodoncia, genera problemas periodontales, espacios remanentes, dientes inclinados al sitio de exodoncia y profundización de mordida.

- Incisivos lingualizados.

- Retardo en la erupción de permanentes en los casos en que el procedimiento se realice de manera inadecuada.

- Retraso del crecimiento mandibular. Sin embargo, el estudio de Whitney [11], en 851 pacientes tratados y 23 controles, no registró cambios en la dirección ni en el nivel de crecimiento entre los pacientes con extracciones y aquellos sin extracciones [27].

- Retención prolongada o permanente, que asegure el mantenimiento de los resultados [30].

La extracción seriada podría resultar un mal procedimiento si no se realiza de manera adecuada e individual; es decir, no puede ser aplicada como una receta de cocina simplificando los procesos [8], es peligroso hacerlo. Por tanto, es importante involucrar la evaluación de todas las características que influyen en el diagnóstico adecuado, y contar con conocimientos de anatomía, crecimiento y desarrollo, y fisiología muscular para tomar decisiones durante el periodo de desarrollo [7, 28, 30, 32].

Los aparatos usados en este procedimiento son el arco lingual, el botón palatino y la placa de Hawley con plano anterior, en casos de mordida profunda [1].

Tradicionalmente, las alternativas de secuencias para la exodoncia de deciduos y permanentes han sido descritas a la manera de recetas de cocina para fomentar la memoria [7]. Pero la 
secuencia a emplearse es individual y propia de cada paciente, y depende de su estadio de desarrollo dental, de la posición de gérmenes y de su tipo de crecimiento.

\section{SECUENCIA DE EXODONCIAS Y JUSTIFICACIÓN}

a. Extracciones de caninos deciduos (Figura 22):

- Proporcionar espacio para la alineación espontánea de los incisivos.

- Cuando el lateral superior está a la mitad de su proceso eruptivo (7 a 8 años) y la raíz del canino permanente aún no está en estadio 7.

b. Extracciones de los primeros molares deciduos:

- Acelerar la erupción del primer premolar.

- Cuando el desarrollo radicular del primer premolar está en la mitad (10 a 11 años) $[1,7,29]$.

c. Extracción de primer premolar:

- Proveer espacio para los caninos permanentes.

- Cuando la erupción del canino está en proceso (estadio 7 o más), se debe examinar mediante palpación o radiografía (10-12 años) [1, 24, 33].

\section{CASOS CLÍNICOS}

\section{Caso clínico 1}

Paciente clase I esquelética y dental con overjet y overbite normales, apiñamiento anteroinferior moderado a severo; radiográficamente, los permanentes aún no tienen la mitad de la raíz formada y el bicúspide va a erupcionar antes que el canino. El objetivo es lograr la autoalineación de los incisivos [1, 7, 29]. Se puede iniciar con la exodoncia del canino deciduo (Figuras 17 y 18) y esperar el desarrollo. Con esta primera exodoncia, el canino permanente retrasa su erupción, pues queda sin espacio debido a la autoalineación de los incisivos. Meses después de las exodoncias, una vez que el apiñamiento anterior haya mejorado y los bicúspides presenten más de la mitad de la raíz formada, se continúa con la extracción de los primeros molares deciduos con el fin de acelerar la erupción del bicúspide [1, 7, 29] (Figura 19). A continuación, se realiza la exodoncia de primer bicúspide antes de que los caninos erupcionen [1, 7] (Figura 20).

Cuando ya hayan erupcionado los segundos bicúspides completando la erupción de la dentición permanente, se procede con el tratamiento de ortodoncia correctiva para corregir relaciones dentales como mordidas profundas, caninos inclinados a distal, inclinación mesial de los segundos bicúspides, cierre de espacios residuales, y para lograr una relación molar clase I [1, 7, 29] (Figura 21). La retención se maneja de manera convencional, como cualquier otro tratamiento de ortodoncia $[1,7,29]$.
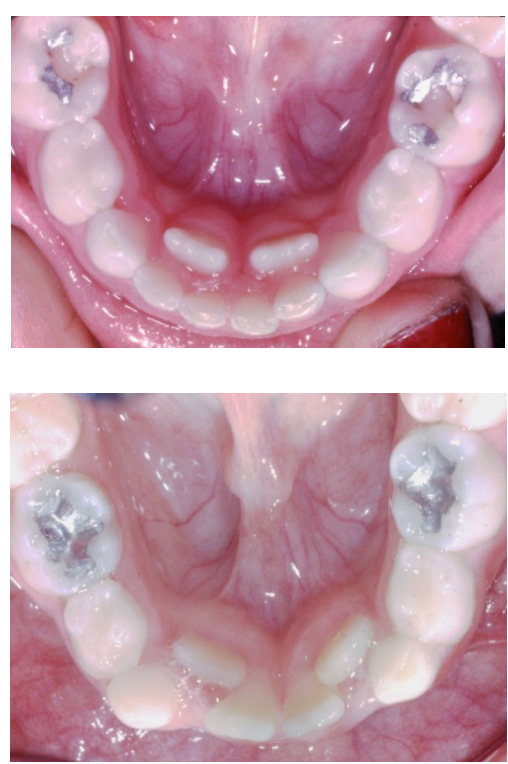

FIGURA 17. Proceso de erupción de centrales y laterales con apiñamiento por discrepancia en la longitud de arco

Fuente: elaboración propia 


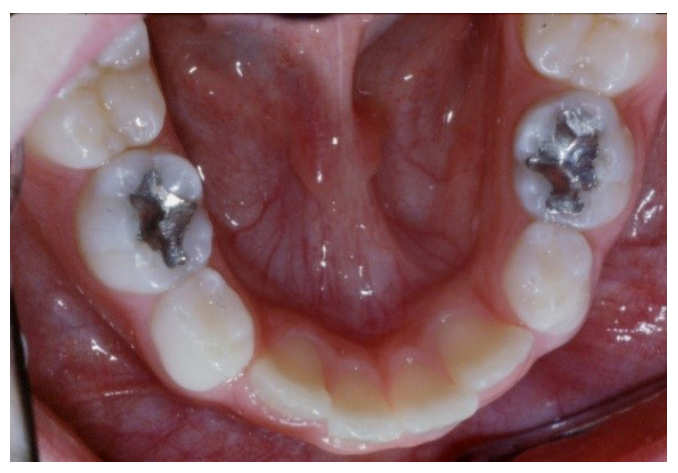

FIGURA 19. Incisivos alineados luego de exodoncia de caninos e indicación de exodoncia de primeros molares

FIGURA 18. Exodoncia de caninos deciduos

Fuente: elaboración propia
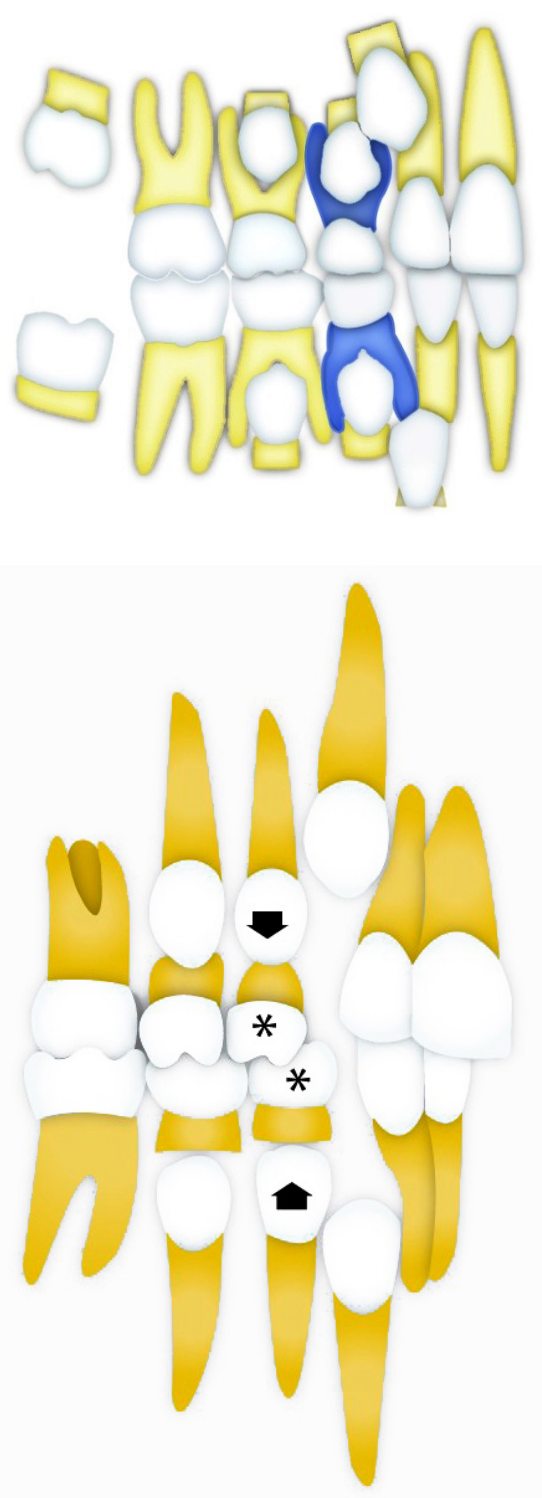

Fuente: elaboración propia
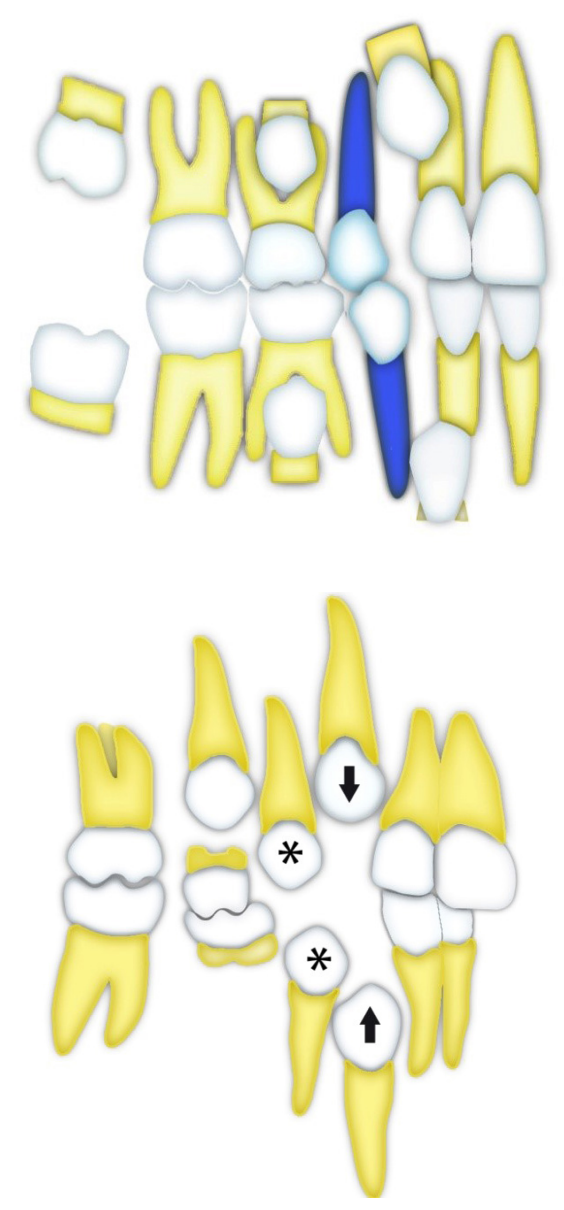

FIGURA 20. Exodoncia de primeros premolares antes de erupción de caninos

Fuente: elaboración propia 

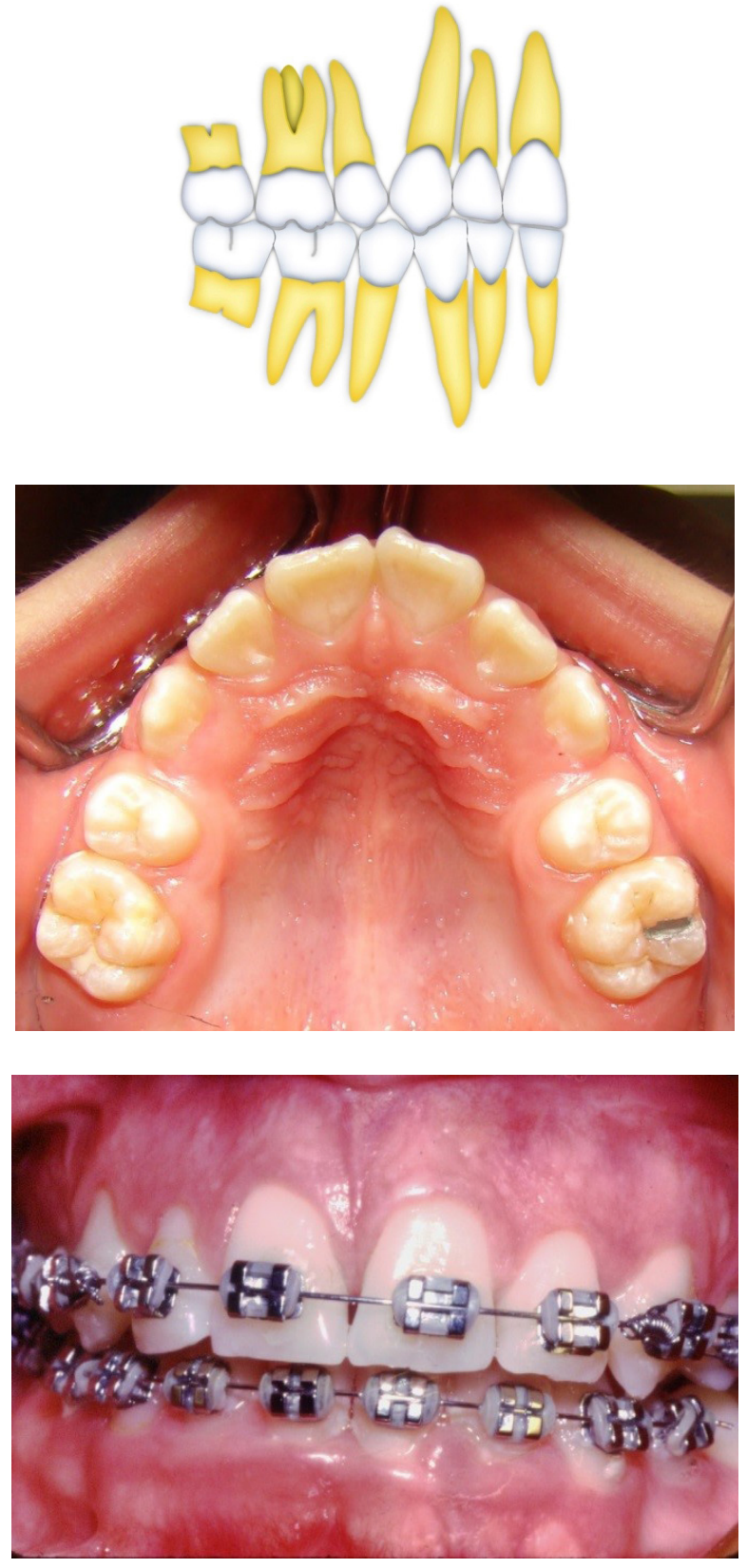

FIGURA 21. (A-B) Angulaciones de las raíces en los dientes próximos a la extracción y presencia de espacios residuales. (C) Tratamiento de ortodoncia posterior a extracción seriada.

Fuente: elaboración propia

\section{Caso clínico 2}

Paciente clase I esquelética y dental con overjet y overbite normales, con discrepancia dentoalveolar superior e inferior severa, que presenta exfoliación prematura de caninos deciduos a causa de la erupción de los laterales por la discrepancia severa de espacio. Radiográficamente, los bicúspides están más adelantados en su erupción que los caninos y tienen formada la mitad de la raíz. Se inicia con la exodoncia de los primeros molares deciduos [1, 7, 29] (Figura 22), para luego proceder con la exodoncia de primeros bicúspides una vez que hayan erupcionado y así permitir la erupción de los caninos. Finalmente, se realiza el tratamiento de ortodoncia correctiva para alineamiento y ajuste de oclusión, en los casos en que sea necesario (Figura 23).

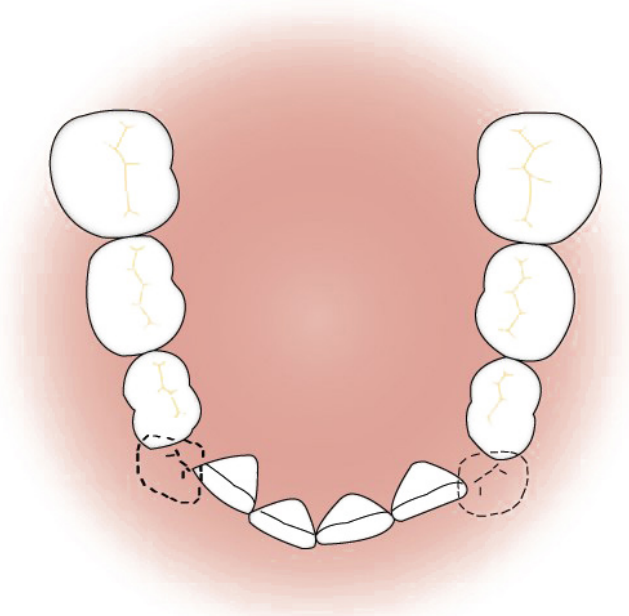

FIGURA 22. Exfoliación prematura de caninos deciduos por erupción de laterales

Fuente: elaboración propia

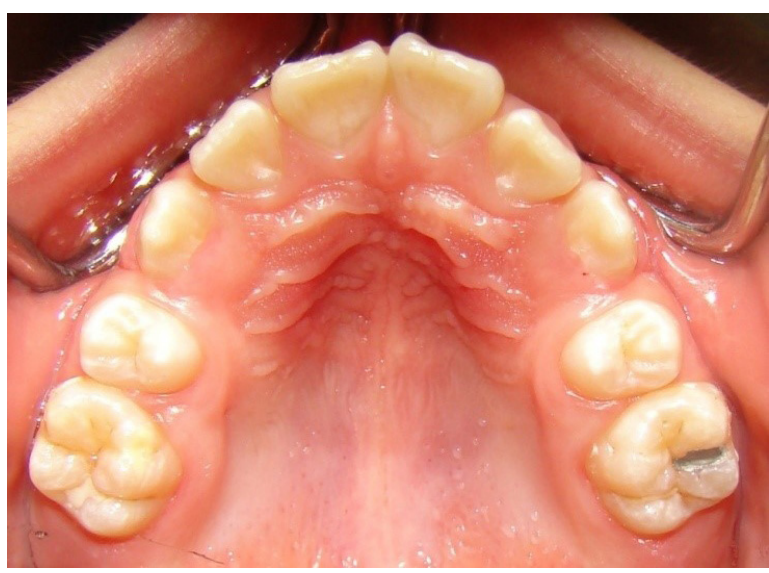

FIGURA 23. Caninos en erupción luego de exodoncia de primeros premolares

Fuente: elaboración propia 


\section{Caso clínico 3}

Paciente clase I esquelética y dental con apiñamiento moderado y protrusión dentoalveolar. Radiográficamente, las coronas de caninos y bicúspides permanentes están al mismo nivel intraalveolar, pero el canino presenta mayor formación radicular y está erupcionando más rápido que el bicúspide. Se inicia con la exodoncia de los primeros molares con el objetivo de que el bicúspide erupcione primero [1, 7, 29] (Figura 24). Se continúa con la exodoncia de los caninos deciduos y de los primeros bicúspides, al mismo tiempo [1, 7, 29]. El tratamiento de ortodoncia correctiva se aplica para lograr el cierre del espacio que queda después de la exodoncia de bicúspides y que puede ser utilizado para la corrección de la protrusión dentoalveolar.

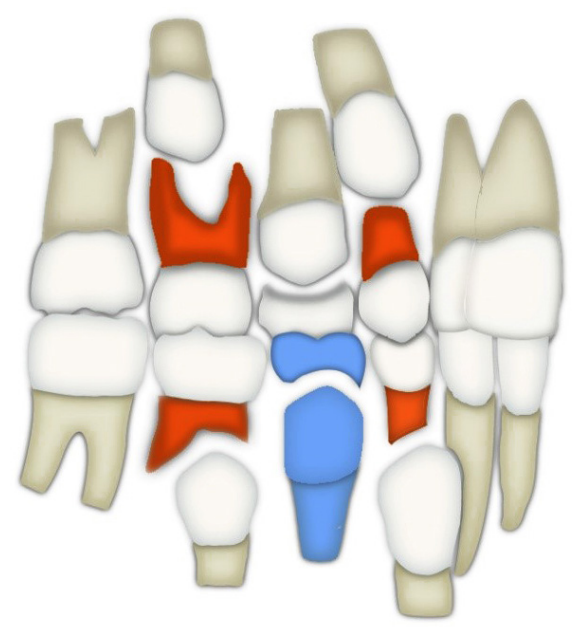

FIGURA 24. Exodoncia de primeros molares deciduos antes de caninos deciduos

Fuente: elaboración propia

\section{Caso clínico 4}

Paciente clase I esquelética y dental con discrepancia severa superior e inferior. Radiográficamente, se observa que el canino permanente va a erupcionar antes que el primer bicúspide, por lo tanto, se realiza la exodoncia del primer molar deciduo y la enucleación de los primeros premolares para asegurar que el canino erupcione hacia distal [1, 1, 29] (Figura 25). A continuación, se procede con la exodoncia de los caninos superiores y del primer bicúspide superior. Es importante tener en cuenta que, en la mandíbula, el bicúspide erupciona después del canino; en el maxilar, la secuencia se invierte y casi nunca se requiere de una enucleación [1, 7, 29] (Figura 26).

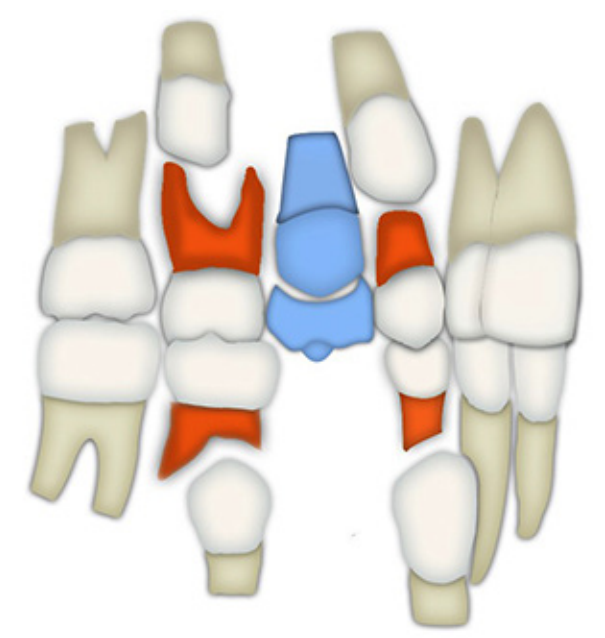

FIGURA 25. Exodoncia de los primeros molares deciduos y enucleación de los primeros molares permanentes

Fuente: elaboración propia

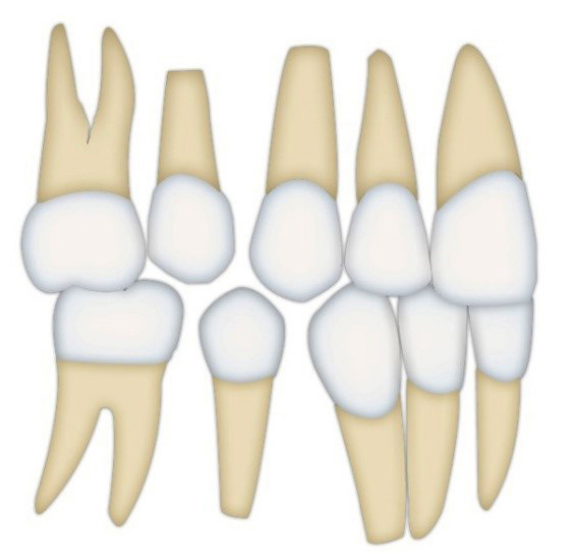

FIGURA 26. Espacios residuales e inclinación radicular de posteriores luego de extracción seriada

Fuente: elaboración propia 


\section{ASPECTOS RELEVANTES DE LA EXTRACCIÓN SERIADA}

Aunque, luego de la extracción seriada, el apiñamiento usualmente se reduce durante la dentición mixta y permanente temprana, el estudio realizado por Little, con una evaluación longitudinal de los pacientes, muestra que la extracción seriada no tiene mejores resultados que las exodoncias tardías o extracciones terapéuticas de los premolares [42]. E] caso ideal para la extracción seriada (pérdida prematura de canino deciduo, desviación extensa de la línea media, incisivos irregulares o impactados, recesión gingival en superficie labial de centrales inferiores y medidas de longitud de arco desfavorables) es fácil de reconocer por no tener grandes deficiencias en el desarrollo. Sin embargo, distinguir entre un caso límite y uno ideal supone bastante experiencia clínica $[18,23]$.

Los efectos de la extracción seriada han sido ampliamente estudiados. Por ejemplo, en el estudio de Yoshira et al, realizado en
32 mujeres, midiendo la amplitud dental, la longitud de arco y el índice de irregularidad, se encontró que este último disminuía con la extracción seriada: las pacientes comenzaron con un índice de irregularidad de $10.25 \mathrm{~mm}$ y terminaron con $2.29 \mathrm{~mm}$. Solo se halló un mayor índice en los casos de dientes de gran tamaño [40-42]. También se reportó la presencia de un espacio residual, de $4.56 \mathrm{~mm}$ en promedio, en el sitio de la extracción.

En otro estudio, este autor determinó el tipo de movimientos que sufren los incisivos y los molares durante la extracción seriada: el primer molar se inclina primero a mesial y luego a distal, y el incisivo se inclina a distal, solucionando el apiñamiento. El canino se mueve de 1.73 a $2.35 \mathrm{~mm}$ a distal y el segundo premolar lo hace a mesial entre 2.8 y $2.91 \mathrm{~mm}$. Cabe apuntar que los resultados de estos estudios deben tomarse con precaución, puesto que en ninguno se describen las características basales de la muestra, como relación esquelética, overjet y overbite [42-45].

\section{REFERENCIAS}

[1] Ghafari J. Early treatment of dental arch problems. II. Guidance in alignment and occlusion. Chicago: Quintessence International. 1986;17(8):489.

[2] Bishara S. Ortodoncia. Ciudad de México: McGrawHill; 2003.

[3] Hotz R. Guidance of eruption versus serial extraction. Am. J. Orthod. Dentofacial Orthop. 1970;58(1):1-20.

[4] Gianelly A. Treatment of crowding in the mixed dentition. Am. J. Orthod. Dentofacial Orthop. 2002 jun;121(6):569.

[5] Gianelly A. Arch width after extraction and non extraction treatment. Am. J. Orthod. Dentofacial Orthop. 2003;123(1):25.

[6] Isaacson RJ. Increase in arch perimeter due to orthodontic expansion. Am. J. Orthod. Dentofacial Orthop. 1991;100(5):421-427.

[7] Dale JG. Vip interview Jack G. Dale. Interview by Samir E Bishara. World J. Orthod. 2006 primavera;7(1):95-99.

[8] Dale JG. Serial extraction. Nobody does that anymore! Vip interview Jack G. Dale. Interview by Samir E Bishara. 2000 may;117(5):564-566.

[9] Kau C, et al. Kau C, Durning P, Richmond S, Miotti A, Harzer W. Extracciones como una forma de intercepción en una dentición en desarrollo. Un ensayo clínico controlado. J. Orthod. 2004;31:107-114. 
[10] Boley J. Serial extraction revisted: 30 years in retrospect. Am. J. Orthod. Dentofacial Orthop. 2002 jun;121(6):575.

[11] Nolla CM. The development of the permanent teeth. J. Dent. Child. 1960;27:254-266.

[12] Power S, Short M. An investigation into response of palatally displaced canines to the removal of deciduous canines and an assessment of factors contributing to favorable eruption. Britsh. J. Orthod. 1993;20:215-223.

[13] Lindauer S, Rubenstein L, Hang W, Andresen W, Issacson R. Canine impactation identified early with panoramic radiographs. J. Am. Dent. Assoc. 1992;123(3):91-97.

[14] Ericson S, Kurol J. Early treatment of palatally erupting maxillary canines by extraction of the primary canines. Eur. J. Orthod. 1988;10:283.

[15] Botero L, Botero P. Diagnóstico y tratamiento temprano de la malposición intralveolar de caninos permanentes. Rev. Fac. Odont. U de A. 2002;13(2):21-29.

[16] Baccetti T, Leonardi M, Armi P. A randomized clinical study of two interceptive approaches to palatally displaced canines. Eur. J. Orthod. 2008;30(4):381-385.

[17] Chaushu S, Kaczor-Urbanowicz K, Zaduruska M, Becker A. Predisposiong-factors for severe incisor root resorption associated with impacted maxillary canines. Am. J. Orthod. Dentofacial Orthop. 2015;147:5260.

[18] Bonetti G, Zarini M, Parenti S, Marini I, Gatlo M. Preventive treatment of ectopic ally erupting maxillary permanent canines by extraction of deciduous canines and first molars: A randomized clinical trial. Am. J. Orthod. Dentofacial Orthop. 2011;139:316-323.

[19] Nanda SK. The developmental basis of occlusion and malocclusion. Chicago: Quintessence International; 1983.

[20] Celikoglu M, Kamak H, Oktay H. Investigation of transmigrated and impacted maxillary and mandibular canine teeth in an orthodontic patient population. J. Oral Maxillofac. Surg. 2010 may;68(5):1001-1006. doi: 10.1016/j.joms.2009.09.006.

[21] Chintakanon K, Boonpinon P. Ectopic eruption of first permanent molars: prevalence and etiological factors. Angle Orthod. 1998;68(2):153-160.

[22] Barberia-Leache E, Suarez-Clúa M, Saavedra-Ontiveros I. Ectopic eruption of the maxillary first permanent molar: characteristics and occurrence in growing children. Angle Orthod. 2005;75:610-615.

[23] Dewel B. Serial extraction: precautions limitation ad alternatives. Am. J. Orthod. Dentofacial Orthop. 1976;69(1):95.

[24] Dewel B. Serial extraction, second premolars and diagnostic precautions. Am. J. Orthod. Dentofacial Orthop. 1978;73(5):575.

[25] Grewe JM, Hermanson PC. Influence of severity of malocclusion on the duration of orthodontic treatment. Am. J. Orthod. Dentofacial Orthop. 1973;63(5):533-536.

[26] Moorees et al. 26. Moorrees C, Fanning E, Gron A. Consideration of dental development in serial extraction. Angle Orthod. 1963;33:44-54.

[27] Little R Et al. Little R, Riedel R, Stein A.Mandibular arch length increase during the mixed dentition. Postretention evaluation of stability and relapse. Am. J. Orthod. Dentofacial Orthop. 1990;97(5):393-404.

[28] Ringenberg QM. Influence of serial extraction on growth and development of the maxilla and mandible. Am. J. Orthod. Dentofacial Orthop. 1967;53:19-26

[29] Dewel B. Prerequisites in serial extraction. Am. J. Orthod. Dentofacial Orthop. 1969 jun;55(6):533.

[30] Graber T. Serial extraction: A continuous diagnostic and decisional process. Am. J. Orthod. Dentofacial Orthop. 1971;60(6):541.

[31] Little R. The effects of eruption guidance and serial extraction on development dentition. Pediatr. Dent. 1987;9(1):65. 
[32] Moorees et al. 26. Moorrees C, Fanning E, Gron A. Consideration of dental development in serial extraction. Angle Orthod. 1963;33(1):44-59.

[33] Mayoral J. Ortodoncia principios fundamentales y práctica. Madrid: Labor; 1877.

[34] Kesling P. Mejorando la oclusión final con la extracción selectiva de premolares. J. Clin. Orthod. 1996 otoño: 324.

[35] Moyers R. Handbook of Orthodontics. 4ta ed. London: Year book medical publishers; 1988.

[36] Lloyd Z. Serial extraction as a treatment procedure. AJO. 1956;42(10):728.

[37] Baumrind A. The decision to extract. Part II. Am. J. Orthod. Dentofacial Orthop. 1996;109(4):393.

[38] Odenrick L, Trocmé M. Facial, dentoalveolar and dental morphology in serial or early extraction. Angle Orthod. 1985;55(3):206.

[39] Ackerman J, Proffit W. Preventive and interceptive orthodontics: a strong theory proves weak in practice. Angle Orthod. 1980;50(2):75.

[40] Arvystas M. The rationale for early orthodontic treatment. Am. J. Orthod. Dentofacial Orthop. 1998;113(1):15.

[41] Ngan P, Fields H. Orthodontic diagnosis and treatment planning in the primary dentition. J. Dent. Child. 1995;62(1):25.

[42] Little R. Serial extraction of first premolars postretention evaluation of stability. Angle Orthod. 1990;60:255-262.

[43] Yoshira T. Relationship between closure extraction space and changes in dentition. J. Clin. Ped. Dent. 2002;26:147.

[44] Yoshihara T, Matsumoto Y, Suzuki J, Sato N, Oguchi H. Effect of serial extraction alone on crowding: relationships between tooth width, arch length and crowding. Am. J. Orthod. Dentofacial Orthop. 1999;116(6):691-691.

[45] Yoshihara T, Matsumoto Y, Suzuki J, Sato N, Oguchi H. Effect of serial extraction alone on crowding: spontaneous changes in dentition after serial extraction. Am. J. Orthod. Dentofacial Orthop. 2000(6);118:611616.

[46] Naoumova J, Kurol J, Kjellberg H. A systematic review of the interceptive treatment of palatally displaced maxillary canines. Eur. J. Orthod. 2011;33:143-149. 


\section{CAPÍTULO 6}

\section{TRATAMIENTO DE ALTERACIONES TRANSVERSALES \\ Paola María Botero Mariaca}

Los problemas transversales están entre aquellos a los que comúnmente se enfrentan los odontológos generales y especialistas. Son de las pocas alteraciones que deben tratarse inmediatamente sean detectadas, a fin de evitar alteraciones esqueléticas o funcionales. Existen muchos tipos de tratamientos y aparatos que pueden emplearse para la corrección, su selección dependerá del diagnóstico del problema y de su etiología. En este capítulo se muestran los elementos claves para un correcto diagnóstico, y las opciones de tratamiento con sus respectivas consideraciones biomecánicas y efectos dentales y esqueléticos.

\section{Aspectos GENERALES}

Las relaciones en el plano transversal en las zonas posteriores de los arcos determinan la forma de interdigitación de los dientes en dicha zona en sentido frontal. Cuando existe una mordida cruzada posterior, las cúspides vestibulares superiores ocluyen en las fosas de los inferiores o hacia la cara bucal de los estos (Figura 1) [1-3]. Las mordidas cruzadas pueden presentarse de manera unilateral o bilateral y pueden comprometer uno o varios dientes. Otro tipo de problema transversal es la mordida en tijera, la cual ocurre cuando las cúspides palatinas de los superiores ocluyen en las bucales de los inferiores y se denomina síndrome de Brodie [2, 3].
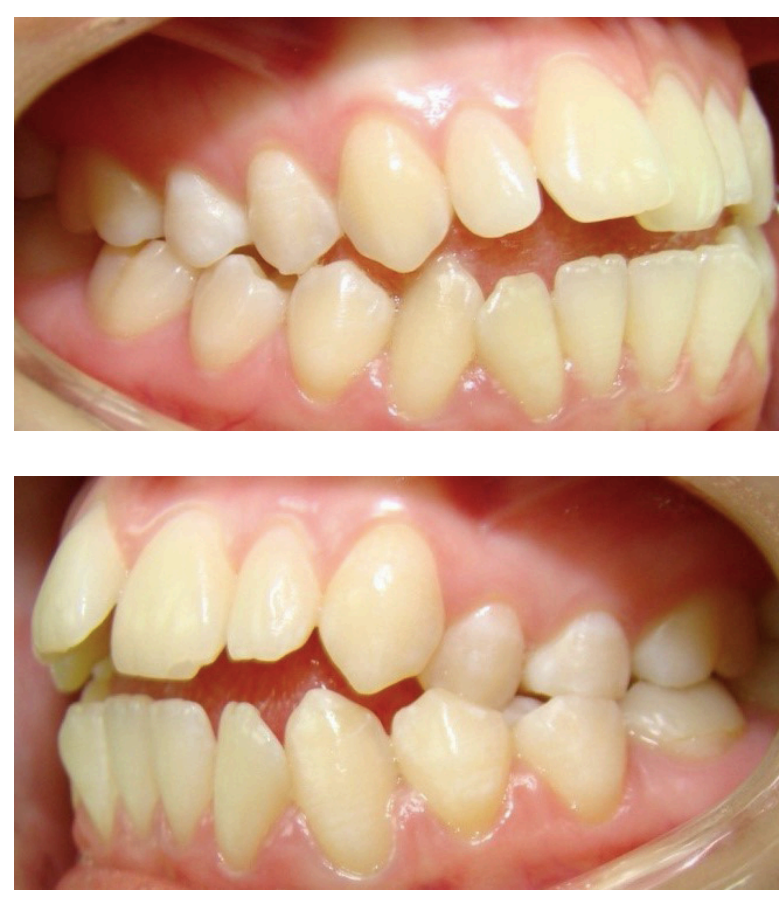

FIGURA 1. Mordida cruzada posterior bilateral Fuente: elaboración propia

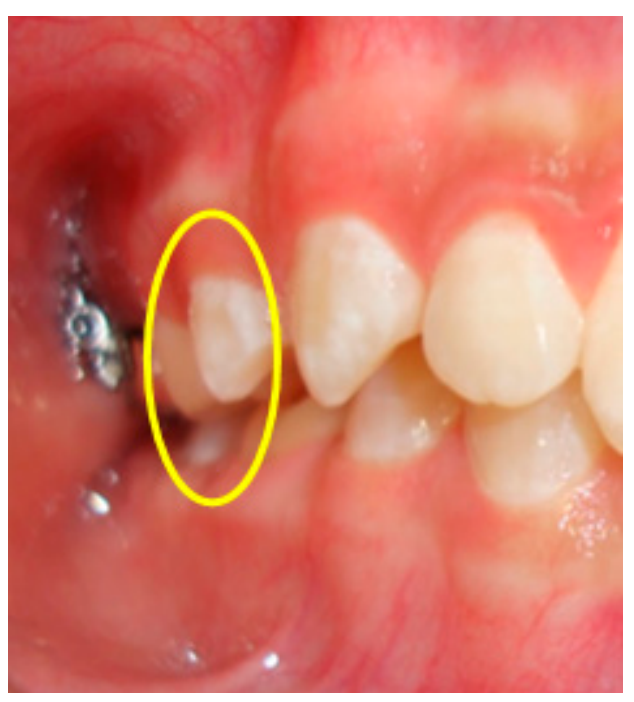

FIGURA 2. Mordida en tijera posterior en un solo diente Fuente: elaboración propia 
Normalmente, la amplitud del cráneo se completa en un 95\% a los 6 años de edad, y lo hace totalmente a los 14 años en mujeres y a los 17 años en hombres. A los 6 años, la amplitud facial en mujeres está completa al 86\% y en hombres al 83\%. A partir de allí, hasta los 11 años en mujeres y los 13 años en hombres, aumenta de 1.5 a $2 \mathrm{~mm}$, con un pico de crecimiento a los 14 años en mujeres y a los 15 años en hombres. El crecimiento termina a los 17.5 años en mujeres y a los 18 años en hombres.

La amplitud bizigomática aumenta en mayor proporción entre los 2 y los 6 años con la erupción de los molares; para los 12 años, la amplitud maxilar está completa al 98\% en mujeres y al 95\% en hombres; entre los 6 y los 18 años, la amplitud intermolar aumenta $2.0 \mathrm{~mm}$ en mujeres y $6.3 \mathrm{~mm}$ en hombres. Por otro lado, la amplitud mandibular aumenta $15.8 \mathrm{~mm}$ en mujeres y $20.9 \mathrm{~mm}$ en hombres entre los 6 y 18 años.

Los factores que influencian el crecimiento transversal son la genética, la edad (pico de crecimiento transversal entre los 14 y 15 años), el género (55.7 en mujeres, 59.5 en hombres), la raza, los patrones de crecimiento (los individuos hiperdivergentes tienen menor amplitud intermolar), los hábitos (respiración oral que constriñe el maxilar), los músculos (fuerzas musculares altas, aumentan el crecimiento sutural y, por ende, la aposición ósea) y el tipo de maloclusión (clase i división 1 presentan amplitud transversal disminuida) [4].

Antes de instaurar la terapia necesaria, es importante establecer la etiología de la alteración transversal. Puede ser de origen dental, esquelético o funcional. Para determinar la verdadera discrepancia transversal esquelética se debe evaluar la diferencia entre la distancia maxilar (yugal-yugal) y la mandíbular (Ag-Ag) (Figura 3). Usualmente, la diferencia debe ser de $5 \mathrm{~mm}$, siendo mayor la maxilar (Tabla 1) [5]. El punto yugal, punto J o punto Mx se localiza en la parte más profunda de la concavidad del contorno lateral del maxilar, donde este se inserta con el cigoma y la distancia entre los dos representa el ancho esqueletal maxilar. El punto antigonion (Ag) está ubicado en la escotadura antegonial mandibular, la cual se encuentra en el contorno del borde inferior del cuerpo mandibular por delante del ángulo goniaco. La distancia entre los dos representa el ancho mandibular esqueletal [6].

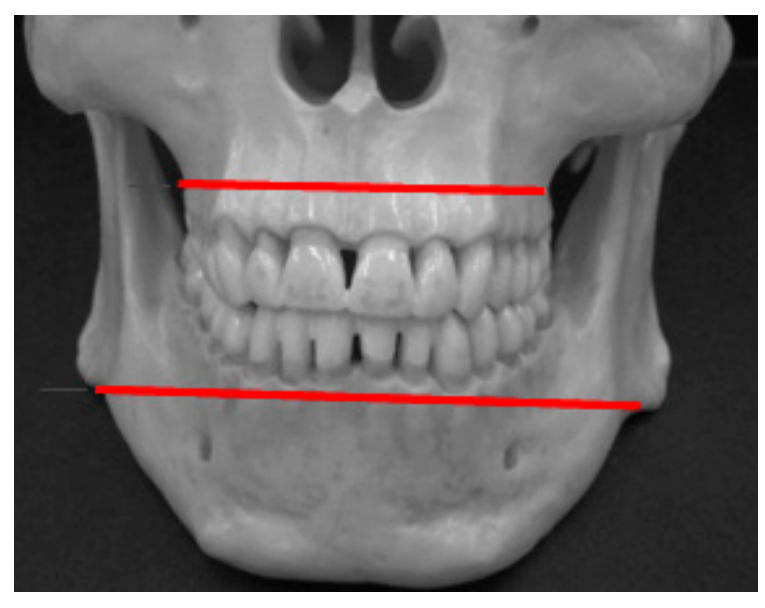

FIGURA 3. Distancia yugal-yugal maxilar y antegonial-antegonial mandibular

Fuente: elaboración propia

TABLA 1

Promedio de las dimensiones faciales transversales

\begin{tabular}{cccc}
\hline Edad & $\begin{array}{c}\text { Maxilar } \\
\text { (yugal-yugal) }\end{array}$ & $\begin{array}{c}\text { Mandibular } \\
\text { [antegonial-antegonial) }\end{array}$ & Radio \\
\hline 9 & $62.0 \mathrm{~mm}$ & $76.0 \mathrm{~mm}$ & $81.6 \%$ \\
\hline 10 & $62.6 \mathrm{~mm}$ & $77.4 \mathrm{~mm}$ & $80.9 \%$ \\
\hline 11 & $63.2 \mathrm{~mm}$ & $78.8 \mathrm{~mm}$ & $80.2 \%$ \\
\hline 12 & $63.8 \mathrm{~mm}$ & $80.2 \mathrm{~mm}$ & $79.5 \%$ \\
\hline 13 & $64.4 \mathrm{~mm}$ & $81.6 \mathrm{~mm}$ & $78.9 \%$ \\
\hline 14 & $65.0 \mathrm{~mm}$ & $83.0 \mathrm{~mm}$ & $78.35 \%$ \\
\hline 15 & $65.6 \mathrm{~mm}$ & $84.4 \mathrm{~mm}$ & $77.7 \%$ \\
\hline 16 & $66.2 \mathrm{~mm}$ & $85.8 \mathrm{~mm}$ & $77.4 \%$ \\
\hline
\end{tabular}

Fuente: elaboración propia

El diagnóstico transversal debe basarse en el establecimiento de la discrepancia esquelética, la cual puede ser enmascarada por inclinaciones 
dentales tanto maxilares como mandibulares. Es importante también cuantificar la magnitud de la discrepancia, a través de un examen más objetivo como el uso de radiografías posteroanteriores. Dichas radiografías permiten diagnosticar las discrepancias esqueléticas en amplitud entre los maxilares [6].

Las alteraciones transversales se pueden evidenciar también durante la evaluación de la curva de Wilson. Un paciente con problema transversal presenta una curva más profunda, porque las cúspides linguales de los molares superiores están ubicadas más abajo que las vestibulares. Esto se debe a la constricción maxilar y la subsecuente compensación dental. Esta inclinación genera la discrepancia entre la relación céntrica y la máxima intercuspidación, y de este modo aumenta el potencial de interferencias en el lado de trabajo y no trabajo [6].

La prevalencia de este tipo de alteraciones es del 5\% al 8\% en niños de 3 a 12 años, el 90\% de los cuales presenta desviaciones laterales de la mandíbula. La alteración funcional se diagnostica al encontrar una mordida cruzada unilateral que involucra varios dientes, desviación mandibular, posición condilar asimétrica, relación sagital de clase II subdivisión y una desviación del mentón hacia el lado de la mordida cruzada [7]. Las alteraciones transversales son multifactoriales, se deben a hábitos (succión digital, respiración oral, etc.), interferencias anatómicas localizadas, secuencia de erupción atípica y traumas [7]. Su tratamiento temprano, mediante la expansión maxilar, beneficia el desarrollo dental normal debido a que se corrige el patrón de cierre mandibular, lo que finalmente genera ajustes dentoesqueléticos favorables durante el crecimiento [8].

En la literatura se describen tres tipos de expansiones. La primera es la expansión ortodóntica, que se logra mediante el uso de arcos en casos de ortodoncia correctiva completa (brackets) o con aparatos removibles, cuyo efecto único es el movimiento dental a vestibular. La expansión pasiva es aquella en la que las fuerzas de la musculatura bucal y labial se retiran de la oclusión; normalmente se logra con el uso de aparatos funcionales y sucede por medio de fuerzas intrínsecas y no por la aplicación directa de fuerzas extrínsecas. Por último, la expansión ortopédica se obtiene mediante la separación de la sutura media palatina.

Las opciones de tratamiento dependen de la etiología del problema. Las mordidas cruzadas de origen dentoalveolar requieren de una expansión, conocida como expansión lenta maxilar, la cual tiene un efecto ortodóncico de vestibularización de molares; esto aumenta la distancia transversal del arco. Con este procedimiento se genera una expansión dentoalveolar del 70\% [8-11] y se produce separación de la sutura media palatina en un 30\%. Normalmente se aplica una fuerza de 400 a 500 gr $[12,13]$. Realizado a edades tempranas, este procedimiento puede producir una modificación mayor de la base apical [1].

La aplicación de fuerzas leves y continuas sobre la sutura media palatina genera menor resistencia en las estructuras circunmaxilares. Esto hace que la expansión lenta sea asociada a un procedimiento fisiológicamente estable, con menor potencial de recidiva, que la expansión rápida palatina [8, 9, 14, 15].

Las mordidas cruzadas esqueléticas se corrigen mediante la disyunción o efecto ortopédico, que genera separación de la sutura media palatina, aumentando la base apical. Con este procedimiento también ocurren cambios dentales por causa de la inclinación bucal de los dientes posteriores [16]; se espera una apertura de la sutura de un 70\% e inclinaciones dentales en los sitios de anclaje de un 30\%. La fuerza utilizada oscila entre 1400 a 4500 gr $[1,17]$. De la disyunción total producida, un 43\% ocurre en la zona anterior, 31\% en la zona media y $16 \%$ en la zona posterior de la sutura, debido 
a la resistencia del paladar blando, sus músculos $[1,8,18]$ y las suturas circunmaxilares [11].

\section{EXPANSIÓN RÁPIDA PALATINA}

\section{ANATOMÍA DE LA SUTURA MEDIA PALATINA}

La sutura media palatina está conformada en la zona anterior por los huesos maxilares y en la zona posterior por los huesos palatinos. En el periodo infantil, la sutura es ancha y en forma de Y en la zona frontal. La osificación se inicia con espículas, desde los bordes marginales, y con islas en la zona media de la hendidura. Las espículas van formando áreas festoneadas que aumentan con la maduración y la interdigitación se va generando. La fusión ocurre tempranamente en la zona posterior y va progresando hasta la zona anterior, con la reabsorción del hueso cortical en los bordes y la formación del hueso cancelar.

La edad de cierre es muy variable, puede ir desde los 15 años hasta los 71 años, sin guardar relación con la edad cronológica. Según su proceso de cierre, la sutura se clasifica en cinco estadios, que pueden ser analizados de manera más precisa en una tomografía axial computarizada Cone Beam. Los estadios son los siguientes (Figura 4):

a. Estadio A: línea recta de alta densidad con poca interdigitación o sin ella; se presenta entre los 5 y los 11 años. b. Estadio B: la sutura toma una forma irregular con una línea de alta densidad festoneada, en la que puede haber áreas pequeñas que se acercan y se separan por pequeños espacios de baja densidad. En la mayoría de los casos, ocurre hasta los 13 años; en el 23\% de los hombres y el $15.7 \%$ de las mujeres, entre los 14 y 18 años, y $3 \%$ de adultos.

c. Estadio C: dos líneas de alta densidad festoneadas paralelas cerca una de la otra y separadas por espacios pequeños de baja densidad de manera recta o irregular. Se presenta entre los 11 y 18 años y en 13\% de adultos.

d. Estadio D: fusión de la sutura media con maduración, progresando de la zona posterior a la anterior. La zona anterior de los huesos maxilares tiene una densidad menor a la de la zona posterior (huesos palatinos). Ocurre entre este estadio y el siguiente; en mujeres, el 25\% entre los 11 y 14 años y entre los 14 y 18 años el 57.9\%, y en hombres, el 23\% entre los 14 y 18 años.

e. Estadio E: fusión de la sutura, ya no es visible debido a que el hueso tiene la misma densidad. Se encuentra en un 53\% de adultos [19].

Es posible establecer una serie de preguntas para determinar de manera más práctica el estadio de la sutura a evaluar (Figura 5).

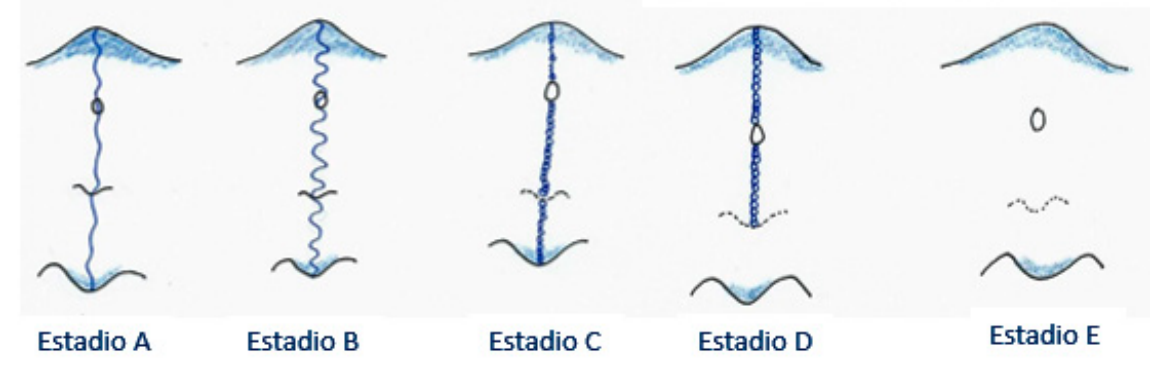

FIGURA 4. Esquema de estadios de formación de la sutura media palatina 


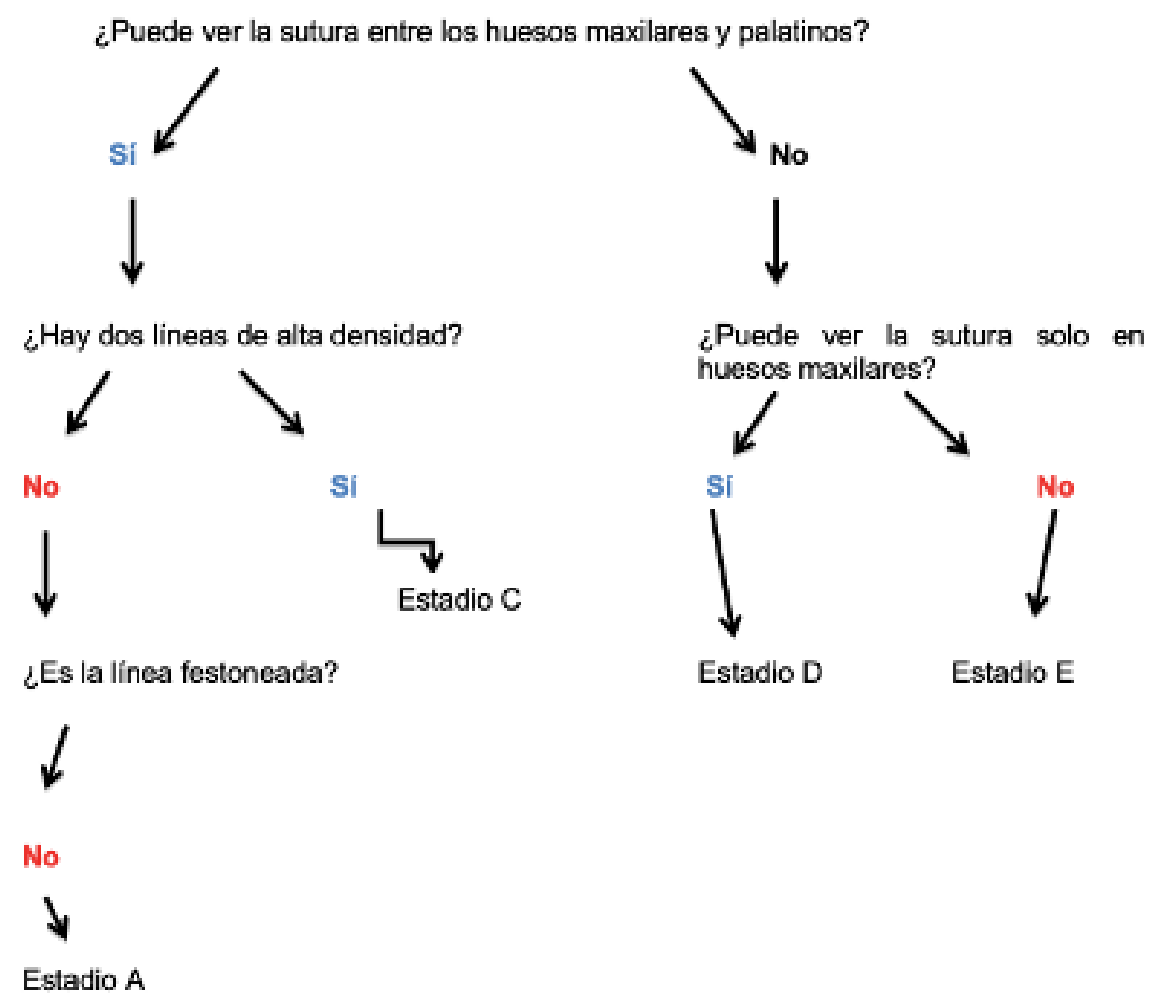

FIGURA 5. Preguntas para guiar el proceso de determinar el tipo de sutura

Fuente: elaboración propia

\section{FISIOLOGÍA DE LA DISYUNCIÓN}

Las suturas que responden a las fuerzas de expansión son tejidos que absorben el estrés y la tensión cuando se aplican las fuerzas a los huesos. Durante una expansión, el centro de rotación se ubica alrededor de la espina nasal posterior, la fuerza de expansión se distribuye en el maxilar y se extiende a las estructuras circunmaxilares. Se produce reabsorción en la zona posterior del maxilar y, por tanto, también su desplazamiento posterior. Algunos autores aseguran que la rotación del maxilar generada durante la expansión hace que contacten con los platos pterigoideos, lo que induce movimiento anterior del maxilar (Figura 6).
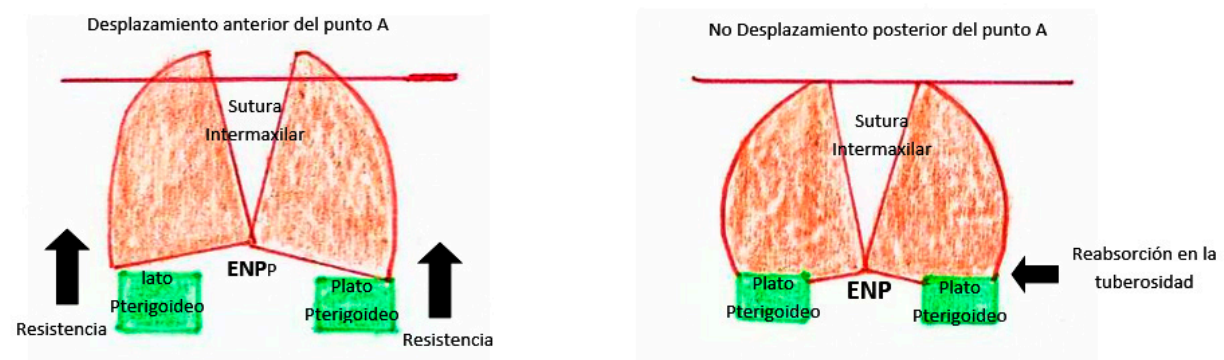

FIGURA 6. (A) Desplazamiento anterior del maxilar durante la disyunción, (ambas mitades del maxilar rotan afuera y atrás alrededor de ENP, las estructuras circunmaxilares desplazan el maxilar adelante). (B) Desplazamiento posterior del maxilar durante la disyunción, (cada mitad del maxilar rota afuera y atrás alrededor de ENP, que actúa como centro de rotación, esto genera reabsorción en la zona posterior de la tuberosidad] 
Una vez se aplica una fuerza transversal, se presenta una inclinación lateral de los dientes posteriores. Para la primera semana despúes de la aplicación se evidencia compresión y estrechamiento de los tejidos blandos del paladar y los tejidos periodontales [1]. Después de estos procesos se produce un movimiento de translación en cuerpo, a medida que el hueso cortical bucal comprimido se reabsorbe [20]. En el caso de fuerzas altas que sobrepasen la capacidad bioelástica de los tejidos y produzcan hialización, se da la separación ortopédica de los huesos maxilares [11], la cual puede ser asimétrica debido a la resistencia que ofrecen las diferentes estructuras circundantes [8].

Desde el punto de vista frontal, una vez aplicada la fuerza ocurre una rotación lateral de los procesos palatinos, lo que genera, en consecuencia, un mayor movimiento en la zona alveolar y menor en la zona de la bóveda palatina. Así, se produce un patrón triangular con la base del triangulo a nivel de la corona de los incisivos $[8,11]$, presentándose el fulcrum del movimiento cerca de la sutura frontomaxilar [21] (Figura 7).

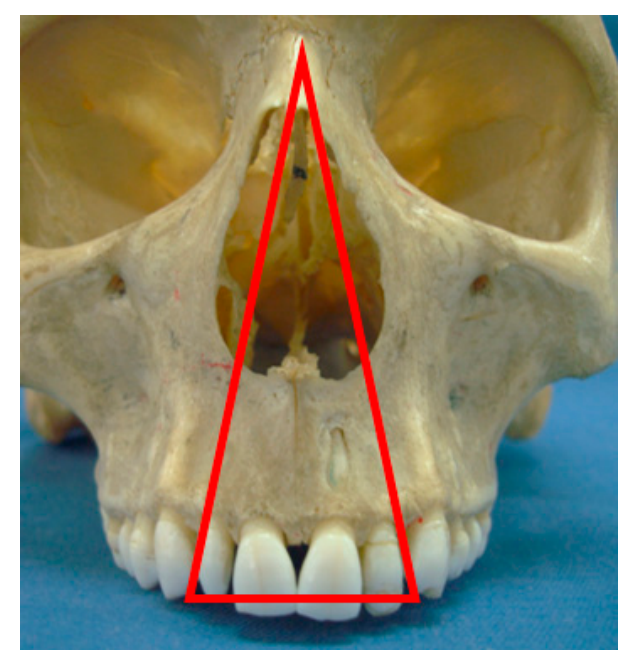

FIGURA ?. Patrón de disyunción en sentido frontal

Fuente: elaboración propia

Oclusalmente, la separación se da de forma no paralela; la mayor apertura de la sutura está ubicada en anterior, con menor separación progresiva a posterior [8, 22] (Figura 7).
Dentalmente, el efecto del aparato es contrario, pues el mayor efecto ocurre en la zona posterior (Figura 8). Se sugiere que la gran resistencia de la sutura en posterior se debe a la articulación del maxilar con huesos del cráneo, como el cigomático [23].

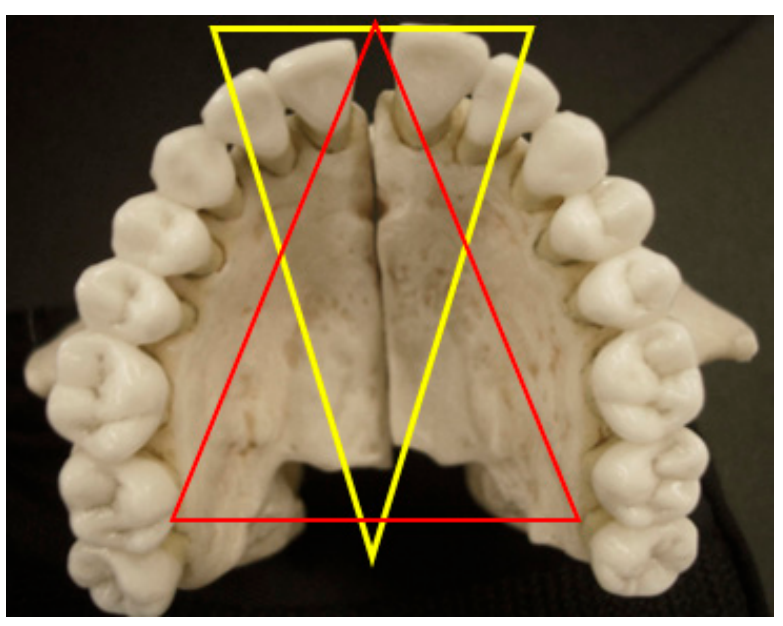

FIGURA 8. Patrón de disyunción visto desde oclusal. Triángulo amarillo: efectos esqueléticos. Triángulo rojo: efectos dentoalveolares

Se alcanza hasta $10 \mathrm{~mm}$ de separación de la sutura media palatina (con un promedio de $6 \mathrm{~mm}$ ) a nivel oclusal; sin embargo, a nivel apical la separación es menor: 4.4 mm en promedio [24]. Sagitalmente se reporta un desplazamiento hacia delante, con una mayor proyección del punto A del maxilar. Sin embargo, estos resultados no siempre son demostrados después del tratamiento [8, 11]. En sentido vertical, se observan extrusiones dentales posteriores, lo cual genera mordida abierta por la rotación mandibular horaria. Esto puede corregirse espontáneamente por la recidiva hacia lingual de los molares.

En otras suturas se ha observado una desorganización estructural, lo que significa que han sido afectadas con la expansión rápida, como la lamboidal, parietal, media sagital, frontomaxilar, cigomaticomaxilar, cigomaticotemporal y pterigopalatina. Cabe recordar que la mayor resistencia a la apertura no la ejerce la sutura misma, sino las estructuras circundantes, como el hueso esfenoides y el cigomático [9, 25]. 
Debido al patrón de separación de los procesos palatinos, se genera un diastema entre los incisivos centrales, aproximadamente a los 5 días de iniciar la expansión rápida y a los 10 días de la expansión lenta. Se cierra espontáneamente a causa de las fibras transeptales [26, 27]. Biológicamente, el ligamento periodontal se comprime (hialinización), se dobla el proceso alveolar, se separa la sutura y, finalmente, los dientes se inclinan $[28,29]$.

En sentido sagital se presenta desplazamiento del punto A hacia adelante; sin embargo, este avance no se reporta en todos los estudios existentes [8, 11]. Verticalmente ocurre extrusión de posteriores que produce de manera transitoria una rotación mandibular hacia abajo y hacia atrás, la cual se recupera con la recidiva de los molares al movimiento dental.

En diferentes estudios se han reportado hallazgos como desorganización estructural, lo cual permite establecer que la expansión rápida tiene efecto en las siguientes suturas: lamboidal, parietal, media sagital, frontomaxilar, cigomaticomaxilar, cigomaticotemporal y pterigopalatina. La resistencia a la separación de la sutura ocurre en las estructuras circundantes, como son el hueso esfenoides y el hueso cigomático $[9,25]$. Según el patron de disyunción de los huesos palatinos, a nivel oral se evidencia un diastema entre los incisivos centrales superiores a partir del día 5 de expansión rápida y del día 10 en casos de expansion lenta.

\section{EFECTOS SECUNDARIOS DE LA EXPANSIÓN}

a. Diastema entre centrales superiores: la separación de los incisivos ocurre entre el quinto y sexto día de activación en protocolos de activación de 2/4 de vuelta diaria [9].

b. Dolor en la sutura: se manifiesta principalmente en las zonas frontomaxilar y cigomáticomaxilar en pacientes adultos. Los niños refieren dolor en la sutura media palatina y en los molares.

c. Apertura de la mordida: se debe a la rotación hacia abajo del maxilar y a la extrusión de los dientes donde se ancla el aparato, que además producen una rotación abajo y atrás de la mandíbula [28]. Esta rotación induce a cambios esqueléticos, como la inclinación del plano mandibular, el aumento de altura facial anterior, el aumento en la convexidad facial y la apertura de la mordida en la región anterior $[13,29]$. Aunque el maxilar se mueve inferiormente según SN-PMS y SN-ANS, y consecuentemente se genera la rotación mandibular abajo y atrás, los cambios verticales finales son menores a 2 grados; por tanto, no son de relevancia clínica. En conclusión, los cambios verticales que suceden con la expansión son pequeños y transitorios; el hueso se mueve con los dientes y luego estos se verticalizan.

d. Adelantamiento del maxilar: el proceso de adelantamiento del hueso maxilar es reportado inmediatamente después de aplicación de la fuerza, el cual puede estar acompañado según lo reportado por un descenso maxilar que aumenta la medida de los ángulos SNA y ANB [26, 29]. Estos cambios pueden ser temporales [30] y son confirmados con la evidencia presentada por Velásquez [31], donde no se evidencian diferencias verticales o anteroposteriores después de 3 años de seguimiento.

e. Cambios en la base nasal: con la expansión se produce un aumento en la amplitud de la cavidad nasal debido a los cambios en el piso de la nariz cerca a la sutura media $[11,28,31]$. Las paredes nasales se mueven en sentido lateral con un aumento del 18\% en el volumen nasal final que es conservado a través de los años [29, 30], mientras que los cambios posteriores en la misma zona son menores [32]. Es importante 
resaltar que no todos los efectos en la cavidad nasal se traducen en mejoría en la respiración nasal de los pacientes que reciben expansión, debido a que los resultados están influenciados por la etiología del problema, además de la localización y severidad de la obstrucción nasal; por lo que es claro que la respiración oral no es indicación de realizar una disyunción en pacientes que no tengan problemas transversales [32].

f. Efectos en la respiración: la respiración nasal contribuye al desarrollo ideal del complejo nasomaxilar; los huesos maxilares forman la mitad de la cavidad nasal y, por tanto, una disyunción generaría cambios en su anatomía. Las válvulas nasales son el área de sección cruzada más pequeña y son las que dan la resistencia nasal; por la forma en la que sucede la disyunción (triangular con base en los incisivos), las válvulas nasales se afectarían también. En un estudio realizado con los disyuntores tipo Hass y Hyrax, se vio que la bóveda palatina aumenta en volumen, con una estabilidad de 11 meses. La inclinación del paladar disminuyó, lo que sugiere que la expansión rápida palatina expandió la base maxilar más que el proceso alveolar, pues este se dobla hacia bucal. Se observó, además, una disminución de la resistencia nasal en un $25.5 \%$, que se mantiene estable con el tiempo. El área del paladar aumenta en un $35.1 \%$ entre $\mathrm{T} 1$ y T2, y disminuye un $7.5 \%$ entre T3 y T4; la inclinación del paladar disminuye en un 2.8\%; el volumen nasal aumenta en un 18\% y se estabiliza [31].

g. Aumento de distancia intermolar mandibular: en algunos estudios se muestra que, al instaurar una terapia de disyunción maxilar, se presentan algunos cambios mandibulares de manera espontánea. Por cada milímetro de disyunción se produce $0.66 \mathrm{~mm}$ de aumento de la distancia intermolar mandibular [24], aunque esto no ocurre en todos los pacientes. En otros estudios se reporta el uso de disyuntores superiores junto con aparatos que generan cambios transversales en la mandíbula, como la bompereta y la placa de Schwarz.

h. Inclinación vestibular de los dientes posteriores: se ha observado una inclinación vestibular de 3.1 grados [24].

i. Efectos en el perímetro de arco: según un estudio realizado por Adkins, en 21 pacientes (entre los 11 y 17 años) tratados con Hyrax con bandas en molares y premolares, la disyunción genera cambios en las dimensiones de los arcos. Por cada milímetro de expansión transversal se genera $0.7 \mathrm{~mm}$ de aumento en el perímetro de arco y una disminución de $0.4 \mathrm{~mm}$ en su longitud por lingualización de los incisivos superiores [21]. Se debe tener en cuenta que $1 \mathrm{~mm}$ de aumento en distancia intercanina provee $0.73 \mathrm{~mm}$ de espacio para ubicar incisivos y $1 \mathrm{~mm}$ de expansión molar provee $0.27 \mathrm{~mm}$ de espacio [13].

j. Efectos en la posición condilar: el efecto de la ERP, según ciertos autores, es el adelantamiento mandibular y, por tanto, la corrección espontánea de una relación esquelética clase II en algunos casos. Otros autores reportan que la mandíbula sufre una rotación abajo y atrás. En estudios recientes, el cóndilo muestra un movimiento anterior y abajo de 0.44 a $0.66 \mathrm{~mm}$; sin embargo, no se observan cambios en la relación molar. Durante la ERP, el maxilar inicialmente rota abajo y adelante produciendo la rotación abajo y atrás de la mandíbula, que no se presenta en todos los pacientes debido a la compensación producida por un movimiento condilar, en respuesta a la expansión. Definitivamente, las fuerzas aplicadas a través de los aparatos de disyunción no se limitan a la sutura media palatina, 
sino que se observa estrés en los cóndilos, la base craneal y la fosa pterigopalatina del hueso esfenoides [33].

\section{EFECTOS ADVERSOS}

La fuerza ejercida por los aparatos de expansión produce compresión del ligamento periodontal en los dientes donde se ancla el aparato, por lo que se han reportado hallazgos de reabsorciones en las raíces de los dientes, incluso 9 meses después de activado el aparato [8]. En artículos donde se han tratado animales [9] y humanos [34-36], se han encontrado dehisencias óseas y pérdida de inserción con retracciones gingivales. Por otro lado, al aplicar la fuerza se generan cambios fibróticos y aumenta el diámetro de los vasos sanguíneos de la pulpa, que desaparecen 18 meses después.

\section{FACTORES QUE INFLUYEN EN UNA DISYUNCIÓN}

La presencia de los efectos de la disyunción depende de la edad del paciente, la magnitud de la fuerza y el tipo de aparato seleccionado $[1,27,28]$ :

a. Influencia de la edad. Una vez el individuo termina su crecimiento puberal, existe menor separación de la sutura media palatina, mientras que antes y durante el pico de crecimiento la respuesta es mayor, generando los cambios ortopédicos requeridos, al no haber fusión de la sutura y al encontrar actividad celular en la zona [13, 15, 26, 30, 37]. A mayor edad, la resistencia de los tejidos a las fuerzas aumenta gracias a la interdigitación de la sutura que ocurre alrededor de los 12 o 13 años [13, 37]. En diversos estudios, como el de Bacetti [21, 38], se muestra que los resultados de los cambios esqueléticos de mayor magnitud y estabilidad durante el pico de crecimiento; mientras que los cambios dentoalveolares predominan en edades después del pico de crecimiento. La expansión rápida palatina es más efectiva hasta que la sutura sea radiográficamente visible, la cual se reporta entre los $30 \mathrm{y}$ 50 años; sin embargo, a mayor edad la resistencia de los tejidos aumenta y la capacidad de adaptación disminuye [1]. A pesar de que la sutura media puede estar permeable a edades posteriores al pico de crecimiento, el resto de las suturas que participan del proceso se cierran tempranamente, lo que afecta la respuesta ante la fuerza que se aplique. [11, 25]. Al nacer, las suturas se encuentran separadas por tejido conectivo, y a partir de los 6 meses y hasta el 1 año de vida se van interdigitando de manera progresiva, sustituyendo el tejido conectivo por fibroso de manera progresiva hasta los 10 a 13 años, cuando se cierra totalmente. La osificación completa de ese tejido fibroso ocurre hacia los 40 o 50 años de vida [39, 40].

b. Magnitud de la fuerza. A menor edad del paciente es menor la fuerza que se debe transmitir al complejo maxilar para lograr una disyunción de la sutura [35]. En una expansión rápida palatina se aplican fuerzas entre 1500 a 5000 gr [8, 41]. La fuerza aplicada para la disyunción genera compresión del ligamento periodontal, se dobla el proceso alveolar, se separa la sutura media palatina y se produce inclinación dental.

c. Tipo de aparato seleccionado. Los aparatos pueden ser removibles o fijos dependiendo de la necesidad de expansión lenta o expansión rápida.

\section{EVALUACIÓN DEL PROCESO DE DISYUNCIÓN}

Es importante realizar una evaluación previa de la sutura de cada paciente para determinar el estadio en el que se encuentra y, asimismo, evaluar la presencia de los efectos esqueléticos durante el proceso de disyunción. Dicha evaluación debe realizarse radiográficamente a 
los 8 días de iniciada la activación del aparato. Tradicionalmente se han utilizado las radiografías oclusales para evaluar la sutura media; no obstante, en estudios recientes se muestra cómo el vómer y las demás estructuras externas de la nariz se superponen a las estructuras de la sutura media palatina, dando lugar a una evaluación equivocada. Se recomienda, entonces, el uso de la tomografía axial computarizada Cone Beam, pues, además de su precisión, permite una evaluación tridimensional de la estructura [19].

\section{DESVENTAJAS DE LA EXPANSIÓN RÁPIDA PALATINA}

Entre las desventajas de la expansión rápida se encuentran las mordidas abiertas, los microtraumas de la articulación temporomandibular, el microtrauma de sutura media palatina, la reabsorción radicular, el dolor y la inclinación dental excesiva. Por su parte, la expansión lenta produce menor resistencia del tejido alrededor de la estructura circunmaxilar y, por tanto, mejora la inclinación ósea en la sutura, lo cual la hace más fisiológica.

\section{INDICACIONES DE LA EXPANSIÓN RÁPIDA PALATINA}

La corrección temprana de estos problemas está indicada para eliminar prematuros, permitir la erupción dental en mejores posiciones y realizar cambios dentoesqueléticos benéficos durante el crecimiento. Al aplicar una fuerza transversal, los cambios iniciales producen una inclinación lateral de los dientes posteriores debido a la compresión y el estiramiento del periodonto y del tejido blando del paladar. Si las fuerzas aplicadas son de suficiente magnitud para sobrepasar la fuerza bioelástica de los elementos suturales, los segmentos se separan ortopédicamente. La separación y el reposicionamiento de los segmentos palatinos continúan hasta que la fuerza de distribución es reducida por debajo de la fuerza tensil de los segmentos suturales. La reorganización y la remodelación del tejido conectivo sutural y óseo ocurren durante la estabilización del arco expandido [42].

\section{PROTOCOLO DE EXPANSIÓN/CONTRACCIÓN ALT-RAMEC}

Es un protocolo especial de activación de aparatos de disyunción maxilar para su uso con aparatos de protracción maxilar. Fue desarrollado en 2005 con el fin de generar mayor crecimiento sagital de maxilares hipoplásicos en niños con o sin paladar hendido. El protocolo consiste en la activación del expansor durante 7 semanas, alternando expansión y contracción de la siguiente manera: una semana de expansión (abriendo el tornillo) y otra de contracción (cerrando el tornillo), terminando en la última semana con expansión; con una activación diaria de una vuelta completa (4/4 de vuelta que equivalen a $1 \mathrm{~mm}$ ) [37-39]. Sin embargo, otros autores describen un protocolo de 2 semanas (una de expansión y otra de contracción), con 2/4 de vuelta de activación diaria [39].

El protocolo inicial fue expansión/contracción alternada durante 9 semanas, con $1 \mathrm{~mm}$ por día de expansión y contracción. Fue aplicado con un aparato de doble bisagra, pero también puede ser usado un Hyrax convencional; sin embargo, el aparato de doble bisagra permite más movimiento anterior del maxilar con la protracción, debido a que expande y rota las dos mitades del paladar, con menor probabilidad de reabsorción en la zona posterior, detrás de las tuberosidades.

El efecto de este protocolo es mayor en el avance del maxilar, gracias a su eficiencia en la apertura de las suturas circunmaxilares. En 
el 2009, en un estudio en gatos, se comparó el protocolo Alt-RAmec y el protocolo convencional de ERP, dando como resultado que las suturas intermaxilares y nasomaxilar se abrieron en un 100\%. En las suturas articuladas directamente con el maxilar y en las indirectas, la separación fue mayor con Alt-RAMEC que con ERP, exceptuando la sutura frontomaxilar. Entre los efectos secundarios reportados tenemos el dolor en varios sectores de la cara, pero no se presentan fracturas o problemas adicionales a los que una expansión genera.

\section{ESTABILIDAD}

Sin realizar tratamiento de ortodoncia posterior, la estabilidad a largo plazo de una ERP puede ser del 30\% al 40\% [24, 43]. El efecto inmediato de la expansión rápida palatina (de 2 a 4 semanas después de la activación) es dental en un 60\% y en un 40\% esquelético. Se observa un aumento en la distancia intermolar coronal de $6.7 \mathrm{~mm}$ y apical de $4.4 \mathrm{~mm}$. El efecto a largo plazo no puede establecerse claramente con la evidencia disponible; sin embargo, el efecto neto en adolescentes, a nivel de la distancia intermolar coronal, es de $3.7 \mathrm{~mm}$ [43]. Para las correcciones transversales se pueden usar aparatos fijos o removibles, de acuerdo a los objetivos que se pretendan con el paciente, la etiología del problema y la edad.

\section{APARATOS FIJOS}

\section{Hass}

Aparato diseñado por Angell en 1960 [44] y Haas en 1961 [13]. Consta de un tornillo incorporado con acrílico en la zona media, está dividido sagitalmente en dos partes iguales y en contacto con la mucosa palatina [20] (Figura 9). El acrílico fue adicionado con la finalidad de que ejerciera mayor presión sobre los procesos palatinos y, por ende, mayor cantidad de separación sutural. Actualmente, este aparato ya no es usado debido a las lesiones de la mucosa palatina que producía el acrílico y fue reemplazado por un aparato más higiénico llamado Hyrax. Según las investigaciones que comparan los dos aparatos, ambos tienen el mismo efecto de disyunción.

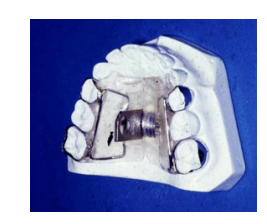

FIGURA 9. Expansor tipo Hass

Fuente: elaboración propia

\section{Hyrax}

El aparato Hyrax, diseñado inicialmente por Biederman [45], cuenta con un diseño más higiénico, al ser hecho solo con alambre de acero inoxidable soldado de diferentes calibres: 0.45 [44], 0.50 [8], 0.55 [24]. Va anclado a molares y primeros bicúspides [46] o en segundos molares deciduos y caninos deciduos [47] (Figura 10), dependiendo del tipo de dentición. El tornillo de la línea media va ubicado lo más cercano al paladar, con el ánimo de fascilitar la higiene y mejorar la ventaja mecánica, por lo que su ubicación depende de la anatomía de dicha estructura y tamaño del tornillo. El tornillo más usado es el conocido como tornillo de Fisher, el cual viene de diferentes tamaños: 5, 7, 10 y $12 \mathrm{~mm}$. El más usado es el de $12 \mathrm{~mm}$, que logra expansiones entre $6 \mathrm{~mm}$ y $7 \mathrm{~mm}$. Cada tornillo trae una configuración de 360 grados, que corresponde a $1 \mathrm{~mm}$ de activación, mientras que cada cuarto de vuelta corresponde a 45 grados o $0.25 \mathrm{~mm}$. Gracias a este diseño, el Hyrax puede producir fuerzas entre 1360 y 4535 g; sin embargo, luego de varias activaciones secuenciales se puede acumular en los tejidos fuerzas hasta de 9000 gr (Figura 11) [11]. 


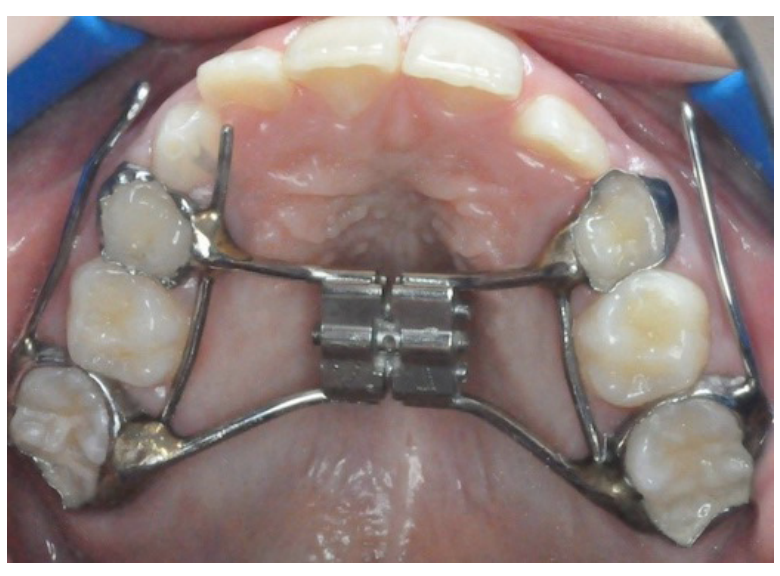

FIGURA 10. Expansor tipo Hyrax

Fuente: elaboración propia

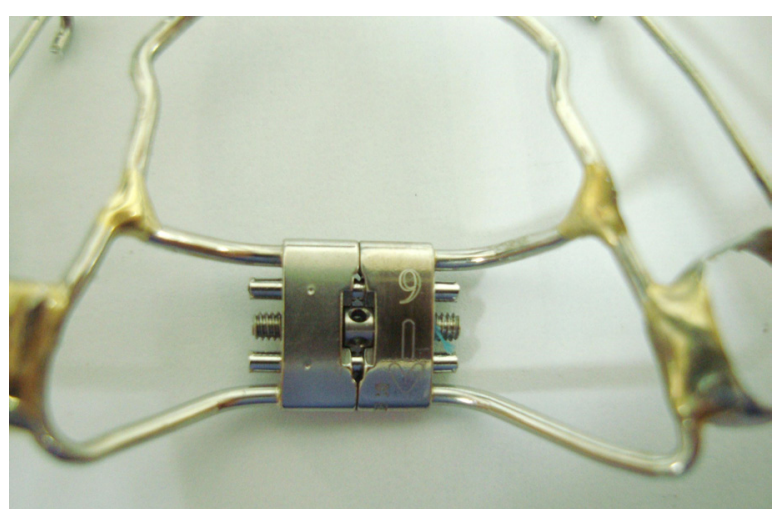

FIGURA 11. Tornillo tipo Fisher

Fuente: elaboración propia

La periodicidad de la activación del tonillo depende de la edad. En pacientes en dentición decidua o mixta temprana o individuos menores de 9 años, se recomienda realizar $1 / 4$ de vuelta diaria [46]; mientras que pacientes entre los 9 y los 13 años se realiza una vuelta completa una vez cementado y diariamente se activa con $2 / 4$ vueltas, una en la mañana y otra en la noche [22, 30, 37, 48, 49]. Finalmente, en pacientes mayores de 13 años, se recomienda la activación de 1 vuelta diaria luego de cementado [22, 30, 34, 37, 50, 51] (Figura 12).

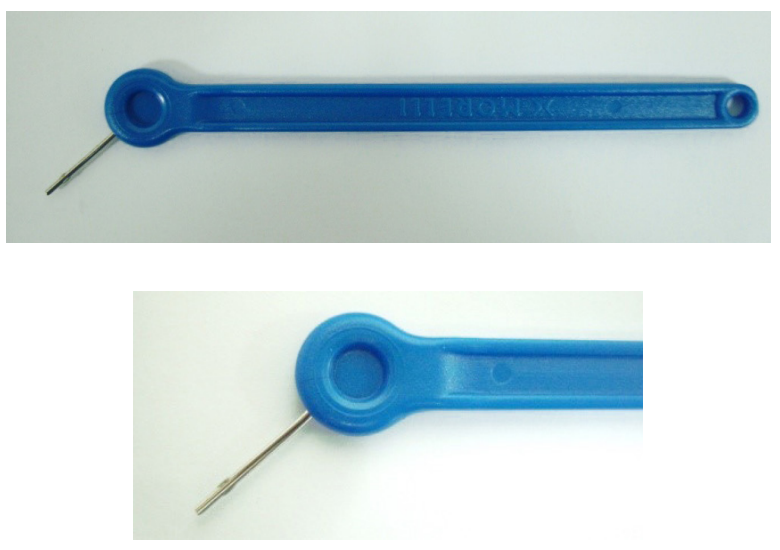

FIGURA 12. Llave para activar tornillo

Fuente: elaboración propia

Para determinar la cantidad de activaciones y el total de tiempo, basta con calcular la magnitud de la expansión a realizar (clínicamente y en los modelos) y transformarla en el número de cuartos de vuelta necesarios para obtenerla [22]. La cuantificación de los milímetros que se requieren para corregir la mordida cruzada debe realizarse restando la distancia intermolar inferior (tomada desde las cúspides mesiovestibulares) de la distancia intermolar superior (tomada desde las cúspides de los molares superiores), y adicionarle 2 o $3 \mathrm{~mm}$ para tener en cuenta la recidiva $[1,8,20,52]$. Una vez determinada la cantidad de milímetros, se debe seleccionar el tamaño del tornillo a utilizar (5, 7, $10 \circ 12$ $\mathrm{mm})$. En algunas ocasiones, cuando existen mordidas cruzadas severas, puede ser indispensable emplear dos tornillos para lograr la disyunción requerida.

La duración del tratamiento activo se calcula según la cantidad necesaria de milímetros de disyunción y el protocolo de activación que se va a emplear. Por ejemplo, si el paciente requiere $8 \mathrm{~mm}$ de disyunción en total $(5 \mathrm{~mm}$ para la corrección más $3 \mathrm{~mm}$ de recidiva) y el protocolo de activación es de 2/4 de vueltas al día, el tratamiento activo duraría 16 días. 
Una disyunción se considera adecuada cuando el aspecto oclusal de la cúspide lingual del primer molar superior contacta con el oclusal de la cúspide bucal del molar inferior [52]; en ese momento ya no se requiere más activación. El periodo de retención debe ser de 3 a 6 meses $[8,10,17,28,52]$, debido a la tendencia de recidiva de los tejidos periodontales y palatinos (incluyendo músculos). Se puede dejar el mismo aparato como retención, bloqueando el tornillo, con acrílico o con alambre de ligadura, para evitar que se devuelva. También se puede emplear una barra transpalatina en los casos en los que se retire el expansor; sin embargo, la retención en la zona de los premolares se vería comprometida.

El Hyrax convencional presenta un anclaje con cuatro bandas (dos en primeros molares y dos en premolares o primeros molares deciduos, según la etapa de la dentición). En años recientes, se le ha introducido un cambio al disminuir su anclaje a dos bandas (en primeros molares superiores) y agregándole una barra lingual hasta los caninos deciduos. Al comparar el aparato con cuatro bandas y el de dos, el primero tiene la ventaja de ser más estable; mientras que el otro tiene más fácil inserción e higiene, y puede ser más confortable [54]. Lamparski compara los dos aparatos y no encuentra diferencias significativas en la distancia intermolar e intercanina, ni en la inclinación molar; pero el de cuatro bandas presentó menor recidiva [54]. Davidovich [49] encontró mayor expansión en el de cuatro bandas, principalmente a nivel de la amplitud intermolar $(6.38+\backslash-4.44)$, en comparación con el de dos bandas (1.05 +\- 5.15). Además, se observó que con las cuatro bandas la expansión a nivel del canino ocurría hasta los 17 años, mientras que con dos bandas sucedía hasta los 12 años.

Al comparar los dos aparatos, no hay diferencias estadísticamente significativas en la distancia intermolar e intercanina o en la inclinación molar; sin embargo, en casos de anclaje a cuatro bandas se presentó menor recidiva [54]. En el estudio de Davidovich [49] se reporta mayor efecto a nivel de la amplitud intermolar $(6.38+\backslash 4.44)$ con el anclaje de cuatro bandas, en comparación con el de dos bandas $(1.05+\backslash$ - 5.15). La expansión a nivel de caninos se produce en casos de 4 bandas hasta los 17 años, mientras que en los de 2 bandas solo hasta los 12 años.

Para el control vertical de los molares, se le puede adicionar planos posteriores de mordida al Hyrax, generando la misma cantidad de expansión [26] (Figura 13). Estos ajustes reducen los efectos indeseables en sentido antero posterior y vertical [21, 26, 36]. Sin embargo, otros estudios reportan que los efectos en estos dos planos no son diferentes sin el uso de los planos [32]. Asanza [25] por ejemplo hace una comparación entre las dos condiciones en una evaluación a corto plazo (4 meses) y encuentra resultados similares, pero reporta que en casos sin bloques posteriores se reporta que el maxilar se desplaza abajo produciendo abajo y atrás de la mandíbula con consecuente aumento de la altura facial anterior. Con el uso de la adición de los planos de mordida posterior, se evidencia un movimiento menor del maxilar hacia abajo, por lo que no se ven los cambios verticales en la altura facial anterior.

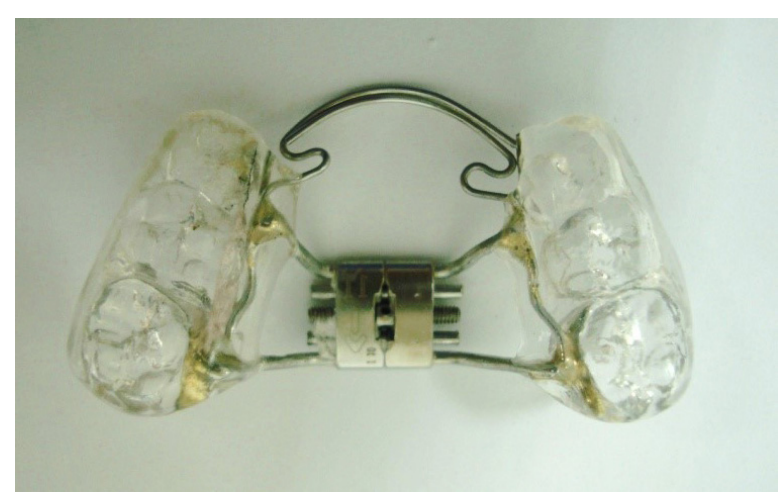

FIGURA 13. Paciente con Hyrax y planos de mordida posterior en boca

Fuente: elaboración propia 
Al Hyrax también se le pueden adicionar elementos en la zona anterior, como brazos que permiten corregir mordidas cruzadas anteriores o rejillas para controlar la posición de la lengua en pacientes con deglución atípica o con empuje lingual simple. Las rejillas no pueden ser como las convencionales, pues no pueden ser unidas en la zona anterior ya que evitarían la separación de los procesos palatinos (Figura 14).
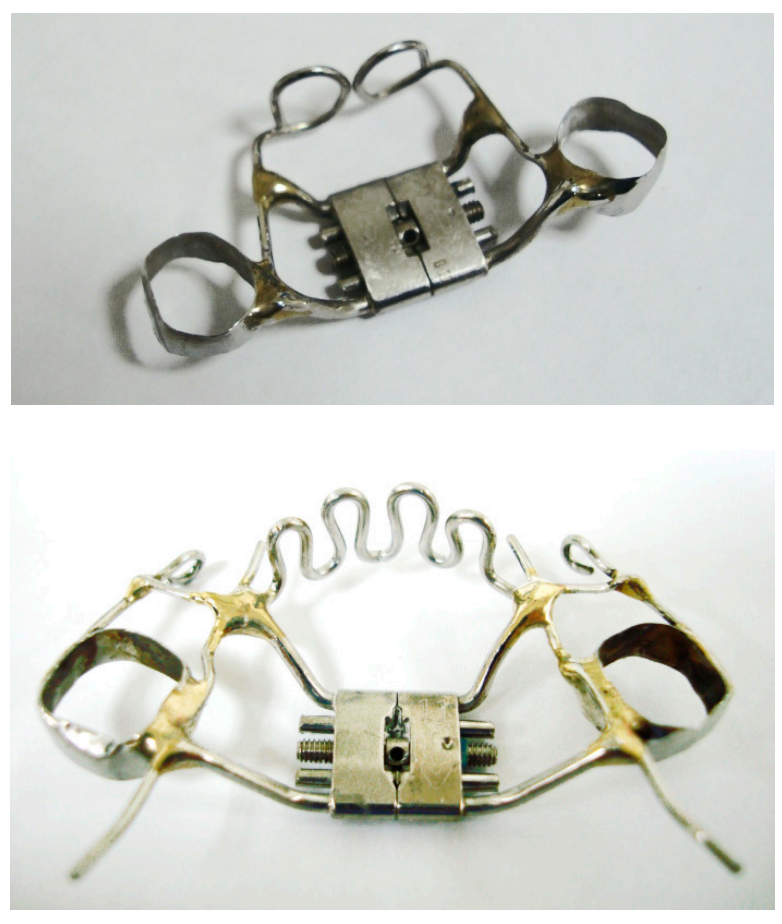

FIGURA 14. Hyrax con dos tipos de rejillas en la zona anterior Fuente: elaboración propia

\section{EXPANSIÓN PALATINA LENTA}

La expansión lenta es un procedimiento que pretende generar un aumento dentoalveolar del arco. Para obtener este efecto, se realiza un patrón de activación diferente, según el aparato empleado (más espaciado), ya sea fijo o removible. Es considerada una expansión más fisiológica que la rápida, pues produce menor resistencia del tejido alrededor de la estructura circummaxilar y, por tanto, mejor formación ósea en la sutura. Esta apreciación se basa en que, para adaptarse y minimizar la hemorragia y el desgarro, la rata máxima que el tejido de la sutura soporta es de $1 \mathrm{~mm}$ por semana [41].

- Fuerza. En una expansión lenta, dependiendo de la edad, se aplica una fuerza de 1020 a 2040 gr en la región maxilar [11]. Ejerce 2 lb de fuerza por activación, mientras que una expansión rápida palatina aplica entre 3 y 10 lb de fuerza.

- Efectos. Se ha reportado aumento en la distancia intercanina e intermolar de 3.2 $\mathrm{mm}$ y $4.8 \mathrm{~mm}$. respectivamente. Se ve un aumento final del perímetro de arco, por el aumento en su amplitud (no por el aumento en la longitud). Se afirma que este tipo de expansión genera más efectos dentales (70\%) que esqueléticos (39\%); por tanto, dependiendo de la edad, es posible observar separación de la sutura palatina al utilizar aparatos para expansión lenta (esto ocurre a las 2 semanas de haber iniciado la activación) [18]. Se reporta también una relación de 6:1 entre efecto esquelético y dentario [43].

- Duración del tratamiento. Dependiendo de la magnitud del problema, el tratamiento puede durar entre 14 y 42 días.

- Estabilidad. Habría menor recidiva con expansión lenta que con expansión rápida.

\section{Quad Helix}

Aparato fijo intraoral utilizado para modificar la forma del arco superior en la etapa del desarrollo de la dentición. Al activarse produce presiones que expanden el arco e influyen sobre la sutura palatina media. Fue descrito por Ricketts como una modificación del resorte en W de Coffin, entre 1973 y 1975 (Figura 15), pues estos aparatos presentaban alto grado de distorsión durante su activación [55]. 


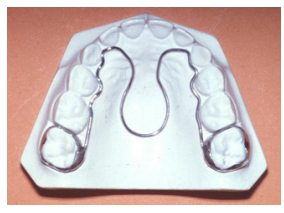

FIGURA 15. Arco en W

Fuente: elaboración propia

\section{Fabricación}

Se realiza en alambre de acero inoxidable 0.036", cromo cobalto 0.038" [28] o alambre Elgiloy azul de $1 \mathrm{~mm}$. Consta de un puente anterior, dos puentes palatinos y dos brazos laterales unidos entre sí por cuatro helicoides; los brazos linguales se extienden hasta mesial del canino o de los primeros molares deciduos, según la extensión de la mordida cruzada. Las bandas (en primeros molares permanentes o segundos molares deciduos) van soldadas al aparato y este debe quedar separado de la mucosa por $1 \mathrm{~mm}[18,56]$. Los helicoides posteriores deben extenderse más distal a las bandas, y los anteriores lo más anterior posible. Los cuatro helicoides incrementan el rango de aplicación de la fuerza, la flexibilidad, el control de los molares y la capacidad de adaptación del aparato [20, 56]. Las hélices que se le agregan al aparato adicionan $25 \mathrm{~mm}$ de alambre, lo que hace que la fuerza sea menor y más continua, pues tiene un mayor rango de activación [57]. El segmento anterior debe ser ancho, de tal manera que el aparato se mantenga separado de la posición de la deglución de la lengua, evitando que irrite los tejidos blandos del paladar o de la lengua. Los resortes helicoidales distales deben extenderse más allá de la banda del primer molar para permitir la rotación y expansión del molar (Figura 16).

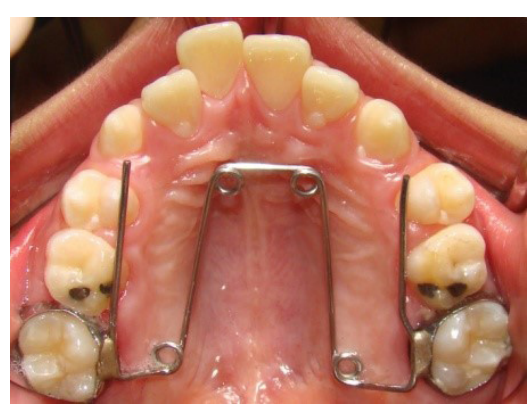

FIGURA 16. Quad Helix

Fuente: elaboración propia

\section{Indicaciones}

a. Mordidas cruzadas unilaterales o bilaterales.

b. Casos de leve expansión en la dentición mixta, en los que se identifica falta de espacio.

c. Casos de clase II, en los que los arcos deben ampliarse y los molares rotar hacia distal.

d. Sistema de anclaje para manejo de clase III, donde el arco superior se va a ampliar.

e. Hábitos de succión digital o empuje lingual, realizando modificaciones [58].

f. En ciertos pacientes de labio y paladar fisurados, ya sea unilateral o bilateral.

\section{Activación}

La activación inicial se realiza en los brazos laterales antes de cementar el aparato, abriendo las hélices anteriores y posteriores para lograr efecto tanto anterior como posterior. Antes de la cementación definitiva, se debe calzar en cada uno de sus lados para corroborar la acción de expansión (Figura 17). La activación se repite cada 6 semanas o 45 días, hasta lograr la expansión deseada. La cantidad de cada activación se determina colocando el aparato en boca: debe estar activo hasta la mitad bucolingual de amplitud de molares y hasta el borde incisal a nivel canino [18]. La activación 
selectiva de las hélices anteriores y posteriores es posible; para una expansión posterior, se recomienda la activación en el sector anterior, mientras que la activación en la zona posterior tiene efectos en la zona anterior [55].

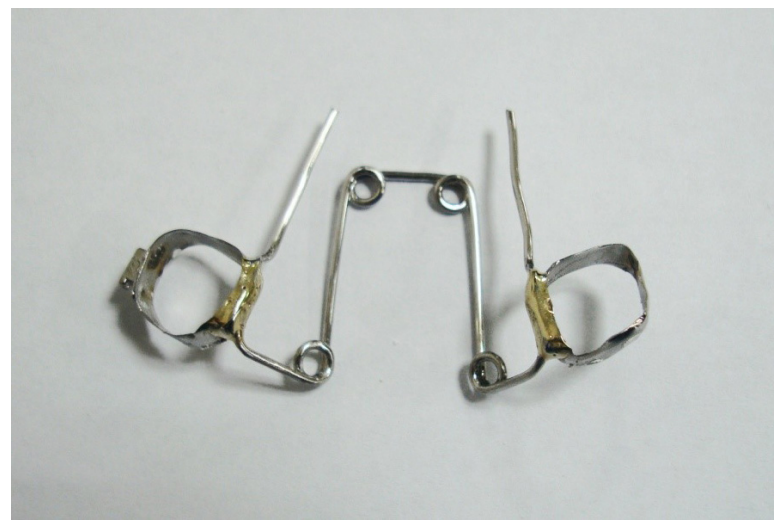

FIGURA 17. Quad Helix

Fuente: elaboración propia

La activación intraoral comprende dos ajustes: el primero para expandir a nivel de la región molar y el segundo para rotar el molar y expandir los sectores posteriores. A medida que el aparato trabaja por sí mismo, la porción palatina tiene tendencia a bajar, separándose del techo de la boca, por tanto, debe doblarse nuevamente hacia palatino para impedir la interferencia de la lengua. La activación se realiza en el puente anterior o abriendo los helicoides con una pinza tres picos (Figura 18). Cuando existe una rotación mesial marcada de los molares, el primer paso es permitir su rotación distal antes de la expansión; esto se logra manteniendo los brazos palatinos separados de los sectores de los molares primarios y de los caninos.
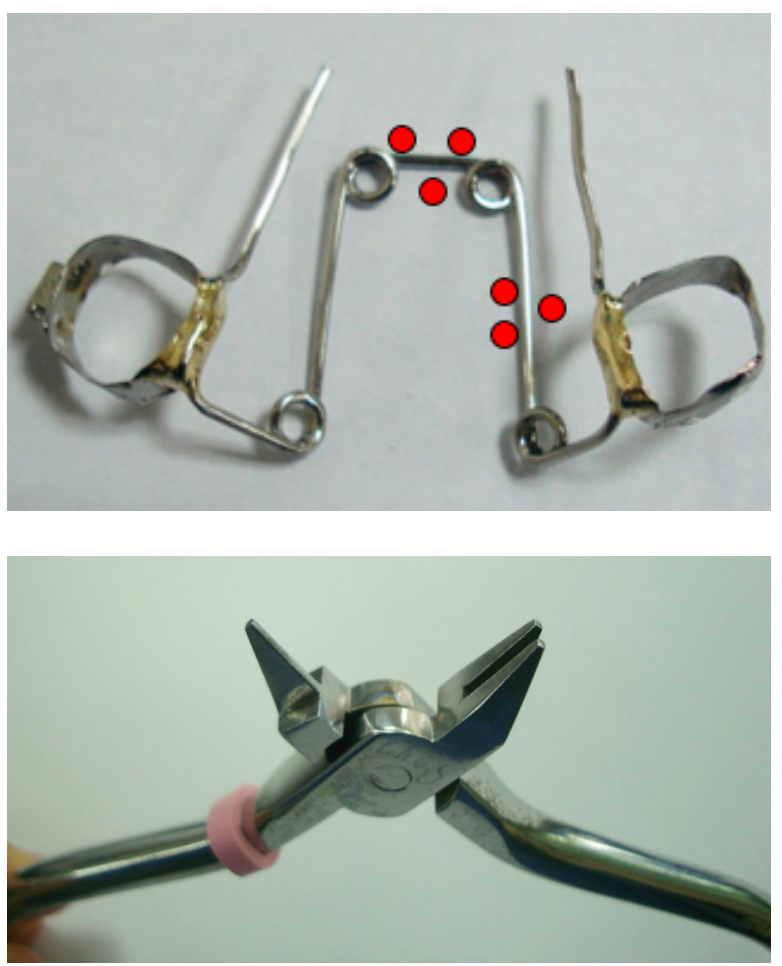

FIGURA 18. Quad Helix con la ubicación de la pinza tres picos y pinza tres picos

Fuente: elaboración propia

Algunos estudios [59] muestran que la fuerza producida por cada milímetro de expansión varía de 88 a 130 gr. El aparato genera un efecto ortodóntico versus el ortopédico de 6:1, produciendo una separación de la sutura de $0.92 \mathrm{~mm}$ y un aumento de la distancia intermolar de $5.88 \mathrm{~mm}$. Para contrarrestar la inclinación bucal del molar, se le puede añadir un torque bucal de la raíz antes de cementar el aparato. El Quad Helix también puede ser usado como mantenedor de espacio [57].

La expansión se considera terminada cuando la superficie oclusal de la cúspide lingual del primer molar superior ocluye en el aspecto oclusal de la cúspide vestibular del primer molar inferior, es decir que se genera una sobreexpansión de 2 a 3 mm [18, 48]. La retención puede ser de 6 semanas [1, 14], aunque algunos recomiendan mayor tiempo, entre 3 y 6 meses para estabilizar las suturas $[9,15,60,61]$. 
Para expansiones asimétricas, el diseño debe ser modificado: se deja el alambre lateral como anclaje en el lado de no expansión y se lo retiradel lado de la mordida cruzada [3]. Además, se le pueden soldar rejillas en el puente anterior, en forma de spurs o con una disposición vertical, para lograr un control de hábitos simultáneo a la corrección transversal [58]. También se le pueden adicionar brazos para vestibularizar los incisivos centrales y laterales, e incluso elaborarlo en el arco inferior donde se denomina Bihelix (ver ítem expansión inferior y Figura 19) [62].
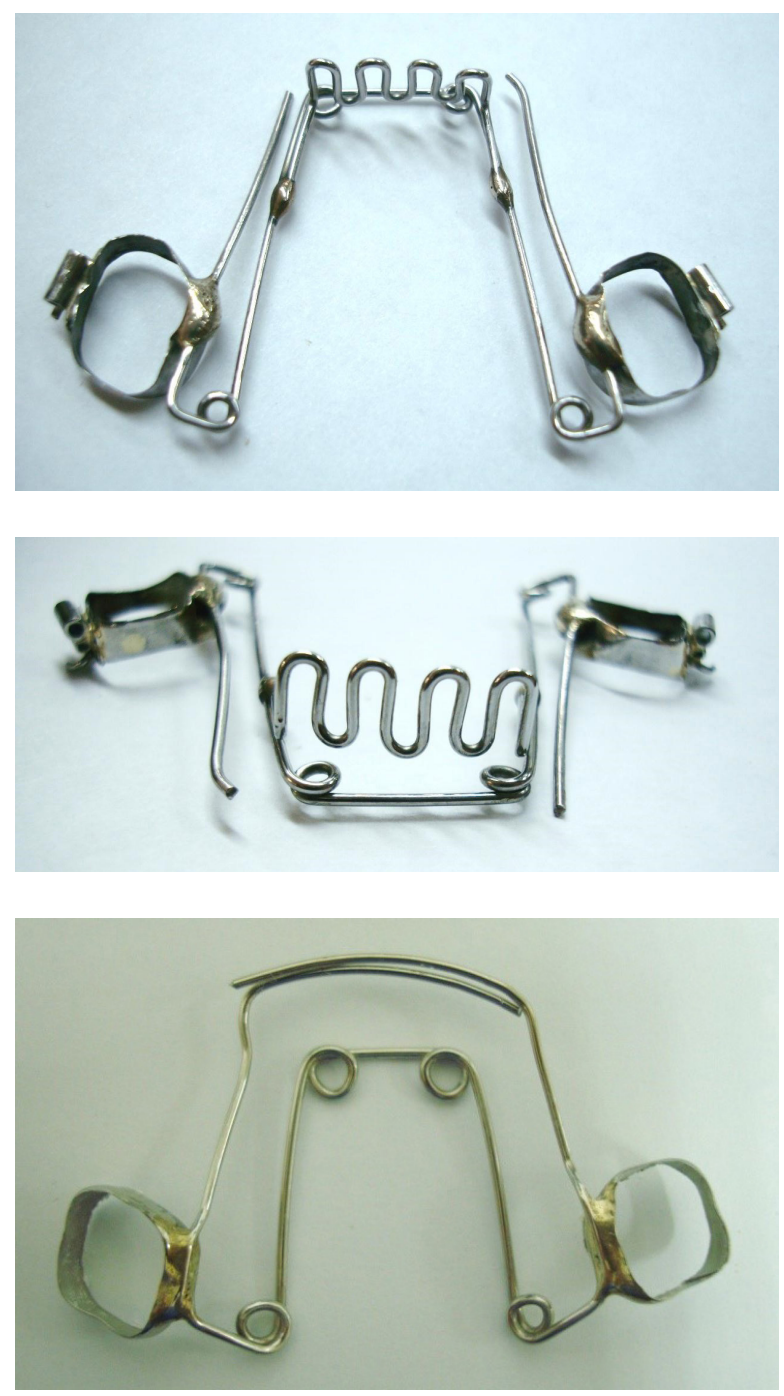

FIGURA 19. (A-B) Quad Helix con rejilla. (C) Quad Helix con brazos anteriores

Fuente: elaboración propia
Cuando se emplean los aparatos de Quad Helix y Adams Porter en pacientes que tengan inicio de cierre de la sutura palatina, no se genera separación de esta durante su activación, sino solo efectos dentoalveolares, contrario a lo que sucede en menores de 9 años, donde la permeabilidad de la sutura permite la disyunción $[8,15,20,52]$, tal como es demostrado por Bell [14] según las radiografías oclusales. Las ventajas de estos dispositivos son el buen anclaje y retención, efectos mínimos sobre el habla y acción continua sobre un periodo específico, sin necesidad de activación del paciente.

\section{Expansor de Nitanium}

El expansor de níquel titanio fue desarrollado en 1993 por Arndt y es considerado un aparato con propiedades especiales, al estar realizado en Nitinol, que cuenta con memoria de forma y transición de temperatura; así, la fuerza se distribuirá de forma uniforme, lenta y continúa durante la expansión. Con estos efectos, se logra mantener la integridad del tejido al reposicionar y remodelar el tejido óseo [63]. La expansión generada es una expansión lenta, con una disyunción que varía entre 50\% y 80\% de los pacientes, dependiendo de la edad [41, 59]. El Nitinol empleado es de 0.035”, trabajándolo con una doble ansa en forma de $\mathrm{M}$ y conectado a las bandas de primeros molares. En la zona anterior, con la finalidad de aplicar expansión en zona canina, se emplea un alambre en acero inoxidable 0.032". El expansor se consigue prefabricado en varios tamaños y su selección va a depender de la distancia intermolar de cada paciente (Figura 20). 


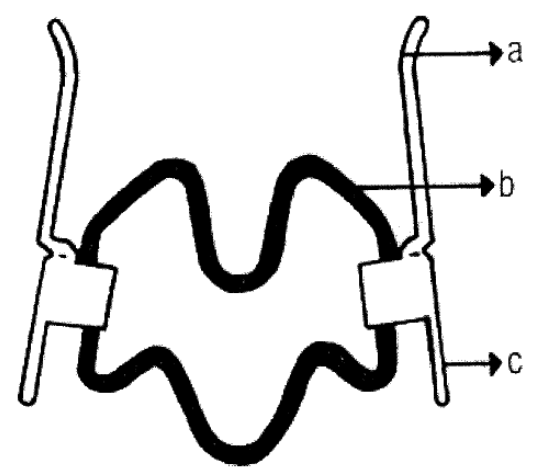

FIGURA 20. Expansor de Nitanium [63]

Fuente: elaboración propia

\section{Aparatos removibles}

Consisten en una placa acrílica con ganchos Adams en los primeros molares permanentes (o segundos molares temporales) o ganchos circunferenciales en los primeros molares o caninos temporales. Se coloca un tornillo (tipo Fisher) en la mitad del acrílico para generar expansión dentoalveolar con una activación de $1 / 4$ de vuelta por tres veces a la semana (en días no continuos), pues el sistema de anclaje del aparato no soporta fuerzas altas y se desaloja. Por tal motivo, no se puede obtener una separación de la sutura media palatina con diseños como este [65] (Figura 21).

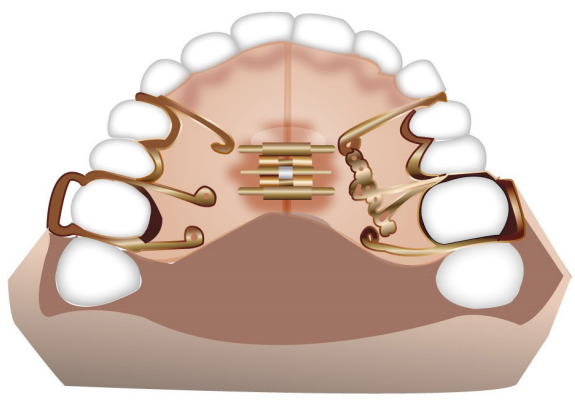

FIGURA 21. Placa de Hawley con tornillo

Fuente: elaboración propia
Los tornillos con acrílico son menos rígidos y permiten más inclinación de los procesos palatinos en los planos frontales y sagitales indeseables. Puede agregarse un plano de mordida posterior en los casos en que el engranaje oclusal evite una corrección rápida del problema, y un arco vestibular para retención o como control sagital de los incisivos superiores. Para poder estabilizar los cambios logrados con la expansión, deben ocurrir cambios histológicos como la reorganización del tejido conectivo y óseo del maxilar que eviten el colapso por fuerzas residuales luego de terminar la activación; por lo que se recomienda retención de 3 meses, permitiendo la estabilidad durante 24 horas al día [1, 18]. En la Tabla 2 se puede observar la comparación entre los dos tipos de expansión en cuanto a sus efectos dentales y esqueléticos, y su biomecánica.

\section{EXPANSIÓN DEL ARCO INFERIOR}

Debido a su inestabilidad, la obtención de espacio en el arco mandibular es una tarea difícil. Reidel, por ejemplo, asegura que la forma del arco inferior no puede ser alterada con ningún aparato por la osificación de la sutura de la sínfisis al año de vida. A partir de ese momento, los cambios mandibulares obedecen a procesos de aposición y reabsorción. Además, las distancias intermolar e intercanina disminuyen con el crecimiento, aunque algunos autores aseguran lo contrario, considerando el doblaje mandibular ante las fuerzas oclusales y funcionales $[64,65)$. Por otro lado, los pacientes braquicefálicos tienen arcos más amplios y pueden ser expandidos con resultados más predecibles que los dolicocefálicos.

Entre los aparatos empleados para la expansión inferior se encuentra el Bihelix, el cual ha sido poco utilizado y estudiado. Se emplea en individuos de 7 a 11 años de edad, con activaciones cada 3 meses, logrando expansión 
dental en la zona de molares y premolares (Figura 22) [66, 67].

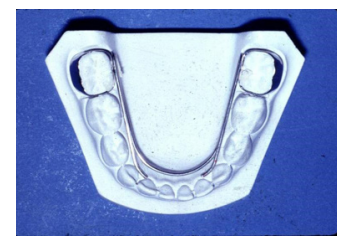

FIGURA 22. Bihelix

Fuente: elaboración propia

Otro aparato usado para la expansión inferior es el Crozat, un aparato que puede ser fijo o removible, confeccionado en alambre sin ningún tipo de acrílico. Consiste en una barra metálica con ansa soldada a bandas y apoyos en oclusal de los molares para control vertical. Se le puede adicionar ganchos para movimientos dentales controlados (Figura 23).

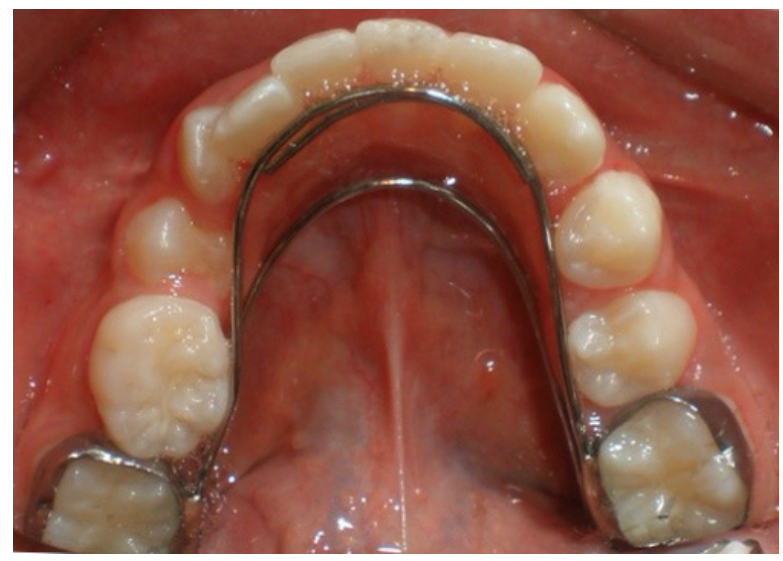

FIGURA 23. Crozat

Fuente: elaboración propia

Se ha intentado hacer tratamientos usando Crozat modificado con bompereta, en el arco inferior, y con Quad Helix para el arco superior. El Crozat se fabrica en alambre 0.40", extendido hasta distal de los laterales. Se reporta un aumento en la distancia intercanina de $3.2 \mathrm{~mm}$ (86\% de la expansión); de $4.8 \mathrm{~mm}$ en la distancia intermolar, y un aumento en longitud de $1.4 \mathrm{~mm}$ debido al movimiento anterior de los incisivos. El perímetro aumenta 6. $2 \mathrm{~mm}$ en el superior y $4.2 \mathrm{~mm}$ en el inferior; esto se debe al aumento en la amplitud y no en la longitud del arco.

Otro aparato que se emplea en el arco inferior es la placa de Schwarz, que se utiliza en combinación con el Hyrax u otro tipo de expansor del arco superior. Esta placa es igual a un bilateral de acrílico removible, posee dos ganchos en gota a cada lado, y se le adiciona un tornillo de expansión tipo Fisher en la zona media. La activación es de 1/4 de vuelta semanal para evitar su desalojo [68-70]. Está contraindicado en pacientes que presenten anquilosis de molares deciduos, antes o durante el proceso de expansión (Figura 24). Este aparato produce una inclinación ortodóntica de los dientes posteriores inferiores, ya que al verticalizarlos se obtiene una inclinación más normal de estos. De no continuarse con ortodoncia después de retirado el aparato, el resultado sería inestable.

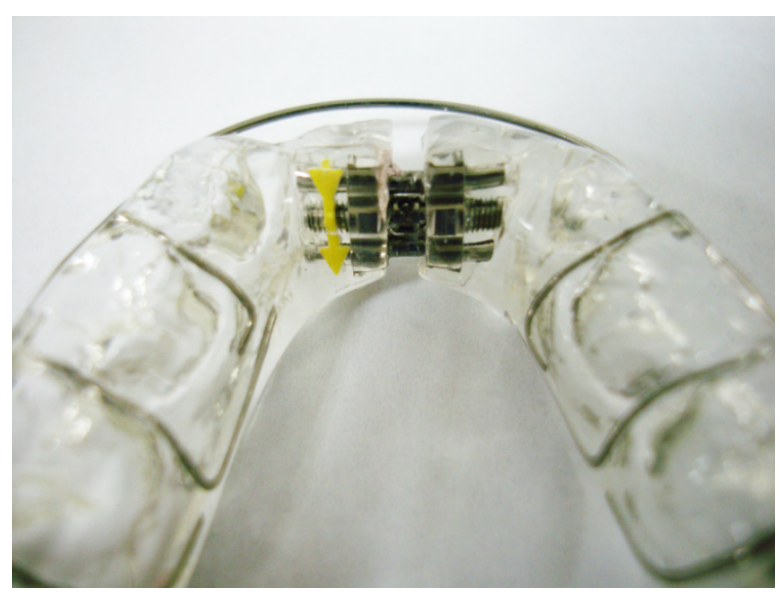

FIGURA 24. Placa de Schwartz

Fuente: elaboración propia

Es importante aclarar que el proceso de expansión del arco inferior solo es recomendable en los casos en que la discrepancia transversal lo requiera y no como tratamiento para las discrepancias dentoalveolares. 


\section{REFERENCIAS}

[1] McNamara JA Jr. Mixed Dentition Treatment. En: Graber TM, Vanarsdall RL, editores. Orthodontics: Current principles and techniques. 2. ${ }^{\text {a }}$ ed. St. Louis: Mosby; 1994. p. 507-541.

[2] Marshall SD, Southard KA, Southard TE. Early Transverse Treatment. Semin. Orthod. 2005;11(3):130-139.

[3] Castañer A. Interceptive orthodontics: the need for early diagnosis and treatment. Med. Oral Patol. Oral. 2006;11:E210.

[4] Nanda R, Snodell S, Bolly P. Transverse growth of maxilla and mandibule. Semin. Orthod. 2012;18:100117.

[5] Ricketts R. Perspectives in the clinical application of cephalometrics. The first fifty years. Angle Orthod. 1981;51(2):115-150.

[6] Vanarsdall R. Transverse dimension and long term stability. Semin. Orthod. 1999;5(3):171-180.

[7] Bell R, Kiebach T. Posterior crossbites in children: Developmental-based diagnosis and implications to normative growth patterns. Semin. Orthod. 2014;20(2):77-113.

[8] Bell, R. A review of maxillary expansion in relation to rate of expansion and patients age. AJO. 1982;8(1):32.

[9] Björk A, Skieller V. Growth in width of the maxilla by the implant method. Scand. J. Plast. Reconstr. Surg. 1974;8:26-33.

[10] Story E. Tissue response to movement of bones. Am. J. Orthod. Dentofacial Orthop. 1973;64:229-247.

[11] Bishara SE, Staley RN. Maxillary expansion: Clinical implications. Am. J. Orthod. Dentofacial Orthop. 1987;91:3-14.

[12] McNamara JA. Maxillary transverse deficiency. Am. J. Orthod. Dentofacial Orthop. 2000;117:567-570.

[13] Haas AJ. Rapid expansion of the maxillary dental arch and nasal cavity by opening the midpalatal suture. Angle Orthod. 1961;31(2):73-90.

[14] Mew JR. Relapse following maxillary expansion. Am. J. Orthod. Dentofacial Orthop. 1983;83:56-61.

[15] Hicks EP. Slow maxillary expansion: a clinical study of the skeletal versus dental response to low magnitude force. Am. J. Orthod. Dentofacial Orthop.1978;73:121-141.

[16] Mundstock KS. Rapid maxillary expansion with the hyrax appliance: An oclusal radiographic evaluation study. World J. Orthod. 2007;8:277-284.

[17] Ekstrom C, Henrikson CO, Jensen R. Mineralization in the midpalatal suture after orthodontic expansion. Am. J. Orthod. Dentofacial Orthop. 1977;71:449-455.

[18] Bell, RA. The effects of maxillary expansion using a quad-helix appliance during the deciduous and mixed dentitions. Am. J. Orthod. Dentofacial Orthop. 1981;79:152-159.

[19] Angelieri F, Cevidanes LH, Franchi L, Gonçalves JR, Benavides E, McNamara JA Jr. Midpalatal suture maturation: classification method for individual assessment before rapid maxillary expansion. Am. J. Orthod. Dentofacial Orthop. 2013 nov;144(5):759-69. doi: 10.1016/j.ajodo.2013.04.022.

[20] Sarver DM, Johnston MW. Skeletal changes in vertical and anterior displacement of the maxilla with bonded rapid palatal expansion appliances. Am. J. Orthod. Dentofacial Orthop.1989;95(6):462-466.

[21] Adkins M, Nanda R, Currier G. Arch perimeter changes on rapid palatal expansión. Am. J. Orthod. Dentofacial Orthop. 1990;97:194-199.

[22] Lione R, Baccetti T. Treatment and posttreatment skeletal effects of rapid maxillary expansion studied with low-dose computed tomography in growing subjects. Am. J. Orthod. Dentofacial Orthop. 2008;134:389-392.

[23] Marcotte MR. The instantaneous transverse changes in the maxilla due to different points of force application. J. Dent. Res. 1977;56:465-470. 
[24] Vargo J, Buschang PH, Boley JC, English JD, Behrents RG, Owen AH. Treatment effects and short-term relapse of maxillomandibular expansion during the early to mid-mixed dentition. Am. J. Orthod. Dentofacial Orthop. 2007 abr;131(4):456-463.

[25] Starnbach H, Bayne D, Cleall J, Subtelny JD. Facioskeletal and dental changes resulting from rapid maxillary expansion. Angle Orthod. 1966;36:152-164.

[26] Asanza S, Cisneros GJ, Nieberg LG. Comparison of Hyrax and bonded expansion appliances. Angle Orthod. 1997;67(1):15-22.

[27] Lander PT, Mulh ZF. Changes concurrent with orthodontic treatment when maxillary expansion is a primary goal. Am. J. Orthod. Dentofacial Orthop. 1995;108:184-193.

[28] Sanddikcioglu, M. Skeletal and dental changes after maxillary expansion in the mixed dentition. AJO. 1997;111(3):32.

[29] Chung CH, Font B. Skeletal and dental changes in the sagittal, vertical, and transverse dimensions after rapid palatal expansion. Am. J. Orthod. Dentofacial Orthop. 2004;126(5):569-575.

[30] Velásquez P. Rapid maxillary expansion. A study of the long-term effects. Am. J. Orthod. Dentofacial Orthop. 1996;109(4):361-367.

[31] Oliveira NL. Relationship between rapid maxillary expansion and nasal cavity size and airway resistance: Short- and long-term effects. Am. J. Orthod. Dentofacial Orthop. 2008;134:370-382.

[32] Montgomery W, Vig PS, Staab EV, Matteson SR. Computed tomography: A three-dimension study of the nasal airway. Am. J. Orthod. Dentofacial Orthop. 1979;76:363-375.

[33] Aquino C, Columbano J, Maris E, da Cuhna M, Issamu L. Immediate changes in condylar position after rapid maxillary expansion. Am. J. Orthod. Dentofacial Orthop. 2014;145(6):771-779.

[34] Gamba D, Castanha J. Longitudinal Effects of Rapid Maxillary Expansion. A Retrospective Cephalometric Study. Angle Orthod. 2007:77(3):442-448.

[35] Greenbaum KR, Zachrisson BU. The effect of palatal expansion therapy on the periodontal supporting tissues. Am. J. Orthod. Dentofacial Orthop. 1982;81:12-21.

[36] Watson WG. Expansion and fenestration or dehiscence. Am. J. Orthod. Dentofacial Orthop. 1980;77:330332.

[37] Wertz RA. Skeletal and dental changes accompanying rapid midpalatal suture opening. Am. J. Orthod. Dentofacial Orthop. 1970;58(1):41-66.

[38] Baccetti T. Treatment timing for rapid maxillary expansion. Angle Orthod. 2001;71:343-350.

[39] David KB, O’Brien M. A bieweekly review of clinical neurological practical. Surgical management of craniosynostosis. Part I. Pathophysiology and initial evolution. Contemporary Neurosurg. 1985;7:1-2.

[40] Bell WH, Epker BN. Surgical orthodontic expansion of the maxilla. Am. J. Orthod. Dentofacial Orthop. 1976;70:517-28.

[41] Lagravere M. Skeletal and dental changes with fixed slow maxillary expansion treatment. A systematic review. JADA. 2005;136:194-199.

[42] Mew J. Evaluation of expansion. Br. J. Orthod. 1992 nov;19(4):332-333

[43] Marshall S, Shroff B. Long term skeletal changes with rapid maxillary expansion A review of the literature. Semin. Orthod. 2012; 8:128-133.

[44] Frank S, Engel G. The effects of maxillary quad-helix appliance expansion on cephalometric measurements in growing orthodontic patients. Am. J. Orthod. Dentofacial Orthop, 1982; 81(5):378-389.

[45] Angell EC. Treatment of irregularities of the permanent adult teeth. Dent. Cosmos. 1860;1:540-544.

[46] Biederman WA. Hygienic appliance for rapid expansion. J. Pract. Orthod. 1968;2:67-70.

[47] Schneidman E, Wilson S, Erkis R. Two-point rapid maxillary expansion: an alternate approach to traditional treatment. Pediatr. Dent. 1990;12:92-97. 
[48] Geran RA, McNamara JA. A prospective long-term study on the effects of rapid maxillary expansion in the early mixed dentition. Am. J. Orthod. Dentofacial Orthop. 2006;129:631-640.

[49] Cozza P, Giancotti A, Petrosino A. Rapid palatal expansion in mixed dentition using modified expander: a cephalometric investigation. J. Orthod. 2001;28:129-134.

[50] Davidovitch M. Skeletal and dental response to rapid maxillary expansion with 2 versus 4 band appliances. Am. J. Orthod. Dentofacial Orthop. 2005;127:483-492.

[51] Bishara SE. Ortodoncia. México DF: Mc Graw Hill; 2003. p. 466-476.

[52] Handelman CS. Nonsurgical Rapid Maxillary Expansion in Adults: Report on 47 Cases Using the Haas Expander. Angle Orthod. 2000;70:129-144.

[53] Manguerza OE, Shapiro PA. Palatal mucoperiotomy: An attempt to reduce relapse after slow maxillary expansion. Am. J. Orthod. Dentofacial Orthop. 1980;78:546-558.

[54] Sari Z, Uysal T, Usumez S, Basciftci FA. Rapid maxillary expansion. Is it better in the mixed or in the permanent dentition? Angle Orthod. 2003 dic;73(6):654-661.

[55] Lamparski D. Comparison of skeletal and dental changes between 2 point and 4 point rapid palatal expanders. Am. J. Orthod. Dentofacial Orthop. 2003;123(3):321-328.

[56] Ricketts RM, Bench RW, Gugino CF, Hilgers JJ, Schulhof RJ. Técnica bioprogresiva de Ricketts. Buenos Aires: Médica Panamericana;1991. p. 245-249.

[57] Asher C. The removable Quadhelix appliance. Br. J. Orthod. 1985;12:40-45.

[58] Bench R. The quad-helix appliance. Semin. Orthod. 1998;4(4): 231-237.

[59] Cozza P, Giancotti A, Rosignoli L. Used of a modified quad helix in early interceptive treatment. J. Clin. Orthod. 2000;34(8):473.

[60] Chaconas SJ, Caputo A. Orthopedic force distribution produced by maxillary orthodontic appliances. Am. J. Orthod. Dentofacial Orthop. 1982;82(6):492-501.

[61] Graber TM. Orthodontics Principles and Practice. 3ra ed. Philadelphia: WB Saunders Co; 1972.

[62] Cotton LA. Slow maxillary expansion: Skeletal versus dental response to low magnitude force in Macaca Mulatta. Am. J. Orthod. Dentofacial Orthop. 1978;73:1-10.

[63] Boysen, B et al. Three dimensional evalution of dentoskeletal changes after posterior cross- bite correction by quad hélix or removable appliances. Br. J. Ortho. 1992;19(2):97-107.

[64] Arndt WV. Nickel titanium palatal expander. J. Clin. Orthod. 1993;27:129-137.

[65] Karaman AI. The Effects of Nitanium Maxillary Expander Appliances on DentofacialStructures. Angle Orthod. 2002;72:344-354.

[66] Iseri H. Change in the width of the mandibular body from 6-23 years. An implant study. Eur. J. Orthod. 2000;22(3):229-238.

[67] Maki K, et al. Expansion of the mandibular arch in children during the mixed dentition period. A clinical study. J. Clin. Pediatr. Dent. 2006;30(4):329-332.

[68] Housley J, et al. Stability of transverse expansion in the mandibular arch. Am. J. Orthod. Dentofacial Orthop. 2003;124(3):288-293.

[69] O'Grady PW, McNamara JA Jr, Baccetti T, Franchi L. A long-term evaluation of the mandibular Schwarz appliance and the acrylic splint expander in early mixed dentition patients. Am. J. Orthod. Dentofacial Orthop. 2006 ago;130(2):202-213.

[70] Wendling LK, McNamara JA Jr, Franchi L, Baccetti T. A prospective study of the short-term treatment effects of the acrylic-splint rapid maxillary expander combined with the lower Schwarz appliance. Angle Orthod. 2005;75(1):7-14. 


\section{CAPÍTULO 7}

\section{TRATAMiENTO DE ALTERACIONES SAGITALES - CLASE II \\ Paola María Botero Mariaca}

Los problemas sagitales de clase II son alteraciones que presentan diferentes manifestaciones orales y esqueléticas, por lo que la etiología del problema es la base para la selección de los aparatos a utilizar en su corrección. También es importante considerar el tiempo exacto para tratar los problemas según su etiología, y así lograr resultados eficientes y eficaces. En este capítulo se muestran los elementos claves para un correcto diagnóstico y las opciones de tratamiento con las correspondientes consideraciones biomecánicas y sus efectos dentales y esqueléticos.

\section{Aspectos GENERALES}

La maloclusión clase II es una alteración de las relaciones oclusales en sentido sagital, que puede combinarse con alteraciones transversales o verticales. Su prevalencia varía según el tipo de población estudiada; en Estados Unidos se encuentra entre el $25 \%$ y el $30 \%$, en Asia y América Latina entre el 10\% y el 15\%. En estudios realizados en población colombiana, específicamente en Bogotá, se reporta una prevalencia del $20.8 \%$ al $24.9 \%$, mientras que en Envigado (Antioquia) se registra una prevalencia mayor de $43.5 \%$.

Su etiología es multifactorial, con influencias genéticas y medioambientales. Puede ser dental, dentoalveolar o esquelética. Las alteraciones esqueléticas se deben a la posición o al tamaño aumentado del maxilar (Figura 1), a una mandíbula pequeña o posicionada hacia atrás (con respecto a la base craneal). También pueden producirse por combinación de ambas.
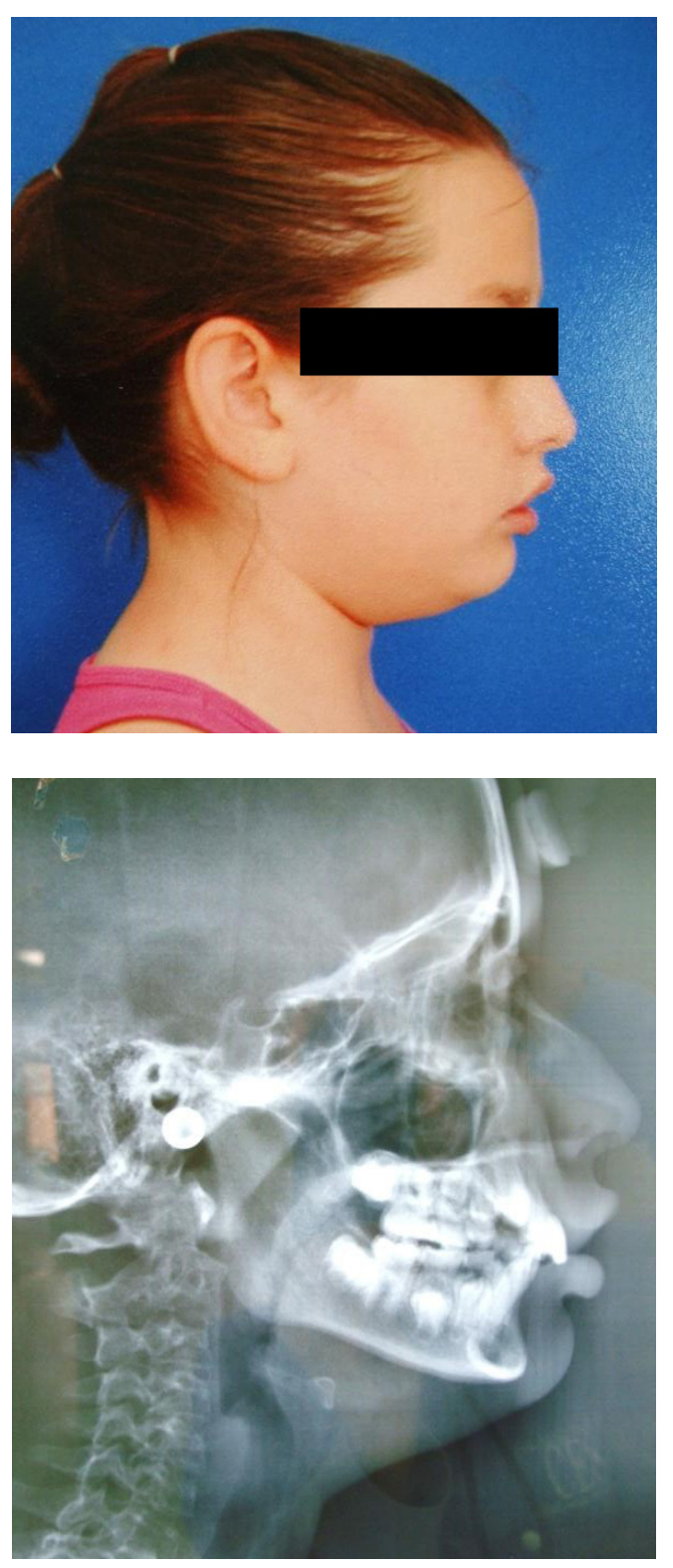

FIGURA 1. Paciente clase II esquelética por prognatismo maxilar

Fuente: elaboración propia

Según sus características dentales y esqueléticas, la maloclusión clase in puede dividirse en dos tipos principales: clase in división 1 y clase II división 2 (Figura 2). La primera presenta incisivos superiores vestibularizados; overjet aumentado; maxilar superior estrecho; mordida abierta, normal o profunda; perfil convexo; función muscular de labios y mentón alterada; y esqueléticamente un ángulo ANB y Wits 
aumentados (prognatismo maxilar, retrognatismo mandibular o combinación de ambos). Los individuos con maloclusión clase II división 2 presentan incisivos (de 2 a 6 dientes anteriores) lingualizados y extruidos; overjet mínimo; mordida profunda; arco superior con amplitud normal; distancia intercanina inferior disminuida; perfil ligeramente convexo o recto, por presentar mentón prominente; labio inferior curvo; línea labial alta; ANB ligeramente aumentado (prognatismo maxilar con retrognatismo mandibular); punto B retrognático con referencia a la base craneal, y crecimiento horizontal [1-3].
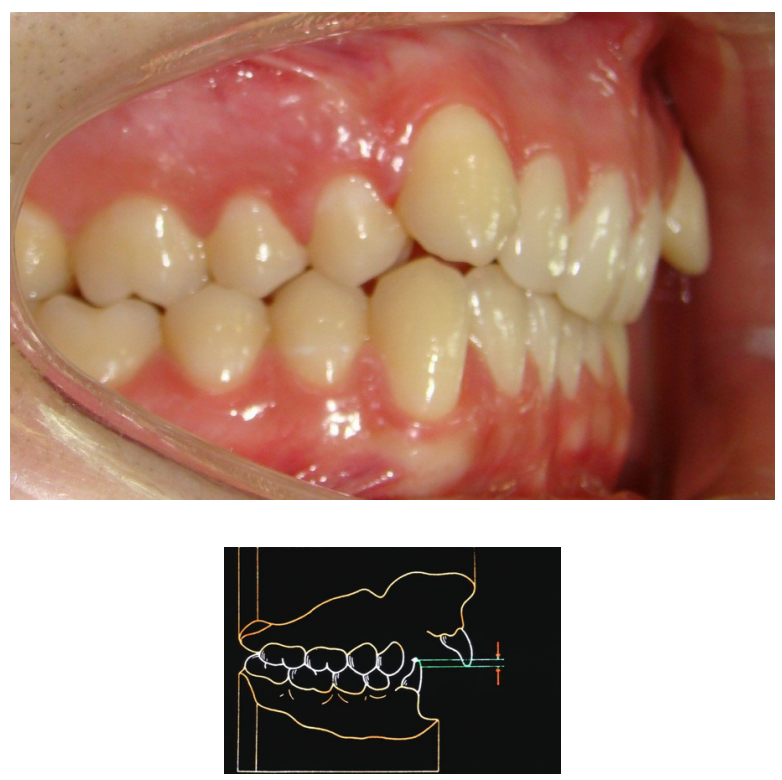

FIGURA 2. Maloclusión clase II división 1 y división 2

$$
\text { Fuente: elaboración propia }
$$

La orientación del tratamiento depende de la etiología del problema y la edad, la cual influye en la posibilidad o no de modificar la estructura alterada. Cuando la etiología es maxilar, el tratamiento debe empezar entre los 8 y 12 años, para intervenir durante el pico de crecimiento del hueso maxilar; si el problema es mandibular se busca intervenir durante el pico de crecimiento general, ya que el estímulo es más eficiente para generar un crecimiento de esa estructura (Tabla 1).
TABLA 1

Pico de crecimiento maxilar y mandibular

\begin{tabular}{|c|c|c|}
\hline & $\begin{array}{l}\text { Picos de crecimiento } \\
\text { maxilar }\end{array}$ & $\begin{array}{l}\text { Picos de crecimiento } \\
\text { mandibular }\end{array}$ \\
\hline $\begin{array}{l}\text { Primer } \\
\text { pico }\end{array}$ & 6 a 8 años de edad & $\begin{array}{l}\text { Desde el nacimiento } \\
\text { hasta los } 3 \text { años de } \\
\text { edad }\end{array}$ \\
\hline $\begin{array}{l}\text { Segundo } \\
\text { pico }\end{array}$ & $\begin{array}{l}\text { Coincide con el pico de } \\
\text { crecimiento puberal: } \\
10.5 \text { a } 13 \text { años en } \\
\text { mujeres } \\
12.5 \text { a } 15 \text { años en } \\
\text { hombres }\end{array}$ & $\begin{array}{l}6 \text { a } 7 \text { años mujeres } \\
8 \text { a } 9 \text { años en hombres }\end{array}$ \\
\hline \multirow[t]{2}{*}{$\begin{array}{l}\text { Tercer } \\
\text { pico }\end{array}$} & No presenta & $\begin{array}{l}\text { Coincide con el pico de } \\
\text { crecimiento puberal: } \\
11 \text { a } 12 \text { años en } \\
\text { mujeres } \\
11 \text { a } 15 \text { años en } \\
\text { hombres }\end{array}$ \\
\hline & $\begin{array}{l}\text { No es propiamente } \\
\text { un pico pero aunque } \\
\text { el crecimiento sagital } \\
\text { cese de los } 12 \text { a } 14 \\
\text { años, el crecimiento } \\
\text { vertical continua hasta } \\
\text { los } 16 \text { años }\end{array}$ & $\begin{array}{l}\text { El crecimiento mandi- } \\
\text { bular presenta un cre- } \\
\text { cimiento residual hasta } \\
\text { los } 21 \text { años de edad }\end{array}$ \\
\hline
\end{tabular}

Fuente: elaboración propia

\section{TRATAMIENTO DE PROGNATISMO Y MACROGNATISMO MAXILAR}

\section{TRACCIONES EXTRAORALES}

Las tracciones extraorales están entre los tratamientos posibles para las maloclusiones clase II esqueléticas, con origen en una protrusión maxilar y/o un maxilar aumentado de tamaño. Este tipo de aparato ha sido empleado desde comienzos del siglo XIX hasta la fecha $[4,5]$.

Definición. Es un aparato extraoral a través del cual se aplican fuerzas a la cavidad oral (específicamente en los primeros molares). Dichas fuerzas se generan externamente mediante un sistema de anclaje extraoral, apoyado en la zona occipital, cervical o parietal del sistema estomatognático.

Clasificación. Las tracciones extraorales se clasifican en tres, según la ubicación del punto 
de apoyo de la fuerza y su dirección de aplicación [6]. Todas tienen efectos sagitales similares pero diferentes efectos verticales y transversales:

a. Tracción cervical, baja o recta: el punto de apoyo es el cuello, genera efecto de extrusión, como distalización y lingualización de los molares; el maxilar responde con redirección y restricción del crecimiento. Está indicada en pacientes mesocefálicos con crecimiento horizontal.

b. Tracción alta o parietal: el punto de apoyo se encuentra en el cráneo; genera intrusión, vestibularización y distalización sobre los molares. A nivel del maxilar, produce un efecto rotacional debido a que presenta el punto de apoyo por encima de la corona del cráneo. Está indicada en pacientes dolicofaciales.

c. Tracción combinada u occipital: constituye la combinación de las dos anteriores; está indicada en pacientes sin alteraciones verticales evidentes, gracias a que la fuerza resultante evita que existan rotaciones óseas y dentales.

Algunos autores sugieren que la selección del tipo de tracción debe basarse en el tipo de rotación mandibular, según el ángulo del plano mandibular y el plano de Frankfort. La tracción cervical estaría indicada en pacientes con ángulos menores a 37 grados; la tracción alta, en ángulos mayores de 41 grados; y la tracción combinada en pacientes con ángulos entre 37 y 41 grados. Por otro lado, Tortop sugiere que la selección del tipo de tracción depende del plano oclusal, el plano mandibular y las diferencias verticales observadas en el primer molar [7].

\section{Tracción cervical o baja}

Tracción extraoral donde la fuerza de anclaje se ubica en la zona cervical del paciente (cuello; Figura 3).

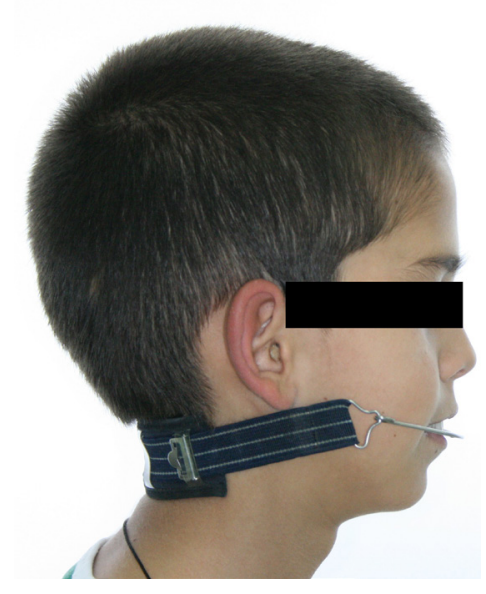

FIGURA 3. Paciente con tracción cervical en posición

Fuente: elaboración propia

\section{Componentes}

1. Arco extraoral. Arco en acero formado por un arco interno y uno externo, unidos con una soldadura en la parte media anterior (Figura 4). En la zona de la soldadura, el arco presenta una marca: un rombo o una L, dependiendo del fabricante (Figura 5). La finalidad de la marca es que el clínico establezca el derecho o el revés del arco [8].

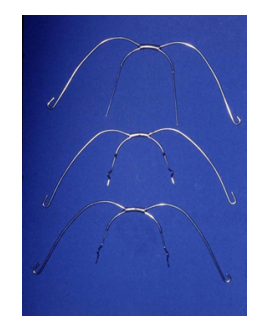

FIGURA 4. Arco extraoral para tracciones Fuente: elaboración propia 


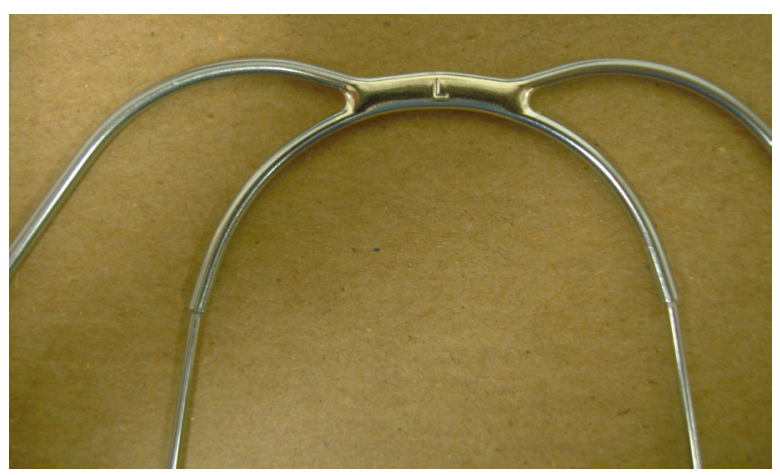

FIGURA 5. Marca en forma de $L$ en la soldadura que une el arco interno con el arco externo

Fuente: elaboración propia

2. Arco interno. Alambre en acero inoxidable de 0.045" o 0.052"; su extremo posterior se inserta en los tubos de las bandas de los primeros molares. Presenta dos diseños: el primero tiene ansas preformadas y ubicadas anterior al primer molar (Figura 6), que permiten realizar ajustes verticales y transversales de manera rápida. Este arco viene en diferentes tamaños (3.5 a $5.5 \mathrm{~mm}$ ), que se eligen según la longitud del arco del paciente. Esta se puede medir en el modelo, usando la regla flexible que trae la tracción, en la que se aprecian los tamaños de arcos internos a los que corresponde cada longitud de arco (Figura 7) [8].
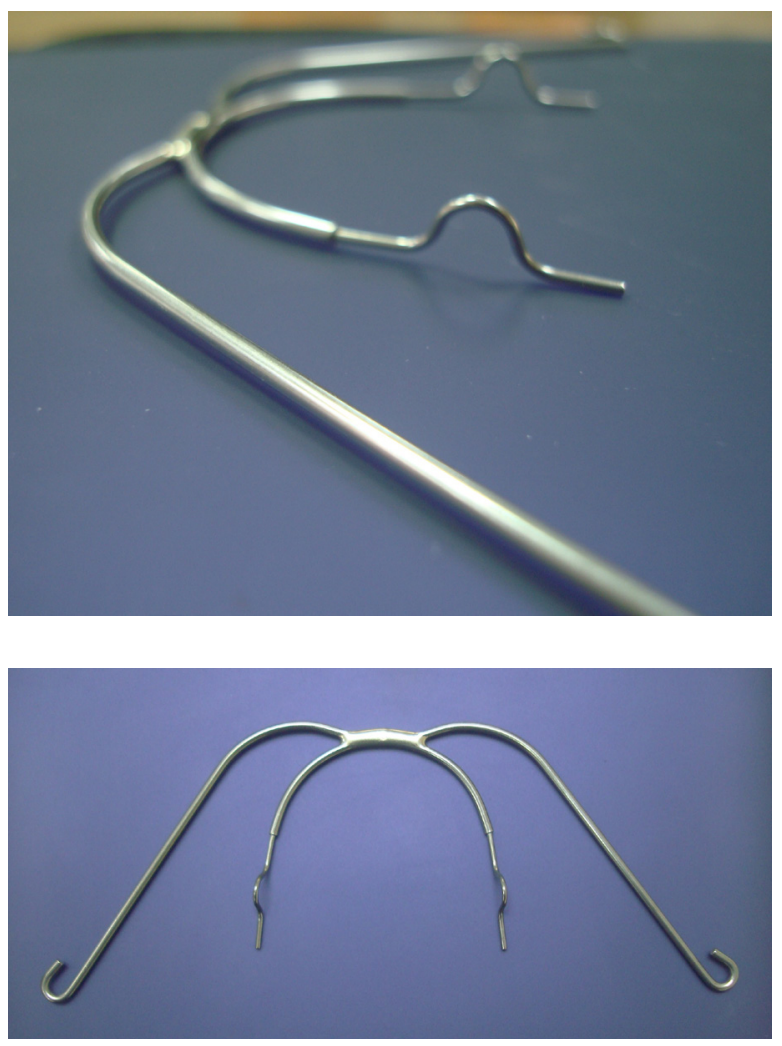

FIGURA 6. Arco interno con ansas

Fuente: elaboración propia

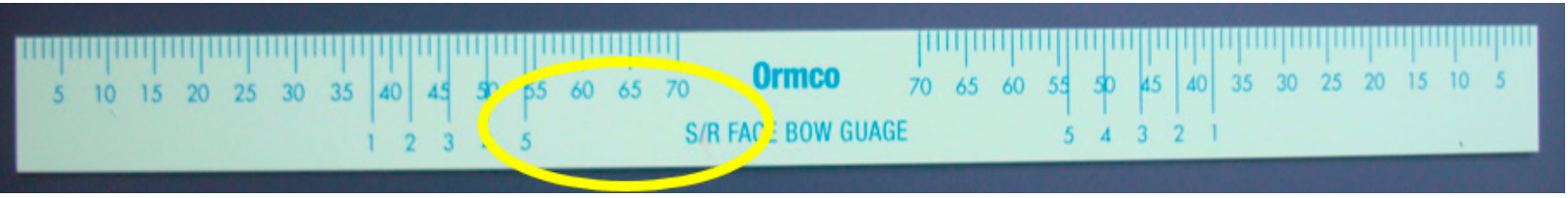

FIGURA ?. Regla flexible milimetrada

Fuente: elaboración propia

El segundo diseño es el arco estándar; es liso (sin ningún tipo de doblez), para permitir al clínico hacer los dobleces de ajuste, según la longitud de arco del paciente. Se pueden hacer ansas en sentido vertical, similares a las que vienen preformadas, o dobleces de bayoneta en sentido horizontal. Estos se realizan mesiales a los molares superiores, con la finalidad de generar un tope para el arco y así mantener la distancia de su zona anterior con respecto a la cara vestibular de los incisivos superiores (Figura 8). Los dobleces y las ansas se elaboran con la ayuda de la pinza tres picos y con la pinza 139 (Figura 9). Después del doblez, la parte final debe quedar paralela a los tubos para facilitar la inserción del aparato. Por otro lado, al 
arco interno se le puede hacer un doblez hacia adentro para desrotar los molares.
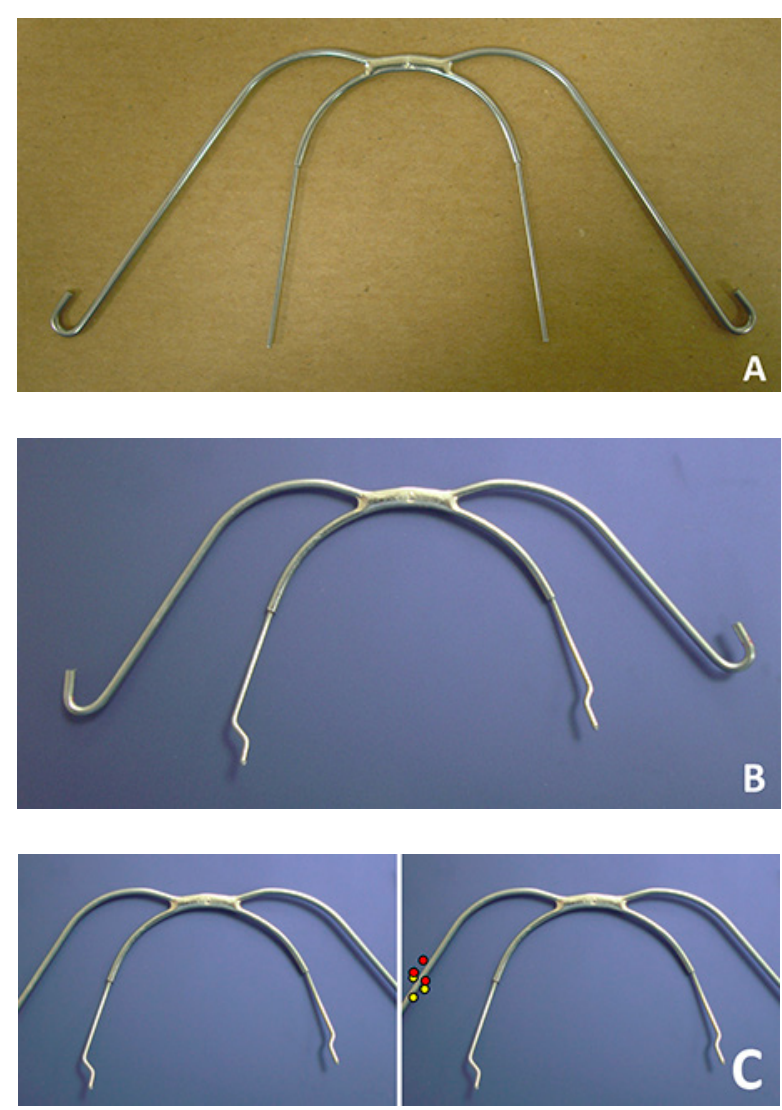

FIGURA 8. (A) Arco interno estándar sin dobleces. (B-C) Bayonetas realizadas en arco externo con ayuda de pinza tres picos. Círculos rojos: ubicación de la pinza en el primer doblez. Círculos amarillos: ubicación de la pinza en el segundo doblez

Fuente: elaboración propia

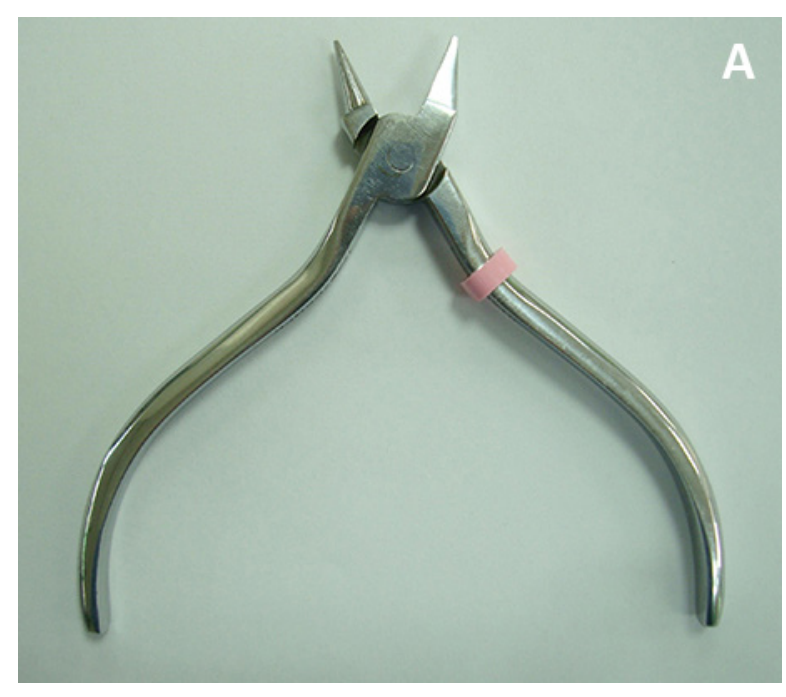

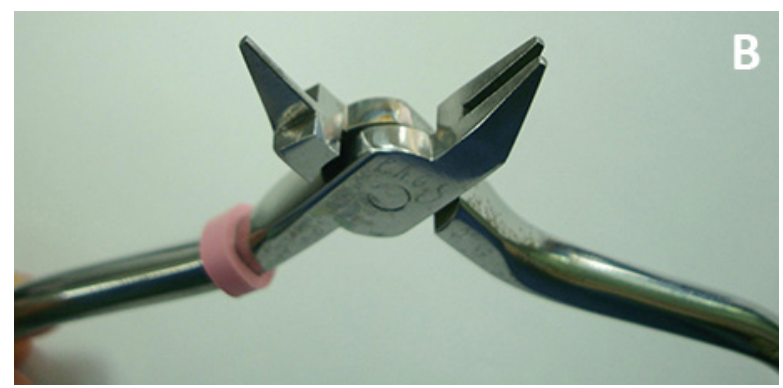

FIGURA 9. (A) Pinza 139. (B) Pinza tres picos

Fuente: elaboración propia

Durante el proceso de adaptación del arco interno, se deben tener las siguientes consideraciones:

- Debe adaptarse según la forma del arco del paciente.

- Los dobleces (bayoneta o ansa] realizados en los arcos en mesial de los primeros molares tienen el objetivo de evitar el deslizamiento del arco hacia distal de la arcada; esto permite que funcione como escudo, separando la musculatura.

- Es necesario verificar que exista una separación de 3 a $4 \mathrm{~mm}$ en la zona premolar.

- El efecto en el overjet es determinante para establecer la distancia que debe llevar el arco interno con respecto a los incisivos superiores. Si se quiere reducir el overjet, el arco interno debe ir en contacto con los incisivos [6]. Si no se desean cambios en el overjet o si se busca una distalización adecuada del molar, el arco interno debe quedar separado de los incisivos de 5 a $7 \mathrm{~mm}$ en la zona anterior.

- El punto de unión de los arcos interno y externo debe coincidir con la línea media facial del paciente (la marca que tiene la soldadura de los arcos puede 
servir como guía para su ubicación). Verticalmente, debe quedar ubicado en la mitad de los labios para la comodidad del paciente (Figura 10).

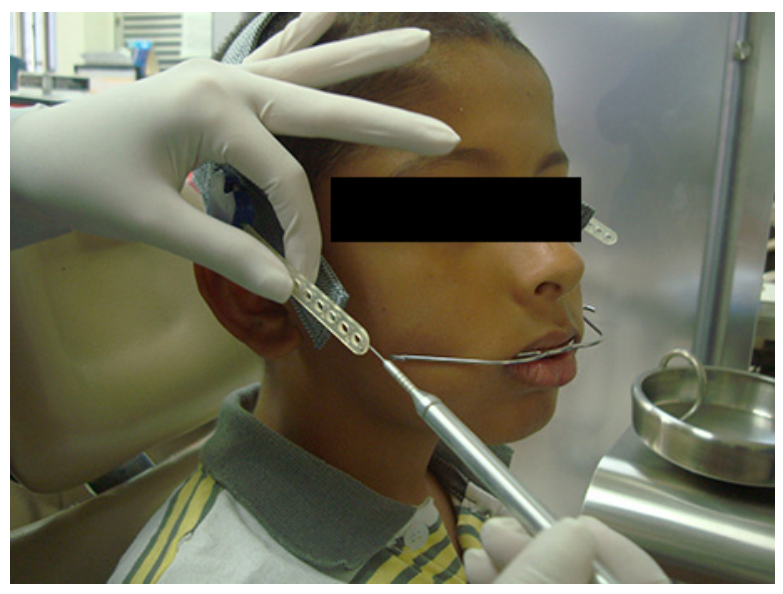

FIGURA 10. Arco externo en posición en la mitad de los labios

Fuente: elaboración propia

3. Arco externo. Tiene un diámetro de 0.062" o 0.072". Cada uno de sus extremos termina en forma de gancho, donde se inserta el elástico o resorte para la tracción (Figura 11). Según los objetivos del tratamiento, en sentido anteroposterior, este arco puede ser corto, mediano o largo en longitud, con relación al arco interno. En sentido vertical, puede colocarse paralelo al arco interno o con inclinación hacia arriba o abajo (entre 10 y 20 grados). Con una inclinación hacia arriba se disminuye la extrusión de los molares, que rotan en contra de las manecillas del reloj, y con una inclinación hacia abajo, los molares se extruyen y rotan a favor de las manecillas del reloj. Si se aplica una fuerza ortopédica cuando el arco externo se encuentra doblado hacia abajo, se habla de una rotación caudal del maxilar, y de una rotación craneal, en el caso contrario [8].
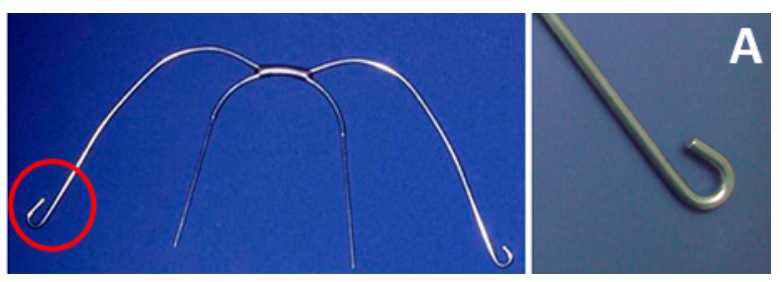

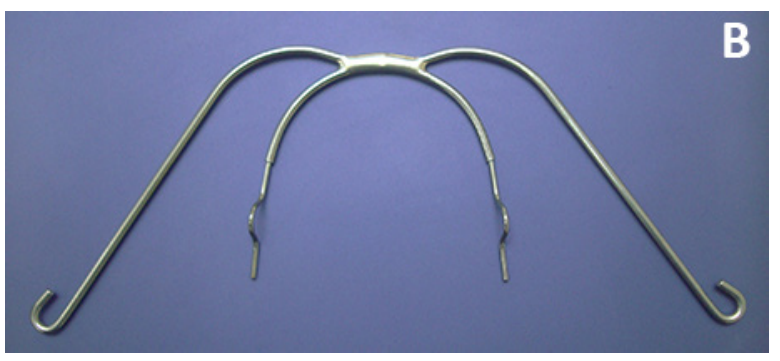

FIGURA 11. (A) Gancho para anclaje de la banda elástica (resaltado en círculo). (B) Arco extraoral de tracción

Fuente: elaboración propia

La longitud del arco externo puede ajustarse según las necesidades del paciente: puede ser corto (antes del centro de resistencia del maxilar o del diente), mediano (a nivel del centro de resistencia del maxilar o del diente) o largo (después del centro de resistencia del maxilar o del diente). El arco mediano, al pasar por el centro de resistencia, no genera ninguna inclinación en el molar; cuando es corto o largo, el momento de la fuerza se incrementa y, por tanto, la inclinación o rotación del diente o del maxilar.

En sentido transversal, se puede separar o abrir ambos lados (hacia afuera de la mejilla) entre 8 y $10 \mathrm{~mm}$. Esto contrarresta el efecto de lingualización que se presenta con este tipo de tracción, producto del punto de origen de la fuerza.

En los casos en que se requiera mayor distalización en un molar que en otro (distalización asimétrica), el arco externo debe quedar más largo y separado de la mejilla que el otro. Así aumenta la fuerza de distalización en el molar que necesite mayor movimiento.

4. Cinta o banda elástica. Tiene un ancho de $2.5 \mathrm{~mm}$ y un sistema de corredera para dar los ajustes necesarios (Figura 12). Conecta el arco facial con la unidad de anclaje. Esta transmite la fuerza al arco externo y este, a su vez, lo hace al arco interno, que lo trasmite a los primeros molares. Viene con un protector para el cuello del paciente (Figuras 
13 y 14). La fuerza aplicada puede ser ortodóntica (movimientos dentales únicamente) u ortopédica (movimiento del maxilar); la primera se trataría de una fuerza continua (24 horas de uso del aparato) de 150 a 200 gr, y la otra sería una fuerza intermitente (14 horas diarias de uso) de 400 a 500 gr (con un máximo de 1000 gr). La fuerza se puede determinar con el uso de un dinamómetro (Figura 15) [8].

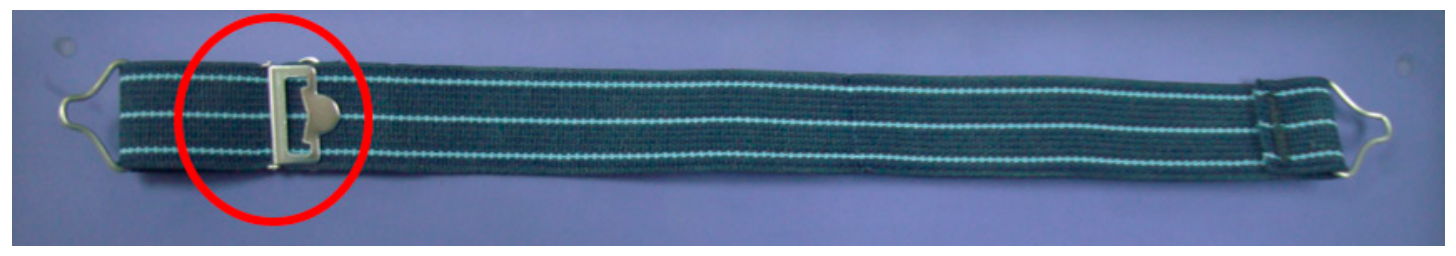

FIGURA 12. Cinta elástica y mecanismo de ajuste para establecer fuerza necesaria

Fuente: elaboración propia

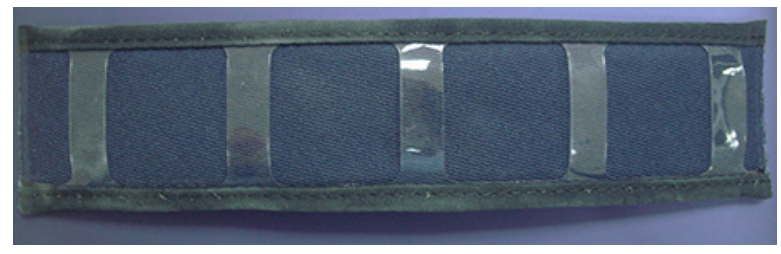

FIGURA 13. Protector de cuello para insertar banda elástica Fuente: elaboración propia

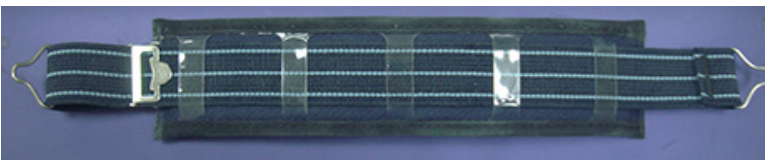

FIGURA 14. Banda elástica en posición dentro del protector Fuente: elaboración propia

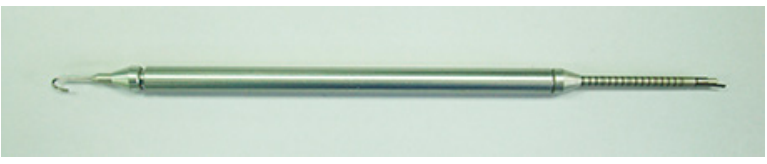

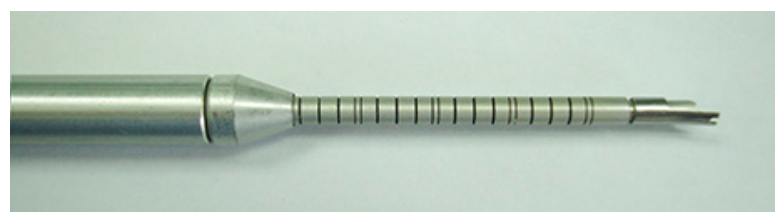

FIGURA 15. Dinamómetro

Fuente: elaboración propia

La medición del dinamómetro es en onzas, mide un total de 16 oz equivalentes a 453.60 gr (Tabla 2). Cada onza viene demarcada por una línea (Figura 15) y su lectura puede hacerse con ayuda de una tabla (Tabla 3). El gancho del dinamómetro se ubica en uno de los extremos metálicos de la banda elástica (Figura 16; con la banda en posición en el cuello del paciente) y se procede a llevarlo hasta el gancho del arco externo, donde se registra la medida de la fuerza.

TABLA 2

Tabla de registro de gramos y onzas del dinamómetro

\begin{tabular}{cccccccccccccccccc}
\hline Onzas & 1 & 2 & 3 & 4 & 5 & 6 & 7 & 8 & 9 & 10 & 11 & 12 & 13 & 14 & 15 & 16 \\
\hline Gramos & 28,35 & 56,7 & 85,1 & 113,4 & 141,7 & 170,1 & 198,4 & 226,8 & 255,1 & 283,5 & 311,8 & 340,2 & 368,5 & 396,9 & 425,2 & 453,6 \\
\hline
\end{tabular}

Fuente: elaboración propia 
TABLA 3

Representación del dinamómetro

\begin{tabular}{|c|c|c|c|c|c|c|c|c|c|c|c|c|c|c|c|c|}
\hline $0 z$ & 1 & 2 & 3 & 4 & 5 & 6 & 7 & 8 & 9 & 10 & 11 & 12 & 13 & 14 & 15 & 16 \\
\hline $\mathrm{gr}$ & 28,35 & 56,70 & 85,05 & 113,4 & 141,7 & 170,1 & 198,4 & 226,8 & 255,1 & 283,5 & 311,8 & 340,2 & 368,5 & 396,9 & 425,5 & 453,6 \\
\hline
\end{tabular}

Fuente: elaboración propia

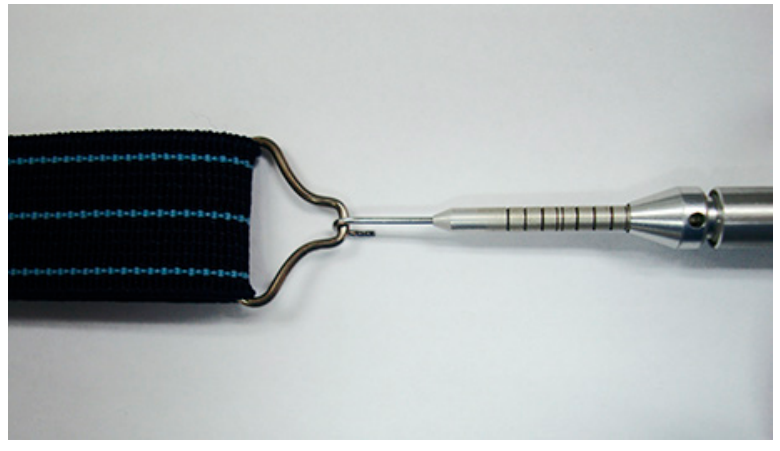

FIGURA 16. Forma de medir la fuerza con el dinamómetro Fuente: elaboración propia

5. Unidad de anclaje. Corresponde al punto de apoyo (cervical), y distribuye la fuerza a los dientes y a las estructuras esqueléticas adyacentes.

6. Bandas en acero y tubos dobles. Las bandas se adaptan en los primeros molares permanentes, donde se sueldan los tubos dobles (Figura 17) o el tubo redondo sencillo de 0.45 " a 0.50 ". Idealmente, el tubo redondo debe ir hacia gingival para estar más cerca del centro de resistencia del molar; sin embargo, por higiene y para evitar inflamación del margen gingival, los tubos se sueldan hacia oclusal.

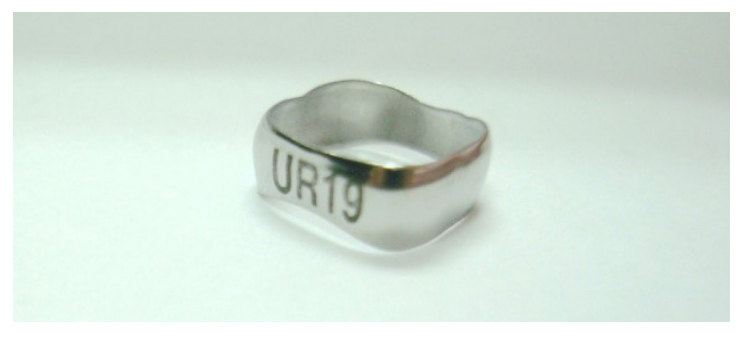

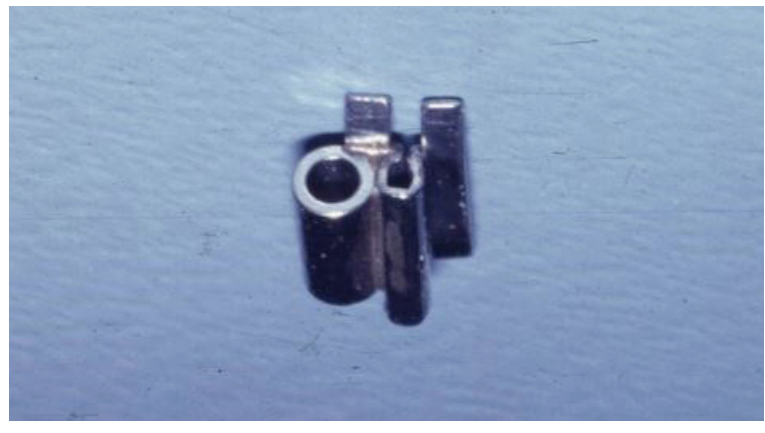

FIGURA 17. Banda y tubo doble (tubo rectangular $y$ tubo redondo de 0.45 " o 0.5 ")

Fuente: elaboración propia

\section{Biomecánica}

1. Centro de resistencia. se debe tener en cuenta el centro de resistencia del molar o del maxilar, dependiendo del tipo de efecto dental o esquelético que se desee lograr. El centro de resistencia del molar está a nivel de la trifurcación y su ubicación depende de la dimensión de la raíz y de la condición de los tejidos de soporte. El centro de resistencia del maxilar se ubica en el área posterior de la sutura cigomática maxilar [8] o en la parte posterosuperior de la fisura pterigomaxilar [8]. Cuando los dientes se encuentran unidos, como en los casos de pacientes con un aparato intraoral tipo Hawley o aparato funcional, surge otro centro de resistencia que es dentoalveolar y se ubica en la zona apical, entre los bicúspides (Figura 18) [8]. 

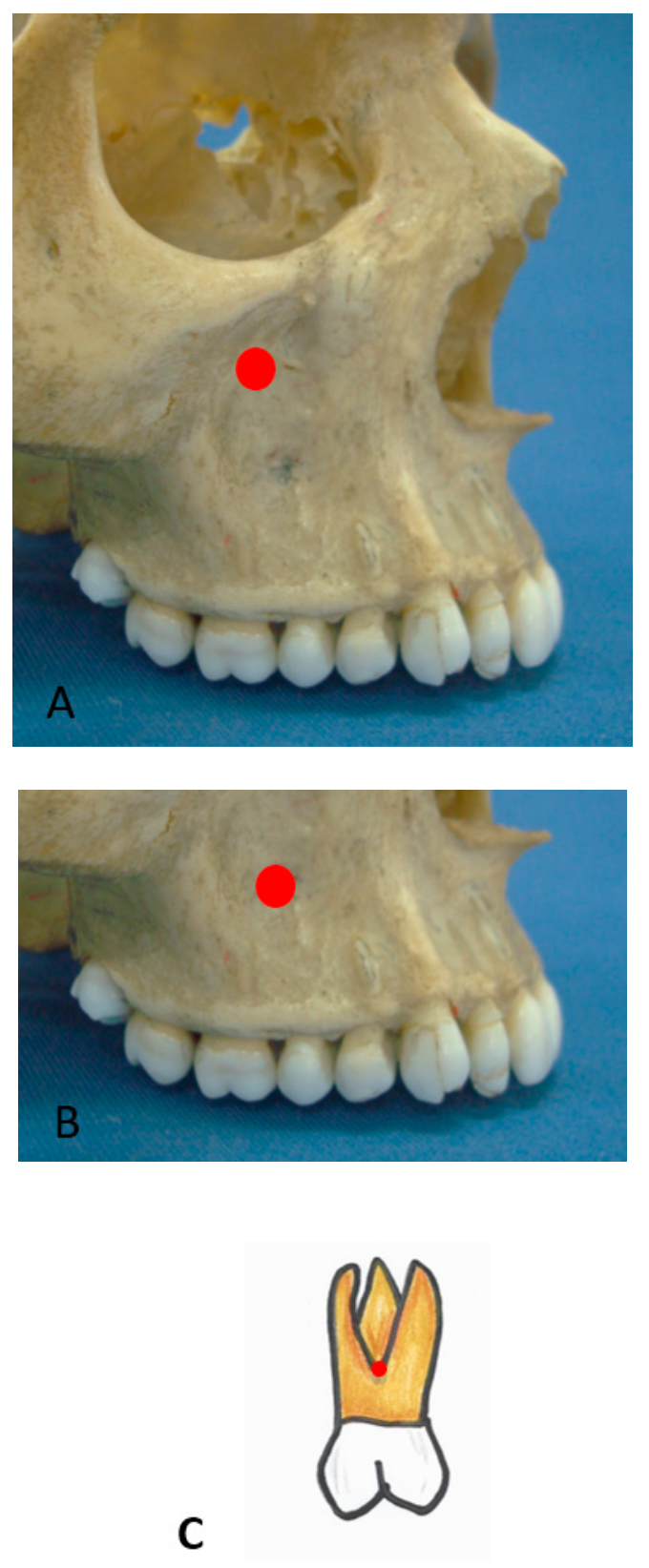

FIGURA 18. Centros de resistencia. (A) Centro de resistencia del maxilar. (B) Centro de resistencia dentoalveolar.

(C) Centro de resistencia dental

Fuente: elaboración propia

2. Centro de rotación. Centro en el cual rota una estructura; en el caso de la tracción, son los molares o el maxilar. El maxilar o el molar, según el tipo de respuesta esperada, rotarán a favor o en contra de las manecillas del reloj, lo cual depende respectivamente de que la fuerza pase por debajo o por encima del centro de resistencia [8].
3. Fuerza. Cantidad vectorial que tiene la capacidad de modificar el estado de reposo de un cuerpo. Guarda relación con la intensidad, el punto de aplicación, la línea de acción y la dirección. En la tracción, la fuerza se aplica por medio de los resortes o cintas elásticas, para mover los molares o el maxilar en los tres planos del espacio (sagital, vertical y transversal). Las fuerzas aplicadas pueden ser dentales o esqueléticas. Las fuerzas dentales deben ser continuas (idealmente 24 horas) y de intensidad baja (150 a 200 gr); y las fueras ortopédicas deben ser intermitentes (12 a 14 horas al día) y de intensidad alta (400 a 500 gr) [8].

4. Intensidad: el grado o nivel de una fuerza que se aplica sobre un objeto natural o un dispositivo mecánico. Se expresa en gramos.

5. Punto de aplicación: son los molares superiores que, con las bandas y tubos, reciben la fuerza mediante el arco extraoral.

6. Línea de acción: para determinarla, se debe mirar la banda del extraoral del arco externo con respecto al cuerpo sobre el cual se está aplicando; refleja la dirección en que se mueven los molares.

7. Dirección: orientación de la fuerza que se está aplicando respecto al eje de rotación de los molares y el maxilar.

8. Momento de una fuerza: momento es la tendencia rotacional de un objeto, generada por una fuerza que pasa lejos del centro de resistencia de este. La fuerza produce un desplazamiento del diente en dirección a la línea de aplicación de la fuerza, pero al pasar lejos del centro de resistencia hace que el diente se desplace con una rotación. Para determinar la dirección de la rotación del momento, se continúa la línea de acción de la fuerza alrededor del centro de resistencia del objeto. 
Por ejemplo, cuando la fuerza pasa por encima del centro de resistencia, el molar rota la corona a mesial y la raíz a distal; por el contrario, si la fuerza pasa por debajo del centro de resistencia, la corona va hacia distal y la raíz a mesial (Figura 19).

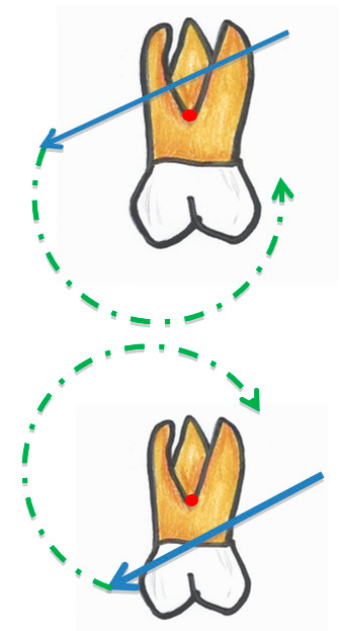

FIGURA 19. Dirección del momento de fuerzas, que pasan por encima o por debajo del centro de resistencia del molar

Fuente: elaboración propia

9. Duración del tratamiento: los estudios reportan que los efectos del aparato se pueden evidenciar entre los 6 y 12 meses de tratamiento. Sin embargo, si el objetivo de la tracción es el control de crecimiento maxilar, esta debe dejarse como retención hasta que ese hueso termine su crecimiento.

10. Sistema de fuerza: es importante particularizar las diferentes fuerzas que actúan sobre las estructuras:

- Fuerza actuante: dada por los elásticos extraorales.

- Fuerza recíproca: punto de apoyo dado fuera de la cavidad oral.

- Fuerza direccional: las fuerzas actúan igual y opuestas, desarrolladas por un elemento activo. En el caso de la tracción, es la cinta que presiona el cuello o la parte de apoyo en la cabeza, que están fijos, por lo que este extremo recíproco se estabiliza y el arco extraoral actúa en los molares.

- Fuerza de resistencia: dada por las fibras intraalveolares de los molares y las suturas del complejo craneofacial; los molares deben resistir la fuerza y transmitirla al maxilar y a las suturas

Como se mencionó, la línea de acción es la dirección en la que actúa la fuerza, la relación de esta hacia el centro de resistencia del maxilar o del primer molar determina si se da rotación o translación. Cuando una fuerza no pasa a través del centro de resistencia del maxilar o del molar se da un momento, cuya magnitud es determinada por el producto de la magnitud de la fuerza y la distancia perpendicular de la línea de la fuerza al centro de resistencia (Figura 20). La dirección de la línea de la fuerza puede ser cambiada ajustando la longitud del arco central o doblando el arco externo hacia arriba o abajo, para producir el efecto clínico deseado [9].

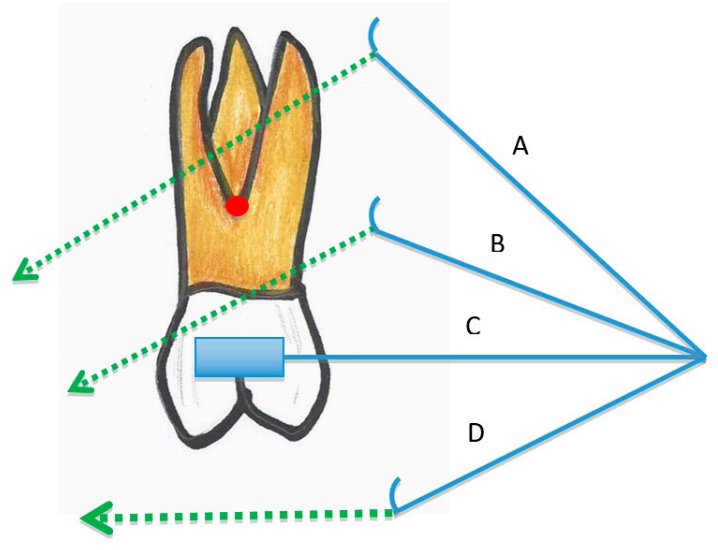

FIGURA 20. Sistema de fuerzas aplicadas a un molar a través de un arco externo con diferente inclinación.

(A) Fuerza encima del C. R. que genera extrusión, movimiento mesial de la corona y distal de la raíz. (B) Fuerza por debajo del C. R. hacia arriba que genera movimiento distal de la corona, con momento horario. (C) Arco interno adaptado al tubo de la banda del primer molar. (D) Fuerza por debajo del C. R. hacia abajo que genera extrusión, movimiento distal de la corona, con momento horario

Fuente: elaboración propia 
Pasos para la instalación:

a. Determinar el centro de resistencia donde se aplica la fuerza del casquete (diente, arco o maxilar).

b. Determinar el sistema de fuerzas que pasan a través del centro de resistencia; puede ser horizontal, vertical o inclinación de plano oclusal.

c. Marcar el centro de resistencia en la mejilla del paciente.

d. Adaptar el arco interno según lo descrito anteriormente. Luego se procede a adaptar el arco externo determinando su longitud e inclinación, según las necesidades verticales del paciente, esto determina la línea de acción de la fuerza.

e. Seleccionar la magnitud de la fuerza extraoral, ajustando la banda elástica según la cantidad de fuerza requerida, con el uso del dinamómetro.

Aplicaciones clínicas de la fuerza extraoral [9]:

a. Control de anclaje.

b. Desplazamiento de molares a distal.

c. Cambios ortopédicos.

d. Control de la inclinación del plano oclusal.

\section{Efectos}

Para entender los efectos de los aparatos destinados a controlar el crecimiento del maxilar, debemos conocer cómo es el crecimiento normal de esta estructura. El maxilar crece abajo y adelante, con reabsorción en la zona anterior y aposición en la zona posterior (tuberosidad). Gracias al crecimiento aposicional a nivel posterior y por el crecimiento de otras estructuras como la base craneal y el septum nasal, el desplazamiento final del maxilar es abajo y adelante [10].
Las tracciones extraorales pueden presentar varios efectos, dependiendo del ajuste de sus componentes, el tipo de tracción empleada (anclaje) y las necesidades de los pacientes. Tradicionalmente, la tracción cervical ha estado contraindicada en pacientes con crecimiento vertical o hiperdivergente, debido a la posibilidad de generar cambios en la rotación vertical mandibular y extrusión molar maxilar. Sin embargo, en estudios recientes se muestra que, si se realizan los ajustes biomecánicos adecuados, los efectos verticales se pueden controlar e incluso evitar [10].

Dependiendo del modo en que se active el aparato, los efectos esperados pueden ser de dos tipos: dentales y esqueléticos:

a. Dentales: la relación molar cambia gracias a una distalización del primer molar superior. Los estudios muestran una reducción de la clase II de 3.7 a 6.9 mm, una mejoría en la relación canina de $1.9 \mathrm{~mm}$ (28\%) y una reducción del overjet entre 0.8 y $4.75 \mathrm{~mm}(11 \%)[11,12]$. Los cambios en el overjet no son muy notorios, debido al incremento en la labialización de los incisivos que ocurre con la tracción (entre 0.5 y 5.5 grados). Sin embargo, hay un estudio que reporta lingualización de 2.28 grados; y otros muestran una reducción del overjet de $1.5 \mathrm{~mm}$ [12]. Cuando el efecto de labialización no es deseado, se contrarresta empleando aparatos adicionales a las tracciones extraorales que tengan arcos vestibulares; la fuerza aplicada en los primeros molares se transmite a los incisivos, generando un control de su posición labial o incluso una lingualización.

La inclinación del brazo externo hacia abajo produce distalización (0.91 a $6.8 \mathrm{~mm}$ ), extrusión del primer molar (de $1.9 \mathrm{~mm}$, en niños y de $5.0 \mathrm{~mm}$ en niñas) e inclinación del molar hacia distal, debido a que la fuerza aplicada pasa por debajo del centro de resistencia del molar. El arco externo 
inclinado hacia arriba inclina las raíces a distal a medida que la corona se distaliza, y se incrementa el ángulo sN-PP en un $85 \%$ de los casos. Con respecto a la extrusión, existen resultados diferentes según el estudio y la biomecánica del aparato: unos reportan una extrusión de 2.3 a 3.5 mm; otros de $1.25 \mathrm{~mm}$, mientras que otros de solo $0.56 \mathrm{~mm}$, y finalmente algunos estudios no reportan extrusión. El doblez hacia arriba del arco externo, de 10 a 20 grados, controla la cantidad de extrusión del molar o incluso la evita [10-14]. Por otro lado, la extrusión del molar también se puede ver compensada por el movimiento anterior de la mandíbula, en presencia de un adecuado crecimiento durante el tratamiento y por un crecimiento aumentado de la altura de la rama. Esto hace que el ángulo del plano mandíbular no cambie con el tratamiento [7].

Otro efecto dental que se observa con la tracción es el aumento de la distancia intercanina e intermolar superior y, ligeramente, las inferiores. El aumento en la distancia intermolar se reporta en los casos en que el arco interno de la tracción se expande entre 8 y $10 \mathrm{~mm}[15,16]$. Sin embargo, no se lograron cambios esqueléticos transversales y la cantidad de expansión dental fue menor que la alcanzada por otros medios de expansión ortodóncica. Por tanto, los pacientes que presentan apiñamiento superior muestran una corrección cuando se aumentan la longitud y el perímetro del arco.

b. Esqueléticos: los efectos esqueléticos dependen de varios factores como el diseño biomecánico del sistema, la edad del paciente y la duración del tratamiento. Comparando la aplicación de una tracción a los 7 años versus una a los 12 años, se observan más efectos en la modificación del crecimiento entre más temprano se aplique; la recidiva posible afecta solo a los dientes y el complejo maxilar permanece igual.
Si se empieza el tratamiento en etapas de dentición mixta, se recomienda dejarla como retención hasta que erupcione el último diente permanente. Con la tracción cervical disminuye el sNA (entre 0.6 y 3.3 grados) y, por tanto, el ANB $[6,16]$.

La tracción que introdujo Klohen en 1947 empleaba el arco externo ligeramente más largo que el interno y doblado hacia arriba, para evitar la extrusión e inclinación del molar, teniendo en cuenta solo sus efectos sagitales. Pero, desde 1960, se retomó con Schudy la evaluación de la parte vertical para la selección del tipo de tracción a aplicar [17].

La tracción cervical no produce ningún efecto a nivel de la mandíbula; no obstante, durante el uso de la tracción, su rotación es antihoraria. A largo plazo, cuando se deja de usar el aparato, se puede ver cómo recupera su patrón de rotación. El SNB puede incrementarse entre 0.7 y 2.6 grados $[18,19]$. Por otro lado, esta tracción genera una disrupción del crecimiento mandíbular, volviéndolo más vertical; este efecto termina al retirar el aparato, por tanto, la mandíbula regresa a su patrón de crecimiento normal [20].

c. Faciales: la inhibición del crecimiento del maxilar, junto con el crecimiento normal de las otras estructuras faciales, disminuye la convexidad facial. Sin embargo, esta disminución fue más evidente en el perfil esquelético que en el perfil de tejidos blandos, y el tratamiento no afectó significativamente el grosor de los labios.

\section{Edad de intervención}

La mejor edad de intervención es durante la dentición mixta temprana, ya que el sistema esquelético es dinámico y fácil de remodelar. En la mayoría de los artículos, la edad mínima de uso de los aparatos es de 7 años y la edad 
máxima es 23 años. Los mejores efectos esqueléticos se logran durante la etapa prepuberal $[9,21,22,23]$.

\section{Duración del tratamiento}

Se encuentran reportes de tratamientos de 6 a 14 meses, aproximadamente. Entre más tiempo de uso, el efecto obtenido es mejor [6].

\section{Tracción alta o parietal}

La tracción alta o parietal es otro tipo de tracción extraoral, que tiene anclaje en los huesos parietales del cráneo (Figura 21).

\section{Biomecánica}

Para el diseño biomecánico del sistema se consideran los mismos principios descritos en el caso anterior. Lo único que cambia es el vector de fuerza, es decir, la dirección y la línea de acción, así como el lugar de origen. El anclaje pasa de ser cervical a ser parietal, y esto genera efectos diferentes. El arco externo de la tracción generalmente es corto y tiene una inclinación de 10 a 15 grados hacia arriba, para lograr que la fuerza pase a través del centro de resistencia del maxilar [21]. Se puede colocar acompañada de una barra transpalatina, que minimiza los efectos transversales de la tracción y los efectos sagitales sobre el molar, y que maximiza el efecto ortopédico del aparato [1].
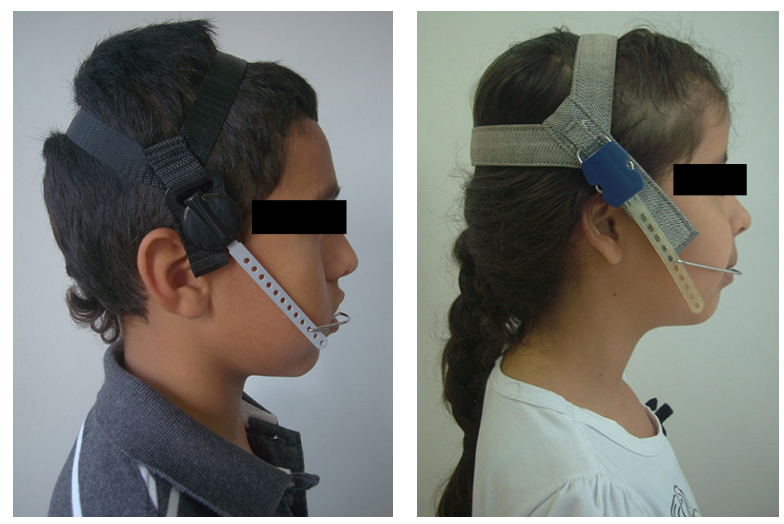

FIGURA 21. Pacientes con tracción alta en posición, con diferentes tipos de gorro

Fuente: elaboración propia

\section{Componentes}

a. Arco extraoral: es un arco de acero igual al ya descrito en la tracción cervical; el diseño (estándar o con ansas), el proceso de adaptación, los dobleces posibles y su tamaño también son iguales. El único elemento que cambia es el sitio de anclaje, por tanto, el tamaño del arco se determina con base en la ubicación de los centros de resistencia del maxilar o del molar, según el efecto que se pretenda (Figura 4).

b. Gorro: puede ser de diferentes materiales y diseños, dependiendo de la marca. Es un gorro que abarca todo el cráneo y se ancla principalmente en la zona parietal. Existe una sola talla y tiene aditamentos que permiten adaptarlo al tamaño de la cabeza de cada paciente. La parte del gorro que queda cerca de la oreja posee un elemento en el que se insertan las bandas elásticas (Figura 22).
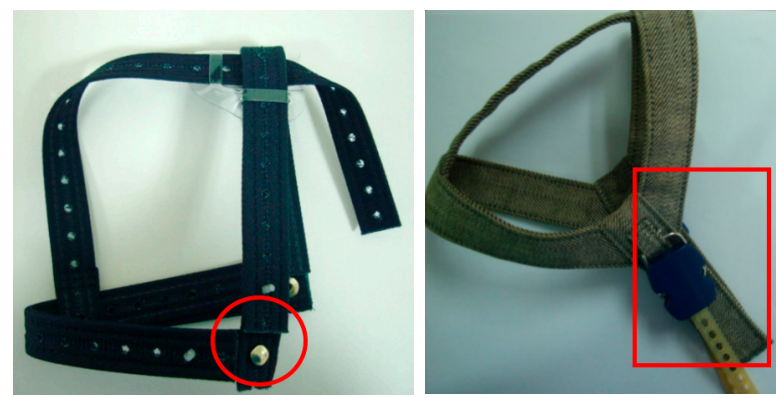

FIGURA 22. Gorro de tela para tracción alta y aditamentos que lo unen a las bandas elásticas

Fuente: elaboración propia

c. Bandas elásticas: son dos bandas en tela elástica, que transmiten la fuerza desde el gorro al arco extraoral. Traen un sistema de ajuste, que les permite aplicar la fuerza ortodóntica u ortopédica requerida (Figura 23), y un gancho en cada extremo para unirse al gorro y al arco extraoral. Estas bandas elásticas suelen quedar muy largas y la aplicación de la fuerza necesaria no es posible. Para solucionar esta situación, solo hay que recortar uno de sus extremos y volverlas a ajustar. 


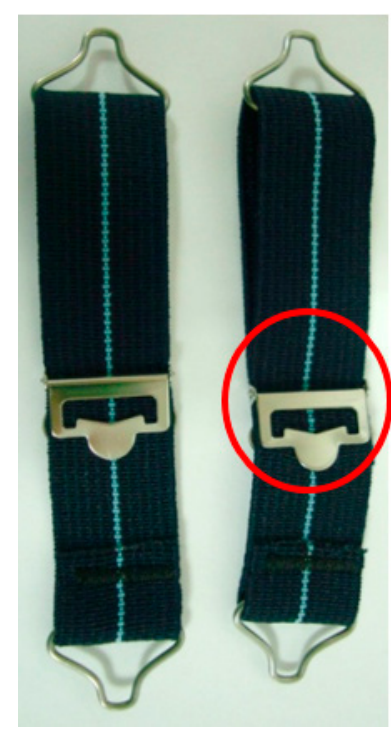

FIGURA 23. Bandas elásticas y aditamento que permite que las bandas se acorten o se alarguen

Fuente: elaboración propia

d. Bandas plásticas: son dos bandas de plástico, que van desde el gorro de la tracción hasta el arco extraoral. Cada banda presenta orificios, en los cuales encaja el arco extraoral, y al frente de cada orificio tiene un número. El orificio en que el paciente debe colocárselo se determina según la distancia que exista desde el gorro al arco externo (Figura 24). El sistema viene conformado por la banda plástica que encaja en el aditamento que presenta el gorro. Para ensamblarlo, el aditamento se inserta en el gorro y luego se le inserta la banda plástica (Figura 25).

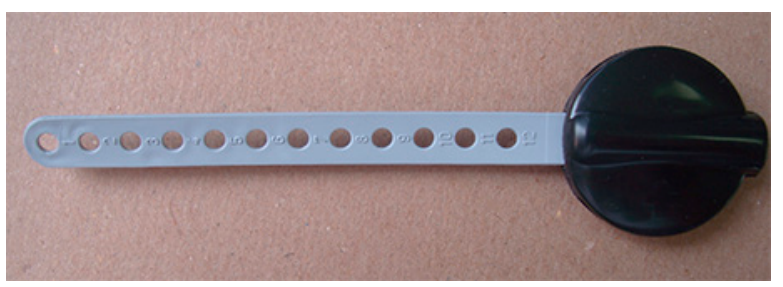

FIGURA 24. Banda plástica para tracciones altas

Fuente: elaboración propia
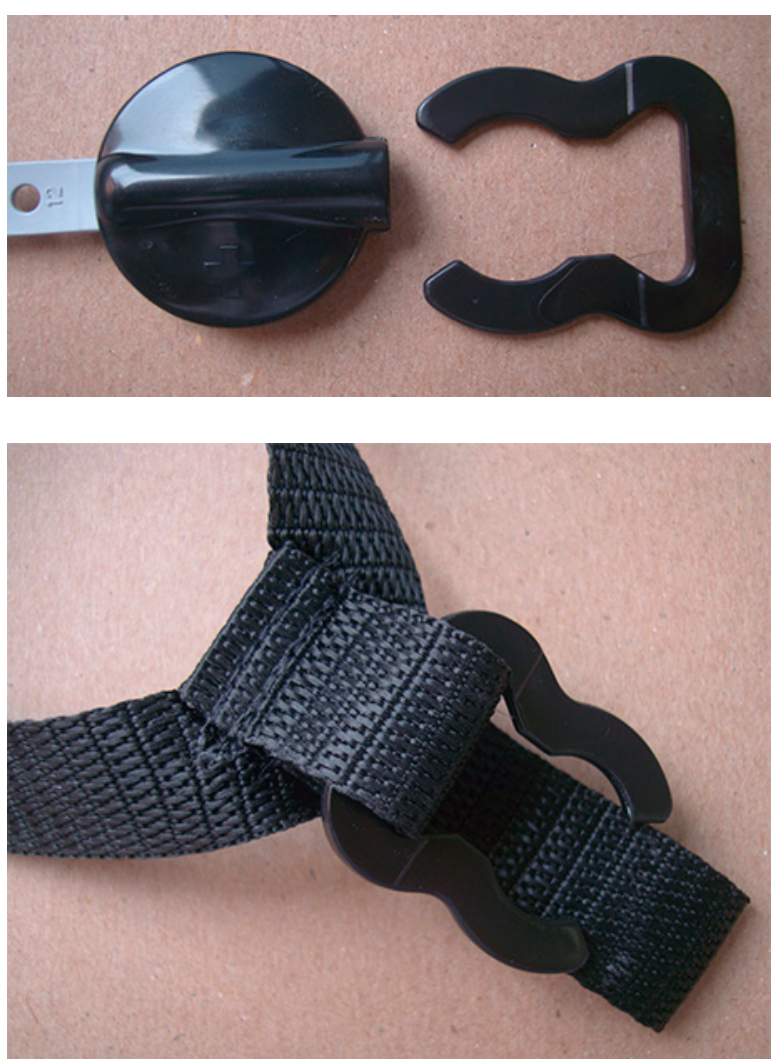

FIGURA 25. Ensamble de la banda plástica en el gorro

Fuente: elaboración propia

e. Tubos y bandas: se utilizan mismos tubos y bandas empleados en la tracción cervical (Figura 17).

\section{Efectos}

a. Dentales: sagitalmente, la tracción parietal genera la distalización de molares y el control vertical de estos [6]. Al compararla con la tracción cervical, se observa que la tracción alta controla mejor el desarrollo vertical del primer molar [21]. Transversalmente, genera vestibularización de molares, debido a que el punto de origen de la fuerza se encuentra a nivel parietal. Por tanto, en los casos en que este efecto sea indeseable, se requiere el uso de una barra transpalatina.

b. Esqueléticos: además de restringir el crecimiento sagital del maxilar, se genera un control vertical del crecimiento maxilar 
con una rotación caudal anterior del plano palatino [6]. Si se busca un control vertical completo, es importante colocar la tracción junto con algún aparato que controle el desarrollo vertical del molar inferior, pues el efecto secundario del control vertical superior es la extrusión de los molares inferiores [6]. Algunos autores han reportado que, en comparación con la tracción cervical, la tracción alta es menos eficaz para controlar las estructuras maxilares en dirección anteroposterior [7].

\section{Tracción combinada u oblicua}

La tracción combinada u oblicua es la tracción extraoral que combina la tracción alta y la baja: emplea el gorro y la banda elástica cervical al mismo tiempo (Figura 25). Es denominada tracción occipital porque el vector resultante pasa a través del hueso occipital (Figura 26).

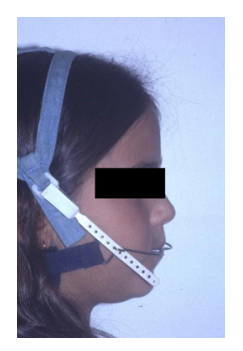

FIGURA 26. Tracción extraoral combinada en posición Fuente: elaboración propia

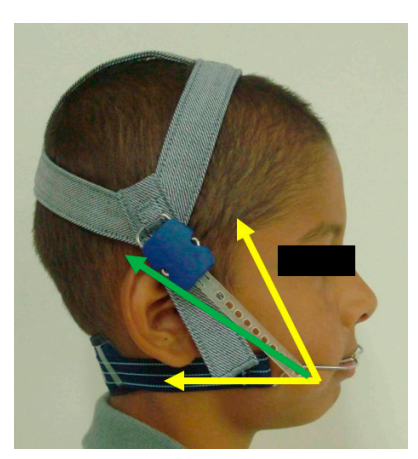

FIGURA 27. Vectores de fuerza de tracción combinada. En amarillo: vectores que ejercen los componentes de la tracción. En verde: el vector resultante que pasa a través del hueso occipital

Fuente: elaboración propia

\section{Componentes}

a. Arco extraoral: es un arco en acero igual al descrito anteriormente. El diseño puede ser estándar o con ansas (Figura 4) y su adaptación depende de las necesidades biomecánicas de cada paciente.

b. Gorro: se trata del mismo gorro descrito para la tracción alta (Figura 21).

c. Bandas elásticas: son dos bandas que transmiten la fuerza desde el gorro al arco extraoral (Figura 21) y se usan de manera similar a lo ya descrito.

d. Bandas plásticas: son dos bandas plásticas que transmiten la fuerza desde el gorro al arco extraoral (Figura 23); su uso es similar al descrito en la tracción alta.

e. Cinta elástica: es la misma cinta o banda descrita en el caso de la tracción cervical (Figura 15).

f. Tubos y bandas: se utilizan los mismos tubos y bandas que en la tracción cervical (Figura 17).

\section{Biomecánica}

Para el diseño biomecánico del sistema se toman en cuenta los principios señalados en el apartado que corresponde a la tracción cervical; solamente cambia el vector de fuerza, esto es, la dirección, la línea de acción y el lugar de origen de la fuerza. El anclaje es combinado entre cervical y parietal, por supuesto esto genera efectos diferentes. En la tracción combinada se suman los vectores producidos por las tracciones cervical y alta, para generar una fuerza resultante en dirección oblicua, a través del hueso occipital. Los vectores sagitales se suman, mientras que los verticales, al ser opuestos, se cancelan.

Para lograr un efecto esquelético, se debe emplear una fuerza de 450 a 500 gr, distribuida proporcionalmente entre el gorro y la banda 
cervical, a fin de anular los efectos verticales, y debe medirse con el dinamómetro (Figura 28). Se puede aplicar más fuerza en uno de los dos componentes, de acuerdo a las necesidades verticales del paciente. Por ejemplo, se puede colocar más fuerza en el gorro en los casos en que la rotación maxilar o el movimiento molar sean necesarios para que ocurran una rotación horaria maxilar o una intrusión molar, respectivamente. Por otro lado, la fuerza de la banda elástica cervical podría ser mayor que la del gorro, en pacientes que requieran de una rotación antihoraria maxilar o de una ligera extrusión de molares. Cabe aclarar que, a pesar de poder colocar fuerzas diferenciales entre sus componentes, los efectos verticales que se logren van a ser menores que los efectos obtenidos por cada uno de los componentes por separado.

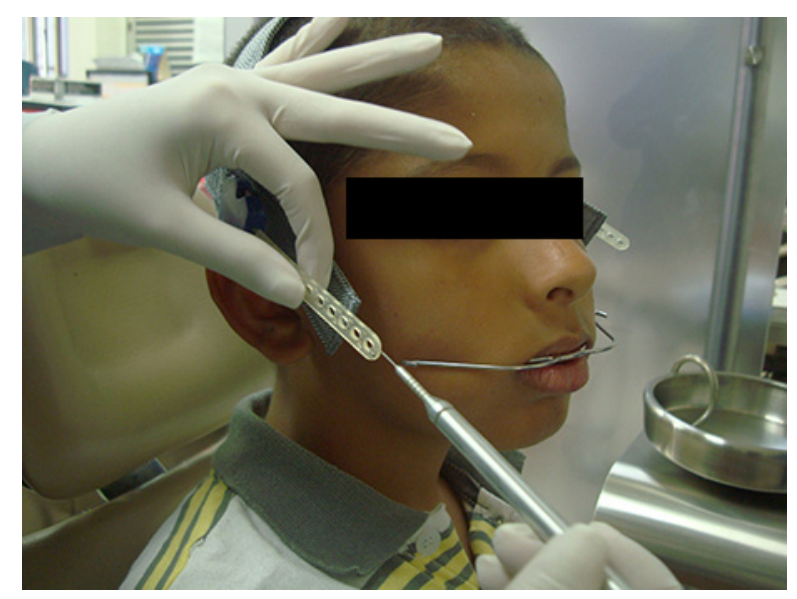

FIGURA 28. Medición de las fuerzas con dinamómetro

Fuente: elaboración propia

\section{Efectos}

La tracción combinada elimina las desventajas de la tracción cervical y de la tracción alta al anular sus efectos verticales.

a. Dentales: se logra distalización de molares de 3.6 a $4.0 \mathrm{~mm}$, sin reportar diferencias con la distalización lograda con la tracción alta y mostrando que es menor a la reportado por la tracción cervical; sin embargo, la forma de desplazamiento del molar ocurre de manera diferente. Los efectos verticales en el molar o en el maxilar dependen de la cantidad de fuerza que se ponga en cada componente (el cervical o el parietal). Cuando el componente de la fuerza es mayor en la parte cervical, ocurre mayor inclinación distal del molar. La distancia intercanina aumenta con el uso de la tracción. Transversalmente, esta tracción no genera ningún efecto en los molares.

b. Esqueléticos: hay un control sagital del crecimiento maxilar, sin ningún tipo de rotación o inclinación.

\section{Tracción cervical y placa de Hawley}

Se combina el uso de la tracción cervical con una placa de Hawley (arco vestibular hasta caninos y ganchos circunferenciales en molares; Figura 29), con la finalidad de disminuir el efecto dental sobre los molares y aumentarlo en los incisivos. Se genera su retrusión al transmitir hacia ellos la fuerza de los molares a través de la placa de Hawley. Por tanto, el efecto ortopédico aumenta [1]. En casos de mordida profunda, a la placa se le puede agregar un plano de mordida anterior, lo cual disminuye la intercuspidación y facilita la corrección sagital. Con esta combinación de aparatos, se restringe el crecimiento maxilar entre 0.5 y 1 grado, con disminución de 1 grado en el ANB (y sin cambios significativos en el $\mathrm{SNB})$, verticalización de los incisivos superiores e inferiores, distalización de molares y mesialización de los molares inferiores de $2.7 \mathrm{~mm}$ (comparado con la mesialización de $1 \mathrm{~mm}$ en pacientes sin tratamiento) [12]. 


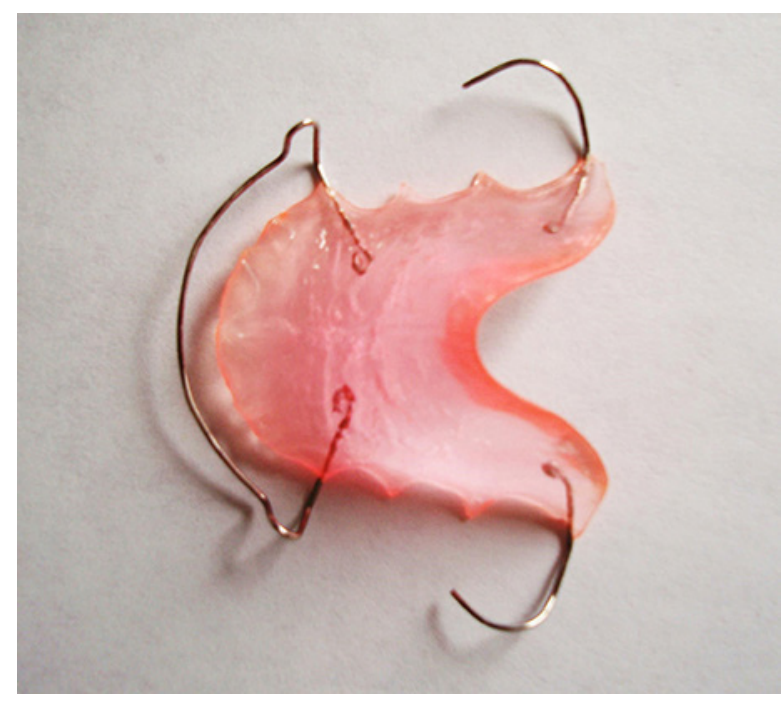

FIGURA 29. Placa de Hawley con ganchos circunferenciales $y$ arco vestibular corto

Fuente: elaboración propia

\section{Tracción extraoral y aparato funcional bimaxilar}

La combinación del uso de una tracción extraoral (principalmente, la tracción alta) con el uso intraoral de un aparato funcional bimaxilar surge de la necesidad de un mayor control en la dimensión vertical posterior del paciente [7]. Con esta combinación se generan efectos como la restricción anterior del maxilar (1.4 a 2.3 mm); la inhibición del desplazamiento mesial y vertical de los dientes maxilares; la mejoría en la posición de los dientes posteriormandibulares; la remodelación del cóndilo y la fosa, y la mejora del patrón muscular. Los efectos dentales son similares a los reportados para el uso de la tracción extraoral con placa de Hawley. Se observa lingualización de incisivos de 5.3 grados y vestibularizacion de los inferiores de 4.2 grados, y una disminución del overjet de 4 a $5.4 \mathrm{~mm}$. El overbite disminuye en $2.2 \mathrm{~mm}$ y los molares inferiores se mesializan $3.5 \mathrm{~mm}$ [12]. Esqueléticamente, se advierte un aumento del sNB entre 0.6 a 2 grados [12].

En los casos en que la etiología de la clase in sea una combinación de prognatismo maxilar y retrognatismo mandibular, se puede confeccionar un aparato funcional con avance mandibular. Esto generará un desplazamiento mandibular anterior, con un incremento en el desarrollo vertical de la mandíbula.

\section{ESTABILIDAD}

La evidencia muestra que la disminución del SNA es estable, el sNB no se afecta con el tratamiento o con el crecimiento, y cualquier cambio en el ángulo del plano mandibular se recupera con el crecimiento continuo. Definitivamente, los cambios verticales con la tracción cervical no son comprobados.
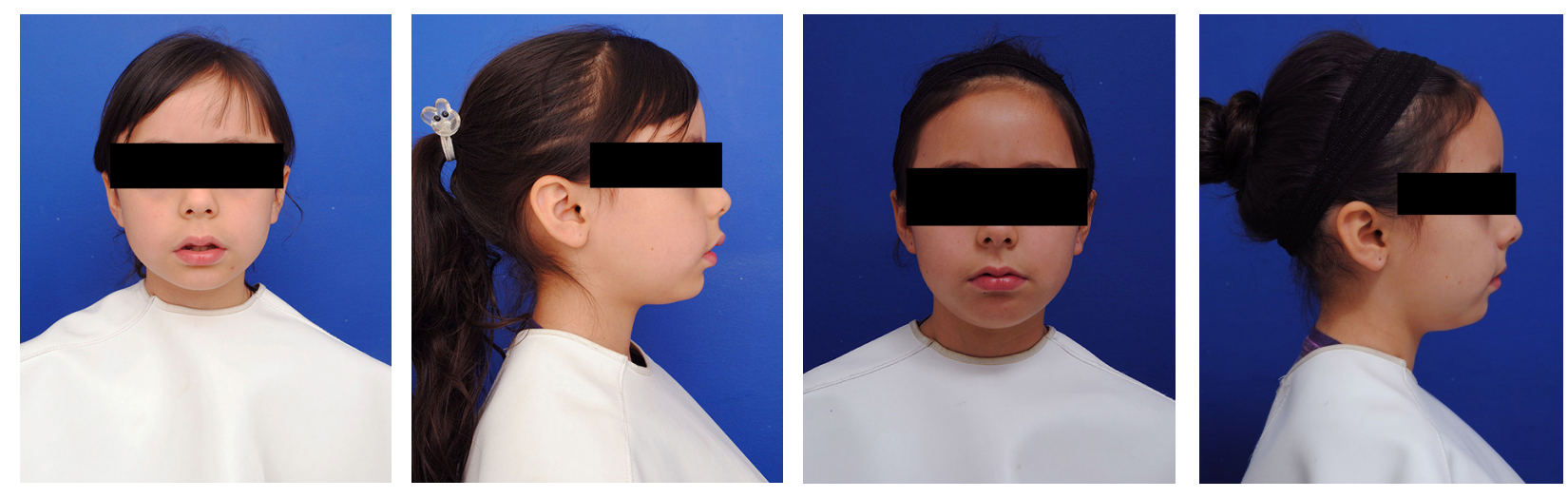

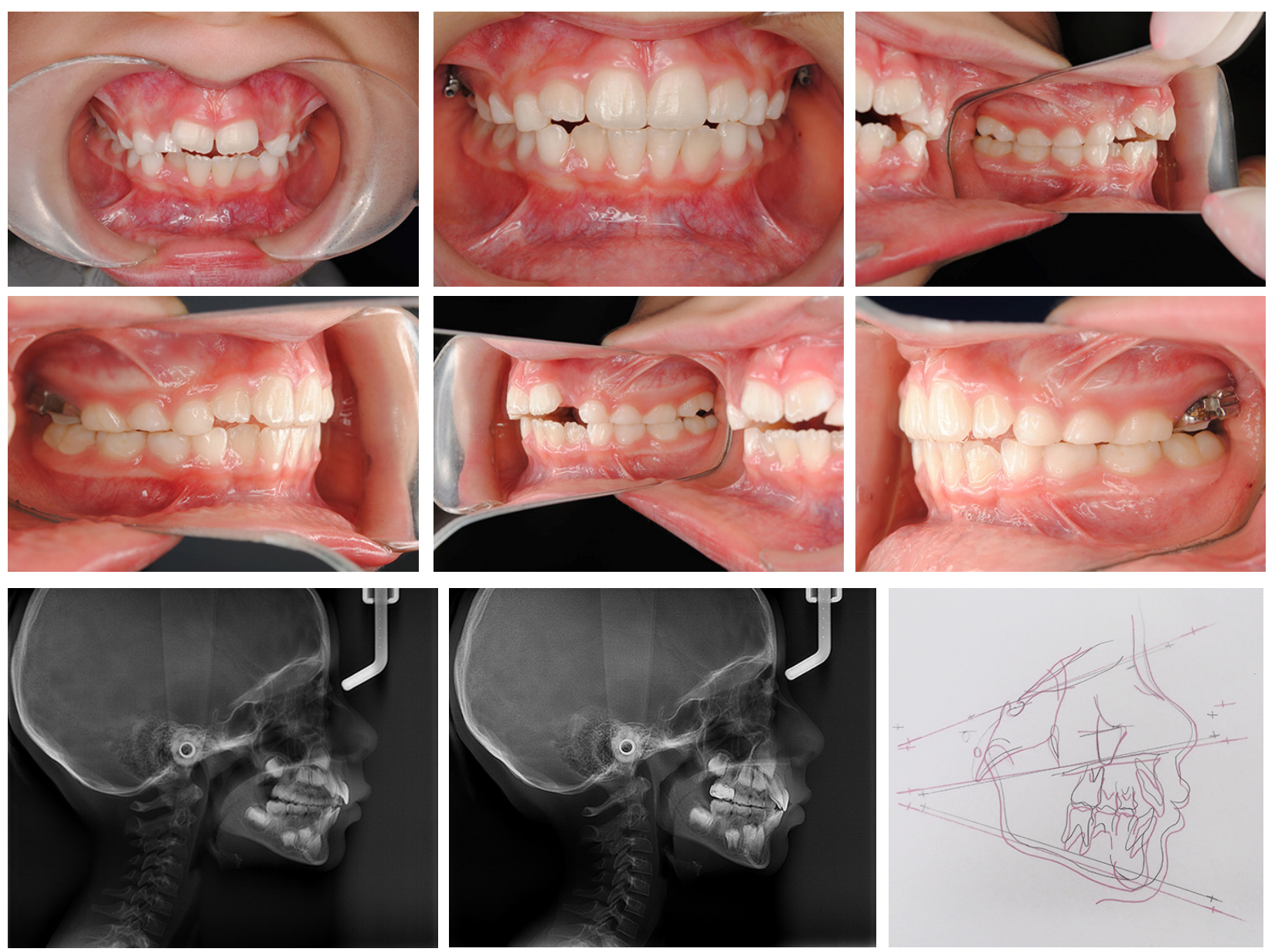

FIGURA 30. Antes y después del tratamiento con tracción alta

Fuente: elaboración propia

TABLA 4

Medidas iniciales y finales de radiografías cefálica lateral

\begin{tabular}{ccc}
\hline MEDIDA & RADIOGRAFÍA INICIAL & RADIOGRAFÍA FINAL \\
\hline Angulo SNA & 80 & 76 \\
\hline Angulo SNB & 70 & 72 \\
\hline Distancia A a perpendicular de FH & 6 & 1 \\
\hline Distancia Pog a perpendicular de FH & -9 & -4 \\
\hline Angulo SN/PM & 42 & 39.5 \\
\hline ENA-Mn & 59 & 57 \\
\hline ANB & 8 & 6 \\
\hline
\end{tabular}

Fuente: elaboración propia 


\section{REFERENCIAS}

1. Bishara S. Class II malocclusions: diagnostic and clinical considerations with and without treatment. Semm. Orthod. 2006;12:11-24.

2. Karlsen A. Craniofacial characteristics in children with angle class II div 2 malocclusion combined with extreme deep bite. Angle Orthod. 1994;64 (2):123.

3. Walkow T, Peck S. Dental arch width in class II division 2 deep-bite malocclusion. AJo. 2002;122(6):608-613.

4. Alió-Sanz J, Iglesias-Conde C, Lorenzo-Pernía L, Iglesias-Linares A, Mendoza-Mendoza A, Solano-Reina E. Effects on the maxilla and cranial base caused by cervical headgear: A longitudinal study. Med. Oral Patol. Oral Cirg. Bucal. 2012 sep 1;17(5):e845-e851.

5. Godt A, Berneburg M, Kalwitzki M, Göz G. Cephalometric analysis of molar and anterior tooth movement during cervical headgear treatment in relation to growth patterns. J. Orofac. Orthop. 2008 may;69(3):189200.

6. Nanda R, Dandajena T. The role of headgear in growth modification. Semin. Orthod. 2006;12:25.

7. Tortop T, Yüksel S. Treatment and Posttreatment Changes with Combined Headgear Therapy. Angle Orthod. 2007;77(5):857-863.

8. Graber TM. Ortodoncia Teoría y práctica. Editorial Mosby-Doyma 1991 540-548. Estados Unidos

9. Nanda R. Biomecánica en ortodoncia clínica. Buenos Aires: Panamericana; 1998.

10. Godt A. Molar and canine occlusal changes in study casts before and after treatment with cervical headgears. J. Orofac. Orthop. 2006;67:27.

11. Kirjavainen M, Kirjavainen T, Haavikko K. Change in dental arch dimensions by use of an orthopedic cervical headgear in class II correction. Am. J. Orthod. Dentofacial Orthop. 1997;111(1):59-66.

12. Southard T, Marshall S, Allareddy V, Moreno L, Holton N. An evidence-based comparison of headgear and functional appliance therapy for the correction of class II malocclusions. Semin. Orthod. 2013;19:174-195.

13. Melsen B. Distal molar movement with kloehn headgear is it stable? Am. J. Orthod. Dentofacial Orthop. 2003;123(4):374-378.

14. Varlik SK, Iscan HN. The effects of cervical headgear with an expanded inner bow in the permanent dentition. Eur. J. Orthod. 2008 ago;30(4):425-430.

15. Baumrind S, Korn EL, Isaacson RJ, West EE, Molthen R. Quantitative analysis of the orthodontic and orthopedic effects of maxillary traction. Am. J. Orthod. Dentofacial Orthop. 1983 nov;84(5):384-398.

16. Mantysaari R. The effects of early headgear treatment. Eur. J. Orthod. 2004;26:59.

17. Lima Filho R, Lima A, De Oliveira Ruellas A. Longitudinal study of anteroposterior and vertical maxillary changes in skeletal class II patients treated with Kloehn cervical headgear. Angle Orthod. 2003;73(2):187193.

18. Kim R, Muhl Z Changes in mandibular growth direction during and after cervical headgear treatment. Am. J. Orthod. Dentofacial Orthop. 2001;119:522.

19. Kirjavainen M, Et al. Orthopedic cervical headgear with an expanded inner bow in class II correction. Angle Orthod. 2000;70(4):317-325.

20. Mair A, Hunter S. Mandibular growth direction with conventional class II non extraction treatment. Am. J. Orthod. Dentofacial Orthop. 1992;101:543-549.

21. Burke M, Jacobson A. Vertical changes in high-angle class II division 1 patients treated with cervical or occipital pull headgear. Am. J. Orthod. Dentofacial Orthop. 1992;102:501-508.

22. Kirjavainen M, Kirjavainen $\mathrm{T}$ Change in dental arch dimensions by use of an orthopedic cervical headgear in class II correction. Am. J. Orthod. Dentofacial Orthop. 1997;111(1):59-66.

23. Hershey H, Houghton C, Burstone C. Unilateral face-bows: a theorical and laboratory analysis. Am. J. Orthod. Dentofacial Orthop. 1981;79(3):229-249. 


\section{CAPÍTULO 8}

\section{TRATAMIENTO DE ALTERACIONES DE CLASE III}

Paola María Botero Mariaca

Las maloclusiones clase III, a pesar de tener una marcada influencia hereditaria, pueden ser interceptadas desde edades tempranas; su severidad y grado de compromiso estético disminuyen en los pacientes en crecimiento. Sin embargo, la estabilidad de la corrección lograda depende de la continuidad en el control del crecimiento hasta que este culmine. Su etiología multifactorial también tiene un papel importante en la selección del tratamiento interceptivo. En este capítulo se muestran los elementos claves para un correcto diagnóstico y las opciones de tratamiento, junto a sus respectivas consideraciones biomecánicas y efectos dentales y esqueléticos.

\section{Aspectos GENERALES}

El tratamiento temprano de alteraciones clase III dentoesqueléticas, a través de la modificación del crecimiento, se acompaña de varias estrategias terapéuticas que restringen el crecimiento mandibular, estimulan el crecimiento maxilar e inducen cambios dentoalveolares. El tratamiento para este tipo de discrepancia sagital depende de la etiología del problema, que puede ser esquelética (maxilar hipoplásico, mandíbula prognática o una combinación de los dos; Figuras 1 y 2), dentoalveolar (inclinaciones dentales inadecuadas y relaciones molares de clase III) y funcional (pseudo-clase III), generada por una deflexión mandibular anterior por un prematuro (inclinaciones dentales inadecuadas que impiden un correcto acople anterior; Figura 3).
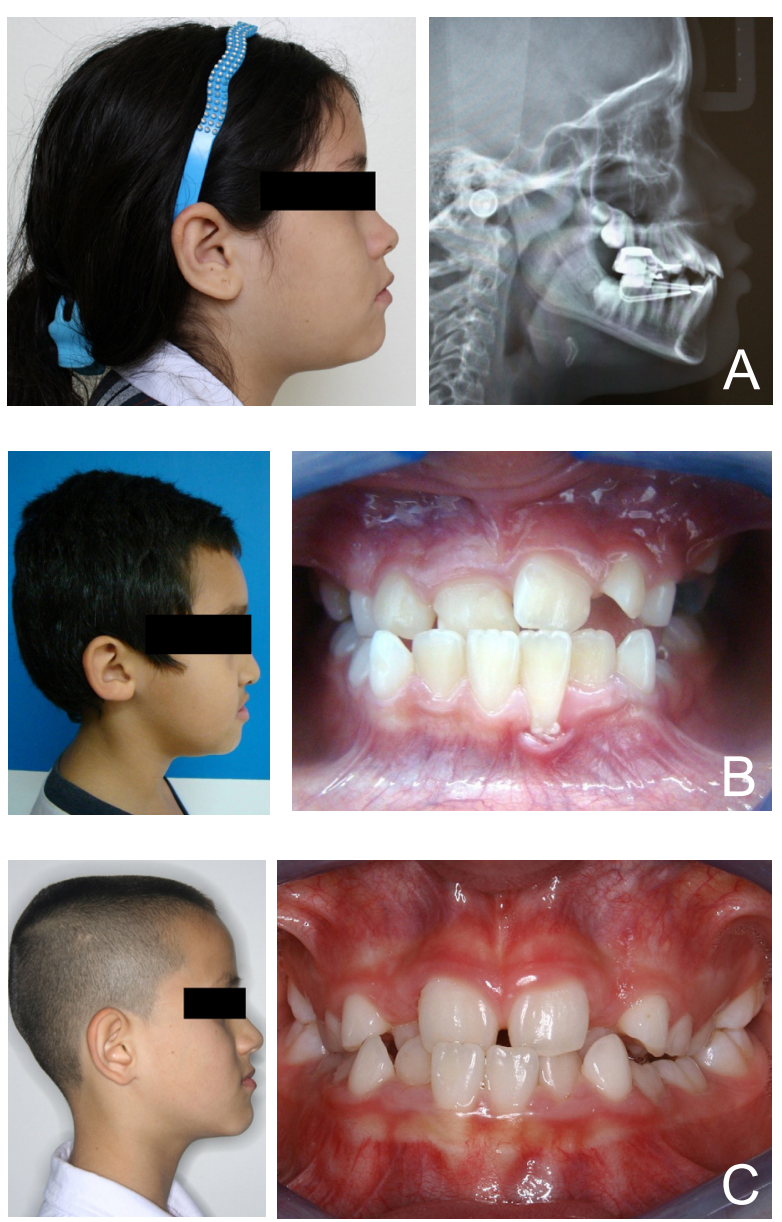

FIGURA 1. (A) Paciente clase III por prognatismo mandibular. (B) Paciente clase III por micrognatismo maxilar. (C) Paciente con retrognatismo maxilar y prognatismo mandibular

Fuente: elaboración propia

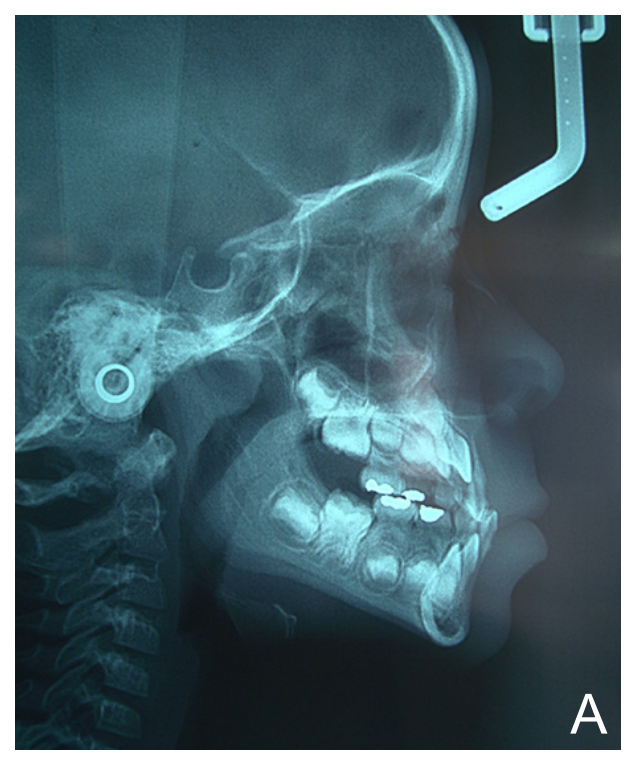




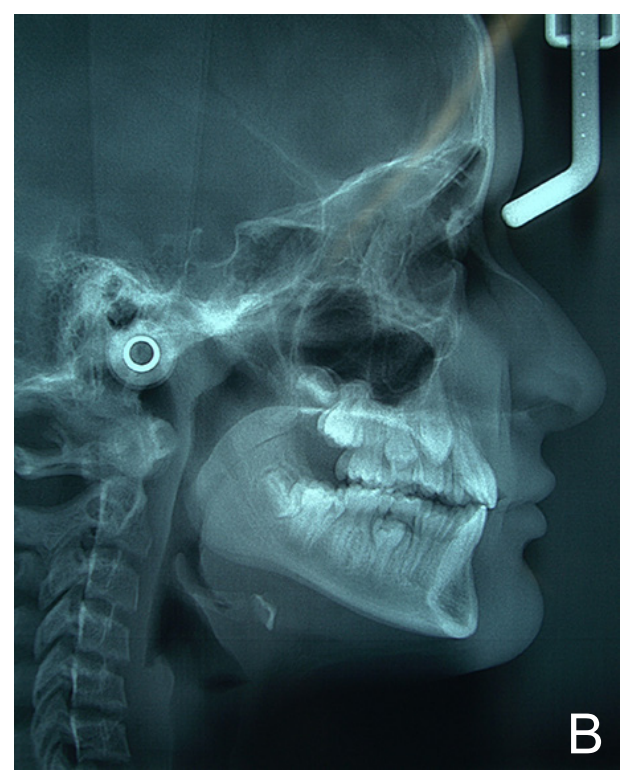

FIGURA 2. (A) Paciente clase III esquelético por hipoplasia maxilar con birotrusión bimaxilar. (B) Paciente clase III esquelética por prognatismo mandíbula

Fuente: elaboración propia

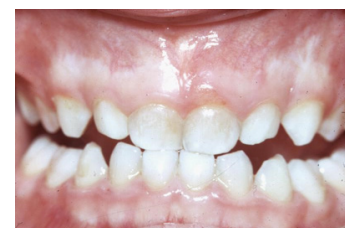

FIGURA 3. Relación anterior en céntrica en un paciente pseudo III

Fuente: elaboración propia

\section{CRECIMIENTO MAXILAR EN PACIENTES CLASES III}

En pacientes clase III, el maxilar se observa retrusivo desde edades tempranas y se mantiene así durante la etapa de crecimiento [1]. La rata de crecimiento anual sagital en una paciente clase I es de 0.8 a $1 \mathrm{~mm}$ por año, mientras que en una clase II se observa una rata de $0.4 \mathrm{~mm}$ anuales [2]. Un maxilar retrusivo en pacientes clase iI se mantiene así durante el crecimiento; el tercio inferior aumenta, el tejido blando ayuda a camuflarlo, el overbite disminuye y el overjet negativo se mantiene constante [1].

\section{CRECIMIENTO MANDIBULAR EN PACIENTES CLASES III}

En pacientes sin maloclusión, la longitud mandibular se desarrolla principalmente en el cóndilo, cuyo crecimiento puede ser posterior, superior o anterior, dependiendo del patrón, con un radio de 10:1, entre superior y posterior. Paralelo a ese crecimiento, existe un patrón de aposición-reabsorción. En la rama ocurre una aposición posterior y reabsorción anterior; en el proceso goníaco se genera un desplazamiento posterior y superior; en el borde inferior, una reabsorción posterior y aposición anterior; en la sínfisis, una aposición posterior, superior e inferior; en el mentón se modela abajo y atrás; por último, el punto B se desplaza superior y posterior. Estos cambios influyen en la rotación y desplazamiento mandibular final [3].

El desplazamiento de las mandíbulas en crecimiento es inferior y anterior, mientras rotan adelante entre 0.5 y 1.0 grados por año. Los rotadores anteriores muestran mayor crecimiento condilar hacia anterior que los rotadores posteriores, y presentan ángulos goniacos más pequeños y una disminución mayor en su crecimiento. Normalmente, el gonion sufre el doble de remodelación que el cóndilo y, entre los 10 y 15 años, la rotación verdadera de la mandíbula es de 2 a 3.3 grados. El desplazamiento mandibular inferior fue de 9.6 a $12.7 \mathrm{~mm}$; y el anterior, de 1.9 a $2.7 \mathrm{~mm}$. Se presenta mucha variación individual tanto en magnitud como en dirección de movimiento, debido a que hay estructuras más susceptibles que otras a los factores epigenéticos locales y a los factores medioambientales. Por tanto, existe un mayor potencial de respuesta a intervenciones clínicas en los crecedores horizontales que en los verticales. Los cambios condilares, que se generan con el crecimiento, pueden estar relacionados con la habilidad de crecimiento intrínseco del condilo y modulados por las cargas funcionales. La rotación 
final va a depender de la forma de remodelación de la rama [3].

En pacientes clase III, el crecimiento mandibular es mayor (2.4 mm anuales en clase I y 2.9 mm anuales en clases III), ocurre durante más tiempo y su pico se evidencia casi un año más tarde (entre los 10 y 11 años en mujeres y entre los 13 y 14 años en hombres) [4]. La rata de crecimiento mandibular anual es de $2.16 \mathrm{~mm}$ para el cuerpo, $3.16 \mathrm{~mm}$ para la rama y 4.31 $\mathrm{mm}$ para la longitud mandibular. El mayor crecimiento ocurre durante el pico de crecimiento, a excepción de la rama [20]. El aumento en la longitud mandibular fue de $3 \mathrm{~mm}$ por año en mujeres y un poco más de $3 \mathrm{~mm}$ en hombres; después del pico de crecimiento, el incremento anual disminuye a 1.5 a $2 \mathrm{~mm}$ anuales [4].

La cavidad glenoidea en los pacientes clase III se ubica más anterior, gracias a que el ángulo de la base craneal se encuentra más agudo (121 a 124 grados), en comparación con la clase I (129 a 131 grados). No hay diferencias en la posición maxilar entre los individuos clase i y clase iII, pero en la mandíbula sí: durante los 11 años de observación hubo un incremento (Condileon-Gnation) de $30 \mathrm{~mm}$, con un promedio anual de $2 \mathrm{~mm}$, y el mayor crecimiento fue entre los 13 y 14 años. Los individuos clase iII tiene un pico tardío, con un crecimiento más pronunciado y con una duración más larga. Entre los 15 a 16 años, se ve un incremento en longitud mandibular, mayor en los individuos clase iI que en los individuos clase I $[3,5]$.

Para cualquier tipo de tratamiento es importante tener en cuenta los momentos en los que ocurren los picos de crecimiento maxilar y mandibular, ya sea para estimularlos o controlarlos (Tabla 1).
TABLA 1

Picos de crecimiento

\begin{tabular}{|c|c|c|}
\hline $\begin{array}{l}\text { Picos de } \\
\text { crecimiento }\end{array}$ & Maxilar & Mandibular \\
\hline Primer pico & Nacimiento a 3 años & Nacimiento a 3 años \\
\hline Segundo pico & 6 a 8 años & $\begin{array}{l}\text { Mujeres: } 6 \text { a } 7 \text { años } \\
\text { Hombres: } 7 \text { a } 9 \text { años }\end{array}$ \\
\hline \multirow[t]{2}{*}{ Tercer pico } & \multirow{2}{*}{$\begin{array}{l}\text { Pubertad } \\
\text { Mujeres: } 10.5 \text { a } 13 \\
\text { años } \\
\text { Hombres: } 12.5 \text { a } 15 \\
\text { años }\end{array}$} & $\begin{array}{l}\text { Pubertad } \\
\text { Mujeres: } 11 \text { a } 12 \text { años } \\
\text { Hombres: } 11 \text { a } 15 \\
\text { años } \\
\text { [1 año más tarde que } \\
\text { en clase I] }\end{array}$ \\
\hline & & $\begin{array}{l}\text { Crecimiento residual: } \\
16 \text { a } 17 \text { años: } 3 \mathrm{~mm} \\
\text { por año } \\
\text { Crecimiento hasta los } \\
21 \text { años }\end{array}$ \\
\hline
\end{tabular}

Fuente: elaboración propia

TRATAMIENTO DE CLASE III

\section{CLASE III POR ALTERACIONES FUNCIONALES Y DENTALES}

Para el tratamiento de la clase iII por alteraciones funcionales y dentales, se pueden utilizar los siguientes aparatos:

\section{Plano inclinado}

Este aparato está indicado para el tratamiento de pacientes con un diagnóstico de pseudoclase III, por incisivos superiores con una erupción hacia lingual o incisivos inferiores con una erupción hacia vestibular. Se genera así un prematuro que obliga a una deflexión mandibular anterior, una mordida cruzada anterior en la relación habitual y una relación borde a borde anterior en céntrica (Figura 4).

El plano inclinado es un plano elaborado en acrílico de autocurado, el cual va cementado en los incisivos inferiores y construido en un ángulo de 45 grados con respecto al plano 
oclusal maxilar. La idea del plano es que contacte desde lingual el incisivo superior (que está erupcionando con una inclinación labial), para aplicar una fuerza a vestibular y redirigir su erupción. El plano debe ser oblicuo para aumentar el componente vestibular de la fuerza y así lograr una corrección más rápida. No debe usarse más de 8 a 15 días pues genera sobreerupción posterior y mordida abierta anterior. Otra consideración importante es que debe usarse preferiblemente cuando los incisivos superiores no han completado su erupción. Tiene la desventaja de ser incómodo para la masticación (Figura 4) [6].

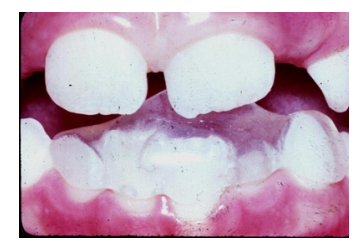

FIGURA 4. Plano inclinado en posición

Fuente: elaboración propia

\section{Progenie}

Aparato removible que consta de una placa acrílica superior, con el arco vestibular que desciende hasta bucal, en el tercio medio de los incisivos inferiores (Figura 5). Puede tener o no planos de mordida posterior, los cuales facilitan el descruzamiento de la mordida al generar una separación anterior. En la zona anterior del aparato se añaden unos ganchos de entrega para vestibularizar incisivos superiores o un tornillo anterior (tipo Fisher) que protruya la premaxila (Figura 6). Está indicado principalmente en casos de pseudo-clase III o después del uso de una máscara facial como aparato de retención. Idealmente, se usa 24 horas o durante un mínimo de 14 horas diarias, incluyendo la noche [7].

\section{Efectos}

Entre sus efectos tenemos el crecimiento arriba y adelante del cóndilo, como compensación del crecimiento mandibular, y la disminución en la protrusión mandibular (punto B, Pogonion y Go) cuando se usa de manera prolongada. Sin embargo, no se reportan cambios en la longitud mandibular en rama y cuerpo. También se ha observado que produce protrusión maxilar (1.87 mm), cierre del ángulo goniaco, cambio en la inclinación de la rama y el eje condilar. En general, la forma de la mandíbula cambia [8].

Dentro de los cambios dentoalveolares tenemos la vestibularización de incisivos superiores y la lingualización de incisivos inferiores. Facialmente, se aprecia una disminución del ángulo nasolabial. Si este aparato es usado tempranamente, ocurren cambios en la forma mandibular, lo que a su vez genera cambios en su posición, debido a que disminuye su protrusión (0.17 mm en comparación de 2.04 en pacientes sin tratamiento) $[8,9]$.
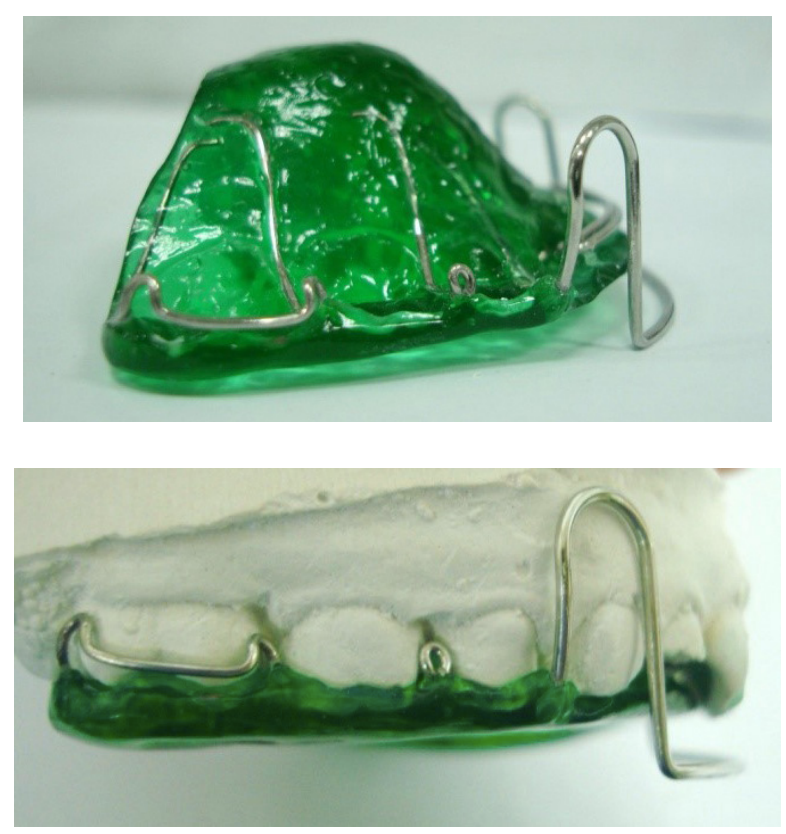

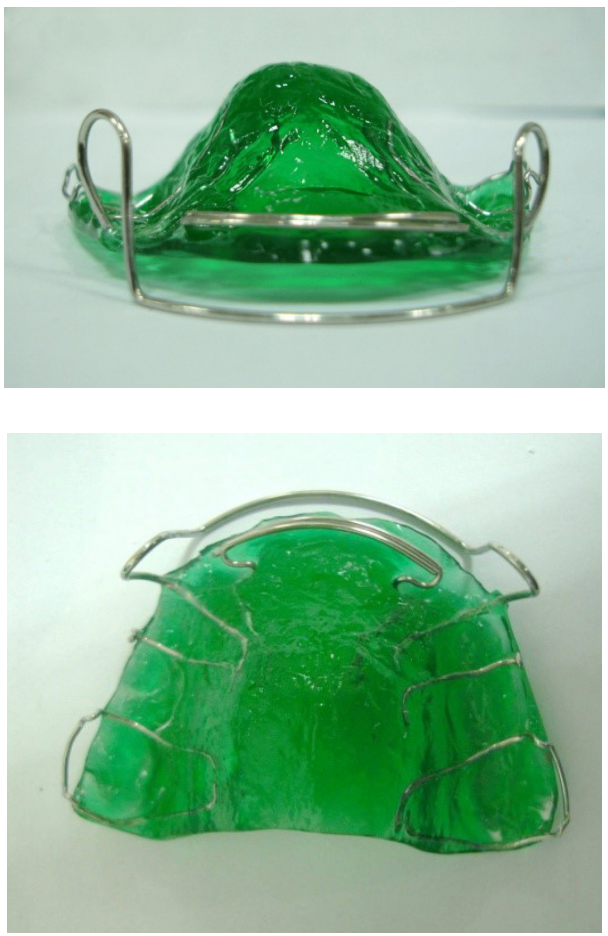

FIGURA 5. Diferentes vistas del Progenie

Fuente: elaboración propia

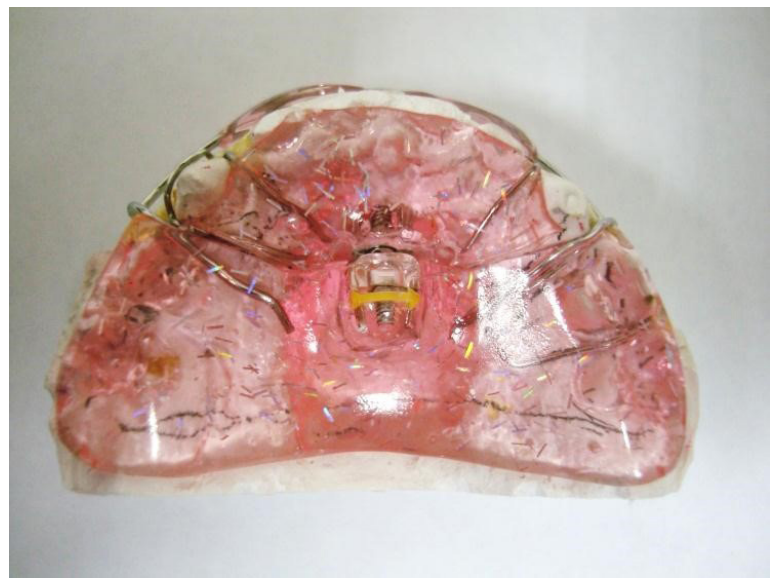

FIGURA 6. Vista lateral y oclusal del Progenie con brazos y tornillo

Fuente: elaboración propia

\section{Máscara facial}

La máscara facial es un aparato removible empleado para la corrección de hipoplasias maxilares en pacientes con tipo esquelético clase III (Figura 7). El tratamiento de la hipoplasia maxilar asociada a una maloclusión clase III debe iniciarse a una edad temprana [10] y su capacidad de modificar esqueléticamente el paciente depende de la edad que este tenga, la terapia utilizada, el componente genético de la alteración, la severidad del problema y el tipo de crecimiento que presenta.
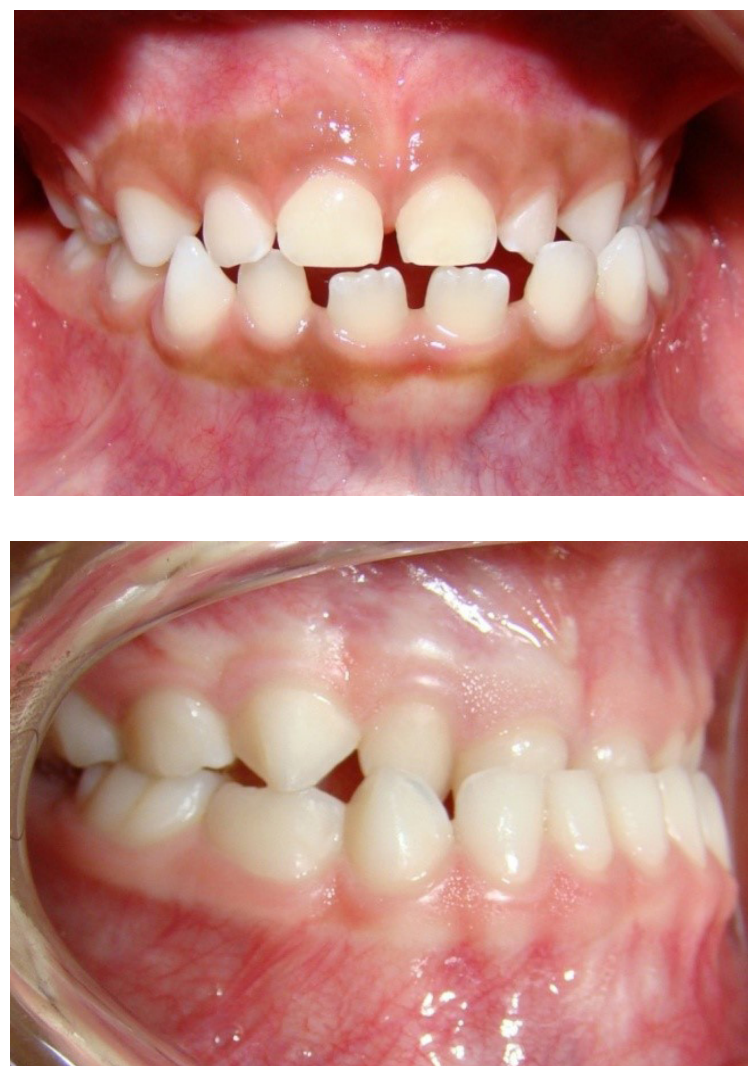

FIGURA ?. Pacientes con mordida cruzada anterior por hipoplasia maxilar

Fuente: elaboración propia

Los estudios en animales han demostrado que el movimiento adelante del maxilar debido al uso de la máscara facial es atribuido a una remodelación de las suturas circunmaxilares, particularmente la cigomático-maxilar, la cigomático-frontal, la fronto-maxilar, la cigomático-temporal y las suturas palatinas transversas [11, 12]. La sutura que más resistencia ofrece frente a los movimientos de protracción y disyunción es la cigomático-maxilar [13]. 
La máscara facial se constituye uno de los tratamientos mas antiguos en aplicarse para tratamientos temprano de clases III, según lo reportado en la literatura. Recientemente se le han generado ajustes para evitar los efectos secundarios y potenciar los esqueléticos, a través del uso de placas corticales bimaxilares [14].

\section{Diseño del aparato}

La máscara facial introducida por Oppenheim en 1944, y modificada por Dalaire y Petiti posteriormente para mayor confort del paciente, es la más usada en la actualidad [15]. La más empleada en nuestro medio es la máscara de
Petit, un aparato extraoral con componentes metálicos y plásticos. Los plásticos constituyen los apoyos en la frente y el mentón, que le dan estabilidad. Estos apoyos se encuentran conectados por una barra metálica en la zona media de la cara, la cual presenta una barra transversal a nivel de la boca, que sirve como anclaje de los elásticos. La distancia entre los apoyos plásticos debe ser graduable para adaptar correctamente los apoyos a la forma y el tamaño de la cara del paciente. La barra transversal también debe tener la posibilidad de modificar su posición para ajustar adecuadamente el vector de fuerza según las características de cada paciente (Figura 8).

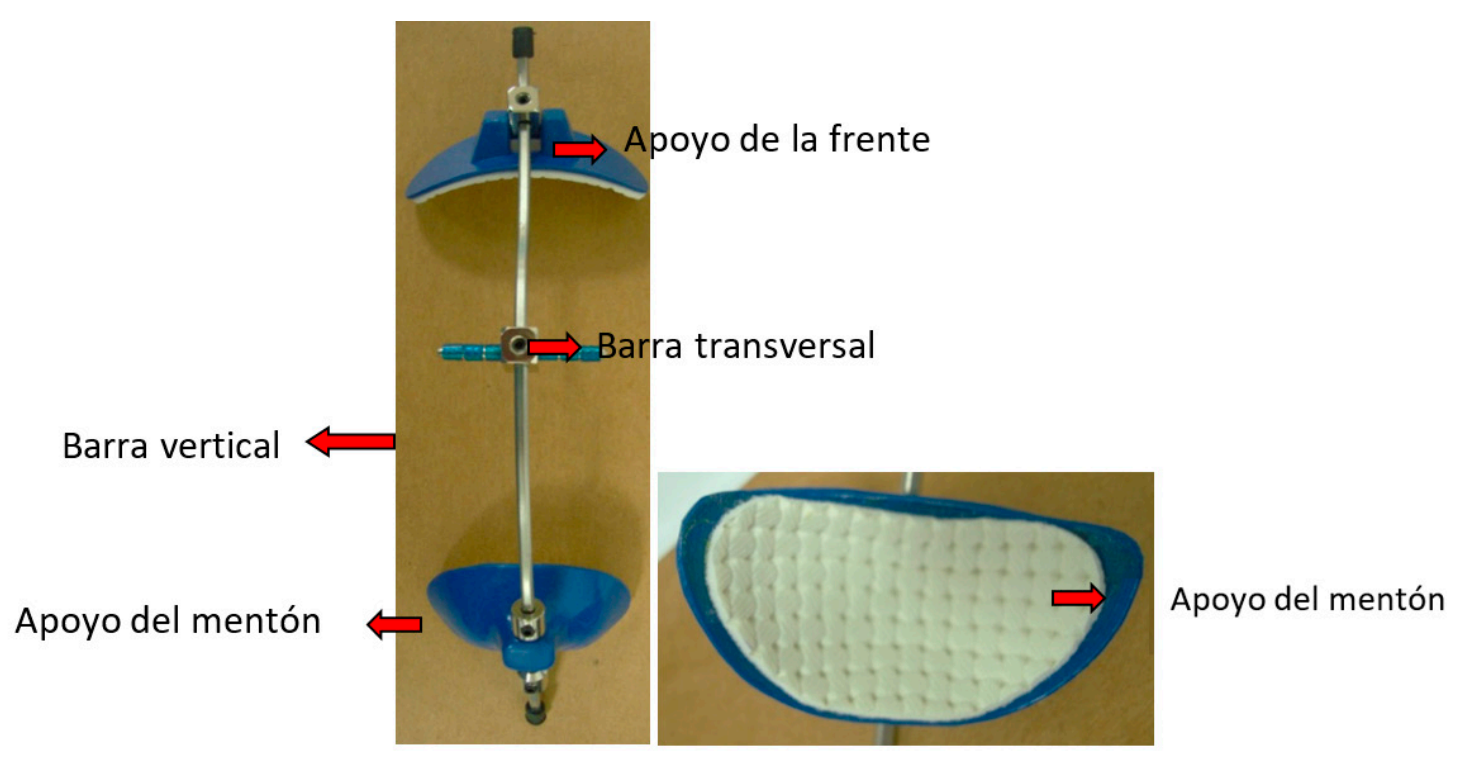

FIGURA 8. Máscara facial

Fuente: elaboración propia

Para el anclaje intraoral de la máscara es usual emplear el Hyrax (Figura 9), que paralelamente produce disyunción de la sutura palatina y activación a nivel celular en las diferentes suturas maxilares; mediante lo cual se logra una desarticulación del maxilar produciendo mayor movimiento del mismo, con
$1 \mathrm{~mm}$ de diferencia con casos sin expansión rápida, que podría ser considerado como no significativo $[16,17,18]$. La disyunción también se puede lograr con el uso de Quad Helix, cuando el paciente se encuentra en edad temprana (Figura 10). 


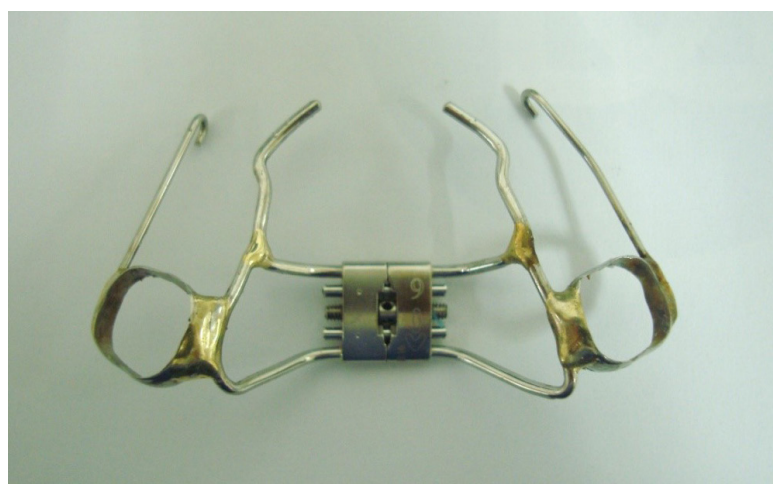

FIGURA 9. Aparato Hyrax con brazos para máscara facial Fuente: elaboración propia

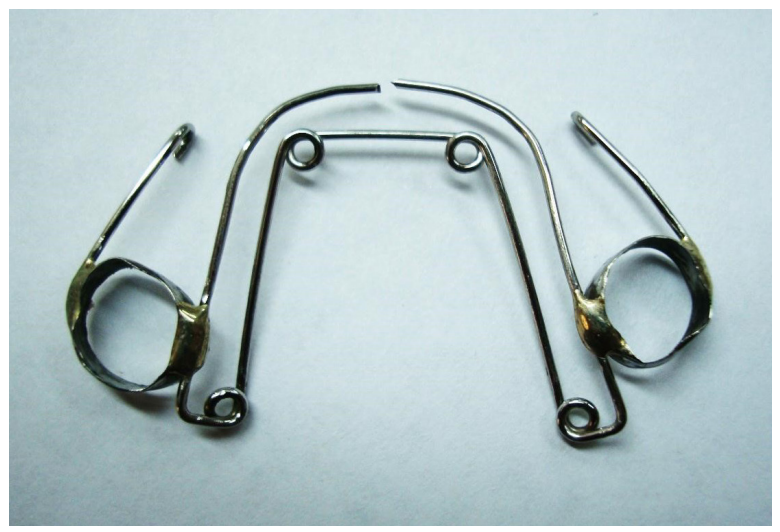

FIGURA 10. Quad Helix para traccionar maxilar Fuente: elaboración propia

\section{Efectos}

Los efectos de la máscara están ligados al patrón de crecimiento normal en los pacientes con maloclusiones clase III. El pico de crecimiento del maxilar ocurre a los 10 años en mujeres y a los 12 años en hombres; y el pico de crecimiento mandibular se presenta entre los 11 y 12 años, con un crecimiento mayor a partir de los 7 años en los hombres. Normalmente, el pico de crecimiento en los hombres ocurre dos años después que el de las mujeres y dura, por tanto, dos años más. El aumento de la longitud mandibular anual es de $3 \mathrm{~mm}$ en mujeres y un poco más de $3 \mathrm{~mm}$ en hombres para un total de $18 \mathrm{~mm}$ en mujeres y de $21.5 \mathrm{~mm}$ en hombres, entre los 8 y 16 años, (comparado con el total de $26 \mathrm{~mm}$ en los pacientes clase I, o sea, $2.4 \mathrm{~mm}$ por año). Durante la pubertad, el crecimiento es de 3 $\mathrm{mm}$ para mujeres y $3.7 \mathrm{~mm}$ en hombres, y dura aproximadamente hasta los 15 años. El Wits y el ANB disminuyen con la edad, mostrando que la clase iII se agrava [4].

El movimiento del punto A hacia delante, que genera la máscara facial, puede incrementarse con la remodelación dentoalveolar, producida con la inclinación a vestibular de los incisivos superiores. Por cada 10 a 14 grados de proinclinación de incisivos superiores, se reporta un movimiento anterior del punto A entre 0.6 y $1.7 \mathrm{~mm}[20]$.

Con el aparato se logran efectos de adelantamiento del maxilar de 3 a $5 \mathrm{~mm}$ en 31\% de los casos [14], rotación antihoraria del maxilar de 0.91 grados, rotación horaria mandibular en $21 \%, 28 \%$ de vestibularización de incisivos superiores y lingualización de los inferiores en un $20 \%[21,22]$. En la zona de la mandíbula se reduce el SNB en 1.54 grados gracias a la rotación horaria y la restricción del crecimiento [23]. Los mejores resultados esqueléticos con este tipo de aparatos se logran al aplicarse en edades tempranas de dentición decidua y mixta inicial $[24,25,26]$, con una mejor estabilidad y control vertical de la mandíbula [27].

\section{Desventajas}

Entre las desventajas de la máscara facial están la incomodidad que experimentan los pacientes, pues se trata de un aparato vistoso; la poca colaboración del paciente y las lesiones que puede provocar en la piel, principalmente del mentón (en climas cálidos). Estos factores conducen al poco uso del aparato, lo cual deriva en resultados insatisfactorios [28].

\section{Efectos de la máscara con o sin expansión rápida palatina}

Se ha recomendado la expansión rápida palatina con uso de máscara facial porque, 
al aplicar una fuerza de disyunción sobre el maxilar, sus suturas intermaxilares y circunmaxilares se ven afectadas. Esto propicia el movimiento anterior del maxilar por medio de la máscara y, por lo tanto, su efecto ortopédico. Al expandir se disminuye la tensión y se facilita la protracción maxilar [29].

En la mayoría de los casos, la protracción se combina con una disyunción del maxilar, indicada en pacientes que presentan, además de la hipoplasia o retrognatismo maxilar, una discrepancia transversal. La cantidad y duración de la disyunción dependerá de la magnitud de la discrepancia transversal, según lo reportado anteriormente (v. cap. 6). En los pacientes que no presentan problemas transversales, la disyunción es menor y dura menos (1/4 de vuelta diario, durante 1 semana o 10 días), de modo que solo se logre la activación sutural previa a la protracción, sin crear un problema de mordida en tijera. No obstante, el efecto de la disyunción sobre la protracción presenta controversia. Un estudio realizado por Kim en 1999 reportó que cuando la expansión se hace antes de la protracción se obtienen más efectos esqueléticos en menor tiempo de tratamiento; y cuando no se hace expansión, existe mayor vestibularización de los incisivos [30].

Al comparar pacientes con y sin disyunción, ciertos estudios concluyen que hay mayor desplazamiento vertical del maxilar y menor rotación del maxilar en sentido anteroposterior en aquellos pacientes con disyunción. Esto se debe a que la expansión desarticula el maxilar generando una respuesta positiva a la protracción [18] y una mayor proliferación celular [31]. Los efectos de la máscara facial con disyunción son los siguientes: movimiento anterior del punto A de $1.5 \mathrm{~mm}$ (en los controles ocurre solo $0.3 \mathrm{~mm}$ ); el plano palatal se inclina más y así también el ángulo mandibular; el overjet aumenta $4.4 \mathrm{~mm}$; la relación molar mejora en 3.9 mm; los incisivos se vestibularizan más (porque no sucede el aplanamiento de la zona anterior que ocurre con la disyunción), y la proyección mandibular disminuye en $3 \mathrm{~mm}$ [32]. Sin embargo, el estudio de Vaughn del 2005 no halla diferencias estadísticamente significativas en las cefálicas de los individuos tratados con y sin expansión en la máscara [22, 23, 33].

El protocolo de disyunción en pacientes clase III tratados con máscara facial depende de la magnitud de la alteración transversal que presenten. Cuando existe mordida cruzada posterior, se debe iniciar con un protocolo de 2/4 de vuelta de activación diaria durante 8 a 15 días, dependiendo de la cantidad de expansión requerida. En pacientes sin alteraciones transversales, la desarticulación de las suturas se logra mediante una activación del Hyrax con $1 / 4$ de vuelta diaria durante 7 a 10 días [34].

En la literatura no existe un acuerdo acerca de la cantidad de expansión necesaria para desarticular el maxilar, algunos autores señalan que $5 \mathrm{~mm}$ son suficientes; otros afirman que se requiere de 12 a $15 \mathrm{~mm}$. En pacientes que empiezan el tratamiento con una relación transversal normal, la disyunción de 12 a 15 mm podría generar mordida en tijera. Existen varios factores que pueden afectar la expansión lograda: la cantidad de expansión, la frecuencia de la activación, la articulación directa o indirecta de las suturas circunmaxilares y la orientación de las suturas [33].

\section{Protocolo de expansión-contracción [Alt RAMEC]}

La aplicación de este protocolo (cfr. capítulo 6, de alteraciones transversales), combinado con una protracción maxilar con máscara facial, genera mayor avance maxilar. En pacientes con labio y paladar hendidos, produce un movimiento del punto A de $5.8 \mathrm{~mm}$, contrastable con los $2.6 \mathrm{~mm}$ en aquellos con ERP convencional. 
En pacientes normales, se comparó el movimiento anterior del maxilar con un protocolo de ERP convencional y con uno de expansión-contracción: con el primer protocolo se obtuvo una protrusión maxilar de 1.5 a $3 \mathrm{~mm}$ en un año; y con el otro se alcanzó hasta $5.8 \mathrm{~mm}$ en el mismo periodo $[35,36,37]$. Al comparar la cantidad de avance maxilar logrado en los casos en que la máscara facial se colaca al mismo tiempo que se realiza el protocolo de expansión-contracción y en aquellos en los que se aplica una vez concluido el protocolo, no se encuentran diferencias estadísticamente significativas (3.02 y $3.84 \mathrm{~mm}$, respectivamente) [38]. Entre las desventajas que presentan, este protocolo está el efecto en tejidos periodontales de los dientes de anclaje. Por otro lado, al no haber estudios longitudinales, la estabilidad no ha sido evaluada, y los artículos no son de buena calidad [39, 40].

\section{Biomecánica del aparato}

Los efectos anteriormente descritos dependen de la dirección con la que se aplica la fuerza con respecto al centro de resistencia del maxilar, el cual se ubica debajo de la fosa pterigomaxilar, a nivel apical de los segundos premolares (Figura 11).

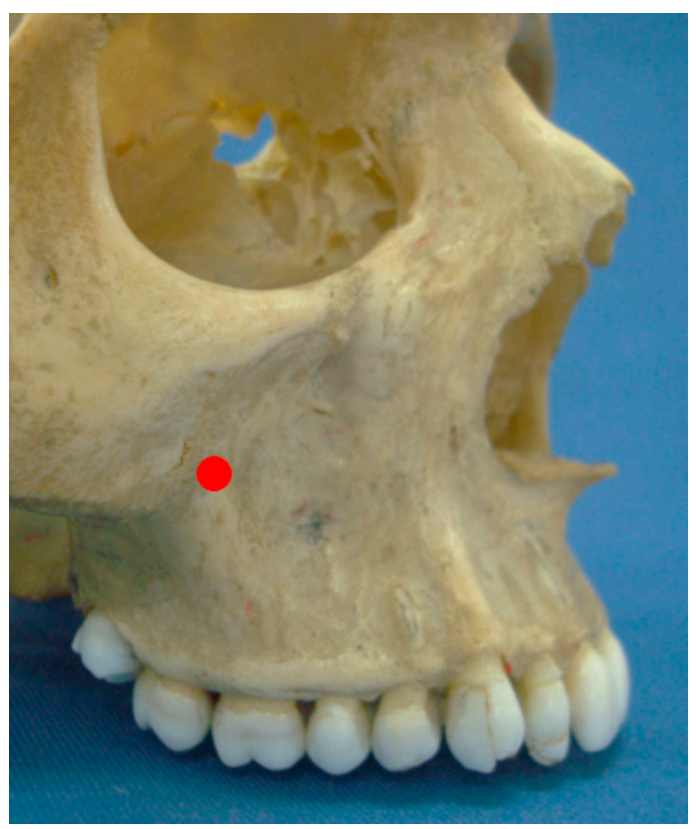

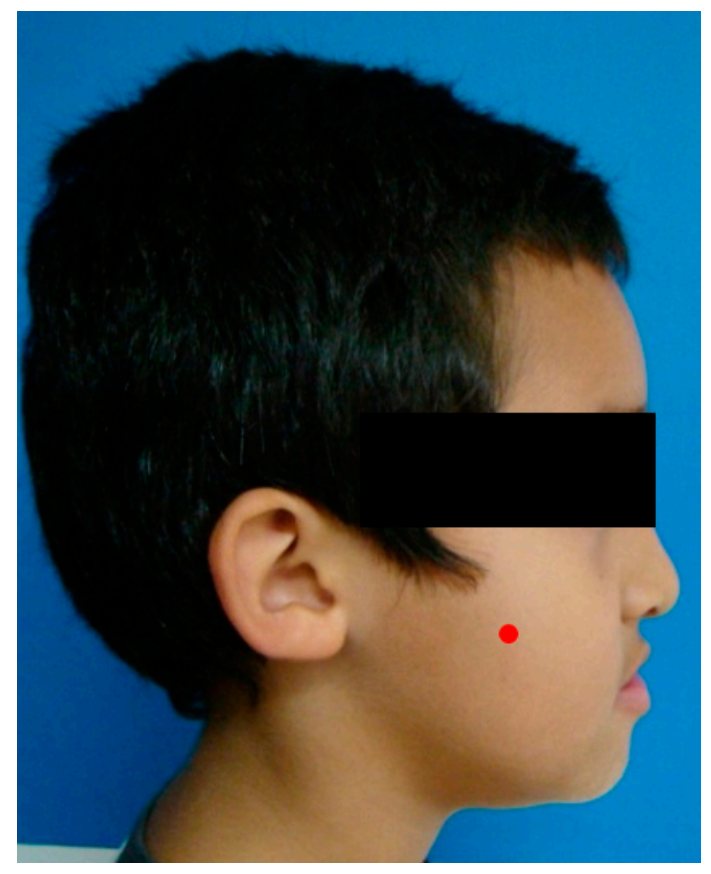

FIGURA 11. Centro de resistencia del maxilar superior

Fuente: elaboración propia

La dirección del vector de fuerza con el que se aplican los elásticos depende de las características verticales del paciente. Suele emplearse un vector de 20 a 45 grados (30 grados en promedio), que evita la rotación anterior del maxilar, generada por la aplicación de la fuerza lejos del centro de resistencia (Figura 12). Para esto, la ubicación vertical de la barra transversal se regula utilizando la llave que viene con el aparato (Figura 13). Con una dirección de elásticos hacia abajo y adelante, el paciente no experimenta molestias cuando cierra los labios. Para evitar una excesiva rotación maxilar anterior, los brazos vestibulares del aparato de anclaje deben ser ubicados lo más anterior posible a nivel de los caninos. La forma del diseño de los brazos vestibulares depende del juicio del operador (Figura 14) [41, 42].

Una fuerza con vector paralelo al plano de Frankfort evita que la mandíbula sea usada como anclaje y disminuye los efectos en la ATM, pero esto no impide la rotación maxilar. 
Al usar el vector paralelo al plano oclusal se genera una rotación en contra de las manecillas del reloj. Las horas mínimas de uso son 10 horas [43].

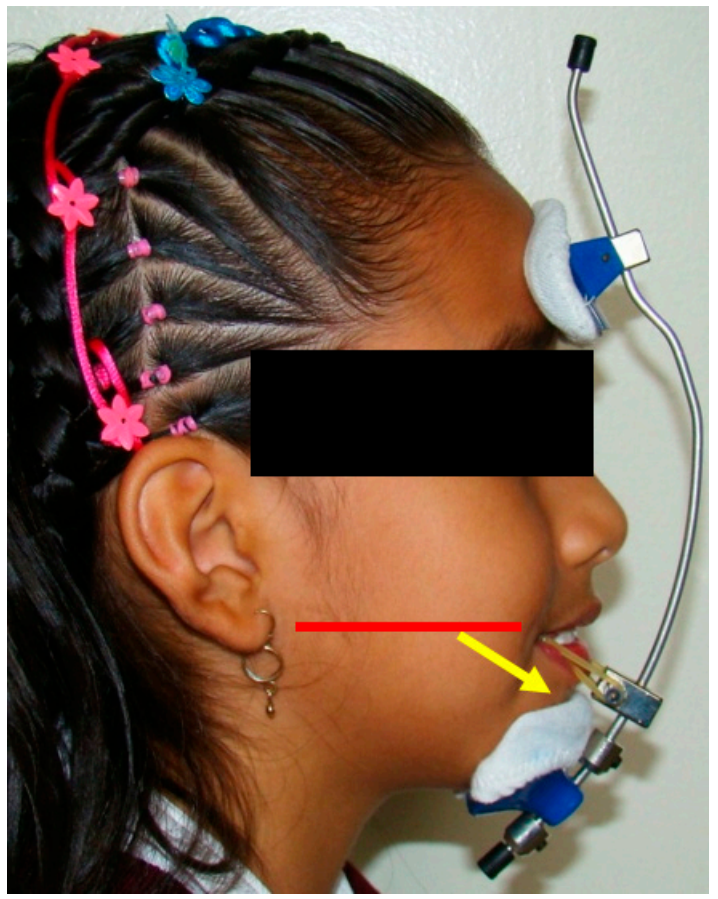

FIGURA 12. Angulación de línea de acción de la fuerza con respecto al plano oclusal

Fuente: elaboración propia

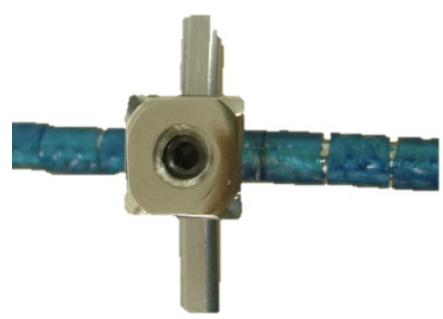

FIGURA 13. Barra transversal y llave con la que se regula su posición

Fuente: elaboración propia

FIGURA 14. Hyrax con diseños de arcos vestibulares diferentes

Fuente: elaboración propia
La fuerza de protracción generada por la máscara facial es aplicada por unos elásticos intermaxilares, que van desde el apoyo intraoral (brazos vestibulares del aparato) hasta la barra transversal de la máscara. La fuerza recomendada es variable, en los estudios se reporta un rango de 180 a 400 gr, e incluso de 800 gr $[16,21,22,41,42]$. Para poder producir la fuerza necesaria, se sugiere una secuencia de elásticos: al momento de colocar la máscara y durante las dos primeras semanas se recomienda usar elásticos 3/8 de 8 oz, luego pasar a elásticos de $1 / 2$ de 14 oz para aumentar la fuerza, $y$ finalmente se emplean los elásticos 5/16 de 14 oz (Figura 15). Algunos autores sugieren el uso de elásticos de $3 / 8$ de 14 oz (Figura 16) en lugar de los de 5/16 de 14 oz. Sin embargo, es importante aclarar que el tipo de elástico se elige según la distancia entre el anclaje intraoral y la barra horizontal de la máscara, que varía de paciente a paciente. La fuerza ejercida por los elásticos se puede medir usando el dinamómetro desde el aparato intraoral hasta la barra transversal de la máscara. Con respecto a las horas de uso, también hay variación, puede ir de 10 a 14 horas diarias [21, 41, 42], hasta un máximo de 24 horas [5, 22, 41, 42], con un promedio de 15.2 horas al día.

Finalmente, se recomienda una fuerza de 300 a 400 gr, con un uso de 14 a 16 horas y una angulación al plano oclusal de 20 grados [44].
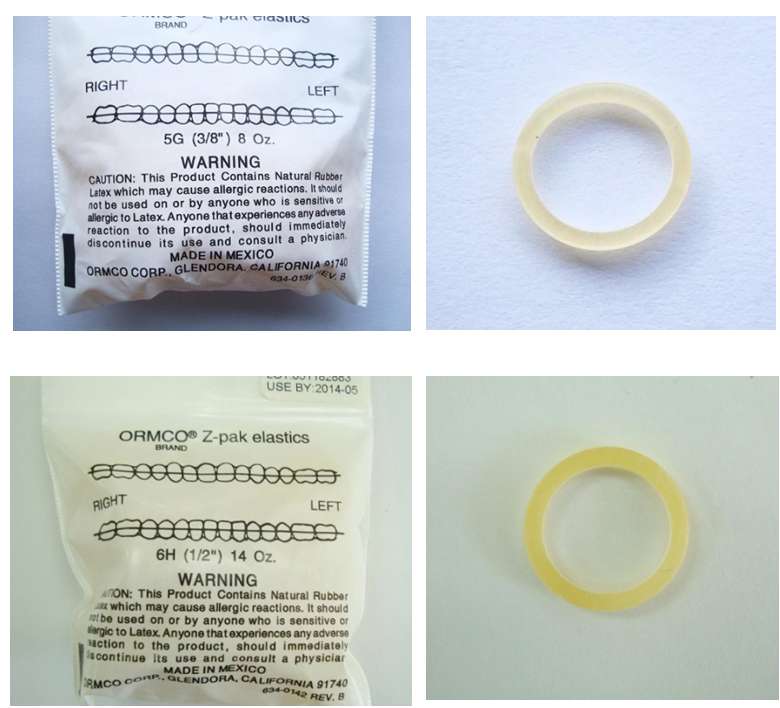


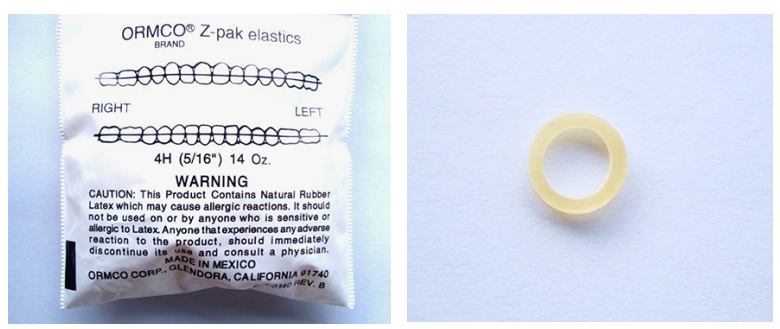

FIGURA 15. Secuencia de elástico sugerida por Baccetti

Fuente: elaboración propia
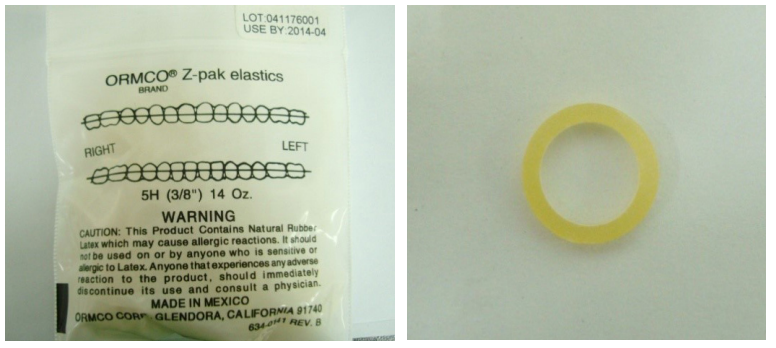

FIGURA 16. Elásticos 3/8 de $14 \mathrm{oz}$

Fuente: elaboración propia

\section{Duración del tratamiento}

Los tratamientos con máscara facial tienen una duración de 9.1 a 12 meses, e incluso pueden extenderse a 16 meses. Algunos estudios reportan que a los 6 meses se obtienen resultados evidentes, por ejemplo, overjet positivo y relaciones molares y caninas clase II. En estos casos, el aparato se emplea como retención entre 3 y 6 meses, aplicando una fuerza menor o reduciendo las horas de usos $[45,46]$. Los mayores cambios ortopédicos se evidencian durante esos primeros 6 meses. Un uso prolongado se traduce en mayores cambios dentoalveolares, como movimiento mesial de los molares y vestibularización de incisivos maxilares.

\section{Estabilidad}

En estudios longitudinales se ha reportado que el patrón de crecimiento clase III, con el que el paciente comienza el tratamiento, se restablece al año postratamiento, cuando se encuentra sin retención. En los pacientes tratados tempranamente, se reporta una ligera recidiva maxilar, y en aquellos tratados tardíamente, la recidiva ocurre a nivel mandibular $[30,45]$.

En los estudios a largo plazo en pacientes con maloclusión clase III, se evidencia que el patrón de crecimiento de estos pacientes se recupera aún después de haber terminado el tratamiento en los casos donde no se usa ningún tipo de retención. En pacientes tratados a edades tempranas hay reporte de recidiva maxilar y en los tardíos dicha recidiva ocurre a nivel mandibular $[30,45]$.

La estabilidad del tratamiento con máscara depende de la magnitud y dirección del crecimiento tardío de la cara, considerando que, a diferencia de la clase I, el pico de crecimiento mandibular en los pacientes clase iII ocurre entre cs3 y cs4 y continúa entre cs4 y cs5 [47]. Los pacientes con mandíbulas prognáticas más que aquellos con maxilares hipoplásicos tienen peor pronóstico, igual que los que inician con un ángulo goniaco abierto. Esto se debe a que un crecimiento vertical se asocia con resultados inestables [47]. En un estudio reciente se mostró una estabilidad adecuada, dos años después del tratamiento [46].

\section{Factores predictores de éxito con máscara facial}

Mediante métodos de regresión logística, se han encontrado variables que pueden predecir el éxito de un tratamiento temprano con máscara facial en pacientes clase iII. Una base craneal aumentada en tamaño hace que la mandíbula esté posicionada más posterior, y así existe más probabilidad de éxito; lo mismo ocurre con un aumento de la rama. Por el contrario, un incremento en la distancia, la longitud mandibular y el ángulo goniaco disminuye esa probabilidad. Este modelo tiene un poder de predicción de éxito del 95.5\%, y solo 70\% de predección de fracasos [48]. 
En otro estudio realizado por Baccetti en pacientes clase iII, tratados con máscara y evaluados 6 años después de concluido el tratamiento (con pico de crecimiento terminado), encontraron como variables predictoras de éxito la longitud de la rama, la angulación de la base craneal y la inclinación del plano mandibular. Se establece que un paciente tiene mayor probabilidad de éxito si presenta una rama corta, una base craneal obtusa y un plano mandibular bajo. La gran diferencia con el estudio anterior - y que genera una contradicción- es respecto a la longitud de la rama: para unos, una longitud disminuida es predictor de éxito; y para los otros, una rama larga representa una mejor condición antes de un tratamiento [49].

Según otro estudio, otras variables predictoras de éxito son el ángulo silla nasion articular (NSAr), pues un ángulo agudo se asocia a mandíbula prognática; el ángulo CondileonGnation-Gonion (Co-Gn-Go), y una altura facial anterior aumentada en los pacientes que recidivan. Se concluye que el Wits es la mejor medida para estabilidad a largo plazo. La medida resultante de la relación AB/PM es una variable que evalúa las relaciones horizontales y verticales del paciente, lo que le otorga un poder de discriminación del 93.3\% [48]. Para la aplicación del valor predictivo de esta variable, se sugiere el uso de la siguiente fórmula matemática:

$\mathrm{X}=0.290 \times(\mathrm{AB} / \mathrm{PM})-0.509 \times(\mathrm{N}$ perpendicular a A) -18.349

Los pacientes que reportan adecuada estabilidad después del tratamiento presentan una base craneal larga, sin diferencias en la posición sagital del maxilar y la angulación de los incisivos, y una la longitud mandibular menor [47-50] (Figura 17).
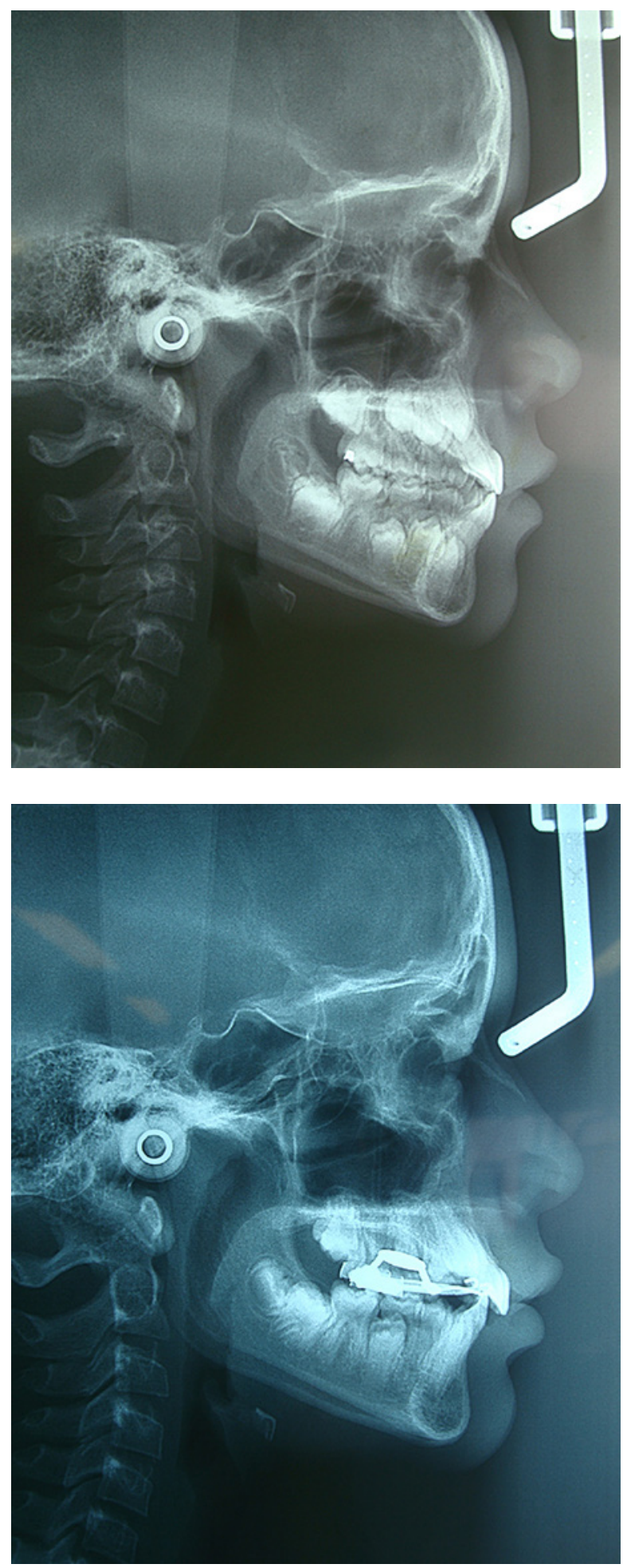

FIGURA 17. Efectos de la máscara facial en paciente clase III esquelético por hipoplasia maxilar

Fuente: elaboración propia 


\section{Caso clínico}
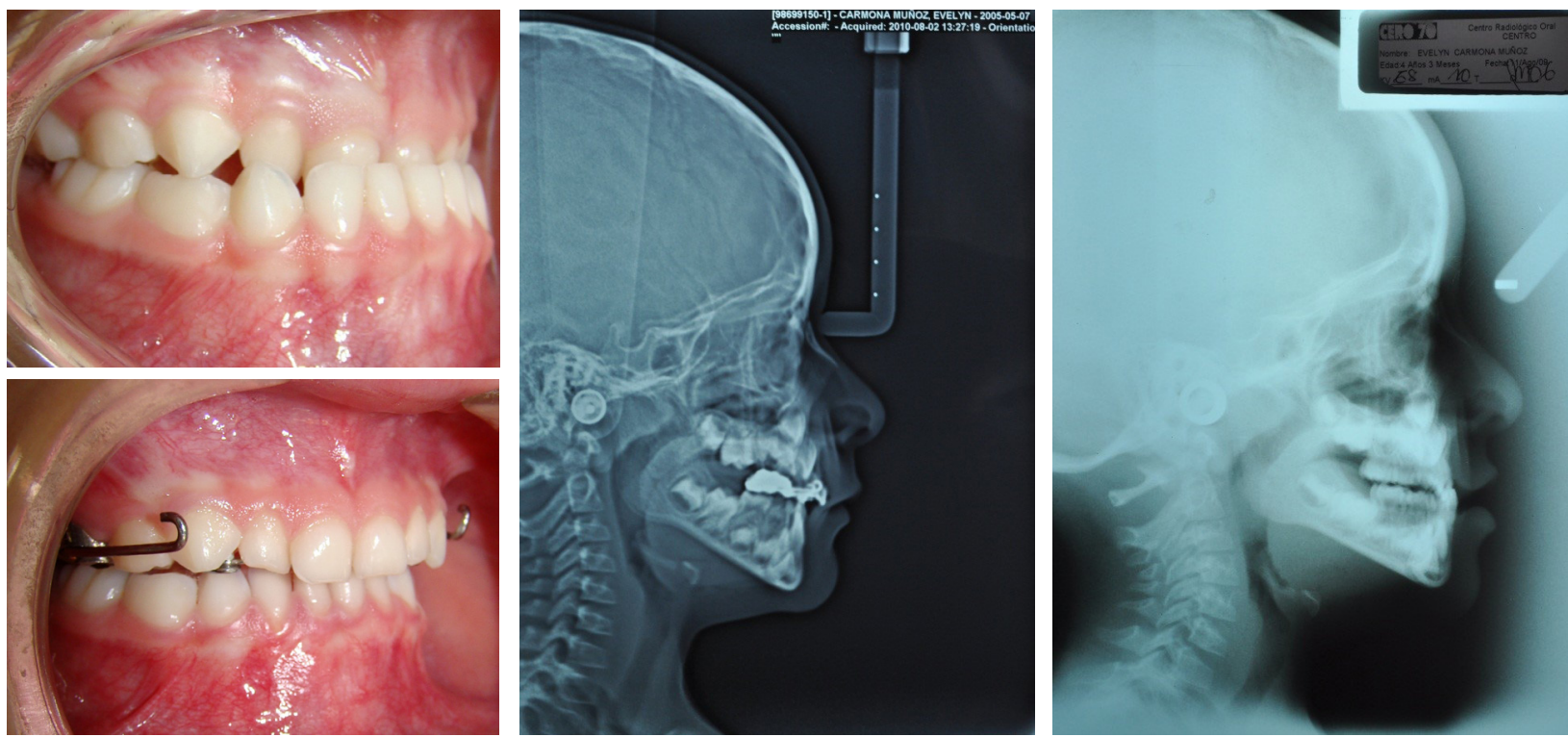

FIGURA 18. Antes y después de la máscara facial de tratamiento de un año

Fuente: elaboración propia
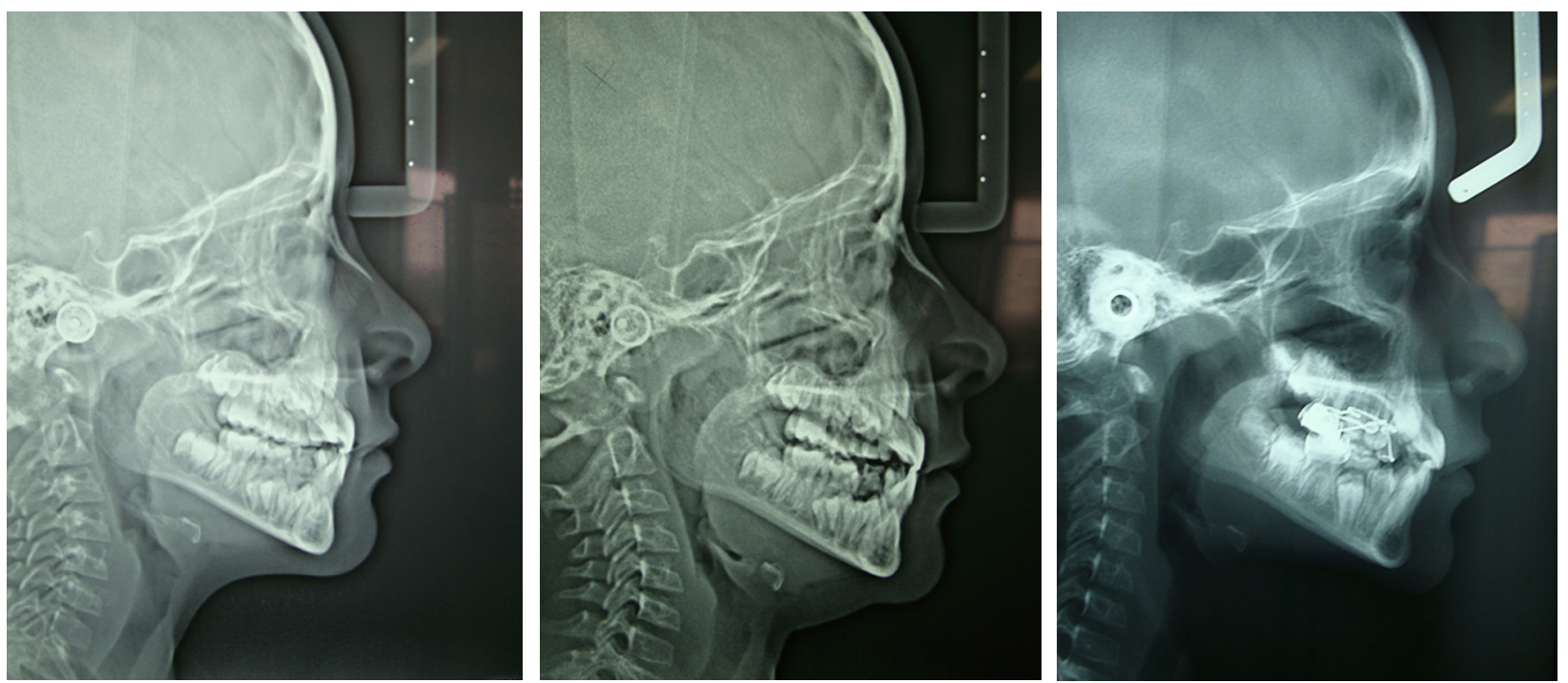

FIGURA 19. Evolución anual después de concluido el tratamiento, (en este período solo tuvo un péndulo)

Fuente: elaboración propia 


\section{Anclaje óseo para protracción maxilar}

Debido a los efectos dentales - muchas veces indeseados-, generados por el uso de la máscara con anclaje dental, se introdujo recientemente un método de protracción maxilar con el uso de anclaje óseo [51]. El objetivo de este anclaje es transferir fuerzas ortopédicas directamente a las suturas circunmaxilares [52], asegurando que esa fuerza esté más cerca al centro de resistencia del hueso. Con este sistema se evitan efectos desfavorables como rotaciones e inclinaciones del maxilar $[53,54]$. Por otro lado, se disminuyen los efectos sobre la longitud de arco (mesialización de los molares y disminución de espacio). Como anclajes óseos, inicialmente se emplearon caninos deciduos anquilosados, implantes óseos integrados e implantes tipo Onplant. Recientemente, se emplean minitornillos y miniplacas, con distintas ubicaciones según la aplicación de la fuerza [55, 56].

\section{Biomecánica del sistema}

Existen dos sitios anatómicos para la ubicación de las miniplacas: el borde inferior del zigomático y la pared nasal lateral. La pared nasal lateral permite un vector de fuerza más cercano al centro de resistencia, con mejor calidad de hueso, pues al ser hueso basal no hay riesgo de lesionar estructuras dentales [52, 57]. Las miniplacas están elaboradas con titanio, que hace posible su oseointegración y su resistencia a fuerzas ortopédicas; además, pueden ser dobladas con facilidad para su instalación en el contorno del hueso. Son fijadas con tornillos monocorticales, permitiendo su carga inmediatamente después de colocadas [58]. Puesto que su ubicación está por encima de las raíces de los dientes, se facilita el movimiento dental ortodóncico paralelo con la protracción [53]. Las fuerzas de protracción pueden aplicarse, en pacientes en dentición mixta, mediante una máscara facial con fuerzas de 300 a 400 gr por lado.

El uso de placas bimaxilares es otra forma de lograr una protracción del maxilar en pacientes en dentición mixta tardía o permanente temprana mayores de 10 años. Es importante que el canino permanente ya haya realizado la erupción para evitar daños en el germen con la colocación de la placa. En el maxilar, las placas van en la zona posterior del borde inferior del hueso cigomático. Se emplean fuerzas ligeras con elásticos intermaxilares de 150 gr por lado, para luego aumentar a 200 gr o 250 gr. El control vertical es adecuado con este tratamiento, por la poca rotación de los maxilares [59] y también se reporta lingualización de incisivos inferiores.

El efecto de protracción es mayor que con anclajes dentales y varía entre 2.9 y $4 \mathrm{~mm}$, alcanzado incluso los $8.6 \mathrm{~mm}$ [53]. Se presentan mayores cambios en la región infraorbitaria (3.3 mm), que generan más cambios en los tejidos blandos [52]. Respecto a la rata de avance del maxilar, se observa que el avance maxilar mensual con la máscara con anclaje óseo es de $0.45 \mathrm{~mm}$, y de $0.24 \mathrm{~mm}$ con la máscara de anclaje dental, con menos efectos secundarios. La protracción con máscara es más idónea en los pacientes con retrusión maxilar severa e hiperdivergentes; mientras que, en pacientes con poco desarrollo vertical e incisivos retroinclinados, los elásticos trabajan mejor [60]. En la Tabla 2, se puede observar la comparación de diseño y biomecánica entre la máscara facial aplicada sobre anclajes dentales y la máscara facial con anclaje óseo. 
TABLA 2

Diferencias entre el anclaje óseo y convencional en la máscara facial

\begin{tabular}{|c|c|c|}
\hline Categorías & Máscara facial con anclaje dental & Máscara facial con anclaje óseo \\
\hline Indicaciones & $\begin{array}{l}\text { Tratamiento temprano de maloclusión clase III, } \\
\text { leve a moderada, con retrusión maxilar y patrón de } \\
\text { crecimiento neutro e hipodivergente }\end{array}$ & $\begin{array}{l}\text { Avances maxilares en pacientes clase III, por retru- } \\
\text { sión maxilar, con compromiso vertical }\end{array}$ \\
\hline Diseño & $\begin{array}{l}\text { Aparato extraoral con anclaje frontal, mentoniano, } \\
\text { dental y elásticos intermaxilares }\end{array}$ & $\begin{array}{l}\text { Miniplacas maxilares con máscara facial } \\
\text { Miniplacas bimaxilares con elásticos intermaxilares }\end{array}$ \\
\hline Horas de uso & $10-14$ horas & 14- 24 horas \\
\hline Dirección del vector & 30 grados debajo del plano oclusal & 30 grados debajo del plano oclusal \\
\hline Fuerza & $180-400 \mathrm{gr}$ & $\begin{array}{l}\text { Miniplacas maxilares: } 400 \mathrm{gr} \\
\text { Miniplacas bimaxilares: } 200-250 \mathrm{gr}\end{array}$ \\
\hline Duración del tratamiento & $6-12$ meses & $6-12$ meses \\
\hline \multirow{4}{*}{ Efectos } & $\begin{array}{l}\text { Esqueléticos } \\
\text { Movimiento anterior maxilar de } 3-5 \mathrm{~mm} \text {, con rota- } \\
\text { ción antihoraria maxilar y horaria mandibular } \\
\text { Incremento de altura facial inferior }\end{array}$ & \multirow{2}{*}{$\begin{array}{l}\text { Esqueléticos } \\
\text { Avances maxilares de } 4-7 \mathrm{~mm} \text {, con ausencia o dis- } \\
\text { minución de rotación mandibular y menor aumento } \\
\text { de la altura anteroinferior. } \\
\text { Movimiento anterior de región infraorbital } \\
\text { Con miniplacas bimaxilares: rotación craneal maxi- } \\
\text { lar y rotación horaria mandibular leves } \\
\text { Con miniplacas con máscara: ambas rotaciones } \\
\text { controladas }\end{array}$} \\
\hline & $\begin{array}{l}\text { Dentales } \\
\text { Linguoversión de incisivos inferiores } \\
\text { Vestibularizacion de incisivos superiores } \\
\text { Mesializaciòn y extrusión de molares maxilares }\end{array}$ & \\
\hline & \multirow{2}{*}{$\begin{array}{l}\text { Facial } \\
\text { Mejoría proyección medio facial } \\
\text { Rectificación del perfil }\end{array}$} & $\begin{array}{l}\text { Dental } \\
\text { Evita los efectos colaterales dentoalveolares de la } \\
\text { máscara facial con anclaje dental }\end{array}$ \\
\hline & & $\begin{array}{l}\text { Facial } \\
\text { Proyección de la prominencia nasal } \\
\text { Perfil convexo }\end{array}$ \\
\hline
\end{tabular}

Fuente: elaboración propia

\section{Mentonera occipital}

La mentonera occipital es un aparato ortopédico (Figura 20) usado en pacientes clase III con aumento de crecimiento sagital mandibular (prognatismo). En el siglo XVIII, se dio inicio al uso de fuerzas extraorales tipo mentonera, con fuerzas ligeras (150 a 300 gr); en 1950, las fuerzas aumentaron al doble (400 a 800 gr) para obtener aplicabilidad a diferentes tipos de maloclusiones [61]. A principios del siglo xx se creía que solo tenía efectos funcionales y, por tanto, se usaba únicamente para pseudoclases III. Sin embargo, desde 1955, ciertos estudios comprobaron su efecto esquelético, pues genera cambios en el patrón de crecimiento mandibular y se considera un buen método para evitar que una maloclusión se deteriore, tanto en dentición primaria como mixta [61]. Desde ese momento, se han realizado diversos estudios para determinar su efecto y estabilidad.

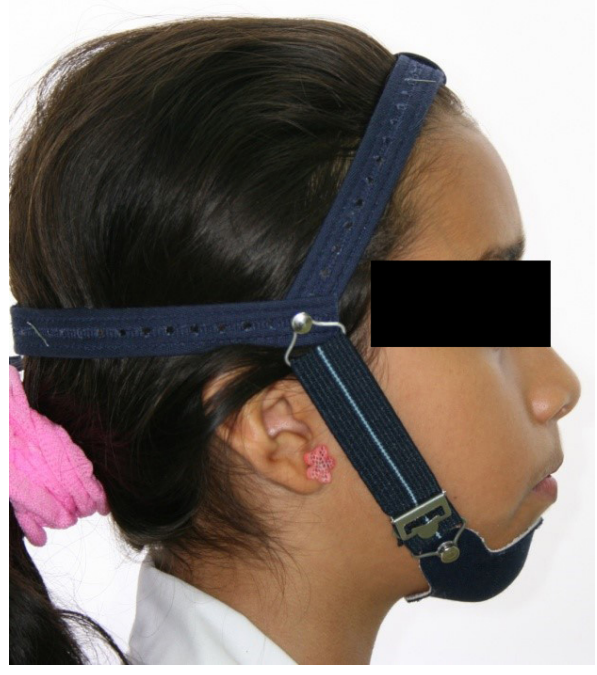

FIGURA 20. Mentonera occipital

Fuente: elaboración propia 


\section{Efectos}

Entre los principales efectos esqueléticos se encuentran el cambio del patrón de crecimiento mandibular a un crecimiento más posterior [62] (disminución SNB, aumento de ANB y Wits, aumento en N-Me y SN-PM) [63-68]; la remodelación de la forma mandibular, al generar un aumento del ángulo goniaco $[36,67,69]$ y doblamiento anterior del cuello del cóndilo [70]; el retardo en el crecimiento mandibular por inhibición del crecimiento del cóndilo, según lo reportado por Ko-Young y Sakamoto. Con respecto a este aspecto, en 1999, Deguchi halló que durante el uso de la mentonera no hubo incremento en la longitud mandibular, como sucede normalmente. En estudios animales se reporta una inhibición de la capa precondroblástica del cóndilo mandibular, disminuyendo cantidad de crecimiento [71], pero esto no ha podido ser comprobado por estudios en humanos [62, 69-71]. Finalmente, el impacto en el crecimiento maxilar es contradictorio: algunos autores reportan adelantamiento del maxilar con el uso de la mentonera [63, 65, 67]; otros no encuentran ningún cambio significativo en el crecimiento maxilar durante la terapia $[64,66]$. Los autores que defienden el efecto de la mentonera señalan que, al corregirse la mordida cruzada anterior, se facilita el crecimiento anterior del maxilar. Dentro de los efectos dentoalveolares se encuentran la lingualización de incisivos inferiores y la vestibularización de incisivos superiores [16, 21, 22, 71].

El efecto de la mentonera sobre la vía aérea ha sido poco evaluado. En un estudio realizado en cefálicas laterales, se comprobó que la mentonera no indujo ninguna modificación, por ejemplo, disminución en la vía aérea; incluso se reportó un aumento de la altura nasofaríngea [72].

\section{Diseño biomecánico}

El análisis biomecánico de la mentonera occipital muestra que el vector de fuerza va dirigido sobre el eje condilar o posterior a este, con la finalidad de controlar el crecimiento sagital mandibular. En los estudios, la fuerza aplicada es muy variable; algunos reportan el uso de fuerzas leves (300 gr), con las que los efectos esqueléticos son menores. Normalmente, se reportan fuerzas entre 600 y 900 gr durante el tratamiento activo, y disminuyen a 200 o 300 gr durante la fase de retención (una vez corregida la mordida cruzada). Para generar los efectos ortopédicos ideales, el aparato debe ser usado de 10 a 14 horas diarias [63-69].

La edad ideal para obtener cambios esqueléticos mayores es entre los 7 y 9 años, ya que se ha comprobado que la corrección sagital del perfil no es tan adecuada después de los 11 años. Además, se reporta que los cambios verticales que se obtienen con la mentonera a edades tempranas se mantienen a largo plazo, porque durante esa etapa la región dentoalveolar se encuentra en proceso de desarrollo [27].

En el caso de este aparato, la mayoría de los seguimientos se realizan a corto plazo y no se registra la estabilidad de los cambios a largo plazo [69, 71]. Su resultado a largo plazo depende del patrón esquelético y facial antes del tratamiento, y probablemente el factor más importante sea la severidad de la discrepancia anteroposterior de los maxilares $[63,73,74]$. En cuanto la estabilidad del control sagital mandibular, se ha visto que los cambios logrados con el aparato no son estables si su uso se suspende antes de la finalización del pico de crecimiento (cs6) del paciente [73]. Se ha hallado que el crecimiento mandibular recobra su patrón al retirarse la mentonera [73]. Puesto que el cartílago condilar queda libre de la presión del aparato, el crecimiento se estimula nuevamente y trata de alcanzar aquel predeterminado genéticamente [75], con una fuerza de 200 a 600 gr, con un promedio de 400 a 500 gr $[61,67,70]$ en fase activa, y de 200 gr como retención [72]. Se recomienda el uso de 300 a 600 gr por lado [76, 77]. 


\section{Componentes}

Casquete o banda cefálica (Figura 21), adaptado en la parte posterosuperior del cráneo, como anclaje (las bandas cefálicas vienen de tamaño único y se adaptan a la cabeza de los pacientes) y una mentonera apoyada en la zona del mentón (Figura 22). La fuerza es aplicada por un resorte elástico que genera los niveles de tensión indicados (Figura 23).

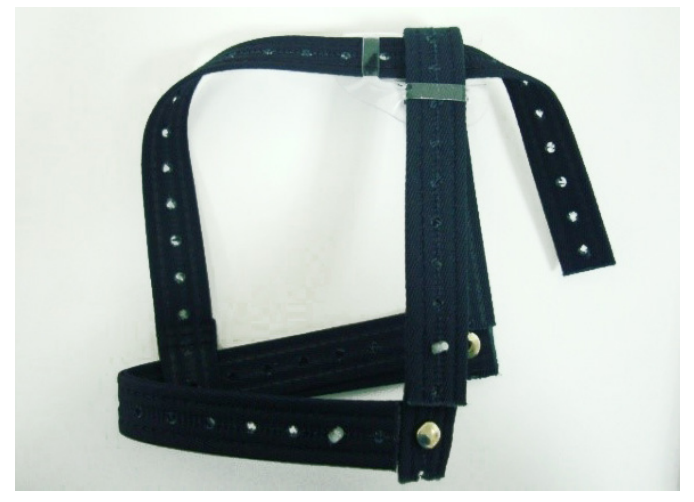

FIGURA 21. Banda cefálica

Fuente: elaboración propia
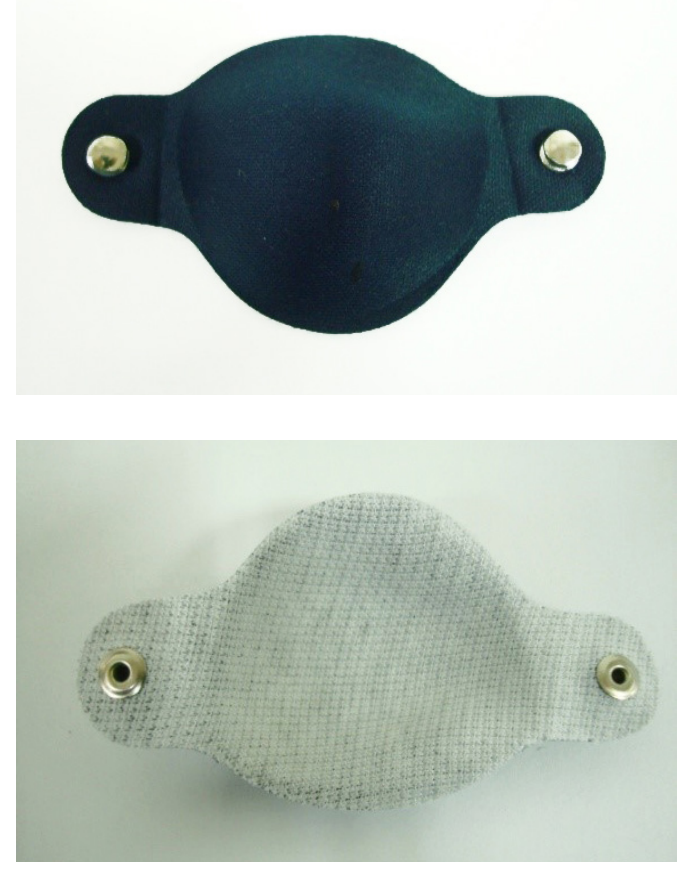

FIGURA 22. Apoyo en el mentón, se aprecia parte externa e interna

Fuente: elaboración propia

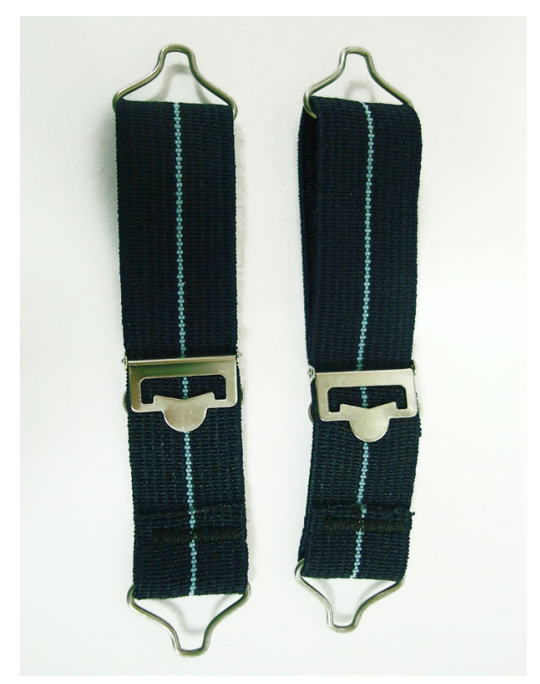

FIGURA 23. Bandas elásticas

Fuente: elaboración propia

\section{Línea de acción de fuerza}

Según la relación de la fuerza y el centro de resistencia (Figura 24) de la mandíbula ubicado a nivel del cóndilo, pueden existir dos tipos de líneas de acción:

a. Línea de fuerza que pasa a través del cóndilo: tiene el fin de impedir el crecimiento mandibular, controlando que el plano mandibular no se abra (Figura 25).

b. Línea de fuerza que pasa por debajo del cóndilo: genera una rotación abajo y atrás. Se recomienda en pacientes con altura facial corta (Figura 25).

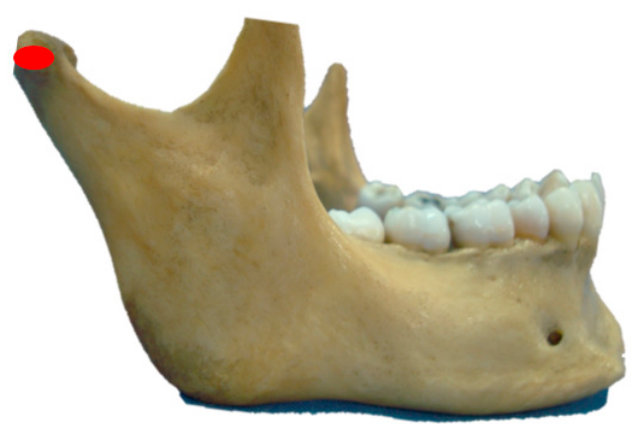

FIGURA 24. Centro de resistencia de la mandíbula Fuente: elaboración propia 


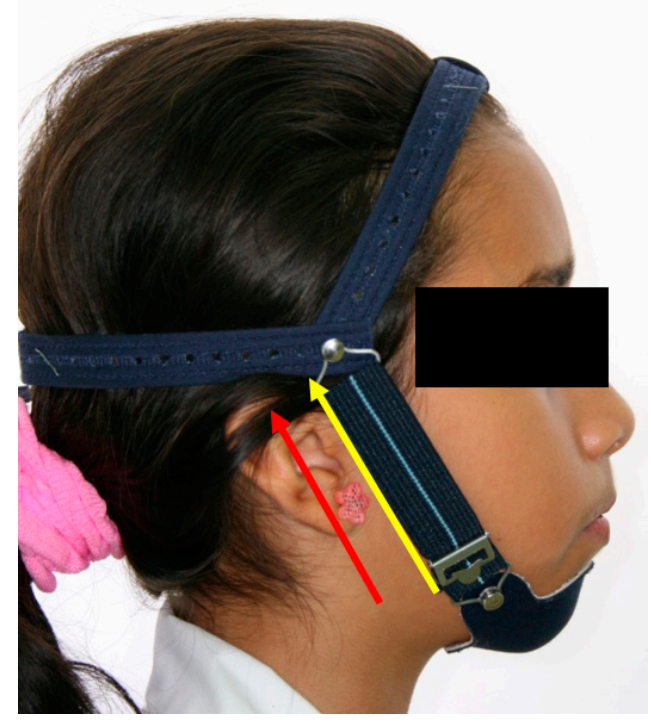

FIGURA 25. Amarillo. Línea de acción de la fuerza que pasa a través del cóndilo. Rojo. Línea de acción de la fuerza que pasa por detrás del cóndilo

Fuente: elaboración propia

\section{Duración de uso}

Se sugiere un uso de 12 a 14 horas al día.

\section{Tracción cervical mandibular}

La tracción inferior es un aparato ortopédico aplicado a los primeros molares inferiores, con el cual se pretende controlar el crecimiento mandibular en pacientes clase III esquelética por prognatismo mandibular. Joho fue el primero en reportar el uso de la tracción aplicada en molares de micos con ángulo goniaco bajo. Los primeros estudios en humanos fueron realizados por Battagel y Orton, quienes emplearon esta tracción junto con un Hawley superior, con plano que vestibulariza los incisivos superiores. Se reportó una mejoría en el overbite con rotación abajo y atrás de la mandíbula, un avance maxilar y una mejoría en la inclinación de los incisivos [78].

\section{Diseño}

El aparato consiste en bandas en los primeros molares con un tubo doble, y un arco de tracción estándar, en el que se hacen dobleces en bayoneta para obtener un tope. Se debe tener la precaución de dejar suficiente espacio para que el arco no interfiera con el selle labial (Figura 26). El arco externo se adapta al contorno de la cara del paciente en sentido transversal, y sagitalmente su longitud depende de cada paciente, dejando que la línea de acción de la fuerza pase por el centro de resistencia del molar permanente (Figura 27) [79]. En otros estudios se observa el uso del arco externo doblado hacia abajo, para compensar el paso de la fuerza por encima del centro de resistencia del molar, generando distalización con inclinación [61].

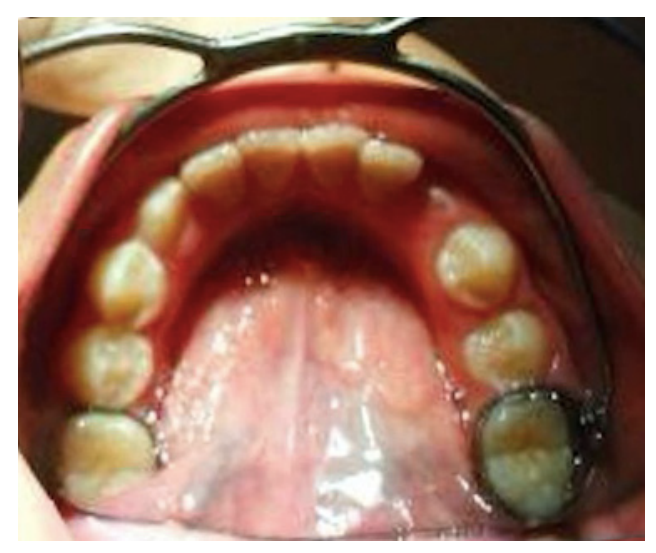

FIGURA 26. Arco en posición en las bandas de los primeros molares

Fuente: elaboración propia

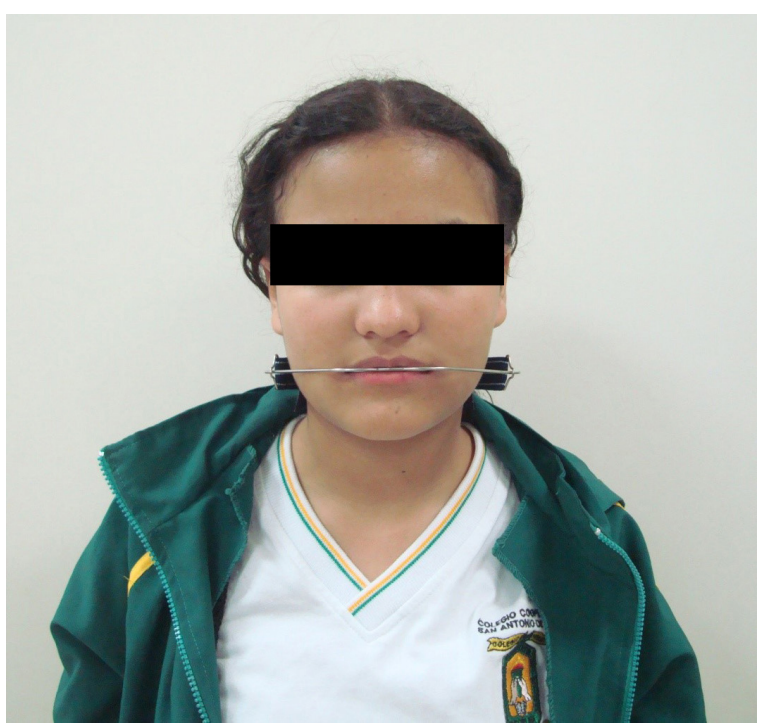




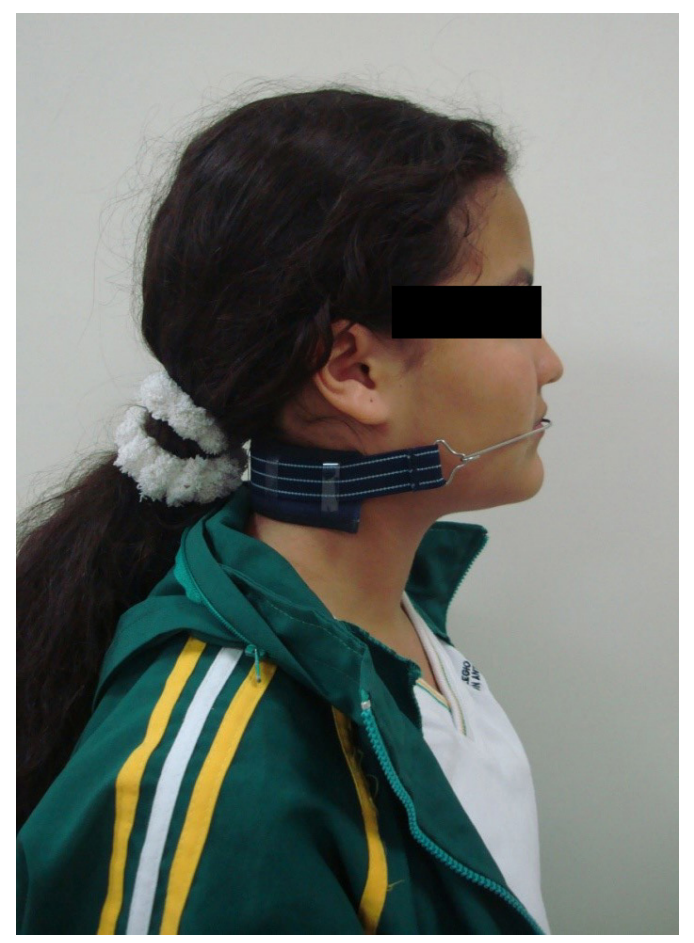

FIGURA 27. Tracción cervical mandibular en posición

Fuente: elaboración propia

\section{Fuerza}

Las fuerzas sugeridas para este tipo de aparato ortopédico son diferentes a las que se aplican en el maxilar superior con el mismo tipo de aparato, para evitar la afectación de la articulación temporomandibular. Se recomienda el uso de 300 gr por lado, por 14 horas al día, aunque en estudios iniciales se empleaban fuerzas de 450 a 500 gr $[61,80]$, con una duración del tratamiento de aproximadamente 2 años y medio [79].

\section{Efectos}

En los primeros estudios en animales se encontró distalización molar, movimiento distal mandibular, remodelación de la ATM y cierre del ángulo góniaco. En humanos, inicialmente fue usado como anclaje para elásticos clase II, y se observó disminución del sNB, aumento del control del crecimiento mandibular, movimiento lingual de incisivos, corrección del ANB y aumento del tercio inferior [61].
Después de un año de tratamiento, se genera inhibición del crecimiento mandibular, con aumento de la altura facial inferior; distalización de molares inferiores; un menor incremento en la longitud mandibular, con mejoría esquelética y dental, y rotación posterior mandibular. La tracción inferior genera un cambio de $4 \mathrm{~mm}$ en el Wits, con una mejoría en el overjet de $2.7 \mathrm{~mm}$; una corrección de relación molar en $4.4 \mathrm{~mm}$, y una rotación mandibular abajo y atrás de 2.8 grados. Se recomienda en pacientes con ángulo mandibular bajo [79].

Los estudios de Battagel y Orton muestran una disminución en el crecimiento relativo de la mandíbula respecto a los controles; un movimiento lingual de incisivos inferiores; una corrección de un grado por año en el ANB, y un aumento de la altura facial inferior.

La tracción inferior con planos posteriores puede ser empleada para facilitar el descruzamiento de la mordida anterior, pues se inhibe el movimiento sagital mandibular producto del crecimiento, se logra movimiento mesial del molar y disminución en la longitud total mandibular. Se genera una rotación mandibular posterior con aumento del ángulo GoMeSN y del ángulo goniaco, y el molar se distaliza y se intruye. Gracias a estos efectos, su uso es más recomendado en pacientes con ángulo del plano mandibular bajo [40].

La comparación entre la tracción y la máscara facial muestra que esta última produce mayor efecto de estimulación maxilar (2.3 mm), y que la tracción inferior controla mejor el crecimiento mandibular (3 mm), produce mayor apertura del ángulo del plano mandibular y con iguales respuestas en sentido vertical. La mejoría en el overjet es mayor con la máscara facial, mientras que la corrección de la relación molar fue mejor con la tracción $[79,81,82]$.

Por otro lado, en un ensayo clínico controlado que compara la tracción cervical mandibular y planos de mordida posterior con la 
mentonera, se observó que no hubo movimiento distal de la fosa en el grupo de tracción — pues la fuerza aplicada hace la presión principal a través del cóndilo y el borde inferior de la cavidad glenoidea (zona más resistente a la reabsorción)_, mientras que la mentonera sí desplazó la cavidad glenoidea (Co-N). Los ángulos GoMeSN y goniaco aumentaron gracias a una rotación posterior mandibular, pero con la mentonera permanecieron igual. La mentonera inhibió el crecimiento sagital del maxilar (disminución de la distancia N-ENA); y la tracción produjo la distalización del molar inferior principalmente y, de manera secundaria, la del superior. Si se quiere evitar el movimiento distal del molar, se puede expandir el arco interno para llevar las raíces a vestibular contra el hueso cortical, y se controla la posición del molar superior (que con el crecimiento se mueve hacia mesial) con el uso normal de la tracción [61].

Los resultados conseguidos con este tipo de aparato son estables si es que el tratamiento incluye el pico de crecimiento puberal del paciente [81] (Figura 28).

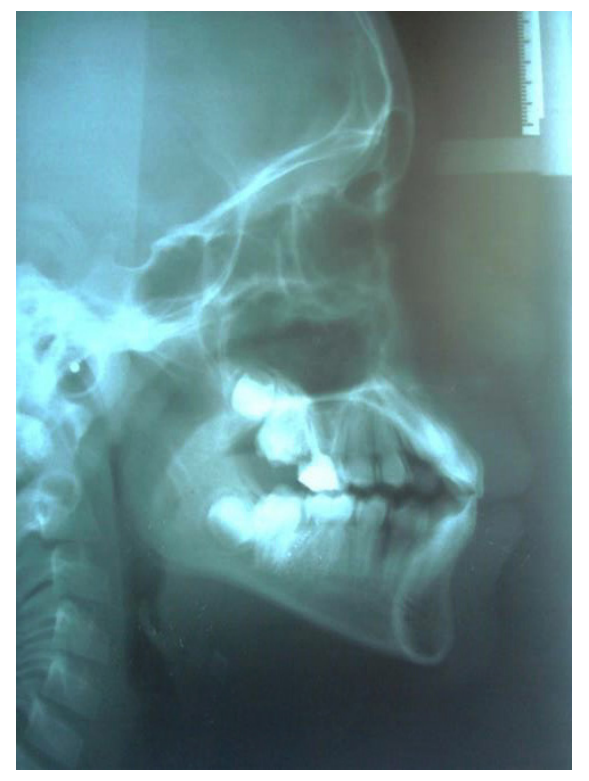

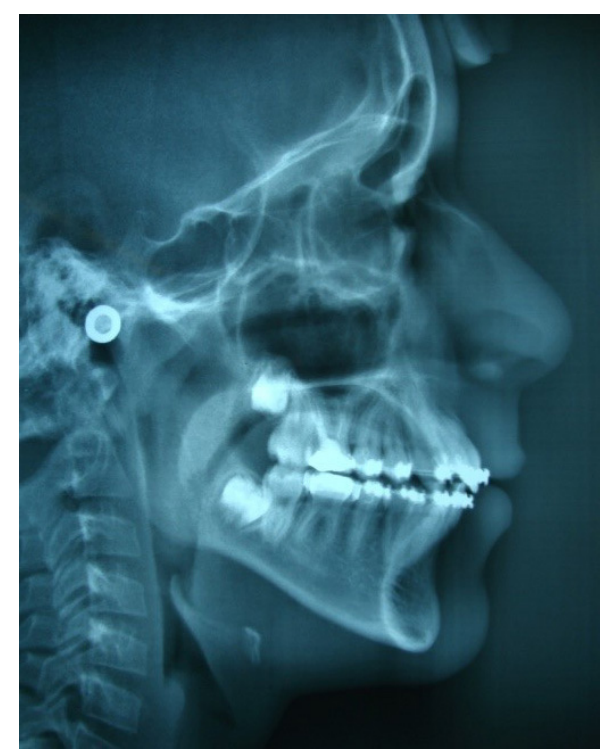

FIGURA 28. Cambios esqueléticos en paciente clase III por prognatismo mandibular luego de tracción cervical mandibular

Fuente: elaboración propia

\section{Efectos secundarios}

La tracción inferior posiciona el cóndilo más posterior y su efecto se puede asociar al riesgo de crear una disfunción articular. Sin embargo, en estudio en micos, no se han advertido cambios inflamatorios degenerativos, sino cambios de remodelación a nivel de la articulación temporomandibular, al aplicar fuerzas restrictivas mandibulares. Por otro lado, en un estudio clínico que aplica el análisis de Helkimo para evaluar los efectos de la tracción cervical inferior en la articulación, no se registraron efectos significativos a nivel de esta estructura, ni signos o síntomas de desórdenes temporomandibulares [82, 83]. El resumen de los efectos de los aparatos empleados para la corrección de una maloclusión clase iII se pueden ver en la Tabla 3. 
TABLA 3

Resumen de los efectos de los tratamientos clase III

\begin{tabular}{|c|c|c|c|c|c|}
\hline $\begin{array}{l}\text { Efectos/ } \\
\text { Aparatos }\end{array}$ & Máscara & Mentonera & Progenie & Tracción inferior & $\begin{array}{l}\text { Aparatos } \\
\text { funcionales }\end{array}$ \\
\hline Maxilar & Avance del maxilar & Ninguno & $\begin{array}{l}\text { Desarrollo de la base } \\
\text { apical maxilar }\end{array}$ & Ninguno & $\begin{array}{l}\text { Desarrollo de la base } \\
\text { apical maxilar }\end{array}$ \\
\hline Mandíbula & $\begin{array}{l}\text { - Rotación vertical } \\
\text { - Aumento de la altura } \\
\text { anteroinferior }\end{array}$ & $\begin{array}{l}\text { - Rotación vertical } \\
\text { - Redirección del crecimiento } \\
\text { mandibular } \\
\text { - Apretura del ángulo goníaco } \\
\text { - }\end{array}$ & Rotación vertical & $\begin{array}{l}\text { - Redirección del crecimiento } \\
\text { mandibular } \\
\text { - Rotación vertical }\end{array}$ & Rotación vertical \\
\hline Dental & $\begin{array}{l}\text { Proinclinación de incisi- } \\
\text { vo superior y lingualiza- } \\
\text { ción del inferior }\end{array}$ & $\begin{array}{l}\text { Lingualización de incisivos } \\
\text { inferiores }\end{array}$ & $\begin{array}{l}\text { Proinclinación de } \\
\text { incisivo superior y } \\
\text { lingualización del } \\
\text { inferior }\end{array}$ & $\begin{array}{l}\text { - Distalización e intrusión del } \\
\text { primer molar } \\
\text { - Proinclinación del incisivo supe- } \\
\text { rior y lingualización del inferior } \\
\text { - Aplanamiento del plano oclusal }\end{array}$ & $\begin{array}{l}\text { Proinclinación de } \\
\text { incisivo superior y } \\
\text { lingualización del } \\
\text { inferior }\end{array}$ \\
\hline
\end{tabular}

Fuente: elaboración propia

\section{Caso clínico}

Paciente de 9 años de edad que comienza tratamiento interceptivo con tracción cervical mandibular. A los 11 años, se procede con el tratamiento de ortodoncia correctiva junto con la tracción.
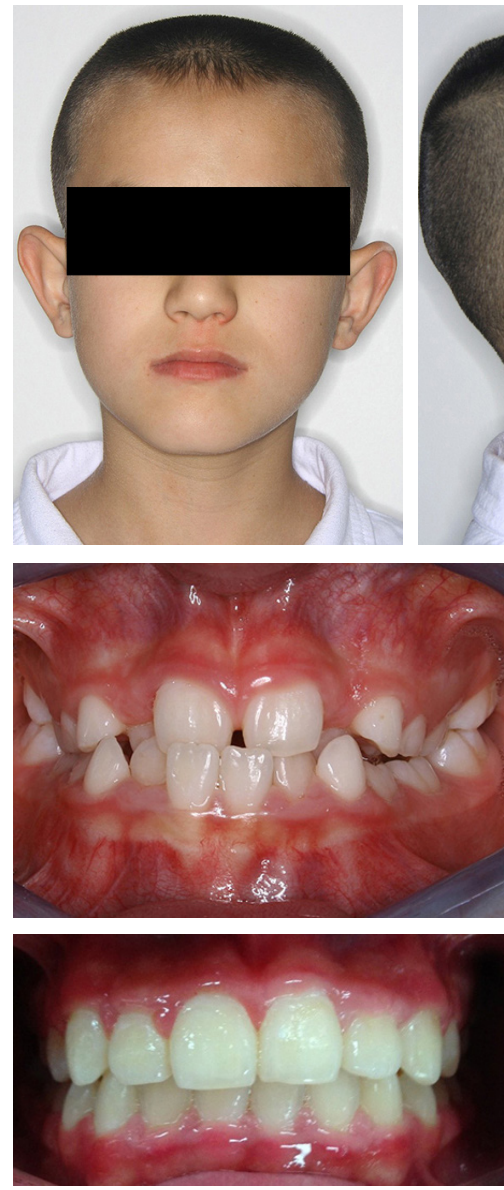
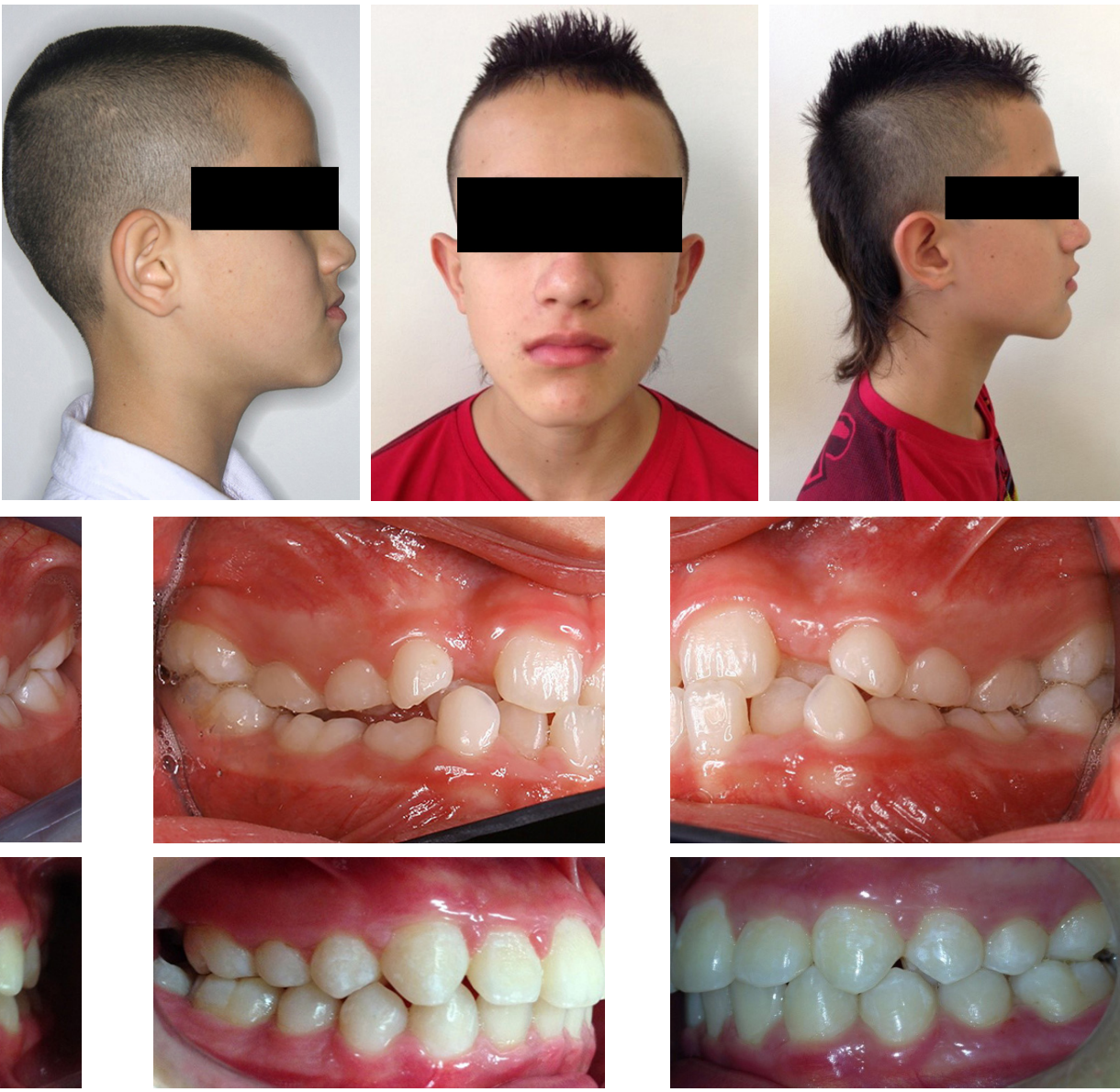

FIGURA 29. Antes y después del tratamiento interceptivo y correctivo 

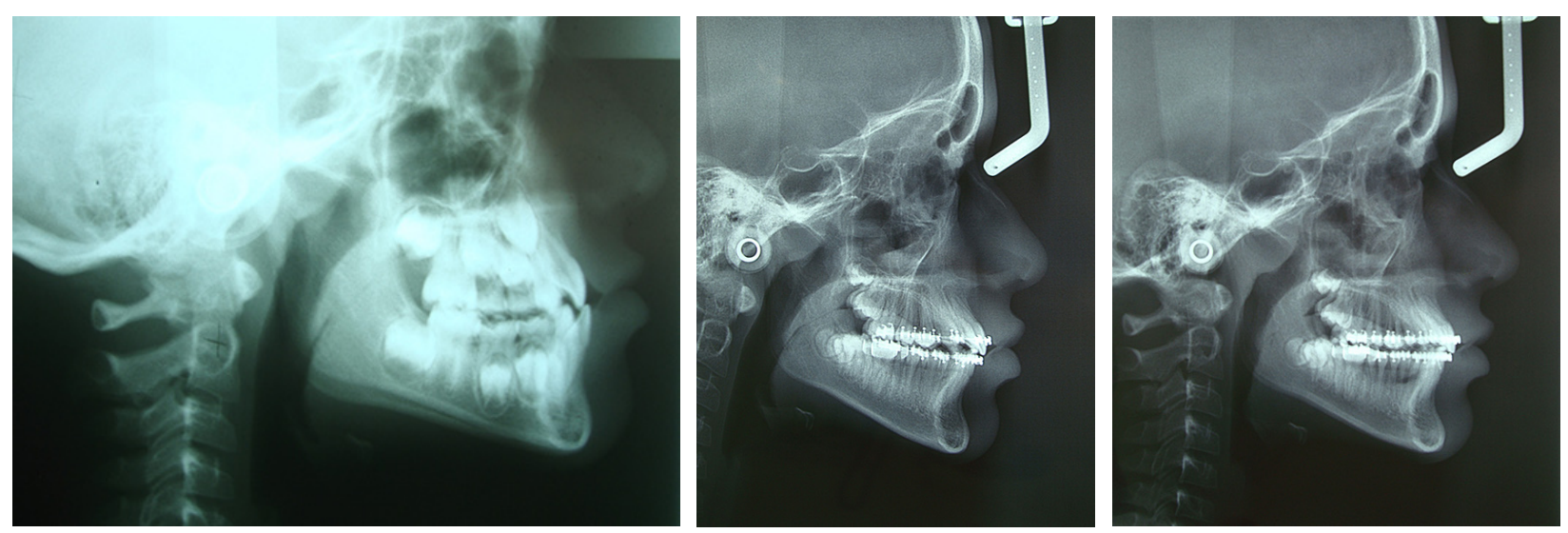

FIGURA 30. Comparación de las radiografías al inicio y al final de la ortodoncia correctiva

Fuente: elaboración propia

TABLA 4

Medidas iniciales, intermedias y finales de radiografía cefálica lateral

\begin{tabular}{cccc}
\hline & & Radiografía & \\
\cline { 2 - 4 } Medida & $\begin{array}{c}\text { Primera } \\
2010\end{array}$ & $\begin{array}{c}\text { Segunda } \\
2012\end{array}$ & $\begin{array}{c}\text { Tercera } \\
2013\end{array}$ \\
\hline SNA & 81 & 82 & 90 \\
\hline SNB & 84 & 81 & 89 \\
\hline Co-A & $83 \mathrm{~mm}$ & 75 & $78 \mathrm{~mm}$ \\
\hline CO-Gn & $113 \mathrm{~mm}$ & 102 & $110 \mathrm{~mm}$ \\
\hline ANB & -3 & 1 & $-1.5 \mathrm{~mm}$ \\
\hline WITS & $-7 \mathrm{~mm}$ & $-3 \mathrm{~mm}$ & 116 \\
\hline Ángulo incisivo superior/PP & 113 & 124 & 88 \\
\hline Ángulo incisivo inferior/PM & 87 & 92 & \\
\hline
\end{tabular}

Fuente: elaboración propia

\section{REFERENCIAS}

1. Miyajima K, McNamara J, Sana M, Murata S. An estimation of craniofacial growth in the untreated class III female with an anterior crossbite. Am. J. Orthod. 1997;112: 425-434.

2. Bishara ES. Textbook of Orthodontics. Philadelphia: W. B. Saunders Company; 2001.

3. Buschang P, Gandini L. Mandibular skeletal and modelling between 10 and 15 years of age. Eur. J. Orthod. 2002;24:69-79.

4. Zionic A, McNamara J, Franchi L, Baccetti T. Semi longitudinal cephalometric study of craniofacial growth in untreated class III malocclusion. AJO. 2009;135:700.

5. Reyes B, Baccetti T, MacNamara J. An estimate of craniofacial growth in class III malocclusion. Angle Orthod. 2006;76(4):577.

6. Sigh, G. Ortodoncia diagnóstico y tratamiento. 2. ${ }^{\text {a }}$ ed. T2. Venezuela: Editorial Amolca; 2009. 
7. Tollaro I, Baccetti T, Franchi L. Craneofacial changes induced by early functional treatment of class III malocussion. AJO. 1996;109:310.

8. Saleh M, Hajeer M, Al Jundi A. Short-term effects and hard-tissue changes following class III treatment using a removable mandibular retractor: A randomized controlled trial. Orthod. Craniofac. Res. 2013;16:75-86.

9. Tollaro I, Baccetti T, Franchi L. Mandibular skeletal changes induced by early functional treatment of class III maloclussion. A superimposition study. AJO. 1995;108(5).

10. Battagel JM. The aetiological factors in Class III malocclusion. Eur. J. Orthod. 1993;15:347-70.

11. Jackson GW, Kokich VG, Shapiro PA. Experimental and postexperimental response to anteriorly directed extraoral force in young Macaca nemestrina. Am. J. Orthod. 1979;75:318-333.

12. Guyer EC, Ellis EE, McNamara JA, Behrents RG. Components of Class III malocclusion in juveniles and adolescents. Angle Orthod. 1986;56:7-30.

13. Hyung S, Baik H, Sung S, Kim K, Cho Y. Three-dimensional finite- element analysis of maxillary protraction with and without rapid palatal expansion. Eur. J. Orthod. 2007;29:118-125.

14. Cha B, Ngan P. Skeletal Anchorage for Orthopedic Correction of Growing Class III Patients. Semin. Orthod. 2011;17:124-137.

15. Ngan P, Hagg U, Yiu C, Wei SSH. Treatment Response and Long-Term Dentofacial Adaptations to Maxillary Expansion and Protraction. Semin. Orthod. 1997;3:255-264.

16. Baik HS. Clinical results of the maxillary protraction in Korean children. Am. J. Orthod. 1995;108:583-592.

17. Cha KS. Skeletal Changes of Maxillary Protraction in Patients Exhibiting Skeletal Class III Malocclusion: A Comparison of Three Skeletal Maturation Groups. Angle. Orthod. 2003;73:26-35.

18. Leonardi R, Sicurezza E, Cutrera A, Barbato E. Early post-treatment changes of circumaxillary sutures in young patients treated with rapid maxillary expansion. Angle Orthod. 2011;81:36-41.

19. Turley PK. Treatment of the Class III Malocclusion with Maxillary Expansion and Protraction. Semin. Orthod. 2007;13:143-157.

20. Bicakci A, Cankaya O, Mertoglu S, Yilmaz N, Abcoglu B. Does proclination of maxillary incisors really affect the sagital position of point A. Angle Orthod. 2013;63:893-897.

21. Kajiyama K, Murakami T, Suzuki A. Comparison of orthodontic and orthopedic effects of a modified maxillary protractor between deciduous and early mixed dentitions. Am. J. Orthod. 2004;126:23-32.

22. Foersch M, Jacobs C, Wreidt S, Hechtner M, Wehrbein H. Effectiveness of maxillary protraction using facemask with or without expansion: A systematic review and meta-analysis. Clin. Oral Invest. 2015. doi: 10.1007/s00784-015-1478-4.

23. Cordasco G, Matarese G, Rustico L, Fatusca S, Caprioglio A, Lindauer S, Nucera R. Efficacy of orthopedic treatment with protraction facemask on skeletal class III malocclusion: A systematic review and matanalysis. Orthod. Craniof. Res. 2014;17:133-143.

24. Baccetti T, McGill JS, Franchi L, McNamara JA, Tollaro I. Skeletal effects of early treatment of Class III malocclusion with maxillary expansion and face-mask therapy. Am. J. Orthod 1998; 113:333-43.

25. Baccetti T, Franchi L, McNamara JA. Treatment and posttreatment craniofacial changes after rapid maxillary expansion and facemask therapy. Am. J. Orthod. 2000;118:404-13.

26. Toyama C, Cevidanes L, Nguyen T, DeClerck H, Franchi L, McNamara J. Three-dimensional analysis of maxillary chances associated with facemask and rapid maxillary expansion compared with bone anchored maxillary protraction. Ajo. 2013;144:705-714.

27. Cozzani G. Extraoral traction and Class III treatment. Am. J. Orthod. 1981;80:638-50.

28. Saadia M, Torres E, Sagittal changes after maxillary protraction with expansion in Class III patients in the primary, mixed, and late mixed dentitions: A longitudinal retrospective study. Am. J. Orthod. 2000;117:66980. 
29. Zhang H, Deng F, Wang H, Huang Q, Zhang Y. Early orthodontic intervntion followed by fixed appliance therapy in a patient with severe class III malocclusion and cleft lip and palate. Am. J. Orthod. Dentofacial Orthop. 2013;144(5):726-736.

30. Kim J. The effectiveness of protraction facemask. A metanalysis. AJO. 1999;115:675.

31. Melsen B. Histological analysis of the postnatal development of the nasal septum. Angle Orthod. 1977;47(7):83-96.

32. Westwood P, Baccetti T. Long term effects of class III treatment with rapid maxillary expansion and face mask therapy. AJO. 2000.

33. Vaughn G, Mason B, Moon H, Turley P. The effects of maxillary protraction therapy with or without rapid palatal expansion: A prospective, randomized clinical trial. Ajo. 2005;128:299.

34. Mandall A, Cousley R, Dibiase A, Dyer F, Littlewood S, Mattick R, et al. Is early class III protraction facemask treatment effective? A multicenter, randomized, controlled trial: 3-Year follow-up. J. Orthod. 2012;39(3):176-185.

35. Wang Y, Chang P, Liou E. Opening of cincunmaxillary sutures by alternate rapid maxillary expansions and constrictions. Angle Orthod. 2009;79(2):230-234.

36. Liou E. Effective maxillary orthopedic protraction for growing class III patients: a clinical application simulates distraction osteogenesis. Prog. Orthod. 2005;6(2):154-171.

37. Liou E, Tsai W. A new protocol for maxillary protraction in cleft patients: repetitive weekly protocol of alternate rapid maxillary expansions and constrictions. Cleft Palate Craniofac. J. 2005;42(2):121-127.

38. Cantuk B, Celikoglu M. Comparison of the effects of face mask treatment started simultaneously and after the completion of the alternate rapid maxillary expansion and contriction procedure. Angle Orthod. 2015;85:284-291.

39. Wang Y, Chang P, Liuo E. Opening of circunmaxillary sutures by alternative rapid maxillary expansion and constrictions. Angle Orthod. 2009;79(2):230-234.

40. Franchi L, Baccetti T, Masucci C, Defraia E. Early Alt-RAmEC and facial mask protocol in class III malocclusion. JCO. 2001;45(11).

41. Kaya D, Kocadereli I, Kan B, Tasar F. Effects of facemask treatment anchored with miniplates after alternate rapid maxillary expansions and constrictions; a pilot study. Angle Orthod. 2011;81(4):639-646.

42. Tortop, T. Face mask therapy with and without expansion. AJo. 2007 oct;132(4).

43. McDonald K, Kapust A, Turley P. Cephalometric changes after the correction of class III malocclusion with maxillary expansion/facemask therapy. Am. J. Orthod. 1999;116(1):13-24.

44. Zhang W, Qu H, Zhang Y. The effects of maxillary protraction with or without rapid maxillary expansion and age factors in treating class III malocclusion. A Meta-Analysis. PloS. One. 2015;10(6):e0130096.

45. Yepes E, Quintero P, Rueda Z, Pedroza A. Optimal force for maxillary protraction face mask therapy in the early treatment of class iII malocclusion. Eur. J. Orthod.

46. Reed E, Kiebach T, Martin C, Razmus T, Gunel E. Stability of early Class iII orthopedic treatment. Semin. Orthod. 2014;20(2):114-127

47. Buschang PH, Sankey W. Early treatment of hyperdivergent open bite malocclusions. Semin. Orthod. 2002;8: 30-40.

48. Gu,Y. Factors contributing to stability of protraction facemask treatment of class III malocclusion. Aust. Orthod. J. 2010;26:171-177.

49. Moon Y, Ahn S, Chang Y. Cephalometric predictors of long term stability in the early treatment of class III malocclusion. Angle Orthod. 2005;75:747-753.

50. Ghiz M, Ngan P. Cephalometric variables to predict future success of early orthopedic class III treatment. AJO. 2005;127:301. 
51. Meneses D, Botero P. Alternativas para el tratamiento de hipoplasias maxilares. Revista CEs Odontología. 2012;25(1):64-81.

52. Kokich VG, Shapiro PA, Oswald R, Koskinen-Moffett L, Clarren SK. Ankylosed teeth as abutments for maxillary protraction: a case report. Am. J. Orthod. 1985;88:303-307.

53. Cha BK, Park YW, Lee NK, Lee YH. Two new modalities for maxillary protraction therapy: Intentional ankylosis and distraction osteogenesis. J. Kor. Dent. Assoc. 2000;38:997-1007.

54. Cha BK, Lee NK, Choi DS. Maxillary protraction treatment of skeletal Class III children using miniplate anchorage. Kor. J. Orthod. 2007;37:73-84.

55. Zhou YH, Ding P, Lin Y, Qiu LX. Facemask therapy with miniplate implant anchorage in a patient with maxillary hypoplasia. Chin. Med. J. 2007;120(15):1372-1375.

56. Hong H, Ngan P, Han G, Qi LG, Wei SH. Use of onplants as stable anchorage for facemask treatment: a case report. Angle Orthod. 2005;75:453-60.

57. Enacar A, Giray B, Pehlivanoglu M, Iplikcioglu H. Facemask therapy with rigid anchorage in a patient with maxillary hypoplasia and severe oligodontia. Am. J. Orthod. 2003;123:571-577.

58. Block MS, Hoffman DR. A new device for absolute anchorage for orthodontics. Am. J. Orthod. 1995;107:251258.

59. Ellen Wen-Ching Ko, Figueroa A, Polley J. Soft Tissue Profile Changes After Maxillary Advancement with Distraction Osteogenesis by Use of a Rigid External Distraction Device: A1-Year Follow-Up. J. Oral Maxillofac. Surg. 2000;58:959-969

60. Sar C, Sahinogly Z, Arman A, Ucklan S. Dentofacial effects of skeletal anchored treatment modalities for the correction of maxillary retrognatia. AJO. 2014;145:41-45.

61. Baccetti T, Franchi L, McNamara J. Cephalometric variables prediction the long term success or failure of combined rapid maxillary expansion and face mask therapy. AJo. 2004;126:16.

62. Arun T, Everdi N. A cephalometric comparison of mandibular headgear and chin-cap appliances in orthodontic and orthopedic viewpoints. J. Marmara Univ. Dent. Fac. 1994;2(1).

63. Basciftci, F. Biomechanical evaluation of chincup treatment with various force vectors. Am. J. Orthod. Orthop. Dentofacial. 2008;134:773.

64. Ko Young, Baek S, Mah J, Yang W. Determinants of successful chincup therapy in skeletal class III malocclusion. AJO. 2004;126:33-41.

65. Sakamoto T, Iwase I, Uka A, Nakamura S. A roentgenocephalometric study of skeletal changes during and after chin cup treatment. Am. J. Ortho. 1984;85:341-350.

66. Deguchi T, Kitsugi A. Stability of changes associated with chin cup treatment. Angle Orthod. 1996; 66(2):139.

67. Deguchi T, Kuroda T, Graber T. Long term application of chin cup force alters the morphology of the dolichofacial class III mandible. Ajo. 1999;116:610-615.

68. Chatzoudi M, Loannidou-Marathiotou L, Papadopoulos M. Clinical effectiveness of chin cup treatment for management of class in malocclusion in pre-puberal patients: A systematic review and metanalysis. Progr. Orthod. 2014;15:62.

69. Üner O, Yüksel S, Ücüncü N. Long term evaluation after chincup treatment. Eur. J. Orthod. 1995;17:135-141.

70. Lui Z Et al. Efficacy of short-term chin cup therapy for mandibular growth retardation in class iII malocclusion. A systematic review. Angle Orthod. 2011;81:162-168.

71. Asano T. The effects of mandibular retractive force on the growing rat mandibule. Am. J. Orthod. Orthop. Dentofacial. 1986;90:464.

72. Abdelnaby Y, Nassar E. Chincup effects using two different force magnitude in the management of class III malocclusions. Angle Orthod. 2010;80:957-962.

73. Tucner B, Kaygizis E, Yüksel S. Pharyngeal airway dimensions after chin cup treatment in class iII malocclusion subjects. J. Oral Reab. 2009;36:110-117. 
74. Sugawara J, Asano T, Endo N, Mitani H. Long term effects of chincap therapy on skeletal profile in mandibular prognatism. AJo. 1990;98:127-133.

75. Abu Alhaija ES, Richardson A. Long-term effect of the chincap on hard and soft tissues. Eur. J. Orthod. 1999;21(3):291-298.

76. Mitani H, Sakamoto T. Chin cap force to a growing mandible. Long-term clinical reports. Angle Orthod. 1984;54(2):93-122.

77. Bowden D. Theoretical considerations of headgear therapy: A literature review. Brit. J. Ortho. 1978;85:14552.

78. Graber LW: Chin cup therapy for mandibular prognathism. Am. J. Orthod. 1977; 72:23-41.

79. Rey D, Oberti G, Baccetti T. Evaluation of temporomandibular disorders in class III patients treated with mandibular cervical headgear and fixed appliances. AJo. 2008;133:399-381.

80. Baccetti T, Rey D, Angel D, Oberti G, McNammara J. Mandibular cervical headgear vs rapid maxillary expander and facemask for orthopedic treatment of class II malocclusion. Angle Orthod. 2007;77(4):619.

81. Arun T, Everdi N. An alternative method to correct class in malocclusion: early treatment. TurkorthodDergisi. 1997;10(3):279-284.

82. Baccetti T, Rey D, Oberti G, Stahl F, McNammara J. Long term outcomes of class III treatment with mandibular cervical headgear followed by fixed appliances. Angle Orthod. 2009;79:828-834.

83. Rey D, Angel D, Oberti G, Baccetti T. Treatment and posttreatment effects of mandibular cervical headgear followed by fixed appliances in class iI malocclusion. AJO. 2008;133:371-378. 


\section{CAPÍTULO 9}

\section{TRATAMIENTO DE ALTERACIONES VERTICALES}

Paola María Botero Mariaca

Las alteraciones verticales como las mordidas abiertas o profundas se encuentran en pacientes con alteraciones sagitales de clase II y clase III, por lo que el diagnóstico y establecimiento de la etiología del problema puede facilitar el proceso de tratamiento. La relación de los hábitos parafuncionales del paciente influencia de forma determinante la evolución y el éxito del tratamiento, de modo que su control es obligatorio.

\section{AsPeCtOS GENERALES}

Las alteraciones en el plano vertical pueden ser de dos tipos: mordidas abiertas (Figura 1) o mordidas profundas (Figura 2). Inicialmente, veremos las diferentes opciones de tratamiento para las mordidas abiertas anteriores. Esta alteración puede ser de origen esquelético o dental; y el tratamiento debe ser planeado dependiendo de su etiología.

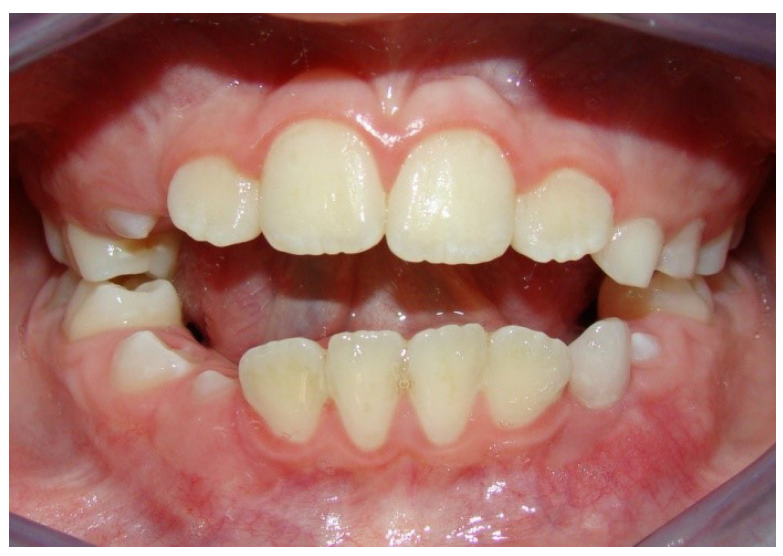

FIGURA 1. Mordida abierta anterior

Fuente: elaboración propia

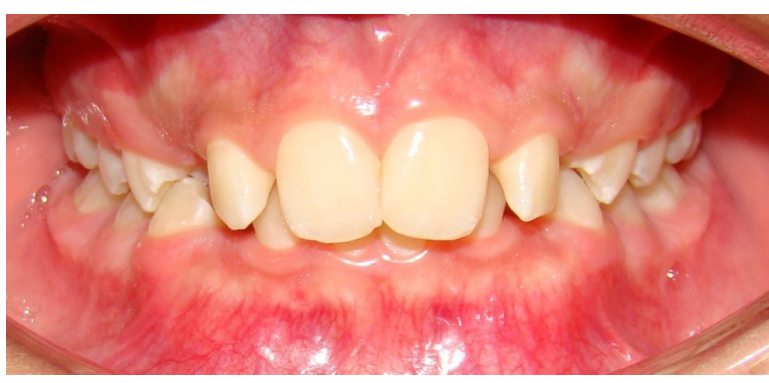

FIGURA 2. Mordida profunda

Fuente: elaboración propia

El origen de las alteraciones verticales es multifactorial; por ejemplo, las anormalidades dentoalveolares pueden afectar el patrón esquelético y estos patrones causan compensaciones dentoalveolares. Dentro de los factores que pueden influir encontramos un exceso vertical del maxilar a nivel posterior o una mandíbula con exceso posterior alveolar, rama corta y una base craneal con un ángulo obtuso. Un crecimiento condilar vertical aumentado genera alteración en la rotación mandibular y, por tanto, en el desarrollo dentoalveolar maxilar y mandibular [1, 2].

Los pacientes de cara corta presentan un crecimiento condilar arriba y adelante, mientras que los de cara larga muestran un crecimiento más posterior. La rotación horizontal ocurre cuando el crecimiento condilar vertical excede la suma del crecimiento vertical del maxilar y de los procesos alveolares. La rotación delante de la mandíbula se da cuando el crecimiento condilar vertical excede la suma del crecimiento vertical de las suturas maxilares y del proceso alveolar maxilar y mandibular [1-3].

La distancia del plano oclusal al plano palatal es de $22.5 \mathrm{~mm}$ en los crecedores verticales; de $19.6 \mathrm{~mm}$ en normales, y $17.1 \mathrm{~mm}$ en cara corta. En la mandíbula, la distancia es de $31.2 \mathrm{~mm}$ en crecedores verticales; de $28.2 \mathrm{~mm}$ en normales y de $28.3 \mathrm{~mm}$ en cara corta. El 
impacto en el tercio inferior es mayor por el desarrollo vertical dental del maxilar, que el de la mandíbula [1-3]. Según Bjork, hay dos indicadores del tipo de rotación (Figura 3):

a. Rotadores anteriores: cabeza del cóndilo que se curva anterior, canal mandibular curvo, canto posterior de la sínfisis, ángulo interincisal obtuso y cara anterior corta.

b. Rotadores posteriores: cóndilo con inclinación recta, canal mandibular recto, la sínfisis se inclina adelante y tercio inferior aumentado.
Los pacientes de cara larga tienen mayor crecimiento dentoalveolar $(5.1 \mathrm{~mm})$ con respecto a los pacientes de cara corta, y esto guarda relación con la musculatura débil de los de cara larga [3].

Las características morfológicas que predicen el patrón de crecimiento vertical incluyen angulación del borde inferior de la mandíbula; angulación del eje Y de crecimiento; ángulo goniaco; inclinación de la rama; radio de la altura facial anterior y posterior; cantidad de movimiento vertical de molar con el tratamiento; cantidad de crecimiento condilar y su dirección, y altura facial anteroinferior [5] (Tabla 1).

TABLA 1

Diferencias en los patrones de rotación mandibular

\begin{tabular}{cll}
\hline \multirow{2}{*}{ Características mandibulares } & \multicolumn{2}{c}{ Patrón de rotación mandibular } \\
\cline { 2 - 3 } & \multicolumn{1}{c}{ Rotán anterior mandibular } & Rotación posterior mandibular \\
\hline Inclinación de la cabeza condilar & Curvada anterior y atrás & Derecha \\
\hline Curvatura del canal mandibular & Curvada & Derecho \\
\hline Forma del borde inferior de la mandíbula & Depresión mandibular plana & Depresión mandibular aguda o marcada \\
\hline Inclinación de la sínfisis & Hacia abajo & Hacia arriba \\
\hline Ángulo interincisal & Obtuso & Agudo \\
\hline Ángulo intermolar & Obtuso & Agudo \\
\hline Tercio inferior & Corto & Largo \\
\hline
\end{tabular}

Fuente: elaboración propia
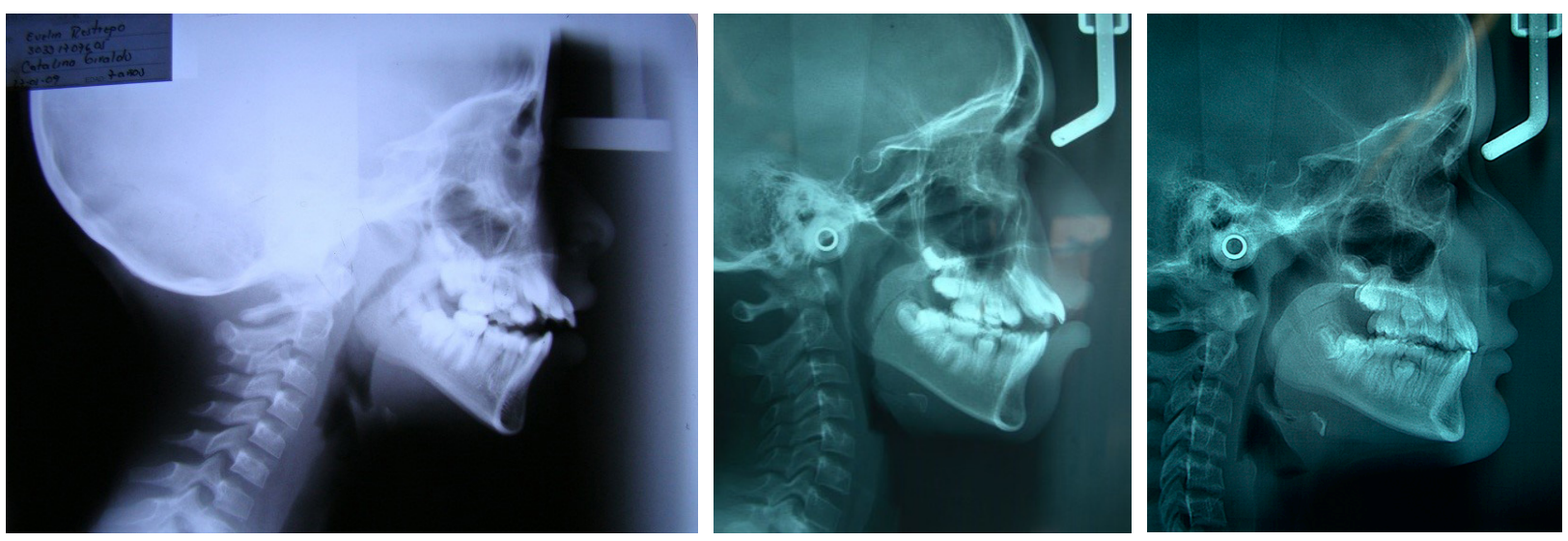

FIGURA 3. (AB) Patrones de crecimiento vertical. (C) Patrón de crecimiento horizontal 
A lo largo de los años, se ha tratado de determinar la asociación de la cara larga con la respiración oral, y se ha visto que no puede considerarse como único factor etiológico. Un 40\% de pacientes respiradores orales presentan cara larga, y no todos los que presentan caras largas tienen obstrucciones nasales que generen respiraciones orales. La posición de la lengua en reposo afecta más las relaciones maxilomandibulares que la lengua en función [1].

El genotipo (genes presentes en una región del genoma) puede influenciar en el fenotipo (propiedades observables y características físicas de un individuo), además del medioambiente. Un medioambiente adverso puede alterar la expresión fenotípica que los genes hubieran promovido en condiciones más favorables [6]. Es así que el medioambiente juega un papel importante en el desarrollo de displasias verticales, pero a veces es difícil de evaluar y varía de paciente a paciente $[1,2]$.

El tratamiento temprano se basa en un diagnóstico temprano. El fenotipo no se autocorrige, el potencial de cambios en rotación mandibular es mayor en la niñez, ciertas características requieren largo tiempo para corregirse, y hay tratamientos disponibles para corregir problemas en las tres dimensiones. La alteración aparece tempranamente y se debe tratar antes del pico de la adolescencia. El $64 \%$ se diagnostica como hiperdivergentes a los 6 años, y se diagnostican iguales a los 15 años [3].

\section{MORDIDA ABIERTA}

Un tratamiento exitoso en pacientes con un fenotipo esquelético hiperdivergente demanda diagnósticos prudentes y una consideración especial del tratamiento. Dentro de las características esqueléticas que presentan los pacientes con mordida abierta, se tienen tres indicadores para predecir la tendencia a una separación anterior en un paciente en crecimiento: a) ángulo de base craneal aumentado, b) orientación de maxilar arriba anterior y c) rama corta y ángulo goniaco obtuso. Una depresión antegonial puede ser un indicador de discrepancia entre el crecimiento condilar y el crecimiento mandibular [6].

Los patrones de crecimiento facial se establecen tempranamente en el desarrollo. Los factores que se asocian al crecimiento favorable en pacientes hiperdivergentes incluyen el aumento del radio de la altura facial posterior y anterior, favoreciendo un crecimiento condilar más anterior. La combinación de estos genera una rotación más anterior que inferior, lo cual mejora el patrón hiperdivergente debido a que la sola inhibición del crecimiento vertical maxilomandibular da lugar a una mejoría del patrón esquelético y una disminución del ángulo goniaco [3]. Las mordidas abiertas simples en dentición mixta se corrigen espontáneamente en un 80\% de los casos. La mordida abierta esquelética se presenta generalmente en fenotipos hiperdivergentes, con características comunes como tercio inferior aumentado, plano mandibular empinado, ángulo goniaco aumentado y ramas cortas [3].

Entre los aparatos que se colocan para controlar o limitar el incremento de la dimensión vertical están la tracción alta con o sin placa; las extracciones; los planos posteriores activos o pasivos; la mentonera vertical, y sus combinaciones, puesto que la mayoría tiende a controlar o cerrar el plano mandibular. La tracción alta modifica el crecimiento maxilar pero la sobreerupción de los molares inferiores evita la autorrotación mandibular. Las extracciones ocasionan compensaciones dentoalveolares efectivas, pero no evitan la extrusión de molares, producida por la mecánica de cierre. Combinar tracción más extracciones no tiene mejores efectos. Mientras que los planos posteriores son efectivos controlando la altura facial anterior, en casos con magnetos se genera asimetría mandibular en postura y mordidas 
cruzadas, y además de intrusión se produce reabsorción radicular $[6,7]$. El control vertical de los primeros molares resulta importante en el tratamiento de las alteraciones verticales; con el tratamiento, el movimiento vertical del molar sucede fácilmente pues es el movimiento de menor resistencia y es la respuesta inmediata.

Otra característica común dentro de los pacientes con patrón de crecimiento hiperdivergente asociado a la presencia de hábitos orales es la constricción transversal, la cual se puede solucionar colocando un Hyrax con planos posteriores o los planos posteriores independientes en el arco inferior [7]. Un tratamiento para corregir la mordida abierta aplicado en etapa prepuberal no genera cambios en el crecimiento, solo se observa intrusión molar de $1.1 \mathrm{~mm}$. El tratamiento realizado en etapa del pico de crecimiento (cs3, cs4 y cs5) muestra cambios en las alturas faciales, en el ángulo plano mandibular y un aumento del crecimiento mandibular (1.5 a $2.2 \mathrm{~mm}$ ), aunque su efecto es limitado [8]. La clave del éxito del tratamiento de alteraciones verticales es el control del desarrollo vertical posterior.

\section{TRATAMIENTO}

\section{Mentonera vertical}

Un crecimiento mandibular aumentado en sentido vertical puede ser la etiología de una mordida abierta anterior. Se han utilizado diversos aparatos tanto intraorales como extraorales para tratar de controlar y redirigir el crecimiento mandibular. Los aparatos intraorales logran un control dentoalveolar, sin generar cambios en la morfología mandibular; por otro lado, los aparatos extraorales como la mentonera vertical han mostrado modificaciones en el patrón de crecimiento mandibular.
El patrón de crecimiento corporal es una de las últimas estructuras en terminar el crecimiento, lo que hace que factores medioambientales la afecten más durante su desarro1lo. La mandíbula presenta coherencia en sus picos de crecimiento con los corporales generales. Un primer pico se observa desde que el individuo nace hasta los 3 años. El segundo pico ocurre primero en niñas entre los 6 y 7 años y niños entre los 7 y 9 años. El tercer pico es el pico puberal, y a pesar de no concordar con una edad específica se reporta en mujeres entre los 11 y 12 años y en los hombres entre 14 y 15 años [2], período en el cual hay máxima aceleración del crecimiento y concuerda con la generación de caracteristicas sexuales secundarias, siendo el pico más evidente y efectivo frente a la cantidad de crecimiento que ocurre [9].

La mentonera ha sido utilizada desde el siglo XIX como control de crecimiento mandibular tanto sagital como vertical, según la dirección de aplicación de la fuerza. La mentonera parietal o vertical presenta un vector anterior al cóndilo generando una fuerza vertical (Figura 4).

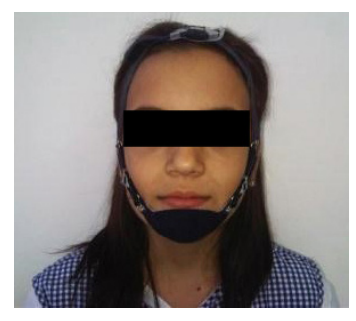

FIGURA 4. Mentonera parietal o vertical

Fuente: elaboración propia

Los efectos de las mentoneras a nivel del cuerpo, rama y cóndilo son diferentes, según el punto de aplicación de la fuerza. Por ejemplo, en un estudio que mide el nivel de estrés generado por fuerzas aplicadas en diferentes direcciones sobre el cóndilo, se midieron a través de elementos finitos, mostrando que las fuerzas más alejadas del centro de resistencia generan 
más estrés por aumento en el momento y por ende en la palanca, mientras que las fuerzas a través del cóndilo son las más aceptadas al generar menos estrés [10].

El uso de mentoneras está indicado en pacientes clase I con mordidas abiertas, clases II y algunas clases ii que presenten crecimiento vertical aumentado. Se debe emplear fuerzas ortopédicas intermitentes de 250 a 400 gr por lado [11, 12], con un vector de fuerza anterior al cóndilo y el cuerpo mandibular [13], el cual estaría a 90 grados del plano oclusal [13, 14] a $3 \mathrm{~cm}$ de distancia del canto externo del ojo [13]. El uso debe ser entre 12 y 14 horas [10], o incluso hay reportes de 16 horas [13].

\section{Efectos}

Dentro de los efectos más frecuentemente reportados se encuentra el cierre del ángulo goniaco [13, 15], disminución del ángulo del plano mandibular $[13,16]$, rotación arriba y delante de la mandíbula $[10,13,14,15]$, disminución en la altura facial anterior gracias al incremento en la altura posterior $[15,17]$, control vertical de los dientes posteriores $[13,15]$, rotación posterior maxilar con disminución en el ángulo de inclinación de la rama [17]. Por otro lado, se manejan cambios en el retardo del crecimiento de la rama [10], ajustes en la posición del mentón por inclinación del cuerpo mandibular $[13,15]$, dentalmente hay extrusión de incisivos inferiores que produce aumento de la sobremordida vertical $[13,18]$.

La mentonera vertical otorga un control importante en este plano del espacio, el desplazamiento normal de un molar con el crecimiento durante los 10 a los 15 años es de 2 y 5 mm, con un promedio de $1 \mathrm{~mm}$ por año, siendo mayor en el arco superior y ocurre como respuesta al crecimiento maxilomandibular [17]. El desplazamiento vertical de los dientes puede llegar entre los 25 y 45 años según diferentes reportes [19-22], el cual a través del crecimiento vertical de los incisivos mantiene la sobremordida vertical adecuada durante el crecimiento. Muchas veces el desplazamiento vertical de los dientes es subestimado debido a la remodelación que ocurre en el piso nasal y el borde mandibular con el crecimiento [17].

El patrón de crecimiento vertical en los pacientes puede ser neutro, hipo o hiperdivergente con diferencias entre ellos hasta de $5.1 \mathrm{~mm}$. Este patrón se ve influenciado por el crecimiento condilar, el cual es en dirección atrás y adelante en pacientes con rotación antihoraria mandibular [19] y por la fuerza muscular, que es mayor para los pacientes hipodivergentes [23] debido a que tienen músculos con mayor área transversal, produciendo caras cortas y ángulos goniacos pequeños [24-27]; lo que evita la extrusión de los dientes posteriores [30]. La variación se evidencia también en la inclinación de las fibras del masetero con respecto al plano oclusal, que es mayor en pacientes hipodivergentes, así como una inserción más superior en la mandíbula $[28,29]$.

Los efectos en pacientes en crecimiento luego de 1 año de tratamiento evidencian una remodelación en la rama gracias al fulcrum que sucede en la zona del primer molar [13, 15], lo que se refleja en un aumento del overbite [31].

Los efectos finales de la mentonera son difíciles de determinar debido a que la mayoría de los estudios son casos clínicos [11, 31] o emplean otro tipo de aparatos adicionales como rejillas, expansores y aparatos funcionales. Lo que es claro es que el uso de la mentonera con aparatos que invadan el espacio libre interoclusal reporta acción de los músculos en los dientes posteriores, controlando el crecimiento vertical de los mismos que se traduce en remodelación mandibular [14].

El control vertical de la mentonera se evidencia en los artículos que combinan su uso con disyuntores como el Hyrax, donde se disminuyen sus efectos verticales [32]. Al combinarla con rejilla se ve un adecuado control de 
la mordida abierta; sin embargo, al tener diferentes aparatos resulta difícil establecer el papel de cada uno en la corrección [33]. En estudios posteriores se evidencia un control en la rotación abajo y atrás de la mandíbula de 2 grados, disminuyendo la altura facial en 2.5 y aumentando la longitud de la mandíbula en $4 \mathrm{~mm}$.

Para establecer los efectos de los aparatos como la mentonera hay que tener presente la magnitud de los cambios que suceden con el crecimiento normal. Se reporta que el crecimiento vertical anual de los molares e incisivos superiores es de $0.35 \mathrm{~mm}$, mientras que los inferiores son de $0.65 \mathrm{~mm}$ [17], que al comparar con tratamiento se evidencian cambios de 0.88 en molares y de 2.4 en incisivos positivos para la corrección de las mordidas abiertas.

\section{Diseño del aparato}

Los componentes de la mentonera vertical son iguales a los descritos en el capítulo de alteraciones de clase III, en el ítem de mentonera occipital. El aspecto que cambia es la forma de adaptación del gorro en el paciente, para lograr que la línea de acción de la fuerza ejercida por los elásticos pase por delante del cóndilo (centro de resistencia de la mandíbula; Figura 5, y Figuras 19, 20 y 21 de capítulo de clase III).

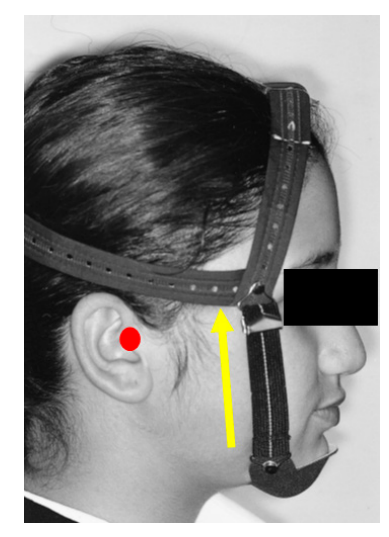

FIGURA 5. Línea de acción de la fuerza (amarillo) anterior al cóndilo mandibular (rojo)

Fuente: autores

\section{Tracción alta}

La tracción alta controla verticalmente al maxilar superior (Figura 6), y el efecto de autorotación mandibular se ha comprobado en estudios animales, pero no en humanos. Sin embargo, se observa un aumento del crecimiento mandibular y el aumento de SNB. Otros de los efectos de la tracción son el desplazamiento superior y distal del maxilar, la rotación horaria del plano palatal y la intrusión relativa de molares superiores. Mientras se ejerce control sobre la parte vertical superior, se ha reportado que el molar inferior continúa con su erupción normal, lo cual podría afectar el resultado final del tratamiento. La descripción biomecánica del aparato puede revisar en el capítulo de tratamiento de las alteraciones sagitales de clase II.

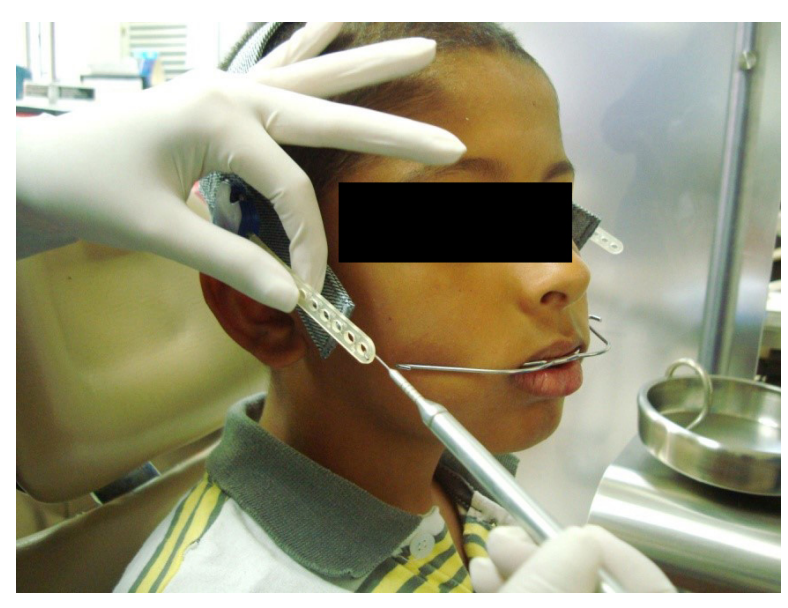

FIGURA 6. Tracción alta

Fuente: autores

Se ha comprobado que la combinación de la tracción alta con aparatos funcionales tiene mayor efectividad, puesto que se controla la posición vertical del molar inferior y del superior, al mismo tiempo [34, 35, 36]. También se puede usar con placas acrílicas inferiores para mayor control vertical.

\section{Bloques posteriores de mordida}

Los bloques de mordida posterior son placas de Hawley con planos de mordida posterior 
(Figura 7), los cuales pueden ser colocados en el arco superior o en el inferior (Figura 8), dependiendo de las necesidades del paciente. Su efecto principal es la inhibición de la erupción posterior y pueden llegar a proveer intrusión de posteriores. Sin embargo, esta intrusión es considerada relativa, ya que basta mantener la posición vertical de los molares durante el proceso de crecimiento para evitar la extrusión normal, y esto podría considerarse una intrusión [3, 5].

Se ha probado, mediante estudios en animales y en humanos, que los planos posteriores producen cambios esqueléticos; sin embargo, estos planos pueden abrir la bisagra (maxilomandibular) más allá de la posición de reposo, tendiendo a incrementar el ángulo goniaco.

Los bloques de mordida son bastante versátiles, se pueden combinar con otros aparatos, como rejillas (Figura 8), mentonera, tracción alta y expansores, a fin de potenciar el control vertical, en los dos primeros casos, o evitar efectos secundarios, en el último [3, 5].
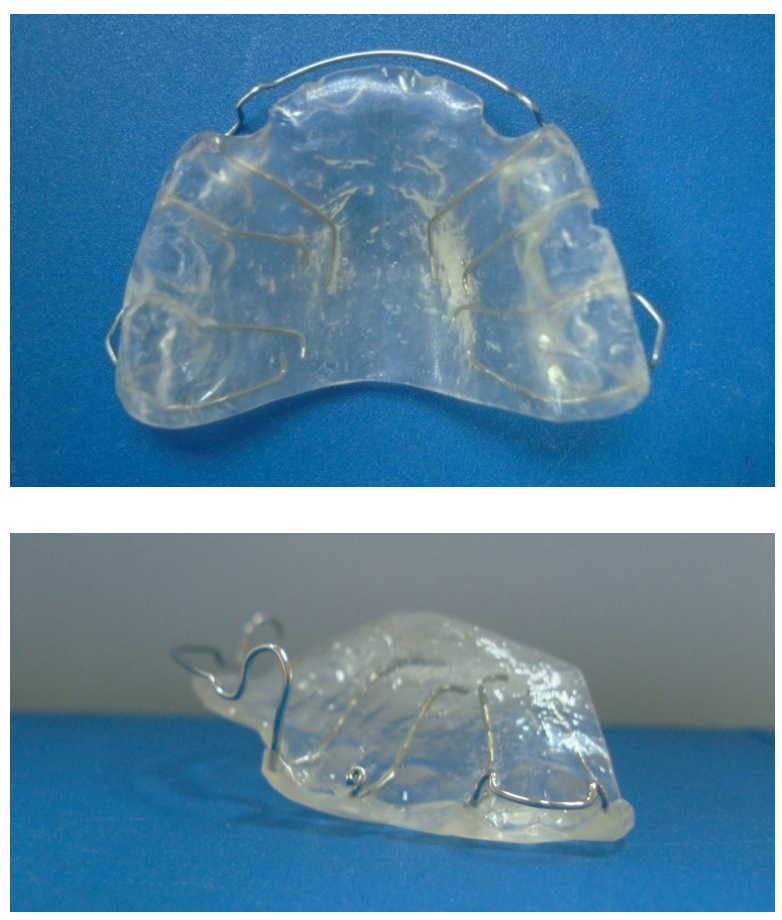

FIGURA ?. Placa de Hawley superior con planos de mordida posterior (vista oclusal y lateral)

Fuente: autores
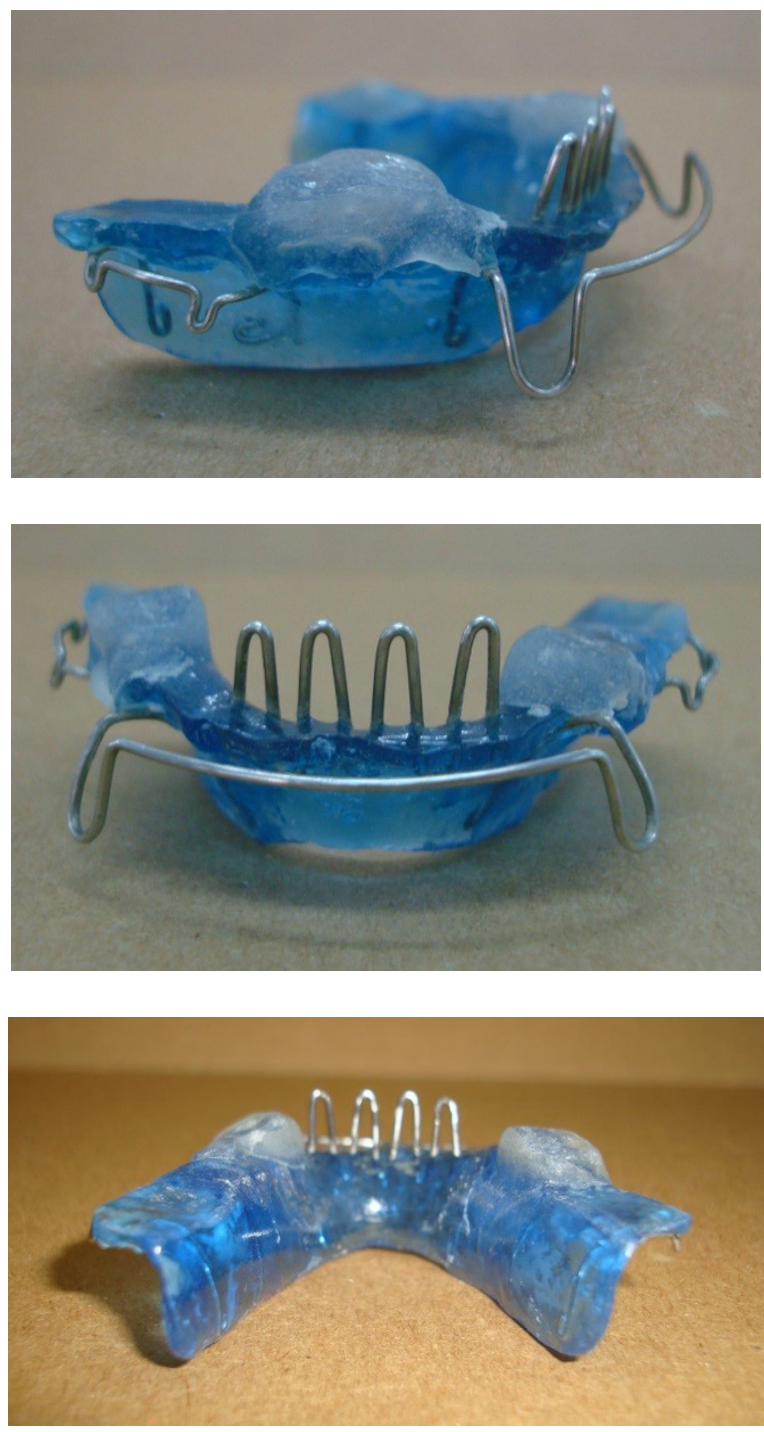

FIGURA 8. Planos de mordida posterior para el arco inferior al que se le adiciona rejilla

Fuente: autores

A los planos posteriores también se les pueden colocar magnetos embebidos en el acrílico. Para estos casos, se emplean al mismo tiempo planos posteriores superiores e inferiores, con una acción repelente entre ellos producida por los imanes. Los estudios en los que estos planos han sido usados muestran su efectividad en el control vertical, logrando una intrusión verdadera de los molares. Sin embargo, causaron efectos secundarios en sentido transversal, al ocasionar desviaciones laterales mandibulares, debido a la inestabilidad resultante de su repelencia [3]. 


\section{Rejilla}

Aparato fijo o removible empleado para la corrección de hábitos de lengua (empuje lingual y degluciones atípicas) y hábitos de succión digital, que en la mayoría de los casos pueden causar una mordida abierta anterior. Su uso en la corrección de las mordidas abiertas va orientado a prevenir que la punta de la lengua se ubique en los dientes anteriores (Figura 9).
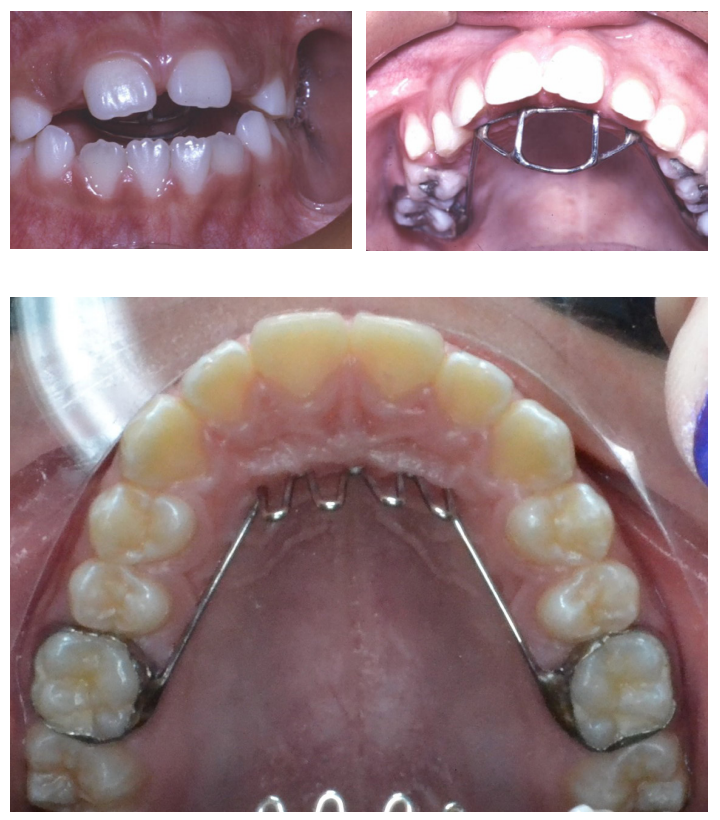

FIGURA 9. Rejillas en posición

Fuente: elaboración propia

\section{Biomecánica}

La rejilla es un aparato diseñado para modificar el comportamiento de la lengua al eliminar los hábitos que esta presenta [37]. Existen dos tipos de rejilla: en forma de canastilla, confeccionada de manera vertical para evitar la protrusión lingual (Figura 10); y en forma digital vertical para impedir la succión digital. También se puede construir en forma de canastilla con una disposición horizontal sobre el paladar, de modo que interfiera con la succión digital. En casos de presencia de hábito de succión digital y protrusión lingual, una rejilla en canastilla vertical es la elección adecuada.

La rejilla idealmente debe estar ubicada lo más anterior posible para no invadir el espacio de la lengua, además debe ser lo más larga posible para evitar la protrusión de la lengua debajo de ella. Independientemente del diseño, es importante enviar ambos modelos y un registro de mordida al laboratorio para que su confección no interfiera con los incisivos inferiores o con la mucosa lingual a estos, pues esto impediría la oclusión.

La disminución del espacio para la lengua genera su reubicación dentro de la cavidad oral hacia la zona posterior, apoyándose en la superficie oclusal, lo cual puede potenciar la rotación antihoraria de la mandíbula [38]. Luego de utilizar la rejilla, la respuesta en el cierre de la mordida de los pacientes depende de la variación individual en la capacidad adaptativa.
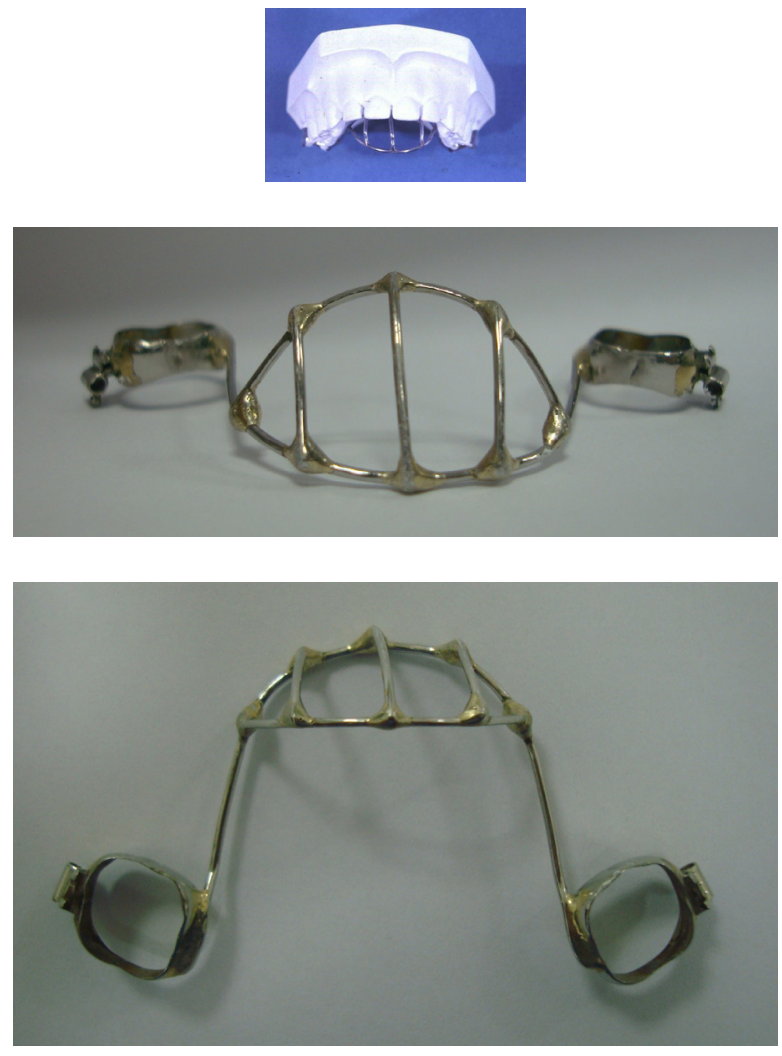


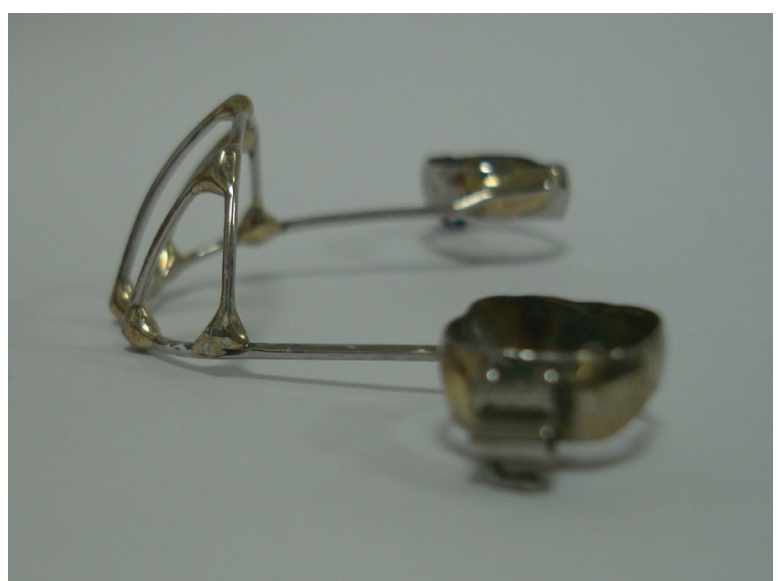

FIGURA 10. Rejilla en forma de canastilla

Fuente: elaboración propia

La rejilla también puede ser construida con spurs en alambre de $0.9 \mathrm{~mm}$ para el control de la succión digital y el empuje lingual con mejores resultados, si se usan durante el crecimiento activo del individuo. Los spurs deben extenderse hasta el cingulum de los incisivos inferiores [38]. La rejilla puede ser usada sola o en combinación con otros aparatos como el Quad Helix (en este aparato, la rejilla es soldada en el puente anterior) (Figura 11) y placas de Hawley. En casos de estas placas, los loops que constituyen la rejilla son construidos en alambre de acero de 0.036" [37].

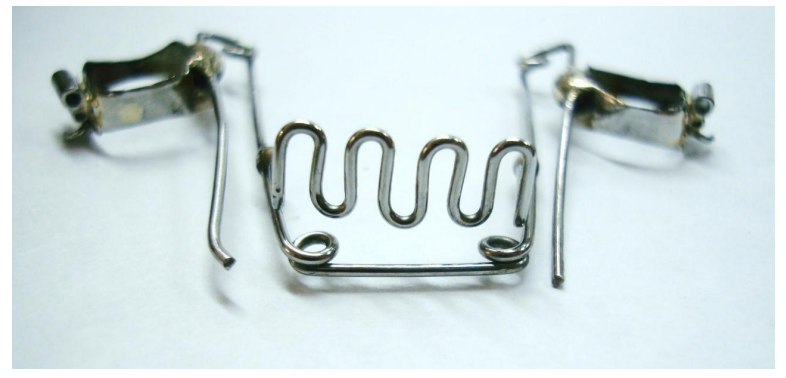

FIGURA 11. Quad Helix con rejilla

Fuente: elaboración propia

\section{Efectos}

Según diversos estudios, el uso de la rejilla debe ser de 1 año [39] o más [40]. Con el uso del aparato, no se observan cambios esqueléticos sino una mejoría en el overbite por extrusión y lingualización, y retrusión de incisivos superiores; y una mejoría de la posición del labio superior. La mejoría clínica puede llegar a ser de un $85 \%$ y se advierte recidiva luego de un año, aunque no se han podido establecer los factores involucrados [41]. Al combinarse con el Quad Helix, se genera una rotación posterior del plano palatal, lingualización de incisivos superiores y retrusión del labio superior. La rejilla permite un desarrollo normal de la zona dentoalveolar anterior, evita la succión digital (entre el 85 al 90\% de los casos) y el hábito de lengua [42]. Con respecto a la corrección de los hábitos, Graber asegura que la eliminación del hábito, como factor etiológico de la mordida abierta, antes de los 3 años, resulta en corrección espontánea de la mordida [38].

En un estudio que analizó, mediante resonancia magnética, la posición de la lengua durante el uso de la rejilla, se encontró que la punta de la lengua se posiciona más posterior y su función durante la masticación y deglución no se ve afectada, por tanto, se observa una adaptación individual. La lengua modifica la parte anterior y el dorso de esta (descienden para lograr propulsión posterior del bolo alimenticio y protección de la vía aérea), pero no la zona posterior [37].

\section{Rejilla inferior}

La rejilla inferior surge de la necesidad de controlar la posición baja de la lengua y de la posibilidad de obtener protrusión mandibular en pacientes clase iI, así como se ha reportado con la colocación de una rejilla en el maxilar [43]. La rejilla puede ser fija, realizada en forma vertical en alambre de acero y soldada a bandas en los primeros molares. Corresponde tener la precaución de que no interfiera con la arcada superior cuando el paciente haga el cierre. Por tal motivo, se debe enviar al laboratorio los modelos superior e inferior y un registro de mordida (Figura 12). 
La rejilla también puede ser removible, adaptada a un Hawley inferior, con los spurs colocados en el acrílico, en lingual de los incisivos inferiores. Debe ser usado por 18 horas al día; se retira solo para comer o realizarse la higiene oral. El promedio de duración del tratamiento es de 14 meses [43]. Sus efectos son la disminución de ANB y Wits, la vestibularización de incisivos inferiores y la lingualización de los superiores. Con respecto a la posición mandibular, se observa que un adelantamiento, generando un efecto similar al que tienen los aparatos funcionales. En sentido vertical, no se advierte ningún efecto y la mordida abierta anterior se cierra por la lingualización de los incisivos superiores por presión del labio [43].
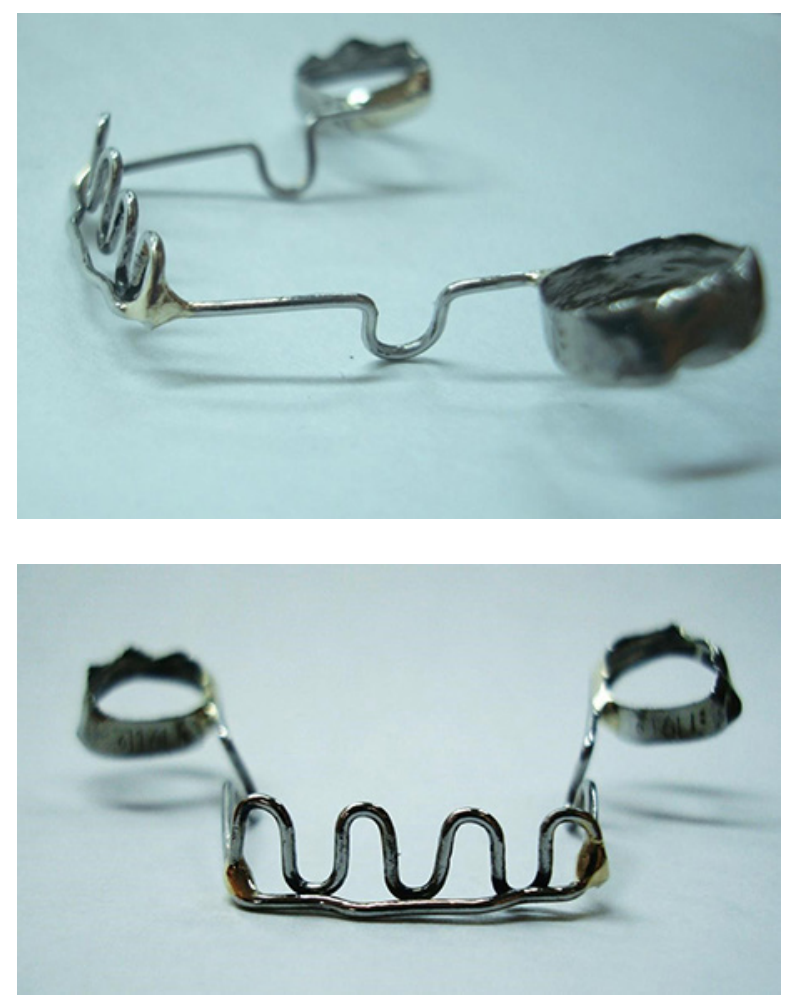

FIGURA 12. Rejilla inferior soldada a arco lingual

Fuente: elaboración propia

\section{MORDIDA PROFUNDA}

Un overbite profundo ocurre cuando por fallo en el crecimiento vertical en la zona posterior o por supraerupción de incisivos (Figura 13).
Con la erupción de molares, normalmente el overbite disminuye, pero la fuerza muscular puede hacer que la mordida se profundice en contra de la fuerza del desarrollo del proceso alveolar [44]. Otra cosa que influye es la musculatura, los de cara corta tienen fuerzas musculares que se oponen a la extrusión.
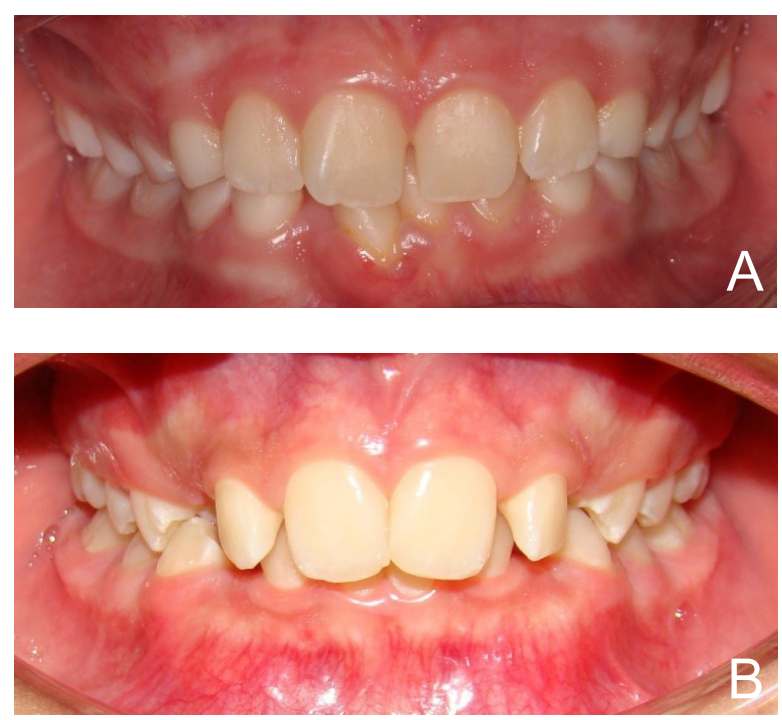

FIGURA 13. Mordida profunda anterior en diferentes etapas del desarrollo dental. (A) Dentición mixta intertransicional. (B) Dentición mixta final

Fuente: elaboración propia

\section{TRATAMIENTO}

\section{Plano de mordida anterior}

El plano anterior fue diseñado por Kingsley en 1880, con una inclinación que permitía saltar la mordida en los pacientes clase is por retrognatismo mandibular. Otros aseguran que fue diseñada por Arkinson, como modificación de la placa de Hawley [45]. Suele ser usado para eliminar interferencias mecánicas por overbite excesivo, facilitar la ubicación de anteroinferiores, eliminar interferencias para movimientos dentales y permitir la extrusión de posteriores. La mordida se abre tanto como lo permite la posición de reposo mandibular; si las fuerzas de la oclusión no están balanceadas, no hay estabilidad en la corrección. Con 
el plano anterior colocado en una placa de Hawley anclada con Adams, se observa extrusión de molares inferiores y premolares superiores e inferiores [44].

Los incisivos inferiores contactan con el plano cuando el paciente entra a oclusión (Figura 14), lo cual impide que se extruyan mientras permite la extrusión de los posteriores. Para tal efecto, debe ser usado 24 horas. Otros estudios han demostrado que el plano anterior puede cambiar la posición anterior de la cabeza del cóndilo en pacientes en crecimiento, además disminuye el overbite por sobreerupción de posteriores, fomenta una relación anteroposterior normal y mejora el perfil. La sobreerupción invade el espacio libre interoclusal; sin embargo, este se mantiene por el cambio en la rotación mandibular. En ninguno de los estudios se ha reportado intrusión de incisivos por causa de este aparato $[46,47]$. Con su uso se pueden controlar los músculos hipertónicos, permitiendo un desarrollo normal de la zona posterior alveolar [47].

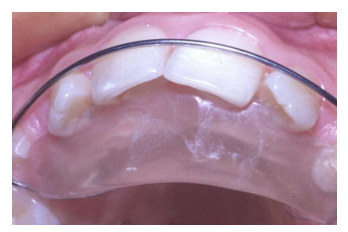

FIGURA 14. Placa de Hawley con plano de mordida anterior Fuente: elaboración propia
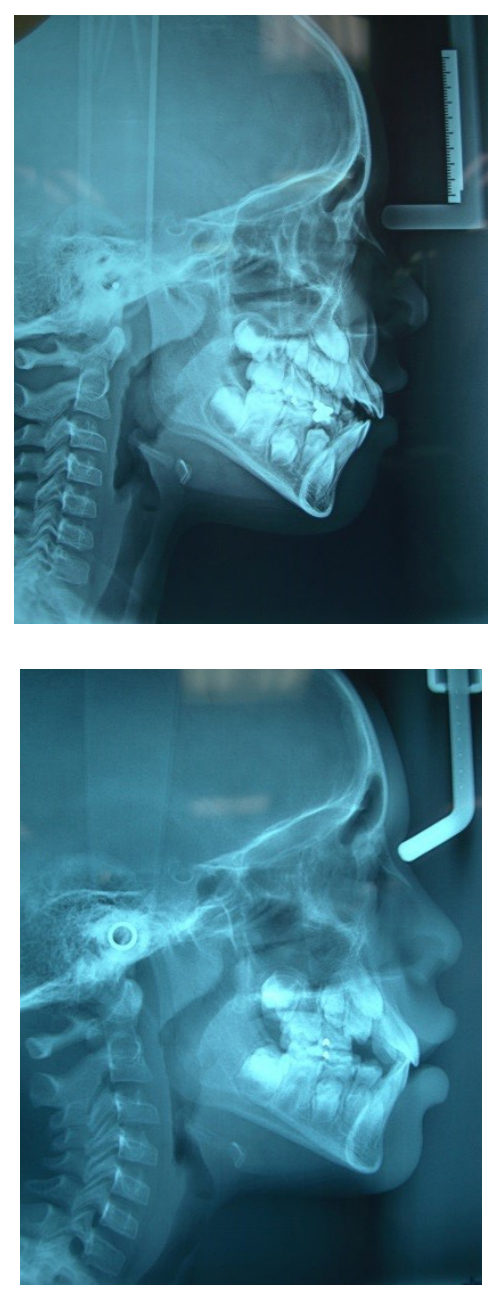

FIGURA 15. Radiografía antes y después del tratamiento con rejilla lingual de mordida abierta anterior

Fuente: elaboración propia 


\section{REFERENCIAS}

1. Vaden J, Perason L. Diagnosis of the vertical dimension. Semin Ortho. 2002;8:120-129.

2. Vaden J. Problemas verticales. Semin Ortho. 2002.

3. Buschang P. Problemas verticales. Semin Ortho. 2002.

4. Pearson LE. Vertical control in treatment of patients having backward-rotational growth tendencies. Angle Orthod. 1978;48:132-40.

5. Skieller V, Björk A, Linde-Hansen T. Prediction of mandibular growth rotation evaluated from a longitudinal implant sample. Am J Orthod. 1984;86:359-70.

6. Kusoto B, Schneide B. Control of vertical dimension. Semin Ortho. 2000;6:33-42.

7. Hartsfield J. Desarrollo de la dimensión vertical. Semin Ortho. 2002;8:113.

8. Baccetti, T, Franchi L, McNamara J. Treatment timming for an orthopedic approach to patients with increased vertical dimensión. AJo. 2008;133: 58.

9. Rainly, DM. A synopsis of craniofacial growth. Appleton-Century-Crofts, 1980. Cap. 4 Pag 41-76.

10. Basciftci, F. Biomechanical evaluation of chincup treatment with various force vectors. Am J Orthod Dentofacial Orthop. 2008;134:773.

11. Majourau A, Nanda R. Biomechanical basis of vertical dimension control during rapid palatal expansion therapy. Am J Orthod Dentofacial Orthop. 1996;106:322-328.

12. Mitani H, Sakamoto T. Chin cap force to a growing mandible. Long-term clinical reports. Angle Orthod. 1984;54(2):93-122.

13. Hakan N. Effects of vertical chincap therapy on the mandibular morphology in open-bite patients. Am J Orthod Dentofacial Orthop. 2002;122:506-11.

14. McNamara, Jr; Baccetti T. Treatment effects of bonded RME and vertical pull chincup followed by fixed appliance in patients with increased vertical dimensión. Am J Orthod Dentofacial Orthop. 2005;128:32636.

15. Cangialosi TJ. Skeletal morphologic features of anterior open bite. Am J Orthod. 1984;85:28-36.

16. Arat M, Iseri H. Orthodontic and orthopaedic approach in the treatment of skeletal open bite. Eur J Orthod. 1992;14: 207-15.

17. Buschang PH, Carrillo R, Liu SS, Demirjian A. Maxillary and mandibular dentoalveolar heights of French-Canadians 10 to 15 years of age. Angle Orthod. 2008;78(1):70-6.

18. Buschang PH, Sankey W. Early treatment of hyperdivergent open bite malocclusions. Semin Orthod. 2002;8:130-40.

19. Lee RS, Daniel FJ, Swartz M, Baumrind S, Korn EL. Assessment of a method for the prediction of mandibular rotation. Am J Orthod. 1987;91:395-402.

20. Arat, ZM, Rübendüz M. Changes in dentoalveolar and facial heihts during early and late growth periods: A longitudinal study. Angle Orthod. 2004;75:69-74.

21. Forsberg CM, Eliasson S, Westergren H. Face height and tooth eruption in adults. A 20 year follow-up investigation. Eur J Orthod. 1991;13:249-254.

22. Iseri H, Solow B. Continued eruption of maxillary incisors and first molars in girls from 9 to 25 years, studied by the implant method. Eur J Orthod. 1996;18:245-256.

23. Vaden JL, Pearson LE. Diagnosis of the vertical dimension. Semin Orthod. 2002;8:120-9.

24. Van Spronsen PH, Weijs WA, Valk J, Prahl-Andersen B, Van Ginkel FC. Acomparison of jaw muscle cross-sections of long-face and normal adults. J Dent Res. 1992;71:1279-1285.

25. Kiliaridis S, Kalebo P. Masseter muscle thickness measured by ultrasonography and its relation to facial morphology. J Dent Res. 1991;70:1262-1265. 
26. Weijs WA, Hillen B. Relationships between masticatory muscle cross-section and skull shape. J Dent Res. 1984;63:1154-1157.

27. Raadsheer MC, Kiliaridis S, Van Eijden TMGJ, Van Ginkel FC, Prahl-Andersen B. Masseter muscle thickness in growing individuals and its relation to facial morphology. Arch Oral Biol. 1996;41:323-332.

28. Takada K, Lowe AA, Freund VK. Canonical correlations between masticatory muscle orientation and dentoskeletal morphology in children. Am J Orthod. 1984;86:331-341.

29. Proctor AD, DeVincenzo JP. Masseter muscle position relative to dentofacial form. Angle Orthod. 1970;40:3744.

30. Proffit WR, Fields HW. Occlusal forces in normal and long-face children. J DentRes. 1983;62:571-574.

31. Sankey W, Buschang P, English J Owen A. Early treatment of vertical skeletal dysplasia: the hiperdivergent phonotype. AJO. 2000;118:317-327.

32. Basciftci FA, Karaman AI. Effects of a modified acrylic bonded rapid maxillary expansion appliance and vertical chin cap on dentofacial structures. Angle Orthod. 2002;72(1):61-71.

33. Torres F, Almeida RR, de Almeida MR, Almeida-Pedrin RR, Pedrin F, Henriques JF. A prospective study of the treatment effects of a removable appliance with palatal crib combined with high-pull chincup therapy in anterior open-bite patients. Am J Orthod Dentofacial Orthop. 2006;129:418.

34. Cozza P, Macedero M, Baccetti T, Franchi L. Treatment and posttreatment effects of quad helix/crib therapy of dentoesqueletal open bite. Angle Orthod. 2007;77(4):640.

35. Shulz S, McNamara J, Baccetti T, Franchi L. Treatment effects of bonded RME and vertical pull chincup followed by fixed appliance in patients with increased vertical dimension. AJO. 2005;128:326.

36. Cozza P, Mucedero M, Baccetti T, Franchi L. Early orthodontic treatment of skeletal open-bite malocclusion. A systematic review. Angle Orthod. 2005;75(5):707-713.

37. Sayin MO, Akin E, Karacay S, Bulakbasi N. Initial effects of the tongue crib on tongue movements during deglutition: A cine magnetic resonance imaging study. AJo. 2006;76:400-405.

38. Everdi N, Kucukkeles N, Arun T, Biren S. Cephalometric evaluation of crib therapy for cases of mixed dentition (open bite). J. Nihon Univ. Sch Dent. 1992;34:131-136.

39. Gautini V, Franchi L, Baccetti T, Mucedero M, Cozza P. Dentoskeletal changes associated with fixed and removable appliances with a crib in open bite patients in the mixed dentition. AJo. 2008;133:77.

40. Justus R. Correction of anterior open bite with spurs: a long term stability. World J of Orthod. 2001;2:219231.

41. Huang G Et al. Stability of open bite treated with crib therapy. Angle Orthod. 1990;60(1):17.

42. Torres F, Almeida R, Almedia A, Almeida-Pedrin R, Pedrin F, Henriques J.Anterior open bite treated with palatal crib and high pull chin cup therapy. Eur J Ortho. 2006;28:210.

43. Emani S, Amir S, Morshedi E. The effect of mandibular tongue cribs on dentoskeletal changes in patients with class II division 1 malocclusions. World J of Orthod. 2010;11(1):23-26.

44. Belger I. Cephalometric analysis of growth in subjects using bite plate. Angle Orthod. 1956;26:42.

45. Hopkins S. Symposium on bite planes. AJO. 1940;26:107.

46. Menezes D. Changes in the dentofacial complex as a result of the bite plane therapy. AJO. 1975;67(6):660.

47. Hemley S. Bite plates, their application and action. Ajo. 1938;24:721. 


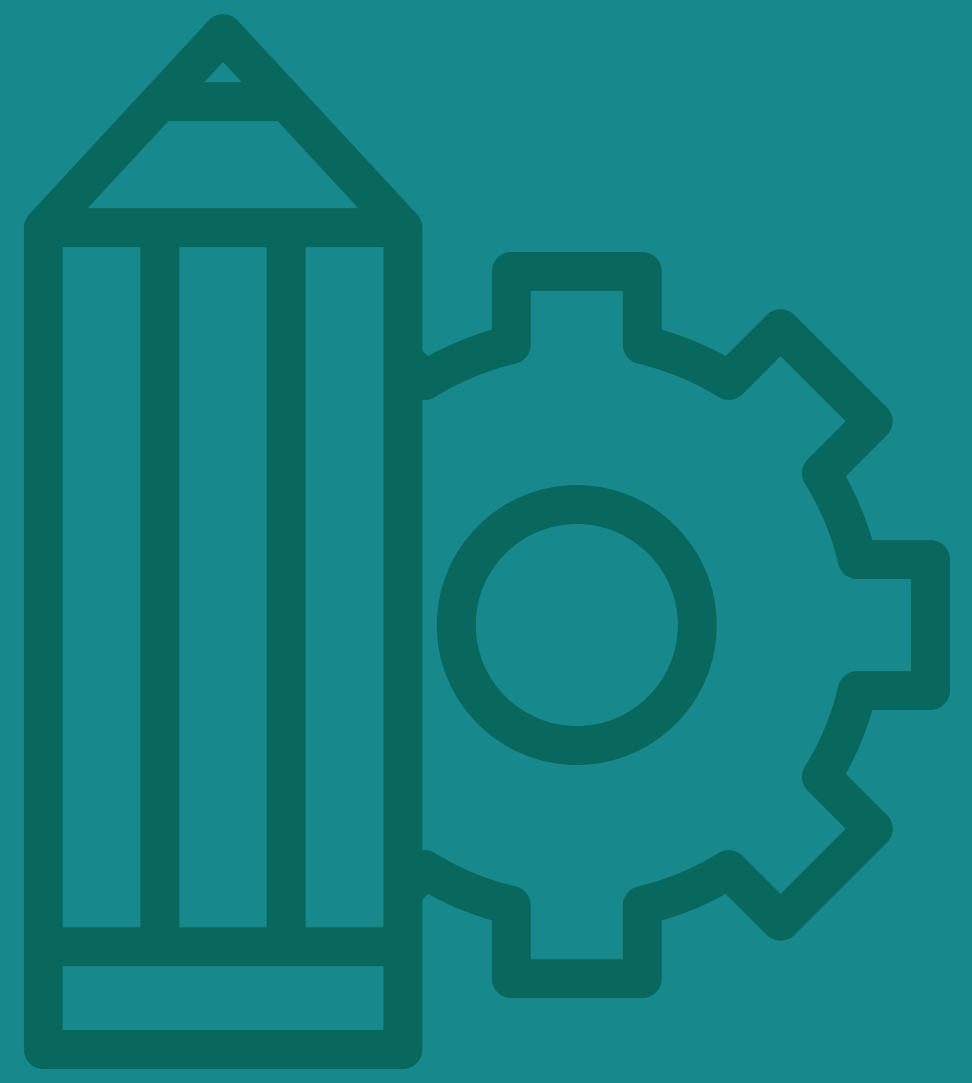

